


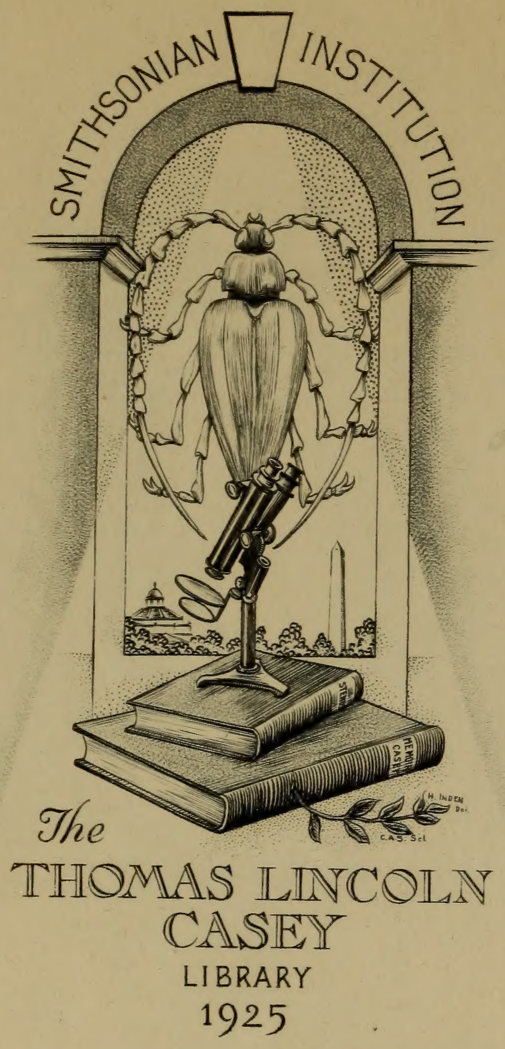








\title{
AN INVESTIGATION OF EVOLUTION IN CHRYSOMELID BEETLES OF THE GENUS LEPTINOTARSA
}

\author{
BY \\ WILLIAM LAWRENCE TOWER \\ Instructor in Embryology, University of Chicago \\ Associate, Station for Experimental Evolution
}

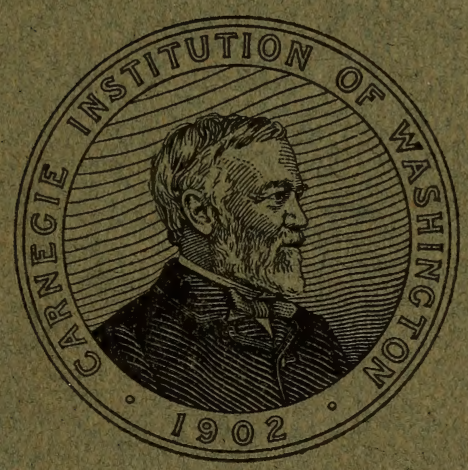

WASHINGTON, D. C.

Published by the Carnegie Institution of Washington 1906 





\title{
AN INVESTIGATION OF EVOLUTION IN CHRYSOMELID BEETLES OF THE GENUS LEPTINOTARSA/
}

\author{
BY \\ WILLIAM LAWRENCE TOWER \\ Instructor in Embryology, University of Chicago \\ Associate, Station for Experimental Evolution
}

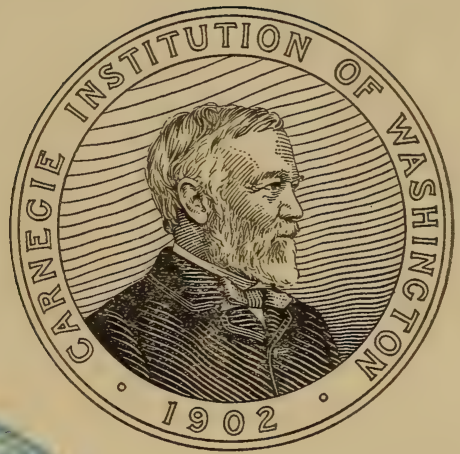

WASHINGTON, D. C.

Published by the Carnegie Institution of Washington I906 
Carnegie institution of Washington, Publication No. 48.

PAPERS OF THE STATION FOR EXPERIMENTAL EVOLUTION AT COLD SPRING HARBOR, NEW YORK, NO. 4. 


\section{PREFATORY NOTE.}

The investigations, the results of which are herein set forth, have been carried out by aid from the Elizabeth Thompson Science Fund, in the collection of the data of distribution and migration of L. decemlineata and in some of the earlier experimental work upon the same species, and by certain grants from the University of Chicago and from the Carnegie Institution of Washington, which have made possible experimental study in the tropics. I desire to express my deep sense of obligation to all these for the aid rendered.

The investigations have been conducted in the Museum of Comparative Zoölogy in Cambridge, in the Biological Laboratory of the Brooklyn Institute of Arts and Science, at Cold Spring Harbor, and in the Hull Zoölogical Laboratory of the University of Chicago; and to the directors of these institutions and their staffs I am under great obligation for much kindly advice and valuable criticisms.

The experimental studies presented in this contribution, with the exception of three small experiments, were brought to an end in July, I904. Through the carelessness of workmen engaged to attend to the heating plant of the university, on the hottest day of the season steam was turned on in full force in the greenhouse where my experiments were, terminating at once the series of experiments and cultures which had been carried with great labor and expense through several years. These cultures have been started again and are now being continued at Chicago and in the tropics of southern Mexico. 



\section{CONTENTS.}

\section{Chapter I.-Geographical, Distribution and Dispersion of Leptinotarsa.}

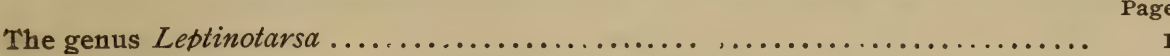

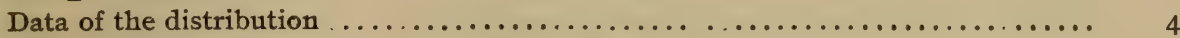

Geographical distribution and dispersion of the genus................... 9

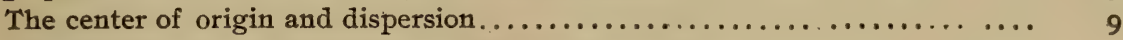

The distribution and migrations of the lineata group................. I4

Distribution and œcology of the species...................... I4

Distribution of $L$. intermedia and decemlineata and probable movements within historic time............................ 2I

Chronological history of dispersal of $L$. decemlineata, 1859 to $1904 \ldots \ldots 25$

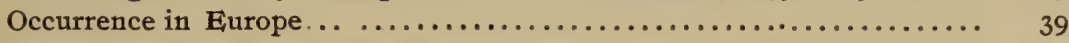

The highways of dispersal and rate of movement................ 39

Other factors which have controlled the direction of movement........ 44

Distribution of $L$. defecta and $L$. juncta and retreat of $L$. juncta....... 49

Distribution of the other groups.............................. 50

The relation of the distribution of the genus Leptinotarsa to natural environmental complexes.................................... 52

Chapter II.-VARIATION IN LEPTINOTARSA.

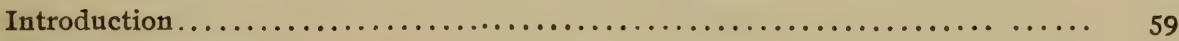

Individual variations $\ldots \ldots \ldots \ldots \ldots \ldots \ldots \ldots \ldots \ldots \ldots \ldots \ldots \ldots \ldots \ldots \ldots \ldots \ldots \ldots \ldots, 6_{2}$

Observations and data of continuous variations .................... $6_{2}$

Color characters...................................... $6_{2}$

Individual variation in the color pattern of the pronotum........ 62

Individual variation in the color pattern of the epicranium $\ldots \ldots \ldots . \quad 72$

Individual variation in the color pattern of the elytra........... 76

Individual variation in the color pattern of the ventral surface..... 84

Individual variation in the color pattern of the legs $\ldots \ldots \ldots \ldots \ldots . \quad 86$

Individual variation in the color pattern of mature larvæ........ 86

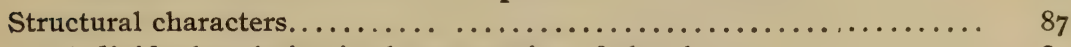

Individual variation in the punctation of the elytra........... 87

Individual variation in the punctation of the pronotum.......... 90

Individual variation in the glands of the elytra.............. 90

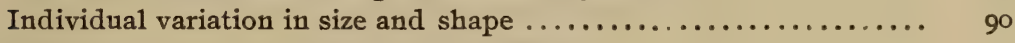

Observations and data concerning extreme variations................... 9 I

The laws of variation in the genus Leptinotarsa................... 92

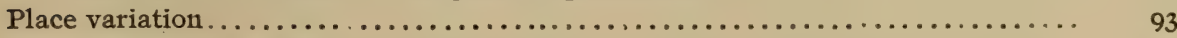

Geographical variation.................................... 105

Distribution and variation and the evidence they afford concerning evolution.... II3

CHAPter III.-Coloration IN LEPTINOTARSA.

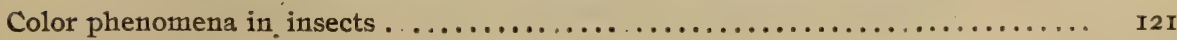

Color classes......................................... I2I

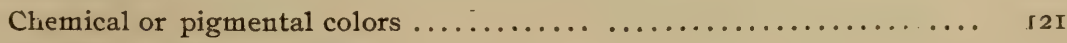

Physical or structural colors. . ......................... I23

Chemico-physical or combination colors.................... I 23 
Color phenomena in insects-Continued. Page

Development of coloration. . . . . . . . . . . . . .

Purity of insect colors.................................... I24

Evolution of the color patterns of insects........................ 125

Laws of coloration..................................... I25

Phylogeny of coloration................................... I26

Effect of environment upon coloration $\ldots \ldots \ldots \ldots \ldots \ldots \ldots \ldots \ldots \ldots \ldots \ldots, 128$

Protective resemblance, warning coloration, mimicry............... 128

The problems of insect coloration to-day ....................... 128

The colors of the genus Leptinotarsa ............................. I29

Chemical or pigmental colors.............................. I29

Physical or structural colors................................. I

Chemico-physical or combination colors........................ I3I

The development of colors in Leptinotarsa ...................... I32

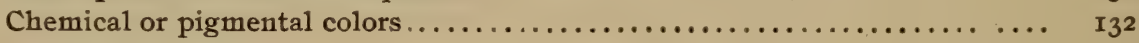

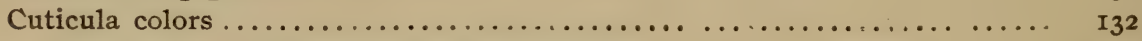

The cuticula, its structure and composition................... r 133

Chemical examination of the cuticula colors.................. I 35

Development of the cuticula colors......................... I 36

Experiments pointing to the existence of enzyme action........... I37

Hypodermal colors................................... I40

Chemical examination of the hypodermal colors................. I40

Microscopical examination of hypodermal colors................ I4I

Development of hypodermal pigments..................... I4I

Diffuse hypodermal pigments................................ I4I

Subhypodermal colors................................ I4 $^{2}$

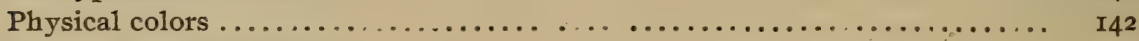

Chemico-physical colors .............................. I42

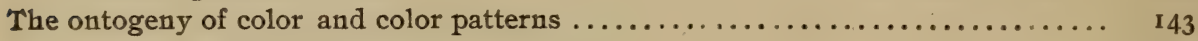

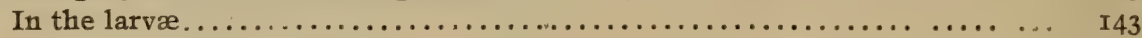

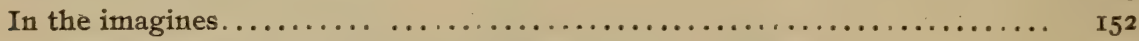

The ontogeny of color on the epicranium and pronotum........... 152

The ontogeny of color on the wings $\ldots \ldots \ldots \ldots \ldots \ldots \ldots \ldots \ldots \ldots \ldots \ldots \ldots \ldots \ldots$

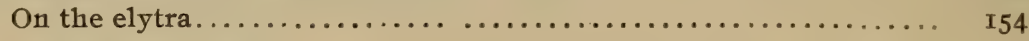

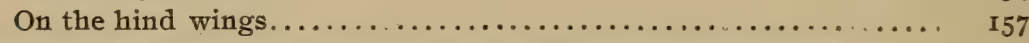

The ontogeny of color on the abdominal and thoracic segments....... I57

General aspects of color and color-pattern ontogeny................. ${ }_{15}^{8}$

Localized stages in ontogeny of coloration........................ I6 $6_{3}$

The experimental modification of color and color patterns............... I68

Modification of color in $L$. decemlineata....................... 168

Temperature experiments............................... 68

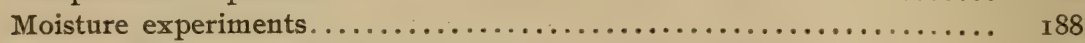

Experiments with temperature and moisture both variable........... I95

Experiments in which temperature and relative humidity vary together in the same direction above or below the normal.............

Experiments in which $L$. decemlineata was reared during successive generations, with both temperature and moisture varying together, or in opposite directions above or below the normal ............

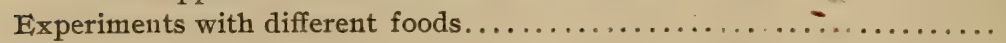

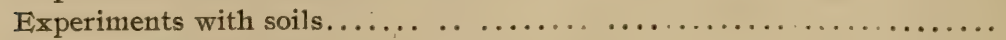

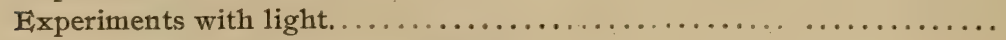

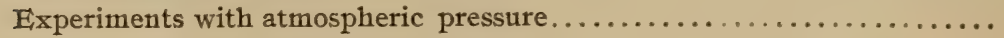


The experimental modification of color and color patterns-Continued. Page

Modification of color in L. signaticollis......................... 209

Temperature experiments........................... 209

Moisture experiments................................. 2II

Modifications of color in other species of Leptinotarsa.............. 2II

General results derived from experimental modification of color.......... 2I2

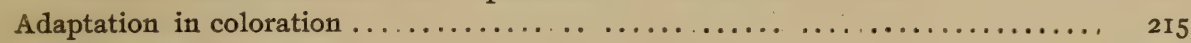

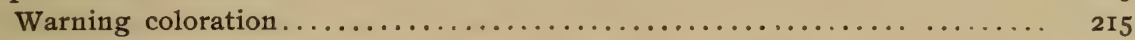

Protective resemblance.................................. 220

The evolution of coloration..................................... 222

Chapteir IV.-Habits and Instincts IN LePtinotaRsa.

Habits and instincts connected with reproduction.................... 229

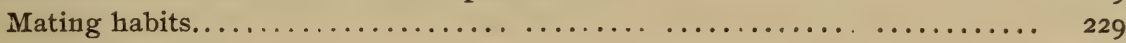

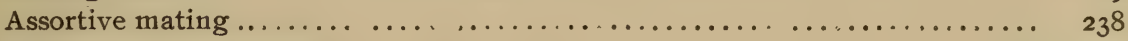

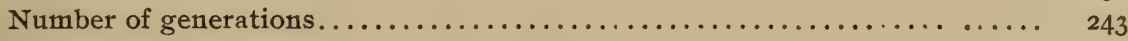

Habits and instincts connected with hibernation and æstivation.............. 245

Habits and instincts connected with self-preservation .................. ${ }_{2} 52$

Chapter V.-Production in Experiment of Races, New Characters, AND SPECIES IN LEPTINOTARSA.

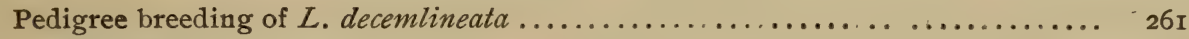

Experiments in race production and modification by artificial selection...... 26I

Selection experiments with color characters .................. 26I

Selection experiments with structural characters. ............... 268

Selection experiments with physiological characters .............. 270

Experimental pedigree breeding of new characters and species........... $27 \mathrm{I}$

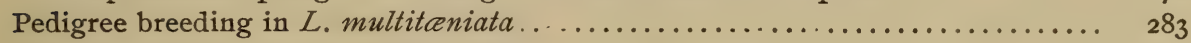

Experiment in production of new characters and species ................ 286

Experiments with $L$. decemlineata .......................... 287

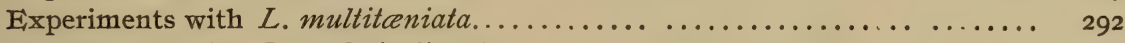

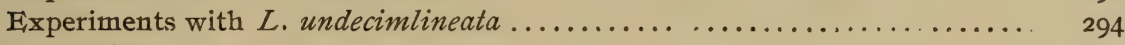

Conclusion......................................... 294

Chapter VI.-The PRoblem of The ORIGiN OF SPECIES-Discussion, SUMmary, AND CONCLUSION.

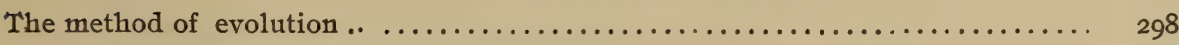

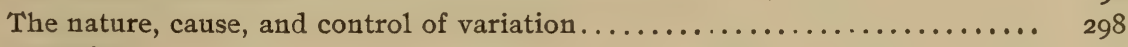

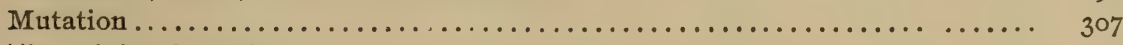

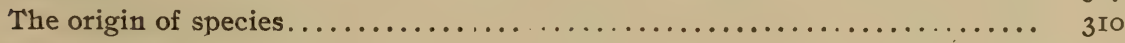

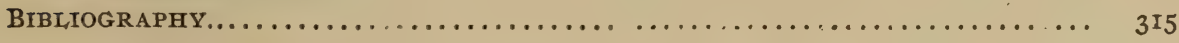





\section{INTRODUCTION.}

Although we hold that the general proof of organic evolution is abundantly self-evident, it is unfortunately all too true that its method is still an open question. The discovery of the method of evolution and the question of the origin of species is not, if we may judge by the prevailing diversity of opinion among biologists, much nearer a solution than it was when Darwin left it. This does not mean that no advances have been made; it simply indicates that the question is deeper, broader, and more difficult to solve than was at first supposed.

The current hypotheses of the method of evolution, each supported by evidence more or less convincing, and each capable of satisfactorily explaining some phenomena, fail utterly to account for all the phenomena in the origin of species. In other words, current hypotheses seem to be partial truths only, and we are probably far from discovering the final truth concerning the method of evolution. Since the publication of the "Origin of Species," the amount of literature concerning the general facts and method of evolution has been stupendous. When we examine this literature, however, we find, unfortunately, that it is far too much the writings of advocates of one or the other of the current hypotheses and all too little that of the investigator. On the question of the method of evolution biologists have grouped themselves into different schools, each strongly maintaining that his method is the real one. With the facts put forward by Darwin and his contemporaries and such new ones as have since been accumulated, these advocates have built up ingenious pleas in favor of their hypotheses, but have had little time left in which to attempt to penetrate farther into the unknown and get new facts and more conclusive evidence.

Biologists have gradually come to see, however, that any further advance rests, not upon controversial and argumentative writings, but upon new investigations so planned and executed as to bring to light new facts and evidence, whatever they may be, and regardless of how they may affect current hypotheses. Already we are beginning to have the fruit of this new line of work, such as the well planned, clearly executed research of De Vries, in which is presented a large body of new facts and evidence concerning the origin of species in plants. Investigations of this character are, however, the work of years, and a long time must necessarily elapse before any great body of new data and evidence from these studies can be accumulated.

Eleven years ago I began the study of evolution in the chrysomelid beetles, especially in certain genera which are confined entirely to America, with the idea that one ought by study, sufficiently long continued and properly con- 
ducted, to obtain new facts and evidence concerning the origin of species. This investigation has continued to occupy the larger share of my time during these years and is in no wise complete, but I venture to present in this contribution a first report of progress and a statement of some of the results obtained in some directions up to the present time.

In this contribution have been brought together data concerning evolution in the genus Leptinotarsa Stål as gathered from various sources and in as far as it applies in the origin of species. In general, the evidence herein presented has been derived from three sources: (I) its natural history, including distribution and œcology, variations, habits, and instincts; (2) development; (3) experiment. In the account herein presented I have in general followed the order in which the investigation has evolved during the past decade, and the conclusions drawn at the end rest upon data and evidence converging from diverse sources and obtained as a result of long observation. The correctness of my conclusions can be determined only by time and added investigation.

W. L. TOWER.

The University of Chicago, HULL, ZOÖLOGICAL LABORATORY, January 30, I906. 


\section{CHAPTER I.}

\section{GEOGRAPHICAL DISTRIBUTION AND DISPERSION OF LEPTINOTARSA.}

\section{The Genus LEPTINOTARSA.}

The genus Leptinotarsa Stål is one of a number of closely allied genera which constitute the major portion of the Chrysomelid fauna of America north of the Isthmus of Panama. In the Mexican and Central American regions 13 genera and about 225 species are known. Of these all but Phoedon, which is a genus of cosmopolitan distribution, are entirely confined to the American continents, and several of them to North America. The genera and their distribution in Mexico and Central America are given in the following table:

TABL, I.-Distribution of the Genera and Species of Chrysomelide in Mexico and Central America.

\begin{tabular}{|c|c|c|c|c|c|c|}
\hline Genera. & $\begin{array}{l}\text { No. of } \\
\text { species. }\end{array}$ & Mexico. & Guatemala. & Nicaragua. & $\begin{array}{l}\text { Costa } \\
\text { Rica. }\end{array}$ & Panama. \\
\hline Phædon. ..... & 8 & 8 & I & I & I & . \\
\hline Plagiodera .... & I8 & Io & 9 & 3 & 3 & 3 \\
\hline Melasoma..... & 3 & 3 & I & I & $\ldots$ & .. \\
\hline Calligrapha... & 38 & 29 & I3 & 6 & 9 & 3 \\
\hline Zygogramma.. & 36 & 30 & 8 & 4 & 5 & I \\
\hline Stilodes...... & I4 & 6 & 6 & 4 & 4 & 6 \\
\hline Leptinotarsa... & 43 & 33 & 8 & 6 & 4 & 2 \\
\hline Labidomera... & 2 & 2 & . & . & . & . \\
\hline Prosicela...... & 3 & I & 2 & .. & .. & . \\
\hline Doryphora .... & 48 & I6 & I7 & 14 & I3 & I7 \\
\hline Desmogramma. & I & . & $\therefore$ & . & . & I \\
\hline Elytrosphœra.. & 9 & 9 & . & . & . & . \\
\hline Pyxis......... & I & I & 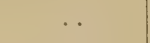 & . & . & . \\
\hline Total... & 224 & 148 & 65 & 39 & 39 & 33 \\
\hline
\end{tabular}

With the exception of Phadon, all of these genera are so closely allied that only trivial characters are used as generic differentials, and these are often highly variable. Within the genera the species form groups, or series, about some central type, and the same type is often found running through several genera. The slight generic differences, the still less pronounced specific characters, and the continuity of the series are strongly suggestive of a recent origin, or at least of a recent rise of species, which may still be going on. 
The genus Leptinotarsa is confined almost entirely to the continent of North America, ${ }^{1}$ extending southward to the Isthmus of Panama and northward to the northern United States. Forty-three species are known, of which three have crossed the Rio Grande into the United States, and an equal number have been found as far south as the Isthmus of Darien. By far the greater portion of the species is found in southern Mexico; only a few are known from Guatemala, and a few from the Mexican Plateau. Within the genus the species are arranged in groups, in each of which some one type of coloration prevails to the exclusion of all others. Between these groups of species there are no intergrades; these are to be sought for in the parent genus Zygogramma, where they are often clearly discernible. Specific differentiation is almost entirely based upon coloration, is by no means easy, and is especially difficult in dead specimens. The life histories are almost entirely undescribed, and the figures of the species that have been published are misleading, as in Jacoby's work in the Biologica Centrali Americana. Many of the species are exceedingly beatitiful in life on account of their delicacy of coloration, but at death this is lost.

The following species are known:

Leptinotarsa calceata Stål.
novemlineata Stål.
dilecta Stȧl.
flavitarsis Guer.
nitidicollis Stål.
obliterata Chev.
lineolata Stål.
pudica Stål.
typographica Jacoby.
distinguenda Jacoby.
cacica Stål.
undecimlineata Stål.
diversa n. sp.
angustovittata Jacoby.
signaticollis Stål.
multitæniata Stål.
oblongata n. sp.
melanothorax Stål.
rubicunda n. sp.
intermedia n. sp.
defecta Stål.
decemlineata Say.

Leptinotarsa juncta Guer. lacerata Stål. heydeni Stål. puncticollis Jacoby. modesta Jacoby. chalcospila Stål. dahlbomi Stål. hogei Jacoby. haldemani Rogers. libatrix Suffr. violescens Stảl. chlorizans Suffr. litigiosa Suffr. tlascalana Stål. rubiginosa Rogers. zetterstedti Stål. ståli Jacoby. evanescens Stål. dohrni Jacoby. belti Jacoby. flavopustulata Stå1.

${ }^{1} \mathrm{~A}$ few species of Leptinotarsa are described from the northern and western portions of South America. There seem to be southward extensions of the northern forms. Little is known concerning them. The references to Leptinotarsas from South America are usually incorrect, or misprints (as in several instances). In other cases there is uncertainty as to the source of the described material. 
The species of this genus, like the rest of the Chrysomelidx of North America, show a marked tendency toward the development of groups about some central type. In Leptinotarsa this is carried to the extent that all of the species fall into well-marked series not connected by intermediate conditions. Each of these is traced with ease backward into the genus Zygogramma, which is the ancestor of the genus Leptinotarsa.

The species fall naturally into the following groups :

Flavopustulata Group.

Leptinotarsa ståli.

evanescens.

dohrni.

belti.

flavopustulata.

HaLdemani Group.

Leptinotarsa dahlbomi.

hogei.

haldemani.

libatrix.

violescens.

chlorizans.

litigiosa.

tlascalana.

LACERATA Group.

Leptinotarsa lacerata.

heydeni.

puncticollis.

modesta.

chalcospila.

RUbiginosa Group.

Leptinotarsa rubiginosa.
LINEATA GROUP.

Leptinotarsa undecimlineata.

diversa.

angustovittata.

signaticollis.

multitæniata.

oblongate.

melanothorax.

rubicunda.

intermedia.

decemlineata.

defecta.

juncta.

Dilecta Group.

Leptinotarsa calceata. novemlineata.

dilecta.

flavitarsus.

nitidicollis.

obliterata.

lineolata.

pudica.

typographica.

distinguenda.

cacica.

ZETTERSTEDTI GROUP.

Leptinotarsa zetterstedti.

The distribution of these groups over North America shows a strong development in numbers and in species in southern Mexico. Only I reaches the northern United States and Canada, 3 reach the southern United States, and 6 northern Mexico, while 30 are found in southern Mexico only, 4 in Guatemala, and 2 as far south as Costa Rica and Panama. 


\section{DATA OF THE DISTRIBUTION. ${ }^{1}$}

\section{FLAVOPUSTULATA GROUP.}

Leptinotarsa ståli Jacoby.

Known only from the headwaters of the Rio Atoyac and the Rio Coetzala, in the region of the southern escarpment ; recorded from Puebla, * Matamoros de Izucar* (Salle), and Atlixco,* all in the State of Puebla.

Leptinotarsa evanescens Stål.

A rare species recorded by Stål from Guatemala and Costa Rica. It has not been recorded since it was first described. Exact localities are not given.

Leptinotarsa dohrni Jacoby.

A rare species described from a single specimen collected by Sallé at Yoltepec. Sallé does not state whether the locality given by him is Yoltepec in the State of Hidalgo or Yoltepec in the State of Oaxaca. In the latter State there are two places of the same name, one in the northern part, 8 miles west of Huajuapan, and another in the southwestern part near Istayulta.

Leptinotarsa belti Jacoby.

Closely allied to $L$. favopustulata and perhaps only a variety of it ; is confined to the Guatemala Plateau and its extension southward into Nicaragua. It is recorded from Chacoj and Panima in Guatemala (Champion), and from the province of Chontales in Nicaragua (Belt).

Leptinotarsa flavopustulata Stål.

Known only from Guatemala, where it is recorded from San Juan in Vera Cruz, and Chacoj (Champion).

\section{Leptinotarsa dahlbomi Stål.}

\section{HALDEMANI GROUP.}

A wide-ranging species which has been recorded from the Rio Grande region of Texas southward to Nicaragua. It is known from the following localities : Texas ; MexicoYolos, Atlixco,* and Puebla,* in the State of Puebla (Sallé); Yucatan (Pilate); and Nicaragua-Chontales and Grenada (Sallé), Cuernavaca, ${ }^{*}$ State of Morelos.

Leptinotarsa hogei Jacoby.

A curious species known only from one locality. It is clearly a Leptinotarsa, but bearsa striking resemblance to Zygogramma ornata, with which it occurs. (MexicoCerro de Plumas.*)

Leptinotarsa haldemani Rogers.

A highly variable species confined to the southern end of the Mexican basin and the upper portion of the escarpment on the south and west. It is recorded from Ventanas (Forrer), Puebla, * Cuernavaca * (Sallé), and Almolonga *2 (Höge). I have found it in all stages at Cuernavaca in Morelos, and at Puebla, ${ }^{*}$ Atlixco, ${ }^{*}$ and Matamoros de Izucar* in the State of Puebla.

Leptinotarsa libatrix Suffr.

Closely allied to the preceding and almost undistinguishable from it. The two do not occupy the same regions and probably represent geographical races of the same species. It is recorded from the following localities: Mexico-Cordoba, * Amatlan, * Jalapa, * and Almolonga, ${ }^{*}$ in the State of Vera Cruz (Sallé, Höge); Xantipa, Mescala, * Savana Grande,

\footnotetext{
${ }^{1}$ Localities where I have collected or known these species to occur are marked with an asterisk $(*)$.

${ }^{2}$ Probably this locality is in the canton of Jalapa in Vera Cruz.
} 
Dos Arroyos, and Chilpancingo, in the State of Guerrero (H. H. Smith); Huetamo, in the State of Michoacan; Tapatchula, in the State of Chiapas (H. H. Smith); and Guatemala-Cerro Zuniil, El Reposo, Volcan de Atitlan, Zapote, and Las Mercedes (Champion).

\section{Leptinotarsa violescens Stål.}

Closely allied to L. libatrix and probably only a modified form of that species, which is found higher up on the eastern and southern slopes of the plateau. It is recorded from Maltrata, ${ }^{*}$ Orizaba, ${ }^{*}$ Cordoba, ${ }^{*}$ Almolonga, ${ }^{* 1}$ and Tuxtla, ${ }^{*}$ all in the State of Vera Cruz (Sallé).

\section{Leptinotarsa chlorizans Suffr.}

A Pacific coast species not seen since it was first described. Recorded from Mazatlan, Sinaloa.

\section{Leptinotarsa litigiosa Suffr.}

Evidently closely allied to the preceding. Recorded from Mazatlan, State of Sinaloa, Mexico.

\section{Leptinotarsa tlascalana Stål.}

Known only from the original description given by Stål, which would place it as a near ally of $L$. dahlbomi. It is quite possible that it is a variation of this well-defined species. The only locality given by Stål is Mexico.

\section{ILACERAT A GROUP.}

\section{Leptinotarsa lacerata Stål.}

Common in the northern and eastern part of the State of Oaxaca and also in the State of Chiapas. Recorded from Oaxaca* (Höge) and Etla (Sallé) in Oaxaca, and at Playa Vicente * (Höge), Paras, ${ }^{*}$ and La Parada ${ }^{2}$ (Sallé) in Vera Cruz; Cuernavaca, ${ }^{*}$ Barranca de San Anton, ${ }^{*}$ State of Morelos.

\section{Leptinotarsa heydeni Stål.}

Stål gives this species as coming from Brazil, but as all known specimens are from Mexico it is probable that Stål was mistaken in the locality. It is known from Tanetza (Salle) and Almolonga*3 (Höge) in Oaxaca,* and Tremax in northern Yucatan.

\section{Leptinotarsa puncticollis Jacoby.}

In many ways resembles $L$. heydeni. Known only from Ventanas in the State of Durango (Forrer), and from Sonora (Jacoby).

Leptinotarsa modesta Jacoby.

Described from three specimens from Guanajuato,* Mexico (Salle); Ocotlan,* Jalisco.

Leptinotarsa chalcospila Stål. Mexico.

Leptinotarsa rubiginosa Rogers.

\section{RUBIGINOSA GROUP.}

A peculiar species not related to any of the other groups in the genus. Recorded from Mazatlan (Suffr.), the Alvarez Mountains (Palmen), Ciudad Milpas (Forrer), Guanajuato (Sallé), and Puebla* (Sallé), Tlalpan, ${ }^{*}$ Sante Fe, ${ }^{*}$ Federal District.

\section{Leptinotarsa undecimlineata Stål.}

\section{LINEATA GROUP.}

The distribution of this species is, with one exception, the widest in the entire genus. According to Stål (1858), this insect is a native of Mexico, Costa Rica, Colombia, and Bolivia.

\footnotetext{
${ }^{1}$ See foot-note 2 on page 4 .

2 A locality "La Parada" often given by Salle has not been located.

${ }^{3} \mathrm{~A}$ name given to a mountain and an accompanying tract of forest-covered hills and areas of bushy savanna in the valley of the Rio Cosolapa.
} 
Curiously enough, the records of Stal are the only ones known from South America, but they are probably accurate, as I have specimens from the Rio Sucio* on the Isthmus of Darien. In Panama* it seems to be generally distributed, especially in the lower portions of the country. In Costa Rica, Rogers and Van Patten record it from the slopes of Volcan de Irazu, and in Nicaragua, Jameson and Belt have found it abundant in Chontales. It does not seem to have been recorded from Spanish Honduras, although Blancaneatux found it near the Rio Sarstoon, in British Honduras. In Guatemala numerous records are known-El Reposo, Purula, Tamahee, Duenas, Capetillo, San Geronimo, Cubliquitz (Champion), and Guatemala (city); in Mexico-from Vera Cruz (city), * Cordoba, * Tuxtla, Orizaba, ${ }^{*}$ Misantla, ${ }^{*}$ Cerro de Plumas (Höge, Sallé), Tierra Blanca, ${ }^{*}$ Motzorongo, ${ }^{*}$ Achotol, ${ }^{*}$ Guadalupe, ${ }^{*}$ Tesonapa, ${ }^{* 1}$ Vista Hermosa,* Los Changos,* Jalapa,* in the State of Vera Cruz; at Oaxaca* (Sallé), Mitla, * Tlacolula,* Rincon Antonio,* Ubero,* Mato Quamado,* Obispo, ${ }^{*}$ Agua Fria,* Perez,* San Marcos, ${ }^{*}$ Juanita, ${ }^{*}$ and Tomellen, ${ }^{*}$ in the State of Oaxaca; Guanajuato (Dugès, Sallé). Its distribution is wide, although it is nowhere a common species and is always local. At no place does it seem to have reached the Pacific slope of the Central American or Mexican region, and it is not common along the Atlantic coast. In Guatemala it is apparently a common species and in Mexico, where it is best known, it is abundant locally. In Mexico it is far from having the general distribution given by Stål; in fact, it is absolutely limited to southern Mexico, especially to the States of Oaxaca, Chiapas, Tabasco, and Vera Cruz.

The distribution of this form is shown on the map (plate I) to be confined entirely to the Atlantic slope and the savannas of Vera Cruz and Tabasco, but appears to be absent from Campeche and Yucatan. To the westward it has occupied the head of the Rio Balsas Valley, finding entrance through the pass afforded by the Rio Quiotepec, and by the Oaxaca plateau.

\section{Leptinotarsa diversa.}

This species is known only from the western portion of the valley of the Rio Grande de Santiago, * La Barranca, ${ }^{*}$ near Guadalajara, Jalisco, Mexico, and near-by barrancas.

\section{Leptinotarsa signaticollis Stål.}

This species, also a close relative of $L$. undecimlineata, is confined to the valleys of the Rio Balsas system. It has not been found outside of this area, and, indeed, not over the entire system. It is recorded from Tacambaro and Morelia (Höge), in Michoacan; Amula and Xucumanatlan (Smith), in Guerrero; Cuernavaca* (Smith), Alarcon,* Cuautla, ${ }^{*}$ and Jojutla,* in Morelos; and Puebla, ${ }^{*}$ Matamoros de Izucar * (Sallé), Atlixco,* and Tatetla,* in the State of Puebla. The distribution is plotted on plate I, along with that of L. undecimlineata. The habitat of this species appears to be a belt of country upon the eastern side of the Rio Balsas Valley.

\section{Leptinotarsa angustovittata Jacoby.}

Recorded from Guanajuato (Sallé); from Morelia and Tacambaro, in Michoacan (Höge); and from Xucumanatlan (Smith), in Guerrero. I have reared it from L. undecimlineata from Tierra Blanca, * in Vera Cruz.

\section{Leptinotarsa oblongata $\mathrm{n}$. $\mathrm{sp}$.}

This species, previously confounded with $L$. multitcniata and $L$. decemlineata, has a peculiar distribution. It is confined to the valleys of the Rio Balsas, Rio Verde, and Rio Tehuantepec, and the headwaters of the Rio Quiotepec, in southwestern Mexico. I have taken it in all its stages at Cuernavaca,* Cuautla, ${ }^{*}$ Yautepec, ${ }^{*}$ Jojutla, ${ }^{*}$ Trienta, ${ }^{*}$ and Puente de Ixtla, ${ }^{*}$ in the State of Morelos; Iguala, ${ }^{*}$ Naranjo,* Los Amates, ${ }^{*}$ and Kilo-

${ }^{1}$ Also spelled Tepextempa, an old Indian town.

${ }_{2}^{2}$ The correct name of this locality is La Barranca de Oblatos. A name applied to part of the cañon of Rio Grande de Santiago near Guadalajara, Jalisco, Mexico. 


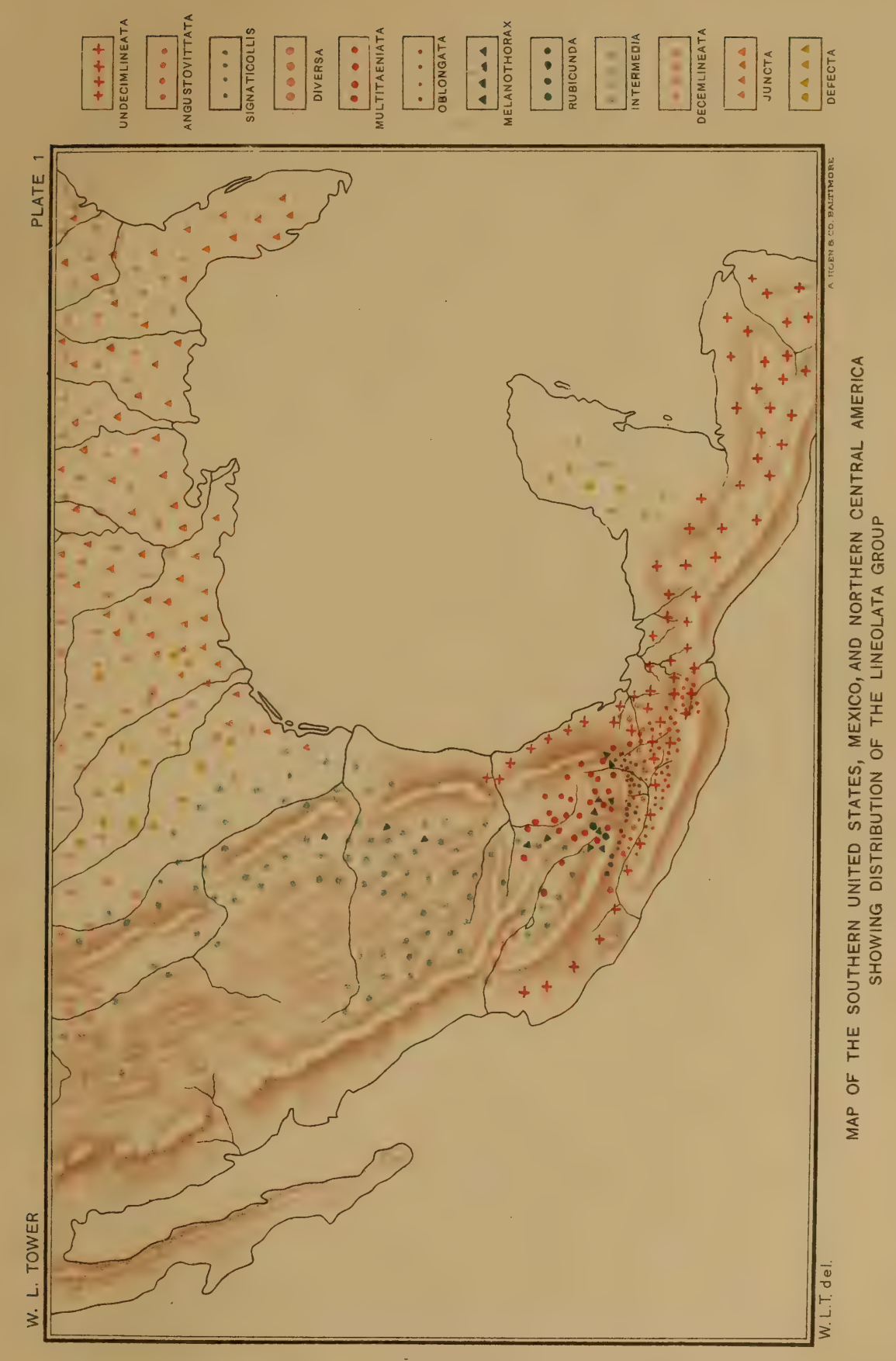



meter I9I * (Cuernavaca Division of the Mexican Central Railroad), Balsas,* and along the Rio Balsas, ${ }^{*}$ State of Guerrero; Puebla, ${ }^{*}$ Cholula,* Atlixco,* Tatetla, * Matamoros de Izucar, ${ }^{*}$ and Tlancualpican, ${ }^{*}$ in the State of Puebla;* Oaxaca, ${ }^{*}$ Mitla, ${ }^{*}$ Tlacolula, ${ }^{*}$ Tula, * San Juan,* El Parian,* Tecomavaca,* and Venta Salada,* in the State of Oaxaca ; and at Guadalupe * and Texcoco, ${ }^{*}$ in the Federal District. It is common at all of these places excepting the last two. It is probable that Höge's record of $L$. decemlineata from Tacambaro, in Michoacan, and Smith's record at Chilpancingo and Venta de Zopilote, in Guerrero, are really records of this species. The distribution is shown on plate I.

Leptinotarsa multitaeniata Stål.

This species is confined to the Plains of Apam, Puebla, the Valley of Mexico, and the headwaters of the Rio Lerma. It is recorded from Puebla,* Atlixco,* Matamoros de Izucar, ${ }^{*}$ and San Marcos, ${ }^{*}$ in the State of Puebla ; ${ }^{*}$ Apizaco* and Tlascala, ${ }^{*}$ State of Tlascala ; * Irolo, ${ }^{*}$ State of Hidalgo ; Toluca ${ }^{*}$ and Ometusco, ${ }^{*}$ State of Mexico ; Mexico City* (Smith), Guadalupe, * Tacubaya,* Tacuba,* Santa Fé,* San Angel,* Tlalpam,* Tlalnepantla, ${ }^{*}$ Texcoco, ${ }^{*}$ and Mixcoac, ${ }^{*}$ in the Federal District; Cerro de Plumas (Höge), and at La Parada (Salle). The latter place I am unable to locate. The distribution is shown on plate $\mathrm{I}$.

\section{Leptinotarsa melanothorax Stål.}

This rather uncommon species is recorded from Mexico City * (Höge) and Guadalupe, * Federal District ; Toluca * (Höge, Sallé), Puebla* (Höge), Guanajuato * (Dugès), and Morelia (Höge).

Leptinotarsa intermedia n. sp.

A form transitional between L. multitcniata and decemlineata, known from the Rio Lerma Valley at Ocatlan, ${ }^{*}$ La Barca, ${ }^{*}$ Guadalajara, * Zopopan, * the Rio Panuco Valley at Rio Verde,* and at Chihuahua.*

Leptinotarsa rubicunda n. sp.

Known only from the high plateau at Toluca* and the basal slopes of Mount Toluca* (altitude 8,500 to 9,500 feet).

\section{Leptinotarsa decemlineata Say.}

Although recorded from Mexico, I have not yet been able to find this species in that country, and am convinced that it is strictly confined to the United States east of the Rocky Mountains. It is common in the Mississippi Valley and its tributaries, and eastward to the Atlantic coast, northward in southern Canada, and southward to the Gulf of Mexico.

\section{Leptinotarsa juncta Stål.}

This species originally had a much wider distribution than at present. It is now limited to a narrow strip along the Gulf of Mexico and the lower Mississippi Valley.

\section{Leptinotarsa defecta Stål.}

A close ally of $L$. juncta, which inhabits Texas, Colorado, Missouri, and Indian Territory. It is recorded from Dallas and Galveston, Texas, and from Pueblo, Colorado. It has been collected by Sallé in Yucatan, but nolocalities are given. Stål likewise records it from the same regions from collections made by Chevrolat and Deyrolle. I have not seen it from these regions and know nothing further concerning it.

\section{Leptinotarsa calceata Stå1.}

\section{DILECTA GROUP.}

Common in the lowlands of the State of Vera Cruz and probably also in the region to the south ; Misantla * (Höge), Vera Cruz * (Salle), Orizaba, ${ }^{*}$ and Motzorongo, ${ }^{*}$ all in the State of Vera Cruz. 


\section{Leptinotarsa flavitarsis Guer.}

Closely allied to the preceding and probably only a local modification of it in southern Mexico, Guatemala, and southward. Baly records it from Mexico and Höge from Tapachula, in Chiapas. It is recorded in Guatemala from Guatemala City (Sallé), Zapote, and Cerro Zumil (Champion) ; from Nicaragua, in the province of Chontales (Jameson and Belt), and from Costa Rica (Salle), but no localities are given.

\section{Leptinotarsa nitidicollis Stål.}

Differs only in slight details from flavitarsis and calceata, and as it is known from only one locality, it is probably only a local variety of one or the other of these species. It is recorded from Tuxtla (Sallé), in the State of Chiapas.

\section{Leptinotarsa novemlineata Stål.}

A close ally of the preceding, recorded from Oaxaca* and Jaquila, in the State of Oaxaca.

\section{Leptinotarsa dilecta Stål.}

Closely allied to the preceding, but known only from the southern end of the plateau and along the escarpment on the south and west sides. It is recorded from Puebla,* Yoltepec, ${ }^{*}$ and Yolos, ${ }^{*}$ in the State of Puebla; Jaquila, in the State of Oaxaca; Cuernavaca, ${ }^{*}$ in the State of Morelos, and La Parada (?) (Salle).

\section{Leptinotarsa obliterata Chevr.}

This species differs in no respect from nitidicollis except in the reduction of the stripes to spots. It is a form characteristic of the lowlands, recorded from Toxpam (Sallé), Almolonga * (Höge), and Cordoba* (Sallé), in the State of Vera Cruz.

\section{Leptinotarsa pudica Stål.}

Smaller than the preceding, but separated from it by constant characters. It is recorded from Cordoba * in Vera Cruz and Jaquila in the State of Oaxaca.

\section{Leptinotarsa lineolata Stål.}

A small species allied to favitarsis and nitidicollis. It is limited to the northern part of the Mexican Basin and to the southern portion of Texas, ${ }^{*}$ New Mexico, ${ }^{*}$ and Arizona.* It is recorded from Chihuahua City* (Höge) and Piños Altos (Buchan-Hepburn) in the State of Chihuahua ; northern Sonora, Texas, New Mexico, and Arizona.

\section{Leptinotarsa distinguenda Jacoby.}

Known only from Teleman and Chacoj (Champion) in Guatemala and the Province of Chontales in Nicaragua (Janson).

Leptinotarsa typographica Jacoby.

Closely allied to lineolata, but of more restricted distribution. It is recorded only from Piños Altos in the State of Chihuahua and Ventanas* in the State of Durango (Höge).

\section{Leptinotarsa cacica Stål.}

A common and variable species from the savannas and foothills of Vera Cruz, Tabasco. and Chiapas. It is recorded from Cordoba, ${ }^{*}$ Orizaba * (Sallé), Misantla* (Höge), Cerro de Plumas, Tesonapa,* Mellan,* Guadalupe,* and Amatlan,* in the State of Vera Cruz, and from Tuxpam, in the State of Chiapas.

\section{ZETTERSTEDTI GROUP.}

Leptinotarsa zetterstedti Stål.

Mexico (Stål), La Barranca, ${ }^{1}$ Guadalajara, Jalisco, Mexico.

\footnotetext{
${ }^{1}$ See foot-note 2, p. 6 .
} 


\section{GEOGRAPHICAL DISTRIBUTION AND DISPERSION OF THE GENUS.}

\section{THE CENTER OF ORIGIN AND DISPERSION.}

In any study of the evolution of organisms it is important to know the origin of the more recent species and to trace as far as is possible their history. By this means one is better able to determine whether the variations and modifications which are observed to arise or which produced experimentally are new or simply repetitions of stages in the phylogeny of the material studied.

To determine the point of origin in a group of organisms already well established over a wide area is by no means an easy task, and only an approximately correct conclusion can be arrived at by indirect methods.

With the animals under discussion all evidence points strongly to the conclusion that there has been but a single center of origin for the genus. The place of origin, or "center of dispersal" (Adams, I9O2), or "center of adaptive radiation" (Osborn, I900), can best be determined by the use of the criteria given by Adams. Aside from the evidence afforded by fossils, evidence wholly lacking in this case, ten criteria are given by this author for the determination of the center of origin, which are more effective than any method of solution hitherto proposed. We will discard at once the notion that because these insects are tropical they necessarily came from South America. This theory of the origin of the fauna of North America deserves less general application. Other areas, as those in Central America and Mexico, have been dry land as long as much of South America and were equally well-adapted to become centers of dispersal. In fact, I suspect that when we know better the fauna of Mexico and Central America we shall find abundant evidence that these regions have been strong centers of origin and dispersal, and that they have supplied both North and South America with many of their characteristic forms.

The ten criteria for the determination of the center of origin are:

(I) Location of the greatest differentiation of a type.

(2) Location of dominance or greatest abundance of individuals.

(3) Location of synthetic or closely related forms. (Allen.)

(4) Location of maximum size of individuals. (Ridgway, Allen.)

(5) Location of greatest stability and productiveness in crops. (Hyde.)

(6) Continuity and convergence of lines of dispersal.

(7) Location of least dependence upon a restricted habitat.

(8) Continuity and directness of individual variation or modification radiating from the center of origin along the highways of dispersal.

(9) Direction indicated by biogeographical affinities.

(Io) Direction indicated by annual migration in birds. (Palmen.) 
Obviously some of these are of more value than others, and some are of no use whatever for our purposes (No. IO). Others are based primarily upon the unproven assumption that evolution has been by certain methods (No. 8).

The first criterion is easy of application in the present case. Of the 43 . known species of Leptinotarsa, 3 have been found north of the Rio Grande, 6 in the North Mesa, 25 in the South Mesa and the escarpment, $2 \mathrm{I}$ in northern Central America, and 2 reach as far south as Panama and the Isthmus of Darien. Clearly the area of greatest specific differentiation for the genus is southern Mexico, or the region occupied by the southern end of the Mexican division of the North American region and the northern end of the Central American region. This area, situated in the main between the plateaus of Mexico and Guatemala, is now maturely dissected and immensely diversified. Three-fourths of the species of the genus are found in this region, and of these nearly the entire number are confined entirely thereto. In the lineata group, of the 12 known species 3 are found in the country to the north of the Rio Grande, I both north and south, I in the North Mesa, 8 in southern Mexico, and I in Guatemala and southward to the Isthmus of Darien. In this group the same proportions hold, $i . e$., three-fourths of the species in the region in which the genus as a whole shows its dominance, with a stronger representation to the north than to the south. By this first criterion the center of origin is clearly shown to be in southern Mexico.

The second criterion is not as easy of application as the first, largely because the data from many regions are meager or altogether wanting. First, to consider the genus as a whole: North of the Rio Grande, one species, $L$. decemlineata, is exceedingly abundant, surpassing all of the other species in the genus in point of numbers of individuals. Dominance in this area is not of the kind that would have significance in the object of our search, because the records show that this species in the region where it is most abundant is an introduced species, a new member of the fauna, and is at present subject to the laws governing such cases. If, however, this fact were not known, if the introduction had taken place Ioo or 200 years ago, or even if the introduction had passed unnoticed, we should be obliged to place the dominance of individuals in the Mississippi Valley and eastward. Dominance, or great abundance, of individuals is a point carefully avoided in his notes by the professional collector, the records of the collectors who have worked in Mexico and Central America being silent on this point.

Excepting in the case of $L$. decemlineata, my observations indicate a region of great abundance of individuals in southern Mexico. One species, L. undecimlineata, appears, however, to be common and widely distributed in Guatemala. Large series have been recorded from there and extensive collections exist in several museums. We conclude in regard to the second criterion that it shows the center of origin of these beetles to be in southern Mexico, but that the evidence derived from this criterion may be seriously 
distorted or even entirely falsified by recent migrations and introductions that can not be easily detected.

The third criterion is not different to any extent from the first. None of the species found north of the Rio Grande are closely related. In southern Mexico, however, the species are as a rule closely related, as, for example, L. undecimlineata, signaticollis, angustovittata, and diversa. This rather unimportant criterion also points to southern Mexico as the center of origin.

The fourth criterion is not, in my opinion, one of any great value. Size is a character dependent upon nutrition and specialization. Thus $L$. decemlineata is larger in New England, New York, and along the southern shore of the Great Lakes than it is in its original area of distribution, in Colorado, Kansas, and Nebraska, the difference in size in the two being about 20 per cent. Likewise Pieris rapa is larger in America than in Europe, and Passer domesticus lays larger eggs in America than it does in Europe (Bumpus). So cases might be multiplied in which it is known that the maximum size of a species is attained, not in the original habitat, but in the area later occupied by it, as in the case of decemlineata in this genus. It is not possible to apply this criterion to the genus Leptinotarsa.

The fifth criterion, like the preceding, is of comparatively little value. No one would claim that the wild potato of the tropics would under any circumstances give as many tubers per acre as the cultivated potato of Europe and America, or that the wild jungle-fowl in India is as prolific as its domesticated races, or that the hare of Europe is as prolific in its native home as it has proven to be in Australia, or that wild grains are as productive as cultivated varieties. Productiveness is a character of high specialization in so many cases, such as cultivated varieties, often, if not always, accompanying introduction into a new habitat, that it seems to me to be of little use for the purpose for which Hyde proposed it. Stability, however, is quite another matter, for we may have stability as the result of rigorous selection, as in cultivated varieties, or stability as a specific property of the species, as it occurs in nature.

The sixth criterion is of prime importance and one which, when the evidence is good, is sufficient to determine beyond question the center of adaptive radiation. Rarely can the highways of dispersal be determined from records or from the correlation existing between the movements of animals. In the majority of cases this data can be determined only by a study of the continuity and directness of individual variation and modification along certain lines. Adams's eighth criterion is in reality a highly necessary part of his sixth, it being merely a method of determining the important data in his sixth. This criterion presupposes, however, that all evolution has been by continuous variation. It is quite probable, however, that if the theory of the origin of species by mutation should prove to be of wide application this criterion would be of little use. If the mutation theory 
is true, then continuity and directness of variation are no longer of any great value in the determination of relationships and the phylogeny of animals.

In Leptinotarsa the lines of dispersal are short and not any too clearly marked. This is due to the fact that the habitats of the various species are only a few miles apart, and that they have been produced, not by wide separation, but by unlike topographic and climatic conditions situated in the main very close together. It is not possible, therefore, to say with certainty that lines of dispersal exist, except in one or two cases. The lines of dispersal which can be determined, those of intermedia and decemlineata, point southward to southern Mexico as a center of origin.

The seventh criterion, "location of least dependence upon a restricted habitat," does not appear in this case, at least, to be of any great weight. For example, $L$. decemlineata in the eastern United States is less dependent upon a restricted habitat than is any other member of the genus. That this is true is shown by the fact that it regularly feeds upon some dozen or fifteen species of food plants and has been found upon about forty. No other member of the genus has so many food plants, nor does decemlineata in its original habitat in Colorado, western Kansas, and Nebraska. Likewise it occurs on dry or wet or sandy soils, on clay or rich alluvium, on plain, hillside, or mountain slope, in the open, and even in the forest. In the case of this species least dependence upon a restricted habitat is a new character (habit) and not an original one. In its original home it feeds almost exclusively upon S. rostratum and lives in the open country (savanna and steppe formations); never upon mountain slopes nor in wooded areas.

Other members of the genus known to be nearer to the point of adaptive radiation, as undecimlineata, have only one species of food plant and are restricted to a very narrow habitat-the open portion of the country. The genus is never found upon mountain sides or in woodland formations. Likewise multitaniata, the direct ancestor of decemlineata, feeds only upon S. rostratum and its allies, and does not live upon any other. In this case "least dependence upon a restricted habitat" is a late acquisition of the species and not an original character.

That Adams's seventh criterion is often one of value is certain, but the case cited above, and others equally good that can be brought forward, would serve to weaken seriously one's confidence in this criterion as one of general value. It might be useful in specific cases, when the other evidence and the history of the group are so fully known that the recent acquirement of this character is beyond question, but when we know this much about the animals in question, the criterion is no longer needed in the search for the center of adaptive radiation. It would be already known from more reliable evidence.

The eighth criterion, "continuity and directness of individual variation or modifications radiating from the center along the highways of dispersal," 
is no criterion at all, although it has been shown in the discussion of the sixth criterion that continuity and directness of individual variation or modification may be of value in the determination of highways of dispersal. The eighth criterion assumes, if I understand it correctly, a knowledge of the center of origin and highways of dispersal previous to the beginning of the study of the data to determine that center of origin. It certainly is impossible to apply this to the genus Leptinotarsa, although it does assist very directly in the solution by criterion No. 6 .

The ninth criterion, "direction indicated by biogeographical affinities," seems to be a loose reiteration of the ideas expressed in No. 3, as applied to a somewhat broader area. It is, however, a criterion of no value from the standpoint of this group of animals.

The tenth criterion, "direction of annual migration in birds" (Palmen) has no bearing upon the present case.

To sum up the evidence derived from the application of these criteria, it appears that I, 2, and 3 point conclusively to southern Mexico as a center of origin; 4 is shown to be of no value, and 5 is based, seemingly, upon wrong conceptions and data. The important criterion, 6, points unmistakably to the same area as Nos. I, 2, and 3, while from criteria $7,8,9$, and ro we derive nothing of value. Our evidence clearly indicates that southern Mexico is the center of origin or adaptive radiation of the genus Leptinotarsa. There is nothing to even suggest an origin in South America, and we may well surmise that like results will be obtained concerning other groups of animals when adequately studied.

The following criteria are adequate for determining the center of origin or adaptive radiation without the introduction of any of doubtful value:

(I) Location of greatest differentiation of a type. (Adams.)

(2) Continuity and convergence of lines of dispersal. (Adams.)

(3) Location of synthetic or closely related forms. (Allen.)

(4) In some cases, location of dominance or great abundance of individuals. (Adams.)

These criteria cover fully all cases and are not open to the very serious objections that may be advanced against the others.

The distribution and dissemination of these beetles can be best considered by groups of species, as we shall then be able to follow closely one line of species differentiation at a time and examine the effect of the different environmental complexes in controlling and directing distribution and dissemination. 
THE DISTRIBUTION AND MIGRATIONS OF THE LINEATA GROUP.

\section{Distribution AND CECOLOGY OF THE SPECIES.}

LEPTINOTARSA UNDECIMLINEATA Stål.

It is highly probable, although it can not be absolutely proven by actual observation, that the Guatemala-Chiapas Plateau, when perhaps it had a much lower altitude, was the original habitat, the center of origin, and first center of dispersal for this group of beetles. That L. undecimlineata is the most primitive of all the species in this group and close to the parent form is reasonably certain. The data of its distribution, which has been given, shows that, as far as is known, it is the only species of the group in Guatemala. It is evident that it did not come from South America, but is strictly a Central American form.

Of its habitat or habits in Guatemala I know nothing. In Chiapas, Oaxaca, and Vera Cruz I have been able to study it in nature and to discover some of the factors which control its range of distribution and confine it to a restricted habitat.

In a very general way the distribution is shown on plate I, where $L$. undecimlineata is shown to be distributed over the American Continent to the foot of the great escarpment on the southern end of the Mexican region. It is distinctly a tropical species. The distribution is irregular, it being confined to the valley floors and the low coastal plains of Vera Cruz, Oaxaca, Tabasco, and Chiapas, and southward, and it is not known from the Pacific coast regions.

Throughout the entire area in which I have studied this species it is always found in open grassland formations (plate 2), never in the forests, and is local in its distribution, being limited to isolated colonies in narrow and precise habitats, from which it does not wander far. These colonies are maintained from year to year in almost exactly the same spot. The situation in which the colonies thrive best is where there is a growth of their food plant upon the edge or within a few feet of the edge of a small, deeply-cut stream, so deeply cut that the chances of overflow are slight, or on a slightly elevated mound in the meadow or savanna, but there must be either an abundant supply of telluric water or the superficial soil must be kept moist by frequent precipitation. The soil most favorable to it is a fine residual or alluvial soil sufficiently free from clay and cementing materials, so that it does not become too hard during dry times. These are the general conditions best adapted to this insect-conditions which can be realized only in rather restricted areas. The immediate edges of the rivers in the country in which it lives are subject to extensive overflow, and hence are impossible sites, as are also the open, level flood plains. Neither a hillside nor the talus slopes at the foot of a hill provide the ideal conditions. In fact, only that portion of the valley situated between the upper limits of the rainy season floods and the talus slopes of the hillsides provides the conditions necessary for 


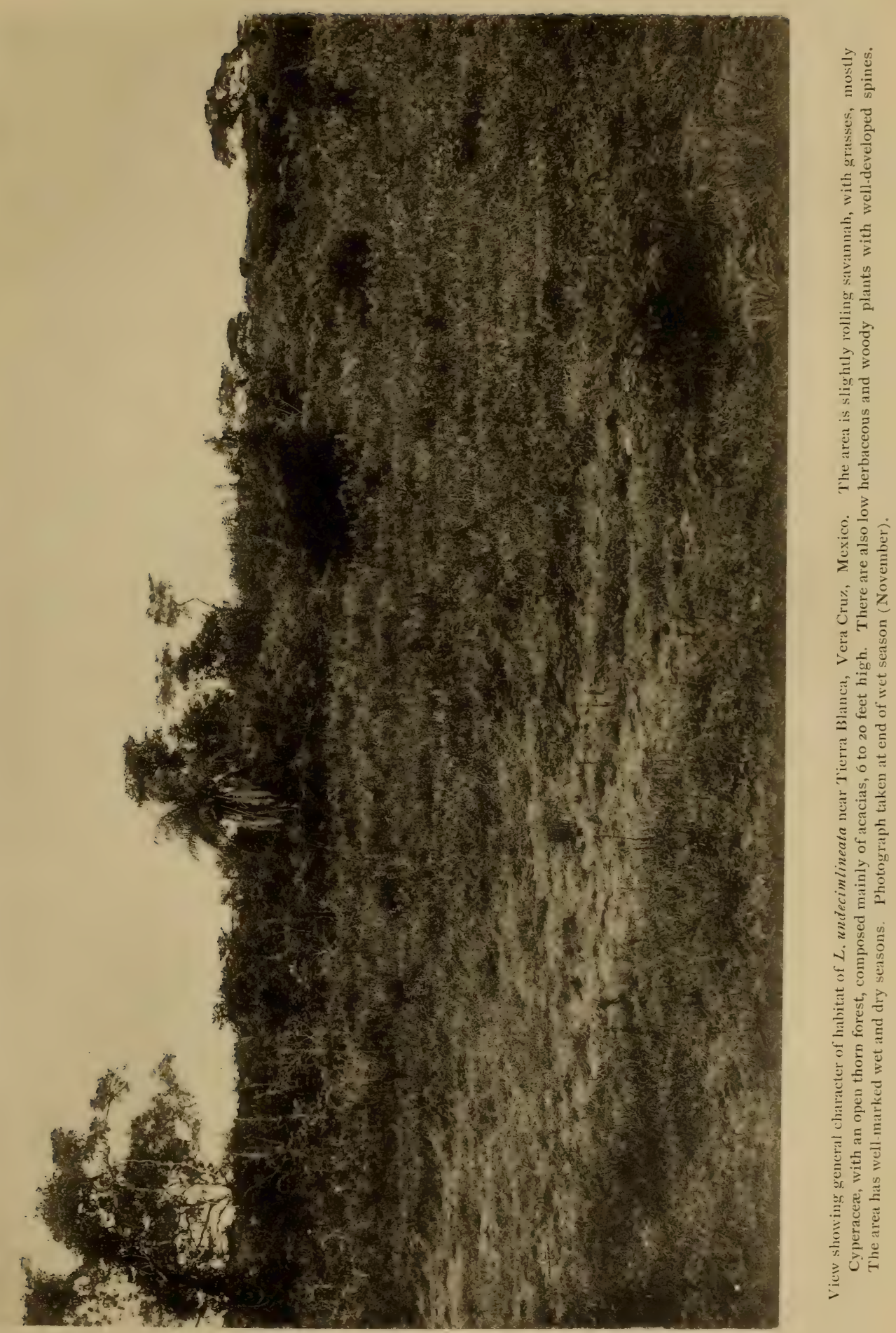



habitat formation-a region which, in the mountainous parts of the country, is frequently wanting altogether, and when present is usually narrow and level and deeply cut by tributary streams. The food plant of this beetle grows from the edge of the river to the talus slopes, and even far up on the hillsides; and, while stray beetles are often found in locations where environmental conditions are adverse, the characteristic, well-developed colonies are never thus located, because any extended existence and development in these places is not possible.

The distribution of $L$. undecimlineata is in isolated colonies and it does not occupy the wide range of habitats that its food piant does. The isolation is strikingly apparent to one searching for these beetles, wide stretches of country often existing between the colonies. When found the insects are usually numerous, and I have often been able to collect from Ioo to 300 specimens in a short time within a radius of a few feet.

From these colonies dispersion occurs by flying and not by any means of transportation that I have been able to discover. This flight is observed to begin at the opening of the rainy season, when the insects emerge from æstivation, to continue slightly during the rainy season, and to increase greatly toward its close.

An instructive illustration of the manner in which the dispersion of this beetle takes place was afforded by the recent building of a railroad through a perfectly flat, frequently flooded savanna near Tierra Blanca. The food plant grows generally over the savanna, but the beetle is entirely absent, excepting at a few points along the road where the work of constructing ditches to keep the road-bed intact has created new localities with favorable conditions for their existence. Over a distance of about i 8 kilometers there are now located flourishing colonies at each place where the work of the railroad builders has made existence possible, while on the unmodified savanna I have not been able to locate a single colony, and doubt if there are any. In this instance the advance into a new area has occupied two years and has been rapid. That transportation did not bring about the starting of these colonies is certain, as the work of railroad construction was entirely suspended during the rainy season, when the beetles are active and dispersion takes place. It is perfectly clear that in this case the distribution was brought about by some few individuals from a colony happening by chance to discover the newly created habitat, proper for æstivation and for the breeding of the next generation. In each generation many will perish by not being able to reach the proper habitat after once having abandoned the parent colony, but the fact remains that some do discover proper habitats, and when such are found new colonies are established. In this way, in regions where previously existence was impossible, as in the case of the savanna described above, new colonies are established. In the case of the savanna near Tierra Blanca the production of favorable locations was, 
it is true, due to the processes of railroad building, but if the same conditions had been produced by floods or other natural agencies which may act rapidly to change local conditions by cutting new waterways, the newly created possible habitats would in all probability have been seized upon with equal suddenness.

We see how definitely undecimlineata is limited in its distribution to a particular portion of the locality in which it lives, and it is probable, therefore, that its present distribution through the valleys of Vera Cruz, Oaxaca, Tabasco, and Chiapas has been a growth dependent upon the development of appropriate habitats at successively higher and higher levels in the river systems, so that the beetle has been brought by a series of steps nearer and nearer to the Mexican region. Its food plant everywhere precedes it, and as fast as appropriate conditions of soil and moisture are developed at any place, the beetle occupies it. This process of reaching out for new sites is easily seen on the eastern slopes of the Mexican highlands at Orizaba or Jalapa, in the State of Vera Cruz, where well-established colonies are found. From these colonies numerous individuals find their way to points higher up on the valleys, where food, temperature, and moisture are favorable, but where permanent colonies are not established, because the conditions of existence at these points are unfavorable to astivation and pupation; and as long as the conditions demanded are not fulfilled no permanent colony can be established. It is not necessary that the soil should be of a special chemical composition or temperature and rainfall of special amounts, but it is essential that during pupation and æstivation the beetle shall not be subjected to excessive desiccation or moisture, and that the soil shall be porous enough to admit of an abundant supply of air.

The southward distribution of this insect is not well known. The data is meager, consisting of records of capture, and I have not been able to visit these southern regions to study its habits and distribution there. However, from the data which we have, it seems probable that it occupies the same habitat there as elsewhere, and that it is limited by the same determining factors as in the northern portion of its range. It has extended south to the isthmuses of Panama and Darien. It is everywhere a Caribbean or Gulf coast form, never, as far as our knowledge goes, occurring upon the Pacific slopes.

\section{LEPTINOTARSA DIVERSA.}

The narrow range and the few observations that have been made upon this species do not permit of any extended discussion of its distribution or the control of its habitat. It is, as I have pointed out, a close ally of undecimlineata, and, like it, is confined to a narrow habitat. In the barrancas of the Rio Grande de Santiago it occurs upon clumps of Solanum sp.?, which grow near the edges of the cliffs and upon their faces and the steeper sides of the 
PLATE 3.

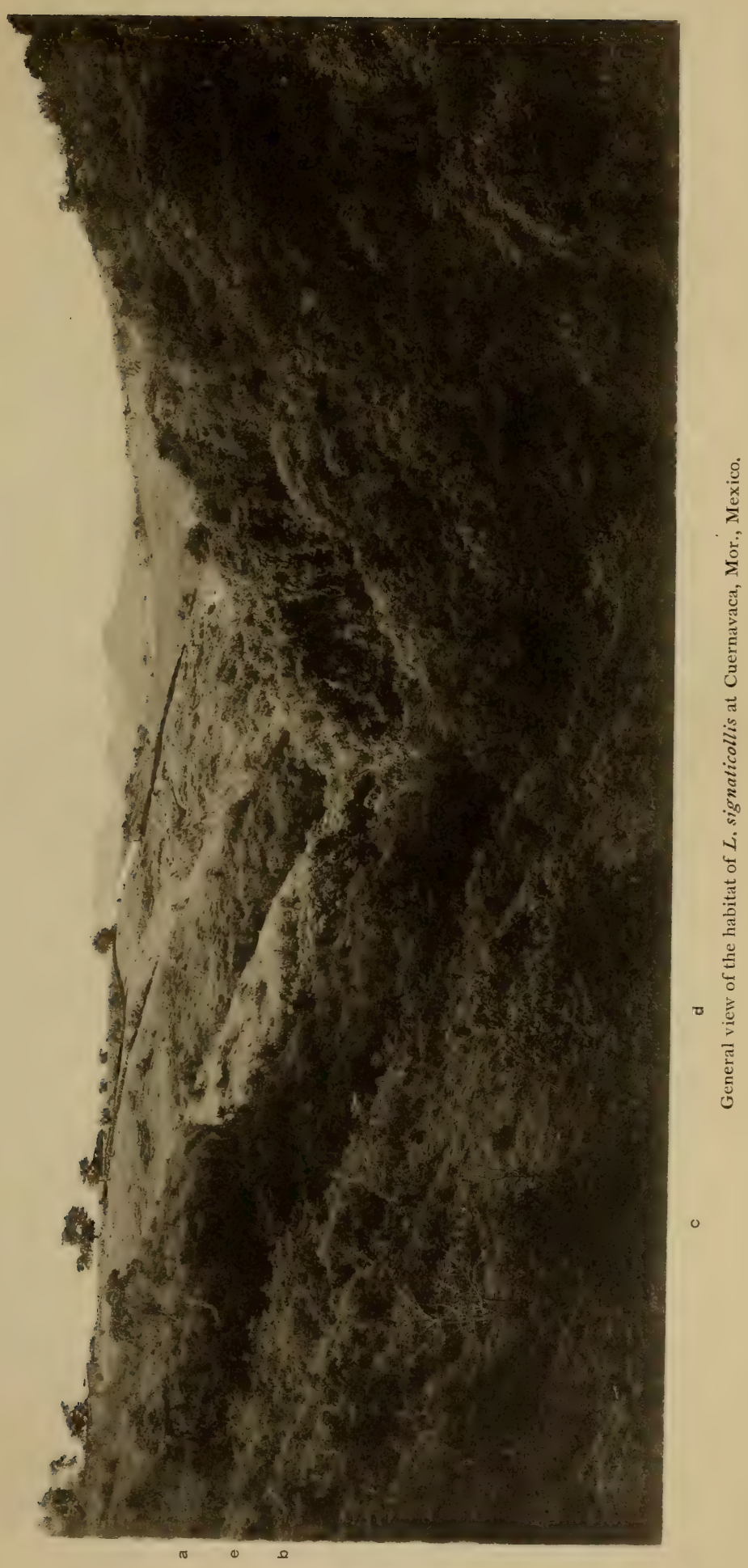



barrancas. It does not seem to extend outside of these limits, but is distinctively a cliff and talus-slope form. Just what relation this species has to the preceding from the standpoint of distribution it is impossible at present to say.

LEPTINOT ARSA SIGNATICOLLIS.

Apparently this species and the two preceding ones nowhere occupy the same locality. The data of its distribution would indicate this, and, although they are closely related, I have nowhere been able to find them living together. Like the two preceding species, this one is an inhabitant of a particular portion of the country. On plate I is shown the general distribution, where it is represented as limited to the western side of the Rio Balsas Valley, and on plates 3 and 4 are shown photographs of the habitat and its relation to the general physiographic features of the country. It occupies the northern and eastern tributary valleys of the Rio Balsas system, between the altitudes of 4,000 and 5,500 feet. This distribution embraces the lower portion of the Mexican escarpment, many of the great washes, as at Cuernavaca, and the upper portion of the lower country leading up thereto.

L. signaticollis, like undecimlineata, is confined to a narrow local habitat. Its food is Solanum sp., and it lives in colonies which continue in the same place from year to year. The general habitat best adapted to this species is similar to that occupied by undecimlineata, and is shown in plate 4. The favored locality for a colony is usually a growth of its food plant upon or near the edge of a small stream or ditch, cut somewhat deep into the soil of the flatter portion of the valley floor, or on the upper slopes of the larger barrancas (plate 3). It is rarely found near the edge of the smaller barrancas, or at the foot of the hills.

The rigid restriction of both the food and the beetles to a narrow habitat tends to produce a band or zone upon either side of the valleys in which, at points where the proper conditions have been developed by the side streams, colonies of signaticollis are found. This band or zone is in some cases rather sharply drawn, as at Cuernavaca, and less rigidly in others, as in the region of Atlixco and Matamoros. The difference is, however, one of topography. At Cuernavaca the topography is sharp and decisive ; at Atlixco and Matamoros it is more open, less rugged, and the zone of possible habitat formation is much broader and correspondingly less distinct. This restriction to so narrow a habitat has resulted in isolation, often of great intensity; but this has not brought about local variation, so that each valley shows the same peculiarities seen in adjacent ones. The intense isolation and segregation has not been of any apparent utility in the production of local forms or races of $L$. signaticollis.

As far as I am able to observe, the same method of dispersal is found in signaticollis as in the preceding species, but $I$ have not had an opportunity to study its method of spreading over a new area. 


\section{LEPTINOTARSA ANGUSTOVITTATA.}

The relation of this species to environmental complexes can not at present be discussed. It is known from only a few localities, is never abundant, and I have never been able to study it to any extent in nature. The fact, however, that I have reared it in experiment from undecimlineata and that it is intermediate between undecimlineata and signaticollis, is suggestive, but its full significance must await experimental elucidation.

\section{LEPTINOTARSA MULTITAENIATA.}

This species, like undecimlineata, is a central one about which closely related species are grouped. The data of its distribution is given on page 7 , and on plate $I$ is plotted its distribution. It is limited to the Valley of Mexico, the Plains of Apam, and the flat mesa southward to Puebla and Matamoros in Puebla ; eastward it extends to the foot of the Sierra Madre Orientale, and northward to about $20^{\circ} 30^{\prime \prime}$ north latitude. It is everywhere confined to the level country, never being found in the lowlands nor upon the mountain sides.

The area which is the habitat of this species is distinct topographically, being sharply marked off from the rest of the Mexican Plateau. It is level, but is surrounded by high hills and mountain chains with volcanic peaks to the east, south, and west, and cut off by a rugged range to the north. It is highest in the Valley of Mexico ( 7,400 feet), sloping southward to Puebla (7.09 1 feet), and rising slightly towards the Sierra Madre Orientale. It is practically level, with a variation of only a few hundred feet in altitude. Over it are scattered low hills, often of volcanic origin, small volcanic cones, eroded necks, and lava flows with steep sides covered with talus. The streams, which are all of small size, have beds deeply cut from io to 50 or Ioo feet in depth, with perpendicular walls in a stiff, sticky deposit of modified volcanic ejecta. The drainage is largely to the south, through the Rio Atoyac into the Rio Balsas system, and to a limited extent to the northeast and east through the short Gulf coast streams.

The rainfall is least in the lee of the Sierra Madre Orientale, where pine barrens and semi-arid grassland conditions are extensively developed; it increases gradually to the westward, and is largest in the Valley of Mexico. The northeast trade winds, striking the high eastern mountains, lose the greater part of their moisture upon the eastern slopes and pass over the mountains as cold dry winds, bringing but little moisture to the eastern portion of the country, which is always semi-arid. To the westward these winds become warmer and more moist, and the rains more abundant, until in the Valley of Mexico the rainy season has copious daily showers.

This region is a rather old land area which had stood for a long time at a much lower altitude and had been worn down to base level with residuals about it. Subsequent volcanic action and mountain building produced 


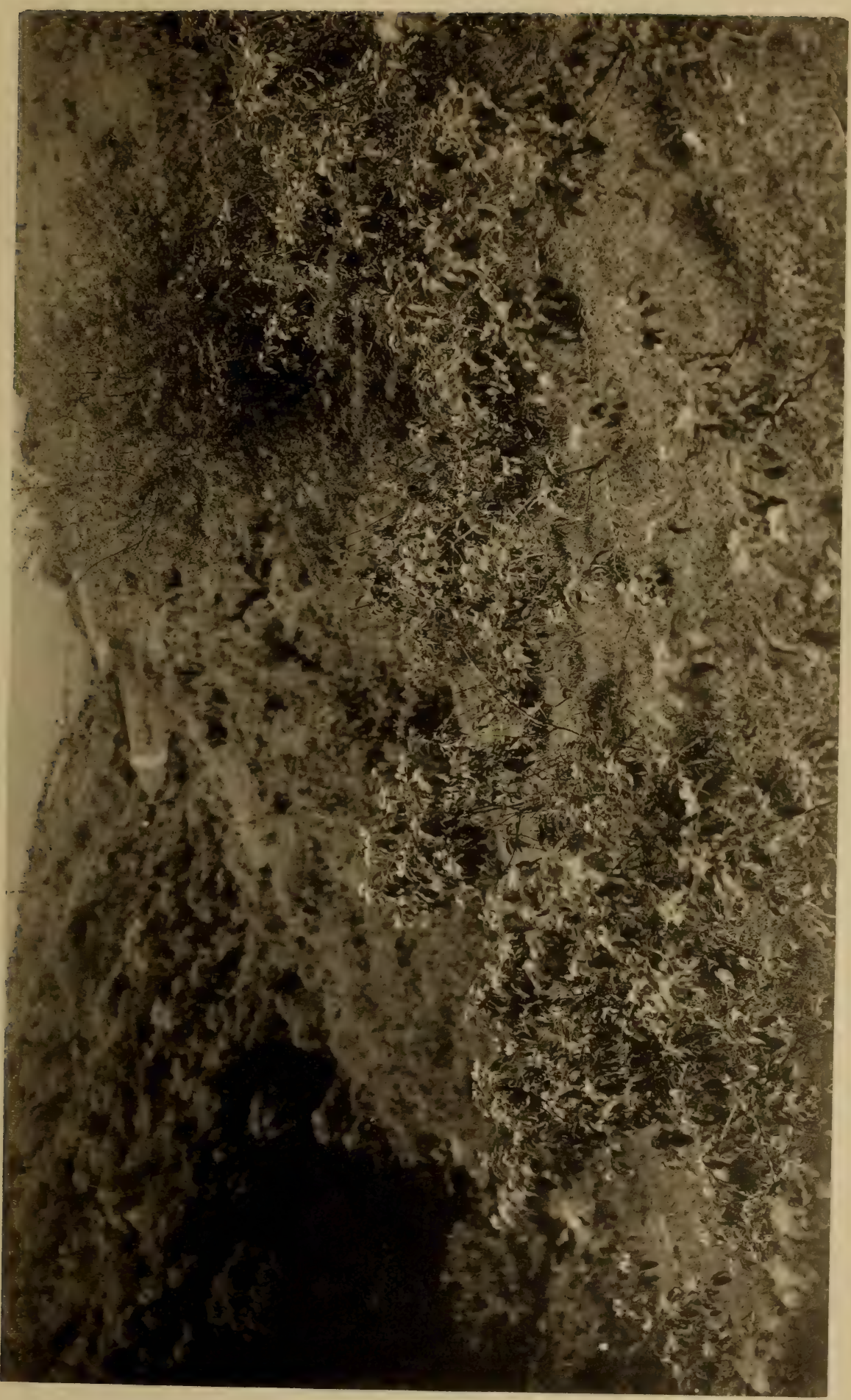



basins like the Valley of Mexico, where were located great Tertiary lakes which have been filled with sediment and volcanic ejecta until only remnants remain, as, for example, the shallow lakes in the Valley of Mexico. In these lakes various 'Tertiary land vertebrates have been preserved. Subsequently, the whole area was elevated and the precipitation lessened, and the lakes began to dry up, the volcanic ejecta and the sediment brought down from the surrounding mountain ranges was too abundant to be removed by the streams, and the old valleys became filled up with a thick covering of adobe soil, largely of modified volcanic débris. The area now presents all of the characters of a mountain park or basin.

This region has served as a second center of dispersal for these beetles, and one in which new forms have originated and are probably now being produced. Beyond doubt multitaniata is the parent form of this group.

In its habitat multitcniata is a typical grassland form, where it feeds upon Solanum rostratum or its allies, and has a much wider habitat than any of the preceding species. It is most abundant about Puebla and in the Valley of Mexico, especially upon the western side; and it becomes less and less common to the eastward and to the north until it finally vanishes. The food plant is generally distributed, especially about places where cattle, horses, or burros are pastured or in waste places, the seed being carried to these places in the hair of the animals. The general aspect of its habitat is shown in the photograph on plate 5 , which shows an almost pure steppe.

As in the preceding species, the control of the distribution within the habitat is dependent primarily upon moisture which is regulated by soil and the precipitation. The soil conditions demanded are a fine, moist adobe earth, so situated as regards drainage, either by streams, ditches, or a porous subsoil, that it shall not remain saturated with water for any length of time. If the soil remains saturated, or if it dries out too quickly, fatal results will rapidly follow to pupæ or æstivating imagines and will produce a high rate of mortality, if not complete extinction. Over the Valley of Mexico and about Puebla the optimum conditions are extensively developed, but even in these places the beetle thrives best near a ditch or the edge of a small stream (plate 6), which is cut deep enough so that the danger of overflow is slight, insuring adequate drainage and an abundant supply of telluric water. Over the Plains of Apam the soil conditions are more variable, and, consequently, the distribution is much less uniform than in other portions of the habitat. The hillsides, talus slopes, or water-washed sands are tabooed, as also, to a less degree, the low, marshy areas. The condition demanded for existence by $L$. multitcniata are much like those of the preceding species, but the distribution in isolated colonies is not found. The continuous distribution so characteristic of this species is due to the topographic development of the area in which it lives, which has produced over wide areas the conditions requisite for proper habitat formation. It is of interest to note in connec- 
tion with the horizontal extent of its habitat that this species shows the greatest range of individual variation of any in the group, a condition dependent upon fluctuating differences in its habitat which are sufficient to produce marked individual variation, but are not of enough magnitude to act as barriers to its distribution. From the optimum conditions there is a continuous series of gradations in the environment to the minimum, whereas, in the case of the species previously described, the changes in the habitat are rapid, often abrupt, and serve as effectual barriers.

Closely associated with this species are the forms or species melanothorax, oblongata, intermedia, rubicunda, and decemlineata, which are the direct descendants of this ancestral stock. In some cases the difference between the species is so slight that separation is difficult, and is especially so in museum material. In life, however, the differences are abundant and definite, so that the various species can be recognized easily.

LEPTINOTARSA OBLONGATA.

This species, clearly distinct from the preceding, has been by previous writers confounded with multitaniata. The food plant and the conditions which govern its position in any particular place are the same as for multiteniata, and need not be restated. In the upper part of the Rio Atoyac Valley the two species live together upon the same plant, but are, as I have determined by breeding experiments, physiologically isolated. The same is true in the Valley of Mexico, where this species also occurs, although rather sparingly. From the Plains of Apam this species extends southward into the Rio Balsas Valley and the Oaxaca-Guerrero Highlands, but does not reach as far south as the Isthmus of Tehuantepec. Everywhere its habitat is narrower than that of the preceding species, and its range of variation is less. This form is a direct descendant of multiteniata, which has become established in the region where it now lives.

\section{LEPTINOTARSA MELANOTHORAX.}

Associated with multitaniata is a form described under the above name. It is never common only a few specimens appearing at any one time. Its food is Solanum rostratum, and the controlling factors of its habitat are the same as those for multitceniata. Its distribution is irregular, as is also its occurrence in any locality. I have reared this form from eggs laid by multitaniata. It is an elementary species which appears at various localities at frequent intervals, but which has not yet been able to become established as a member of the fauna of the habitat into which it is born. The point to be noted in this connection is the fact that the appearance of this elementary species occurs at several points rather constantly, as is shown in the data of its distribution. We shall have occasion to consider this case again in a later portion of this paper. 
PLATE 5.

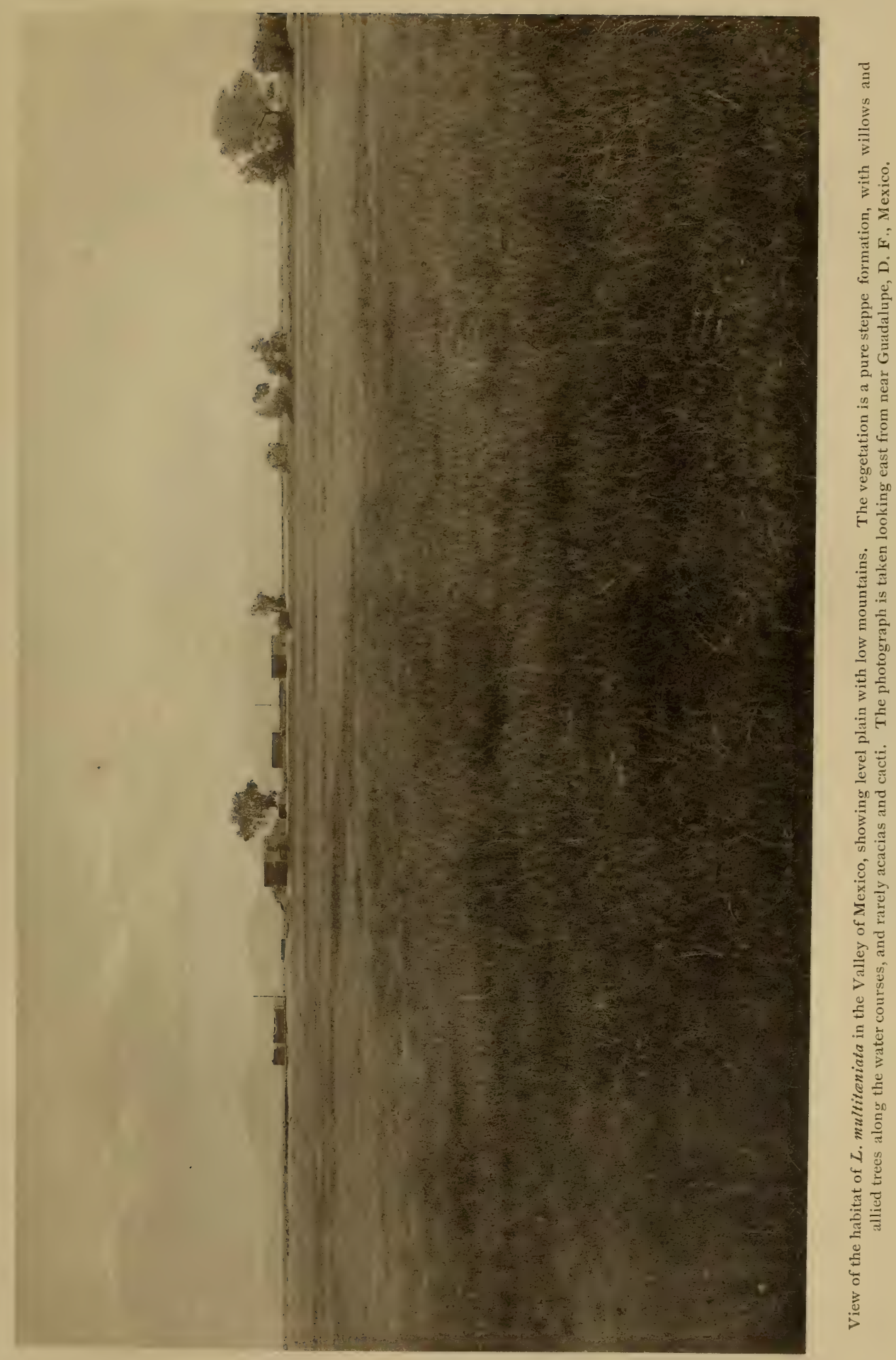



LEPTINOT ARSA RUBICUNDA.

At Toluca, Mexico, at an altitude of 8,500 to 9,000 feet, is found another form, derived from multitaniata, with which it lives. This form (rubicunda) is, however, able to maintain itself only within a narrow area as a member of the fauna. Its distribution is shown on plate $I$. As far as I am able to determine, the habitat of this form is limited to the flat plain about Toluca, where it lives upon Solanum rostratum in physiological isolation from multitceniata. It is able to reproduce itself without change, as I have proven by breeding it for six consecutive generations. This form is a developing species, as is shown by the fact that my specimens of multitaniata from Toluca have given me as an extreme variation a form exactly like the rubicunda which I obtained at Toluca. These extreme variations were almost completely sterile when crossed with the parent species, but freely fertile when crossed with the rubicunda strain from Toluca. This experimental evidence I shall present in detail in another chapter of this paper, but the facts above noted are strong enough evidence to serve as a basis for asserting that rubicunda is a species which is able to maintain itself as an independent member of the fauna of its habitat. Whether it can do this to the extent of widening its boundaries and adapting itself to slightly changed conditions only time, careful observation, and experiment can determine. ${ }^{1}$

\section{DISTRIBUTION OF LEPTINOTARSA INTERMEDIA AND DECEMLINEATA AND PROBABLE MOVEMENTS WITHIN HISTORIC TIME.}

\section{LEPTINOTARSA INTERMEDIA.}

Over the central table-land in the valleys of the Rio Panuco, the Rio Grande de Santiago y Lerma, and the Rio Grande systems, and throughout southern and western Texas, New Mexico, and Arizona occurs, sparsely distributed, another form, to which I have given the name intermedia. Its food and habits and the conditions of its habitat are the same as those of multitceniata, excepting that it occupies a region of much less rainfall. Like multiteniata, it shows a wide range of individual variation corresponding to its horizontally extensive habitat. The distribution is decidedly discontinuous, due largely to the conditions of climate, and more remotely to topography.

In the southern portion of its range this form merges with multitaniata and to the north with decemlineata. Over most of its range it is in life distinguishable from either of these species by constant characters in both larva and adult.

The distribution of this form within the area occupied by it is not to any great extent controlled directly by topography, because everywhere proper conditions of topography and soil are present. The relative humidity and

\footnotetext{
${ }^{1}$ The distribution of L. rubicunda was in September, I906, limited to a tract of about Io acres in extent, where only a very few specimens were found. In August, I903, it was found over an area of some 7 or 8 square miles. Apparently it is being exterminated,
} 
rainfall are the controlling factors. Whenever and wherever there is sufficient moisture this species and its food plant thrive; wherever moisture is lacking for a year both fail to develop and lie dormant in the earth in æstivation until such time as the rains come to awaken them. This direct control by the precipitation is productive of an irregular distribution and complete absence from many otherwise favorable localities, and is due to its living in the transitional zone between grasslands and desert. The photograph of its general habitat (plate 7) shows the nature of this zone.

A rather striking feature of the distribution of this species is the fact that it is most abundant along highways of human traffic, and often present there only. Since the beginning of the occupation of northern Mexico by the Spanish two chief routes of travel to the north, those along the eastern and western edges of the plateau, have been in almost constant use. Along these-the eastern leading into Texas, the western into New Mexico and Arizona-Solanum rostratum is distributed as a weed, growing largely, not as a native plant, but as one introduced through transportation by beasts of burden. It everywhere grows best about corrals, stables, and watering places where cattle congregate. Mr. Pringle, who for twenty years has studied and collected extensively the flora of Mexico, tells me he is fully convinced that these plants, as well as others, have been carried from places in southern Mexico northward into the regions where we now find them by Spanish pack-trains and caravans. From the study of the distribution of intermedia, I had also come to the conclusion that these insects had been able to spread northward only by means of some outside help, and Mr. Pringle's observations concerning the food plant is strong evidence in support of this conclusion. It is highly probable that previous to Spanish occupation and exploration these beetles and their food plant were limited to the area at present occupied by multitaniata.

From the conquest of Mexico, in I52I, until the close of the sixteenth century numerous exploring expeditions traversed the country north, west, and south. Early in the seventeenth century colonies were established in northern Mexico, Texas, New Mexico, and Arizona, and the final conquest of these regions was completed in 1691 . It was during this period that the main routes of travel to the north became established, and it is probable, if the above hypothesis be true, that it was during this period that Solanum rostratum and $L$. multiteniata were able to extend their habitats into the northern part of the Mexican area through aid in transportation. L. intermedia, therefore, has probably occupied its present area of distribution since early in the eighteenth century.

Whether the above hypothesis be true or not one fact is certain, that intermedia exists to-day most abundantly along the three chief routes of Spanish travel and commerce, and often there only. No feature of topography or climate could be productive of such a distribution. Moreover, I have found 


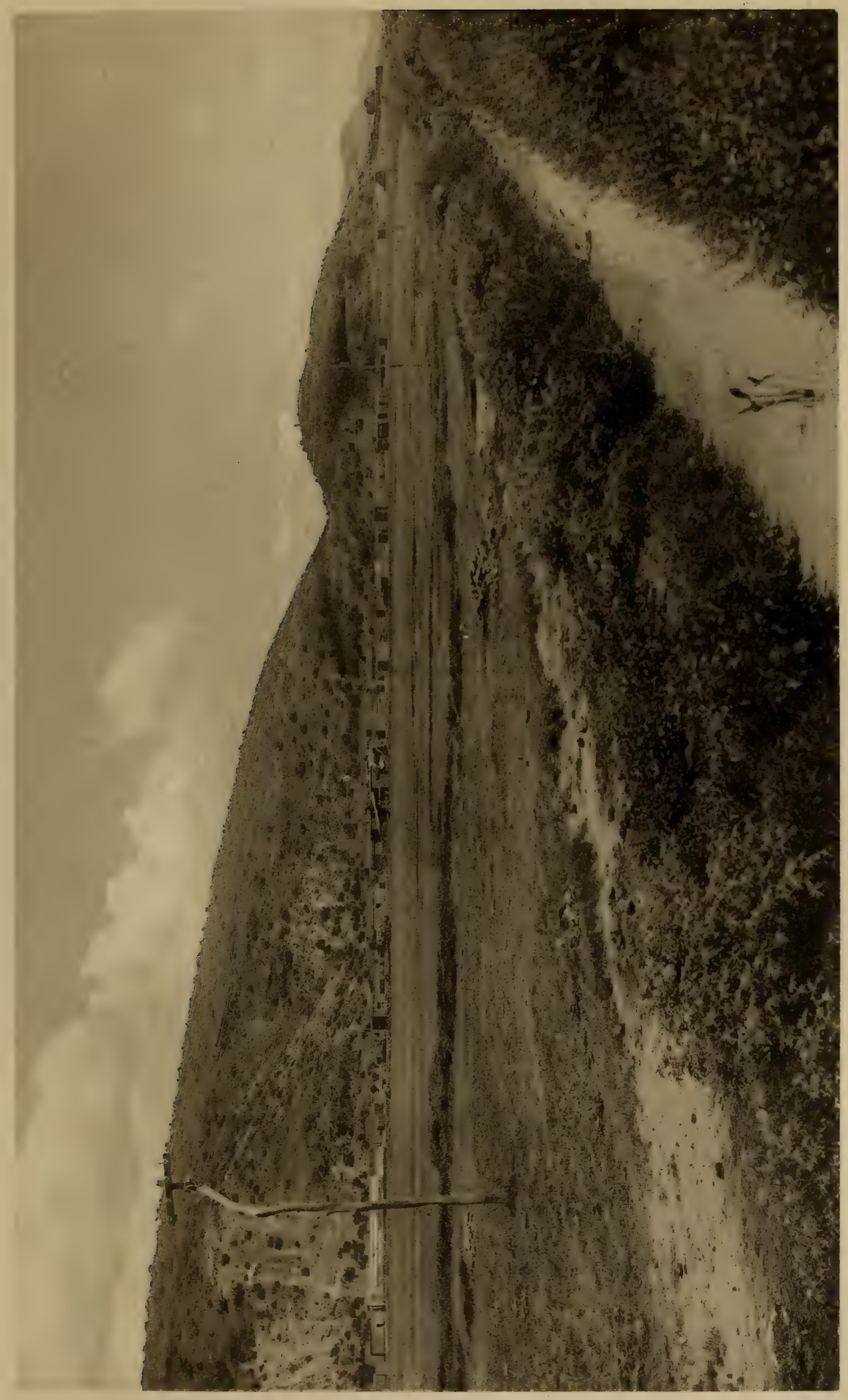

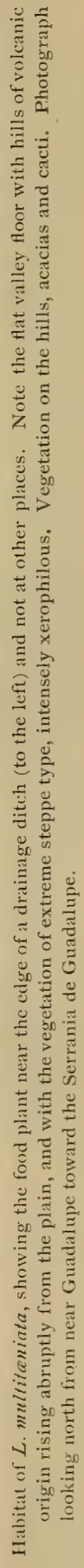



in several instances that as new routes of travel become more and more commonly used, as, for example, those leading to irrigated arid lands, S. rostratum and $L$. intermedia soon increase along these lines and enter areas not hitherto occupied by them.

LEPTINOTARSA DECEMLINEATA PREVIOUS TO 1859.

Greater doubt exists concerning the original distribution of this species than of that of any other. I have shown it to be highly probable that the movements of Spanish travel and commerce resulted in the dispersal of Solanum rostratum, an essentially tropical plant, into Texas, New Mexico, and parts of Arizona. We know that this plant was and is now found farther north than the most northern limits of Spanish activity, and we may now inquire into the factors which were possibly active in its dissemination over the Great Plains as far as the boundary between the United States and Canada.

Solanum rostratum grows best about places where cattle congregate, especially about drinking places and wallows, although it is found elsewhere. Its seed pods are well adapted to being transported by large mammals, being armed with hooks and spines, which provide efficient means whereby they are held in the hair of the cattle and thus carried often for long distances. That this method of transportation has been the means of spreading this plant over the country to the east of its original habitat is a fact known from many records. I have often observed burro trains, cattle, and horses which had gathered at places where Solanum rostratum was growing to leave these places with its burs entangled in the hair of their coats so firmly that a considerable journey might be completed without their becoming dislodged. This plant is therefore liable to be carried in any direction by cattle, but principally in the lines of travel followed by packtrains. The heavy seeds, devoid of any means of dispersal, are largely dependent upon this means for their dissemination. If we grant that Spanish caravans brought this plant into Arizona, New Mexico, and Texas, and that without outside assistance it would be impossible for it to spread long distances to the north of the range of Spanish activity, what agencies were present in this portion of North America at this time that would be able to bring about this result?

The agents most likely to do this seem to be, first, migratory mammals ; second, wandering bands of men, and third, possibly, birds. Other agencies, such as wind, water, and storms, are clearly of little effect in this case. The third agency suggested is also of such slight importance, if of any, that we may as well discard it at once. Of the two remaining possibilities it seems to me that the first has in this case by far the stronger hold upon our attention and the greater chance of being a true cause of dispersal. It is known that huge herds of bison on the Great Plains ${ }^{1}$ migrated south into Texas

\footnotetext{
${ }^{1}$ Although the bison ranged much farther east at this time, the huge herds of the Great Plains seem to have been distinct from the eastern bison.
} 
and New Mexico in the winter and north in the summer, and further, that the area throughout which this plant was found before it began to spread eastward was coincident with the range of the Great Plains herds of bison at the end of the eighteenth century. Now, while I have often seen the burs of this plant clinging to the hair of cattle, I have not seen them on bison and know of no record of it ; but if they will cling tenaciously to the hair of the cattle of the Great Plains to-day, there is no reason to believe that the thick, curly hair of the bison would form a hold any less secure. On the contrary, the bison would be a far more efficient agent of dissemination because of the ease with which the seed pods would become firmly entangled in its hair and be transported perhaps to great distances.

We know from actual records that this plant has advanced steadily eastward in the last fifty years, chiefly by the means of transportation described above, and if this has been its method of dispersal in recent years, in the absence of evidence that conditions have changed we must regard the same method as the essential one in the time before records were made.

Wherever the food plant goes the beetles go also, provided the soil and climate are favorable, and over the area now occupied by Solanum rostratum conditions for the existence of $L$. intermedia were favorable. Into this region these beetles must have spread gradually, and on the eastern slope of the Rocky Mountains have undergone modification which resulted in the production of $L$. decemlineata. The original distribution of decemlineata was on the eastern slope of the Rocky Mountains northward to the Canadian boundary, eastward into western Kansas and Nebraska, and southward into Texas and New Mexico. In this habitat it was found by Say in 1823 . Then, as now, it was probably sparsely distributed over the area, feeding upon Solanum rostratum. I know of no record of its having been found at an elevation of over 8,000 feet, or in the Great Basin.

In this habitat it remained in stability until 1845 or 1850 , when the western extension of human colonization introduced into its habitat a new factor by the addition to the flora of a new plant, Solanum tuberosum, which proved an acceptable food.

About I 845 or 1850 the settlers in the Mississippi Valley, in making their advance westward, brought the cultivated potato into the edge of the habitat of decemlineata, where the beetle soon learned to use it as a food. This extension of the area wherein $S$. tuberosum was grown into the habitat of decemlineata resulted in the removal of a previously existing barrier to further eastward dispersion. This barrier was the wide stretch of country in which no food plant had hitherto been available and into which it could not go without food. The advent of this new food, however, completely removed the barrier, and there lay open to the eastward an expanse of territory where optimum conditions of existence were developed. Into this 


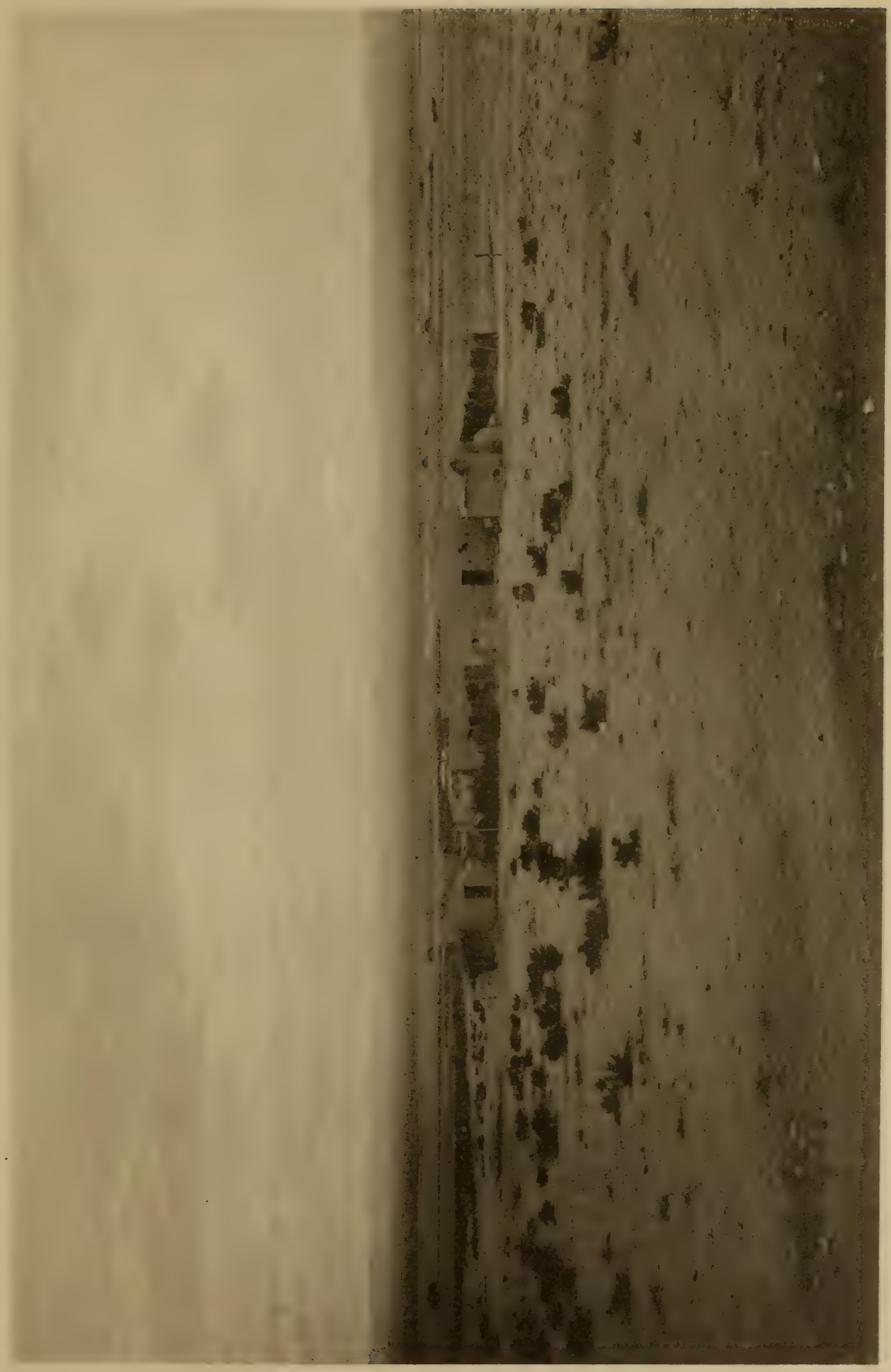



area it began to spread-at first slowly and in small numbers and unnoticed; then in increasing numbers and more rapidly, making itself felt as an economic factor in agriculture. Onward it advanced yearly, in increasing numbers and speed, until in twenty years from the time of its start it had reached the Atlantic Ocean, a barrier heyond which it has not been able to successfully pass. Fortunately the history of this advance is known from extensive records, so that it can be traced in detail from year to year.

CHRONOLOGICAL HISTORY OF THE DISPERSAL OF LEPTINOTARSA DECEMLINEATA, 1859 TO 1904.

Change or extension of habitat is apparently a common phenomenon. I say apparently common, because we suppose that this has happened and is going on continuously in the life of all species of animals ; but those that we can trace and study from year to year are few. It is true that cases of which we have records enabling us to trace the dispersal may not add extensively to our ideas or speculations as to what the results of dispersal and change of habitat have been; they are, however, of prime importance in judging the results derived from less certain cases and in keeping speculation within bounds. Hence is presented in this place the history of the dissemination of decemlineata as it has been worked out from records and data of diverse kinds.

It has already been shown from whence this beetle came and how it probably attained its center of dispersal along the eastern slope of the Rocky Mountains, where, for a time at least, it was in a state of stability. It has also been shown how a very slight change in the flora of the habitat was sufficient to upset the stability of the species and to start it upon a prolonged and extensive dispersal. I shall now present the history of this dispersal year by year and then consider it for information concerning the effects of climate, topography, and other factors which have influenced or controlled this dissemination.

1859. - The first recorded appearance of this beetle east of its original habitat was for the year 1859 by Hazen (1865). According to this author "the potato-bug ( $L$. decemlineata) was first discovered in 1859 about roo miles west of Omaha City, Nebraska, whence they have been marching eastward annually." No other record of this beetle for this year is known to me. I do not know on what evidence Hazen made his statement, but Walsh and Riley (I868) accepted it as correct. The delaying of the publication of this record for six years detracts somewhat from its value. However, it is of interest to note that this first discovery was in the line of the old emigrant trail from Omaha to Denver, Colorado.

I861. - The first authentic records are found in the annals of this year. At Atchison, Kansas, it was numerous and destructive. Colman (1862), 
editor of the Valley Farmer, published the following letter from Mr. Thomas Murphy of that place :

ATCHISON, Kansas, May 22, 1862 .

EDTTOR VALLEX FARMER : . . . . My object in sending them is to see if you personally or through your valuable journal can find out any method or remedy by which I can get rid of them. I cultivate about Io acres of land for the purpose of raising potatoes for my hotel ; it is situated on high prairie land. Last August, soon after a heavy shower of rain, these bugs suddenly made their appearance in large numbers on the potato vines They were so numerous that in many instances they would almost cover the whole vine. It is no exaggeration when I tell you that we have often in a very short time gathered as many as 2 bushels of them. When cold weather set in they disappeared. Early this spring I was setting out some apple trees, and away down in the hard yellow clay I found these bugs apparently dead, but put them in the sun and they immediately came to life. They have again made their appearance in my garden in large numbers. Last year they ate up everything green on the potato vines, then commenced on the tomatoes, and so on, on everything green. Strange to say, they trouble no one else.

Yours, etc.,

THOMAS MURPHY.

This occurrence some 200 miles from the point of "first discovery," in I859, is of interest. There is not the slightest doubt as to the accuracy of this record, because specimens received by Colman were sent to Walsh for identification; it, however, throws grave doubt upon the statement made by Hazen as to the "first discovery." In the sparsely settled condition of Kansas, Nebraska, and Iowa at that time the beetle would be hardly able to travel 200 miles in two years, when in the more thickly settled portions of the country it was able to advance only 50 or 80 miles in a year. It is also recorded from Gravity, Taylor County, Iowa, by Edgerton (I86I), who states "they made their appearance upon the vines as soon as the potatoes were out of the ground, and there being a cold, wet spell about that time they devoured them as fast as they were up."

These two occurrences, so widely separated from the record of 1859 , are very conclusive evidence that the beetle must have been much farther east in 1859 than Hazen's record places it. The records at Gravity, Iowa, and Atchison, Kansas, are not those of first introduction, but of first ravages, which always occur from two to four years after the date of actual introduction. It is therefore certain that the beetles were in western Iowa and eastern Kansas in $185^{8}$ or 1859 , if not at an earlier date. This date places the front of the advance for the year I86I somewhat to the east of Gravity, in Iowa, and Atchison, in Kansas (plate 8), and it is certain that the advancing hordes had reached the two points mentioned by 1860 , if not before, and I have drawn the yearly lines of advance according to this interpretation of the data.

1862. - In this year Emery records the presence of the potato beetle in Crescent City, Pottawattamie County, Iowa, where it "first appeared" in I862. Specimens were sent to Walsh for identification, hence the record is accurate. In this case the first record of appearance is also one of first 
ravages, as is evident from Emery's statement-" they infest the potato, egg-plant, tomato, and horse nettle."

The editor of the Wisconsin Farmer (April I3, I867) states that he found this beetle abundant in Grant County, Wisconsin, as early as I 862, although no specimens were seen from that locality in that year by any entomologist. The publication of this record five years after the date when the insect was first noticed, and then from "I remember" data, might throw some doubt upon its validity were it not true that in the near-by State of Iowa all of the records for the year are of first ravages, so that we are warranted in concluding that the State was almost completely overrun with this insect as early as I86r, and in that event its presence in southwestern Wisconsin in 1862 is most natural.

I863. - Additional evidence that this beetle was generally distributed over Iowa is furnished by the record from New Sharon, Nebraska County, where its ravages were so severe "that some were discouraged from planting potatoes" (Fitch, I863). This bit of evidence from Iowa, indicating extensive damage to the potato crop, further confirms the opinion that the beetle was in Iowa in $\mathrm{s} 860$ or earlier. In any event, the great numbers and the widespread damage to crops clearly indicate a residence of at least two or three years, and also add greatly to the probability of the correctness of the record from Wisconsin in the year 1862 .

1864. - In the records of this year we find that the beetles had crossed the Mississippi River into Illinois at several points. In August of the year I864 Walsh received specimens and the following data from the State geologist (Worthen):

It is committing the most destructive ravages on the potato crop in the vicinity of Warsaw, Illinois. I find that the same insect in the same year appeared near New Boston, Illinois. In the autumn I captured two specimens in Rock Island, Illinois, but it has not yet reached a point lying 30 miles east of us in such numbers as to be noticed by farmers. I hear that it has swarmed this year at Mount Carroll, Illinois. It does not appear to have advanced any considerable distance into the State, but it must have crossed the river into Illinois in I864-65 at five different points. The northernmost lies over 200 miles from the southernmost. These records, all setting forth the damage done, indicate an earlier introduction into Illinois than that given by Walsh, certainly as early as $\mathrm{I} 863$, so that in the year $\mathrm{I} 864$ the eastern limits of the beetle were certainly a considerable distance east of the Mississippi River.

On plate 8 the eastern limits of the beetles for this year have been drawn on the basis of these conclusions.

1865.-Abundant reports of the potato beetle in Iowa attest its general distribution in large numbers over the State. So great was the damage done that the potato crop was reduced to half the usual amount. Timble (1865) records placing on the table of the New York Farmers' Club "a large handful of letters, boxes, bottles, and packages from Iowa, all of them con- 
taining a repetition of the same sad story." We learn from this data that it required four years in which to disperse generally over the State of Iowa, to become well adapted to its habitat, and to increase sufficiently in numbers to be at the end of that time a dangerous foe to agriculture. In this year we have the first records from Calloway and Putnam Counties, Missouri, of the beginning of a southward advance. Neither record is of first introduction, because the beetle had been abundant for some years in the neighboring counties in Iowa. The record in Calloway County, Missouri, which is one of first ravages, marks the beginning of the southward extension along the Missouri-Mississippi Valley. It is probable that a large portion of the State of Missouri north of the Missouri River was quite as generally inhabited by the beetles as was Iowa.

In Wisconsin, the editor of the $\mathrm{W}$ isconsin Farmer (April I3, I867) states that the beetle was abundant in the St. Croix River Valley in I865, and that it existed in small numbers in Marquette County in the same year. It was also reported by Priest, from Mosinee, Marathon County, Wisconsin, I865, where it did great damage to the potato crop. No specimens from either locality were seen by entomologists. Walsh ( I 866b), for reasons which he does not state, doubts the accuracy of the Mosinee record, but accepts the statement of the editor of the Wisconsin Farmer, which is based upon less certain evidence. In Illinois, at Mount Carroll, it was found in large numbers ("swarms," Shimer, I865; Walsh, 1865). At Warsaw, Rock Island, and Alton it was abundant and did much damage to potatoes and egg-plants. It was reported by Riley near Chicago in small numbers (Walsh).

For the first time in the history of the advance of this beetle the records of the year are sufficiently complete to enable one to draw the eastern boundary with some degree of exactitude. The front of the distribution begins at the north in the St. Croix River Valley (plate 8), passes in a southeasterly direction across Wisconsin to Marathon County, and onwards in the same direction to the shore of Lake Michigan at Chicago. From Chicago the line runs almost straight in a southwesterly direction through Alton, Illinois, on the Mississippi River, and across eastern Missouri to the Missouri River, which it follows to the region of Kansas City, Kansas, and then runs northward across northeastern Kansas. In Wisconsin, Iowa, and Illinois the distribution of the beetle west of this line was general, while in Missouri and Kansas it was still local in character.

Walsh (I865), calling attention to the rate of advance of this insect during six years, says: "From Omaha, Nebraska, to Rock Island, Illinois, is over 360 miles. If the above statement is correct (Hazen), the insect has traveled 360 miles in six years, at the rate of 60 miles a year. At this rate it will reach the Atlantic in fourteen years" (i.e., 1879). 
W. L. TC

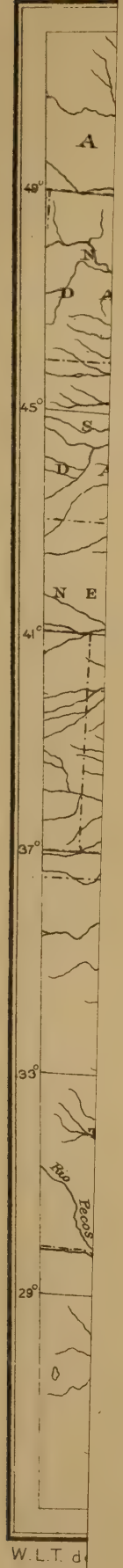





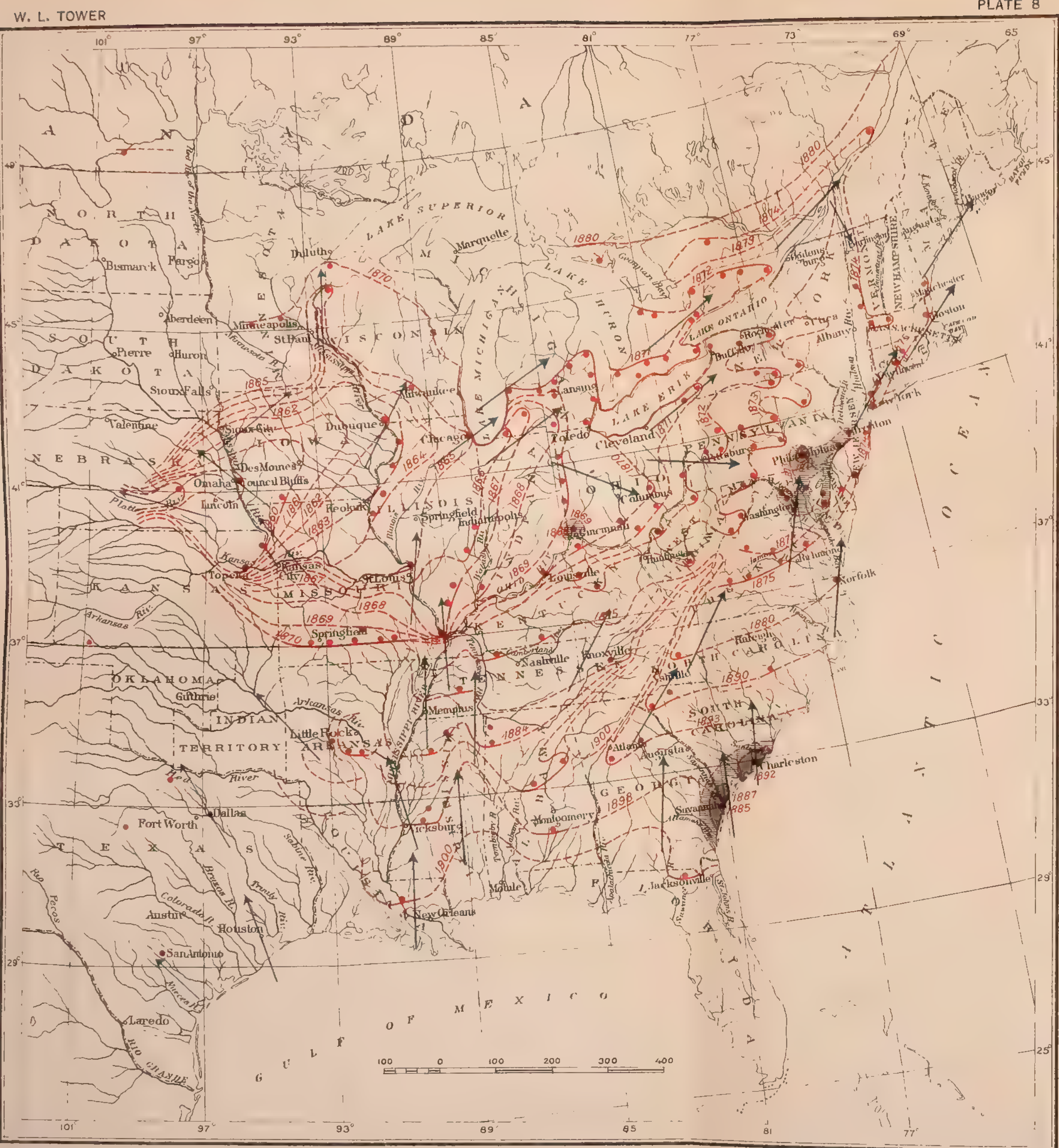

MAP OF EASTERN UNITED STATES AND LOWER CANADA SHOWING YEARLY LINES OF ADVANCES OF L. DECEMLINEATA DURING ITS EASTWARD MIGRATION, 1859-1904

Important records are indicated by red dots, advance introductions by a uniform neutral tint The prevailing direction of the wind during summer is shown by a blue arrow 

I866. - During this year the beetle spread slowly eastward, but not as far as in the preceding years. It seems to have been mainly occupied in completely overrunning the area east of the Mississippi River, which it had already covered, so that in this year it is recorded as injurious to a greater or less extent throughout Illinois and Wisconsin. In the trans-Mississippi region it does not appear to have been more than ordinarily abundant, nor to have done any great amount of damage. In the southern counties of Wisconsin considerable injury was done to the crops (Wisconsin Farmer). In Illinois it was recorded from Bloomington by Walsh ( $1866 b$ ), from Woodford County, and from Athens, Menard County, by Dodge. It was abundant in Marshall, Bureau, Champaign, Coles, and Lake Counties (Walsh), and in Winnebago County (Dodge, I866). It was found near St. Louis, Missouri, but had not been found in the southern part of the State (Walsh). In July it was abundant in Missouri at Hannibal (New York Semi-weekly Tribune, August 10, 1866), and at Florisant, in St. Louis County (Cultivator and Country Gentleman, vol. xxviIr, p. I6, July 5, I866). The only eastern advance of any moment recorded was that into western Indiana: "As I predicted, this insect has now spread into . . . . western Indiana. According to Dr. Worthen it occurred in this locality even in 1866." It was also recorded from Hardin County, Kentucky, and from Indiana County, Pennsylvania (Dodge), but no specimens were seen, and the records are clearly inaccurate.

The eastern front of the recorded area of distribution at the end of this year follows the same general course as the boundary for I 865 , excepting that it has advanced from 50 to 70 miles. The southward extension does not appear to have been great, but the lack of records indicates only a freedom from injury to crops. Throughout most of the infested area the insect was moderately abundant and destructive, but in the following year there was a marked decrease in the number of individuals and in the consequent ravages. I867. - From Indiana the beetle spread eastward into southwestern Michigan, where it was reported by Gage (I867) at Dowagiac as having appeared for the first time. It had covered the entire northern and central part of Illinois and northern and western Indiana, and had spread into southwestern Michigan (Rep. Ind. Hort. Soc., Jan., I 868). In the same year Dodge (I867) records "fearful" ravages in De Kalb and Putnam Counties, Illinois, and its rapid spread and general destructiveness in Brown County, Wisconsin. According to Walsh (1867a), it invaded the southern part of Illinois, being recorded from Union, Marion, and Effingham Counties. Over the infested area as a whole the beetle caused little damage to crops, and, as a result, the records of this year are few and show no great change in the area of distribution. The eastern boundary was advanced about 50 miles, excepting on the south in Illinois, where there was a rapid progress to the lower part of 
the State. The recorded dates and occurrences make the spread seem rapid, while in reality they are merely notices of first damage to crops. In the following year the insect was more numerous and covered more new ground to the east.

I868. - Several important and interesting records are found in the annals of this year. In the north Gilman (I870) states: "Last summer (1868), to my sure knowledge, it had reached the south shore of Lake Superior and the northwest corner of Michigan, where it abundantly manifested its presence." In Minnesota it was found in Houston County (Am. Agr., vol. 27, p. 248 , I867), and in southwest Michigan it was reported as numerous by Gage, who kept careful records of its numbers, ravages, habits, and foes. Gage states that it was abundant at Dowagiac, Cass County, and appeared for the first time at Decatur, Van Buren County, I 2 miles northeast of Dowagiac. We know nothing of its distribution in the southern counties of Indiana, but in the northeastern it continued to move slowly eastward, reaching nearly to the Ohio State line. Dodge records the beetle as injurious in Columbia, Jackson, Green, Lake, Brown, Vernon, Douglas, and Bayfield Counties, Wisconsin, in Appanoose County, Iowa, and in Ford County, Illinois.

In this year is recorded the first unquestionable introduction in advance of the general horde. The editor of the Ohio Farmer (July, I868) writes as follows: "We have now to record the actual presence of . . . . D. Io-lineata in the southwestern corner of Ohio, a very few specimens of this pest having been taken within the past week in Hamilton County." The main body of the beetles was still orer roo miles away. This introduction seems to have come from the region of Cairo, Illinois, or St. Louis, Missouri, by means of the steamers or barges which are constantly passing up and down the Ohio River. I am sure that the coal barges which go down the river from Pittsburgh, Pennsylvania, have carried into the States along the Ohio River, and perhaps also into the lower Mississippi Valley, many of these beetles from Pennsylvania and Ohio. In August, 1900, at McKeesport, Pennsylvania, I counted 52 of these beetles on one barge of a "tow" loaded and on its way to New Orleans, Louisiana, and as there were eleven barges in this "tow," it is a low estimate to say that altogether it was probably carrying 300 or 400 beetles south into the lower Mississippi Valley. The vicissitudes of such a journey are great, but it would seem that at least I or 2 per cent of these beetles might stand a fair chance of reaching the lower part of the river valley

I869. - The river barges are probably also responsible for the occurrence of the beetle so far ahead of the general horde, not only in Hamilton County, Ohio, but also in the region about Louisville, Kentucky, where it was recorded in the following year (F. J. Key, letter to Riley in I87I). The beetle was less abundant in this year than during the previous one, doing but little damage and attracting but little attention. In the following year 
the numbers increased, and the data affords many interesting cases of rapid advance in various directions.

I870.-In the trans-Mississippi region the beetle was numerous, but the injury done was local and due almost entirely to ignorance or to indolence on the part of those farmers who had not yet learned how to deal with the pest. In subsequent years, although the beetle was abundant, few records occur of "great ravages."

In Michigan the advance was definitely in a northeasterly direction. The concise reports for the years of the migration of this beetle over the State enable us to trace with precision the spread from county to county. It had covered about half the southern peninsula of Michigan, being numerous in most of the counties and doing considerable damage. The returns of the county agricultural societies report it as present in Barry, Cass, Eaton, Genesee, Hillsdale, Ingham, Lapeer, Shiawassee, and Tuscola Counties (Rep. State Bd. Agr. Mich., I870), and in Marion County (Dodge, 1870). In Ohio, Richmond (Rep. State Bd. Agr. Ohio, I871, p. 542) records the beetle from the garden of J. H. Klippert, in Erie County, and Dodge records it from Van Wert and Mercer Counties. It was also reported by others from Butler, Champaign, Henry, Hocking, Miami, Morgan, Pickaway, Preble, Putnam, and Shelby Counties (Ohio Agr. Rep., I870). In Missouri it was recorded from the vicinity of Springfield by Holman, and from Greene, Webster, Phelps, Reynolds, Dent, and Texas Counties by Riley (187I). Shirner reports that it was present in the vicinity of St. Paul, Minnesota, and that in Indiana and Illinois it was abundant in some places and not in others. South of the Ohio River it was recorded from Covington, Kentucky (Riley).

The front of the recorded distribution for this year is materially different from that of 1868 or 1869 . Beginning in the north near Bigstone Lake, Minnesota, the line runs eastward to Minneapolis and northeast to the head of Lake Superior, then southeast and by east across two-thirds of the northern half of Wisconsin, and then south and southeast to Grand Rapids, Michigan. From Grand Rapids the line runs easterly, and then northeasterly to the head of Saginaw Bay, then turns south to Detroit and follows the lake shore to Erie County, Ohio, and then southeasterly to Morgan County. Thence it follows the Ohio River Valley into the south, crosses Missouri to Springfield, and passes west into Kansas, where we have no data of its distribution. The distribution shows for this year a remarkable advance in two directions-in Michigan to the northeast, and to a great excess over the usual 70 or 80 miles covered annually; and in Ohio to the southeast, where the rapidity of advance was so great that the horde along the Ohio River outstripped all others in the race towards the Atlantic Ocean. The rapid advance in Michigan, as also that in Ohio, was due to the fact that the axis of the advance was in the track of well-developed winds, $i . e$, the prevailing westerlies. 
$I 87 I$. - Over the whole of the infested area the beetle appears to have been more numerous this year than during the two or three preceding. Riley (I87I) gives the following account of an occurrence in the Lake Superior region :

Juno Hurlburt, who has been engaged in surveying and prospecting in that part of the country, ... found them in immense quantities in a potato field belonging to some Indians on the Menomonee River, yet this potato patch was on a clearing of about 20 acres, and to his certain knowledge there could not have been another potato patch within 150 miles.

Riley attributes this occurrence to their being carried down stream to that point. Dodge records the beetle as iniurious in Columbia, Ozaukee, Outagamie, Portage, Richland, Dane, Fond du Lac, Green Lake, Iowa, Juneau, Kenosha, St. Croix, and Sheboygan Counties, Wisconsin; in Fillmore, Carver, Houston, Kandiyohi, Meeker, and Ramsey Counties, Minnesota ; in Barry, Bay, Cass, Kent, Kalamazoo, Monroe, Newaygo, Ottawa, and Van Buren Counties, Michigan, and in several counties of Ohio, Indiana, Illinois, and Iowa. It was also found in Livingston, Manistee, Saginaw, Shiawassee (crop a failure), and Tuscola Counties, Michigan (Rep. Sta. Bd. Agr., I87 I), while south of the lakes it had spread from eastern Ohio into western Pennsylvania and New York. In Missouri the southward spread was slight. "It has not yet reached the southern counties"' (Riley).

The chief event in the history of this year's spread is the invasion of Canada. The beetle had been abundant in eastern Michigan and Ohio, especially along the shore of Lake Erie, but before the end of the year it had crossed the lake and overrun a large portion of the Province of Ontario. Riley (I87I) describes its methods of crossing the lake thus : "In the spring the Detroit River was swarming with the beetles and they were crossing Lake Erie on ships, chips, staves, and any floating object." The following agricultural societies reported its presence in their section of the country : Bothwell, Brandt (S.), Elgin (E.), Essex, Huron, Kent, Lamberton, Middlesex (E.), Oxford (N.), Simcoe (N.), Wentworth (N.), and York (N. and W.). The insect did but little damage in this year (Ann. Rep. Comm. Agr. and Pub. Work, Prov. of Ont., on Agr. and Arts, I87 I). They were most numerous on the western frontier between Sarnia, Lamberton County, on the north, and Amberstburg, Essex County, on the south, and inland from 20 to 40 miles (Sanders and Reed). They were found along the north shore of Lake Erie in small numbers as far east as Toronto, York County.

The front of the area occupied this year is bounded by a line which, beginning at the western end of Lake Superior, runs southeasterly across the middle of Michigan to Saginaw Bay; thence along the shore of Lake Huron to Port Huron, across the St. Clair River to Sarnia, in Lamberton County, through Stratford, in Perth County, to Toronto, in York County; thence 
back along the southern shore of Lake Erie to western New York and Pennsylvania; thence in a southwesterly direction to the Ohio River Valley, and having followed closely along the valley to Cairo, Illinois, passes westward across the lower part of Missouri into Kansas (plate 8).

1872. - Over the whole of the area occupied by this beetle there was a decrease in numbers this year, which, in Wisconsin, amounted to over 50 per cent. Dodge also states that in Michigan, Ohio, and Illinois the beetles were not as abundant as in I87I; that in Missouri they were numerous in Phelps, Perry, and Franklin Counties, and were spreading south, but had not yet reached the southern counties, and that in Kansas they were found in small and constantly decreasing numbers. Along the Ohio River they extended east to Harrodsburgh, Mercer County, Kentucky (J. B. Clark, letter to Riley, 1872). In Ohio they were found in every county in the State (Klippert, Rep. Sec. Sta. Bd. Agr., I872), while S. S. Rathborn reported to Riley that the beetle had appeared in Lancaster County, Pennsylvania. This latter introduction, so far ahead of the main body of the beetles, probably took place through the agency of some cargo, and was important in determining the spread of the beetles to the south and east, and in enabling them to reach the seacoast a year or two earlier than had been predicted by Walsh.

In Canada, Clementi records the beetle from North Duro, in Peterboro County, Ontario. The following agricultural societies also report its presence: Addington, Bothwell, Brandt (S.), Durham (W.), Elgin (E.), Essex, Fontenac, Grey (S.), Hastings (N. and E.), Lamberton, Middlesex (N., W., and E.), Niagara, Norfolk (N.), Northumberland (W.), Oxford (N. and S.), Perth (S.), Peterboro (E.), Simcoe (S.), Victoria (S.), Welland, and Wellington (N. and S.) (Rep. Comm. Agr. Ont., I872). It gradually spread eastward through Ontario, reaching Kingston in September (Rogers, I872). It was abundant in most of the western counties of the Province of Ontario, but did comparatively little damage.

The boundary, which in Wisconsin and Minnesota changed but little from that of the previous year, crossed Lake Michigan in the region of Manistee, and passed due east across the State and through the northern part of the Province of Ontario to Kingston, whence, turning back, it retreated along the northern shore of Lake Ontario to the Niagara River, crossed over, and then followed the southern shore of the Lake and inland to the region of Syracuse, New York; thence southeast in a tongue-like projection to Elmira, New York; then back along the shore of Lake Erie. Here there is another tongue-like projection into western Pennsylvania, and then the line turns back and westward along the Ohio River Valley, with the beginning of tongue-like projections into West Virginia and Kentucky. 
The feature of most interest in this year is the rapid spread over Ontario and the advance down the St. Lawrence River Valley. Of interest also is the rapid pushing out of projections along the natural highways which penetrate the Appalachian highland and afford easy passages to the Atlantic coast area.

I873. - In this year, over most of the area in which the beetle was now a resident, it was found in only moderate numbers, although it was abundant in some counties and did more or less injury to crops. In Minnesota, Wisconsin, Michigan, Iowa, Illinois, Indiana, and western Ohio almost no damage was done, and consequently it passed almost unnoticed. In northeastern Ohio it was a pest, one newspaper describing their abundance in the following words: "Clouds of Colorado potato-beetles.... The scene suggested to Bible readers locusts in ancient days." Riley remarks that he has good authority for the statement that at best only a few dozen could be seen at one time by a single person. In this year the insect covered the whole Province of Ontario (C. J. S. Bethune), fifty-nine agricultural societies reporting its presence, but in most instances only a small amount of damage was done.

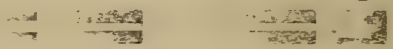

During the two years following the advance introduction into Lancaster County, Pennsylvania, which was first noticed in 1872 , the beetle advanced eastward and southward with great rapidity. It spread east into Salem County, New Jersey, and into Caroline, Dorchester, Frederick, Queen Anne, Cecil, Baltimore, and Washington Counties, Maryland (Glover). It was found in the District of Columbia, where living specimens were taken to the United States Department of Agriculture for identification. It was also found in Prince William and Page Counties, Virginia, and in Butler, Clearfield, Franklin, Northampton, Perry, Bedford, Huntingdon, Cambria, Juniata, Armstrong, and Indiana Counties, Pennsylvania (Glover). In New York it was reported from Erie County, and in West Virginia from Monroe, Preston, Hardy, Jefferson, Marion, Brooke, Tyler, Fayette, and Pleasants Counties (ibid.). No specimens were seen from these West Virginia localities. It was also recorded from Nicholas, Anderson, Clarke, Lexington, and Fayette Counties, in Kentucky, and from Fentress County, in Tennessee.

The boundary of the invasion in Minnesota and Wisconsin does not change in this year; in Michigan it has moved northward, but is parallel with that of the preceding year. From Michigan the line crosses Lake Huron to Georgian Bay, passes along the northern border of the Province of Ontario and the St. Lawrence River Valley to near Montreal, where it turns southward in a tongue along the Lake Champlain Valley, then westward along the southern side of the St. Lawrence Valley to western New York. In New York, Pennsylvania, and West Virginia the tongue-like projections 
noticed in the preceding years have now almost completely penetrated the Appalachian highland, and in Pennsylvania and Maryland they have nearly united with the Lancaster colony.

1874. - From the region west of New York and Pennsylvania but few records are found in this year's reports, although the beetle was numerous and destructive in almost all of the counties of Ontario. The center of interest was along the Atlantic coast, where in many places it was abundant and did much damage. It was found in Quebec in small numbers and in western Vermont (C. J. S. Bethune). It was also reported from Williamstown, Massachusetts (J. S. Kingsley), and from western Connecticut (New York Weekly Tribune, August 26, 1874). In New York it was recorded from Allegany, Chautauqua, Delaware, Erie, Madison, Tioga, Wayne, and Wyoming Counties ; in New Jersey from Burlington, Gloucester, Monmouth, and Salem Counties; in Delaware from Kent County; in Maryland from Allegany, Baltimore, Caroline, Cecil, Carroll, Dorchester, Frederick, Harford, Montgomery, Prince George, and Queen Anne Counties; and in Virginia from Culpeper, Fauquier, Greene, Highland, Page, and Prince William Counties (Mo. Rep. U.S. Dept. Agr., 1874). Almost every county in Pennsylvania was invaded by the beetles, and at many places they were numerous and did considerable damage. At Germantown they swarmed (Riley, I874), as also at Cape May, New Jersey (New York Weekly Tribune, July 22, 1874).

I875. - At the beginning of this year the beetle was distributed along the seacoast from New York to Chesapeake Bay, and by the end it had overrun most of the remaining territory of the coast States. It reached Boston, Massachusetts, in the autumn. It penetrated farther into Vermont and was reported from New Hampshire and Maine. It was found in the central portion of the latter State, which led Fernald to believe that it was taken there by rail. It was reported from Skowhegan, Somerset County, from Saco, in York County, and Temple, in Franklin County, Maine (Packard), and it seems to have penetrated as far as the Kennebec River (C. H. Fernald). In New York, Pennsylvania, New Jersey, Delaware, and Maryland it was generally distributed ; but in Virginia, West Virginia, and Kentucky it had not extended any farther south.

I876. - Eastern Connecticut, Rhode Island, and Cape Cod do not seem to have been occupied until 1876 . The insects were abundant and did considerable damage in many of the counties of the New England States. It is related that they were washed ashore in many places in such numbers as to poison the air with the "noxious vapors" arising from their decaying bodies. The captain of a New London vessel relates "that while at sea (Long Island Sound) they boarded him in such numbers that the hatches had to be closed." At Cape May, Long Branch, Rockaway, and Newport they proved a great nuisance to the pleasure seekers, being crushed and killed in 
large numbers by the continual promenading along the beach; while in New York they are reported to have stopped a train upon the New York Central Railroad (New York 'Times). They' were abundant everywhere and by the end of the year had overrun the entire northern and eastern part of the United States, excepting northern Maine. In Canada they were still spreading to the northeast along the St. Lawrence River Valley. In Virginia the boundary was pushed south into the highlands, but remained stationary at the seacoast; while in Kentucky the beetle was recorded from the southern counties of the State. In the Mississippi Valley it was slowly spreading in the south, but how fast or how far it is impossible to determine because of the lack of data from that region.

From the time the beetle had completely overrun the Northern States fewer and fewer records of it are found as the years go by, and such as are found are limited to notes and data of no value. The State reports and agricultural papers contain no more notices of its spread, and as a result the history of this beetle in the northeastern portion of the St. Lawrence Valley or the migration into the Southern States can not be followed in any detail. Almost all of the data of the southern spread for the last twenty years would be wanting were it not for the careful collecting of records concerning it by the Division of Entomology of the United States Department of Agriculture.

1877. - In this year the beetle was found in Knoxville, Tennessee (Nicholson, Can. Ent., vol. IX, p. I74, I877). This author believes that it was brought in with the seed from the north, but it is highly improbable that this method of spreading the beetle ever occurs. Seed potatoes are always sorted at frequent intervals, and I know from actual observation and experiment that the beetles do not stay in potato sacks or barrels, but crawl out at the first opportunity, and, moreover, it is not possible for them to pass the winter in such situations, as death would certainly intervene.

I878. - The continued spread of the beetle to the northeast resulted, in I 878 , in the almost complete overrunning of the Dominion of Canada. It was found at St. Johns, New Brunswick, and had spread through the Maritime Provinces (Saunders).

1879. - In this year, in the northwest, it was recorded from Manitoba (Comstock, Can. Ent., vol. XI, p. 196, 1879), where it seems to have become well established; but whether it came from the east or from the original area of distribution in the west we have no means of determining. It was also reported in May from Lynchburg, Virginia (Cor. U. S. Dept. of Agr.).

1880.-In this year the beetle was recorded from South Carolina (Riley, Can. Ent., vol. XII, p. I73, I880), and from Manitoulin Island, Lake Huron, where it had been for a number of years, but had not thrived or made any headway (Saunders, I880). In the correspondence of the United States 
Department of Agriculture it is reported from Jefferson, Marion County, Texas, in April, I880, and St. Agatha, Manitoba, in August.

1884. - In I884 the beetle was recorded in Manitoba from Manchester and Dufferin Counties and from Portage la Prairie, which would indicate that it was spreading rapidly in the northwest. In the St. Lawrence Valley, especially near Quebec, its numbers were said to have shown a marked decrease during the four years between I 880 and I 884 (Can. Ent., vol. XVI, p. 207, 1884).

1885.-Although from the south the records are meager, the spread in that direction has shown many features of interest. From I874 or I875, when the beetle had reached the middle of Virginia along the Allegheny highlands, until this year, I885, it had spread very slowly southward, and even more slowly along the coast than elsewhere; but in this year, May ro, it was found at Savannah, Georgia, on Wilmington Island (Cor. Div. Ent., U. S. Dept. Agr.). It was certainly imported into this place, probably in the hold of some vessel, where it had become imprisoned while the vessel lay at her dock in some northern port. Although it was fairly abundant there this year, no further records of it are available until March, I887, nor from that date until five years later.

I888. - For the Mississippi River Valley notes of occurrences are even more rare than for the Atlantic slope. F. M. Webster records the beetle in this year from Jackson, Mississippi, on hearsay evidence, although the record is probably valid. It was also found in Tyler, Smith County, Texas (Cor. Div. Ent., U. S. Dept. Agr.).

I889. - In 1899 Phares sent specimens to the Division of Entomology, United States Department of Agriculture (Insect Life, vol. II, p. 22), from Madison Station, Madison County, Mississippi. At that time this was the southernmost point from which the beetle had been recorded.

I890.-Earle reported it from the middle of Mississippi in this year, but said that it had not reached the southern part of the State (Insect Life, vol. III, p. 84, I890).

I89I. - In the extreme southwest it was found in Las Cruces, Donna Ana County, New Mexico (Townsend, Insect Life, vol. IV, p. 26, I89I), where it was not uncommon. In the correspondence of the Division of Entomology, United States Department of Agriculture, it is recorded from Birmingham, Alabama, in July, and from Fayetteville, Cumberland County, North Carolina. Concerning the latter occurrence the following facts are on file: Hon. William G. Le Duc, in reply to questions from L. O. Howard, states that the beetle first appeared there in abundance in I89I, so that he places I89o as the date of introduction. They were plentiful there in 1892,1893 , and I894, but less so in 1895 . On the authority of Colonel Broadfoot, "Potatobugs appeared here four or five years ago"' (July I, I 895). 
1892. - In the northwestern part of Alabama the insect was reported as abundant (Insect Life, vol. v, p. 356, I892). It was also recorded from Yemassee, Hampton County, South Carolina, in May, and from "Hay Field Farm," Charleston Neck (Cor. Div. Ent., U. S. Dept. Agr.). The following information concerning this latter record was placed on file by H. M. Simons : The beetle, in the opinion of Mr. Simons, first appeared there in 1892 , on a nearby farm, where it was abundant on guinea squash. The bugs were hand-picked, but appeared the next year (1893) in a field across the road, where they covered an area of about 2 acres. A few bugs were found on his own farm, but they came into his fields late in the season. In I894 they appeared on March 6, on the potatoes, and gradually increased in numbers. It is evident from this account and from that of the appearance at Fayetteville, North Carolina, that the insect is far less active there as a migrant than in the States farther north.

1893. - Hubbard (Insect Life, vol. VI, p. 282, I893) reported the occurrence of $L$. decemlineata at Fort Assinniboine, Montana, where it had not come in contact with the cultivated potato. This record represents probably the northern limit of its original habitat. It was also recorded from Jacksonville, Calhoun County, Alabama (Cor. Div. Ent., U. S. Dept. Agr.).

1895. - In this year it was again recorded from Charleston, South Carolina, where it seems to have been introduced a third time (ibid.).

I896. - The only record of this year that is of importance is that at Seneca, Oconee County, South Carolina (ibid.).

1897. - More records for the beetle are known this year from the south, and they mark a considerable extension of its bounds. It is reported in May from Victoria, Marshall County, and Oxford, Lafayette County, Mississippi ; from Dye, Montague County, Texas (ibid.), and from fifteen counties in the northern half of Mississippi (Weed, I897).

1898. - Recorded from Lenoir, Caldwell County, North Carolina, in May.

I899. - Recorded from Sheridan and Silver City, Grant County, Arkansas, in August (ibid.).

I90o.-Prof. A. L. Quaintance informs me that in this year the beetle was found in large numbers at Experiment, Georgia, and that it has entirely replaced or crowded out $L$. juncta, which, in I899, was one of the most abundant insects in that locality.

I9OI to I905.- Since the year I900 no records of any value concerning the farther advance of this beetle have been found, and, as it now covers nearly the entire eastern part of the United States, further records of this nature are not to be expected.

The dissemination of this insect over the eastern United States, now completed, has occupied a period of fifty years, and of these we have accurate 
records for the last forty-six-i.e., I 859 to 1905 . During this period it has become a common resident in all of the country wherein it has been at all able to gain a foothold. It has gone from habitat to habitat, from one climatic or topographic area to another, without undergoing any marked change; it everywhere has shown itself to be a plastic form, well fitted to undertake the extensive migrations that it has so successfully accomplished.

\section{OCCURRENCE IN EUROPE.}

During the years in which $L$. decemlineata was spreading eastward over the United States and lower Canada, everywhere proving a serious pest to the potato crop, the people of western Europe were intently watching its progress and dreading the time when it might be transported to their lands, where, in the thickly populated countries, its presence would prove even more disastrous than in the United States and Canada. So great was the apprehension felt that many German States published popular information about this pest, and German schoolmasters were required to instruct the school children concerning it. The French government likewise published an elaborate bulletin describing this beetle and its ravages.

As anticipated, it was transported to Europe in 1875 or 1876 , probably in the holds of vessels, appearing in England, Sweden, and Germany; but such prompt and effectual measures were taken to suppress it that it was soon exterminated. Since then, although frequently introduced, as far as I can learn, it has not been able to gain a foothold in any continental country. It has been introduced at various times into England and Ireland, and it was reported in Igoo to have become established in the Pyrenees Mountains. None of these introductions, however, have been able to spread over more than a few acres, and have all been promptly exterminated.

The dissemination of this beetle has ceased for the time being. The Atlantic Ocean has proven a hard barrier to cross, but it has crossed it in the past and will do so again and again, until finally it will probably become established as a member of the fauna of Europe. When this happens, it will spread, as it did in this country, until it is found in all the countries of Europe in which it is possible for it to live.

The Highways of Disphersal, and Rate of Movement.

This dispersal, covering a large area of country of diverse climatic and topographic conditions, affords an opportunity in a specific case for examining closely some phases of migration.

There is no reason to suppose that the dispersion of organisms from their center of origin is ever uniform in all directions. We know, in fact, that it is more pronounced in some directions than in others, owing to various directive factors-winds, temperature, and topographic features-such as those natural highways which afford lines of least resistance to migration. 
The center of dispersal for $L$. decemlineata was on the eastern slope of the Rocky Mountain Plateau in Colorado, Nebraska, and Kansas, between the altitudes of 7,000 and 3,000 feet. The dispersal was started by the introduction of a single species of plant into the habitat of decemlineata, which, taken as a food, furnished a base of supplies in the country to the east. This opportunity was seized, and decemlineata advanced steadily eastward, increasing its numbers and extending its habitat. The line of advancement from its original habitat was at first narrow, being dependent upon the earliest westward extension of civilization along the Platte River Valley and through northern Kansas.

Having passed its original bounds, the whole eastern half of North America lay open to it. Which way should it go? What factors should determine the direction of its advance? Two highways were already developed-one leading directly in the route of emigrant trains, stage lines, and settlers' farms, along the North Platte River to eastern Nebraskd and Iowa ; another, less important, along the route followed by certain stage lines from Atchison, Kansas, to Denver, Colorado. That the beetle probably followed both of these lines of travel and settlement is indicated by its simultaneous appearance at both termini. These lines of dissemination were dependent upon the fact that it was along the routes of travel that settlements had been made and a series of bases of food supply had been created.

However, about I86o, after they had crossed the Missouri River, a more thickly settled portion of the country was encountered, with wider distribution of their new food plant, which removed all further necessity of following paths of human travel. The beetles were now free to respond naturally to the control of the climatic and topographic features of the country into which they were migrating. Throughout the remainder of this dissemination we find them following well-defined trends of movement, frequently along paths or natural highways where human movements are also active. They have not, however, followed these because of the presence of man; rather, both have followed the same highway because topographic conditions and climatic causes have determined for all organisms the highways of movement.

The chief trends of movement found are as follows: (I) Northward, up the Mississippi River Valley ; (2) northeastward, along the Great Lakes-St. Lawrence River Valley; (3) southward, down the Lake Champlain and Hudson River valleys ; (4) southeast and east, along the Missouri and Ohio River valleys; (5) seven distinct movements along natural highways from the western region into and through the Appalachian highlands to the Atlantic coast; (6) northward and southward along the Atlantic coast, and (7) southward along the Mississippi River Valley (plate 9). As the result of transportation by man, the following centers of dissemination were estab- 
PLATE 9

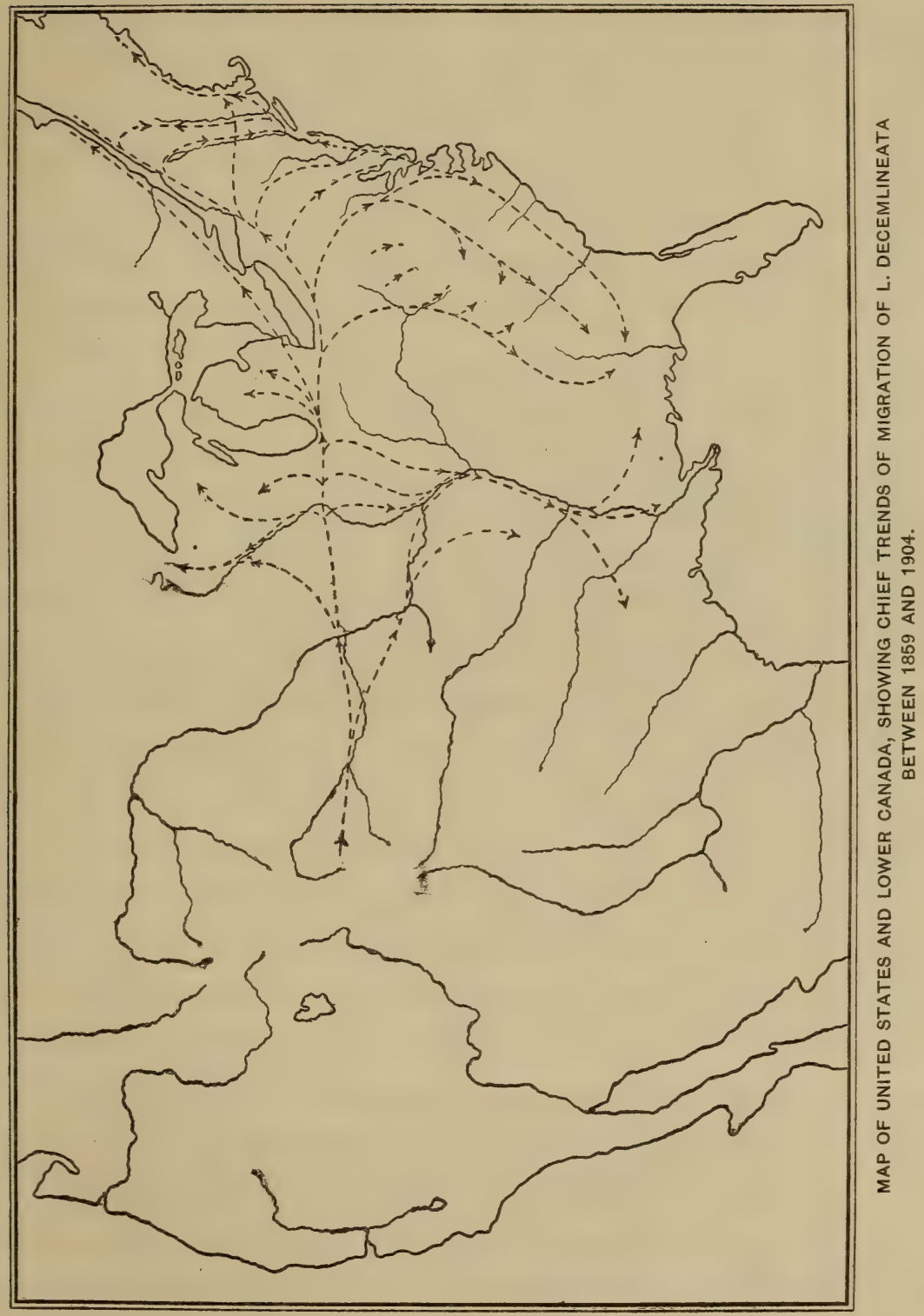



lished: Hamilton County, Ohio, I868; Lancaster County, Pennsylvania, I872; and Charleston, South Carolina (I892), and Savannah, Georgia (I 885) (plate 8).

None of these, however, changed in any material way the general movement. The seven trends of migration found all follow natural highways of dispersal or paths of least resistance. These highways are absolutely independent of organisms, but are the results of geologic and geographic forces which are at work upon the continent. In the main these highways are associated with river valley developments, and also, to some extent, with coastal plains. The existence of these natural highways has been recognized by many writers, but Webster (I898, I903), who has studied the trends of insect migration, does not seem to have correlated them in any degree with natural topographic highways.

$L$. decemlineata, on its escape from its habitat, entered an area devoid of natural barriers, across which it was able to spread in any direction, with the results shown on plate 8 , where the yearly lines of advance show a nearly even expansion in all directions. What irregularities there were were produced by winds and moisture, which we shall discuss presently. As soon as it reached the Mississippi Valley, the first great natural highway that was encountered, there was a marked change in its behavior. Previous to $1863-64$ it had crossed wide stretches of country each year, but after entering the Mississippi Valley its advance was checked for two years. In this period we find it extending northward with great rapidity, reaching nearly to the headwaters of the river in 1865 , and also southward, although much more slowly, down the valley. Thus this natural highway served for movement in both directions at the same time, but much more rapidly in one direction than in the other. Webster (1898, I903) has thought of the Mississippi Valley as a highway only for northward migration of southern forms, but Adams (I902) and others regard it as a pathway for both north and south migration, and it is here shown that movement in both directions occurs. The difference in the rate of movement in the two directions is due largely to winds, temperature, and moisture, climatic factors whose directive influence I shall discuss later.

On passing eastward out of the Mississippi Valley the beetle again spread out, this time in a broad wave over Illinois, Wisconsin, and western Indiana. This wave extended from near the head of the Mississippi Valley southward to the junction of the Mississippi and Ohio rivers and eastward to the southern end of Lake Michigan. Over this territory natural barriers of any size or importance were absent. On passing the southern end of Lake Michigan it entered the great natural highway of the Great Lakes-St. Lawrence system. Along this it now spread with great rapidity in the years I 866 to I880 northeastward across the State of Michigan and through 
southern Ontario, on the northern shore of the lakes, covering great stretches of the country each year (plate 8). In this rapid and direct advance the advantages of the natural highway were not entirely responsible for the accelerated rate of movement. The strong southwesterly winds which sweep down this basin aided very materially in this dissemination, especially in the early years. On the southern side of the lakes the St. Lawrence Valley advance was less rapid, the difference in the rate of movement being due to the fact that the southern side is broad, and there was a large area to cover, whereas upon the northern side the habitable area was narrow, and, as a result, there was greater concentration of the animals along the front, and therefore a greater chance for marked advance each year.

The southern column, working eastward and southward through Indiana, Ohio, and adjacent States, soon encountered the Appalachian highlands. There resulted a turning of the column northeastward, with a concentration in the region of the lakes, and the formation of several independent columns which moved eastward along natural highways across the Appalachian Mountains. That portion of the southern column which had concentrated near the lakes, moving rapidly eastward along their southern shores and down the St. Lawrence Valley, finally turned south along the Lake Champlain and Hudson River valleys, penetrated the Appalachian barrier in the north, and gained entrance to eastern New York and New England. The most prominent of the minor columns which were crossing this barrier moved along the valleys of the Mohawk, Delaware, Susquehanna, and Potomac rivers, while still smaller lines of advance were developed in the valleys of the Cheat, Kanawha, Licking, Kentucky, Cumberland, and Tennessee rivers. To the north the barrier was penetrated, first by the Delaware, Susquehanna, and Potomac columns, and later by the Mohawk (plate 9).

The establishment of the colony at Lancaster, Pennsylvania, in I87 I or 1872 , and the arrival of the beetles from the west over the Delaware, Susquehanna, and Potomac highways produced a strong center of dispersal from which movement along the Atlantic coast began. The northward dissemination along the Atlantic slope during the years 1872 to 1876 was rapid, it being accelerated by climatic factors, principally winds, which retarded the movement to the south. There is evidence also of a strong local control of the direction and rapidity of migration by small features of the topography, as, for example, the movement up the Connecticut River Valley and in the river valleys in Maine.

In the south the available habitat of the beetle was limited, and the cultivation of its food plant by no means as general as to the north and west; consequently, advance was generally quite slow. Over the Piedmont belt the retardation of the southward movement between the years I872 and I 900 was less marked, and here the beetle became fairly common and gener- 
ally distributed; whereas along the Atlantic Coastal Plain its movements were irregular and uncertain, and although its advance still continues, complete occupation of the region has not thus far been effected.

In 1872 and 1873 there branched off from the general horde advancing eastward through Illinois, Indiana, and Ohio several columns which moved southward along the river valleys of the Allegheny Plateau, and in the years following showed a well-marked trend of migration. About I891 or I892 these columns, having worked slowly down the western side of the Appalachian barrier and extended southward beyond it, united with the southward trend of migration along the Piedmont belt, thus completely encircling the Appalachian Mountains. These two united columns have since I 894 or 1895 been working slowly southward, but have not as yet been able to reach the Gulf coast.

The topographic area comprised within the Ozark Plateau and the Ouachita Mountains, situated between the Great Plains on the west, the prairies on the east, and the Coastal Plains area on the south, is one well adapted to retard migration, if not to serve as an effectual barrier. Unfortunately, almost nothing is known concerning the dissemination of $L$. decemlineata in this region. We know that from middle Missouri it extended very slowly to the southern counties (Riley), but this may well have been due to other than topographic causes. Over much of this area it is not common, and it is probable that in many places it does not exist. A possible trend is indicated to the east of the Ozark Plateau, which passes the eastern end of the Ouachita Mountains through Arkansas, into northeastern Texas, where decemlineata is found. This trend arose from the Mississippi Valley movement and may be considered to be a part of it.

It may be of value at this point to compare the dissemination of $L$. decemlineata with that of other forms that have spread over the same regions and have been influenced by the same natural causes. The data of the dissemination of Pieris rapa L. has been gathered and published by Scudder ( 1887), and although he does not place any stress upon the relation of the spread of this insect to topographic and climatic conditions, a study of the published data and lines of yearly advance shows the same general control of dissemination as that found in $L$. decemlineata. It is of interest to compare the spread of these two insects, one a native of the Great Plains, which began its advance eastward at about the same time that the other, a native of Europe, was introduced into the east and began its march westward. Although the advance of Pieris rapa has been against the action of powerful climatic factors, the lines of its most rapid and successful advance have been along such natural highways as those afforded by the St. Lawrence-Great Lakes system. Other species of insects have responded in like manner to these same influences. Webster, in his study of the distribution of the chinch bug, has come to the conclusion that it entered the United States from the south through 
natural gateways, and has followed in its advance many of the highways that have been mentioned in the preceding pages.

In following the history of the spread of $L$. decemlineata it is evident that when a natural highway is encountered the beetles respond at once to the change and the control of their direction of movement. They either go or do not go along a certain path, and the choice is made at once and not after generations of indecision and futile trials. It is clear that in this dispersion the routes followed were natural ones, and were almost entirely independent of man, notwithstanding the frequent statements to the contrary. Human advance nearly always follows natural highways, but this in nowise alters or invalidates the conclusions regarding the part played by these topographic features in the dissemination of $L$. decemlineata.

\section{Other Factors Which Have Controlled THE DIRECTION OF MOVEMENT.}

We shall now consider some of the habits of $L$. decemlineata and the various climatic factors of its environment which have been of importance in directing the lines of its most rapid advance and aiding in its general dispersal.

The life cycle and habits of this beetle are such as to aid greatly in any migration in which it may be engaged. All through its range it is doublebrooded in the summer, the second brood passing the winter as an imago. In Minnesota, Lugger ( 1895 ) records three broods in one year, which I believe to be incorrect. All through its habitat the beetles appear on the first warm days of spring, flying about or crawling along the sunny sides of fences. They are thus active for some time before their food plants are up and egglaying can begin, and during this period they undoubtedly do a considerable amount of traveling. During the eastward migration this period between the emergence from the ground and the time for egg-laying to begin was occupied in extending its bounds. When the number of beetles which hibernated was large, so that the mortality resulting from the vicissitudes of the winter would leave a goodly number to emerge alive in the following spring, a considerable and important advance would result. The best example of this occurred in the spring of $187 \mathrm{I}$. The beetle had been numerous and destructive in Michigan and Ohio in 1870 , when there is recorded a rapid spread northeast into the Province of Ontario. There was a similar condition in 1872 and 1873 in the Lancaster County, Pennsylvania, colony, when there followed a rapid spread down the shores of Chesapeake Bay.

The spring dissemination, however, is not of as great importance as that which comes later in the season. As soon as the food plants appear above the ground the beetles cease their wandering habits, and late in May begin to lay their eggs. The first brood reaches maturity in about 35 days, or about the first of July, and after feeding for a few days they pair and deposit the eggs for the second brood, which reaches maturity about the middle of August. The last brood does not pair until the following spring, although 
they remain active for about three weeks, or even longer, in the autumn, before seeking a place in which to hibernate. It was in this interval between the emergence of the second brood and the beginning of its hibernation that most of the area of advance was covered. During this time both sexes are active; the females are not laden with ripe ova, and are therefore able to fly with greater ease than in the following spring, or than are the females of the first summer brood. Riley notes that the fall brood has a tendency to migrate. He records seeing them "swarming in the air or traveling on foot," and he believes that "most of the advance ground was covered in the latter part of the growing season." Under the best of conditions this insect is a poor flyer without outside aid ; it can be driven some distance, but when undisturbed it never flies far without settling down to rest.

The existence of this active period was of great importance in the advance eastward. The females, when laden with ripe ova, fly with difficulty, and only simall distances are covered before the eggs are deposited. Hence, if the second brood had paired and deposited its eggs within a few days after emergence, as did the first, it is evident that there would have been but little flying about, and as a result its advance would have been far less rapid and the history of its dissemination quite different. If we compare $L$. decemlineata with Ocneria dispar in its spread over Massachusetts, the importance of a period of free and easy movement in the life cycle as an aid in rapid dissemination is at once apparent. In $O$. dispar the spread has been exceedingly slow, owing in part to the inability of the females to fly, but as much or more to the short time the female imago lives. The female is fertilized almost immediately upon hatching from the pupa, deposits her eggs within a few feet of the spot where the larval and pupal stages have been passed, and then dies. If the female moved about for three or four weeks and then hibernated, and did not deposit her eggs until the next spring, all other conditions remaining the same as at present, the spread of this insect would have been much more rapid and its partial subjection a much greater task than the State has found it. The existence and duration of this period of free and active movement is a factor of prime importance in determining the rate of dissemination of any insect, and must, I think, in the case of introduced insect pests, receive due consideration in the discussion of the probability of suppression or the possibility of extermination.

In the eastward spread of the beetle it early became evident that the advance was more rapid in some directions than in others, and this acceleration and retardation have been found throughout its whole history. I have shown that there was little transportation by human agencies, and further that the insect is a poor flyer; hence the covering of the wide stretches of country that were overrun year by year required some outside aid. This aid I have found to come largely from winds, as is demonstrated by the following experiments : On a clear, calm day in August or early September 
put mature, active beetles in a shallow tray mounted on a tripod or other support. In an hour or so all of the beetles will have crawled out and the larger part will have taken flight from the edges of the tray; but the directions of these flights will be as many as there are beetles. Under such conditions there is no one direction in which they show a tendency to travel. In fact there is not, as has been stated by Riley, Walsh, and others, any instinct or tendency that causes them to migrate in a certain direction. This experiment has been tried many times in Massachusetts, on Long Island, New York, in the Ohio River Valley, and on the shores of Lake Michigan, and always with the same result as that given above. But let the same experiment be tried on a day when a steady breeze is blowing 6 to 8 miles an hour, but with other conditions similar, and a strikingly different result is obtained. The beetles all start out from the tray as before in as many different directions as there are beetles, but when the direction is against or even across the wind they soon become tired with their exertions and drift with the wind, often for a considerable distance. These experiments and close observation of the beetles as they start of their own accord from their food plant have uniformly given the same result-that while the beetle is able to fly some distance against a strong wind, it almost invariably turns and drifts back with the wind for a much greater distance than it has flown against it, the actual or net movement or migration being in the direction of the wind, $i$. e., with the wind.

The influence of the wind is well shown along the Atlantic coast or the shores of Lake Michigan when there is an "offshore" breeze. The beetles are then carried out over the water and, becoming exhausted, fall to the surface, where they float, and not infrequently are washed ashore in such numbers that they form a small windrow along the beach. In 1876 , when they were abundant along the Atlantic coast, they were blown out to sea in large numbers, and, being washed back upon the beaches, were so numerous that they were obnoxious to the pleasure seekers there.

The ease with which the wind determines the direction of flight of this beetle is well known on the shores of Massachusetts, where an on-shore breeze is often well developed for days at a time. Then the beetles are found flying away from the shore or crawling about on objects to the leeward of the potato patches from which they started, and if a nearby beach be searched very few living or freshly killed beetles will be found. But let this sea breeze be overpowered by the prevailing westerlies, as it often is, and the beetles are all found to be flying with the wind or driven by it toward the sea, and if the beach be searched a day or two later there will be found numbers of freshly killed or living beetles.

On plate 8 is plotted by means of arrows the prevailing wind direction for the months from May to September, inclusive. It is evident that the lines of most rapid advance are correlated with the prevailing wind direction 
for the growing season. This acceleration by the wind is especially noteworthy when the wind happens to correspond in direction with a natural highway, as in the Great Lakes-St. Lawrence Valley. In this region the lines of distribution from 1866 to 1872 became wider apart, until in I87I, 1872 , and 1873 great stretches of country were overrun each year. While other factors helped to produce this result, such as the beetles being carried on the waters of the lakes, the major part of the advance ground covered each year was due to the aid given by the wind to the natural migratory power of the beetle. Immediately after crossing the Missouri River and entering upon the prairie country the influence of winds upon the dissemination of $L$. decemlineata was clearly shown in the rapid advance to the northeast into Wisconsin. This advance was, as shown on plate 8 , in general coincident with the direction of the wind. Topographic barriers and natural highways were absent, the wind serving almost, if not entirely, as the controlling factor in that region. In the Mississippi Valley, also, we find that the rapid northward advance was in part due to the existence of a natural highway and in part to the influence of the wind.

It is not always that winds have been favorable to the migration of this beetle. Whereas in the above cases aid of a substantial kind was given, in others it has acted as a strong retarding agent, the best examples of this being found in the history of the southward advance. The migration down the Mississippi Valley was, as we have seen, slow, owing almost entirely to the fact that there is a strong indraft of air northward during the summer months. How effectually this wind served to retard the migration may be indicated by the fact that it required about 32 years (I867-I900) to cover the territory from Cairo, Illinois, to New Orleans. The slowness of this advance appears still more striking if we compare it with the migration from the southern end of Lake Michigan to the Atlantic coast, a distance about equal, which required seven years. In other words, fourteen generations were required for the beetle to advance from Lake Michigan to the Atlantic coast, and more than sixty to cover the distance between Cairo and the Gulf of Mexico. Likewise, the dissemination over the Atlantic Coastal Plain and the Piedmont belt has been retarded to a considerable extent by adverse winds.

Cyclonic disturbances often transport birds and strong-flying insects long distances from their native habitats, and these, coming to rest upon a distant land, might under favorable conditions be able to start a colony. But while numerous cases occur every year of the flight for hundreds of miles of strongwinged Lepidoptera and Orthoptera, when aided and controlled by the wind, we do not yet know of a single instance in which this flight has resulted in a permanent dispersion. For example, Erebus odora, a strongwinged noctuid, which breeds in southern Mexico and southward, is found in numbers every year in the United States, and to some extent in Canada. 
Although more or less worn specimens showing the effects of long flight are found year after year in the same localities, it does not breed in these places, and hence this dissemination is futile, as there can be by this means no extension of its bounds. These isolated and sporadic cases of transportation, always accompanying the development of the tropical cyclones, which in the latter part of the summer sweep up through Central America, Mexico, and the United States, have only a remote bearing upon the true dissemination of animals. In the dissemination of $L$. decemlineata we find a true example of the aid afforded by winds in the dispersion of animals, and not one of the sporadic cases usually mentioned as such, nor one in which the conditions for starting a new colony are too difficult to be realized, excepting in rare instances.

Other factors also have aided in the dissemination of this beetle-temperature, moisture, sunshine, food, and soil-but of these none have played any conspicuous part in directing its movements. On the north low temperature and in the south high temperature and high humidity have established seemingly effectual barriers to prevent the beetle from extending beyond its present limits. Between these bounds, however, temperature and moisture are too nearly uniform to be of any moment in the control of dissemination. Food has had a greater influence than the preceding, especially in the south, where the cultivation of the potato is by no means general, and, consequently, the distribution of the beetle has been somewhat retarded and irregular.

To sum up, in the distribution of L. multitaniata, intermedia, and decemlineata over North America the chief directive factors have been: first, habits-i. e., easy flight at the period of its life cycle best adapted for the extension of its bounds; second, direct response in flight to the direction of winds; third, climatic barriers to the north and south due to temperature and moisture ; and fourth, the amount of its food available. Of these the first is of the greatest importance. If, as has already been pointed out, a period of easy flight had not previously been developed, probably no dissemination could have taken place. The development of this habit dates far back in the history of the species, certainly to the time when multiteniata began to spread out over northern Mexico, if not earlier. Previous to the beginning of this dissemination it was of no very general importance in the economy of the species, but changes in the environment resulted in the raising of this habit into one of prime importance as far as ability to undergo rapid dispersal was concerned. Now that the dissemination is over for the present, this habit again sinks into a position of relatively small importance in the economy of the species. While emphasizing the importance of this habit, I do not mean to underestimate the influence of environment upon the spread of this beetle, but I do believe that we must understand better the habits and constitution of an organism before we decide concerning the relative potency of the various factors in its distribution and evolution. 


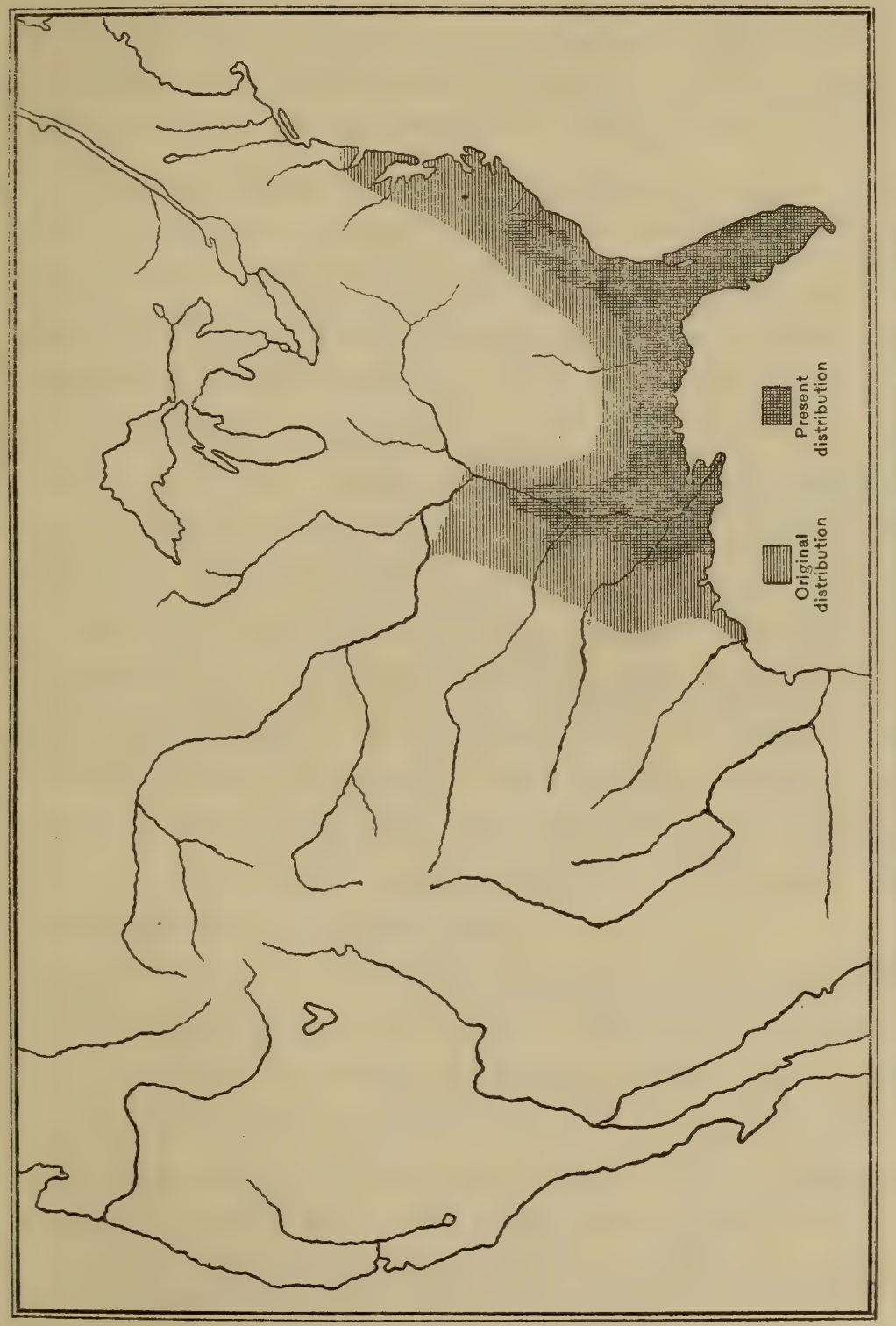



Distribution OF L. DEFBCTA AND L. JUNCTA AND RETREAT OF L. JUNCTA.

Leptinotarsa juncta Guer. and $L$. defecta Stål are two closely related species with a peculiar distribution. $L$. defecta is known from Texas, Arkansas, and Missouri, and Stål has described it from Yucatan. As far as I am able to learn, neither juncta nor defecta occurs in Mexico or Central America, and as careful search along the coast belt of Mexico has failed to reveal any traces of these beetles, I strongly suspect that Stål's record from Yucatan is incorrect.

L. juncta had originally a much wider range than at present. In 1865 it was found throughout the Atlantic Coastal Plain from Maryland south to the Gulf of Mexico, over the entire Piedmont belt, along the Gulf coast into eastern Texas, and up the Mississippi Valley to southern Illinois. It apparently entered the Allegheny Plateau along several river systems, especially the Coosa-Alabama or Allegheny River. Westward it spread into southern Missouri, Kansas, Arkansas, and Texas. Over this entire area it was a common form feeding upon Solanum caroliniense (plate ro).

But with the advent of $L$. decemlineata into the eastern United States juncta very soon retreated or was exterminated. Evidently the two are unable to live in the same habitat, for, although they have different food plants, juncta disappears in any locality soon after the arrival of decemlineata. For example, it was formerly abundant about Washington, District of Columbia, and in parts of Maryland, but $\mathrm{Dr}$. Howard states that since the advent of decemlineata into that region juncta has retreated southward, and the same is true in southern Illinois, where it is no longer found. Professor Quaintance informs me that in 1899 and previously juncta was perhaps the most common insect about the station grounds at Experiment, Georgia, but that in I90o it was found in only very small numbers, its place having been taken by decemlineata; nor is it longer found in Virginia, the Carolinas, Kansas, Missouri, and the upper Mississippi Valley.

Why juncta should retreat before decemlineata is a question of considerable interest, as the two species have entirely different food plants, and it can not be that juncta is crowded out by the larger numbers of decemlineata. I am informed by Professor Quaintance that the two species hybridize freely in uature, although the eggs that are laid are not fertile, at least in so far as his observations go. Concerning this crossing in nature and its effect upon junct $r$ I shall have more to say in a later paper. The full explanation of the extinction of juncta is to be found in the fact that the two species cross freely in nature, and that this natural crossing has resulted in a most interesting and peculiar case of prepotency in one species and of submergence in the other. 


\section{DISTRIBUTION OF THE OTHER GROUPS.}

The distribution of the other groups presents on examination much the same history as that found in the lineata group, with the exception that none of them are as widely distributed or as variable, or present the interesting series of migrations and the interrelation of species, as does the lineata group; hence the history of this group has been presented in full, while the others may be passed over with only a few comments.

In the lineata group it was shown that the various species are restricted in a striking manner to natural environmental complexes. In the other groups also this same limitation is seen, and the extent to which the development of the different groups has given rise to species in the natural divisions of the country can best be shown by the following table:

TABLE 2.-Distribution of Leptinotarsa by Groups in the Different Faunal Areas.

\begin{tabular}{|c|c|c|c|c|c|}
\hline Faunal area. & $\begin{array}{l}\text { Lineata } \\
\text { group. }\end{array}$ & $\begin{array}{l}\text { Dilecta } \\
\text { group. }\end{array}$ & $\begin{array}{l}\text { Haldemani } \\
\text { group. }\end{array}$ & $\begin{array}{l}\text { Lacerata } \\
\text { group. }\end{array}$ & $\begin{array}{c}\text { Flavopustulata } \\
\text { group. }\end{array}$ \\
\hline $\begin{array}{l}\text { CENTRAL A MERICA : } \\
\text { Guatemala - Chiapas } \\
\text { Plateau. }\end{array}$ & undecimlineata. & $\begin{array}{l}\text { flavitarsis. } \\
\text { nitidicollis. } \\
\text { distingueuda. }\end{array}$ & $\begin{array}{l}\text { libatrix. } \\
\text { dahlbomi. }\end{array}$ & $\ldots$ & $\begin{array}{l}\text { evanescens. } \\
\text { belti. } \\
\text { flavopustulata. }\end{array}$ \\
\hline $\begin{array}{l}\text { O a xaca-Gue r r e ro } \\
\text { highlands. }\end{array}$ & $\begin{array}{l}\text { undecimlineata. } \\
\text { oblongata. }\end{array}$ & $\begin{array}{l}\text { novemlineata. } \\
\text { dilecta. } \\
\text { obliterata. }\end{array}$ & $\begin{array}{l}\text { libatrix. } \\
\text { dahlbomi. }\end{array}$ & lacerata. & \\
\hline Pacific slope ................. & & & & & \\
\hline Atlantic slope... & $\begin{array}{l}\text { undecimlineata. } \\
\text { angustovittata. }\end{array}$ & $\begin{array}{l}\text { pudica. } \\
\text { obliterata. } \\
\text { cacica. }\end{array}$ & $\begin{array}{l}\text { hogei. } \\
\text { libatrix. } \\
\text { violescens. }\end{array}$ & chaicospila. & \\
\hline Yucatau............................ & $\ldots \ldots$ & & dahlbomi. & heydeni. & \\
\hline $\begin{array}{l}\text { NORTH AMERICA : } \\
\text { Mexican escarpment: } \\
\text { H u m id eastern } \\
\text { slope. }\end{array}$ & & $\begin{array}{l}\text { calceata. } \\
\text { obliterata. } \\
\text { cacica. }\end{array}$ & & & \\
\hline $\begin{array}{l}\text { Moist southern } \\
\text { slope. }\end{array}$ & $\begin{array}{l}\text { signaticollis. } \\
\text { oblongata. }\end{array}$ & & haldemani & lacerata. & dohrni. \\
\hline Dry western slope. & $\begin{array}{l}\text { signaticollis. } \\
\text { oblongata. }\end{array}$ & dilecta. & & & \\
\hline Pacific lowlands......... & diversa. & ...... & $\begin{array}{l}\text { chlorizans. } \\
\text { litigiosa. }\end{array}$ & & \\
\hline Gulf lowlands ........... & undecimlineata. & & & & \\
\hline Southern mesa............ & $\begin{array}{l}\text { rubicunda. } \\
\text { multitæniata. } \\
\text { melanothorax. }\end{array}$ & diiecta. & $\begin{array}{l}\text { dablbomi. } \\
\text { tlascalana. }\end{array}$ & modesta. & ståli. \\
\hline Northern mesa............. & $\begin{array}{l}\text { intermedia. } \\
\text { melanothorax. }\end{array}$ & $\begin{array}{l}\text { lineolata. } \\
\text { typographica. }\end{array}$ & & puncticollis. & \\
\hline Great Plains............... & $\begin{array}{l}\text { decemlineata. } \\
\text { defecta. } \\
\text { juncta. }\end{array}$ & & dahlbomi. & & \\
\hline Atlantic Coastal Plain & $\begin{array}{l}\text { decemlineata. } \\
\text { juncta. }\end{array}$ & & & & \\
\hline
\end{tabular}




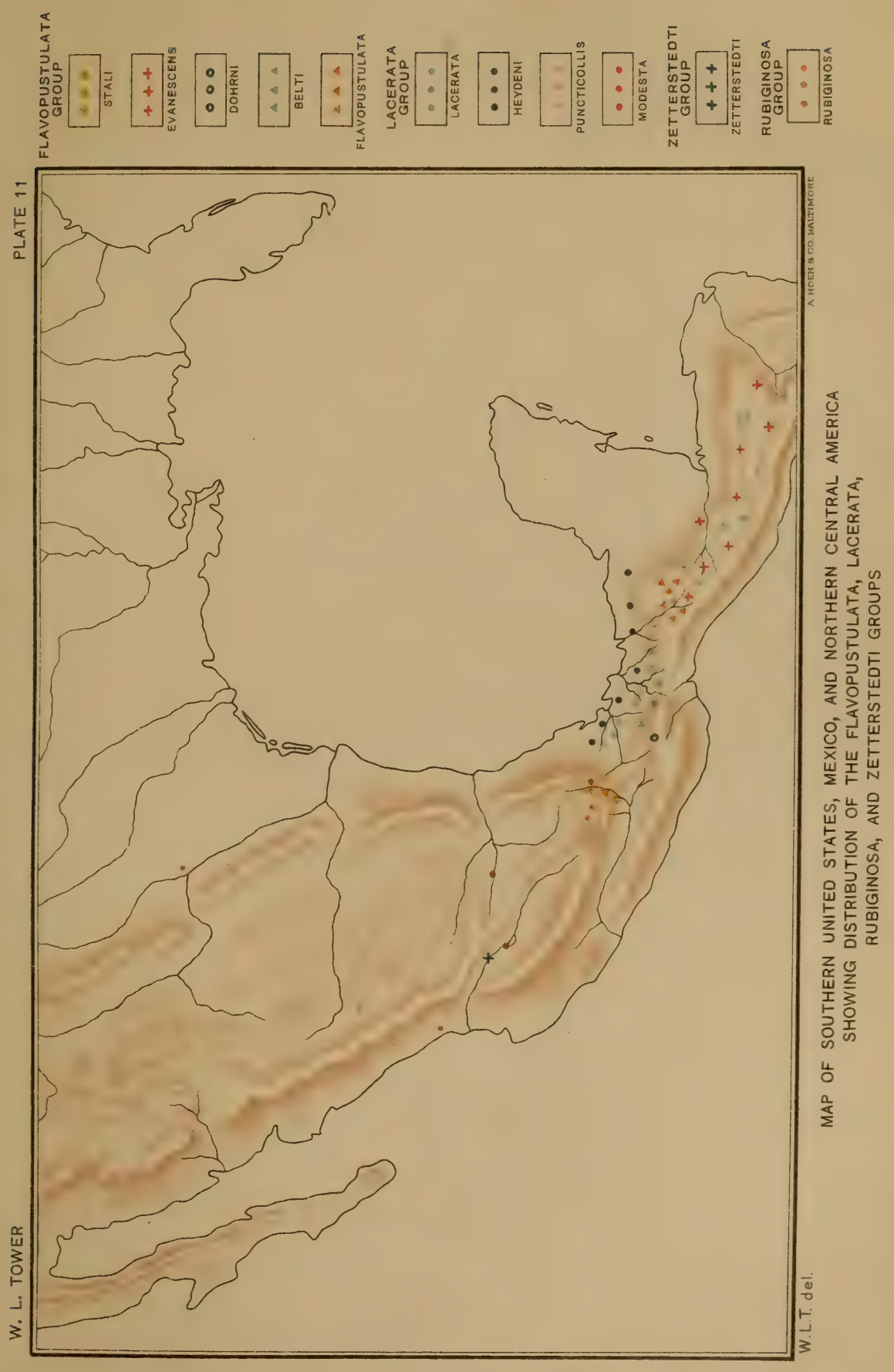





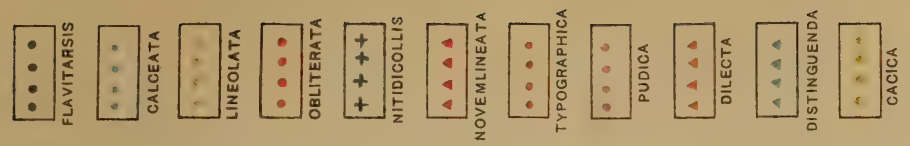

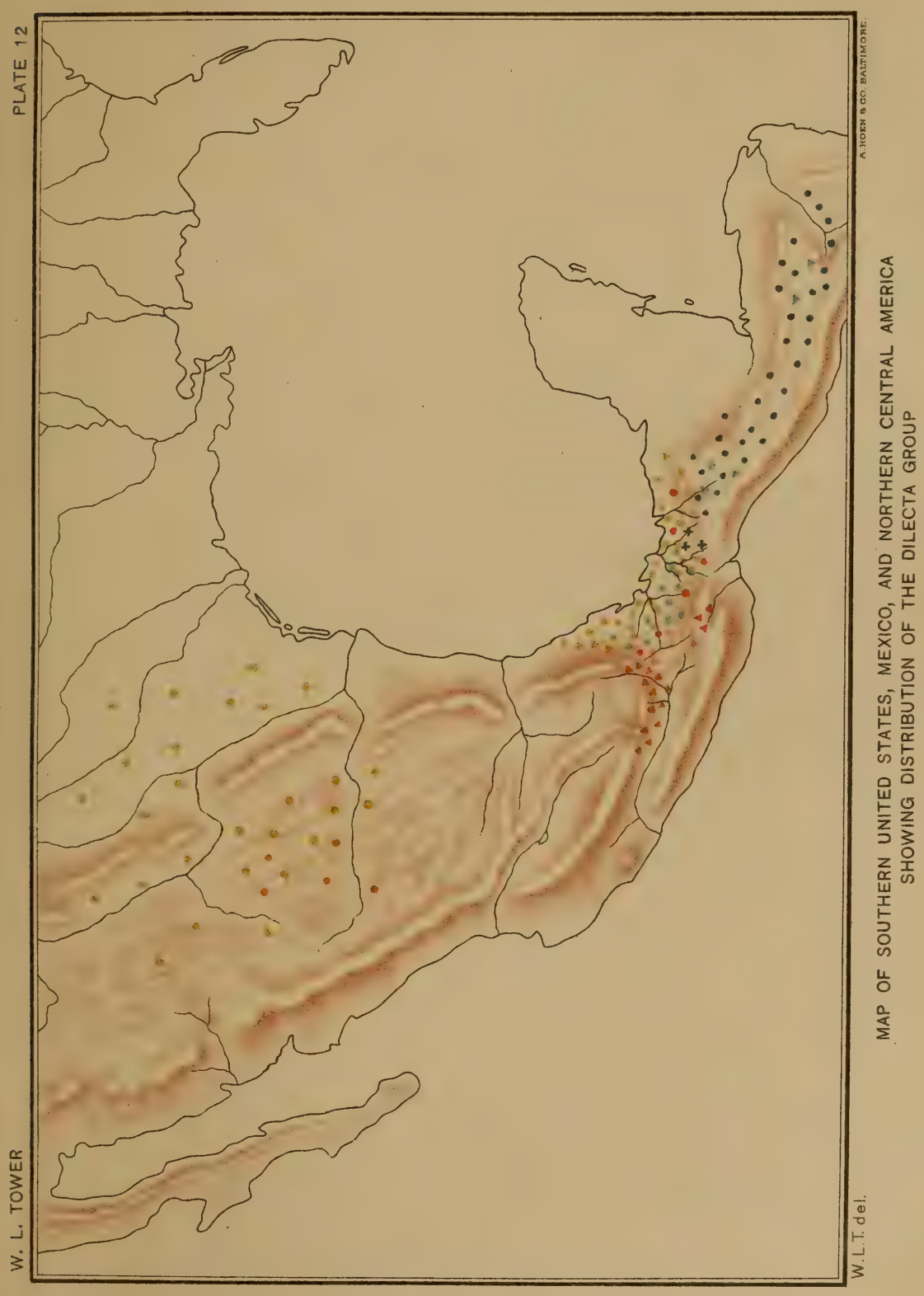





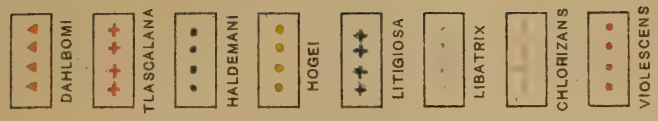

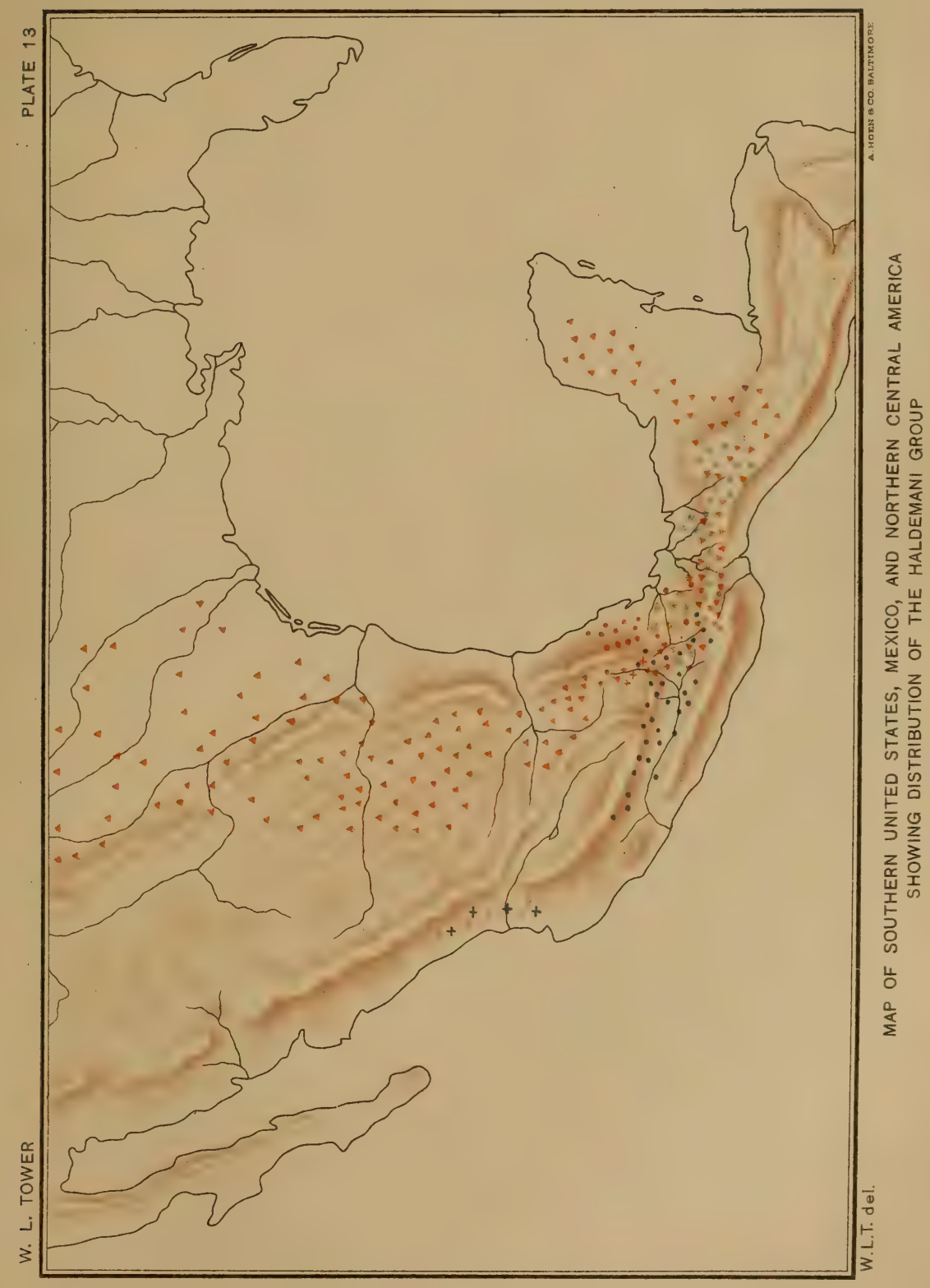



In the lineata group it is evident that there are two chief centers of distribution, one Central American and one North American, and that in each of these a series of species has developed along lines independent of the others. In the dilecta group there are also two distinct sets of species, one Central American and one North American, both of which have followed the highlands and moved northward over the Mexican Plateau. In the haldemani group, however, the species, with the exception of L. dahlbomi, a few rare species from the Pacific slope and lowlands of the Mexican area, and one doubtful species from the north end of the mesa, all develop on the Central American area. The lacerata group shows an advance eastward from the center of origin into Yucatan, then northward along the Atlantic slope, and finally up into the mesa from the eastern side, while the flavopustulata group barely reaches the North American area. (See plates I I, I2, and I3.)

From the foregoing table may be drawn additional confirmation of the correlation between species formation in the genus and natural physiographic areas. What information we can derive from their geographical distribution is strongly in favor of the view of a close correlation of species development with topography and climate.

The general œcological relations of each of the species in the lineata group has been given, in as far as it is concerned in the distribution of the species. In the other groups in the genus Leptinotarsa the same factors have the controlling influence in the distribution of the various species and in the determination of habitats. In some of the groups certain species are found with a general distribution over a wide area of country. Most conspicuous of these is $L$. dahlbomi (plate I 3 ), which, of all the species in the genus, is the least dependent upon a restricted habitat for its existence. In its wide and varied range of distribution, from Guatemala and Yucatan northward across the Rio Grande into Texas and New Mexico, it encounters a greater variety of topographic and climatic conditions than any other species in the genus and is one of the least variable. Others, as, for example, L. libatrix, violescens, lacerata, undecimlineata, and others, are restricted to a very narrow local habitat by similar environmental conditions. Some of the species in this genus, L. rubiginosa, for example, are extremely limited in their distribution, owing to the rarity of their food plants and the conditions of existence which they seem to demand. The main œcological factors which control the distribution of all the groups of this genus are, first, moisture ; second, temperature ; third, soil ; and fourth, altitude. 


\section{THE RELATION OF THE DISTRIBUTION OF THE GENUS LEPTINOTARSA TO NATURAL ENVIRONMENTAL COMPLEXES.}

The geographical distribution of animals, or animal geography, is usually considered from one of two viewpoints-the static or the dynamic. Considered from the static standpoint, the facts of distribution are taken and arranged in order according to some empirically chosen standard, and zones, subzones, or other unnatural areas of distribution are established. The study of animal distribution from this standpoint is a dead and profitless pursuit. Dynamically considered, animal geography seeks to explain the facts of animal distribution as we now find them in terms of the relation of the animals to each other and to their environmental complexes. It is the dynamic aspect of the distribution of these beetles that I shall consider in the remainder of this paper.

One of the most striking facts of animal geography is the correlation which exists in any large group of animals between the development of its various species and groups of species and the environmental complexes of the country which forms the habitat of the animals in question, specific differentiation following directly upon changes in the environmental complex. This correlation has long been recognized, but whether the relation is cause and effect or only apparently so, and how the various lines of specific differentiation came into being, are open questions.

The groups of species in Leptinotarsa occupy in a marked way one or more of the natural complexes into which the country in which they live is divided. All the groups have their origin in the same area, and from this center have spread out and developed in different lines of species differentiation in the different topographic and climatic areas of the country in which they live.

On examining the table on page 50 it is evident that the two chief areas into which the territory inhabited by these beetles is divided-the Central American and the North American-have almost no species in common. Only one species, $L$. dahlbomi, can be said to be common to both areas, while another, $L$. dilecta, is found to be an inhabitant of both along their boundary. It is probable, however, that as the number of local records is increased more species will be found to have crossed over from one area to the other and penetrated for short distances inward. This sharp demarkation between the species that are Central American and those that are North American is characteristic of the genus as a whole as well as of each group of species in the genus-a fact that may be seen by an examination of the table. All of the groups excepting rubiginosa and zetterstedti have species to represent them in both areas.

In order to examine more closely into the distribution of the species according to topographic areas, let us look for a moment in some detail at the 
Central American area. Although many of the species present are common to two of the three areas into which the Central American region is naturally divided, only three, L. dahlbomi, undecimlineata, and libatrix, are distributed throughout. The number of endemic species in each of the different areas is of considerable interest. Thus the oldest land area from the standpoint of the geologist, the Guatemala-Chiapas Plateau, has but two endemic species, L. belti and evanescens; the next oldest, the Oaxaca-Guerrero highlands, has two, L. lacerata and novemlineata, while the youngest of all, the Atlantic slope and lowlands, has four, L. hogei, violescens, pudica, and chalcospila.

In the North American area the distribution of these beetles shows a similar series of facts. There is no one species that is common to the entire area, and although the escarpment and the south mesa have four specimens in common-L. oblongata, multitenata, dahlbomi, and dilecta-the different subdivisions have, in general, but few species in common. This area is rich in endemic forms, there being four on the escarpment, six on the South Mesa, three on the North Mesa, one on the Great Plains, and one in the Atlantic Coastal Plain.

From whatever standpoint we examine the distribution of these beetles, whether of large or restricted areas of the country, it is evident that the groups of species in the genus Leptinotarsa and the species themselves are confined to particular habitats, which habitats are natural topographic and climatic areas or combinations or subdivisions thereof, and that the various groups and species are in some way very closely correlated with the physical conditions of their habitat. Similar correlations are known to exist in many other groups of animals, but not always to the extent found in this genus. The question is how this distribution and the limitation of the various species to climatic or topographic areas came to exist as we now find it. Were the various species produced as the genus was dispersed from its original center by the action of the environment upon a plastic race so that each group and each species represents the effect of some particular environmental complex encountered? Or were the species produced essentially as we now find them in some ancestral habitat, and from this disseminated, each seeking unconsciously the habitat best adapted to its particular needs and, having found it, establishing itself therein? Can we account for the present distribution on the hypothesis of direct modification in response to environmental stimuli accompanied by natural selection? or must we invoke the aid of unknown factors which will operate to produce species having structures and constitutions adapted to various remote environmental complexes, and then, by chance dissemination, have the newly modified organisms and the appropriate habitats broight together, with the final result that the entire genus shall present a uniform and perfect correlation and adaptation to its environment? Are the phenomena of animal geography to be explained on 
the basis of variation and natural selection or on the basis of "mutation" and "segregation in the fittest environment"?

It is almost impossible to obtain direct evidence upon these questicns; hence we must depend to a large extent upon the indirect and circumstantial. Aside from experimentation, which is usually not possible, evidence from two sources only is available in the attempted solution of this question - that from distribution and migration and that from the study of geographical variation. Herein only the facts from distribution and migration are con. sidered, the data and arguments from geographical variation being presented in the next chapter.

If the distribution of these species has been produced by variation in direct response to environment and natural selection, we should find evidences of continuity of species differentiation, as the different races or groups were disseminated over the country; but if mutation and "segregation in the fittest environment" has been responsible for the present distribution of the genus, continuity of distribution could hardly be expected, and its general occurrence would be improbable; hence continuity of specific differentiation in a given group of species in its distribution over a country should give us some evidence as to what the evolution of the group in question has been.

In the distribution of the species in this genus evidences of continuity in specific differentiation, correlated with natural environmental complexes, are found, the series of species in the lineata group presenting a striking example of this phenomenon. The most generalized species and the probable ancestor of the group, L. undecimlineata, gives rise, as the result of certain environmental conditions in nature and in experiment, to a form, angustovittata, which is a close approximation to signaticollis. In this series of three species undecimlineata inhabits the low, hot, and moist country to the south and east of the Mexican highlands, angustovittata occurs as a regular member of the fauna of the lower portion of the escarpment of the Mexican Plateau on the east, south, and west, while higher up on the southern and western sides of the escarpment signaticollis is found. Between these three species there are variations of an intermediate character, both in nature and experiment. It is true that angustovittata arises as an extreme variation in experiment, and also, as I have observed, in nature, and that intermediate stages are rare; but this fact is indisputable, that this species arises in direct response to the stimulus of a certain environmental complex, and that it is a stable species both in nature and in experiment. From the distribution of this series of three species-undecimlineata, angustovittata, and signaticollis-in three closely placed environmental complexes, we have strong evidence for the orthogenetic evolution of species as the result of response to changes of environment. If they had originated as the result of mutation and if their present distribution were the result of segregation 
in a favorable habitat, it would be a remarkable coincidence that these species, which represent steps in an orthogenetic specific differentiation, should occupy habitats which are also steps in habitat differentiation.

Additional evidence along this line is afforded by other species in this group. Distributed over the South Mesa, the Escarpment, the North Mesa, the Great Plains, and the eastern portion of the United States, is a series of species that show the most perfect continuity, not only in their distribution, but also in their geographical variations. We are also able to follow the migrations of these species over different habitats. The species multitaniata, intermedia, and decemlineata present continuity in distribution and specific differentiation over a wide area to an unusual degree. On pages 18 to 49 the data of the distribution of these beetles is given and discussed at length, and it seems only too evident that the dissemination and specific differentiation of the race in response to environment have gone hand in hand. So continuous is the distribution and the geographical variation in these species that their separation is difficult. In this group, wherein continuity in distribution is indisputable, another process is also at work. At Toluca, Mexico, there exists a species (rubicunda) which arises as an extreme variation from multitaniata. This species is able to maintain itself as a member of the fauna at Toluca, and, in as far as can be determined from observation, it is far less successful in the struggle for existence than the parent form with which it lives. It has a very restricted distribution, owing to its dependence upon a particular environmental complex, in direct response to which it has perhaps arisen. At this same place, as also at others, another form (species) arises as an extreme variation of multitcniata. This is the species melanothorax, which is found in almost every generation of multitaniata at Toluca, although it is not able there nor at any other point in the habitat of its parent species to become established as a member of the fauna. Evidently it is ill adapted to the environment into which it is born. There are environmerts, however, to which it is adapted, but to reach these requires a numerical strength sufficient to enable it to spread out; and a species so ill adapted to the habitat into which it is born that it can not maintain itself will not develop the numerical and physical strength that is necessary to enable it to seek new and more favorable habitations. The theory of "segregation in fittest environment " could be of no use in the explanation of the early stages in specific diferentiation and dissemination, as it is impossible to see how an " unadaptive mutation" (Davenport) is able to find its proper place in nature. If it is unadapted, as in the case of melanothorax, does not the very fact of its unadapted condition so hamper it in the development of that numerical and physical strength necessary for any extensive movement that dissemination would never occur? It must always remain an ill-adapted member of the fauna into which it has been born, unless by chance it is carried into some 
more favorable habitat, and accidental causes are insufficient for the explanation of natural phenomena. A species must possess a certain amount of adaptation to its original habitat in order to live and gain strength to spread out into one to which it is better adapted, as did decemlineata by migration. In the group of beetles to which decemlineata belongs the development of the present distribution and specific differentiation has certainly been profoundly influenced by factors of the environment in which it lived. At least no other conclusion is warranted from the data at our command.

If we should examine the data concerning the other groups in the genus Leptinotarsa in the same manner as we have the lineata group, a similar set of observations and the same arguments would be given. As far as I am able to discover, they all show the same exact limitation to and dependence upon a particular environmental complex. All of the species of the genus are limited to grassland habitats-that is, to areas in which there is a frequent atmospheric precipitation of greater or less amount, which keeps the surface of the ground and the lower stratum of air moist during the summer or growing season and with a distinct dry or winter season. The temperature is of little moment, as long as it is not low enough to inhibit growth processes during the moist season. The essential vegetation is perennial grasses growing in bunches with annual, herbaceous, or woody plants, often of considerable size. The environmental complex, which I here term "grasslands," is a natural combination of physiographic, climatic, and plant conditions, which together form an environmental complex outside of which Leptinotarsa can not live. Within this general type of habitat there are, however, extensive and often striking differences, and the grasslands are further divided by local or edaphic conditions into grasslands that are physiologically moist and physiologically dry. The physiologically dry areas are differentiated by local or edaphic conditions which differ in individual cases but produce in the end the same general type of environmental complex-savanna, steppe, or semi-desert. We recognize, therefore, four chief divisions of the grass'andsmeadow, savanna, steppe, and semi-desert. Each of these is modified locally by edaphic conditions and between them there are all possible transition stages, and the change from one to the other is never abrupt, although it may be rapid ; there is never any discontinuity.

Some idea of the distribution of the species of Leptinotarsa in the four chief types of grassland habitats may be gained from the table on page 58 . From this table it is evident that the species of Leptinotarsa are limited to the physiologically dry grasslands, only one being found in physiologically moist areas. By far the larger portion of the species are found in the savannas, a few in the steppe, and also in the semi-desert. Although lim ited almost entirely to the savanna type of grassland habitat, it differs greatly in its edaphic factors even in nearby areas, and it is the changes in 
the edaphic factors with which the species are most closely correlated Each of the groups in the genus represents a line of specific differentiation which has in the main been brought about in a savanna habitat, but as far as anything that can be discovered in the distribution of the beetles is concerned, it is impossible to say whether this specific differentiation is due to the direct influence of the environment, to selection, to the effects of isolation, or to segregation. It would be an easy matter to build up from the distribution of the species of this genus a good argument in support of the idea that the species have arisen through the action of isolation and segregation or by selection. Either or both may be responsible for the conditions found, but as far as I am able to discover there is not one whit of evidence to indicate which.

The distribution of the species does, however, indicate in the strongest terms that there has been no discontinuity in the evolution of the genus, and in the absence of positive evidence to the contrary we may safely hold that the theory of mutation and segregation in fittest environment can not in this instance be used in the explanation of the distribution and dissemination of Leptinotarsa. It matters little whether specific differentiation has been rapid or extremely slow, and of this we have no means of gaining information, but of the continuity of the dispersion and species formation there is in this case not the least doubt.

The present geographical distribution of a group of animals is the result of a long series of processes, of action of organism upon organism, and of environment upon organism. From our study of the distribution of these beetles we have gained information as to what the geographical history of the genus has probably been, what forces were most active in the distribution of the group, and the extended correlation existing between distribution, specific differentiation, and environment. From this we get a general view, a clue here and there, of what may perhaps be of vital importance in evolution. At no point are we able to put our finger upon any one fact and say with any certainty that this is the result of that factor in the environment or of any method of evolution. The facts presented in this chapter, those of geographical distribution, become more significant when considered in relation to the facts to be presented in the next chapter, on "Variation." 
TABLE 2A.-Distribution of Leptinotarsa by Groups in the Four Chief Types of Grassland Habitats within the Topographic Areas given in Table 2.

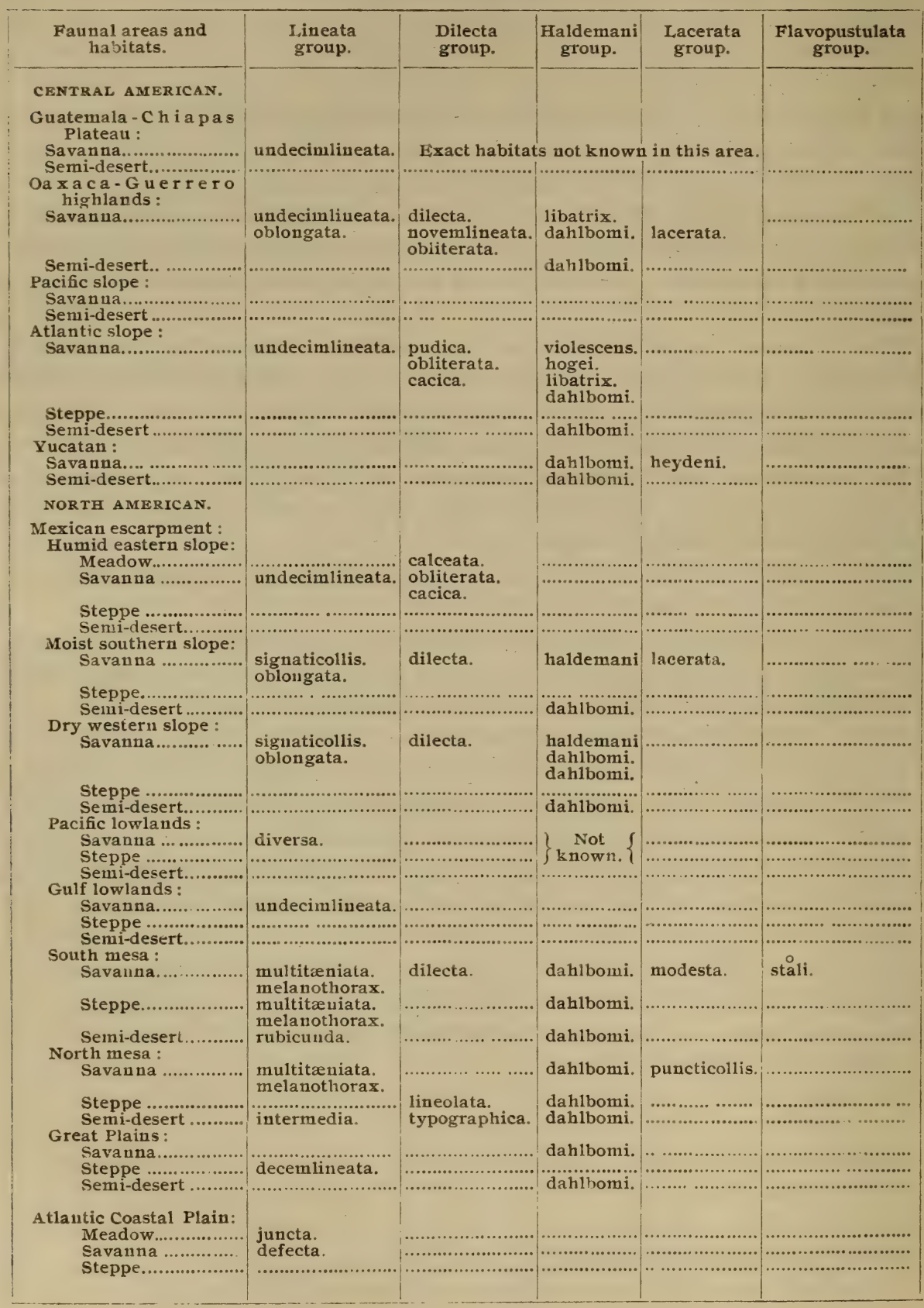




\section{CHAPTER II.}

\section{VARIATION IN LEPTINOTARSA.}

The characters chosen for the study of variation in these beetles are color characters and structural characters. The color characters are of two kinds, special and general. The special color characters are the elements and combinations of elements of the color patterns; the general are the effects of the combined color patterns in the production of melanism or albinism or tendencies toward other general colors. The first have to do largely with continuous or individual variability ; the second, with place and geographical variation. The structural characters which are considered are form, size, punctation, and glandular openings.

\section{Special color characters :}

(a) The color pattern on the pronotum: In the species not unicolorous, as in the lineata group, the color pattern is composed of a series of bilaterally symmetrical spots, designated $a, b, c, d, e$, and $f$ on the right side, and $a^{\prime}$, $b^{\prime}, c^{\prime}, d^{\prime}, e^{\prime}$, and $f^{\prime}$ on the left side, and $a m$ and $p m$ for the two median spots (text-fig. I). The unicolorous pronota we shall discuss from the standpoint of their intensity of color (melanism) and their development of metallicism.

(b) The color pattern on the epicranium: In the species not unicolorous the epicrania have color centers or areas which we shall designate on the right side as $g, h, i$, and on the left as $g^{\prime}, h^{\prime}, i^{\prime}$ (text-fig. I).

(c) The color pattern of the elytra: On the elytra, excepting in unicolorous species, there are stripes of color related morphologically to the veins of the wing (text-fig. I), with certain others presently to be described. The areas of color development parallel to the veins are the costal (cos.), subcostal (s.cos.), ramous ( $r a$.), medius (med.), cubitus (cub.), and anal $(a n$.$) . At a right angle to the veins at the base of the wing is an area of$ color development, the basal, or first band (bas.); a corresponding area at the apical portion of the wing, the marginal, or fifth band (mar.), and between these three areas, also at right angles to the veins, the proximal, or second band (prox.), the middle, or third band $\left(m_{.}\right)$, and the distal, or fourth band (dist.) (text-fig. 3). It will be shown in the third chapter that these color areas (fig. 3 ) are related to structures, and are invariable in position excepting as the structures vary.

(d) The color pattern of the ventral abdominal surface: In the lineata group only is there a color pattern on the ventral surface. The elements of 
this are designated according to the areas and segments thus: First segment, $I$ os, $I \mathrm{~ms}, I$ is on the right side, and $I o s^{\prime}, I m s^{\prime}, I i s^{\prime}$ on the left side ; second segment, $2 o s, 2 m s, 2 i s$, and $2 o s^{\prime}, 2 m s^{\prime}, 2 i s^{\prime}$; third segment, 3 os, $3 m s, 3$ is, and $3 o s^{\prime}, 3 m s^{\prime}, 3 i s^{\prime}$.

In the account of the special color characters use will be made of formulæ to represent given conditions. Thus the formula for the pronotum of text-fig. I would be $f^{\prime}, e^{\prime}, d^{\prime}, c^{\prime}, b^{\prime}, a^{\prime} ; a, b, c, d+e,-$, where the sign plus indicates

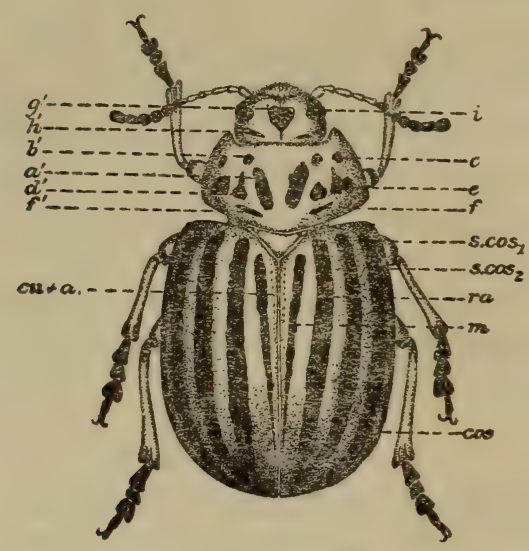

FIG. I.

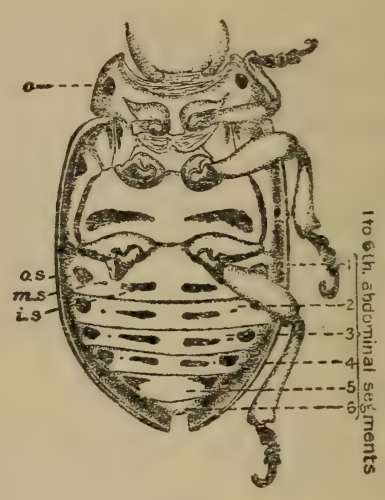

FIG. 2.

FIG. I. $-L$. decemlineata. To show the areas of cuticula color which in this genus enter into the formation of the color pattern. $i$, eye; $g^{\prime}$, left anterior lateral epicranial spot; $h^{\prime}$, left posterior lateral epicranial spot; $a^{\prime}$, left inuer tergals (united); $b^{\prime}$ and $d^{\prime}$, left middle tergals; $c$ and $e$, right outer tergals; $f$ and $f^{\prime}$, spots arising from the division of the posterior balf of the middle tergals : $s . \cos I$ and $s . \cos 2$, ou er and inner subcostal stripes; $r a$, ramous stripe; $m$, medius stripe; $c u+a$, cubitus and anal stripes fused. (The two last stripes were wanting in the specimen drawu, but their positiou is indicated.)

FIG. 2. - L. decemlineata. To show the elements of the color pattern formed by the cuticula pigment on the ventral surface, especially on the abdominal surface. os, outer sternal areas; ms, middle sternal areas ; is, inner sterna! areas.

fusion of spots and the sign minus absence of spots; while for text-fig. 2 the formula for the ventral abdominal surface is :

$$
\begin{aligned}
& \text { 1. } o s^{\prime}, m s^{\prime}, i s^{\prime} \text {; is, } m s, o s . \\
& \text { 2. } o s^{\prime}, m s^{\prime}, i s^{\prime} ; \text { is, } m s, o s . \\
& \text { 3. } o s^{\prime}, m s^{\prime}, i s^{\prime} ; \text { is, } m s, o s . \\
& \text { 4. } o s^{\prime}, m s^{\prime}, i s^{\prime} ; i s, m s, o s . \\
& \text { 5. } o s^{\prime}+m s^{\prime}+i s^{\prime} ; i s+m s+o s .
\end{aligned}
$$

General color characters :

(a) Melanism, or the tendency to a dark color exhibited in relation either to geographical distribution or to environmental changes.

(b) Albinism, or the tendency opposite to melanism.

(c) Xanthism, or the racial tendency toward a yellowish condition.

(d) Rufism, or a racial tendency toward a reddish condition.

(e) Metallicism, or a racial tendency toward a metallic coloration. 
Structural characters :

(a) The form-index, which is determined by multiplying the greatest anterior-posterior length by the greatest transverse diameter and the division of this result by the greatest dorso-ventral diameter of the thorax.

(b) Size ; determined by measuring the greatest anterior-posterior length.

(c) Punctations on the pronotum and elytra.

(d) Glandular openings on the elytra and pronotum.

The nature of my material has made measurements almost impossible, especially in the color characters, hence I have in the main seriated it into classes by inspection, and this method has on actual trial given exactly the same seriations as were obtained by measurements. It seemed, therefore, inadvisable

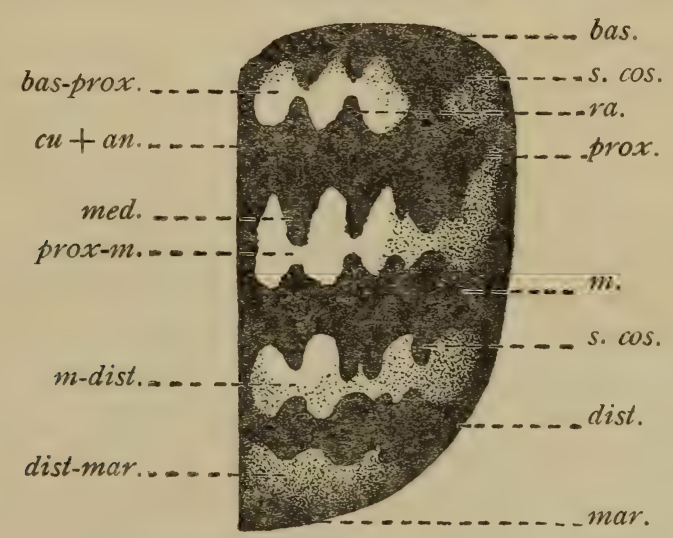

FIG. 3.-L. lacerata. To show areas of cuticula color in banded species

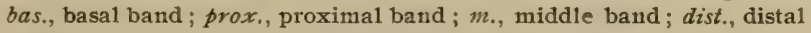
band; mar., marginal band. Other abbreviations as in text-fig. I.

to employ the complicated methods of statistical investigation elaborated by Pearson. I have, moreover, proven to my own satisfaction by actual test that the highly complicated methods of biometry are no more reliable in their results as far as this material is concerned than other methods far less cumbersome and slavish. It has been sufficient to determine the range of variation, the empirical mode and the per cent of variates therein, and the mean.

The color characters have been treated as though the material were all of one sex. This I am warranted in doing, owing to the fact that there is no dimorphism, nor even a distinguishable difference in the color pattern of the two sexes. That no error was introduced by ignoring sex is shown by the production in every case of clearly defined monomodal curves. As seriation of the color characters of the two sexes gives identical results, this material may be treated as though it were homogeneous, and as if sex were nonexistent. 


\section{INDIVIDUAL VARIATIONS.}

OBSERVATIONS AND DATA OF CONTINUOUS VARIATIONS.

COLOR CHARACTERS.

INDIVIDUAL, VARIATION IN THE COLOR PATTERN OF THE PRONOTUM.

Variation in the color pattern of the pronotum in the lineata group. - The composition of the color pattern is shown (text-fig. I) to consist of spots of dark pigment upon a lighter ground. On plate I4, figs. I to I2, is given a series of figures of pronota in L. undecimlineata to illustrate the directions of modification which the color pattern undergoes. In figs. I to 9 , inclusive, is shown the most common and almost the only series of variations exhibited upon the pronotum in these beetles ; $i$. e., fusion or apparent fusion of the color areas by the extension of the spots peripherally or in certain directions, so that continuous color areas are produced. From any given condition, excepting the extremes, variation proceeds in two opposite directions toward reduction of the pigmented area and toward increase thereof.

If in this series we consider fig. 6 as the modal type, then figs. 5, 4, 3 . 2 , and I show stages in the reduction of pigment and also where separation of spots first occurs. Thus in fig. $5, d, e$ and $d^{\prime}, e^{\prime}$ become separated by an area of hypodermal color, and this is broadened in figs. 4, 3, 2, and I. In figs. $I$ and 2 is seen the last process of reduction which occurs in this species, namely, the separation of $a$ and $a^{\prime}$ and the loss of $c$ and $c^{\prime}$, With this reduction, however, two spots hitherto merged in $a+a^{\prime}$, am and $p m$, are brought into view. In figs. 3 and 4 the separation of $a+b$ and $a^{\prime}+b^{\prime}$ is shown. In the opposite direction fig. 7 shows the union of $d+e+J$ and $d^{\prime}+e^{\prime}+f^{\prime}$, and in fig. 8 a further fusion of spots, so that the formula am

for the color pattern is now $c^{\prime}, f^{\prime}+e^{\prime}+d^{\prime}+b^{\prime}+a^{\prime}+a+b+d+e+f, c$, while in fig. 9 this process of increase in the area of individual spots is further extended.

In this series the variations are definite in two chief directions, and other lines are not common, although they do exist. These less frequent variations consist in irregularities in the fusion, as, for example, where we find a pattern which may be represented by the formula $c^{\prime}, f^{\prime}, d^{\prime}+e^{\prime}, b^{\prime}$, am $a m$ $a^{\prime}+a+b+d+e+f, c$, or $c^{\prime}-^{\prime}, d^{\prime}, e^{\prime}, b^{\prime}+a^{\prime}+a+b, d, e+f, c$. These pm $p m$

irregularities are due, however, to the failure of a given spot to develop symmetrically with its fellow of the other side. Spots are sometimes wholly absent, most commonly $f$ and $f^{\prime}$, the others in this series being about alike in the frequency of their failure to develop. 


\section{Explanation of Plate i4.}

Figs. I to 12 represent variations in color pattern on the pronotum of $L$. undecimlineata. Figs. I, 2, 3, II, and I2 are from Panama. Figs. 4, 5, and 6 are from Tierra Blanca, Vera Cruz, Mexico. Figs. 7, 8, 9, and to are from Orizaba, Vera Cruz, Mexico.

Figs. ${ }_{3}$ to 22 illustrate variations in color pattern of the pronotum in L. multitan ata. All the figures given are taken from beetles collected at Guadalupe, Federal District, Mexico.

Figs. 23 to 30 illustrate variations in color pattern on the pronotum in L. decemlineata. Figs. 23, 24, and 29 are from specimens collected at Cold Spring Harbor, New York. Figs. 24 and 26 are from specimens collected at Dalhart, Texas. Figs. 27 and 28 are from specimens collected at McPherson, Kansas. Fig. 30 is a variation obtained in Georgia and also produced experimentally.

Figs. $3 \mathrm{I}$ to 35 illustrate variations in elytral color pattern in $L$. undecimlineata. Figs. $3 \mathrm{I}$ and 32 are from specimens taken at Tierra Blanca, Vera Cruz, Mexico. Fig. 33 is a variation of undecimlineata found at Tierra Blanca. Figs. 34 and 35 are from specimens taken at Orizaba, Vera Cruz.

Figs. 36 and 37 illustrate the transverse fusions found in the elytral color pattern in L. decemlineata, from specimens taken at Chicago, III.

Figs. 38 and 39 illustrate variations in elytral color pattern in L. juncta, from specimens taken at Baton Rouge, Louisiana.

Fig. 40 illustrates color-pattern condition in elytra of $L$. defecta, from a specimen taken at Dallas, Texas.

Figs. 4I to 45 illustrate variations in color pattern of elytra of L. lineolata. Figs. 4I, 42, and 43 are from specimens collected in Chihuahua, Mexico. Figs. 44 and 45 are from specimens taken at Deming, New Mexico.

Figs. 46 to 48 illustrate variations in elytral color pattern of $L$. dilecta, from specimens taken at Atlixco, Mexico.

Figs. 49 to 52 illustrate variations in elytral color pattern of $L$. zetterstedti, from specimens collected at La Barranca, near Guadalajara, Jalisco, Mexico.

Figs. 53 and 54 illustrate variations in L. pudica, from specimens taken at Peras, Vera Cruz, Mexico.

Figs. 55 to 57 illustrate variations in elytral color pattern of $L$. lacerata, from specimens collected at Oaxaca, Oaxaca, Mexico. 
(iv:) (av: 6V: 6บ: 6V:0 (2)

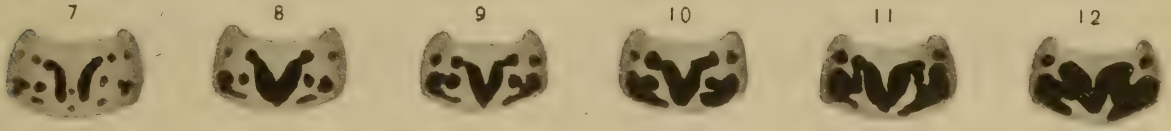

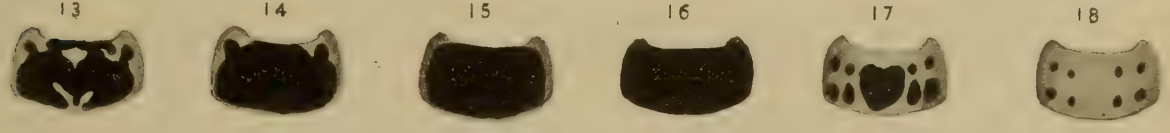

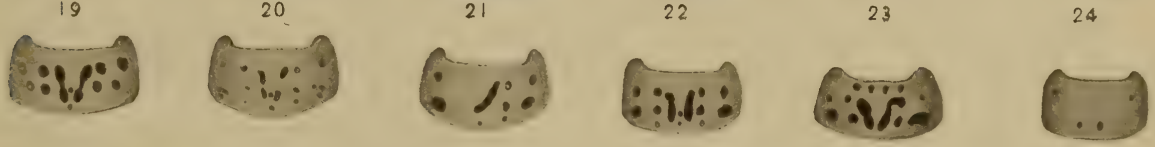
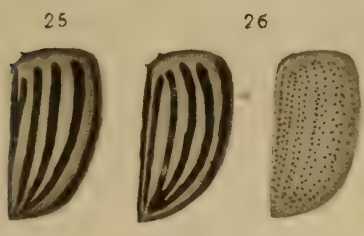
27 28 29 30
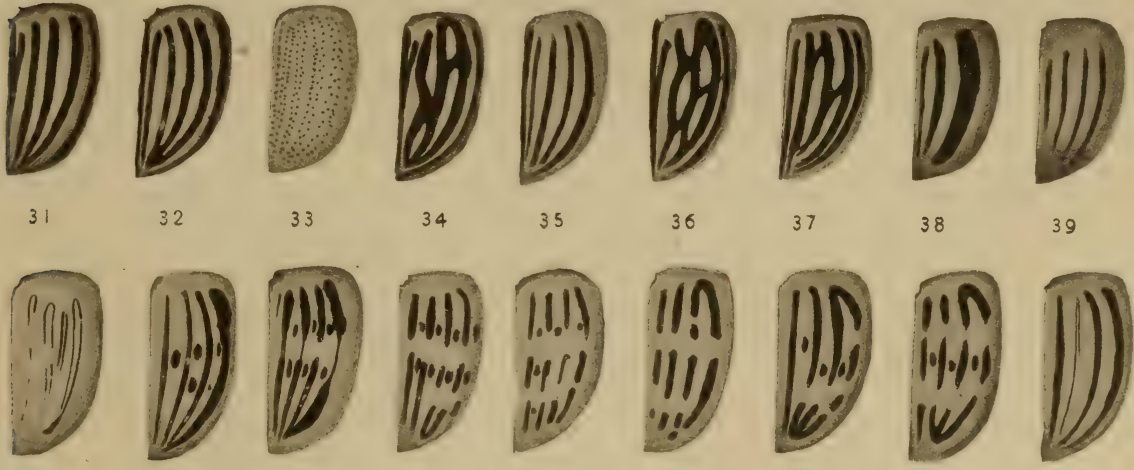

39

40

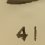

42

$43 \quad 44$

45
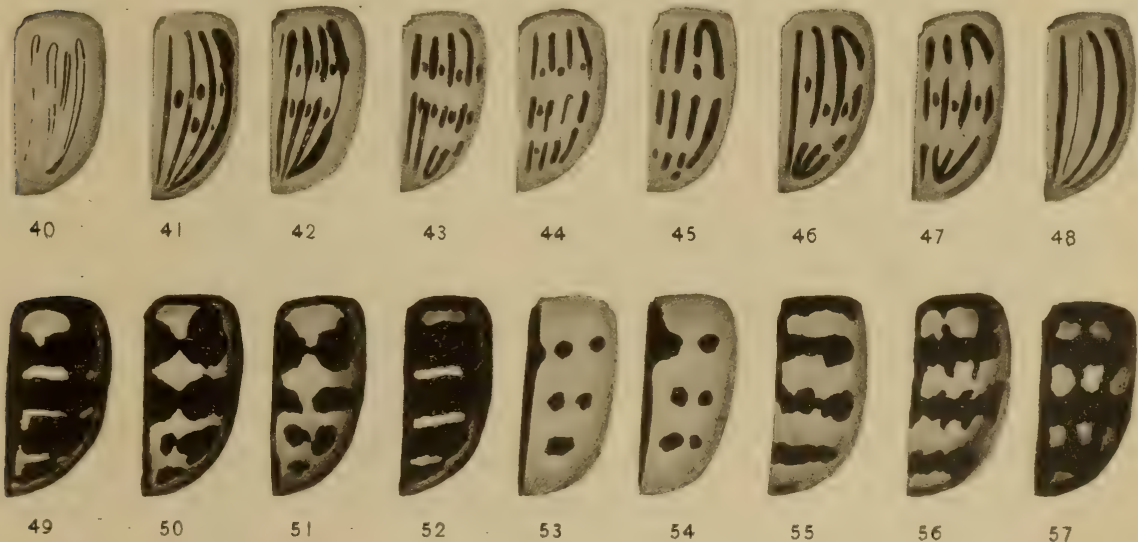

51

52

53

54

55

56

48 

Besides the variations described, certain others which are abmodal occur from time to time. These, while of no great number or apparent importance in evolution, are of value in the interpretation of certain phases of color variation. Some of these are found on plate I4, figs. IO, II, and I2.

In diversa, angustovittata, and signaticollis, which are the closest allies of undecimlineata, the same kind and direction of variation are found. I have not drawn figures of these species, but the variations appear in the tables.

The color patterns of L. multitaniata and decemlineata show a series of variations of the same general nature as those of $L$. undecimlineata, as will be apparent from a study of figs. 13 to 22 on plate 14 , in which are shown the variations of these two species. In this series there is found the same definite tendency toward reduction of the elements of the color pattern on the one hand and increase on the other, the extremes being represented by figs. 22 and 30. Irregularities and abnormalities are of the same nature as those in L. undecimlineata and are to be explained on the same basis.

With the exception of melanothorax, all of the species in the lineata group have this same type of color pattern.

The frequency and direction of fusion of the spots is of interest and shows in the different species variation along definite lines which is apparent in the following tables:

TABLE 3.-Direction and frequency of the fusion of spots on the pronotum in L. undecimlineata (Mexico, Guatemala, Costa Rica, Panama), I,200 individuals.

\begin{tabular}{|c|c|c|}
\hline $\begin{array}{l}\text { Order of } \\
\text { frequencycof } \\
\text { occurrence. }\end{array}$ & Formulæ showing color pattern. & $\begin{array}{l}\text { Individuals } \\
\text { showing } \\
\text { fusions. }\end{array}$ \\
\hline I & $p m \stackrel{a}{\underset{a^{\prime}}{+} a m}$ & $\left\{\begin{array}{l}\text { Per cent. } \\
94\end{array}\right.$ \\
\hline 2 & $\begin{array}{c}a+b \\
p m+a m \\
a^{\prime}+b^{\prime}\end{array}$ & 92 \\
\hline 3 & $\begin{array}{l}d+e \\
d^{\prime}+e^{\prime}\end{array}$ & \} \\
\hline 4 & $\begin{array}{l}d+e+f \\
d^{\prime}+e^{\prime}+f^{\prime}\end{array}$ & \}$\quad 63$ \\
\hline 5 & $\begin{array}{c}a+b+d+e+f \\
\stackrel{+a m}{+a m}+a^{\prime}+b^{\prime}+d^{\prime}+e^{\prime}+f^{\prime}\end{array}$ & \} \\
\hline 6 & $\begin{array}{c}a+b+d+f+e+c \\
\stackrel{+a m}{+a}+a^{\prime}+b^{\prime}+d^{\prime}+f^{\prime}+e^{\prime}+c^{\prime}\end{array}$ & \} \\
\hline
\end{tabular}


TABLE 4.-Direction and frequency of the fusion of the spots on the pronotum of L. diversa (Mexico), 100 individuals.

\begin{tabular}{|c|c|c|}
\hline $\begin{array}{l}\text { Order of } \\
\text { frequency of } \\
\text { occurrence. }\end{array}$ & Formulæ showing color pattern. & $\begin{array}{l}\text { Individuals } \\
\text { showing } \\
\text { fusions. }\end{array}$ \\
\hline I & $p m+\underset{a^{\prime}}{a}$ & $\left\{\begin{array}{l}\text { Per Cent. } \\
100\end{array}\right.$ \\
\hline 2 & $\begin{array}{c}a+b \\
p m+a m \\
a^{\prime}+b^{\prime}\end{array}$ & 98 \\
\hline 3 & $\begin{array}{l}d+e \\
d^{\prime}+e^{\prime}\end{array}$ & 93 \\
\hline 4 & $\begin{array}{l}d+e+f \\
d^{\prime}+e^{\prime}+f^{\prime}\end{array}$ & 74 \\
\hline 5 & $\begin{array}{c}a+b+d+e+f \\
p m+\underset{+a m}{a^{\prime}+b^{\prime}+d^{\prime}+e^{\prime}+f^{\prime}}\end{array}$ & 62 \\
\hline
\end{tabular}

TABLE 5.-Direction and frequency of the fusion of the spots on the pronotum of L. signaticollis (Mexico), I,00o individuals.

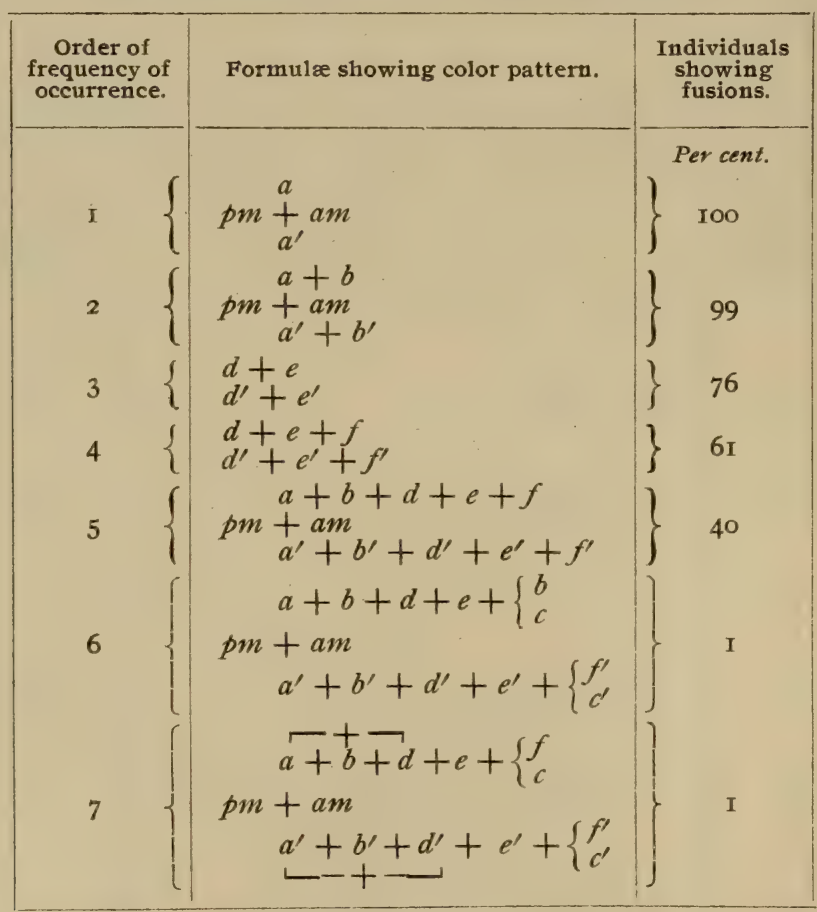

In the fusions of the spots indicated in table $5, a$ and $d$ are united by a lateralward extension of $a$ and a medianward extension of $d$. (See plate 14, fig. 19.) The fusion is indicated by the sign $-+\longrightarrow$. 
COLOR PAT'TERT OF PRONOTUM.

TABLE 6.-Direction and frequency of the fusion of the spots on the pronotum in $L$. multitaniata (Mexico), 4,200 individuals.

\begin{tabular}{|c|c|c|}
\hline $\begin{array}{l}\text { Order of } \\
\text { frequency of } \\
\text { occurrence. }\end{array}$ & Formulæ showing color pattern. & $\begin{array}{l}\text { Individuals } \\
\text { showing } \\
\text { fusion. }\end{array}$ \\
\hline & & Percent. \\
\hline I & $p m \stackrel{a}{+} a m$ & 75 \\
\hline 2 & $\begin{array}{c}a+b \\
p m+a m \\
a^{\prime}+b^{\prime}\end{array}$ & \} \\
\hline 3 & $\begin{array}{l}d+e \\
d^{\prime}+e^{\prime}\end{array}$ & $5^{2}$ \\
\hline 4 & $\begin{array}{l}d+e+f \\
d^{\prime}+e^{\prime}+f^{\prime}\end{array}$ & $4 \mathrm{I}$ \\
\hline 5 & $\begin{array}{c}a+b+d+e+f \\
p m+a m \\
a^{\prime}+b^{\prime}+d^{\prime}+e^{\prime}+f^{\prime}\end{array}$ & \} \\
\hline 6 & $\begin{aligned} a+b+d+e+\left\{\begin{array}{l}c \\
f\end{array}\right. \\
p m+a m \\
a^{\prime}+b^{\prime}+d^{\prime}+e^{\prime}+\left\{\begin{array}{l}f^{\prime} \\
c^{\prime}\end{array}\right.\end{aligned}$ & 6 \\
\hline 7 & $\begin{array}{l}\text { Hypodermal color exposed as } \\
\text { a narrow lateral margin. }\end{array}$ & \} \\
\hline 8 & Total melanism ..... & 2 \\
\hline
\end{tabular}

TABLE 7.-Direction and frequency of the fusion of the spots on the pronotum in L. oblongata (Mexico), I,00o individuals.

\begin{tabular}{|c|c|c|}
\hline $\begin{array}{l}\text { Order of } \\
\text { frequency of } \\
\text { occurrence. }\end{array}$ & Formulæ showing color pattern. & $\begin{array}{l}\text { Individuals } \\
\text { showing } \\
\text { fusion. }\end{array}$ \\
\hline & & Percent. \\
\hline I & $p m, \stackrel{a}{+a m}$ & \} $2 I$ \\
\hline 2 & $p m+\underset{a^{\prime}}{a}+a m$ & \{ \\
\hline 3 & $\begin{array}{l}d+e \\
d^{\prime}+e^{\prime}\end{array}$ & $4 \mathrm{I}$ \\
\hline 4 & $\begin{array}{l}d+e+f \\
d^{\prime}+e^{\prime}+f^{\prime}\end{array}$ & \} \\
\hline 5 & $\begin{array}{c}a+b+d+e+f \\
p m+a m \\
a^{\prime}+b^{\prime}+d^{\prime}+e^{\prime}+f^{\prime}\end{array}$ & \} \\
\hline 6 & $\begin{array}{l}c+e+f \\
c^{\prime}+e^{\prime}+f^{\prime}\end{array}$ & \} \\
\hline
\end{tabular}


TABLE 8.-Direction and frequency of the fusion of the spots on the pronotum in L. rubicunda (Mexico), 200 individuals.

\begin{tabular}{|c|c|c|}
\hline $\begin{array}{l}\text { Order of } \\
\text { frequency of } \\
\text { occurrence. }\end{array}$ & Formulæ showing color pattern. & $\begin{array}{l}\text { Individuals } \\
\text { showing } \\
\text { fusion. }\end{array}$ \\
\hline I & $p m \underset{a^{\prime}}{a}+a m$ & $\left\{\begin{array}{l}\text { Percent. } \\
100\end{array}\right.$ \\
\hline\{ & $\begin{array}{c}a+b \\
p m+a m \\
a^{\prime}+b^{\prime}\end{array}$ & \} \\
\hline\{ & $\begin{array}{l}e+d \\
e^{\prime}+d^{\prime}\end{array}$ & \\
\hline\{ & $\begin{array}{c}a+b+d+e+f \\
p m+\underset{+a m}{a^{\prime}+b^{\prime}+d^{\prime}+e^{\prime}+f^{\prime}}\end{array}$ & \} \\
\hline
\end{tabular}

TABLE 9.-Direction and frequency of the fusion of the spots on the pronotum in L. intermedia (Mexico), 300 individuals.

\begin{tabular}{|c|c|c|}
\hline $\begin{array}{l}\text { Order of } \\
\text { frequency of } \\
\text { occurrence. }\end{array}$ & Formulæ showing color pattern. & $\begin{array}{l}\text { Individuals } \\
\text { showing } \\
\text { fusion. }\end{array}$ \\
\hline\{ & $p m, \quad \begin{array}{l}a \\
+ \\
a^{\prime}\end{array}$ & $\left\{\begin{array}{l}\text { Percent. } \\
40\end{array}\right.$ \\
\hline 2 & $p m \underset{a^{\prime}}{\stackrel{a}{+} a m}$ & \{ \\
\hline 3 & $\begin{array}{c}a+b \\
p m+a m \\
a^{\prime}+b^{\prime}\end{array}$ & \} \\
\hline 4 & $\begin{array}{l}d+e \\
d^{\prime}+e^{\prime}\end{array}$ & 32 \\
\hline 5 & $\begin{array}{l}e+f \\
e^{\prime}+f^{\prime}\end{array}$ & 36 \\
\hline 6 & $\begin{array}{l}d+e+f \\
d^{\prime}+e^{\prime}+f^{\prime}\end{array}$ & \} \\
\hline 7 & $\begin{array}{c}a+b+d+e+f \\
p m+a m \\
a^{\prime}+b^{\prime}+d^{\prime}+e^{\prime}+f^{\prime}\end{array}$ & \} \\
\hline
\end{tabular}


TABLE 10.-Direction and frequency of fusion of the spots on the pronotum in L. decemlineata (United States and Canada), 6,200 individuals.

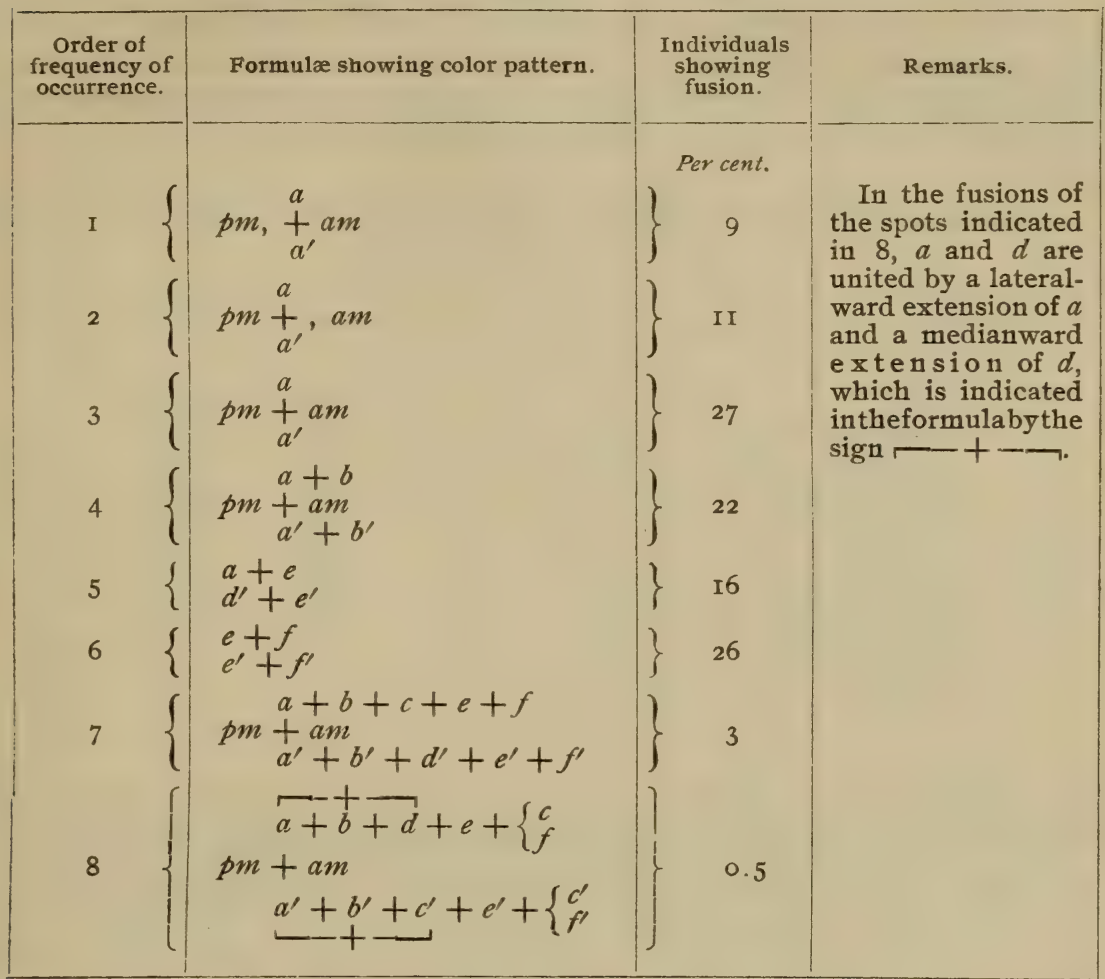

TABLE II.-Direction and frequency of the fusion of the spots on the pronotum in L. juncta (United States), 200 individuals.

\begin{tabular}{|c|c|c|}
\hline $\begin{array}{l}\text { Order of } \\
\text { frequency of } \\
\text { occurrence. }\end{array}$ & Formulæ showing color pattern. & $\begin{array}{l}\text { Individuals } \\
\text { showing } \\
\text { fusions. }\end{array}$ \\
\hline I & $p m, \underset{a^{\prime}}{+a}$ & $\left\{\begin{array}{c}\text { Percent. } \\
4\end{array}\right.$ \\
\hline 2 & $p m, \stackrel{a}{+}, a m$ & \} \\
\hline 3 & $p m \stackrel{a}{\underset{a^{\prime}}{+}} a m$ & 3 \\
\hline 4 & $\begin{array}{c}a+b \\
p m+a m \\
a^{\prime}+b^{\prime}\end{array}$ & 2 \\
\hline 5 & $\begin{array}{l}d+e \\
d^{\prime}+e^{\prime}\end{array}$ & \} \\
\hline
\end{tabular}


In the preceding tables of the fusion in the pronota of the different species of the lineata group it appears that the directions of fusion are the same for all, but the frequency of the fusion of a given spot varies in different species, and this frequency is constant for large series and might be used as a specific differential. In the following comparative table of the fusions of $a^{\prime}+a$ and $d+e$ the difference in the percentage appears :

TABLE I2.-Comparative frequency of fusion of $a^{\prime}$ and $a, d^{\prime}$ and $e$, in the species of the lineata group.

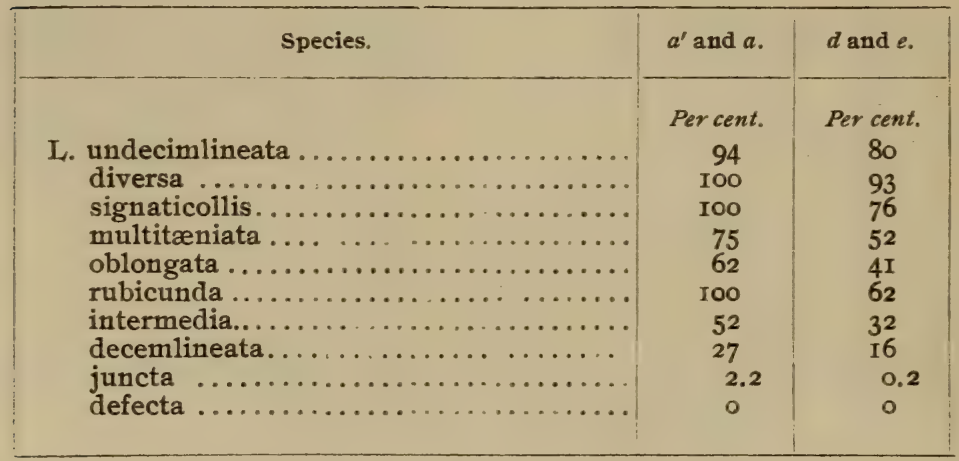

The illustrations on plate 14 and the figures given in tables 3 to I I show conclusively that the fluctuating variations of the pronotal color pattern in the lineata group do not occur promiscuously and in all directions, but in two well-defined lines. Rarely abnormal conditions occur, but these are the results of pathological conditions operating during pupation. Individual variation is definite.

Variation in the proportion between the areas of dark and light pigment gives interesting facts along the same line. Twenty classes illustrative of this color relation have been established, of which fig. 30, plate I4, represents one extreme, with the value of I, and fig. 32 the other, with the value of 20. Somewhere between the extremes in this series all the species of the lineata group find their proper places. The distribution of the classes into which each species falls can best be shown by tables.

The proportion of light to dark color on the pronotum of these beetles shows in table 13 a tendency toward melanism on the one hand and albinism on the other. Thus some of the species have their mode at the darker end of the series (L. diversa), while others have theirs at the lighter end. In all, however, the variations of this character obey Quetelet's law of individual variability. With one exception no two of the species have exactly the same modal condition as regards this character, a fact clearly shown in table I4. 
TABLE 13.-Variation in the proportion between the pigmented and unpigmented areas on the pronotum of $L$. undecimlineata, $L$. diversa, $L$. signaticollis, $L$. multiteniata, $L$. intermedia, $L$. decemlineata, and $L$. oblongata. ${ }^{1}$

\begin{tabular}{|c|c|c|c|c|c|c|c|}
\hline \multirow{2}{*}{ Classes. } & \multicolumn{7}{|c|}{ Per cent of frequency. } \\
\hline & $\begin{array}{l}\text { L. undecim- } \\
\text { lineata. }\end{array}$ & L. diversa. & $\begin{array}{l}\text { L. signati- } \\
\text { collis. }\end{array}$ & $\begin{array}{l}\text { L. multita- } \\
\text { niata. }\end{array}$ & $\begin{array}{l}\text { L. inter- } \\
\text { media. }\end{array}$ & $\begin{array}{l}\text { L. decemli- } \\
\text { neata. }\end{array}$ & L. oblongata. \\
\hline Class I & $\ldots$ & $\ldots$ & $\ldots$ & $\ldots$ & $\ldots$ & 0.1503 & $\ldots$ \\
\hline 2 & $\ldots$ & $\cdots$ & $\ldots$ & $\ldots$ & $\ldots$ & 0.1503 & $\ldots$ \\
\hline 3 & $\cdots$ & $\ldots$ & $\ldots$ & $\ldots$ & $\ldots$ & 0.4509 & $\ldots$ \\
\hline 4 & $\cdots$ & $\cdots$ & $\ldots$ & $\ldots$ & $\ldots$ & 0.6012 & $\ldots$ \\
\hline 5 & $\cdots$ & $\ldots$ & $\ldots$ & $\ldots$ & I & 1.5030 & $\ldots$ \\
\hline 6 & $\ldots$ & $\ldots$ & $\ldots$ & $\cdots$ & 2 & 2.2545 & $\ldots$ \\
\hline 7 & $\cdots$ & $\cdots$ & $\ldots$ & 0.7098 & 4 & 4.2084 & $\cdots$ \\
\hline 8 & 0.712 & $\ldots$ & $\ldots$ & I. 8928 & 6 & 7.9059 & $\ldots$ \\
\hline 9 & 2.436 & $\ldots$ & $\ldots$ & $3 \cdot 3124$ & I8 & 28.6675 & I \\
\hline ro & 3.348 & $\ldots$ & I & 6.6248 & 36 & 24.9498 & 3 \\
\hline II & $7 \cdot 308$ & $\ldots$ & 2 & Io 3664 & $2 I$ & I6.8938 & 7.2 \\
\hline 12 & 4.872 & $\ldots$ & 4 & 23.2688 & Io & $7.605 \mathrm{I}$ & I6. 4 \\
\hline$I_{3}$ & 8.120 & $\ldots$ & 8 & I9 6678 & 2 & 3.7575 & 39.0 \\
\hline 14 & 22.860 & 5 & I 6 & 14.4326 & $\ldots$ & 0.7515 & 18.4 \\
\hline I5 & 38.164 & 25 & 56 & 9.8972 & $\ldots$ & o. $\mathrm{T}_{5} \mathrm{O} 3$ & II. 6 \\
\hline 16 & I2. I 80 & 70 & I3 & 4.9686 & $\ldots$ & $\ldots$ & 3.4 \\
\hline I7 & $\ldots$ & $\ldots$ & $\ldots$ & 2.6026 & $\ldots$ & ... & $\ldots$ \\
\hline 18 & $\ldots$ & $\ldots$ & $\ldots$ & 2.0196 & $\ldots$ & $\ldots$ & $\ldots$ \\
\hline I9 & $\ldots$ & $\ldots$ & $\ldots$ & 0.2366 & $\ldots$ & $\ldots$ & $\ldots$ \\
\hline 20 & $\ldots$ & $\cdots$ & $\cdots$ & $\cdots$ & $\cdots$ & $\cdots$ & $\ldots$ \\
\hline
\end{tabular}

L. undecimlineata: $\mathrm{N} .=\mathrm{I}, 230$ individuals. Mean of classes $=12.92892$.

$L$. divers $:$ N. $=100$ individuals. Mean of classes $=15.65$.

L. signaticollis : $\mathrm{N}_{\mathbf{N}}=\mathrm{I}, 000$ individuals. Mean of classes $=\mathrm{I} 4.67$.

L. multitceniata: $\mathrm{N}_{.}=4,220$ individuals. Mean of classes $=12.762124$.

$L$. intermedia $:$ N. $=200$ individuals. Mean of classes $=9.92$.

L. decemlineata: $\mathrm{N} .=6,650$ individuals. Mean of classes $=9.647779$.

$L$. oblongata : $\mathrm{N} .=500$ individuals. Mean of classes $=\mathrm{I}_{3} .024$.

TABLE 14.-Position of the empirical mode of the species of the lineata group upon the scale of color proportion used in the foregoing tables, and the per cent of variates in the modal class, which indicates the variability of each species.

\begin{tabular}{|c|c|c|c|c|c|}
\hline Class. & Species. & $\begin{array}{l}\text { Per cent } \\
\text { in modal } \\
\text { class. }\end{array}$ & Class. & Species. & $\begin{array}{c}\text { Per cent } \\
\text { in modal } \\
\text { class. }\end{array}$ \\
\hline $\begin{aligned} & \text { Class } 3 . \\
& 5 . \\
& 9 . \\
& 10 . \\
& 12 .\end{aligned}$ & $\begin{array}{l}\text { L. defecta . . . . . . . } \\
\text { L. juncta......... } \\
\text { L. decemlineata... } \\
\text { L. intermedia...... } \\
\text { L. multitæniata.... }\end{array}$ & $\begin{array}{l}54 \\
60 \\
28.6675 \\
36 \\
23.2688\end{array}$ & $\begin{array}{r}\text { Class } 13 . \\
16 . \\
20 .\end{array}$ & $\begin{array}{l}\text { L. oblongata ..... } \\
\left\{\begin{array}{l}\text { L. undecimlineata } \\
\text { L. diversa........ }\end{array}\right. \\
\text { L. melanothorax. }\end{array}$ & $\begin{array}{l}39 \\
38.164 \\
70 \\
100\end{array}$ \\
\hline
\end{tabular}

The numbers of individuals used in the above tables are large, so that the probability of inaccuracy in the modes and percentages is slight, and the fact that the determinations in each case are made from material taken from several generations further enhances the probability of accuracy.

The modes shown in table 14 and the variations shown in the preceding tables are for the species. The modes for different generations and for

\footnotetext{
${ }^{1}$ The empirical mode in this and all following tables is indicated by being set in boldfaced type.
} 
single lots of variates show deviation from these species modes and values, the result of place variation, a phenomenon which will be considered later.

In the individual variation of the color pattern of the pronotum two facts appear-first, that the variations, while numerous, are not promiscuous, but in definitely directed lines; second, that the species tend to segregate their variations about modes arranged along the chief directions of individual variation.

Variation in the color of the pronotum in the dilecta group.-The pronotum in this group has a uniformly colored surface, which, however, shows in some species variations of interest, especially in the intensity of its metallicism. Thus, in the series of species $L$. calceata, $L$. dilecta, and L. lineolata there are variations in the color of the pronotum from reddish-brown to dark metallic green. The range of color is divided into six classes, as follows: (I) reddish-brown; (2) dark reddish-brown; (3) dark reddishbrown with a greenish sheen; (4) light metallic greenish-red; (5) bright metallic-green, and (6) dark metallic-green. In table $5_{5}$ is given the frequency of the variations seen in the different species.

TABLE 15.-Variation in the color of the pronotum in L. calceata, L. dilecta, and L. lineolata.

\begin{tabular}{|r|r|r|r|}
\hline & \multicolumn{3}{|c|}{ Per cent of frequency. } \\
\cline { 2 - 4 } Classes. & L. calceata. & L. dilecta. & L. lineolata. \\
\cline { 2 - 4 } Class I & $\ldots$. & $\ldots$. & 8 \\
2 & $\ldots \ldots$ & 1 & 9 \\
3 & 2 & 2 & 12 \\
4 & 22 & 10 & 29 \\
5 & 72 & 85 & 41 \\
6 & 4 & 2 & 1 \\
\hline
\end{tabular}

L. calceata $: \mathrm{N} .=50$ individuals. Mean of classes $=4.78$.

L. dilecta $: \mathrm{N} .=3$ oo individuals. Mean of classes $=4.85$.

L. lineolata : N. $=300$ individuals. Mean of classes $=3.89$.

I have not been able to procure enough material of the other species of this group to give satisfactory seriations or data of color variation. In the three species seriated above the variations are plainly limited to very narrow lines ; one series of color changes-reddish-brown to metallic-green. These are the only variations known. All three species show a mode on class 5, bright metallic-green, although the range of variation is greatest in lineolata and least in calceata.

Variation in the color of the pronotum of the haldemani group.- -None of the species of this group possess color patterns, and the only variations are those of intensity of color. The pronotum of $L$. dahlbomi, the most widely ranging 
member of the genus, is black or deep brown, appearing black by reflected light, and is almost invariable in color. L. hogei has the thorax dark brown with a greenish iridescence, which in the few specimens at hand appears to be slightly variable toward a stronger development of the metallic-green portion of the coloration. The species haldemani, libatrix, and violescens present a series of color variations from black to deep metallic-blue, a range which may be divided into the following classes: (I) Black, (2) polished black, (3) black with faint blue iridescence, (4) light metallic blue-black, (5) metallic blue-black, (6) deep blue-black, (7) violet. In the following table is given the frequency of the variations seen in the different species :

TABLE 16.-Variation in the color of the pronotum in $L_{s}$. haldemani, L. libatrix, and L. violescens.

\begin{tabular}{|r|r|r|r|}
\hline & \multicolumn{3}{|c|}{ Per cent of frequency. } \\
\cline { 2 - 4 } Classes. & L. haldemani. & L. libatrix. & L. violescens. \\
\cline { 2 - 4 } Class I & 62 & $\ldots$ & \\
\hline 2 & II & 3 & $\ldots$ \\
3 & 24 & 4 & $\ldots$ \\
4 & 3 & 82 & I \\
5 & $\ldots \ldots$ & 6 & 3 \\
6 & $\ldots \ldots$ & 3 & 4 \\
7 & $\ldots$. & 2 & 92 \\
\hline
\end{tabular}

L. haldemani: $\mathrm{N} .=200$ individuals. Mean of classes $=\mathrm{x} .68$.

L. libatrix: $\mathrm{N} .=100$ individuals. Mean of classes $=4.08$.

$L$. violescens: $\mathrm{N} .=100$ individuals. Mean of classes $=6.87$.

No other lines of color variation in the pronotum of this group are known to me. However, some of the species of this group I have not had an opportunity to examine. The variability of the three species studied is low, a fact plainly indicated by the high percentage of variates in the modal class, and, like the preceding groups, is limited to two directions.

Variation in the color of the pronotum in the other groups. - In the lacerata group, as far as is known from the specimens available, the individual variation of the pronotum is extremely slight. In the rubiginosa and zetterstedti groups the species are constant, presenting only the slightest oscillations, too slight to be measured with any degree of success, while in the flavopustulata group, as far as I know, the color of the pronotum is invariable.

The study of the individual variation of the color and color pattern of the pronotum warrants the following conclusions :

(I) Variation is definite in opposite directions.

(2) No trace of indeterminate variation exists anywhere.

(3) The variations follow exactly Quetelet's law. 
INDIVIdUal, VARIATION IN THE COLOR PATtern OF THE EPICRANIUM.

Variation in the color pattern of the epicranium in the lineata group. -The color pattern of the epicranium, while simple, is no less variable than that of the pronotum. It consists of two spots placed just laterad of the median line and two placed at the outer posterior angle behind the eyes (text-fig. I). In the variations of this area a range is exhibited from complete melanism to total xanthism and albinism. On plate $\mathrm{I} 5$, figs. I to 7 , is shown the range of variation found in $L$. multiteniata and $L$. melanothorax (fig. 8). This species shows an almost complete series from one extreme to the other. Only at the xanthic and albinic end of the series are stages wanting to make a complete series in this one species. These are supplied, however, by its northern modifications, intermedia and decemlineata, which complete the series (plate 15 , figs. I 2 to 16 ). The range of variation found in L. decemlineata, as shown in these figures, is considerably less than that found in multiteniata, but greater than in the other species of the group. The variations of undecimlineata are shown in figs. 9 to II, plate 18 .

The direction of the fusion of the spots on the epicranium is well shown in figs. I to 6 . In fig. I all of the spots $g, h, i$ and $g^{\prime}, h^{\prime}, i^{\prime}$ are distinct pigment areas. In fig. 2 are shown the first steps in the fusion, the union posteriorly of $g$ and $g^{\prime}$ to form a V-shaped spot and the medianward extension of $h$ and $h^{\prime}$. This process is continued in fig. 3 until $g$ and $g^{\prime}$ have formed a heart-shaped spot in the center of the epicranium, which becomes more pronounced in fig. 4. In fig. 5 is shown the caudalward extension of this spot until it meets the medianward extension of $h$ and $h^{\prime}$, and all combine in the posterior median border of the epicranium. Further variation consists in the lateralward and cephalward spread of the spots $g$ and $g^{\prime}$ and $h$ and $h^{\prime}$, as shown in figs. 5 to 7 . No other variations of the color pattern of the epicranium of the lineata group are known, excepting rare abnormal conditions of asymmetrical variation caused by unequal development upon the two sides. These, however, are due to accidental causes acting during pupation, and are of no interest in this connection.

The proportion of light to dark color in the epicranium of the lineata group is of interest, showing, as it does, a series of gradations much like that found in the pronotum. It has been convenient to establish ten classes to represent these gradations, class I (plate I5 $_{5}$, fig. I2) indicating total xanthism or albinism and class Io (plate 15, fig. 8) total melanism. The variation in this character of the different species in the lineata group has been studied by seriations, which can best be presented in the form of tables. 



\section{Explanation of Plate 15.}

Figs. I to 8 illustrate variations in color pattern on the epicranium of L. multitaniata. All from specimens taken at Guadalupe, Federal District, Mexico.

Figs. 9 to II illustrate variations in color pattern on the epicranium of $L$. undecimlineata. All from specimens taken at Tierra Blanca, Vera Cruz, Mexico.

Figs. I2 to 16 illustrate variations found in color pattern of epicranium of $L$. decemlineata. All from specimens taken at Chicago, Illinois.

Figs. I7 to 24 illustrate the variations found in color pattern of ventral surface of abdominal segments in L. multitaniata. All from specimens taken at Guadalupe, Federal District, Mexico.

Figs. 25 to 29 illustrate variations in color pattern of ventral surface of abdominal segments in L. decemlineata. All from specimens taken at Chicago, Illinois.

Figs. 30 to 32 illustrate reduction of pigment on the ventral abdominal surface in L. undecimlineata. All from specimens taken at Tierra Blanca, Vera Cruz, Mexico.

Figs. 33 to 40 illustrate variations in color pattern of ventral surface of thoracic segments in L. multitaniata. All from specimens taken at Guadalupe, Federal District, Mexico.

Figs. $4 \mathrm{I}$ to 44 illustrate variations in color pattern of ventral surface of thoracic segments in $L$. decemlineata. All from specimens taken at Chicago, Illinois.

Figs. 45 to 52 illustrate variation in color pattern of the legs in L. multitaniata. All from specimens taken at Guadalupe, Federal District, Mexico.

Figs. 53 to 57 illustrate variation in color pattern of mature larvæ of L. multitaniata, from Guadalupe, Federal District, Mexico.

Figs. $5^{8}$ to 62 illustrate variation in color pattern of mature larvæ of $L$. decemlineata, from McPherson, Kansas.

Figs. 6.3 to 67 illustrate variation in color pattern of mature larvæ of $L$. signaticollis, from Cuernavaca, Morelos, Mexico. 


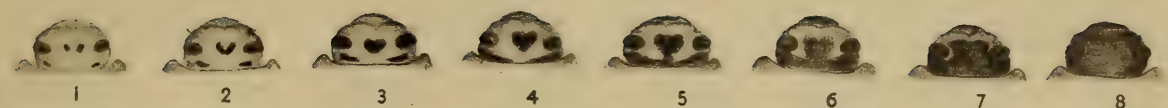

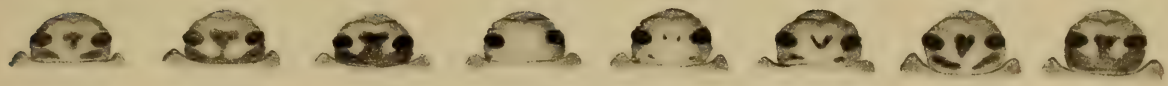
9

10

11

12

13

14

15

16

C:

17
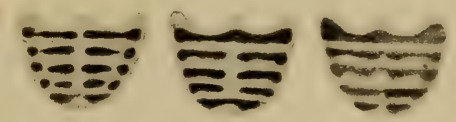

20

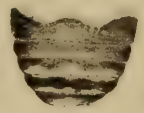

22

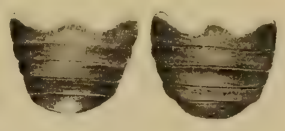

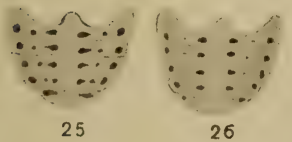
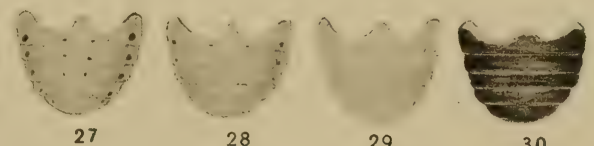

23

24

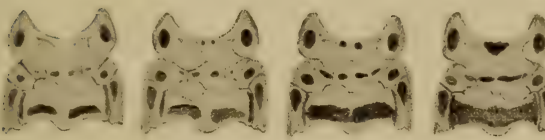

33

34

35

36
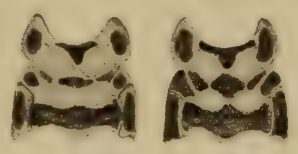

37
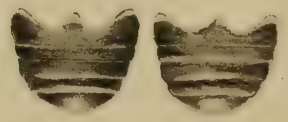

31

32
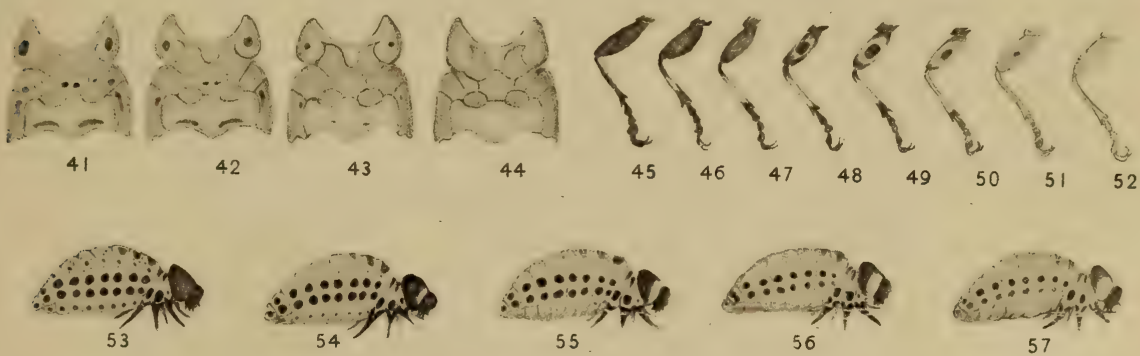

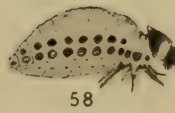
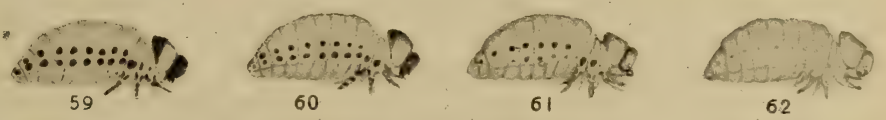

$\underset{63}{0}+\frac{1}{64}$
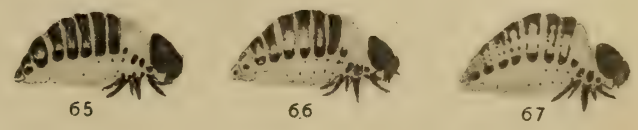

TABLE 17.-Variation in the proportion between the pigmented and unpigmented areas in the epicranium of $L$. undecimlineata, $L$. diversa, $L$. signaticollis, $L$. multiteniata, L. oblongata, $L$. decemlineata, and $L$. intermedia.

\begin{tabular}{|c|c|c|c|c|c|c|c|}
\hline \multirow{2}{*}{ Classes. } & \multicolumn{7}{|c|}{ Per cent of frequency. } \\
\hline & $\begin{array}{l}\text { L. undecim- } \\
\text { lineata. }\end{array}$ & L. diversa. & $\begin{array}{l}\text { L. signati- } \\
\text { collis. }\end{array}$ & $\begin{array}{l}\text { L. multita- } \\
\text { niata. }\end{array}$ & $\begin{array}{l}\text { L. oblon- } \\
\text { gata. }\end{array}$ & $\begin{array}{l}\text { L. decem- } \\
\text { lineata. }\end{array}$ & $\begin{array}{l}\text { L. inter- } \\
\text { media. }\end{array}$ \\
\hline Class I & $\ldots$ & $\ldots$ & $\ldots$ & $\ldots$ & & 2 & $\ldots$ \\
\hline 2 & $\ldots$ & $\ldots$ & $\ldots$ & 0.4728 & 0.6308 & 5 & 4 \\
\hline 3 & $\ldots$ & $\ldots$ & $\ldots$ & 0.9456 & 3.7848 & 12 & 16 \\
\hline 4 & $\ldots$ & $\ldots$ & $\ldots$ & $3.546 \mathrm{I}$ & $\mathrm{r} 4.8218$ & 54 & 60 \\
\hline 5 & 0.90 & $\ldots$ & I & 17.2577 & 67.5158 & 20 & I5 \\
\hline 6 & I5.30 & 8 & 2 & 10.4019 & 10.4082 & 7 & 4 \\
\hline 7 & 24.32 & 26 & 12 & 13.4754 & I. 8924 & $\ldots$ & I \\
\hline 8 & 47.75 & 66 & 25 & 22.9314 & 0.6308 & $\ldots$ & $\ldots$ \\
\hline 9 & II. 73 & $\therefore$ & 52 & 27.8959 & 0.3154 & $\ldots$ & $\ldots$ \\
\hline Io & $\ldots$. & $\ldots$ & 8 & 3.0732 & ... & ... & ... \\
\hline
\end{tabular}

L. undecimlineata : (Panama, Costa Rica, Nicaragua, Guatemala, Mexico). N.=1,230 individuals. Mean of classes $=7.5447$.

L. diversa: (Jalisco, Mexico). N. = Ioo individuals. Mean of classes $=7.58$.

L. signaticollis: (Mexico). N. $=1,000$ individuals. Mean of classes $=8.45$.

L. multitaniata : (Mexico). $\mathrm{N}_{.}=4,230$ individuals. Empirical modes = greater, class 9 ; less, class 5 . Mean of classes $=7.2733$.

L. oblongata: (Mexico). N. $=3,170$ individuals. Mean of classes $=4.9303$.

L. decemlineata: (United States and Canada). N. $=6,650$ individuals. Mean of classes $=4.000$.

L. intermedia : (Mexico). N. $=$ Ioo individuals. Mean of classes $=4.0200$.

TABLE I8.-Position of the empirical mode of the species of the lineata group upon the scale of color proportion used in the foregoing tables.

\begin{tabular}{|c|c|c|c|c|c|c|}
\hline Classes & & Species. & $\begin{array}{l}\text { Per cent } \\
\text { in modal } \\
\text { class. }\end{array}$ & Classes. & Species. & $\begin{array}{l}\text { Per cent } \\
\text { in modal } \\
\text { class. }\end{array}$ \\
\hline Class 2 & $\begin{array}{l}2\{ \\
4\{\end{array}$ & $\begin{array}{l}\text { I. defecta........ } \\
\text { L. juncta........ } \\
\text { I. decemlineata... } \\
\text { L. intermedia.... } \\
\text { L. multitæniata ... } \\
\text { L. oblongata ..... }\end{array}$ & $\begin{array}{l}82 \\
68 \\
54 \\
60 \\
\text { I } 7.2577 \\
67.5 \text { I } 53\end{array}$ & $\begin{array}{r}\text { Class } 8\{ \\
9\{ \\
\text { I0 }\end{array}$ & $\begin{array}{l}\text { L. mndecimlineata . } \\
\text { L. diversa........ } \\
\text { L. multitæniata... } \\
\text { L. signaticollis.... } \\
\text { L. melanothorax... }\end{array}$ & $\begin{array}{l}47.75 \\
66 \\
27.8959 \\
52 \\
100\end{array}$ \\
\hline
\end{tabular}

Comparison of the epicranium and pronotum in the lineata group. - The color pattern of the epicranium shows, as far as the proportion of pigmented to unpigmented areas is concerned, essentially the same phenomenon as that exhibited by the pronotum-that is, the modes for the different species are located at various points along the scale of proportion used. If we compare table I 8 with table I4, which gives the position of the modes of the pronotum, we see that in the main the position of the modes for each species is the same in both tables. In both melanothorax occupies the highest place and defecta the lowest, while undecimlineata and diversa are in both cases in the same modal class. Signaticollis changes its position in table 8 to one 
above that of undecimlineata, and multitaniata shows two modes, the high mode being the same as that of signaticollis and the low one the same as that of oblongata.

The percentage of individuals found in the modal classes is shown in the following table :

TABLE 19.-Comparison of the per cent of individuals in the modal classes of the different species of the lineata group.

\begin{tabular}{|c|c|c|c|c|c|}
\hline \multirow{2}{*}{ Species. } & \multicolumn{2}{|c|}{$\begin{array}{l}\text { Per cent in modal class } \\
\text { in seriation of- }\end{array}$} & \multirow{2}{*}{ Species. } & \multicolumn{2}{|c|}{$\begin{array}{l}\text { Per cent in modal class } \\
\text { in seriation of - }\end{array}$} \\
\hline & Pronotum. & Epicranium. & & Pronotum. & Epicranium. \\
\hline $\begin{array}{l}\text { L. angustovittata. } \\
\text { defecta......... } \\
\text { juncta ........ } \\
\text { rubicunda..... } \\
\text { melanothorax . } \\
\text { decemlineata... }\end{array}$ & $\begin{array}{l}\text { Per cent. } \\
\ldots \ddot{7} \\
60 \\
85 \\
\text { I0o } \\
26.6675\end{array}$ & $\begin{array}{c}\text { Per cent. } \\
\ldots \ldots \\
54 \\
58 \\
90 \\
\text { I00 } \\
54\end{array}$ & $\begin{array}{l}\text { L. oblongata ...... } \\
\text { intermedia.... } \\
\text { multitæniata . } \\
\text { signaticollis ... } \\
\text { diversa...... } \\
\text { undecimlineata }\end{array}$ & $\begin{array}{l}\text { Per cent. } \\
39 \\
25.5 \\
23.2688 \\
56 \\
70 \\
38.164\end{array}$ & $\begin{array}{l}\text { Per cent. } \\
67.5158 \\
29 \\
27.8959 \\
52 \\
66 \\
47.75\end{array}$ \\
\hline
\end{tabular}

In this table it is apparent that where the percentage of individuals in any modal class is high when the pronotum is taken as the standard, the per cent of individuals in the corresponding class of the epicranium is also high and in most of the species higher than in the pronotum. In only a few cases does the percentage of individuals in the modal class of the epicranium fall below that of the corresponding class of the pronotum, and even in these cases the differences are slight, being only 4 per cent in L. signaticollis and $L$. diversa.

The range of variation in the color values in these two parts of the body is also of interest. It is shown briefly in the following table :

TABLE 20.-Comparison of the range of variation of color proportion in the pronotum and epicranium of the species of the lineata group.

\begin{tabular}{|c|c|c|c|c|c|c|c|c|c|}
\hline \multirow{2}{*}{ Species. } & \multicolumn{2}{|c|}{$\begin{array}{l}\text { Range in } \\
\text { classes. }\end{array}$} & \multicolumn{2}{|c|}{$\begin{array}{l}\text { Per cent occu- } \\
\text { pied of pos- } \\
\text { sible range. }\end{array}$} & \multirow{2}{*}{ Species. } & \multicolumn{2}{|c|}{$\begin{array}{l}\text { Range in } \\
\text { classes. }\end{array}$} & \multicolumn{2}{|c|}{$\begin{array}{l}\text { Per cent occu- } \\
\text { pied of pos- } \\
\text { sible range. }\end{array}$} \\
\hline & $\begin{array}{l}\text { Prono- } \\
\text { tum. }\end{array}$ & $\begin{array}{l}\text { Epicra- } \\
\text { nium. }\end{array}$ & $\begin{array}{l}\text { Prono- } \\
\text { tum. }\end{array}$ & $\begin{array}{l}\text { Epicra- } \\
\text { nium. }\end{array}$ & & $\begin{array}{l}\text { Prono- } \\
\text { tum. }\end{array}$ & $\begin{array}{l}\text { Epicra- } \\
\text { nium. }\end{array}$ & $\begin{array}{l}\text { Prono- } \\
\text { tum. }\end{array}$ & $\begin{array}{l}\text { Eppicra- } \\
\text { nium. }\end{array}$ \\
\hline $\begin{array}{l}\text { L. defecta .... } \\
\text { juncta... } \\
\text { rubicunda. } \\
\text { melanotho- } \\
\text { rax ... } \\
\text { decemline- } \\
\text { ata...... } \\
\text { oblongata. }\end{array}$ & $\begin{array}{r}\text { I } \\
\text { I5 } \\
8\end{array}$ & $\begin{array}{l}3 \\
4 \\
3\end{array}$ & $\begin{array}{r}20 \\
30 \\
20 \\
\\
5 \\
\\
75 \\
40\end{array}$ & $\begin{array}{l}30 \\
40 \\
30 \\
10\end{array}$ & $\begin{array}{r}\text { L. intermedia. } \\
\text { multitæni- } \\
\text { ata ...... } \\
\text { signaticol- } \\
\text { lis........ } \\
\text { diversa. . } \\
\text { undecimli- } \\
\text { neata.... }\end{array}$ & $\begin{array}{r}7 \\
13 \\
7 \\
3\end{array}$ & $\begin{array}{l}9 \\
6 \\
3\end{array}$ & $\begin{array}{l}35 \\
65\end{array}$ & $\begin{array}{l}40 \\
90 \\
60 \\
33 \cdot 3 \\
50\end{array}$ \\
\hline
\end{tabular}


From this table it is apparent that the range of variation is in every case greater in the epicranium than in the pronotum; but in most of the species the variability of the pronotum is greatest-a fact easily seen by comparing the per cent of variates in the modal class; that is, the epicranium shows variates in more of the classes between the possible extremes of variation than does the pronotum, but on the average in the group has the variates less widely distributed.

The color patterns of the pronotum and epicranium represent, the one a complex and the other a simple condition, and it appears from the comparison of data in tables 19 and 20 that the simpler color pattern has the greater range of variation, but lower variability.

Variation in the color of the epicranium of the dilecta group.-The epicranium in the dilecta group, like the pronotum, shows only a uniformly colored surface varying in intensity and in the same directions as the pronotum-that is, from red-brown to bright metallic green. These variations are not of great moment, but such as occur are presented in the following table :

TABLE 21.-Variation in color of epicranium in L. calceata, L. dilecta, and L. lineolata.

\begin{tabular}{|r|c|c|c|}
\hline Classes. & L. calceata. & L. dilecta. & L. lineolata. \\
\cline { 1 - 4 } Class I & $\ldots$. & $\ldots$ & 6 \\
2 & $\mathrm{I}$ & $\mathrm{I}$ & $\mathrm{II}$ \\
3 & 3 & 3 & $\mathrm{15}$ \\
4 & $\mathbf{1 8}$ & $\mathbf{9}$ & 26 \\
5 & $\mathbf{7 3}$ & $\mathbf{8 4}$ & $\mathbf{4 0}$ \\
6 & 5 & 3 & 2 \\
\hline
\end{tabular}

L. calceata: $\mathrm{N} .=$ Ioo individuals. Mean of classes $=4.78$.

L. dilecta $: \mathrm{N} .=$ Ioo individuals. Mean of classes $=4.85$.

$L$. lineolata $: N_{0}=300$ individuals. Mean of classes $=3.89$.

Variation in the color of the epicranium of the haldemani group.- As in the dilecta group, a color pattern on the epicranium of the species of this group is wanting, there being found only changes in color from a dull black to a violet. The classes into which the material falls are the same in number as are those of the pronotum given on page $7 \mathrm{I}$.

Table 22 shows the variation found in this group. From a comparison of this table with table 16 , it is evident that there is a strong correlation between the variations of the epicranium and pronotum. Other than this correlation and the fact of the limitation of its variation to narrow lines and very low variability, this group presents in the color pattern of these parts no points of interest from the standpoint of individual variation. 
TABLE 22.-V Variation in color of epicranium in L. haldemani, L. libatrix, and

I. violescens.

\begin{tabular}{|r|c|c|c|}
\hline Classes. & $\begin{array}{c}\text { L. halde- } \\
\text { mani. }\end{array}$ & $\begin{array}{c}\text { L. liba- } \\
\text { irix. }\end{array}$ & $\begin{array}{c}\text { L. vio- } \\
\text { lescens. }\end{array}$ \\
\cline { 1 - 2 } Class I & 61 & & \\
2 & 12 & 2 & $\ldots \ldots$ \\
3 & 25 & 5 & $\ldots \ldots$ \\
4 & 2 & 80 & 2 \\
5 & $\ldots$ & 8 & 3 \\
7 & $\ldots$ & 4 & 4 \\
7 & $\ldots$ & $\mathrm{I}$ & 91 \\
\hline
\end{tabular}

L. haldemani: N. $=200$ individuals. Mean of classes $=\mathbf{I} .62$.

L. libatrix: $\mathrm{N} .=300$ individuals. Mean of classes $=4.10$.

$L$. violescens: $\mathrm{N} .=100$ individuals. Mean of classes $=6.84$.

Individoal, Variation IN THE COLOR PatTern OF THE El,ytra.

The elytra present more interesting and significant variations in their color pattern than do any other portion of the body, and the fact that their color characters are used as specific differentials adds much interest to a study of their variation.

An elytron has six veins (text-fig. I), between which there are six interspaces where pigment is laid down. This deposition of pigment gives either stripes or rows of spots as found in the lineata and dilecta groups (plate I4, figs. 3I to 48), or in other members of the genus transverse bands, or rows of spots in transverse series, situated at definite points upon the wings (figs. 49 to 57 ). In the whole genus the transverse markings occur at definite and homologous points upon the elytra, and in their modifications follow certain well-defined laws.

Variation in the elytral markings in the lineata group. - The elytra of this group all present a color pattern composed of alternating stripes due to the deposition of cuticular and hypodermal pigments. These dark and light stripes are situated, the one between the veins, and the other over the veins (text-fig. I), excepting that between the subcostal and ramous veins there are two stripes of dark color which behave very differently from the others, and rarely there are found elements of transverse bands producing transverse fusions. The extreme reduction of the anal portion in the elytra in Coleoptera has compressed the anal and cubital areas into a narrow zone along the inner border of the elytra.

In the twelve species of this group the variation consists of an increase or a decrease in the dark color. The extremes of variation in color are represented by L. signaticollis (plate 14 , fig. 33 ) and L. melanothorax or L. undecimlineata (plate 14 , figs. $3 \mathrm{I}$ and 34 ), while the extremes of lateral fusion between the longitudinal stripes are represented by decemlineata and undecimlineata (plate 14 , figs. 34, 36, and 37). The variations of increase and decrease 
of the longitudinal stripes are the normal individual variations, while the lateral unions between stripes are rare and sporadic in their occurrence.

The stripes are most variable at their ends, especially at the distal end, where the major portion of the variation occurs. The most common variation is the reduction in the length of the stripes, so that they do not reach the posterior angle of the wing (plate I4, figs. 3 I to 37 ). In the different species of the group the variation produced by a reduction in the length of the stripes is always more marked in juncta and defecta than in the others. It is to be noted that reduction in the stripes begins first near the anal edge of the wing and proceeds most rapidly there, and that when stripes are wanting it is the anal and cubital stripes, or those that are morphologically the posterior members of the series, that drop out first, while the subcostal stripes are the least variable and the ones which are last to go in a reduction of pigmentation. At the proximal end the variation is slight and unimportant. The two subcostal stripes differ from the others in their behavior in that in most of the species they are fused at both ends of the elytron, and in juncta, and often in melanothorax and rubicunda, along their entire length (plate I4, fig. 38). Variations in these stripes consist in separation, first in the middle, then at the posterior end, then at the anterior end, then the reduction of the posterior member of the pair, and finally of the anterior member; or this variation may be reversed.

The transverse fusion of stripes is most common in decemlineata, melanothorax, and undecimlineata (plate I4). In almost all species this consists in the union of the cubital and anal areas and their further fusion with the medius from the region of the first transverse band through the rest of their length. A common variation is the union of the remaining stripes, the subcostal and ramous, posteriorly in the region of the fourth transverse band. These variations, which result from the reduction of the anal and marginal portion of the wing, are common in all of the species where fusion occurs. Other transverse fusions of sporadic occurrence are figured on plate 14, figs. 34,36 , and 37 . In these we have the union of the ramous and posterior subcostal stripes by means of a transverse band in the region of the first transverse bar (plate 14, fig. 36), of the subcostals in the region of the second transverse bar, and of the ramous and posterior subcostal in the region of the third transverse bar. In the figures on plate 14 it is evident that the transverse fusions, both common and sporadic, occur only at the region of the formation of transverse bars of dark color. This is common in other species of the genus, the one exception being the two subcostal stripes, which, unlike all the other stripes on the elytron, fuse for their entire length.

In forms like signaticollis and angustovittata, where the dark markings are absent, we occasionally find that the position of the stripes is indicated by small deposits of pigment at the proximal and distal ends, especially in the region of the anterior subcostal stripe. 
Variation in the color pattern of the group proceeds in two directions, one antero-posterior, the other from right to left, and between these there are no intermediate conditions. All variations are restricted definitely in position by controlling forces which we shall study later. In these two directions variations of fluctuating character following Quetelet's law abound.

Quantitative study of the variations of the elytra in the lineata group.- The quantitative study of these variations has been made by seriations into classes. We shall examine first, the frequency of certain types of variation, and, second, the proportion of light to dark in the color of the elytra.

TABLE 23.-Frequency of variation in the elytra in L. undecimlineata, L. multiteniata, L. decemlineata, and L. juncta, expressed in percentages.

\begin{tabular}{|c|c|c|c|c|}
\hline Classes of variations. & $\begin{array}{l}\text { L. undecim- } \\
\text { lineata. }\end{array}$ & $\begin{array}{l}\text { L. multita- } \\
\text { niata. }\end{array}$ & $\begin{array}{l}\text { L. decem- } \\
\text { lineata. }\end{array}$ & L. juncta. \\
\hline 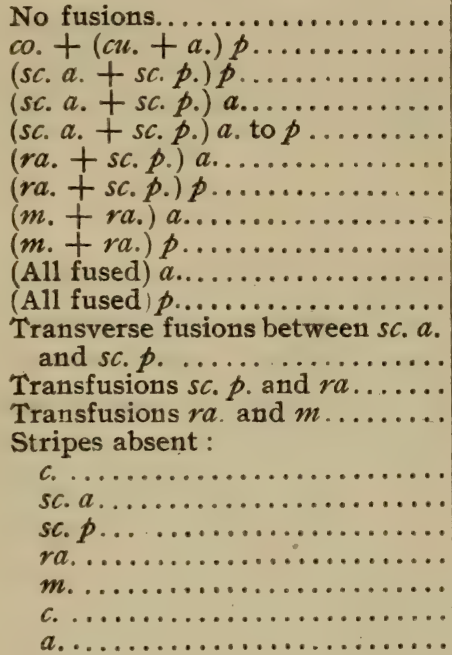 & 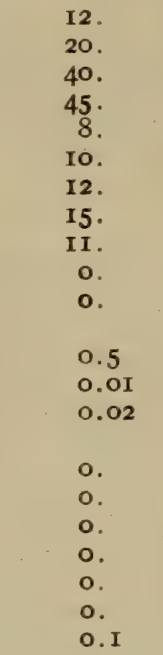 & $\begin{array}{l}\text { II. } \\
12 . \\
80 . \\
30 . \\
\text { I. } \\
4 . \\
29 . \\
18 . \\
3 . \\
6 . \\
1 . \\
1.3 \\
0.1 \\
0.09 \\
0 . \\
0 . \\
0 . \\
0 . \\
0 . \\
0 . \\
0.2\end{array}$ & $\begin{array}{l}31 . \\
3 . \\
65 . \\
19 . \\
0.1 \\
24 . \\
2 . \\
18 . \\
70 . \\
5 . \\
1.5 \\
2 . \\
1.4 \\
1.1 \\
0.5 \\
0 . \\
0 . \\
0 . \\
0.2 \\
1.6 \\
4 .\end{array}$ & $\begin{array}{l}5 . \\
0 . \\
85 . \\
95 . \\
76 . \\
1 . \\
0 . \\
0 . \\
0 . \\
0 . \\
0 . \\
78 . \\
0 . \\
0 . \\
100 . \\
0 . \\
0 . \\
0 . \\
2 . \\
18 . \\
98 .\end{array}$ \\
\hline
\end{tabular}

The frequency with which certain types of fluctuating variations occur is of interest, especially when we consider them with reference to the possibility of their being of use in the production of new species or modifications. In table 23 the variations are designated by classes and formulæ similar to those used in the discussion of variation in the pronotum. In these formulæ $c .=$ costal stripe; $s c_{0}=$ subcostal stripe ; $r_{0}=$ ramous; $c u=$ cubital ; $m .=$ median ; $a .=$ anal ; $s c_{.} a .=$ anterior subcostal $;$ and $s c . p .=$ posterior subcostal. Fusions are indicated by + , and the absence of a stripe by the abbreviation for it followed by minus in parentheses (-). a

$(S c . a .+s c . p$.$) p. and (s c . a .+s c . p$. $) a$. indicate that the two subcostal stripes $p$ 
are fused posteriorly or anteriorly, respectively. Union at other than the anterior or posterior ends is indicated by formulæ like $s c . a .+s c . p . I$, which shows fusion at the first transverse band.

This table shows a most decided race tendency in each species in the frequency of certain variations. Thus, in undecimlineata, almost no stripes are wanting, the anal stripe being absent in only o. I per cent of the cases ; but in multitceniata, decemlineata, and juncta is found an increasing tendency for stripes to be missing, until in juncta and defecta a maximum is reached. In the various types of fusion also we find the same racial tendency for a particular variation to increase or decrease as we follow it through a group of species. These racial tendencies are of importance in geographical variation and species modification, which we shall discuss in the latter part of this chapter.

Variation in the proportion between the pigmented and unpigmented areas in the elytra of the lineata group. - The variation in the proportion existing between the light and dark color of the elytra of the group is significant, indicating, as it does, racial tendencies or trends of variation. These tendencies have been studied by seriations along a scale of values in which o indicates total albinism or xanthism, or complete absence of dark color, and 20 a uniform black or dark color over the whole elytral surface. The data derived from this source is presented in the form of a table giving the frequency which each species shows in any given class.

TABLE 24.-Variation in the proportion of light to dark color in the elytra of L. undecimlineata, $L$. signaticollis, $L$. diversa, L. multitaniata, L. rubicunda, L. oblongata, L. decemlineata, $L$. juncta, and $L$. defecta.

\begin{tabular}{|c|c|c|c|c|c|c|c|c|c|c|}
\hline \multicolumn{2}{|c|}{ Classes. } & $\begin{array}{l}\text { L. unde- } \\
\text { cimline- } \\
\text { ata. }\end{array}$ & $\begin{array}{l}\text { L. sig- } \\
\text { nati- } \\
\text { collis. }\end{array}$ & $\begin{array}{l}\text { L. di- } \\
\text { versa. }\end{array}$ & $\begin{array}{l}\text { L. multi- } \\
\text { taniata. }\end{array}$ & $\begin{array}{l}\text { L. rubi- } \\
\text { cunda. }\end{array}$ & $\begin{array}{l}\text { L. ob- } \\
\text { long- } \\
\text { ata. }\end{array}$ & $\begin{array}{l}\text { L. decem- } \\
\text { lineata. }\end{array}$ & juncta. & $\begin{array}{l}\text { L. de- } \\
\text { fecta. }\end{array}$ \\
\hline \multirow[t]{16}{*}{ Class } & I... & $\cdots$ & I5 & . & $\cdots$ & . & $\cdots$ & . & . & 3 \\
\hline & $2 \ldots$ & $\cdots$ & 45 & - & . & . & . & 0.5 & 0.5 & 8 \\
\hline & $3 \ldots$ & . & 40 & . & . & . & . & I & I. 5 & 24 \\
\hline & $4 \cdots$ & $\cdots$ & . & . & . & . & . & 1.5 & 3 & 60 \\
\hline & $5 \ldots$ & I & $\ldots$ & $\therefore$ & .. & .. & I & 2 & I5 & 3 \\
\hline & 6... & I & $\cdots$ & $\cdots$ & 0.5 & . & I & 2 & 66 & 2 \\
\hline & $7 \ldots$ & 3 & $\cdots$ & . & 0.5 & .. & 2 & 3 & 10 & .. \\
\hline & 8... & 5 & . & - & I & . & 2 & 21 & 2 & . \\
\hline & $9 \ldots$ & 7 & . & 2 & 2 & . & 4 & 44 & 2 & . \\
\hline & 10... & $2 I$ & $\cdots$ & 3 & 6 & . & 52 & I9 & . & . \\
\hline & II... & 41 & . & 22 & I I & 2 & $2 I$ & 3 & $\cdots$ & . \\
\hline & $12 \ldots$ & I4 & . & 65 & 23 & 3 & Io & 2 & . & .. \\
\hline & $I_{3} \ldots$ & 6 & . & 5 & 29 & 20 & 6 & I & . & .. \\
\hline & 14. : & $\mathbf{I}$ & . & 2 & $2 I$ & 60 & I & . & . & . \\
\hline & $15 \ldots$ & . & . & I & 4 & I4 & .. & . & . & .. \\
\hline & 16... & $\cdots$ & $\cdots$ & $\cdots$ & 2 & $\mathbf{I}$ & $\cdots$ & $\because$ & $\cdots$ & $\cdots$ \\
\hline \multicolumn{2}{|c|}{ Individuals. } & 1,000 & 100 & 100 & 4,000 & 100 & 500 & $5, \infty 00$ & 200 & 100 \\
\hline
\end{tabular}


In the preceding table are shown conditions similar to those found in the epicranium and pronotum - that is, variation in the position of the modes of the different species upon the scale of values, and the wide difference in the percentages of the scale covered by the range of each species. When presented in tabular form these conditions become more evident.

TABLE 25.-Position of the modal condition of the species of the lineata group in the scale of values used for proportion of light to dark color in the elytra; also the per cent of total range covered by each species and per cent of variation in modal class.

\begin{tabular}{|c|c|c|}
\hline Position of mode of species upon scale of value. & $\begin{array}{l}\text { Per cent of } \\
\text { range. }\end{array}$ & $\begin{array}{l}\text { Per cent of } \\
\text { value in modal } \\
\text { class. }\end{array}$ \\
\hline 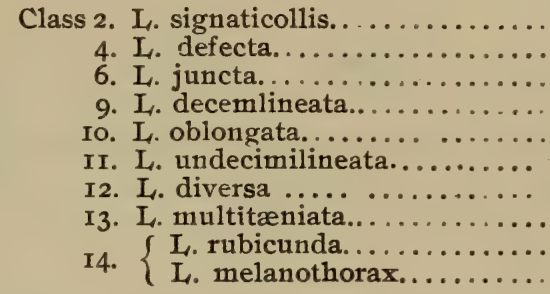 & $\begin{array}{l}15 \\
20 \\
30 \\
60 \\
50 \\
50 \\
35 \\
55 \\
30 \\
25\end{array}$ & $\begin{array}{l}45 \\
60 \\
66 \\
44 \\
52 \\
41 \\
65 \\
29 \\
60 \\
75\end{array}$ \\
\hline
\end{tabular}

Comparison of the above table with tables $14,18,19$, and 20 reveals the fact that there is in the variation of the elytra the same racial tendency to proceed in a definite direction along a given line of modification, and that each species of the group is segregated about a modal condition which is placed in the main at similar positions along the scale of value used for the different parts. Among the various species the only conspicuous difference between the modal states of the elytra and those of the pronotum and epicranium is found in L. signaticollis, which is at the lowest end of the scale in the elytra and high upon the scale in the pronotum and epicranium.

Variation in the elytra of the dilecta group.-The elytral color pattern consists of longitudinal stripes, as in the lineata group, and certain spots belonging to the second, third, and fourth transverse bands. The longitudinal stripes show, moreover, a striking tendency to reduction and to division between the second and third transverse bands, and the entire absence of the costal, anal, and cubital stripes. Only the two subcostals, the ramous and the median stripes, are found, and these are often greatly reduced. On plate 14 , figs. $4 \mathrm{I}$ to 48 , are shown some of the variations which the color patterns of the elytra of this group undergo. The same two directions of variation are found, the longitudinal and the transverse, but in this group the variation in the transverse direction is much more pronounced, all modi- 
fication tending to the production of transverse markings, or rows of spots, caused by the breaking up of the longitudinal stripes in the spaces between the transverse bands (figs. $4 \mathrm{I}$ to 45 ). The addition of these new spots to the transverse bands (figs. $4 \mathrm{l}$ to 43 ) complete, as in fig. 45 , a color pattern of transverse rows of spots. Fusions between these different color areas are so rare that they may be considered to be non-existent.

The process of the reduction of the longitudinal bands, begun in the lineata group and carried to completion in L. signaticollis, takes in this group a somewhat different trend, in that the stripes are broken up into spots by their reduction in the spaces between the transverse bands. This takes place first in the spaces between the second and first transverse bands, and also first in the posterior stripes. Sometimes, however, the reduction is first seen in the anterior subcostal stripe (fig. 46), and this is later followed by a reduction in the space between the third and fourth bands. If after the reduction of the stripes in the space between the bands there should occur an expansion of the spots, a pattern of transverse bands of solid color would be produced, such as occurs in other species of the genus.

Variation in the percentage of light to dark color in the elytra of the dilecta group. - The seriations in this character show it to be one of the least variable of any in the genus. This is explainable by the fact that as reduction of the stripes goes on development of the spots belonging to the system of bands as a rule goes on also, and thus the balance of color proportion is remarkably well preserved. The variations found as the result of seriation in this character are presented in the following table :

TABLE 26.-Y Yariation in proportion of light to dark color in elytra of the dilecta group.

\begin{tabular}{|c|c|c|c|c|c|c|}
\hline \multirow{2}{*}{ Species. } & \multicolumn{5}{|c|}{ Class. } & \multirow{2}{*}{ Remarks. } \\
\hline & 6 & 7 & 8 & 9 & 10 & \\
\hline 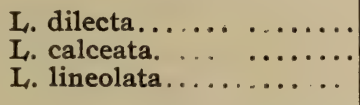 & $\begin{array}{l}2 \\
\cdots \\
\cdots\end{array}$ & $\begin{array}{l}8 \\
8 \\
2\end{array}$ & $\begin{array}{r}81 \\
90 \\
8\end{array}$ & $\begin{array}{r}9 \\
2 \\
84\end{array}$ & $\begin{array}{l}\cdots \\
\because 6\end{array}$ & $\begin{array}{l}\text { N. }=100 \text { individuals. } \\
\text { N. }=300 \text { individuals. } \\
\text { N. }=50 \text { individuals. }\end{array}$ \\
\hline
\end{tabular}

Variations in the elytra of the haldemani group.-The color of the elytra of the beetles in this group presents only the variations of the uniformly colored surface, to which is added in most cases a modification of physical origin. The colors are largely physico-chemical. As is the pronotum and epicranium, the color of the elytra is only slightly variable. Seriations on the basis of the same classes used in the case of the pronotum gave the results shown in table 27 . 
TABLE 27.-Variation in color of elytra in L. haldemani, L. libatrix, and L. violescens.

\begin{tabular}{|c|c|c|c|c|c|c|c|c|}
\hline \multirow{2}{*}{ Species. } & \multicolumn{7}{|c|}{ Class. } & \multirow{2}{*}{ Remarks. } \\
\hline & I & 2 & 3 & 4 & 5 & 6 & 7 & \\
\hline $\begin{array}{l}\text { L. haldemani ... } \\
\text { L. libatrix. . . . } \\
\text { L. violescens. . . }\end{array}$ & $\begin{array}{l}\cdots \\
\cdots \\
\cdots\end{array}$ & $\begin{array}{l}\ldots \\
\cdots \\
\cdots\end{array}$ & $\begin{array}{l}2 \\
3 \\
\cdots\end{array}$ & $\begin{array}{l}8 \\
5 \\
\cdots\end{array}$ & $\begin{array}{r}68 \\
6 \\
I\end{array}$ & $\begin{array}{r}22 \\
82 \\
5\end{array}$ & $\begin{array}{r}4 \\
94\end{array}$ & $\begin{array}{l}\mathrm{N}_{.}=500 \text { individuals. } \\
\mathrm{N}_{.}=200 \text { individuals. } \\
\mathrm{N}_{.}=100 \text { individuals. }\end{array}$ \\
\hline
\end{tabular}

Variations in the elytra of other groups.-The beetles in these groups comprise species of which I have not been able to obtain a sufficient number for quantitative study, but which, nevertheless, present interesting and suggestive color-pattern conditions. In these species the pattern consists largely of bands, stripes being almost entirely wanting. When stripes do exist they are made up of the coalesced anal, cubital, and often medial stripes, and are found only along the anal edge of the elytron. These coalesced stripes are compressed into a narrow sutural line of dark color, from which bands extend across the wing (plate I4, figs. 49 to 57 ). These figures explain themselves and show clearly the way in which the color pattern of bands of dark color, bands connected by longitudinal stripes, and spots of hypodermal color on a dark background are produced by the development of the band and stripes, or both. In plate I4, figs. 55 to 57 , are shown, in L. lacerata, the transition from a pure banded condition to one in which the bands are connected by the partial development of certain of the stripes; and finally by the further coalescing of bands and stripes, is shown the production of a pattern with light spots. In L. pudica (plate I4, figs. 53 and 54) we see the opposite process in the formation of black spots on a light background by a reduction of the bands, which leave spots at the points of crossing of the bands and stripes. In L. zetterstedti is shown much the same process at work.

The color patterns of the elytra of the genus Leptinotarsa show certain important and interesting phenomena. The rarity of abmodal cases and of sports, or extreme variations, is striking. Where these exist they are limited entirely to certain species of the lineata group. The variations are almost always continuous and fall in every instance about a single modal condition which is, as far as the evidence goes, constant for the character and species. We shall see later that the modes of the different species vary geographically and from year to year, but the modes for the entire species seem to be a constant quantity.

By far the most interesting phenomenon exhibited by the color patterns of the elytra in these beetles is the rigid directing of variation along certain welldefined lines. In no species is there the slightest evidence of promiscuous or indeterminate variation. 
In the lineata group, e. $g$., the evolution of species has clearly followed narrow, fixed lines in the color pattern of the elytra, and that this has resulted in the production of species in certain directions only. It is in the directions in which the species have evolved that we find the individual variations fuctuating on either side of the mode toward other closely related species until, in very many cases, they overlap. It is also to be noted that individual variation does not extend in other directions than those mentioned. We can explain this condition only on the basis that the variation of the species is controlled and directed by the constitution of the organism independent of the conditions of its existence. The study of variation can not give us the reasons for these phenomena; it can simply discover the facts concerning the direction and extent of variations and the laws which they follow. As to why they follow these laws variation studies must remain forever silent. Embryology and experimentation only can offer aid in the solution of these difficulties.

In the elytra the following laws hold for the variations exhibited by the color pattern:

(I) There exist two primary sets of color-pattern markings: (a) bands across the wing and $(b)$ stripes along the length of the wing. All color patterns in the genus consist either of stripes or modifications thereof, bands or modifications thereof, or combinations of the two. Unicolorous conditions, either melanic, albinic, xanthic, or rufic, result from complete fusion of bands and stripes, or complete reduction thereof.

(2) We recognize six stripes related to the veins, and five bands. These in all species occupy homologous positions. (See third chapter, on the development of color patterns, for causes of these conditions.) The point of crossing of a band and stripe is an area of pigment production more resistant to reduction than any other area.

(3) The edges of the wing are more variable than the middle, and the anal edge less variable than the costal in banded species and more variable in striped species. The distal end of the wing is more variable than the proximal. These laws are in accordance with Bateson's (1894) law that the extremes of a series are more variable than the middle.

(4) Individual variations which are limited to definite directions are either along stripes, by the reduction at the extremes, by the breaking up into spots, or by fusion; or it is along bands by reduction at the extremities, by breaking up into spots, or by fusion. Variation in a given species may go along one or the other or both of these lines at the same time, but for a given species the direction of variation is always constant. 
INDIVIDUAL, VARIATION IN THE COLOR PATTERN OF THE Ventral, SURFACE.

The ventral surface of these beetles presents variations of two kinds-first, modifications in the elements of a color pattern, and second, variation in the color intensity of a unicolorous surface. The second is the predominating one in the genus. The first, limited to a part only of the lineata group, is more complicated than the others and of far greater interest.

In the lineata group all the species present a highly variable color pattern excepting undecimlineata, angustorittata, signaticollis, diversa, and melanothorax. In these the ventral surface is unicolorous. The variation of the color pattern of the abdominal segments is shown on plate 15 , figs. I7 to 32 , and that on the thoracic segments in figs. 33 to 40 . As may be seen, the color pattern is made up of a series of spots arranged upon the abdominal and thoracic segments. These spots, which are located over muscle attachments, consist of three sets on either side of the median line. It is from these spots as centers that coloration spreads out, or to which it contracts, as the case may be-that is, color appears here first in development, and disappears here last in reduction. L. multitceniata is the most variable species in the group, exhibiting the series of stages shown on plate I5, figs. I7 to 24, inclusive. An examination of these figures makes plain the manner in which the color spreads from these segmentally placed spots. Fusion moves first laterally, extending until all the spots are united into bands on either side of the median line; next these bands begin to extend across the median line at the anterior end of the series of abdominal segments until they finally fuse, first anteriorly, and then posteriorly. The increasing pigmentation next extends between the bands, first until the entire anterior border of the segments is covered, and then posteriorly until the condition shown in fig. 24 is reached. In figs. 25 to 29 are given stages in the process of reduction, as observed in L.decemlineata, the series starting with a condition like that of fig. I7 in L. multitcniata. First the middle rows of spots on each side are reduced (figs. 25 and 26), then the median rows (fig. 27), and lastly the outer rows (fig. 28). In all the pigment begins to disappear first on the segments at the posterior end and remains longest at the anterior end. In figs. 30 to 32 (plate $\mathrm{I}_{5}$ ) are shown stages in the reduction of the pigment of the ventral surface of L. undecimlineata from Panama, in which it is evident that the color disappears first posteriorly and then anteriorly. On the thoracic segments is shown the same processes at work in L. multitceniata (figs. 33 to 40 ) and L. undecimlineata (figs. $4 \mathrm{I}$ to 44 ).

These variations in the color pattern of the ventral surface are found in the genus only in multitceniata, rubicunda, oblongata, intermedia, undecimlineata, defecta, and juncta, and all present the same strongly marked tendency to modification along the definite lines designated above. Indeed, from the variations figured on plate I $_{5}$, conditions could be selected to illustrate the 
variation of all of the species mentioned above, no other variations being known excepting asymmetrical abnormalities.

The variation of the color pattern upon the ventral side is a metameric one, dominated by the principles of metameric control of variation in such structures, as is shown in the beginning of increase of color at the anterior end and decrease at the posterior end. The variations are in complete accordance with the general laws of progressive development in a metameric series which begins anteriorly, and of regressive development which begins posteriorly. Upon individual segments the variations move distalward and caudalward in increase, or proximalward and cephalward in reduction, and these directions of modification are, as far as this material is concerned, absolutely inflexible, being most rigorously controlled by the structure and constitution inherent in the race.

Quantitatively, the variations of the ventral surface present points of some interest. These have been seriated, as have the variations on other parts of the body, on a scale of value indicating the proportion of light to dark color.

TABLE 28.-Variation in the proportion of light to dark color on the ventral surface of L. multitaniata, L. oblongata, L. intermedia, L. rubicunda, L. decemlineata, L. juncta, and L. defecta.

\begin{tabular}{|c|c|c|c|c|c|c|c|}
\hline Classes. & $\begin{array}{l}\text { L. multi- } \\
\text { taniata. }\end{array}$ & $\begin{array}{l}\text { L. oblon- } \\
\text { gata. }\end{array}$ & $\begin{array}{l}\text { L. inter- } \\
\text { media. }\end{array}$ & $\begin{array}{l}\text { L. rubi- } \\
\text { cunda. }\end{array}$ & $\begin{array}{l}\text { L. decem- } \\
\text { lineata. }\end{array}$ & L. juncta. & L. defecta. \\
\hline Class $1 . . .$. & $\ldots$ & $\ldots$ & $\ldots$ & $\ldots$ & $\ldots$ & I & 6 \\
\hline $2 \ldots$ & $\therefore$ & $\ldots$ & $\ldots$ & $\ldots$ & $\ldots$ & 2 & Iо \\
\hline $3 \ldots$ & $\ldots$ & $\ldots$ & $\ldots$ & $\ldots$ & I & 3 & 72 \\
\hline $4 \ldots$ & $\ldots$ & ... & $\cdots$ & . $\ldots$ & I & 8 & 9 \\
\hline $5 \ldots$. & $\ldots$ & $\ldots$ & $\ldots$ & $\ldots$ & I & I5 & 2 \\
\hline $6 \ldots$ & $\ldots$ & $\ldots$ & $\ldots$ & ... & 3 & 42 & I \\
\hline $7 \ldots$ & $\ldots$ & I & I & $\ldots$ & 7 & I9 & $\ldots$ \\
\hline $8 \ldots$ & $\ldots$ & 2 & 3 & $\ldots$ & 16 & 6 & $\ldots$ \\
\hline $9 \ldots \ldots$ & I & 3 & 6 & $\ldots$ & 35 & 2 & $\ldots$ \\
\hline Io..... & I & 4 & 25 & $\ldots$ & 20 & 2 & .. \\
\hline $11 \ldots .$. & 2 & 20 & 42 & I & I0 & $\ldots$ & $\ldots$ \\
\hline I $2, \ldots$ & 4 & 40 & I7 & I & 3 & $\ldots$ & $\ldots$ \\
\hline $13 \ldots$. & 22 & $2 \mathrm{I}$ & 5 & 2 & 2 & $\ldots$ & $\ldots$ \\
\hline I $4 \ldots \ldots$ & 42 & 5 & I & I 2 & I & $\cdots$ & $\cdots$ \\
\hline 15. & 19 & 2 & $\ldots$ & 60 & $\ldots$ & $\ldots$ & $\ldots$ \\
\hline 16. & 4 & I & .... & 20 & $\ldots$ & $\ldots$ & \\
\hline I 7. & 2 & I & $\ldots$ & 4 & $\ldots$ & $\ldots$ & $\ldots$ \\
\hline I8... & I & $\cdots$ & ... & & .... & & $\cdots$ \\
\hline I9. ... & I & $\ldots$ & $\cdots$ & $\ldots$ & $\ldots$ & ... & $\ldots$ \\
\hline $20 \ldots$ & I & $\ldots$ & $\cdots$ & $\cdots$ & ... & $\cdots$ & . \\
\hline Individuals. & 2,000 & $\mathrm{I}, \infty 00$ & 300 & 100 & 4,000 & 200 & 100 \\
\hline
\end{tabular}

This table shows clearly the range of variation in this color pattern. $L$. multitcniata is the most variable and rubicunda the least. The ventral surfaces in species where this part is unicolorous are not as variable as the unicolorous dorsal parts of the body. As far as is known, they show no points of interest. 
INDIVIDUAL VARIATION IN THE COLOR PATTERN OF THE LEGS.

In the majority of the species of this genus the legs are unicolorous, and are only slightly variable. Such variations as occur on them are minute fluctuations, too slight to be seriated. In several of the species of the lineata group, however, the legs show a color pattern of some interest. On plate 15, figs. 45 to 52 , inclusive, are given the variations found in $L$. multitaniata, which is the most variable of the species in respect to the color pattern on the legs. Here we find a series from total melanism to total xanthism, with all possible intergradations. The stages in color modifications are in this case perfectly evident and need not be described. Of the other species with a color pattern on the legs the condition in L. intermedia is represented by figs. 48 to $5 \mathrm{I}$, in undecimlineata by figs. 48 to 52 , in oblongata by figs. 47 to 50 , in rubicunda by figs. 45 to 49 , in juncta by figs. 50 to 52 , and in defecta by figs. $5^{I}$ and 52 .

As in other color characters in this genus, variation in this is limited to certain directions, as shown on plate 15 . Some species show wide variability, others slight; but none go beyond that indicated in the figures.

The frequency of the variation in the different species, together with the range and the per cent of variates in the modal classes for the different species, are shown in the following table:

TABLE 29.-Frequency of variation in the color pattern of the legs in the lineata group.

\begin{tabular}{|c|c|c|c|c|c|c|c|c|}
\hline \multirow{2}{*}{ Classes. } & \multirow{2}{*}{$\begin{array}{l}\text { Fig. on } \\
\text { plate } 15 .\end{array}$} & \multicolumn{7}{|c|}{ Frequency of variation in the color pattern. } \\
\hline & & $\begin{array}{l}\text { L. multi- } \\
\text { taniata. }\end{array}$ & $\begin{array}{c}\text { L. oblon- } \\
\text { gata. }\end{array}$ & $\begin{array}{l}L \text {. inter- } \\
\text { media. }\end{array}$ & $\begin{array}{l}\text { L. decem- } \\
\text { lineata. }\end{array}$ & $\begin{array}{l}\text { L. rubi- } \\
\text { cunda. }\end{array}$ & L. juncta. & $\begin{array}{l}\text { L. de- } \\
\text { fecta. }\end{array}$ \\
\hline $\begin{array}{r}\text { Class I } \\
2 \\
3 \\
4 \\
5 \\
6 \\
7 \\
8\end{array}$ & $\begin{array}{l}45 \\
46 \\
47 \\
48 \\
49 \\
50 \\
5 \mathrm{I} \\
52\end{array}$ & $\begin{array}{c}\text { Per cent. } \\
\text { I } \\
\text { I2 } \\
28 \\
42 \\
\text { I3 } \\
2 \\
\text { I } \\
\text { I }\end{array}$ & $\begin{array}{c}\text { Per cent. } \\
\ldots . \\
\ldots . \\
\text { I5 } \\
\mathbf{5 8} \\
20 \\
7 \\
\ldots \\
\ldots\end{array}$ & $\begin{array}{c}\text { Per cent. } \\
\ldots . \\
\ldots \\
\ldots \\
\text { IO } \\
\mathbf{7 2} \\
\text { I7 } \\
\text { I } \\
\ldots\end{array}$ & $\begin{array}{c}\text { Per cent. } \\
\ldots . \\
\ldots . \\
\cdots \\
5 \\
12 \\
61 \\
20 \\
2\end{array}$ & $\begin{array}{c}\text { Per cent. } \\
3 \\
\text { I8 } \\
\mathbf{5 2} \\
\mathbf{2 1} \\
6 \\
\ldots . \\
\ldots \\
\ldots\end{array}$ & $\begin{array}{c}\text { Per cent. } \\
\ldots \ldots \\
\ldots \ldots \\
\ldots \\
\ldots \\
\ldots \\
5 \\
75 \\
20\end{array}$ & $\begin{array}{c}\text { Per cent } \\
\ldots \\
\ldots \\
\ldots \\
\ldots \\
\ldots \\
\ldots \\
\text { 10 } \\
90\end{array}$ \\
\hline
\end{tabular}

\section{Individual Variation in the Color Pattern of Mature Larvas.}

The larvæ of these beetles also show marked variations, especially in the later instars. The newly hatched larvæ show few variations in the dark markings, but as they grow modifications in the color markings appear and culminate in the final instar. These modifications are purely of an individual character and are due to acceleration or retardation in growth or to extension 
or reduction in pigmented areas, caused by changes in temperature, moisture, and food supply.

On plate 15 are given figures to show the variations observed in the mature larvæ of L. multitaniata, decemlineata, and signaticollis. In figs. 53 to 57 of multitaniata is shown reduction of the spots and loss of many of them, and in figs. 58 to 62 of decemlineata is shown the variation found in that species. The two species form a rather complete series from the most spotted condition (fig. 53) to the least (fig. 62). In figs. 63 to 67 of signaticollis is another similar series of color variation. In all of the larvæ the variations are in one direction-toward increase or reduction of spots. The young larvæ are hatched with more spots than those shown in fig. 53, and the constant tendency in all of the species is to reduce the number of these areas during the ontogeny of the larvæ. That some succeed better than others is shown in the figures on plate $\mathrm{I} 7$. When seriated these characters follow exactly Quetelet's law for fluctuating variation.

\section{STRUCTURAL CHARACTERS.}

Individual, Variation in the PUNCTATION OF THE EI,YTRa.

In Leptinotarsa, Zygogramma, and Stilodes, as well as in Calligrapha, as observed by Jacoby, the color markings are surrounded by deeply impressed punctations, which lie above the columns of chitin and hypodermal cells connecting the two lamellæ of the wing. These punctations are so correlated with the color markings that they may be considered a part of the general scheme of ornamentation found upon the elytra.

The plan of the punctations found in the genus Leptinotarsa is shown in decemlineata. There are two rows of these punctations between each two veins, and four in the subcostal space; and they correspond exactly in position to the edges of the stripes. Besides the stripes of punctations there are bands which lie at right angles to the stripes. These bands of punctations are well developed in some species, are absent in others, and appear in still other species as rather infrequent variations.

Thus there are two systems of punctation-stripes and bands. The wing exhibits one or the other of these, either as predominant or, more rarely, both equally developed. In addition to these larger punctations there are also smaller ones which are distributed without any discernible scheme of arrangement.

In the lineata group the punctations show much the same series of variation as was found in the dark stripes already considered. There is a tendency to fusion at the ends, toward reduction distally and posteriorly, and toward the union of the stripes by transverse rows of punctations similar to the variations found in the dark markings. Variations of the punctations in undecimlineata 
and in decemlineata show similar conditions. In species like signaticollis and angustovittata the punctations become more variable. In all but two of the species of the group the punctations are arranged in irregular double rows, as in undecimlineata, decemlineata, and signaticollis. These irregular double rows allow of considerable latitude in variation. In signaticollis the lateral displacement is often so extreme that the rows of punctations are almost indistinguishable. In two of the species, however, juncta and defecta, the punctations occur in a single even row, without any observable lateral deviation. In these two species, juncta and defecta, the variation occurs almost entirely at the distal and posterior portions of the wing. In reduction the distal and anal punctations disappear first, later the proximal and costal, and last of all the subcostal.

The arrangement of the punctations and some of the variations in $L$. calceata, dilecta, and lineolata, in the dilecta group show, as in dilecta, a decided tendency to reduction at the interbands, and this system of ornamentation, like that of the coloration, is much reduced distally and in the anal area of the elytron. The purely fluctuating variations in the dilecta group are not as numerous nor as extensive as in the lineata group. In the dilecta group, however, the variations tend to reduction of the stripes and bands and to production of spots or rings of punctations which surround the color areas. In species like $L$. zetterstedti this reduction of the stripes and development of the bands is more pronounced, although the stripes are still recognizable. In lacerata, pudica, and modesta are found variations in which the system of bands is prominent, and the stripes are largely obscured. In the unicolorous species, such as haldemani and violescens, the system of stripes is variable to a considerable extent.

It is found that the punctations vary in some directions and not in others. Moreover, the stripes and bands vary most in the apical and anal portions of the wing, to some extent at the proximal end, and least at the center. Finally, they follow the same line and the same direction of variation as do the color areas of the elytral color pattern. There is apparently a strong correlation between the two.

In the quantitative study of the punctations the plan has been to seriate them into classes by inspection, and to some extent by counting. The frequent variations of this character, found on seriating, while not showing much that is of interest, confirms the conclusions reached concerning individual variation in the color character of the elytra by evidence derived from structural characters. The seriated variations shown in table 30 are completely in accordance with those of the color characters, and, like them, follow Quetelet's law. The smaller punctations, in their variations, also follow the same laws as do the larger ones. 
TABLE 30.-Variation in the elytral punctation in L. signaticollis, L. decemlineata, L. multiteniata, $L$. juncta, $L$. lineolata, $L$. dilecta, $L$. haldemani, $L$. violescens, and L. zetterstedti.

\begin{tabular}{|c|c|c|c|c|c|c|c|c|c|}
\hline Classes. & $\begin{array}{l}\text { L. signa- } \\
\text { ticollus. }\end{array}$ & $\begin{array}{l}\text { L. decemli- } \\
\text { neata. }\end{array}$ & $\begin{array}{l}\text { L. multi- } \\
\text { ianiata. }\end{array}$ & L. juncta. & $\begin{array}{l}\text { L. lineo- } \\
\text { lata. }\end{array}$ & $\begin{array}{l}\text { L. di- } \\
\text { lecta. }\end{array}$ & $\begin{array}{c}\text { L. halde- } \\
\text { mani. }\end{array}$ & $\begin{array}{l}\text { L. vio- } \\
\text { lescens. }\end{array}$ & $\begin{array}{l}\text { L. zetter } \\
\text { stedti. }\end{array}$ \\
\hline Class I & $\ldots$ & $\ldots$ & .. & 2 & $\ldots$ & $\ldots$ & $\ldots$ & $\ldots$. & $\ldots$ \\
\hline 2 & $\ldots$ & 2 & I & I6 & 2 & 5 & I & $\ldots$ & 4 \\
\hline 3 & 2 & 4 & 5 & 71 & I9 & I8 & 9 & 2 & 2I \\
\hline 4 & 4 & 8 & 7 & 10 & 54 & 46 & 22 & 24 & 50 \\
\hline 5 & 5 & 60 & 20 & I & $2 I$ & $2 I$ & 35 & 37 & 19 \\
\hline 6 & 8 & I9 & 52 & $\ldots$ & 3 & 6 & 20 & 22 & 3 \\
\hline 7 & I8 & 6 & Io & $\ldots$ & I & 4 & 10 & 12 & 2 \\
\hline 8 & 41 & I & 3 & $\ldots$ & $\ldots$ & $\ldots$ & 3 & 3 & I \\
\hline 9 & I7 & $\ldots$ & 2 & $\ldots$ & . $\ldots$ & $\ldots$ & $\ldots$ & $\ldots$ & $\ldots$ \\
\hline Io & 5 & $\ldots$ & $\ldots$ & $\ldots$ & $\cdots$ & $\ldots$ & $\cdots$ & $\cdots$ & $\ldots$ \\
\hline
\end{tabular}

L. signaticollis : $\mathrm{N} .=\mathrm{I}, 000$ individuals. Mean of classes $=7.76$.

L. decemlineata $: \mathrm{N} .=4,500$ individuals. Mean of classes $=5.12$.

L. multitceniata: $\mathrm{N} .=2,500$ individuals. Mean of classes $=5.69$.

L. juncta: $\mathrm{N}_{0}=$ Ioo individuals. Mean of classes $=2.92$.

L. lineolata: $\mathrm{N} .=300$ individuals. Mean of classes $=4.07$.

$L$. dilecta $: \mathrm{N} .=200$ individuals. Mean of classes $=4 \cdot 17$

L. haldemani: N. $=$ Ioo individuals, Mean of classes $=5.06$.

L. violescens : $\mathrm{N} .=200$ individuals Mean of classes $=5.25$.

L. zetterstedti: $\mathrm{N}_{0}=100$ individuals. Mean of classes $=3.86$.

TABLE 3I.-Variation in the punctation of the pronotum in L. signaticollis, $L$. decemlineata, $L$. undecimlineata, $L$. lineolata, $L$. dilecta, $L$. haldemani, and $L$. violescens.

\begin{tabular}{|c|c|c|c|c|c|c|c|}
\hline Classes. & $\begin{array}{l}\text { L. signa- } \\
\text { ticollis. }\end{array}$ & $\begin{array}{l}\text { L. decem- } \\
\text { lineata. }\end{array}$ & $\begin{array}{c}\text { L. unde- } \\
\text { cimlineata. }\end{array}$ & $\begin{array}{l}\text { L. lineo- } \\
\text { lata. }\end{array}$ & L. dilecta. & $\begin{array}{l}\text { L. halde- } \\
\text { mani. }\end{array}$ & $\begin{array}{l}\text { L. vioies- } \\
\text { cens. }\end{array}$ \\
\hline Class I & $\ldots$ & $\ldots$ & $\ldots$ & $\ldots$ & $\ldots$ & $\ldots$ & $\ldots$ \\
\hline 2 & $\ldots$ & $\ldots$ & $\ldots$ & $\ldots$ & $\ldots$ & $\ldots$ & $\ldots$ \\
\hline 3 & $\ldots$ & I & $\ldots$. & 8 & 2 & I & \\
\hline 4 & $\ldots$ & 4 & I & 20 & 8 & 8 & 8 \\
\hline 5 & I & I5 & 4 & 29 & 25 & 26 & 27 \\
\hline 6 & 5 & 26 & 15 & $2 I$ & 32 & 42 & 45 \\
\hline 7 & 26 & 30 & 20 & I5 & $2 \mathrm{I}$ & I6 & I4 \\
\hline 8 & 36 & $2 I$ & 24 & 4 & Io & 6 & 6 \\
\hline 9 & 22 & 2 & I6 & 2 & 2 & I & $\ldots$ \\
\hline Io & 7 & I & Io & I & $\ldots$ & $\ldots$. & $\ldots$. \\
\hline II & 2 & $\ldots$ & 6 & $\ldots$ & $\ldots$ & $\ldots$ & $\ldots$ \\
\hline 12 & I & $\ldots$ & 4 & $\ldots$ & $\ldots$ & $\ldots$ & $\ldots$ \\
\hline 13 & $\ldots$ & $\ldots$ & $\ldots$ & $\ldots$ & $\ldots$ & ... & $\ldots$ \\
\hline 14 & $\ldots$ & ... & $\ldots$ & $\ldots$ & $\ldots$ & $\ldots$ & $\ldots$ \\
\hline I 5 & $\ldots$ & $\ldots$ & $\ldots$ & $\ldots$ & . $\ldots$ & $\ldots$ & $\ldots$ \\
\hline
\end{tabular}

L. signaticollis: $\mathrm{N} .=\mathrm{r}, \mathrm{00}$ individuals. Mean of classes $=8.07$.

L. decemlineata: N. $=3,900$ individuals. Mean of classes $=6.56$.

L. undecimlineata : N. $=1,400$ individuals. Mean of classes $=8.04$.

L. lineolata $:$ N. $=200$ individuals. Mean of classes $=5.40$.

$L$. dilecta $: \mathrm{N} .=200$ individuals. Mean of classes $=6.00$.

L. haldemani: N. $=$ Ino individuals. Mean of classes $=5.76$.

L. violescens: $\mathrm{N} .=200$ individuals. Mean of classes $=5.77$. 


\section{Individual Variation in the Punctation of the Pronotum.}

On the pronotum the punctations are most abundant on the posterior and lateral margins. They are highly variable, both individually and geographically. When seriated, as in table $3 \mathrm{I}$, they give results that are in complete accordance with those derived from the seriations in other parts.

\section{INDIVIDUAL, VARIATION IN THE GLANDS OF THE, ElivTRA.}

The beetles of this genus have in the elytra rows of compound hypodermal glands situated between the dark stripes, which secrete a yellow, oily fluid of strong odor and acrid taste. This fluid is strongly repugnatorial, and serves the purpose of protecting these beetles from the attacks of insectivorous animals. As far as is known, these structures exist only in rows beneath the stripes. The number of glands does not vary greatly in any given species, but between the different species there are wicle differences. Thus, in L. signaticollis there are relatively few glands, while in multitaniata and in decemlineata they are numerous. As these glands are strongly protective, species possessing them in abundance would have an opportunity to multiply in numbers, whereas those with fewer glands would be less protected and more acceptable as food for insectivorous animals, and hence less abundant. L. multitaniata, decemlineata, and oblongata possess iarge numbers of these glands; consequently these species are active and the most common and widely distributed ones in the genus; while signaticollis, dilecta, haldemani, and others have fewer and less active glands, and are much less common and widely distributed. The correspondence between the number of glands and the numerical abundance of certain species is suggestive of the part which these glands may play in enabling a species to become a common and widely distributed form. Natural selection would in this case be an important factor in the increase of the species possessing the glands and in the elimination of those with few of these protective structures.

The variations of these glands when seriated give results completely in accordance with those derived from other characters already studied.

In table 32 there is a marked difference in the position of the modes of the species, and also in the range of variation. Thus, in the species of the lineata group, multitcniata and decemlineata show high modes and high ranges of variation, while juncta and signaticollis have modes lower in the scale and a much smaller range of variability. In other groups the modes are low and the range of variation limited.

\section{INDIVIDUAL, VARIATION IN SIZE AND SHaPE.}

Individual variations in size and shape are of interest to a limited extent in geographical and place variation. Both the variation in size and in shape follows exactly the laws of the distribution of fluctuating variations found in other characters, and further discussion of them is unnecessary. 
TABLE 32.-Variation in per cent of frequency in the glands of the elytra in L. undecimlineata, $L$. signaticollis, $L$. multitcniata, $L$. oblongata, $L$. decemlineata, $L$. juncta, $L$. rubicunda, $L$. lineolata, $L$. dilecta, $L$. calceata, $L$. haldemani, $L$. violescens, $L$. libatrix, and L. rubiginosa.

\begin{tabular}{|c|c|c|c|c|c|c|c|c|c|c|c|}
\hline \multirow[t]{2}{*}{ Classes... } & I & 2 & 3 & 4 & 5 & 6 & 7 & 8 & 9 & Io & II \\
\hline & $\begin{array}{c}0 \\
\text { to }\end{array}$ & $\begin{array}{l}25 \\
\text { to }\end{array}$ & $\begin{array}{l}50 \\
\text { to }\end{array}$ & $\begin{array}{l}75 \\
\text { to }\end{array}$ & $\begin{array}{l}\text { Ioo } \\
\text { to }\end{array}$ & $\begin{array}{l}125 \\
\text { to }\end{array}$ & $\begin{array}{l}150 \\
\text { to }\end{array}$ & $\begin{array}{c}175 \\
\text { to }\end{array}$ & $\begin{array}{c}200 \\
\text { to }\end{array}$ & $\begin{array}{l}225 \\
\text { to }\end{array}$ & $\begin{array}{l}250 \\
\text { to }\end{array}$ \\
\hline L, undecimlineata .......... & . & - & & 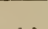 & 6 & 74 & 8 & 2 & 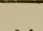 & . & 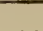 \\
\hline signaticollis............ & $\because$ & 9 & 90 & $\dot{I}$ & . & . & . & & $\cdots$ & $\cdots$ & $\begin{array}{l}\cdots \\
\ldots\end{array}$ \\
\hline multitæniata. . . . . . . . & .. & . & . & I & I & I & 6 & 82 & 8 & I & 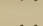 \\
\hline oblongata ............ & . & . & . & . & 2 & 14 & 70 & I2 & 2 & . & . \\
\hline decemlineata .......... & . & . & • & . & 4 & 9 & 71 & 14 & 2 & . & . \\
\hline juncta.............. & $\cdots$ & $\cdots$ & • & $2 \mathrm{I}$ & 60 & I9 & . & .. & .. & . . & . \\
\hline rubicunda.... & & & & . & 26 & 49 & 24 & $\mathbf{I}$ & . & .. & .. \\
\hline lineolata............. & 14 & 72 & Io & 4 & . & . & . & .. & . & . & . \\
\hline dilecta. & 7 & 84 & 8 & I & .. & $\cdots$ & $\cdots$ & $\cdots$ & .. & .. & . \\
\hline calceata.... & I & II & 80 & 6 & 2 & . & .. & . & . & .. & . \\
\hline haldemani............ & .. & Io & 76 & 12 & 2 & . & . & . & .. & .. & .. \\
\hline violescens . . . . . . . . . & . & 7 & 79 & ro & 4 & . & . & . & . & . & .. \\
\hline libatrix ............. & 2 & 74 & I4. & 8 & 2 & . & . & . & . & . & . \\
\hline rubiginosa. ....... & . & 4 & $2 \mathrm{I}$ & 60 & I4 & I & . & . & .. & . & .. \\
\hline
\end{tabular}
L. undecimlineata : N. $=\mathbf{I}, 000$ individuals.
L. signaticollis: $\mathrm{N} .=\mathrm{I}, 000$ individuals.
L. multilaniata: $\mathrm{N} .=2,200$ individuals.
L. oblongata: $\mathrm{N} .=600$ individuals.
L. decemlineata: $\mathbf{N} .=5,200$ individuals.
L. juncta: $\mathrm{N}_{0}=200$ individuals.
L. rubicunda: $\mathrm{N} .=$ roo individuals.
L. lineolata : $\mathrm{N}_{\mathrm{N}}=300$ individuals.
L. dilecta : N. = Ioo individuals.
L. calceata $: \mathrm{N}=100$ individuals.
I. haldemani: $\mathbf{N} .=200$ individuals.
$L$. violescens : N. $=100$ individuals.
L. libatrix : N. = Ioo individuals.
L. rubiginosa: $\mathrm{N} .=100$ individuals.

\section{OBSERVATIONS AND DATA CONCERNING EXTREME VARIATIONS. ${ }^{1}$}

Observations upon variations of this class must of necessity be scanty, excepting in experiment, and even there they are not abundant. In nature several extreme variations have been found. The best and longest known of these is the species $L$. melanothorax, which occurs as a variation of L. multitaniata, but does not become a permanent species. It differs from the parent in general appearance, shape, and color, in the black pronotum and ventral surface, and in the fusions of the two subcostal stripes on the elytra. On plate 16 is represented in fig. 4 the parent species, multitceniata, in life, and in fig. 5 melanothorax. A second extreme variation from multitaniata

\footnotetext{
"I have used "extreme variation" or "extreme variate" in place of "discontinuous variation" and "mutant" because there is no real discontinuity in these variations, but a rapidly developed extreme deviation from the parental state.
} 
is the form rubicunda, shown in fig. 3, plate I6. This I have found in nature and reared in experiment. It breeds true to type.

An interesting extreme variation is that represented in fig. 2, plate 16, described by Jacoby as L. angustovittata. I have found this form in nature and reared it in confinement from $L$. undecimlineata (plate 16 , fig. I), so there can be no doubt of its character. It breeds true to type.

L. decemlineata has proven a species from which several of these variations have arisen, some of which I have shown on plate I6. Six undoubted cases have been observed to arise from this species-L. pallida (plate I6, fig. 7), defectopunctata (plate I6, fig. 6), minuta, tortuosa (plate I6, fig. 9), melanicum, and rubrivittata. These, excepting tortuosa, have arisen several times in nature and in experiment and are known to breed true to type.

It is highly probable that additional variations of this class will be found as observations are extended, and I suspect that many of the species of this genus, which are known only by one or two specimens from one or two restricted localities, are in reality variations of this character and not permanent species.

\section{THE LAWS OF VARIATION IN THE GENUS LEPTINOTARSA.}

From the study of variation in this genus certain rules or laws have been found, which are followed most rigorously by the different species and groups of species. The study of variation can not give us data as to why a given species obeys certain laws, or how modifications are produced therein; it can furnish only exact data as to their existence and extent of influence. It is important that such information should be obtained concerning a form if further investigation of the problems of evolution is contemplated.

(I) Direction of variation.-In all of the species and characters examined in Leptinotarsa variation is determinate, and in few directions, no case of indeterminate variations being found.

(2) Certain special lawes appear, which apply to this genus and perhaps to others as well:

(a) Coloration shows variation in two general directions only, toward the dark and the light, the dark being melanic or metallic and the light albinic, xanthic, or rufic. In any lot of variates modification exists in not more than three directions, two of which are light, are closely related, and intergrade, while the other, the dark, is diametrically opposite.

(b) In the elements of the color pattern there is a tendency for the spots to spread out or contract peripherally and the stripes and bands to extend or contract at their ends. The spots, stripes, and bands are most variable in the posterior or distal portions of the structures on which they occur, and least variable in the anterior and proximal portions thereof. Increase of pigmenta- 



\section{Explanation of Plate i6.}

Figs. I and 2.- - . undecimlineata (I) and its extreme variate angustovittata (2). Drawn from life. It will be noted that the color in life is quite different from the dead specimens.

Figs. 3 to 5. - L. multitaniata (4) and its extreme variates rubicunda (3) and melanothorax (5). Drawn from living specimens. The colors here represented change greatly in death.

Figs. 6 to 9. - L. decemlineata (8) and its extreme variates tortuosa (9), pallida (7), and defectopunctata (6). Drawn from life.

Figs. Io and II.-Larvæ of L. multitaniata (II) and of its extreme variate rubicunda (ro). 

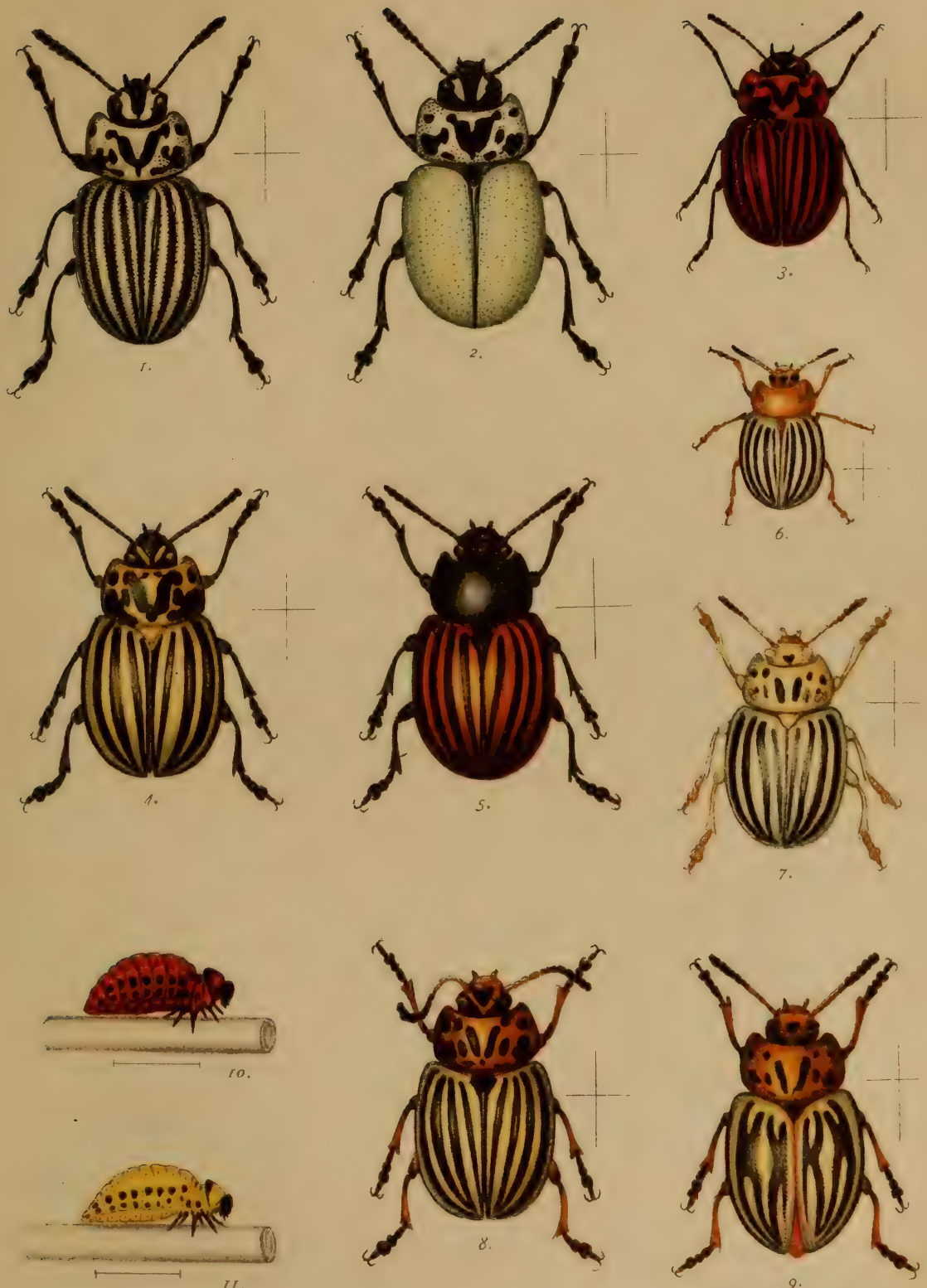

W.L.T. del.

"MUTATIONS" OR RAPIDLY DEVELOPING LARGE INHERITABLE VARIATIONS IN LEPTINOTARSA WITH PARENT SPECIES. 

tion or modification of color pattern moves caudalward or distalward, while decrease moves cephalward or medianward.

(c) On the wings the markings follow the same rules which were found by Mayer (1902) to hold for the wings of Lepidoptera.

(d) Large or extreme variations are determinate and always occur in directions corresponding to the maximum lines of fuctuating variations.

(3) Range of variation.- - In all cases for any given character variation is limited in both directions, but there seems to be no limit to the combinations of characters in the formation of species. The species show differences in the extent to which they exhibit variation in any character, in some the percentage of the total range of variation being high and in others low, and this is a constant quantity, a characteristic of the species.

(4) Correlation of variation.-All variations of color and structural characters are strongly correlated. On the dorsal and ventral surfaces, and between them, correlations in variation are equally strong, so that causes which produce a variation in one part bring about either directly or indirectly corresponding variations in other parts.

\section{PLACE VARIATION.}

The term "place variation" is used to designate a phenomenon more or less general in plants and animals. It has long been recognized that animals and plants vary from generation to generation, from season to season, from year to year, and perhaps in longer periods. Fluctuations in environmental factors, in the intensity of the struggle for existence, in fecundity, and other causes bring about the condition that succeeding generations of the same animals are not even in one restricted locality alike. As frequently as this place variation must have been noted, it has been passed over as unimportant, and has not been studied in animals and only slightly in flowering plants. The researches of Burkhill (I895), MacLeod (I899), Ludwig (I90I), Tower (I902), Shull (1902), Yule (I902), Pearson (I903), Reinöhl (I903), and Shull (I904) have shown the existence of this phenomenon to an unrealized degree, and its importance where studies of evolution and variation are in progress. As has been pointed out by several authors, and especially emphasized by Shull (1904), workers in the field of biometry are all too prone to ignore this phenomenon.

Shull states (p. 372):

The interpretations which students have based upon the assumption that seasonal fluctuations do not occur will have to be greatly revised or discarded altogether, and before we can appreciate the exact bearing of any case of variation upon the great problems of evolution it will be necessary to know the laws governing that variation. 
In a former paper (I902) I have used the term "secular variation" to designate this phenomenon, and have advanced certain views regarding the study of variation. It was shown that biometric work must take into account this fluctuation in the population, and the term "place mode" was expanded to a broader significance. Pearson (1902), however, objected to my use of the term "place mode" in that "it might refer to any constant whatsoever of the frequency - to the mean, mode, variability, or indeed to the whole frequency distribution itself"- and I believe that the point is well taken. Shull (I904) proposes the term "place condition" or "place habit" to designate the phenomenon for which I used the term "place mode." This is, I believe, a good term, not open to biometric or other objections, and I shall use it in this paper. In the interest of uniformity and for certain philological reasons, I use the term "place variations" to designate what I called "secular variations" in 1902. We recognize, then, (I) place variation, or the variation in any given species in the same locality from generation to generation, or from season to season, or year to year; (2) place condition, as the state prevailing in the population of a given species at a particular locality during one generation; and (3) place constant, determined for the population of a given species at a given locality for one generation.

The existence of the phenomenon of place variation was discovered early in the study of this material and was at first interpreted as indicating rapid change in condition. But in succeeding generations, when the variations moved back to the old original condition, the phenomenon with which we now have to deal was recognized. In the genus Leptinotarsa not all species show this phenomenon alike, but all do to some extent.

In L. decemlineata the place variation is extreme, and differs in degree in different places. We can best illustrate this by data from specific localities. Hence I shall give the place variations of decemlineata for a locality in West Bridgewater, Plymouth County, Massachusetts, and for Chicago, Cook County, Illinois, for several generations at each place.

At the first locality collections of $L$. decemlineata were made during the years 1895 to 1902 , or during a period of 16 generations. They were collected from potato fields in which there were about 12 inches of soil, 18 inches to 2 feet of clay subsoil, and a stiff blue till clay beneath. Various characters of the beetles collected at this locality were studied. The table of the distribution of frequencies (table $33 \mathrm{~A}$ ) indicates the proportion of light to dark color on the epicranium and the variations that have been found from generation to generation. Table 33 в shows the corresponding variation in the pronotum; table $33 \mathrm{C}$ that in the elytra; table $33 \mathrm{D}$ that in the abdominal segments, and table $33 \mathrm{E}$ the variation of males and females in size. In table $33 \mathrm{~F}$ are given the polygons of place condition for the species taken as a whole. It is evident that in these 16 generations there is abundant place variation. 
At Chicago I have observed this phenomenon during the years 1902, 1903 , and 1904, or for 6 generations. In the tables of distribution I have given the seriations obtained from this material. In table $34 \mathrm{~A}$ is shown the variation in the proportion of light to dark color in the epicranium, and in tables $34 \mathrm{~B}$, $34 \mathrm{C}$, and $34 \mathrm{D}$ the frequencies for the same relation of the pronotum, elytra, and ventral surface. In table $34 \mathrm{E}$ are given the polygons of variation in size of the two sexes.

Comparing the place condition polygons for decemlineata at the two localities, it appears that at both there is marked place variation, although less at Chicago than at West Bridgewater. However, I know of no reason why continued observation might not show as great place variation at Chicago as at other localities where it has been studied.

That the phenomenon is not limited in the genus to L. decemlineata is shown by the data obtained from the study of $L_{1}$. multitceniata during I903, 1904, and 1905 at Guadalupe, Federal District, Mexico. The soil is a deep, stiff adobe, well drained by ditches. I have shown the variations in the proportion of light to dark color on the epicranium, pronotum, elytra, and ventral surface for these years in tables $35 \Lambda, 35 \mathrm{~B}, 35 \mathrm{C}$, and $35 \mathrm{D}$. In the polygons of distribution of this species we see again a large amount of place variation, even more than in decemlineata.

TABLE 33.-Place variation in the epicranium, pronotum, elytra, ventral surface of abdominal segments, size of males and females, and for the species as a whole of L. decemlineata at West Bridgewater, Plymouth County, Massachusetts. ${ }^{1}$

(A) PLACE VARIATION IN THE EPICRANIUM.

\begin{tabular}{|c|c|c|c|c|c|c|c|c|c|c|c|c|c|c|c|c|}
\hline \multirow{2}{*}{ Year. } & \multirow{2}{*}{$\begin{array}{l}\text { Gener- } \\
\text { ation. }\end{array}$} & \multicolumn{15}{|c|}{ Class. } \\
\hline & & I & 2 & 3 & 4 & 5 & 6 & 7 & 8 & 9 & I0 & II & 12 & 13 & 14 & 15 \\
\hline \multirow{4}{*}{$\begin{array}{l}1895 .\{ \\
1896 .\{\end{array}$} & I.... & I & 4 & I5 & 56 & I8 & 4 & 2. & .. & .. & . & .. & .. & .. & .. & .. \\
\hline & $2 \ldots$ & $\ldots$ & I & 3 & I7 & 20 & 42 & IO & 4 & 2 & I & .. & .. & .. & .. & .. \\
\hline & I.... & $\ldots$ & $\ldots$ & 4 & I6 & 20 & 49 & 9 & 2 & .. & . & . & . & .. & . & .. \\
\hline & $2 \ldots$ & .. & 7 & 60 & I8 & 8 & 5 & 2 & . & . & .. & . & .. & . & . & .. \\
\hline \multirow{2}{*}{ I897. \{} & I.... & 4 & I9 & 52 & 20 & 4 & I & . & . & . & .. & .. & . & . & . & .. \\
\hline & $2 \ldots$ & $\ldots$ & 2 & 20 & 61 & 12 & 4 & I & . & . & . & .. & .. & . & . & . \\
\hline \multirow{2}{*}{ I898. } & I... & I & 3 & I7 & 49 & 19 & 6 & 3 & 2 & .. & . . & .. & .. & .. & .. & . \\
\hline & $2 \ldots$ & 2 & 6 & 25 & 36 & 22 & 5 & 2 & 2 & . & .. & .. & .. & .. & . & .. \\
\hline \multirow{2}{*}{ I899. } & I.. & . & I & 2 & 20 & 45 & 29 & 3 & $\ldots$ & . & .. & .. & .. & .. & .. & .. \\
\hline & 2. & .. & I & 3 & 8 & 22 & 37 & 17 & 8 & 4 & .. & .. & .. & .. & .. & . \\
\hline \multirow{4}{*}{$\begin{array}{l}\text { I900. } \\
\text { I90I }\end{array}$} & I.... & 9 & 36 & 27 & 16 & 7 & 3 & 2 & . & .. & . & .. & . & . & . & . \\
\hline & $2 \ldots$ & 14 & 39 & 31 & II & 3 & I & I & .. & . & .. & .. & .. & . & .. & .. \\
\hline & I.... & . & 7 & I9 & 50 & I8 & 6 & $\ldots$ & . & .. & . & .. & .. & . & . & . \\
\hline & $2 \ldots$ & . & 5 & 22 & 46 & $2 I$ & 3 & 3 & . & . & .. & .. & .. & .. & . & .. \\
\hline \multirow{2}{*}{ I902. } & I ... & .. & I I & 52 & $2 I$ & I I & 4 & I & . & . & . & .. & .. & .. & . & . \\
\hline & $2 \ldots$ & 2 & Io & 48 & 28 & 8 & 3 & I & . & . & . & . & . & . & .. & . \\
\hline
\end{tabular}

${ }^{1}$ In all of these tables the frequencies are given in percentages. 
TABLE 33 -Continued.

(B) PLACE VARIATION IN THE PRONOTUM.

\begin{tabular}{|c|c|c|c|c|c|c|c|c|c|c|c|c|c|c|c|c|}
\hline \multirow{2}{*}{ Year. } & \multirow{2}{*}{$\begin{array}{l}\text { Gener-- } \\
\text { ation. }\end{array}$} & \multicolumn{15}{|c|}{ Class. } \\
\hline & & I & 2 & 3 & 4 & 5 & 6 & 7 & 8 & 9 & I0 & II & 12 & $I_{3}$ & 14 & 15 \\
\hline 7805, & I & $\cdots$ & $\cdots$ & $\cdots$ & . & $\cdots$ & . & I & 5 & I4 & 54 & 20 & 3 & 3 & 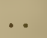 & \\
\hline $1095 \cdot ?$ & $2 \ldots$ & . . & .. & . & . & .. & .. & $\cdots$ & 2 & 2 & I4 & 24 & 41 & 9 & 5 & 3 \\
\hline 1806. \{ & I.... & $\cdots$ & .. & . & .. & .. & .. & $\cdots$ & I & 3 & I6 & 18 & 51 & 7 & 4 & .. \\
\hline & $2 \ldots$ & .. & .. & .. & .. & .. & . & $\ldots$ & 6 & 61 & I9 & 7 & 4 & 3 & .. & .. \\
\hline $1807,\{$ & $1 \ldots$ & .. & .. & .. & .. & .. & I & 3 & 20 & 50 & 22 & 4 & . & 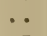 & .. & \\
\hline & $2 \ldots$ & .. & .. & . & .. & .. & .. &. & 2 & 22 & 59 & I4 & 2 & I & . & . \\
\hline I $898 .\{$ & $1, \ldots$ & .. & .. & .. & .. & . & . & I & 2 & 19 & 49 & I 7 & 7 & 3 & I & I \\
\hline 2090.1 & $2 \ldots$ & $\cdots$ & $\cdots$ & .. & .. & I & I & 2 & 6 & 25 & 36 & 22 & 5 & 2 & $\because$ & $\cdots$ \\
\hline I899. \{ & $1 \ldots$ & .. & .. & .. & .. & . & .. & . & I & 3 & 20 & 47 & 26 & 2 & I & . \\
\hline ? & $2 \ldots$ & $\cdots$ & . & $\because$ & $\because$ & $\because$ & . & $\ddot{i}$ & I & 4 & 7 & 23 & 36 & I6 & 9 & 4 \\
\hline I900. \{ & I. & • & . & I & 1 & I & 4 & II & 34 & 20 & I5 & 8 & 2 & 2 & I & .. \\
\hline ? & 2 & . & . & . & .. & - & . & 12 & 41 & 30 & 12 & 2 & I & I & I & 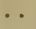 \\
\hline IgOI. \{ & I.... & . & . & I & 2 & 3 & 4 & 7 & 19 & 40 & I5 & 6 & 2 & I & $\dot{0}$ & \\
\hline $1901 .\{$ & 2. & .. & .. & . . & . & I & I & 4 & 5 & I6 & 41 & 21 & 5 & 3 & 2 & I \\
\hline I902. \{ & I.... & . & & -. & $\begin{array}{lll} & \end{array}$ & I & 2 & 5 & II & 44 & I8 & I0 & 4 & 2 & I & I \\
\hline & 2. & .. & . & .. & .. & . & $\begin{array}{ll}\text { I } & \\
\end{array}$ & 3 & 8 & 48 & 26 & I0 & 3 & I & .. & $\cdots$ \\
\hline
\end{tabular}

(C) PLACE VARIATION IN THE ELYTRA.

\begin{tabular}{|c|c|c|c|c|c|c|c|c|c|c|c|c|c|c|c|c|}
\hline $\begin{array}{l}\text { I895. } \\
\text { I896. } \\
\text { I897. } \\
\text { I898. }\{ \\
\text { I899. }\{ \\
\text { I900. }\{ \\
\text { I901. }\{ \\
\text { I902. }\end{array}$ & $\begin{array}{l}1 \ldots . . \\
2 \ldots \\
1 \ldots . \\
2 \ldots \\
1 \ldots . \\
2 \ldots \\
1 \ldots . \\
2 \ldots \\
1 \ldots . . \\
2 \ldots \\
1 \ldots \\
2 \ldots \\
1 \ldots \\
2 \ldots \\
1 \ldots \\
2 \ldots\end{array}$ & 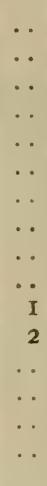 & $\begin{array}{c}\because \\
\because \\
\because \\
\mathrm{I} \\
\because \\
\mathrm{I} \\
2 \\
\cdots \\
\because \\
2 \\
5 \\
2 \\
2 \\
3 \\
2\end{array}$ & $\begin{array}{r}2 \\
4 \\
2 \\
2 \\
6 \\
\ldots \\
\because \\
4 \\
7 \\
7 \\
5 \\
\text { IO } \\
\text { II }\end{array}$ & $\begin{array}{r}3 \\
4 \\
\because \\
5 \\
20 \\
20 \\
17 \\
26 \\
\because \\
1 \\
9 \\
39 \\
18 \\
20 \\
50 \\
47\end{array}$ & $\begin{array}{r}14 \\
17 \\
1 \\
77 \\
51 \\
59 \\
53 \\
35 \\
1 \\
4 \\
35 \\
31 \\
49 \\
46 \\
19 \\
27\end{array}$ & $\begin{array}{r}45 \\
20 \\
19 \\
60 \\
18 \\
14 \\
18 \\
20 \\
2 \\
7 \\
29 \\
10 \\
18 \\
21 \\
11 \\
9\end{array}$ & $\begin{array}{r}19 \\
42 \\
20 \\
18 \\
5 \\
4 \\
6 \\
7 \\
21 \\
23 \\
15 \\
4 \\
6 \\
3 \\
4 \\
4\end{array}$ & $\begin{array}{r}10 \\
13 \\
49 \\
8 \\
1 \\
1 \\
3 \\
3 \\
2 \\
45 \\
39 \\
4 \\
1 \\
.9 \\
2 \\
3\end{array}$ & $\begin{array}{r}5 \\
4 \\
\text { II } \\
\because \\
\because \\
\because \\
\because \\
\text { I } \\
28 \\
\text { I } \\
\text { I } \\
\text { I } \\
\because \\
\text { I } \\
\therefore \\
\therefore\end{array}$ & $\begin{array}{c}\text { I } \\
\therefore \\
\therefore \\
\therefore \\
\therefore \\
\therefore \\
\because \\
\text { I } \\
3 \\
8 \\
. \\
\therefore \\
\therefore\end{array}$ & $\begin{array}{c}\text { I } \\
\cdots \\
\cdots \\
\cdots \\
\cdots \\
\cdots \\
\cdots \\
\cdots\end{array}$ & $\begin{array}{l}\cdots \\
\cdots \\
\cdots \\
\cdots \\
\cdots \\
\cdots \\
\cdots \\
\cdots \\
\cdots \\
\cdots \\
\cdots \\
\cdots \\
\cdots\end{array}$ & $\begin{array}{l}\ldots \\
\ldots \\
\cdots \\
\ldots \\
\ldots \\
\ldots \\
\ldots \\
\ldots \\
\cdots \\
\cdots \\
\cdots \\
.\end{array}$ & $\begin{array}{l}\because \\
\because \\
\cdots \\
\cdots \\
\cdots \\
\cdots \\
\cdots \\
\because \\
\therefore \\
\therefore \\
\therefore\end{array}$ & $\begin{array}{l}\cdots \\
\cdots \\
\cdots \\
\cdots \\
\cdots\end{array}$ \\
\hline
\end{tabular}

(D) PLACE VARIATION IN THE VENTRAI, SURFACE OF THE ABDOMINAL, SEGMENTS.

\begin{tabular}{|c|c|c|c|c|c|c|c|c|c|c|c|c|c|c|c|c|}
\hline $\begin{array}{l}\text { I895. }\{ \\
\text { I896. }\{ \\
\text { I897. }\{ \\
\text { I898. }\{ \\
\text { I899. }\{ \\
\text { I900. }\{ \\
\text { I901. }\{ \\
\text { I902. }\{\end{array}$ & $\begin{array}{l}1 \ldots \ldots \\
2 \ldots \\
1 \ldots \ldots \\
2 \ldots \\
1 \ldots \\
2 \ldots \\
1 \ldots \\
2 \ldots \\
1 \ldots \\
2 \ldots \\
1 \ldots \\
2 \ldots \\
1 \ldots \\
2 \ldots \\
1 \ldots \\
2 \ldots\end{array}$ & $\begin{array}{l}\because \\
\therefore \\
\therefore \\
\therefore \\
\because \\
\because \\
\because \\
\because \\
\because \\
\because \\
\therefore \\
\therefore\end{array}$ & $\begin{array}{l}\cdots \\
\cdots \\
\cdots \\
\cdots \\
\cdots \\
\cdots \\
\cdots \\
\cdots \\
\cdots \\
\cdots \\
\cdots \\
\therefore\end{array}$ & 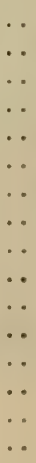 & $\begin{array}{l}\because \\
\because \\
\cdots \\
\cdots \\
\because \\
\because \\
\because \\
\because \\
\because \\
1 \\
\therefore\end{array}$ & 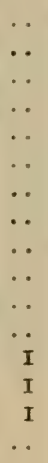 & $\begin{array}{c}. . \\
\because \\
\because \\
2 \\
. \\
. \\
\because \\
\text { I } \\
. \\
\because \\
\text { I } \\
\ddot{I} \\
3 \\
4 \\
. .\end{array}$ & $\begin{array}{r}\text { I } \\
\text { I } \\
\because \\
4 \\
8 \\
\because \\
2 \\
5 \\
5 \\
3\end{array}$ & $\begin{array}{r}5 \\
\text { I } \\
\text { II } \\
\text { I } 8 \\
3 \\
4 \\
7 \\
\text { I } \\
\text { I } \\
42 \\
8 \\
5 \\
\text { II } \\
9 \\
9\end{array}$ & $\begin{array}{r}14 \\
2 \\
4 \\
51 \\
51 \\
19 \\
16 \\
24 \\
2 \\
3 \\
20 \\
18 \\
18 \\
\mathbf{4 2} \\
\mathbf{4 4} \\
\mathbf{4 8}\end{array}$ & $\begin{array}{r}55 \\
16 \\
16 \\
17 \\
21 \\
60 \\
50 \\
36 \\
20 \\
9 \\
16 \\
50 \\
46 \\
20 \\
20 \\
28\end{array}$ & $\begin{array}{r}19 \\
21 \\
20 \\
8 \\
3 \\
13 \\
18 \\
20 \\
46 \\
21 \\
7 \\
17 \\
21 \\
11 \\
10 \\
8\end{array}$ & $\begin{array}{r}40 \\
50 \\
5 \\
1 \\
5 \\
6 \\
7 \\
25 \\
35 \\
4 \\
7 \\
3 \\
4 \\
5 \\
4\end{array}$ & $\begin{array}{r}5 \\
4 \\
6 \\
8 \\
1 \\
\ldots \\
2 \\
1 \\
2 \\
2\end{array}$ & $\begin{array}{c}7 \\
\text { I } \\
\cdots \\
\cdots \\
\cdots \\
\cdots \\
\cdots \\
\because \\
9 \\
I \\
\because \\
I \\
I \\
\cdots \\
\cdots\end{array}$ & $\begin{array}{l}\cdots \\
\ldots \\
\ldots \\
\cdots \\
\ldots \\
\cdots \\
\cdots \\
\cdots \\
\therefore \\
\therefore \\
\therefore\end{array}$ \\
\hline
\end{tabular}


PLACE VARIATION.

TABLE 33-Continued.

(E) PLACE VARIATION IN SIZE OF MALES AND FEMALES

\begin{tabular}{|c|c|c|c|c|c|c|c|c|c|c|c|c|c|c|c|}
\hline \multirow{2}{*}{ Year. } & \multirow{2}{*}{$\begin{array}{l}\text { Gener- } \\
\text { ation. }\end{array}$} & \multirow{2}{*}{ Sex. } & \multicolumn{13}{|c|}{ Class. } \\
\hline & & & I & 2 & 3 & 4 & 5 & 6 & 7 & 8 & 9 & I0 & II & 12 & 13 \\
\hline \multirow{5}{*}{ I895. } & & Male & & I4 & 61 & I8 & & & &. & & & & & \\
\hline & I & Female. & I & 5 & I4 & 55 & $\begin{array}{r}4 \\
19\end{array}$ & 6 & $\cdots$ & $\therefore$ & .. & $\because$. & 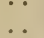 & $\because$ & .. \\
\hline & 2 & Male... & $\cdots$ & .. & 5 & 17 & I9 & 44 & 12 & 3 & & .. & .. & .. & .. \\
\hline & 27 & Female. & .. & .. & & 4 & I4 & 23 & 42 & 14 & 3 & .. & .. & . & .. \\
\hline & I \{ & $\begin{array}{l}\text { Male... } \\
\text { Female }\end{array}$ & $\cdots$ & $\because$ & 5 & I6 & 20 & 42 & $\begin{array}{l}\text { IO } \\
40\end{array}$ & 7 & $\because$ & $\ddot{I}$ & $\cdots$ & .. & .. \\
\hline \multirow[t]{3}{*}{ I8g6. } & & Male... & $\because$ & $\ddot{6}$ & 61 & $\begin{array}{r}4 \\
19\end{array}$ & 13 & $\begin{array}{r}24 \\
4\end{array}$ & 40 & I2 & 5 & 1 & $\cdots$ & . & .. \\
\hline & & Female. & .. & 2 & 5 & 60 & I 8 & $\begin{array}{l}4 \\
8\end{array}$ & $\begin{array}{l}3 \\
7\end{array}$ & $\because$. & . & $\begin{array}{l}\cdots \\
.\end{array}$ & $\begin{array}{l}\cdots \\
\ldots\end{array}$ & $\cdots$ & . \\
\hline & & Male... & 7 & 16 & 50 & 20 & 5 & 2 & .. & $\because$. & . & $\therefore$ & $\therefore$ & $\therefore$ & .. \\
\hline \multirow{3}{*}{ I897. } & & Female. & $\therefore$ & 9 & $\mathrm{r}_{4}$ & 51 & 19 & 6 & $\mathbf{I}$ & .. & . & $\ldots$ & .. & .. & .. \\
\hline & 2\{ & Male... & .. & $I$ & $2 I$ & 60 & I3 & 5 & .. & .. & .. & . & .. & . & .. \\
\hline & & Male. & $\cdots$ & $\because$ & 3 & $\begin{array}{l}2 \mathrm{I} \\
50\end{array}$ & 60 & 12 & 4 & .. & .. & $\cdots$ & $\cdots$ & .. & . \\
\hline \multirow{4}{*}{1898.} & I & Female. & I & $\begin{array}{l}4 \\
3\end{array}$ & $\begin{array}{l}18 \\
18\end{array}$ & 49 & $\begin{array}{l}18 \\
19\end{array}$ & $\begin{array}{l}6 \\
5\end{array}$ & $\begin{array}{l}5 \\
4\end{array}$ & I & . & $\because$ & $\because$ & $\cdots$ & . \\
\hline & & Male & & 8 & 23 & 38 & 21 & 6 & $\begin{array}{l}4 \\
4\end{array}$ & . & .. & $\ldots$ & $\because$ & $\because$ & . \\
\hline & & Female. & & I & IO & 20 & 39 & 20 & 7 & 3 & .. & .. & .. & $\because$ & 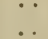 \\
\hline & I & Male & & I & 3 & 20 & 45 & 27 & 4 & 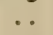 & .. & $\cdots$ & $\cdots$ & $\cdots$ & $\cdots$ \\
\hline \multirow{3}{*}{1899.} & 17 & Female. & & & I & 4 & 20 & 44 & 28 & 3 & .. & $\cdots$ & .. & .. & .. \\
\hline & 2\{ & Male & & I & 4 & 9 & 20 & 34 & I7 & I5 & & .. & .. & . & . \\
\hline & & Female. & 8 & & & 2 & 6 & $3 \mathrm{I}$ & 36 & I5 & 10 & $\cdots$ & .. & .. & .. \\
\hline \multirow{4}{*}{ I90 } & I \{ & $\begin{array}{l}\text { Male... } \\
\text { Female }\end{array}$ & I4 & $\begin{array}{l}37 \\
36\end{array}$ & $\begin{array}{l}25 \\
23\end{array}$ & I8 & 7 & 5 & . & $\cdots$ & . & $\cdots$ & $\cdots$ & $\cdots$ & . \\
\hline & ?) & Male & $\begin{array}{l}12 \\
12\end{array}$ & 39 & $3 \mathrm{I}$ & I4 & $\begin{array}{l}9 \\
4\end{array}$ & 3 & $\begin{array}{l}\cdots \\
\cdots\end{array}$ & $\therefore$ & $\therefore$ & $\therefore$ & $\therefore$ & $\because$. & . \\
\hline & 23 & Female. & II & 40 & 28 & 17 & 3 & I & .. & $\ldots$ & $\ldots$ & & $\cdots$ & & \\
\hline & $\mathrm{x}\{$ & Male. . & I & 6 & 19 & 50 & 18 & 6 & .. & . & . & $\cdots$ & . & .. & $\cdots$ \\
\hline & & Female. & & I & 8 & $\mathrm{I} 7$ & 50 & I7 & 7 & & & .. & .. & .. & \\
\hline & 2\{ & Male... & 2 & 4 & $2 \mathrm{I}$ & 45 & 22 & 3 & 2 & I & . & $\cdots$ & $\cdots$ & . & . \\
\hline & ? & Female. & .. & & I & $2 I$ & 49 & 20 & 8 & I & .. & .. & .. & .. & . \\
\hline & I \{ & Male & .. & II & 52 & $2 \mathrm{I}$ & I0 & 6 & & & $\cdots$ & . & & & \\
\hline \multirow[t]{2}{*}{1902.} & & Female. & . & 2 & 9 & 50 & 22 & II & 5 & I & .. & .. & .. & .. & .. \\
\hline & 2\{ & $\begin{array}{l}\text { Male... } \\
\text { Female. }\end{array}$ & $\begin{array}{l}3 \\
3\end{array}$ & 8 & $\begin{array}{l}44 \\
47\end{array}$ & $\begin{array}{l}33 \\
29\end{array}$ & 6 & 5 & I & . & . & $\cdots$ & $\begin{array}{l}\cdots \\
\ldots\end{array}$ & $\cdots$ & $\cdots$ \\
\hline & & & & & & & & & & & & & & & \\
\hline
\end{tabular}

(F) PLACE VARIATION FOR THE SPECIES AS A WHOLE.

\begin{tabular}{|c|c|c|c|c|c|c|c|c|c|c|c|c|c|c|c|c|}
\hline \multirow{2}{*}{ Year. } & \multirow{2}{*}{$\begin{array}{l}\text { Gener- } \\
\text { ation. }\end{array}$} & \multicolumn{15}{|c|}{ Class. } \\
\hline & & I & 2 & 3 & 4 & 5 & 6 & 7 & 8 & 9 & I0 & II & 12 & 13 & 14 & 15 \\
\hline \multirow{15}{*}{ I895. } & I.. & . & 5 & I4 & 58 & 16 & 7 & & & & & $\ldots$ & $\ldots$ & $\ldots$ & & .. \\
\hline & 2. & .. & I & 3 & I6 & 20 & 43 & IO & 4 & 2 & I & $\ldots$ & $\ldots$ & .. & .. & .. \\
\hline & I. . & .. & 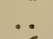 & 4 & 15 & 21 & 40 & I8 & $\begin{array}{l}4 \\
2\end{array}$ & . & .. & $\therefore$ & .. & .. & .. & .. \\
\hline & 2. & .. & 6 & 50 & 29 & 8 & 4 & 2 & I & . & .. & 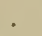 & .. & .. & .. & .. \\
\hline & I. & 2 & $2 \mathrm{I}$ & 50 & 20 & 5 & 2 & .. & $\ldots$ & .. &. & $\ldots$ & $\ldots$ & .. & .. & .. \\
\hline & $2 .$. & .. & 2 & 22 & 51 & 20 & 5 & .. & . & .. & $\ldots$ & . & .. & .. & .. & .. \\
\hline & I. & I & 4 & 16 & 40 & 19 & I5 & 2 & 2 & I & .. & .. & $\ldots$ & .. & .. & .. \\
\hline & 2 & 2 & 6 & 24 & 37 & 20 & 7 & 2 & I & I & . . & . & .. & . & .. & .. \\
\hline & I. . & .. & I & I & 22 & 40 & 29 & 3 & 2 & I & I & .. & $\ldots$ & .. & .. & .. \\
\hline & 2. & $\because$ & I & 4 & 9 & 20 & 30 & $2 \mathrm{I}$ & 7 & 5 & 3 & . & $\ldots$ & .. & .. & .. \\
\hline & I. & 8 & 37 & 27 & 17 & 6 & 3 & 2 & $\therefore$ & $\cdots$ & . & .. & $\ldots$ & .. & .. & . \\
\hline & 2. & I4 & 40 & 30 & II & 5 & & .. & . & $\ldots$ & . & .. & $\ldots$ & .. & .. & .. \\
\hline & I. . & .. & 6 & 20 & 40 & 28 & 6 & 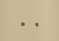 & . & . & . & . & . & . & .. & .. \\
\hline & 2. & .. & 4 & 23 & 46 & $2 I$ & 6 & . & . & . & .. & .. & $\ldots$ & . & . & .. \\
\hline & I. & 2 & 9 & 50 & 23 & 10 & 5 & I & . & . & . & $\cdots$ & $\cdots$ & . & . & . \\
\hline & 2. & 3 & 9 & 45 & $3 \mathrm{I}$ & 7 & 4 & I & . & . & . & . & . & $\cdots$ & . & . \\
\hline
\end{tabular}


TABLE 34.-Place variation in the epicranium, pronotum, elytra, size of males and females, and ventral surface of abdominal segments of $L$. decemlineata at Chicago, Cook County, Illinois.

(A) PLACE VARIATION IN THE EPICRANIUM.

\begin{tabular}{|c|c|c|c|c|c|c|c|c|c|c|c|c|c|c|c|c|}
\hline \multirow{2}{*}{ Year. } & \multirow{2}{*}{$\begin{array}{l}\text { Gener- } \\
\text { ation. }\end{array}$} & \multicolumn{15}{|c|}{ Class. } \\
\hline & & I & 2 & 3 & 4 & 5 & 6 & 7 & 8 & 9 & I0 & II & I2 & $x_{3}$ & 14 & 15 \\
\hline 1902 & 1.... & I & 9 & $3^{8}$ & 41 & 9 & 2 & .. & .. & . & . & .. & $\cdots$ & $\cdots$ & .. & \\
\hline & $2 \ldots$. & .. & 4 & 19 & 50 & $2 x$ & 6 & . & .. & .. & .. & $\ldots$ & $\ldots$ & .. & .. & .. \\
\hline & I... & $\cdots$ & I9 & 45 & 26 & 8 & 2 & . & .. & .. & . & .. & .. & .. & .. & .. \\
\hline & $2 \ldots$ & . & 4 & 19 & 40 & $2 I$ & 6 & 4 & 3 & 2 & I & $\ldots$ & . & .. & .. & . \\
\hline & $x \ldots$ & $\cdots$ & . & 2 & Io & I7 & 35 & $2 \mathrm{I}$ & II & 4 & .. & . & . & .. & . & .. \\
\hline 1904 & $2 \ldots$ & I & 3 & 6 & ro & 20 & 39 & I9 & 2 & .. & .. & .. & .. & . & .. & .. \\
\hline IgO5. \{ & & $\cdots$ & I & 5 & I8 & 52 & 20 & 4 & .. & . & . & .. & .. & . & . & . \\
\hline 1905.7 & 2. & .. & 4 & I7 & 48 & I9 & 8 & 3 & I & .. & .. & .. & . & .. & .. & . \\
\hline
\end{tabular}

(B) PLACE VARIATION IN THE PRONOTUM.

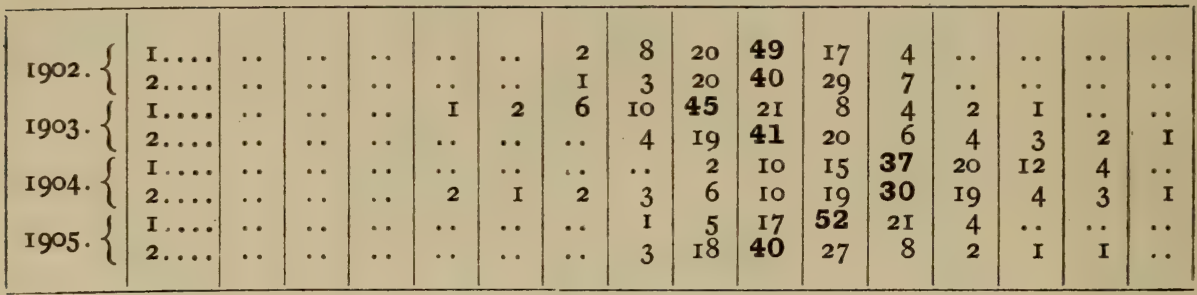

(C) PLACE VARIATION IN THE ELYTRA.

\begin{tabular}{|c|c|c|c|c|c|c|c|c|c|c|c|c|c|c|c|c|}
\hline $\begin{array}{l}\text { 1902. }\{ \\
\text { 1903. }\{ \\
\text { 1904. }\{ \\
1905 \cdot\{\end{array}$ & $\begin{array}{l}1 \ldots \ldots \\
2 \ldots \ldots \\
1 \ldots \ldots \\
2 \ldots \ldots \\
1 \ldots \ldots \\
2 \ldots \ldots \\
1 \ldots \ldots \\
2 \ldots \ldots\end{array}$ & $\begin{array}{l}\cdots \\
\cdots \\
\cdots \\
\cdots \\
\cdots \\
\cdots\end{array}$ & $\begin{array}{l}\because \\
\because \\
\because \\
\ddot{I} \\
\cdots \\
\cdots\end{array}$ & $\begin{array}{r}\because \\
\text { I } \\
. . \\
\ddot{1} \\
. . \\
.\end{array}$ & $\begin{array}{r}\ddot{I} \\
2 \\
\because \\
\because \\
\text { I } \\
\because \\
\because\end{array}$ & $\begin{array}{l}\text { I } \\
4 \\
5 \\
\text { I }\end{array}$ & $\begin{array}{r}\text { I } \\
\text { 19 } \\
\text { II } \\
3 \\
\ldots \\
4 \\
\because \\
2\end{array}$ & $\begin{array}{r}39 \\
45 \\
18 \\
2 \\
5 \\
1 \\
18\end{array}$ & $\begin{array}{r}29 \\
30 \\
20 \\
42 \\
9 \\
9 \\
6 \\
47\end{array}$ & $\begin{array}{r}40 \\
6 \\
9 \\
21 \\
14 \\
18 \\
15 \\
20\end{array}$ & $\begin{array}{r}16 \\
1 \\
3 \\
5 \\
37 \\
32 \\
53 \\
7\end{array}$ & $\begin{array}{r}4 \\
\because \\
3 \\
4 \\
20 \\
18 \\
20 \\
3\end{array}$ & $\begin{array}{r}\because \\
\dddot{1} \\
3 \\
10 \\
5 \\
4 \\
1\end{array}$ & $\begin{array}{l}\because \\
\because \\
2 \\
6 \\
3 \\
1 \\
1\end{array}$ & $\begin{array}{c}\because . \\
\because . \\
1 \\
2 \\
1 \\
\cdots \\
\cdots\end{array}$ & . \\
\hline
\end{tabular}

(D) PLACE VARIATION IN SIZE OF MALES AND FEMALES.

\begin{tabular}{|c|c|c|c|c|c|c|c|c|c|c|c|c|c|c|c|}
\hline \multirow{2}{*}{ Year. } & \multirow{2}{*}{$\begin{array}{l}\text { Gener- } \\
\text { ation. }\end{array}$} & \multirow{2}{*}{ Sex. } & \multicolumn{13}{|c|}{ Class. } \\
\hline & & & I & 2 & 3 & 4 & 5 & 6 & 7 & 8 & 9 & 10 & II & 12 & $\mathbf{I}_{3}$ \\
\hline \multirow{8}{*}{$\begin{array}{l}\text { I902. } \\
\text { I903. }\end{array}$} & & Male. & 2 & 8 & 30 & 49 & 8 & 3 &.. & .. &. &. & . & & \\
\hline & I \{ & Female. & 2 & 7 & $3 \mathbf{I}$ & 48 & 7 & 5 & .. & .. & .. & .. & .. & 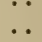 & 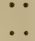 \\
\hline & & Male... & .. & 3 & 20 & 50 & 20 & 7 & .. & .. & .. & .. & .. & $\therefore$ & . \\
\hline & 2\{ & Female. & . & I & 3 & 18 & 51 & 19 & 7 & I & .. & . & .. & . & $\cdots$ \\
\hline & I & Male... & .. & I8 & 46 & 20 & I4 & 2 & $\therefore$ & . & $\ldots$ & .. & .. & . & .. \\
\hline & 12 & Female. & . & I0 & 40 & 30 & 14 & 4 & 2 & $\ldots$ & . & .. & .. & .. & $\cdots$ \\
\hline & 2 & Male... & .. & 5 & 18 & 36 & 25 & 6 & 3 & 3 & 4 & $\cdots$ & .. & .. & . \\
\hline & & Female. & $\cdots$ & I & 4 & I7 & 39 & 24 & I2 & 2 & I & .. & .. & . & . \\
\hline \multirow{4}{*}{1904.} & I \{ & Female. & $\because$ & $\because$. & $\begin{array}{l}1 \\
.\end{array}$ & $\begin{array}{l}11 \\
\text { I4 }\end{array}$ & $\begin{array}{l}15 \\
13\end{array}$ & 32 & $\begin{array}{l}20 \\
24\end{array}$ & $\begin{array}{l}12 \\
12\end{array}$ & $\begin{array}{l}4 \\
5\end{array}$ & $\because$ & $\therefore$ & $\cdots$ & . \\
\hline & J & Male... & 2 & 2 & 5 & II & I9 & 40 & 16 & 5 & .. & .. & .. & . & $\cdots$ \\
\hline & 22 & Female. & .. & 3 & 6 & 10 & I8 & 40 & 12 & 6 & 5 & .. & .. & . & .. \\
\hline & I & Male... & .. & I & 5 & 18 & 50 & 22 & 3 & I & .. & .. & .. & . & . \\
\hline 1905. & & Female. & .. & .. & & I & 23 & 45 & 27 & 4 & $\ldots$ & .. & .. & .. & . \\
\hline 1900. & 2\{ & $\begin{array}{l}\text { Male... } \\
\text { Female. }\end{array}$ & $\begin{array}{r}\text { I } \\
. .\end{array}$ & 3 & $\begin{array}{r}16 \\
4\end{array}$ & $\begin{array}{r}49 \\
17\end{array}$ & $\begin{array}{r}18 \\
54\end{array}$ & $\begin{array}{r}9 \\
18\end{array}$ & $\begin{array}{l}2 \\
6\end{array}$ & $\begin{array}{l}\text { I } \\
\text { I }\end{array}$ & $\begin{array}{l}\text { I } \\
\text {.. }\end{array}$ & $\begin{array}{l}\ldots \\
\ldots\end{array}$ & .. & $\because$ & $\because$ \\
\hline
\end{tabular}


TABLE 34-Continued.

(E) PLACE VARIATION IN VENTRAL SURFACE OF ABDOMINAL SEGMENTS.

\begin{tabular}{|c|c|c|c|c|c|c|c|c|c|c|c|c|c|c|c|c|}
\hline \multirow[b]{2}{*}{ Year. } & \multirow{2}{*}{$\begin{array}{l}\text { Gener-- } \\
\text { ation. }\end{array}$} & \multicolumn{15}{|c|}{ Class. } \\
\hline & & I & 2 & & 4 & 5 & 6 & 7 & 8 & 9 & I0 & II & I 2 & 13 & 14 & 15 \\
\hline & I.... & $\ldots$ & .. & . & I & I & 2 & 8 & 28 & 36 & 20 & 3 & I & .. & $\cdots$ & . \\
\hline & $2 \ldots$ & .. & .. & .. & I & 2 & 20 & 40 & 22 & I4 & I & & .. & .. & .. & $\ldots$ \\
\hline & I $\ldots$ & $\ldots$ & I & 2 & 5 & Io & 46 & 20 & 8 & 4 & 2 & I & I & .. & $\ldots$ & .. \\
\hline 1 & $2 \ldots$ & $\ldots$ & . & $\cdots$ & $\cdots$ & I & 3 & 15 & 45 & $2 \mathrm{I}$ & 6 & 5 & I & 3 & .. & . \\
\hline 190 & I.... & $\cdots$ & .. & . & . & I & 3 & 6 & I4 & 35 & 22 & 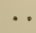 & I3 & 5 & I & .. \\
\hline & $2 \ldots$ & . & I & I & I & 3 & 4 & 6 & 8 & 20 & 30 & I9 & 4 & 2 & I & . . \\
\hline $1905 .\{$ & I.... & $\cdots$ & . & 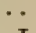 & . & * & $\ddot{i}$ & I & 6 & I 4 & 54 & 21 & 3 & I & $\cdots$ & . \\
\hline & $2 \ldots$ & $\cdots$ & .. & I & . & 2 & I7 & 45 & 23 & 8 & 2 & I & I & 1 & . & . \\
\hline
\end{tabular}

TABLE 35.-Place variation in the proportion of light to dark color in the epicranium, in the pronotum, in the elytra, and in the ventral surface of abdominal segments of L. multitaniata at Guadalupe, Federal District, Mexico.

(A) PLACE VARIATION IN THE PROPORTION OF LIGHT TO DARK COLOR IN THE EPICRANIUM.

\begin{tabular}{|c|c|c|c|c|c|c|c|c|c|c|c|c|c|c|c|c|c|c|c|c|c|}
\hline \multirow{2}{*}{ Year. } & \multirow{2}{*}{$\begin{array}{l}\text { Gener-r- } \\
\text { ation. }\end{array}$} & \multicolumn{20}{|c|}{ Class. } \\
\hline & & I & 2 & 3 & 4 & 5 & 6 & 7 & 8 & 9 & 10 & II & 12 & 13 & 14 & I5 & 16 & 17 & 18 & 19 & 20 \\
\hline $\begin{array}{l}1903 \\
1904 \\
1905\{\end{array}$ & $\begin{array}{l}1 \ldots \\
2 \ldots \\
1 \ldots \\
2 \ldots \\
1 \ldots \\
2 \ldots\end{array}$ & $\begin{array}{l}. \\
. \\
. \\
\therefore\end{array}$ & $\begin{array}{l}\text { I } \\
. \\
\therefore \\
\text { I } \\
. .\end{array}$ & $\begin{array}{r}4 \\
. \\
I \\
2 \\
5 \\
18\end{array}$ & $\begin{array}{r}12 \\
\cdots \\
3 \\
19 \\
21 \\
51\end{array}$ & $\begin{array}{r}49 \\
1 \\
59 \\
55 \\
46 \\
19\end{array}$ & $\begin{array}{r}19 \\
5 \\
2 \mathrm{I} \\
2 \mathrm{I} \\
22 \\
1 \mathrm{I}\end{array}$ & $\begin{array}{r}\text { II } \\
20 \\
53 \\
3 \\
4 \\
\mathrm{I}\end{array}$ & $\begin{array}{r}3 \\
3 \mathrm{I} \\
\mathrm{I} 2 \\
\cdots \\
\mathrm{I} \\
. .\end{array}$ & $\begin{array}{r}\mathrm{I} \\
40 \\
\mathrm{I} \\
\cdots \\
\cdots \\
\therefore\end{array}$ & $\begin{array}{c}3 \\
\therefore \\
\cdots \\
\cdots \\
\cdots\end{array}$ & $\begin{array}{l}\because \\
\because \\
\because \\
\because\end{array}$ & $\begin{array}{l}\because \\
\because \\
\therefore \\
\therefore\end{array}$ & $\begin{array}{l}\because \\
\therefore \\
\cdots \\
\cdots \\
\cdots\end{array}$ & $\begin{array}{l}\because \\
\because \\
\cdots \\
\cdots \\
\cdots\end{array}$ & $\begin{array}{l}\because \\
\because \\
\because \\
\because \\
\therefore\end{array}$ & $\begin{array}{l}\because \\
\because \\
\because \\
\because\end{array}$ & $\begin{array}{l}\because \\
\because \\
\because \\
\because\end{array}$ & $\begin{array}{l}\because \\
\because \\
\because \\
\because \\
\cdots\end{array}$ & $\begin{array}{l}\because \\
\because \\
\because \\
\because \\
\therefore\end{array}$ & $\begin{array}{l}\because \\
\because \\
\because \\
\because \\
.\end{array}$ \\
\hline
\end{tabular}

(B) PLACE VARIATION IN THE PROPORTION OF LIGHT TO DARK COLOR IN THE PRONOTUM.

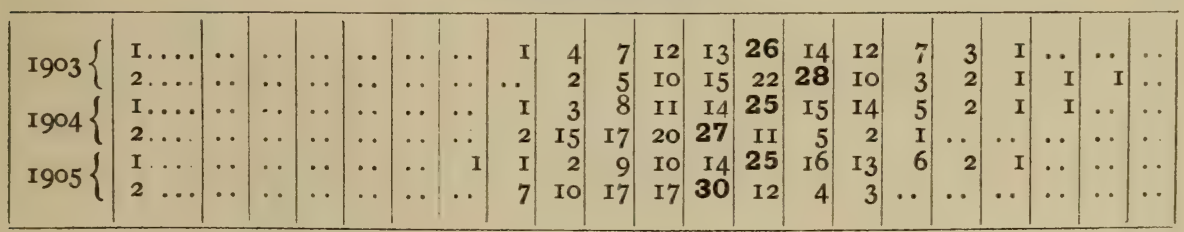

(C) PLACE VARIATION IN THE PROPORTION OF LIGHT TO DARK COLOR IN THE EIYTRA.

\begin{tabular}{|c|c|c|c|c|c|c|c|c|c|c|c|c|c|c|c|c|c|c|c|c|c|}
\hline $\begin{array}{l}1903\{ \\
1904\{ \\
1905\{\end{array}$ & $\begin{array}{l}\mathrm{I} \ldots \\
2 \ldots \\
1 \ldots \\
2 \ldots \\
1 \ldots \\
2 \ldots\end{array}$ & $\begin{array}{l}\because \\
\cdots \\
\cdots \\
\cdots \\
\cdots\end{array}$ & $\begin{array}{l}\because \\
\cdots \\
\cdots\end{array}$ & $\begin{array}{l}\cdots \\
\because \\
\cdots\end{array}$ & $\begin{array}{l}. \\
\cdots \\
\cdots\end{array}$ & $\begin{array}{l}\because \\
\because \\
\cdots\end{array}$ & $\begin{array}{l}\ldots \\
\cdots \\
\cdots\end{array}$ & $\begin{array}{l}\cdots \\
\cdots \\
\cdots \\
\cdots \\
\cdots\end{array}$ & $\begin{array}{c}\boldsymbol{I} \\
\ldots \\
\cdots \\
\cdots \\
\cdots \\
.\end{array}$ & $\begin{array}{c}3 \\
. . \\
3 \\
\mathrm{I} \\
. \\
\mathrm{I}\end{array}$ & $\begin{array}{l}8 \\
5 \\
8 \\
4 \\
5 \\
4\end{array}$ & $\begin{array}{r}\text { II } \\
\text { I0 } \\
9 \\
8 \\
9 \\
\text { I I }\end{array}$ & \begin{tabular}{|r|}
$\mathrm{I} 4$ \\
$\mathrm{I} 5$ \\
$\mathrm{I} 6$ \\
$\mathbf{3 0}$ \\
$\mathbf{3 3}$ \\
$\mathbf{1} 4$
\end{tabular} & $\begin{array}{r}25 \\
20 \\
25 \\
2 \mathrm{I} \\
20 \\
30\end{array}$ & \begin{tabular}{|r|}
$\mathbf{1 5}$ \\
$\mathbf{3 1}$ \\
$\mathbf{1} 5$ \\
$\mathbf{1}$ \\
$\mathbf{1 7}$ \\
$\mathbf{2 3}$
\end{tabular} & $\begin{array}{l}\text { II } \\
\text { II } \\
\text { I4 } \\
\text { IO } \\
\text { II } \\
\text { IO }\end{array}$ & \begin{tabular}{l|}
8 \\
3 \\
5 \\
8 \\
4 \\
4
\end{tabular} & $\begin{array}{l}4 \\
2 \\
4 \\
3 \\
1 \\
2\end{array}$ & $\begin{array}{r}{ }_{2} \\
\mathrm{I} \\
\mathrm{I} \\
. \\
\mathrm{I}\end{array}$ & $\begin{array}{c}\because \\
I \\
\because \\
\because \\
\cdots\end{array}$ & $\begin{array}{l}\cdots \\
\because \\
\because \\
\cdots\end{array}$ \\
\hline
\end{tabular}


TABLE 35-Continued.

(D) PLACE VARIATION IN THE PROPORTION OF LIGHT TO DARK COLOR IN THE, VENTRAL, SURFACE OF THE ABDOMINAL, SEGMENTS.

\begin{tabular}{|c|c|c|c|c|c|c|c|c|c|c|c|c|c|c|c|c|c|c|c|c|c|}
\hline \multirow{2}{*}{ Year. } & \multirow{2}{*}{$\begin{array}{l}\text { Gener- } \\
\text { ation. }\end{array}$} & \multicolumn{20}{|c|}{ Class. } \\
\hline & & 1 & 2 & 3 & 4 & 5 & 6 & 7 & 8 & 9 & I0 & II & 12 & 13 & 14 & I5 & 16 & 17 & 18 & 19 & 20 \\
\hline $\begin{array}{l}1903\{ \\
1904\{ \\
1905\{\end{array}$ & $\begin{array}{l}1 \ldots \\
2 \ldots \\
1 \ldots \\
2 \ldots \\
1 \ldots \\
2 \ldots\end{array}$ & $\begin{array}{l}\because \\
\therefore \\
\therefore \\
\therefore\end{array}$ & $\begin{array}{l}\because \\
\because \\
\because \\
\therefore\end{array}$ & $\begin{array}{l}\cdots \\
\cdots \\
\cdots \\
\cdots \\
\cdots\end{array}$ & $\begin{array}{l}\cdots \\
\cdots \\
\cdots \\
\cdots \\
\cdots\end{array}$ & $\begin{array}{l}\cdots \\
\cdots \\
\cdots \\
.\end{array}$ & $\begin{array}{l}\because \\
\because \\
\therefore \\
\therefore \\
\cdots\end{array}$ & $\begin{array}{c}\cdots \\
\cdots \\
\cdots \\
\cdots \\
\cdots\end{array}$ & $\begin{array}{c}\cdots \\
\cdots \\
\cdots \\
\cdots \\
\ldots\end{array}$ & $\begin{array}{l}\mathrm{I} \\
. . \\
. \\
. \\
4 \\
2\end{array}$ & \begin{tabular}{r|}
3 \\
1 \\
1 \\
5 \\
10 \\
4
\end{tabular} & $\begin{array}{r}8 \\
2 \\
4 \\
7 \\
14 \\
5\end{array}$ & \begin{tabular}{r|}
11 \\
3 \\
6 \\
10 \\
27 \\
11
\end{tabular} & $\begin{array}{r}16 \\
6 \\
12 \\
15 \\
17 \\
17\end{array}$ & $\begin{array}{r}21 \\
10 \\
15 \\
20 \\
11 \\
20\end{array}$ & \begin{tabular}{r|r}
$\mathrm{I} 4$ \\
$\mathrm{II}$ \\
$\mathbf{3 5}$ \\
$\mathrm{I} 6$ \\
8 \\
$\mathrm{I} 6$
\end{tabular} & \begin{tabular}{r|} 
II \\
22 \\
16 \\
12 \\
5 \\
10
\end{tabular} & $\begin{array}{r}8 \\
31 \\
8 \\
7 \\
3 \\
8\end{array}$ & $\begin{array}{l}4 \\
6 \\
3 \\
5 \\
6\end{array}$ & $\begin{array}{r}2 \\
4 \\
. . \\
2 \\
. . \\
\text { I }\end{array}$ & $\begin{array}{l}\mathrm{I} \\
4 \\
\dddot{I} \\
.\end{array}$ \\
\hline
\end{tabular}

TABLE 36.-Place variation in proportion of light to dark color in L. signaticollis at Cuernavaca, Morelos, Mexico, by classes.

\begin{tabular}{|c|c|c|c|c|c|c|c|c|c|c|c|c|c|c|c|c|c|c|c|c|c|}
\hline \multirow{2}{*}{ Year. } & \multirow{2}{*}{$\begin{array}{l}\text { Gener- } \\
\text { ation. }\end{array}$} & \multicolumn{4}{|c|}{ In elytra. } & \multicolumn{6}{|c|}{ In epicranium. } & \multicolumn{6}{|c|}{ In pronotum. } & \multicolumn{4}{|c|}{$\begin{array}{l}\text { On ventral sur- } \\
\text { face of abdom- } \\
\text { inal segments. }\end{array}$} \\
\hline & & I & 2 & 3 & 4 & 5 & 6 & 7 & 8 & 9 & 10 & II & 12 & 13 & 14 & 15 & 16 & 17 & 18 & I9 & 20 \\
\hline $\begin{array}{l}1903 . \\
1904 \\
1905\{\end{array}$ & $\begin{array}{l}2 \ldots . \\
1 \ldots \\
2 \ldots \\
1 \\
2 \ldots \\
2 \ldots\end{array}$ & $\begin{array}{l}10 \\
20 \\
21 \\
2 I \\
\text { II }\end{array}$ & $\begin{array}{r}55 \\
60 \\
34 \\
55 \\
71\end{array}$ & $\begin{array}{r}35 \\
20 \\
45 \\
24 \\
18\end{array}$ & $\begin{array}{l}. \\
\cdots\end{array}$ & $\begin{array}{c}\mathrm{I} \\
. \\
. \\
3 \\
\mathrm{I}\end{array}$ & $\begin{array}{l}3 \\
\text { I } \\
\text { I } \\
8 \\
2\end{array}$ & $\begin{array}{r}11 \\
15 \\
5 \\
12 \\
15\end{array}$ & $\begin{array}{l}26 \\
2 \mathrm{I} \\
3 \mathrm{I} \\
2 \mathrm{I} \\
33\end{array}$ & $\begin{array}{l}52 \\
60 \\
54 \\
50 \\
45\end{array}$ & $\begin{array}{l}7 \\
3 \\
9 \\
6 \\
4\end{array}$ & $\begin{array}{r}I \\
3 \\
\because \\
\because \\
2\end{array}$ & $\begin{array}{l}2 \\
3 \\
6 \\
3 \\
3\end{array}$ & $\begin{array}{r}8 \\
8 \\
\text { I0 } \\
\mathbf{1 I} \\
9\end{array}$ & $\begin{array}{l}20 \\
17 \\
20 \\
17 \\
21\end{array}$ & $\begin{array}{l}58 \\
56 \\
50 \\
57 \\
55\end{array}$ & $\begin{array}{l}\text { II } \\
\text { I3 } \\
\text { I4 } \\
\text { I2 } \\
\text { I0 }\end{array}$ & $\begin{array}{c}. \\
\mathrm{I} \\
\mathrm{x} \\
. \\
. .\end{array}$ & $\begin{array}{r}\mathrm{I} \\
\cdots \\
\mathrm{I} \\
\mathrm{I}\end{array}$ & $\begin{array}{r}3 \\
. \\
4 \\
\cdots \\
\mathrm{I}\end{array}$ & $\begin{array}{r}94 \\
100 \\
98\end{array}$ \\
\hline
\end{tabular}

TABLE 37.-Place variation in proportion of light to dark color in the epicranium, pronotum, elytra, and abdominal segments of L. undecimlineata at Orizaba, Vera Cruz, Mexico.

(A) VARIATION IN PROPORTION OF LIGHT TO DARK COLOR IN THE EPICRANIUM.

\begin{tabular}{|c|c|c|c|c|c|c|c|c|c|c|c|c|c|c|c|c|c|c|c|c|c|}
\hline \multirow{2}{*}{ Year. } & \multirow{2}{*}{$\begin{array}{l}\text { Gener- } \\
\text { ation. }\end{array}$} & \multicolumn{20}{|c|}{ Class. } \\
\hline & & I & 2 & 3 & 4 & 5 & 6 & 7 & 8 & 9 & ro & II & 12 & I3 & 14 & 15 & 16 & 17 & 18 & 19 & 20 \\
\hline $\left.\begin{array}{l}1903 \\
1904 \\
1905\end{array}\right\}$ & $\begin{array}{l}2 \ldots \ldots \\
1 \ldots \\
2 \ldots \\
1 \ldots \\
2 \ldots\end{array}$ & $\begin{array}{l}\cdots \\
\cdots \\
\cdots \\
\cdots\end{array}$ & $\begin{array}{l}\cdots \\
\therefore \\
\therefore\end{array}$ & $\begin{array}{l}\ldots \\
\ldots \\
\ldots\end{array}$ & $\begin{array}{l}\because \\
\because \\
\cdots \\
\cdots\end{array}$ & $\begin{array}{r}\text { I } \\
6 \\
2 \\
. . \\
\cdots\end{array}$ & $\begin{array}{r}10 \\
18 \\
17 \\
7 \\
3\end{array}$ & $\begin{array}{r}29 \\
43 \\
21 \\
28 \\
27\end{array}$ & $\begin{array}{l}50 \\
26 \\
49 \\
53 \\
62\end{array}$ & $\begin{array}{r}10 \\
7 \\
\text { II } \\
\text { 12 } \\
8\end{array}$ & $\begin{array}{l}\cdots \\
\cdots \\
\cdots \\
\cdots\end{array}$ & $\begin{array}{l}\cdots \\
\cdots \\
\cdots \\
\cdots\end{array}$ & $\begin{array}{l}\cdots \\
\cdots \\
\cdots \\
\cdots\end{array}$ & $\begin{array}{l}. \\
\because \\
. \\
.\end{array}$ & $\begin{array}{l}\cdots \\
\cdots \\
\cdots \\
\cdots\end{array}$ & $\begin{array}{l}\ldots \\
\cdots \\
\cdots \\
\cdots \\
.\end{array}$ & $\begin{array}{l}\cdots \\
\cdots \\
\cdots \\
\cdots\end{array}$ & $\begin{array}{l}\cdots \\
\cdots \\
\cdots \\
\cdots\end{array}$ & $\begin{array}{l}\cdots \\
\cdots \\
\cdots \\
\cdots\end{array}$ & $\begin{array}{l}\cdots \\
\cdots \\
\cdots \\
\cdots\end{array}$ & $\begin{array}{l}\cdots \\
\cdots \\
\cdots\end{array}$ \\
\hline
\end{tabular}

(B) VARIATION IN PROPORTION OF LIGH'T TO DARK COL,OR IN THE PRONOTUM.

\begin{tabular}{|c|c|c|c|c|c|c|c|c|c|c|c|c|c|c|c|c|c|c|c|c|c|}
\hline $\begin{array}{l}1903 \ldots \\
1904\{ \\
1905\{\end{array}$ & $\begin{array}{l}\text { I. } \\
\text { I. } \\
2 . \\
\text { I.. } \\
2 .\end{array}$ & $\begin{array}{l}\cdots \\
\cdots \\
\cdots \\
\cdots\end{array}$ & $\begin{array}{l}\cdots \\
\cdots \\
\cdots \\
\cdots\end{array}$ & $\begin{array}{l}\cdots \\
\cdots \\
\cdots \\
\cdots\end{array}$ & $\begin{array}{l}\cdots \\
\cdots \\
\cdots \\
\cdots\end{array}$ & $\begin{array}{l}\cdots \\
\cdots \\
\cdots \\
\cdots\end{array}$ & $\begin{array}{l}\cdots \\
\cdots \\
\cdots \\
\cdots\end{array}$ & $\begin{array}{l}\cdots \\
\cdots \\
\cdots \\
\cdots\end{array}$ & $\begin{array}{l}\cdots \\
\cdots \\
\cdots\end{array}$ & $\begin{array}{l}\cdots \\
\cdots \\
\cdots \\
\cdots\end{array}$ & $\begin{array}{c}\because \\
\mathrm{I} \\
\cdots \\
\cdots\end{array}$ & $\begin{array}{r}3 \\
2 \\
\ldots \\
\therefore \\
.\end{array}$ & \begin{tabular}{l|}
8 \\
7 \\
3 \\
7 \\
2
\end{tabular} & $\begin{array}{r}\text { I0 } \\
\text { II } \\
\text { I4 } \\
\text { I3 } \\
5\end{array}$ & $\begin{array}{r}26 \\
30 \\
28 \\
39 \\
28\end{array}$ & $\begin{array}{l}\mathbf{4 1} \\
\mathbf{3 8} \\
\mathbf{4 9} \\
36 \\
\mathbf{5 1}\end{array}$ & $\begin{array}{r}\mathrm{I} 2 \\
\mathrm{II} \\
6 \\
5 \\
\mathrm{I} 4\end{array}$ & $\begin{array}{l}. . \\
. \\
. \\
. .\end{array}$ & $\begin{array}{l}\cdots \\
\cdots \\
\cdots \\
\cdots\end{array}$ & $\begin{array}{l}\cdots \\
\cdots\end{array}$ & \\
\hline
\end{tabular}


TABLE 37-Continued.

(C) VARIATION IN PROPORTION OF LIGHT TO DARK COLOR IN THE ELYTRA.

\begin{tabular}{|c|c|c|c|c|c|c|c|c|c|c|c|c|c|c|c|c|c|c|c|c|c|}
\hline \multirow{2}{*}{ Year. } & \multirow{2}{*}{$\begin{array}{l}\text { Gener- } \\
\text { ation. }\end{array}$} & \multicolumn{20}{|c|}{ Class. } \\
\hline & & I & 2 & 3 & 4 & 5 & 6 & 7 & 8 & 9 & I0 & II & I2 & 13 & I4 & 15 & 16 & I7 & 18 & I9 & 20 \\
\hline $\begin{array}{l}1903 \\
\text { I904 } \\
\text { I905 }\end{array}$ & $\begin{array}{l}2 \ldots \\
1 \ldots \\
2 \ldots \\
1 \ldots \\
2 \ldots\end{array}$ & $\begin{array}{l}\cdots \\
\cdots \\
\cdots \\
\cdots\end{array}$ & $\begin{array}{l}\cdots \\
\cdots \\
\cdots \\
\cdots\end{array}$ & $\begin{array}{l}\cdots \\
\ldots \\
\cdots \\
\cdots\end{array}$ & $\begin{array}{l}\cdots \\
\cdots \\
\cdots \\
\cdots\end{array}$ & $\begin{array}{l}\cdots \\
\ldots \\
\cdots \\
\cdots\end{array}$ & $\begin{array}{l}\cdots \\
\cdots \\
\cdots \\
\cdots\end{array}$ & $\begin{array}{c}6 \\
\ldots \\
\ldots \\
. \\
.\end{array}$ & $\begin{array}{c}12 \\
\cdots \\
1 \\
2 \\
\cdots\end{array}$ & $\begin{array}{r}2 I \\
5 \\
4 \\
4 \\
4\end{array}$ & $\begin{array}{l}45 \\
23 \\
28 \\
32 \\
36\end{array}$ & $\begin{array}{l}12 \\
55 \\
50 \\
40 \\
39\end{array}$ & $\begin{array}{r}3 \\
14 \\
15 \\
21 \\
20\end{array}$ & \begin{tabular}{l|}
1 \\
3 \\
2 \\
I \\
1
\end{tabular} & $\begin{array}{l}\cdots \\
\ldots \\
\ldots \\
\ldots\end{array}$ & $\begin{array}{l}\cdots \\
\ldots \\
\cdots \\
\cdots\end{array}$ & $\begin{array}{l}\cdots \\
\cdots \\
\cdots \\
\cdots\end{array}$ & $\begin{array}{l}\cdots \\
\cdots \\
\cdots \\
\cdots\end{array}$ & $\begin{array}{l}\ddot{ } \\
\cdots \\
\cdots \\
\cdots\end{array}$ & $\begin{array}{l}\cdots \\
\cdots \\
\cdots \\
\ldots\end{array}$ & $\begin{array}{l}\cdots \\
\cdots \\
\cdots \\
\cdots\end{array}$ \\
\hline
\end{tabular}

(D) VARIATION IN PROPORTION OF LIGHT TO DARK COLOR IN THE VENTRAL, ABDOMINAL SEGMENTS.

\begin{tabular}{|c|c|c|c|c|c|c|c|c|c|c|c|c|c|c|c|c|c|c|c|c|c|}
\hline $\begin{array}{l}1903 \ldots \\
1904\{ \\
1905\{\end{array}$ & $\begin{array}{l}2 \ldots \\
I \ldots \\
2 \ldots \\
1 \ldots \\
2 \ldots\end{array}$ & $\begin{array}{c}\cdots \\
\cdots \\
\cdots \\
\cdots\end{array}$ & $\begin{array}{l}\cdots \\
\cdots \\
\cdots \\
\cdots\end{array}$ & $\begin{array}{l}\cdots \\
\cdots \\
\cdots \\
\cdots\end{array}$ & $\begin{array}{l}\cdots \\
\therefore \\
\cdots \\
\cdots\end{array}$ & $\begin{array}{l}\cdots \\
\cdots \\
\cdots \\
\cdots\end{array}$ & $\begin{array}{l}\cdots \\
\cdots \\
\cdots \\
\cdots\end{array}$ & $\begin{array}{l}\cdots \\
\cdots \\
\cdots \\
\cdots\end{array}$ & $\begin{array}{l}\cdots \\
\cdots \\
\cdots \\
\cdots\end{array}$ & $\begin{array}{l}\cdots \\
\cdots \\
\cdots \\
\cdots\end{array}$ & $\begin{array}{c}\cdots \\
\cdots \\
\cdots \\
\cdots\end{array}$ & $\begin{array}{l}\cdots \\
\cdots \\
\cdots \\
\cdots\end{array}$ & \begin{tabular}{l|}
$\cdots$ \\
$\cdots$ \\
$\cdots$ \\
$\cdots$
\end{tabular} & $\begin{array}{l}\cdots \\
\ldots \\
\ldots \\
\ldots\end{array}$ & $\begin{array}{l}\cdots \\
\cdots \\
\cdots \\
\ldots \\
\ldots\end{array}$ & $\begin{array}{l}\cdots \\
\cdots \\
\cdots \\
\cdots\end{array}$ & $\begin{array}{c}\cdots \\
\cdots \\
\cdots \\
\cdots\end{array}$ & $\begin{array}{c}\cdots \\
\cdots \\
\mathrm{I} \\
\cdots\end{array}$ & $\begin{array}{c}\cdots \\
I \\
I \\
I\end{array}$ & \begin{tabular}{l|}
$\cdots$ \\
$\mathrm{I}$ \\
5 \\
$\mathrm{I}$ \\
$\mathrm{I}$
\end{tabular} & \begin{tabular}{r|}
100 \\
98 \\
93 \\
99 \\
98
\end{tabular} \\
\hline
\end{tabular}

TABLE 38.-Place variation in the proportion of light to dark color in the elytra of L. dilecta at Puebla, Puebla, Mexico.

\begin{tabular}{|c|c|c|c|c|c|}
\hline \multirow{2}{*}{ Year. } & \multirow{2}{*}{$\begin{array}{l}\text { Gener- } \\
\text { ation. }\end{array}$} & \multicolumn{4}{|c|}{ Class. } \\
\hline & & 6 & 7 & 8 & 9 \\
\hline 1903 & $2 \ldots$ & I & 7 & 84 & 8 \\
\hline I ĢO4 & $2 \ldots$ & 6 & II & 72 & II \\
\hline
\end{tabular}

In some of the species of the genus, as, for example, in L. signaticollis, there is relatively little place variation. In the individuals of this species which were obtained at Cuernavaca in the years 1903, 1904, and 1905, almost no variation is found from year to year in the color proportion of the epicranium and pronotum, and no change of mode. (See table 36.) For L. undecimlineata, found at Orizaba, Mexico, in the years 1903, I904, and 1905, ${ }^{1}$ there appears a low place variation, with no modal change of the parts or of the entire species. (See table 37.) In L. dilecta, found at Puebla in the years 1903, I904, and 1905, there is no place variation in the color of the pronotum, nor in size, but considerable is found in the elytra, with slight modal fluctuations. (See table 38.)

Enough data has been presented to show conclusively the existence of place variation in this genus of beetles, and also that some species are more variable in this respect than others. It is perfectly obvious, therefore, that in any

\footnotetext{
${ }^{1}$ The records for 1906 at Orizaba, Mexico, show no change in the place variation of L. undecimlineata.
} 
study of variation, whether individual or geographical, or for whatever purpose, but especially in evolution studies, one may be easily led into serious errors by the gathering of material here and there, and at one time only.

We must first discover whether this phenomenon exists in the form chosen for study, by observations covering several generations, and if it is found its limits must be determined as near as possible. This variation may be expressed by any of the variation constants, or by oscillations of the empirical mode expressed in deviations in classes from the empirical race mode, i. e., the empirical mode of the species.

The causes of place variation in any species are the fluctuations from time to time of the individual factors in its environmental complex. These are moisture, temperature, and food commonly, and other factors less frequently. It is possible in many cases to determine rather exactly the cause of a given place variation, but the determination is not of any great value. Thus from the data given it is possible to show that excessive variations were found during this or that deviation from the normal.

As far as I am able to determine from observations and experiment, place variations result in no permanent modifications, nor do the changes seem to be inherited. They are produced in these beetles during the larval and pupal periods, are somatogenic, and purely fluctuating. Place variation results frequently, as can be seen in the data given, in the production of prophetic and historic skewness; indeed, in the material which I have studied I believe that most of the cases of skewness are due to this cause and do not have the meaning that might be attributed to them.

This place variation must necessarily be a troublesome factor in the study by biometric methods of evolution, geographical variation, or selection. In my own work it has been the rock upon which many cherished schemes have been wrecked, and I suspect it has not yet completed its destructive work. If one would study any of the broader problems of evolution by biometric methods he must first of all determine whether in the material chosen for study this phenomenon exists, and if it is found, too great care or too long a time can not be spent in the elimination of this factor. At present I know of but one method of doing this-that is, by collecting data and material over a sufficiently long period to determine the range of this form of variability. Unhappily this demands time, patience, and often funds which the investigator will not or can not afford. The failure to take into consideration this place variation vitiates the validity of a large part of the biometric work that has been done, and there is no reason to think that it will be otherwise in the future. The consideration of this phenomenon will in a very large percentage of cases make biometric work and the statistical study of variation and evolution efforts of much longer duration than hitherto, but the demonstration of the existence of place variation in no wise vitiates the results which may be obtained by biometric methods when this phenomenon is given due consider- 
ation. We must use care and discretion, for biometric expressions are only a little more precise, only a little less liable to error, than qualitative expressions of biological facts.

Shull (I904) well remarks: "To some these results may seem to preclude the possibility of deriving anything of further value from quantitative studies of variation, while to others many new problems of great interest and importance will be suggested."

As yet we know very little of the laws which govern this phenomenon, or, indeed, of the part which it may play in evolution. In my own studies, data have been gathered which point to the importance of this phenomenon, and may indicate some of the laws by which it is governed.

The data in the foregoing tables show conclusively that place variation affects every part of the animal, and that not all species are alike in their variability. For example, decemlincata and multitceniata are highly variable in this respect, while signaticollis, undecimlineata, and dilecta are among the least variable of all the species. If we compare the place variability of these species with the individual variation of the entire population it is at once apparent that the species with a high individual variability also present a high place variability. Moreover, the highly variable species decemlineata and multitceniata are also widely distributed, while those of low variability are more restricted in their habitat, as signaticollis and dilecta. Hence it follows that wide-ranging species, which are more variable than those of restricted range, are also more variable in one place than are those of narrower distribution. This wide distribution, high individual, and high place variation all indicate in the species a high degree of sensibility to stimuli, and an adaptability and lack of conservative tendencies in the population.

This difference between species we may examine to advantage in the specimens of multitcniata obtained at Guadalupe, Federal District, Mexico, and those of signaticollis from Cuernavaca, Mexico. One lies on the east of the Sierra de las Cruces, the other on the west. One lives in a habitat where the yearly rainfall is from 16 to 20 inches, the other where it is from 50 to 60 inches. In the first generation of multitcniata in 1903 the polygon of place condition was fairly normal, while that of the second generation was strongly skewed prophetically. During the growth of the first generation conditions were average; during that of the second the rainfall was far in excess of the average. We may attribute this place variation to the increased rainfall, although it is possible that it was only the indirect cause. During this same season signaticollis, although subjected to the same variation in precipitation, showed no increased place variation. In the following year (I904), again, under average conditions, the polygon of the first generation in multitcniata showed a historic skewness and that of the second a normal condition, while signaticollis remained invariable. Of the two species one is immensely more susceptible to changes in environment, undergoing modification very readily. 
In the section on variation I have shown that these two species, decemlineata and multitceniata, are the parents of many extreme variates (mutants). In a species which is wide-ranging and highly variable, both individually and as to place, which is highly susceptible to environmental change and shows strong place variation, is there any relation of this phenomenon to the production of sports or mutants? and, if so, what? As far as my evidence goes, it is certain that in the second generation of 1903 , at Guadalupe, the per cent of the form melanothorax was 2.4, or more than ten times the normal under average conditions at that place. Now, this was not accidental, for in the same year and in a corresponding generation the per cent was 3.I at Puebla, which is more than thirty times the normal proportion of this variation at that place. The condition in the environment produced a wide place variation at the time and a larger percentage than normal of extreme variations; whereas in succeeding generations the place variation was obliterated and the normal per cent of melanothorax appeared. These observations would point to the conclusion that the change in the population for a given generation due to place variation gave opportunity in the deviation of the entire population from the normal, for a larger percentage to appear as extreme variations. From observations in nature it is difficult to tie results to special causes, to be sure that what we see happen is the result of this or that cause. Likewise in this case it looks as though there were an important and fundamental relation between this place variation and the production of numerous sports or extreme variations in multiteniata. In 1904 I observed that at Tierra Blanca the unusual condition of excessive precipitation produced angustovittata from undecimlineata in abnormal proportion, and the same has been found in decemlineata. De Vries found that in some years his Oenothera lamarckiana mutants were more abundant than in others. Is it not possible that had he investigated he would have found here also this same relation? If this relation between place variation and the abundant production of extreme variations in plastic species be generally true, and it certainly is for this genus of beetles, are we not a step nearer to understanding better the nature of mutants and the manner in which they are produced? Is it not possible also that here too we have a clue as to how we shall proceed in order to produce experimentally these variations?

Place variation must, I believe, be regarded as a phenomenon of importance, not only in its possibilities for producing false appearances, but also because of the relation which it seems to bear to the appearance of extreme variations or mutants. Whether or not it is of any moment in evolution by slow changes we are not yet in a position to determine, but our evidence would seem to indicate that it is not, as its flucuations are about equal on either side of the average. Long-continued observation of this phenomenon would be highly important, as it would perhaps go a long way towards settling some disputed points regarding the method of evolution in animals. 
The following laws have been found to hold concerning place variation, as far as the present investigation goes:

(I) Place variation is a universal phenomenon, but it varies in its extent, being greatest in species of wide distribution and high individual variability and least in species of restricted habitat and low variability.

(2) Place variation is productive of prophetic and historic skewness in the polygone of distribution. (Unless this factor be accounted for in skew polygons we may safely attribute skewness to this cause.)

(3) The extent of place variation shown by a species is a good index of its susceptibility to external stimuli.

(4) In place variation, whenever there occurs an extreme oscillation of the population there is an accompanying production of an unusually large percentage of extreme variations or mutants.

\section{GEOGRAPHICAL VARIATION.}

Variation in general color, or a tendency toward melanism or albinism, is a common and long-recognized phenomenon, and one exhibited by almost all wide-ranging genera. This variation has been attributed to changes in environmental factors, such as temperature and moisture, to latitude or longitude, to altitude, and more rarely to topography and other natural conditions. In Leptinotarsa abundant variation in the general hue is found from place to place, which may be attributed to moisture, temperature, food, sunshine, soil, and other natural causes. There at least exists a striking correspondence between the variation of these beetles and the changes in their environment.

In the study of the geographical variation of this genus the statements of the conditions found in different places have in every case been based upon a number of generations taken from one locality. In this way the error which might otherwise be produced by place variation is, I believe, to a considerable extent eliminated.

The data of geographical variation as it has been worked out is most easily presented in tables, in which 20 equals total melanism and o total albinism.

TABLE 39-Geographical variation in the general color of Leptinotarsa.

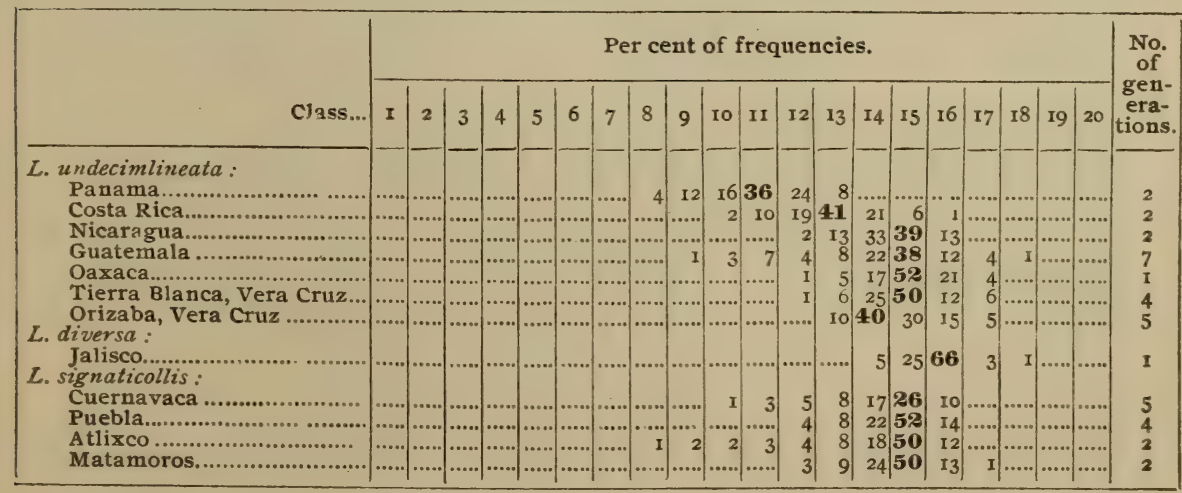


TABL,F: 39.-Geographical variation in the general color of Lebtinotarsa-Continued.

\begin{tabular}{|c|c|c|c|c|c|c|c|c|c|c|c|c|c|c|c|c|c|c|}
\hline & & & & & & & & er ce & ent & of $f$ & freq & ie: & cic & & & & & \\
\hline sS.... & I & 2 & 3 & 4 & 5 & 6 & 7 & 8 & 9 & 10 & II & 12 & 13 & 14 & 4 IS & & 16 & 17 \\
\hline L. multitaniata: & & & & & & & & & & & & & & & & & & \\
\hline $\begin{array}{l}\text { Guadalupe ..... } \\
\text { Tacubaya ...... }\end{array}$ & & & $\cdots$ & & & & & I & 3 & & & & $2 I$ & 12 & & & & 2 \\
\hline San Angel........ & & & & & & $|\cdots \cdot|$ & $\cdots$ & $\begin{array}{l}1 \\
5\end{array}$ & $\begin{array}{r}5 \\
10\end{array}$ & $\left|\begin{array}{r}14 \\
26\end{array}\right|$ & {$\left[\begin{array}{r}30 \\
20\end{array} \mid\right.$} & $\begin{array}{l}19 \\
14\end{array}$ & $\begin{array}{l}14 \\
10\end{array}-1$ & $\frac{9}{8}$ & 8 & $\begin{array}{l}6 \\
5\end{array}$ & \begin{tabular}{l|l}
2 & \\
$\mathrm{I}$ &
\end{tabular} & $\cdots$. \\
\hline Tlalnepantla. & & & & & & & & $\frac{5}{7}$ & II & 255 & 24 & $\begin{array}{l}14 \\
17\end{array}$ & 12 & 4 & 4 & I. & .... & \\
\hline Puebla............ & .... & ..... & ..... & & & & & & $\mathrm{I}$ & 5 & & & 20 & 13 & & 9 & 4 & 2 \\
\hline Matamoros... & & & & & & & & i & 6 & $\mathrm{I} \tilde{\delta}$ & 25 & $2 \%$ & 15 & 9 & b. & 4 . & 4 & \\
\hline Atlixco....... & & & & & & & & 2 & 5 & 20 & $\mathbf{2 4}$ & 26 & 17 & 8 & 8 & $\begin{array}{l}4 \\
4\end{array} 3^{\circ}$ & $\ddot{\mathbf{I}}$ & \\
\hline Toluca.................. & ..... & ..... & & & & & & & & 5 & 15 & & & II & & 9 & 7 & \\
\hline L. oblongata : & & & & & & & & & & & & & & & & & & \\
\hline Oaxaca.... & & & & & & & & & 1 & 3 & 5 & I\& & 10 & I9 & & IO & & \\
\hline Puel & ..... & & & & & & & & 1 & I & 9 & $2 c$ & 35 & 21 & & II & 2 & \\
\hline Matamoros... & ..... & ..... & ..... & ..... & ...... & & & ...... & I & 4 & II & & 37 & 20 & & 9 & & .... \\
\hline Cuernavaca & …. & & & & $\ldots \ldots$ & & & & ... & $\begin{array}{r}4 \\
2\end{array}$ & \begin{tabular}{|c|} 
\\
10
\end{tabular} & 23 & 40 & 21 & & 4 . & & \\
\hline L. rubicunda: & & & & & & & & & & 2 & 10 & 23 & 120 & & & & & \\
\hline Toluca ..... & & & & & & & & $\mathrm{I}$ & 2 & 7 & 18 & 45 & 20 & 6 & & I & & \\
\hline L. melanothorax & & & ... & $\ldots$ & ..... & & & & & & & & & & & & & \\
\hline L. intermedia: & & & & & & & & & & & & & & & & & & \\
\hline Jalisco...... & & & & & I & 2 & & 6 & 19 & 34 & 23 & & & & & & & \\
\hline San Luis Poto & .... & ..... & ...... & ..... & 2 & 6 & 24 & 38 & $2 \mathrm{I}$ & 8 & I & , & & & & & & \\
\hline L. decemlineata: & & & & & & & & & & & & & & & & & & \\
\hline A rizona .......... & & I & & 19 & 48 & 21 & 5 & 2 & & & & & & & & & & \\
\hline Nen & ...... & 3 & Io & 49 & I7 & II & 6 & 2 & $\bar{I}$ & $\mathrm{I}$ & $\cdots$ & ...... & $\cdots$ & ..... & & & & \\
\hline Western Texas ..... & ..... & ..... & $\mathrm{I}$ & 5 & 19 & 42 & $2 \mathrm{I}$ & 8 & 3 & 1 & {$[\ldots .$.} & ..... & ....... & .......... & & & $\ldots$ & $\ldots$ \\
\hline Easteru Te & ….. & ..... & ...... & ...... & I & 6 & I9 & 31 & 20 & II & {$\left[\begin{array}{c}30 \\
9\end{array}\right]$} & 2 & $\mathrm{I}$ & {$[\ldots . .$.} & & & & \\
\hline Loui & $\ldots . .$. & ...... & ...... & ...... & 2 & 9 & 18 & 28 & 22 & I4 & 3 & 2 & $I$ & I & I) & & $\ldots$ & ...... \\
\hline Florida....... & ..... & ...... & ..... & ..... & ..... & I] & 6 & ro & 15 & 27' & 20 & II & 6 & 5 & $4 . .$. & . & .... & ….. \\
\hline Georg & ...... & ...... & ...... & $\ldots . .$. & ...... & ...... & 2 & 5 & 14 & 27 & 34 & 14 & 3 & 3) 1 & i.. & ... & $\ldots$ & $\ldots \ldots$ \\
\hline Virgit & $\ldots \ldots$ & ..... & ..... & ....... & ..... & 2 & II & & & $2 \mathrm{I}$ & 12 & 4 & & &.. & $\ldots$ & & ..... \\
\hline I.org Islan & 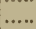 & ..... & ...... & ...... & ...... & 4 & 7 & II & 31 & 18 & $\mathrm{I}_{4}$ & 10 & 3 & 32 & 2 & ... & $\ldots$ & $\ldots .$. \\
\hline Eastern Massachuse & ...... & ...... & ...... & ...... & I & 2 & 5 & 9 & I7 & 30 & 15 & II & 7 & 2 & & I. . & ...... & ..... \\
\hline Southern $\mathrm{I}$ & & & ...... & I & 2 & 4 & $I_{3}$ & Io & 28 & 20 & II & 2 & & & & ... . & 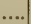 & ..... \\
\hline Nova Scoti & .... & ..... & $\mathrm{I}$ & 3 & 5 & 9 & 15 & 34 & 21 & 9 & 2 & I & ...... & ... & $\cdots$ & & ..... & ..... \\
\hline Ontario and western & & & & & & & & & & & & & & & & & & \\
\hline York ...... & & & & & & 2 & 5 & II & I4 & 29 & I8 & Io & & & & I & & \\
\hline North & $\ldots .$. & …. & $\cdots$ & ..... & ...... & 2 & 6 & $I_{4}$ & 30 & 19 & 15 & 8 & 5 & I & & & & \\
\hline Norther & .... & ...... & ..... & ..... & $\ldots .$. & I & 6 & 15 & 31 & 18 & 15 & 7 & 6 & I & & & ... & ...... \\
\hline Wisconsin... & ...... & ..... & ...... & $\mid \ldots .$. & I & I0 & 18 & 28 & 22 & $I_{3}$ & 4 & 2 & 2 & 2...... & $\ldots$ & $\cdots$ & ... & ..... \\
\hline Dakota... & ..... & ..... & ...... & ....... & 2 & iI & 24 & 27 & 17 & II & 5 & 2 & I & & & & ..... & ..... \\
\hline Colo & ...... & ...... & I & 2 & 3 & II & 23 & 26 & 20 & 9 & 4 & I & ......... & ...... & $\ldots$ & & & \\
\hline Kansas... & …. & 3 & 6 & I4 & 20 & 24 & $2 \mathrm{I}$ & 8 & 3 & 1 & .... & ..... & $\ldots$. & & $\ldots$ & & & $\ldots$ \\
\hline Southern I & & & ..... & ..... & ...... & ..... & 2 & 5 & I4 & 30 & 20 & 14 & Io & 5 & $5 . .$. & ... & & \\
\hline Sout & $\ldots .$. & ...... & & ...... & I & 5 & 6 & 10 & 31 & I9 & $\mathrm{r} 5$ & 7 & 5 & I & $\ldots$ & .. & & \\
\hline Ken & $\ldots$. & ...... & ..... & ..... & I & I & 2 & I7 & 30 & 20 & I4 & 7 & 6 & 5 I & & $\mathrm{I}$ & $\ldots$ & ... \\
\hline Western Pennsylvania........ & $\cdots . .$. & $\cdots . .$. & $\ldots .$. & $\mathrm{I}$ & 2 & 8 & 20 & 28 & 20 & \begin{tabular}{|c|}
15 \\
15
\end{tabular} & $\begin{array}{r}-4 \\
2\end{array}$ & & I & & I... & ... & $\cdots$ & $\ldots$ \\
\hline L. juncta. & & & & & & & & & & & & & & & & & & \\
\hline $\mathrm{Vir}$ & & I & 3 & 20 & 60 & 15 & & & & & & & & & & & & \\
\hline $\mathrm{Gec}$ & $\ldots . .$. & ..... & ...... & 2 & 3 & 15 & 58 & 18 & 4 & & & ..... & & ...... & ... & & . & $|\cdots \cdot|$ \\
\hline Flo & ..... & ..... & ..... & I & 5 & 23 & 52 & I7 & 2 & & |..... & ..... &... & $\ldots$. &... & .. & & $\ldots . .$. \\
\hline Alab & ...... & ..... & I & 3 & & 60 & $\mathrm{I}_{4}$ & 3 & ...... & & & & & & & & & ..... \\
\hline Lo & ..... & I & $\mathrm{x}$ & 3 & 24 & 58 & I2 & I & & ... & ..... & ...... & ...... & ..... & $\ldots$ & ... & ... & ...... \\
\hline Easter! & $\cdots .$. & 2 & 4 & 18 & 62 & Io & 3 & $\mathrm{I}$ & & & & & & & $\ldots$ & & & ...... \\
\hline L. defecta & & & & & & & & & & & & & & & & & & \\
\hline Mid & 2 & 9 & 20 & 64 & & I & & & & & & & & & & & & \\
\hline Indi & I & 8 & 18 & 21 & 51 & I & & & & & & ... & & & ... & & & ... \\
\hline Southeastern Colorado & 2 & 9 & 22 & 60 & 5 & 2 & & & ... & & ..... & & & & ... & & & $\ldots$ \\
\hline L. dilecta & & & & & & & & & & & & & & & & & & \\
\hline & & I & $\mathbf{I}$ & II & 84 & & & & & & & & & & & & & \\
\hline At & ..... & $\ldots$ & $\mathrm{x}$ & 12 & 85 & & & & & & $\cdots$ & $\ldots$ & & & .. & . & & $\ldots$ \\
\hline Mate & ..... & I & 4 & Io & 80 & 5 & & & & & ...... & ... &... &..... &... & .. & & \\
\hline Cuer & & $\ldots$ & 2 & II & 83 & 4 & & & & & & & & - & & & & ...... \\
\hline calceata & & & 4 & 22 & 81 & 3 & & & & ... & ... & $\ldots$ & & ..... & ... & & ... & ..... \\
\hline lineolat & & & & & & & & & & & & & & & & & & \\
\hline $\mathrm{Ch}$ & 6 & II & $I_{3}$ & 28 & 40 & 2 & & & & & & & & & & & & \\
\hline New Me & 2 & 10 & I4 & 32 & 41 & I & & & & & $\ldots$ & & & ..... & & & & \\
\hline Arizo & 2 & 6 & 19 & $3 \mathrm{I}$ & 36 & 6 & & & & & 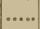 & 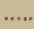 & & & $\ldots$ & & .. & $\ldots$ \\
\hline L. haldemani: & & & & & & & & & & & & & & & & & & \\
\hline Puebla & & ..... & 2 & in & 66 & 22 & & & & & & & & & & & & \\
\hline Atli & ...... & .. & I & I0 & 80 & 19 & & & & & & ...... & & & & & & \\
\hline M & & ....... & 2 & 9 & 28 & 61 & 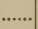 & .... & ..... & ..... & ..... & me & & & 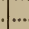 & & & ...... \\
\hline $\mathrm{Cu}$ & $\cdots$ & ....... & ....... & & 84. & 25 & & & & &.. & $\ldots$ & & & .. & & & $\ldots$ \\
\hline L. violescens & & & & & & & & & & & & & & & & & & \\
\hline Orizaba. & & & & & 1 & 9) & 90 & & & & ... & & & & & & & \\
\hline $\mathrm{Co}$ & & ..... & & ....... & 2 & 13 & 85 & & $\ldots$ & & .... & .... & & & & & & \\
\hline L. dahlbomi: & & & & & & & & & & & & & & & & & & \\
\hline Puebla & & & & I0 & 88 & 2 & &. & $\ldots$ & & & & & & & & & \\
\hline exas. & & .... & ...... & 16 & & $\mathrm{I}$ & & & .... & & & & & & .. & & & \\
\hline libat & & & & & & & & & & & & & & & & & & \\
\hline & & & & & & & & & & & & & & & & & & \\
\hline
\end{tabular}


TABLE 40.-Geographical variation in the pronotum of Leptinotarsa.

\begin{tabular}{|c|c|c|c|c|c|c|c|c|c|c|c|c|c|c|c|c|c|c|c|c|c|c|}
\hline & & & & & & & & Per & e & 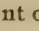 & of $f$ & req1 & uen & & & & & & & & & No. \\
\hline Class... & I & 2 & 3 & 4 & 5 & 6 & 7 & 7 & 8 & 9 & 10 & II & 12 & 13 & 14 & I5 & 16 & 17 & 18 & 19 & 20 & $\begin{array}{l}\text { era- } \\
\text { tions. }\end{array}$ \\
\hline $\begin{array}{r}\text { L. undecimiineata : } \\
\text { Panama............. }\end{array}$ & & & & & & & & & & & & & 20 & & & & & & & & & \\
\hline Costa Rica ............. & & & & & & & & 1 & $\begin{array}{r}3 \\
\ldots . .\end{array}$ & $\begin{array}{r}11 \\
\mathrm{I}\end{array}$ & 2 & 8 & 214 & 40 & 20 & & & & & & & $\begin{array}{l}2 \\
2\end{array}$ \\
\hline $\mathrm{Nic}$ & & & & & & & & & ..... & 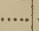 & $\ldots$ & 2 & 3 & Io & 34 & 40 & 11 . & ..... & .... & & ..... & 2 \\
\hline Guater & & $\cdots \cdot$ & $\cdots$. & & $\cdots$ & $\ldots$ & & & 1 & I) & 2 & 4 & 5 & 9 & 22 & 38 & I3 & 5 & $\mathrm{r}$ & & & 7 \\
\hline $\begin{array}{l}\text { Oaxaca............ Vera } \\
\text { Tierra Blanca, }\end{array}$ & & & & & & & & & & & & I] & 2 & 4 & I6 & 5\% & 20 & 5 & ...... & & & I \\
\hline $\begin{array}{l}\text { Tierra Blanca, Vera } \\
\text { Orizaba, Vera Cruz ... }\end{array}$ & & & & & & & & & & & & & 2 & 5 & 26 & 45 & I 7 & 5 & 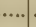 & & ... & 4 \\
\hline & & & & & & & & & & & & … & I & & 40 & 29 & ${ }^{17}$ & 4 & & & & 5 \\
\hline $\begin{array}{l}\text { L. diversa: } \\
\text { Jalisco ....... }\end{array}$ & & & & & & & & & & & & & & & 5 & 2,5 & 80 & & & & & $\mathrm{I}$ \\
\hline L. signaticollis : & & & & & & & & & & & & & & & & & & & & & & \\
\hline $\begin{array}{l}\text { Cuernav } \\
\text { Puebla.. }\end{array}$ & & & & & & & & & & & 2 & $\begin{array}{l}2 \\
1\end{array}$ & 5 & 9 & & 56 & & & & & & 5 \\
\hline Atlixco... & & &. & & & & & .. & II & 2 & 2 & 4 & $\begin{array}{l}4 \\
3\end{array}$ & II & $\begin{array}{l}23 \\
17\end{array}$ & 49 & II & & ..... & & & $\begin{array}{l}4 \\
2\end{array}$ \\
\hline Mata & & & & & & & & & & & & I & 2 & 13 & 20 & 50 & 14. & & ..... & $\ldots .$. & ..... & 2 \\
\hline L. multita & & & & & & & & & & & & & & & & & & & & & & \\
\hline Guad & & & & & & & & $\mathrm{I}$ & 2 & 2 & & 132 & 26 & 20 & 12 & 7 & 6 & 2 & 2 & I & I] & 6 \\
\hline Tac & & & & & & & & ... & 2 & 5 & I3 & 30 & 18 & 15 & 8 & & 2 & ..... & ..... & & & 5 \\
\hline $\operatorname{San} A$ & & & & & & & & $\mathrm{I}$ & 2 & $\mathrm{I}_{3}$ & 25 & $2 \mathrm{I}$ & I5 & 9 & 7 & 6 & I & ...... & ...... & & & 4 \\
\hline T1 & & .. & ..... & & $\cdots$ & & & 1 & 3 & 14. & 29 & 20 & $\mathrm{r} 5$ & I4] & 5. & & $\ldots$. . & ..... & ..... & ..... & ...... & 3 \\
\hline Puc & & & & & & & & & & ..... & 5 & $\left.15\right|^{2}$ & 32 & Is) & I2 & I0 & 6 & 2 & & & & 5 \\
\hline Mat & & & & & $\cdots$ & & & & .... & 7 & 18 & 28 & 18 & 14 & I0 & 3 & 2 & ..... & & & & 4 \\
\hline Atli & & & & & & & & & $\mathrm{I}$ & 4 & 20 & 24 & $2 \mathrm{I}$ & 17 & 8 & 5 . & & ..... & & & & 2 \\
\hline To & & $\ldots$. & .. & & $\ldots$ & & & & & $\ldots$ & $\mathbf{I}$ & $|19|^{2}$ & 29 & $2 \mathrm{I}$ & $\mathrm{II}$ & 8 & 8 & 3 & .... & $\ldots$ & ..... & 4 \\
\hline L. oblon & & & & & & & & & & & & & & & & & & & & & & \\
\hline $\begin{array}{l}\mathrm{Oa} \\
\mathrm{Pue}\end{array}$ & & & & & & & & & & & $I^{\prime}$ & 5 & $2 \mathrm{I}$ & 41 & 18 & $I_{3}$ & I & & & & & I \\
\hline $\begin{array}{l}\mathrm{PI} \\
\mathrm{M}\end{array}$ & & & & $\cdots$ & $\cdots$ & & *. & $\cdots$ & 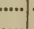 & $\cdots .$. & 2 & 9 & 20 & 35 & 20 & I2 & 2 & $\ldots$ & &... &.... & 4 \\
\hline $\begin{array}{l}\text { Mata } \\
\text { Cuter }\end{array}$ & & & & & & & & & $\cdots \cdot$ & $\cdots .$. & I & II & $2 \mathrm{I}$ & 36 & $2 \mathrm{I}$ & Io. & ... & & & & & 2 \\
\hline $\begin{array}{l}\text { Cuer } \\
\text { L. rubic }\end{array}$ & & & $\cdots$ & & $\cdots$ & & & $\ldots$ & & $\cdots \cdot$ & 3 & 12 & $200^{3}$ & 39 & 21 & 4 & $\mathrm{I}$ & & & .... & $\cdots \cdot$ & 5 \\
\hline L. rubic & & & & & & & & & & 3 & 7 & 18 & 45 & $2 \mathrm{I}$ & 5 & I & & & & & & 4 \\
\hline L. melanothorax .......... & & $\cdots$ & $\cdots$ & ...... & $\cdots$ & $\ldots$ & & $\ldots$ &.. & $\ldots$ & 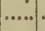 & - & & ..... & 4 & & & & & I & 99 & 5 \\
\hline $\begin{array}{l}\text { L. inter } \\
\text { Jalis }\end{array}$ & & & & & & & & & & & & & & & & & & & & & & \\
\hline is Potosi...... & & & $\cdots \cdot$ & I & & & & & $\begin{array}{r}8 \\
38\end{array}$ & 17 & 35 & 20 & II & 2 & $\mathrm{I}$ & 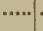 & & & & & & $I$ \\
\hline $\begin{array}{l}\text { San Luis Potosi.. } \\
\text { L. decemlineata: }\end{array}$ & & & & & & & & 24 & & 20 & 9 & 1. & & & & & & & & & & 2 \\
\hline Arizon & & I & & & 45 & 526 & & 9 & I & & & & & & & & & & & & & 4 \\
\hline $\mathrm{Ne}$ & & 4 & & 49 & I 6 & $6 \mathrm{I}$ & & 6 & $\mathbf{I}$ & I & 1 & $\mathbf{I}$. & $\cdots$ & $\cdots$ & $\cdots$ & & & & & & & 5 \\
\hline We & $\cdots \cdot$ & $\ldots$ & 1 & 4 & 4 Is & 9 & & 22 & 9 & 4 & I. & $\ldots . .$. & ..... & $\cdots$ & & 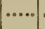 & & & & & & 4 \\
\hline Eas & & $\ldots \ldots$ & $\cdots$ & $\cdots$ & .22 & 2 & 5 & I9 & 31 & 20 & Io & 10 & 3. & $\cdots$ & $\ldots$. & $\ldots$ & .... & & & &.... & 7 \\
\hline Lou & $\cdots \cdots$ & $\cdots$ & $\cdots$ & . 1 & 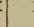 & I I I & & I7 & 30 & 20 & 14 & 5 & 2. & & $\cdots$ & $\ldots$ & & & & & & 3 \\
\hline Flor & $\ldots$ & $\ldots$ & $\ldots$ & $\cdots$ & $\cdots$ & ... & I & 5 & 10 & I6 & 26 & 21 & II & 9 & I & .... & $\cdots$ & & & & & 2 \\
\hline $\mathrm{Ge}$ & $\ldots$ & $\ldots$ & $\ldots$ & $\ldots$ & $\ldots$ & & & 3 & 4 & 14 & 27 & 34 & 14 & 3 & I & {$[\ldots .$.} & & & & & & 5 \\
\hline $\mathbf{V}^{i}$ & & $\ldots$ & $\ldots$ & $\ldots$ & $\ldots$ & ... & 3 & 10 & 20 & 25 & 24 & 16 & $\mathrm{I}$ & I & 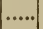 & & & & & & & 4 \\
\hline Lo & & ..... & $\ldots$ & $\cdots$ & $\ldots$ & & 3 & 8 & II & 30 & I9 & 14 & Io & 5 & $\ldots$ & & & & .... & & & 6 \\
\hline Eas & & $\ldots$ & $\ldots$ & $\ldots$ & $\cdots$ & $\ldots$ & & 4 & 9 & $2 \mathrm{I}$ & 30 & 17 & 9 & 7 & 3 & $\cdots$ & & & & & & 16 \\
\hline So1 & & & & $\ldots$ & . & 3 & 4 & I4 & 18 & 27 & $2 \mathrm{I}$ & 12 & i. & $\ldots$ & $\ldots$ & ..... & & & & & & 6 \\
\hline Nov & & $\ldots$. & I & 4 & 4 & 4 & 9 & 15 & 34: & 20 & I0 & 2 & I & .... & $\ldots$. & $\mid . . .$. & .... & .... & .... & .... & ..... & 4 \\
\hline Ontario and western New & & & & & & & & & & & & & & & & & & & & & & \\
\hline $\begin{array}{l}\text { York } \\
\text { North }\end{array}$ & & & & & .. & & I & 6 & 9 & IE & 30 & 18 & 99 & 6 & $4 !$ & & & & & & & 7 \\
\hline $\begin{array}{l}\text { Nor } \\
\text { Nor }\end{array}$ & & ... & $\ldots$ & $\ldots$ & $\ldots$ & $\ldots$ & 2 & $\begin{array}{l}1 \\
0\end{array}$ & & \begin{tabular}{|c|}
$\mathbf{1 5}$ \\
$\mathbf{3 0}$
\end{tabular} & 31 & \begin{tabular}{|l|}
18 \\
\end{tabular} & ro & $\begin{array}{l}8 \\
2\end{array}$ & & & & & & & & $\begin{array}{l}3 \\
8\end{array}$ \\
\hline Wis & & ...... & .... & $\ldots$ & 1 & $\begin{array}{ll}I & \end{array}$ & 3 & $\begin{array}{r}\text { I5 } \\
\text {. }\end{array}$ & 28 & 23 & $\left|\begin{array}{l}20 \\
14\end{array}\right|$ & 15 & $\begin{array}{r}4 \\
2\end{array}$ & $\begin{array}{l}2 \\
1\end{array}$ & a.... & & & & & $\cdots$. & & $\begin{array}{l}8 \\
2\end{array}$ \\
\hline Dal & .... & $\ldots$. & $\ldots$ & 1 & & I $\mathrm{I}$ & & 20 & 27 & $\mid \begin{array}{l}23 \\
17\end{array}$ & II & 4 & 3 & I & .... & $\ldots$. & $\ldots$ & & & & & \\
\hline Colo & & $\ldots$ & $\ldots$ & $\ldots$ & & $3 \mathrm{I}$ & & 24 & 25 & 20 & $\begin{array}{l}1 \\
10\end{array}$ & 5. & ...... & & ...... & {$\left[\begin{array}{l}\cdots \cdots . . . \\
\cdots\end{array}\right.$} & & & & ..... & & 6 \\
\hline & & 2 & 7 & 7.15 & $\begin{array}{l}5 \\
\end{array}$ & $9 \boldsymbol{Z}$ & & 20] & 9 & 2 & $\mathbf{I}$ & I & ...... & $\ldots$ & ..... & {$[\ldots .$.} & .... & $\ldots$ & $\ldots$ & .... & & 4 \\
\hline So & .. & $\ldots$ & $\ldots$ & & 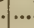 & $\ldots$ & $\ldots$ & 2 & 5 & $\mathrm{I} 4$ & 30 & 20 & 15 & 9 & 4 & I & $\ldots$ & & & .... & & 5 \\
\hline Sou & ..... & $\ldots$ & $\cdots$ & $\cdots$ & & $\mathrm{I}$ & 4 & 6 & & 31 & I9 & 15 & 8 & 6 & & & .... & & & & & 7 \\
\hline Ken & & & & & & $\cdots$ & 2 & & $\mathbf{1 8}$ & 30 & I9 & \begin{tabular}{|l|}
13 \\
\end{tabular} & 8 & 4 & 2 & [..... & & & & & & 2 \\
\hline Western Pennsylvania & & ..... & $\ldots$ & .... & & 2 & 9 & 20 & 29 & 19 & 16 & 2 & 2 & $\mathrm{I}$ & & & ...... & .... & ...... & .... & & 2 \\
\hline L. junct & & & & & & & & & & & & & & & & & & & & & & \\
\hline 8 & & & & 420 & 55 & & & & & & & & & & & & & & & & & 6 \\
\hline $\mathrm{Ge}$ & & ... & 1 & I & & & & 88 & 20 & & & ....... & ....... & & & & & & & & & 5 \\
\hline & & $\ldots . .$. & & $\cdots$ & & 62 & & 61 & 18 & I & $\cdots$ & ....... & ........ & .... & & & & & & & & 3 \\
\hline & & ....... & ... & & 4 I & 961 & & I4 & 2. & ....... & 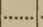 & ....... & ....... & ....... & & $\ldots$ & ....... & & & & & 4 \\
\hline 1, & & .... & 2 & & & & & 12 & 2. & ....... & ....... & ...... & ....... & ...... & & & .... & & ... & & & 4 \\
\hline Texas............ & & 2 & 3 & 3 Is & 96 & $\begin{array}{lll}0 & 1 \\
& 1 & 0\end{array}$ & & 4 & $\mathbf{I}$ & $\cdots \cdot$. & 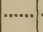 & $\cdots \cdots$ & ...... & $\cdots$ & & & & & & 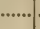 & & 3 \\
\hline $\begin{array}{l}\text { defe } \\
\text { Mi }\end{array}$ & & & & & & & & & & & & & & & & & & & & & & \\
\hline & & II & 17 & 20 & 50 & & & & & ....... & & ....... & 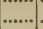 & & & & & & & & & $\begin{array}{l}7 \\
2\end{array}$ \\
\hline orado & 2 & 10 & $2 \pi$ & 60 & & 4 & & & .... & ........ & .... & ....... & $\ldots$. &... & & & & .... & & .... & & 2 \\
\hline L. dile & & & & & & & & & & & & & & & & & & & & & & \\
\hline & & & 2 & & & & & & & & & & & & & & & & & & & 4 \\
\hline & & & 5 & I I & & & & & & $\cdots \cdot \cdot \cdot$ & ...... & .... & ...... & $\cdots$ & & & & & & & & 2 \\
\hline & & ....... & 5 & 5 II & & & & & & $\cdots \cdot \cdot$ & .... & $\cdots \cdot \cdot$ & $\cdots \cdot$ & t & & & & & & ..... & & 2 \\
\hline & & I & 7 & I IC & & & & & & ...... & .... &. & ….. & 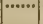 & & & & & & & & 3 \\
\hline $\begin{array}{l}\text { calc } \\
\text { line }\end{array}$ & ... & I & I. & \begin{tabular}{l|l}
422 \\
22
\end{tabular} & 265 & & & & & & & & & & & & & & & & & 2 \\
\hline & & ro & D & $\begin{array}{l}4 \\
4\end{array}$ & & & & & & & & & & & & & & & & & & \\
\hline & .... & II & It & 3 & & & & & $\ldots$. & ....... & ....... & ........ & ........ & ..... & $\ldots$ & & , & ..... & ..... & ...... & ....... & 2 \\
\hline Arizona & I & 7 & 7 I8 & \begin{tabular}{l|l}
8 & 3
\end{tabular} & & & & & & & & & & & & & & & & & & 4 \\
\hline
\end{tabular}


TABLE 4I.-Geographical variation in the epicranium of L. multitaniata, oblongata, intermedia, decemlineata, rubicunda, and melanothorax.

\begin{tabular}{|c|c|c|c|c|c|c|c|c|c|c|c|}
\hline \multirow[b]{2}{*}{ Class... } & \multicolumn{10}{|c|}{ Per cent of frequencies. } & \multirow{2}{*}{$\begin{array}{c}\text { No. } \\
\text { of } \\
\text { gen- } \\
\text { era- } \\
\text { tions. }\end{array}$} \\
\hline & I & 2 & 3 & 4 & 5 & 6 & 7 & 8 & 9 & ro & \\
\hline \multicolumn{12}{|l|}{ L. multitaniata: } \\
\hline Guadalupe.... & & I & 7 & 7 & 8 & 10 & 14 & 20 & 31 & 2 & 6 \\
\hline Tacubaya........................ & ........... & I & 5 & 8 & 9 & 17 & $2 \mathrm{I}$ & 30 & 8 & $\mathbf{I}$ & 5 \\
\hline 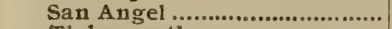 & ........... & ........... & 3 & 8 & $x_{3}$ & 24 & 34 & 12 & 6. & .... & 4 \\
\hline Tlalnepantla ............................. & (.......... & .......... & 2 & 7 & 14 & 27 & $\mathbf{3 5}$ & 14 & $I^{1}$ & & 3 \\
\hline Puebla ...................................... & ........... & ........... & & & 7 & 15 & 18 & 23 & 34 & 3 & 5 \\
\hline 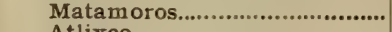 & (.......... & I & I & 5 & II & 18 & 25 & 30 & 8 & $\mathbf{I}$ & 4 \\
\hline 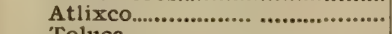 & .......... & I & 5 & II & 14 & 27 & 28 & 12 & 2 & & $\begin{array}{l}4 \\
2\end{array}$ \\
\hline \multirow{2}{*}{\multicolumn{4}{|c|}{ L. oblongata: }} & 4 & 7 & 12 & 23 & 33 & 15 & 6 & 4 \\
\hline & & I & 3 & 14 & 68 & II & 2 & & .......... & & I \\
\hline 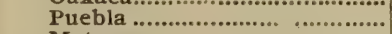 & (n............ & I & 4 & 17 & 60 & 14 & 3 & I & (n........... & & 4 \\
\hline 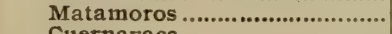 & .......... & 2 & 3 & 12 & 72 & 10 & I & ........... & ........... & & 2 \\
\hline \multirow{2}{*}{\multicolumn{12}{|c|}{ 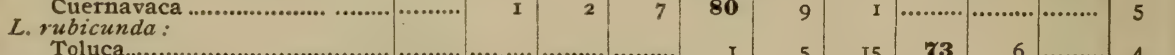 }} \\
\hline & & & & & & & & & & & \\
\hline L. melanothorax. & $\ldots$ & ..... & ( & (n........ & 1 & 5 & 15 & I & $\begin{array}{l}0 \\
1\end{array}$ & 98 & $\begin{array}{l}4 \\
5\end{array}$ \\
\hline \multicolumn{12}{|l|}{ L. intermedia: } \\
\hline Jalisco ......................... & .......... & 5 & 15 & 58 & 17 & 4 & I & .......... & ............ & & I \\
\hline \multirow{2}{*}{\multicolumn{12}{|c|}{ L. decemlineata: }} \\
\hline & & & & & & & & & & & \\
\hline 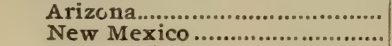 & $\begin{array}{r}7 \\
\text { II }\end{array}$ & $\begin{array}{r}18 \\
69\end{array}$ & $\begin{array}{r}58 \\
12\end{array}$ & $\begin{array}{r}15 \\
6\end{array}$ & $\begin{array}{l}2 \\
2\end{array}$ & ….. & ........... & & ..... & & $\begin{array}{l}4 \\
5\end{array}$ \\
\hline Western Texas ............................ & ........... & $\mathrm{I}_{4}$ & 60 & $2 \mathrm{I}$ & 4 & I. & & & & & $\begin{array}{l}5 \\
4\end{array}$ \\
\hline Eastern Texas............................ & ........... & 2 & $2 \mathrm{I}$ & 48 & $\begin{array}{r}49 \\
19\end{array}$ & 8 & I & I & …........ & ............. & 7 \\
\hline 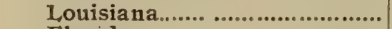 & ............ & I & 14 & 51 & 23 & 9 & 2 & & & & 3 \\
\hline Florida & .......... & ......... & I & 5 & 14 & $2 \mathrm{I}$ & 45 & 12 & I & I & 2 \\
\hline 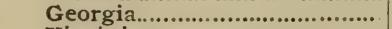 & ............ & ............. & ........... & 2 & 7 & 14 & 18 & 478 & ro & 2 & 5 \\
\hline Virginia ................................ & ........... & ........... & ............ & 3 & 17 & 61 & 13 & 5 & I & & 4 \\
\hline Long Island ............................ & ........... & ........... & I & $x_{3}$ & 59 & 18 & 8 & I & & & 6 \\
\hline Eastern Massachusetts........... & ............. & ........... & ........... & 8 & 58 & 20 & 9 & 5 & ......... & & 16 \\
\hline Southern Maine ......................... & ........... & 2 & 13 & 51 & 24 & 8 & I & I & …....... & ......... & 6 \\
\hline \multirow{2}{*}{\multicolumn{12}{|c|}{ Onta:io and western New }} \\
\hline & & & & & & & & & & & \\
\hline 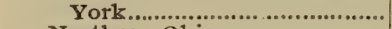 & ..... & I & 13 & 60 & 20 & 5 & I & & & ......... & 7 \\
\hline Northern Ohio........................... & I & 2 & 18 & 61 & 14 & 4 & & & ........... & & 3 \\
\hline Northern Illinois...................... & .......... & 3 & 20 & 48 & 19 & 8 & $\mathrm{I}$ & I & & $\cdots \cdots$ & 8 \\
\hline 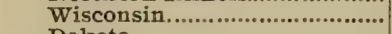 & .......... & 4 & $2 \mathrm{I}$ & 48 & 19 & 7 & 2 & & ........... & (.......... & 2 \\
\hline Dakota............................................... & .......... & I & II & 63 & 14 & 8 & 3 & & ........... & ......... & 3 \\
\hline Colorado & .............. & 2 & & 60 & 19 & 8 & 3 & I & ............ & & 6 \\
\hline 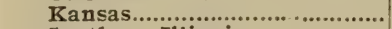 & 4 & I4 & 496 & 27 & 5 & I & & & .............. & ............ & 4 \\
\hline Southern Illinois...................... & ........... & 3 & 13 & 40 & $2 \mathrm{I}$ & 14 & 8 & I & ........... & & 5 \\
\hline 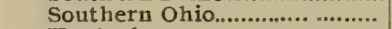 & ............ & 2 & II & 42 & 26 & 10 & 7 & 2 & ............. & ............ & 7 \\
\hline Kentucky....................................... & ........... & I & To & 43 & 22 & I2 & 9 & 2 & I & ........... & 2 \\
\hline Western Pennsylvania.... & ............ & I & I4 & 50 & 20 & 12 & 3 & & & ............. & 2 \\
\hline
\end{tabular}

In the data presented in tables 39 to $4 \mathrm{I}$ certain features of geographical variation are apparent. Some species are more variable than others, and of these more variable species those of wide range are generally most variable and those of limited range least variable. This, however, is not always true. Thus, undecimlineata appears in all of the tables as a wide-ranging species, found from Mexico to Panama, yet it is relatively invariable; whereas dahlbomi is also a wide-ranging species found from Guatemala to Texas and is highly invariable, although it lives in many different environments. On the other hand, multitcniata is highly variable and decemlineata only a little less so, while the species of the dilecta and haldemani groups present. only a moderate amount of variation. 
TABLE 42.-Geographical variation in the ventral surface of Leptinotarsa.

\begin{tabular}{|c|c|c|c|c|c|c|c|c|c|c|c|c|c|c|c|c|c|c|c|c|}
\hline \multirow[b]{2}{*}{ Class.... } & \multicolumn{19}{|c|}{ Per cent of frequencies. } & \multirow{2}{*}{$\begin{array}{c}\text { No. } \\
\text { of } \\
\text { gen- } \\
\text { era- } \\
\text { tions. }\end{array}$} \\
\hline & $\mathbf{I}$ & 2 & \begin{tabular}{l|l}
3 & 4
\end{tabular} & $4 \quad 5$ & 6 & 7 & 8 & 9 & Io & II & 12 & 13 & 14 & 15 & 16 & 17 & 18 & 19 & & \\
\hline multitaniata: & & & & & & & & & & & & & & & & & & & & \\
\hline $\begin{array}{l}\text { Guadalup } \\
\text { Tacubaya }\end{array}$ & & & & & & & & $\ldots$ & $\begin{array}{l}1 \\
3\end{array}$ & $\begin{array}{l}1 \\
8\end{array}$ & & $\begin{array}{r}24 \\
4 \%\end{array}$ & $\begin{array}{r}40 \\
17\end{array}$ & $\begin{array}{r}18 \\
5\end{array}$ & $\begin{array}{l}4 \\
2\end{array}$ & $\begin{array}{l}3 \\
\mathbf{I}\end{array}$. & $\begin{array}{c}\mathrm{I} \\
.\end{array}$ & $\begin{array}{c}1 \\
. .\end{array}$ & .. & $\begin{array}{l}6 \\
5\end{array}$ \\
\hline San Angel & & & & & & & $\cdots$ & i & 3 & 7 & 21 & 43 & $\begin{array}{l}17 \\
18\end{array}$ & 6 & r. & . & $\cdots:$ : & $\cdots$ & $\cdots$ & $\begin{array}{l}5 \\
4\end{array}$ \\
\hline $\mathrm{T}$ & & & & & & & $\mathbf{I}$ & I & 2 & 8 & 20 & 42 & 17 & & I] & I. & 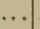 & & & \\
\hline Pue & & & & & & & $\cdots$ & I & & 3 & 7 & 21 & 48 & I4] & 3 & I. & 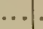 & & & 5 \\
\hline Mat & & & & & & & & & .. & $\mathrm{I}$ & 3 & 30 & 48 & 17 & I. & & ... & ... & $\ldots$ & 4 \\
\hline Atli & .. & & ... & & & & $\cdots$ & & .. & $\mathrm{I}$ & 3 & 26 & 50 & 18 & 2. & ... & & ... & $\ldots$ & 2 \\
\hline Tol & .. & & $\cdots$ & & & & $\cdots$ & & & $\mathbf{I}$ & 7 & 22 & $\mathbf{5 2}$ & I7 & $\mathrm{I}$. & & & $\cdots$ & $\cdots$ & 4 \\
\hline $\begin{array}{l}\text { L. oblongat } \\
\text { Oaxaca }\end{array}$ & & & & & & & I & 2 & & $10 / 4$ & 11 & & & & & I] & & & & \\
\hline $\mathbf{P}$ & & & & & & & I & 2 & 6 & 184 & 28 & $\begin{array}{l}23 \\
22\end{array}$ & $\begin{array}{l}5 \\
6\end{array}$ & $\begin{array}{l}2 \\
2\end{array}$ & $\begin{array}{l}\mathrm{I} \\
\mathrm{I}\end{array}$ &.. & ... & ... & $\cdots$ & $\begin{array}{l}I \\
4\end{array}$ \\
\hline M & & & & & . & $\ldots$ & ... & 7 & & 43 & 23 & 7 & 1 & .. &.. & $\ldots$ & $\ldots$ & .... & $\cdots$ & $\begin{array}{l}4 \\
2\end{array}$ \\
\hline Cuernavac & .. & & .. & & & & I & 4 & 195 & 51 & 22 & 3 & & & $\cdots \cdot$ & & $\cdots$ & $\begin{array}{l}\cdots \\
\cdots\end{array}$ & $\ldots$ & 5 \\
\hline L. rubicunda: & & & & & & & & & & & & a & & & & & & & $\cdots$ & 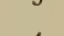 \\
\hline $\begin{array}{l}\text { Tolv } \\
\text { L. mela? }\end{array}$ & & & & & & & & & & . & $\mathbf{I}$ & 2 & & 60 & 20 & 4 & & & & 4 \\
\hline L. inter & .. & & & & & & & & & & $\therefore$ & $\cdots$ & $\cdots$ & & $\cdots$ & $\cdots$ & $\mathbf{I}$ & & 97 & 5 \\
\hline Jalis & & & & & & 1 & & & & 13 & I6 & 6 & I & & & & & & & \\
\hline $\begin{array}{l}\text { San Luis } 1 \\
\text { L. decemlineat }\end{array}$ & .. & & & & $\mathrm{I}$ & 5 & & & 10 & 18 & 7 & $\mathrm{I}$ & .. & ... & $\ldots$ & ... & ... & ... & $\cdots$ & 2 \\
\hline $\begin{array}{r}L \text {. decemlineat } \\
\text { Arizona .. }\end{array}$ & & & & & & & & & & & & & & & & & & & & \\
\hline $\begin{array}{l}\text { Ari } \\
\text { Nev }\end{array}$ & 5 & & $\begin{array}{rl}12 & 48 \\
40 & \end{array}$ & $\begin{array}{l}3 \\
3\end{array}$ & \begin{tabular}{l|l|}
4 & 9 \\
& 2
\end{tabular} & I. & & & & & & & & & .. & & .. & .. & & 4 \\
\hline $\begin{array}{l}\text { New } \\
\text { Wes }\end{array}$ & $\begin{array}{c}8 \\
. .\end{array}$ & $\begin{array}{r}\text { Io } \\
\text { I }\end{array}$ & \begin{tabular}{l|l}
$\mathbf{4} \mathbf{4}$ & 3 \\
2 & 1
\end{tabular} & $\begin{array}{ll}32 & 7 \\
10 & 45\end{array}$ & $\begin{array}{l}7 \\
5\end{array}\left|\begin{array}{r}2 \\
22\end{array}\right|$ & $\mid \begin{array}{r}1 \\
12\end{array}$ & 7 & i & $\cdots$ & $\cdots$ & $\cdots$ & & & $\cdots$ & .. & .. & .. & .. & $\cdots$ & 5 \\
\hline East & $\ddot{. .1}$ & $\ldots$ & 2. & 4 II & $\begin{array}{ll}22 \\
1\end{array}$ & 25 & ro & 2 & & $\begin{array}{l}\cdots \\
\cdots\end{array}$ & $\cdots$ & $\ldots$ & $\cdots$ & ... & $\ddot{. .}$ & & . & $\ddot{. .}$ & $\ldots$ & $\begin{array}{l}7 \\
3\end{array}$ \\
\hline I, or & .. & $\ldots$ & $\mathrm{I}$ & 23 & $3 \quad 13$ & 44 & 20 & I4 & 2 & i. & 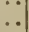 & & & & & & & & & 2 \\
\hline Flor & .. & $\cdots$ & ...... & ..... &... & 3 & 8 & 12 & & $38^{\circ}$ & ; & 2 & $\cdots$ & .. & ... & ... & ... & ... & $\cdots$ & 2 \\
\hline Geo & .. & $\cdots$ & ... & $\ldots$ & $\cdots$ & 2 & 78 & 13 & 284 & 41 & 8 & I) & $\therefore$ & & .. & ... & ... & .. & & 5 \\
\hline Vir & $\mathrm{I}$ & I & 2 & 3 & $2 \quad 3$ & 9 & 18 & 30 & 22 & 8 & I & .. & 1 & & .. & .. & .. & .. & $\ldots$ & 4 \\
\hline LC & .. & & & & 5 & 8 & 18 & 41 & 20 & 5 & I & & & & 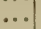 & & & .. & & 6 \\
\hline husetts & .. & $\ldots$ & $\ldots$ & i & I & 7 & 19 & 43 & 21 & 4. & & ... & ... &.. & ... & ... & .. & ... & $\ldots$ & 16 \\
\hline So & .. & $\cdots$ & I & I & 3 & I7 & 40 & 20 & 5 & 3 & I & $\cdots$ & & $\ldots$ & $\ldots$ & .. & ... & ... & $\ldots$ & 6 \\
\hline Nov &. & & ... & 2 & \begin{tabular}{l|l|l|}
4 & 8
\end{tabular} & 16 & 4\% & 19 & 4 & 4 & I & .. & & & $\ldots$ & ... & ... & & & 4 \\
\hline d western & & & & & & & & & & & & & & & & & & & & \\
\hline Yo & $\cdot \cdot$ & & $\cdots$ & $\mathrm{I}$ & 2 & 8 & 18 & 43 & 20 & 4 & I & - & & & & & & & & \\
\hline Nor &.. & $\cdots$ & $\cdots$ & & I & II] & 16 & 45 & 20 & 5. & & & & $\cdot \cdot$ & . & ... & $\cdot$ & $\cdots$ & & \\
\hline No &.. &.. & $\ldots$ & i & I & Io & 16 & 45 & $2 \mathrm{I}$ & 4 & I & & & & $\therefore$ & .. & $\ldots$ & $\ldots$ & $\because$. & 8 \\
\hline &.. & & ... & $\cdots$ & 2 & 8 & 18 & 40 & 25 & 5 & I & $\ldots$ & $\cdots$ & &.. & 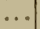 & $\ldots$ & $\ldots$ & $\cdots$ & 2 \\
\hline Dak & .. & $\cdots$ & .. & I & \begin{tabular}{l|l}
5 & 12
\end{tabular} & 50 & 20 & 8 & 3 & I & .. & .. & ... &.. & $\ldots$ & .. & $\ldots$ & $\ldots$ & $\ldots$ & 3 \\
\hline $\mathrm{Cc}$ & 1 & ... & I & 48 & 851 & $2 \mathrm{I}$ & 7 & 4 & 3 & I & 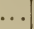 & & & & & .. & $\ldots$ & $\cdots$ & & 6 \\
\hline & & 2 & \begin{tabular}{l|l}
10 & 1 \\
1
\end{tabular} & 1745 & \begin{tabular}{l|l|}
5 & 19
\end{tabular} & 5 & 2 & & & & & .. & & & & & $\ldots$ & ... & & \\
\hline & & & ...... & $\ldots \ldots$ &... & 3 & 10 & & 44 & $2 \mathrm{I}$ & 4 & & & & & & $\ldots$ & $\ldots$ & $\cdots$ & \\
\hline Sc & . & . & ..... & ... & 23 & 9 & 16 & 42 & I8 & 5 & 4 & I & . & $\therefore$ & ... & ... & $\ldots$ & $\ldots$ & $\ldots$ & 7 \\
\hline & & & & & 6 & Io & 16 & & I9 & 6 & 2 & & & & $\ldots$ & $\ldots$ & $\ldots$ & $\ldots$ & $\ldots$ & 2 \\
\hline vania & & & $\ldots$ & $\mathrm{I}$ & 4 & 9 & 16 & 40 & 20 & 6 & 2 & I & & $\therefore$ & $\ldots$ & ... & $\ldots$ & $\ldots$ & $\ldots$ & 2 \\
\hline c. junc & $\mathbf{I}$ & & & & & & & & & & & & & & & & & & & \\
\hline 7 & & & $5 \mid 1$ & 1950 & $\begin{array}{lll}0 & 22 \\
\end{array}$ & & & & & & & & & & & & & & & 6 \\
\hline & & & $\cdots$ & $\begin{array}{ll}\text { I } & 5\end{array}$ & \begin{tabular}{l|l|}
5 & 15
\end{tabular} & 60 & 18 & I) & & & & & & & $\ldots$ & .. & $\ldots$ & $\ldots$ & & 5 \\
\hline & & & $\ldots$ & $\mathbf{I}$ & $\begin{array}{ll}2 & \mathrm{I} 6 \\
\end{array}$ & 51 & 18 & 9 & 3 & & & $\ldots$ & & & & ... & $\ldots$ & $\ldots$ & $\ldots$ & \\
\hline A] & & . & I & & 960 & 15 & 2 & $\ldots$ & ... & ... & 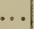 & $\ldots$ & $\ldots$ & $\ldots$ & $\cdots$ & & & & $\cdots$ & 4 \\
\hline Lo & & & 3 & & 58 & 12 & $\mathbf{I}$ & & & & & & & & L I & . & & & & 4 \\
\hline Texas................ & & I & \begin{tabular}{l|l}
4 & 1
\end{tabular} & I9 60 & 0 II & 5 & $\cdots$ & & $\cdots$ & ... & $\cdots$ & $\cdots$ & $\cdots$ & .. & .. & $\cdots$ & $\cdots$ & $\cdots$ & $\cdots$ & 3 \\
\hline L. defe & 4! & & & & & & & & & & & & & & & & & & & \\
\hline $\begin{array}{l}\text { Middle an } \\
\text { Indian Te }\end{array}$ & 2 & Io & & I852 & $\mathrm{I}$ & & & & & & & .... & $\ldots$ & $\ldots$ & ... & ... & … & $\cdots$ & $\cdots$ & $\begin{array}{l}7 \\
2\end{array}$ \\
\hline Southeastern Colorado & 1 & 9 & 216 & 80 & 6 & & & & & & & & & .. & .. & $\ldots$ & $\ldots$ & $\therefore$ & $\therefore$ & 2 \\
\hline
\end{tabular}

TABLE 43--Geographical variation in the color of the elytra of L. dilecta, calceata, and lineolata.

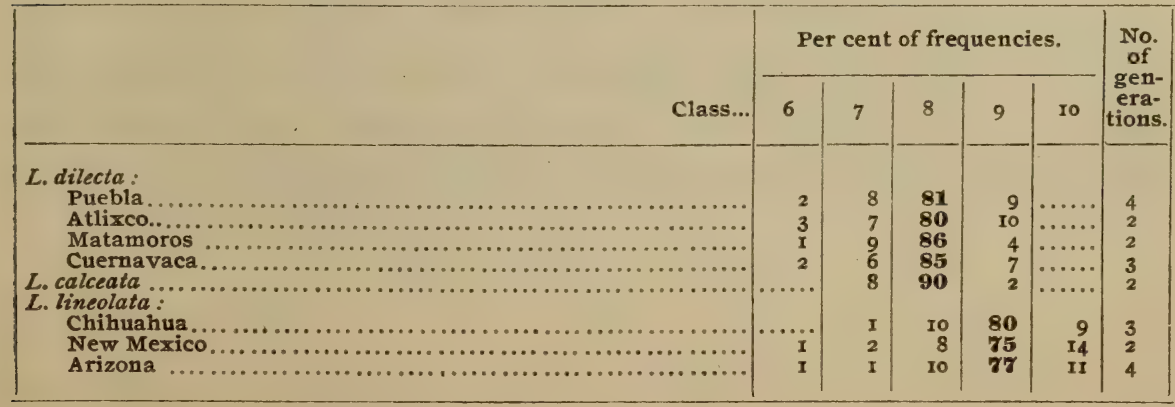


In decemlineata the range is from an albinic condition found in the Rio Grande Valley and in the southern part of Arizona to the highly melanic condition found on the Atlantic coast. From Colorado eastward into Illinois and Ohio and on farther to the Atlantic coast there is apparent an increasing tendency toward melanism, which culminates in New England and the maritime provinces of Canada. Along the Great Lakes-St. Lawrence Valley this same tendency is found, whereas toward the South an albinic tendency prevails which is very distinct to the southwest and less so to the southeast. In this respect the facts presented are in no wise different from those that have long been known, that all animals in the United States are in general more melanic to the north and east, less so to the south, southeast, and middle west, and albinic in the extreme south and southwest. As long ago as I877 Allen recognized this tendency in birds and mammals, and Enteman finds the same to be true in Polistes. L. decemlineata, however, is a form that has in recent years invaded the area in which it is now found, and since becoming a member of the fauna of a wider region, has responded to the conditions of the new environment, and in adapting itself to new habitats has varied in the same general directions as do the other animals with which it lives. It is, therefore, to the environment and not to the animal itself that we must look for the stimuli which are the cause of these modifications. The factor assumed by all to be the most powerful in this general color variation is moisture, and probably temperature is of equal importance. I have gathered some interesting data on this subject concerning decemlineata.

Live material was gathered from various parts of the United States and Canada and was reared at Chicago under various conditions. The specimens which will be considered particularly were from Massachusetts, Georgia, Alabama, Kansas, northwestern Texas, Dakota, and Manitoba. Compared with the material collected at Chicago the beetles from these various localities presented diverse appearances and conditions of coloration. At Chicago, during the years 1902 to 1905 , all were reared under uniform conditions, the result in all cases being a complete and rapid change to the prevailing condition of coloration at Chicago. In all but about I or 2 per cent of the specimens this change was produced in one generation, and at most two were required; nor was there any tendency toward reversion in succeeding generations when reared under the same conditions.

At the same time beetles from Chicago were in experiment subjected to the same conditions of temperature and moisture which obtain in different sections of America, with the result that in one generation modification to the conditions characteristic of the different regions was produced, and this persisted as long as the conditions remained unchanged. In this way I have experimentally modified the general color of these beetles in one direction or another at will, producing by experiment the conditions found in nature in 
diverse habitats. These modifications, however, are no more permanent than those found in nature. Indeed, the conclusion I have reached is that the geographical variation is due solely to place variation, which in a particular locality is rather constantly in one direction. As far as this species is concerned, although marked geographical variations are found, the evidence is conclusive that they are not permanent, and that although the species varies in different localities it has not undergone any constitutional change. In Colorado, New Mexico, and western Texas decemlineata has lived for some hundreds of generations. At Chicago it has been a resident of constant conditions from I 865 to I905, a period of 40 years or 80 generations. At this latter place it varies considerably in general color from the condition in Colorado and western Kansas, and yet a period of 80 generations under uniform conditions has not been sufficient to impress upon the species any degree of change. Likewise the long period of time that it has lived in the Southwest has not changed the constitution of the species. As far as the evidence goes, and I believe that in this case it is remarkably complete, since so much is known of the history of the species, it seems certain that this form has not been altered by its existence in any one of a dozen different habitats, and that it has retained the same constitutional structure and character. Place variation only is found, and this is in a constant direction as long as environmental conditions remain constant and change only as they change.

The geographical variations in general color shown by L. multitaniata are of the same nature as those found in decemlineata, and are altered or produced at will in experiment. As far as I can determine they represent, not a permanent condition in the species, but merely a place variation which is constant as long as the conditions of existence are constant and varies as fast and as frequently as its environment varies. An important but seemingly unanswerable question in this connection is, How long must a species be subjected to given conditions before it will be permanently changed in a given direction? How long must decemlineata live at Chicago in order that the general color conditions characteristic of Chicago may be so firmly impressed upon its constitution that when it is transplanted into slightly differentenvironmental conditions it will retain its Chicago character, at least for some considerable time? The evidence from this investigation would indicate that variations produced by different environmental complexes produce only temporary variation and are not incorporated in the constitution of the species, at least not in some hundreds of generations. L. multiteniata has certainly occupied its present habitat for a long period of time, at least during thousands of generations, and yet in all this time the place variation tendency of different localities has not become incorporated in the constitution of the species, and it is to-day as variable in this respect as it probably was at the beginning. 
Strongly contrasted with the species just discussed are forms like $L$ : undecimlineata and dahlbomi. Undecimlineata, while variable, does not show even in its wide range of habitat any great geographical variability, nor has it been possible in experiment to produce any extreme modifications. L. dahlbomi, of all species in the genus, has been found in the most varied habitatsin the hot, humid valleys of Guatemala and southern Mexico, in the dry, cold plateau, in the dry, hot Rio Grande Basin, in Yucatan, and in other diverse places, yet in all it is the same conservative species, and as far as known is almost free from variation of any kind.

If the data of geographical variation were to be presented for the different elements of the color pattern, for size, variation in punctation, and for glandular openings, it would but be a repetition of what has just been said concerning general color variation in these beetles, and nothing would be added to the value of the above discussion.

It appears that geographical and place variation are closely related; that place variation is in reality the cause of geographical variation. Of most importance, however, is the fact that, as far as it has been possible to determine, geographical variations are transient and form no permanent part of the species. They are, as it were, a suit of clothing used as the weather dictates, and produce no more permanent constitutional modification than does the act of changing one's dress.

Some authors, as, for example, Allen, have attempted to establish a relationship between latitude and longitude and variation. As far as this material is concerned, any such relationship is purely incidental and of no importance. Correspondence between geographical variation and any artificial scheme for dividing the earth's surface by arbitrary lines would, on the employing of enough imagination, show a relationship. The only real relations of geographical variation that I can discover are those to natural features of the earth's surface, to climate, topography, and other natural phenomena.

We have already seen the relation which exists between place variation and geographical variation, and I have shown that place variation is due to the varying conditions of different environmental complexes. In the tables given are found examples of the most exact correspondence of variation to different portions of the habitat. These relations will come out better and in their true light in the next section of this paper. 


\section{DISTRIBUTION AND VARIATION AND THE EVIDENCE THEY AFFORD CONCERNING EVOLUTION.}

In the first chapter and in the first portion of this one has been presented the data of distribution and variation, these being the two sources from which we are prone to draw extensively for evidences of evolution. When taken alone, as has been seen, neither is able to yield much that is certain concerning evolution. Considered together, they may yield important information concerning evolution in organisms. Distribution and variation often, nay, almost always, are able to give rather exact ideas as to what the evolution in a given group has been. In this section we shall examine our data first, for evidence concerning the evolution of the genus Leptinotarsa, and second, for the processes which brought about that evolution.

We can most easily and rapidly arrive at some conclusion as to the evidence which the study of distribution and variation affords concerning the evolution and phylogeny of this genus by examining a specific case with care. Let us first consider the evidence in the lineata group.

The distribution of this group of I2 species of beetles has been described in the first chapter and figured on plate $\mathrm{I}$. Considered from the standpoint of their distribution, the whole group may be separated into three sets of species, each set characteristic of a certain area.

It has already been shown how all available evidence points to the Guatemala-Chiapas plateau as the center of origin of this group of beetles. From this point undecimlineata can be traced northward to the escarpment of Mexico and southward to Panama. Its variations are greater in the extremes of its range than in its central portion, but these variations are, as has been shown in this paper, fluctuating and place variations, as far as can be determined at present. On the north of the habitat of undecimlineata two closely related forms occur, signaticollis and angustovittata, the latter being a variation from undecimlineata. We have seen how these three forms, in their positions on the slopes of the Mexican highlands, are, first, undecimlineata at the lowest points; second, angustovittata midway, and third, signaticollis at the lower edge of the escarpment. Among these three forms there are many close resemblances; the chief differences are those in the elytral ornamentation, the color pattern, and the punctation. These facts argue strongly that these three species represent one line of descent. In this case we have the rather unusual observation of one species arising directly from another, which lends most convincing support to our argument. But to consider only the facts from distribution and variation. The distribution of the three species like windrows along the slope of the Mexican highlands, and the fact that they show in their variations a series of modifications which overlap and are in one direction, offer a condition not easy to explain otherwise than upon the assumption that the species and their variations as we now find them rep- 
resent a line of development in which the three species are steps in a certain direction of evolution. It would be difficult to invent a hypothesis to account for this case other than the one advanced above that would not contain obvious absurdities.

The species multitceniata, oblongata, intermedia, melanthorax, rubicunda, and decemlineata, which are very closely allied forms, are all, excepting decemlineata, confined entirely in their distribution to the Mexican table-lands. This is suggestive. As I have shown in the first chapter, we may regard multitcniata as the central species in this group, variable, plastic, and able to live in diverse habitats. It has spread over a wide area, and as it has been disseminated new species have been produced. In all their variations this series of species shows the same kind and direction of modification; they differ, however, in the extent of their variation and in the portion of the possible scale thereof which they exhibit. Thus, multiteniata, intermedia, and decem-

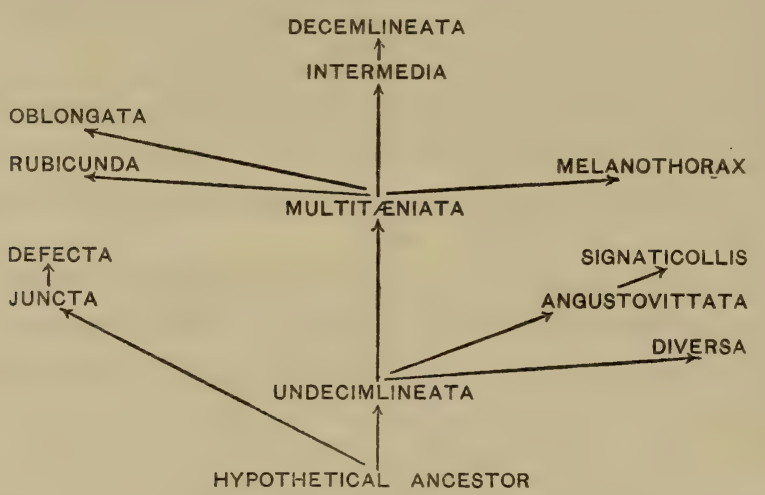

TEXT-FIGURE 4.-Scheme of phylogenetic development of the lineata group, based upon the data of distribution and variation.

lineata, form a series from north to south over the continent, which show not only geographically arranged steps, but steps also in the variations presented; from multitaniata, with variation entirely in the melanic half of the possible series, through intermedia to decemlineata, with its variations in the middle and albinic end of the possible variation series. Thus these three species, and to the south, in like manner, oblongata, show differentiation in one direction, both geographically and in their fluctuating variations. Melanothorax and rubicunda, which live in the same habitat with multiteniata, represent more local species than the rest, while juncta and defecta show one and the same sort of a series in their geographical distribution and their variations.

Is it possible logically to derive any other conclusion from the above data than that the conditions of distribution and variation as found indicate the direction and order of evolution and the relationship of the species? Discarding impossible hypotheses, we are forced to one of two alternatives- 
either that the condition is due to chance, and does not really represent the orderly development of species which it would seem to, or that the data of variation and distribution give the true order of evolution. It must be admitted that the data do permit of the construction of a plausible scheme of the phylogenetic relationship of these species, such as the one shown in textfigure 4 .

A scheme like that given in text-figure 4 is highly plausible, and is apt to so strike one's fancy that other possibilities are ignored, as, for example, the one that the relations suggested by the data employed are due to chance, and have no real meaning.

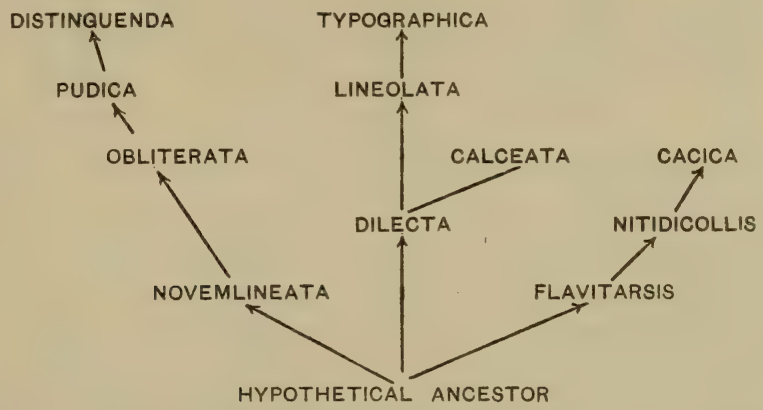

TEXT-FIGURE 5.-Scheme of the phylogenetic development of the dilecta group, based upon the data of its distribution and variation.

The dilecta group consists of a series of species which are widely disseminated and variable and nearly as numerous as those in the lineata group. On plate 12 is represented their distribution over northern Central America and Mexico. Here also are found series of species which in their geographical distribution and their variations show conditions similar to those in the lineata group. The species flavitarsis from Guatemala, nitidicollis from Chiapas, and cacica from the Atlantic slope represent, in as far as their known distribution and variations can indicate, a line of species differentiation from highland to lowland and in a given direction. Another series consists of the species dilecta from the Oaxaca-Guerrero highlands and northward over the South Mesa of Mexico, with its lowland modification, calceata, and its close allies to the north, lineolata and typographica. Still another series is that made up of the species novemlineata, obliterata, distinguenda, and pudica. It has not been possible to obtain as full data of the distribution and variation in the dilecta group as in the lineata group, but all known facts point to species formation in certain directions over the continent-one line of differentiation, that found in the series flavitarsis, nitidicollis, and cacica extending to the north and eastward; another, represented by dilecta and its allies, spreading northward, and so on. The scheme of the phylogeny of this group, shown in text-figure 5 , is based upon its distribution and variation. 
This scheme has exactly the same chance of being true or false, and for the same reasons, as has the one constructed for the lineata group. In a like manner and upon similar data we may build up schemes of phylogenetic de-

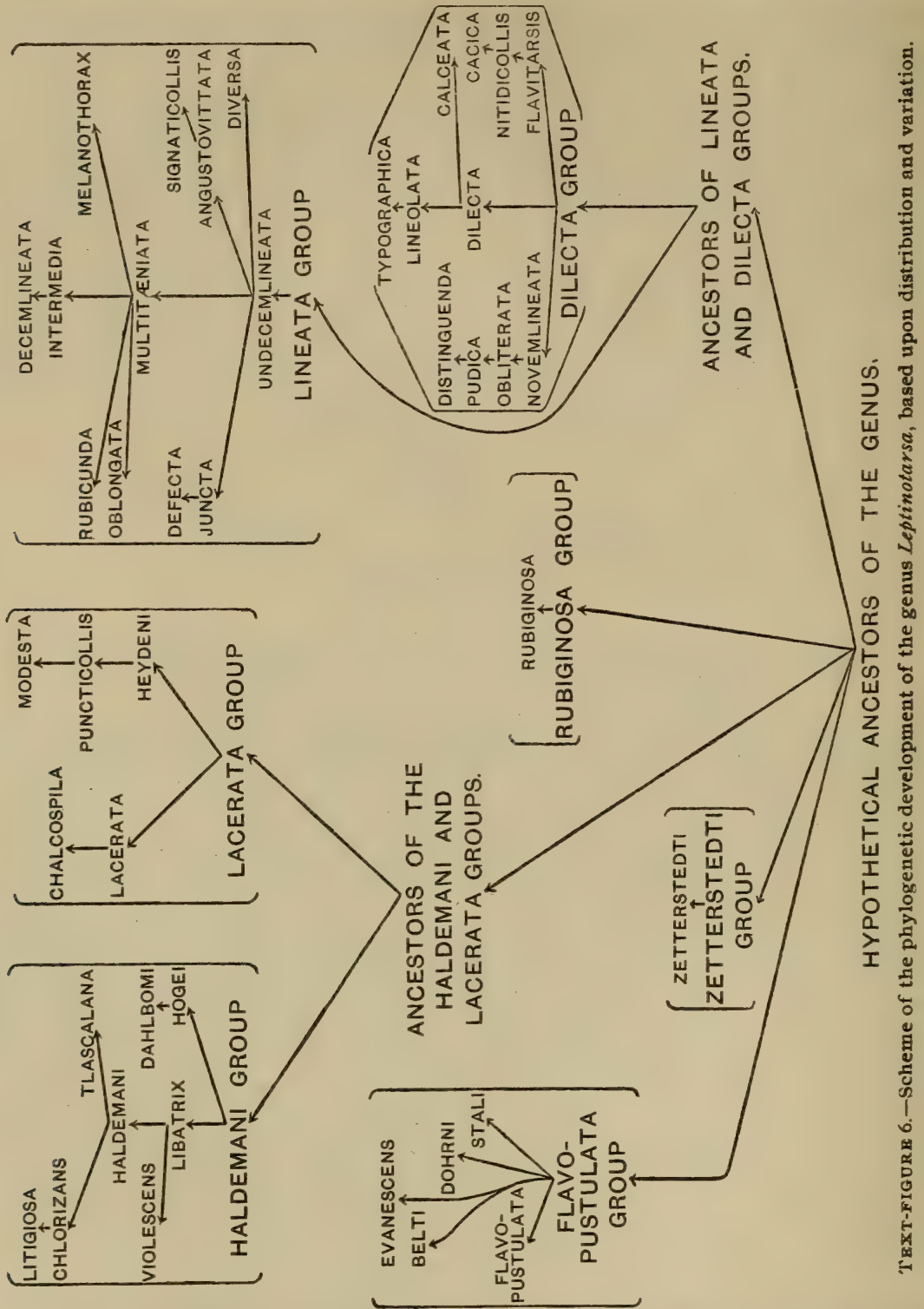

velopment for the other groups of Leptinotarsa, or for the entire genus. In text-figure 6 is represented such a scheme.

In text-figure 6 the phylogeny of the genus Leptinotarsa, as revealed by the study of its variation and distribution, shows uniformly a species formation 
along certain definite lines and in correlation with the natural features of its habitat. The question is whether the many series of species found represent chance arrangements, or whether they indicate species differentiation along definite lines, in correlation with the climatic and topographic areas of their habitat. If in the genus there were only one or two such cases, we might perhaps conclude that they were the result of chance; but when the entire genus shows this phenomenon it is highly improbable that the conditions could be due to chance modifications. On the other hand, it is almost certain that the interpretation of the relationships and the direction of the evolution of species indicated in text-figure 6 is, in the main, correct. In this genus, at least, the study of distribution and variation gives clear ideas as to what the course of evolution has been. We are fortunate in that there are few gaps due to apparent extinctions and in the unusually large amount of exact and reliable data available.

Even though the truth of the above conclusion is admitted to be incontestable, no evidence is produced as to the methods by which the evolution of the genus has been brought about. As far as the above conclusion regarding phylogeny is concerned, it could be explained by any one of the current hypotheses concerning evolution, at least as far as any facts yet discovered are concerned. Slow, accumulated variations and natural selection, directive evolution (Eimer's orthogenesis), neo-Lamarckism, and the mutation theory would each be able in the opinion of its supporters to explain the conditions found.

Can we, in the study of evolution as found in this genus, derive from the data of distribution and variation any evidence as to the method of evolution? This is often attempted, but the conclusions are badly strained and distorted, and not infrequently are entirely unfounded. Nowhere in the data presented is there anything to indicate that slow variations and natural selection has been the method of evolution. We have already considered this case in part in the discussion of place and geographicalvariations, where it has been shown that as far as can be determined slow variations in a given direction have not been incorporated into the species, even after many hundreds of generations. The evidence derived from the place and geographical variations of L. multiteniata and decemlineata would be difficult to explain away by this theory. Its advocates can, and probably will, take refuge in the argument, frequently employed, that we have not evidence covering a sufficiently long period of time; but they have not yet defined what is meant by "a sufficiently long period of time." We have in decemlineata one of the most satisfactory cases known of those which are calculated to give evidence on this point, with complete data and actual specimens for many generations, together with modifications of the required kind. It is shown conclusively, however, that the changes have not as yet become a part of the species. It may be suggested that perchance we may be dealing with one of those rare and special cases 
which are difficult to explain on any basis; but evidence does not appear anywhere in the data of variation and distribution in the whole genus in support of the theory of evolution by slow variations and natural selection. Are these series of species, with their differentiations, in direct and orderly succession from their center of origin over the country, and the continuity of their variations, to be taken as certain evidence in support of this view? In any one of the many examples of this kind which could be mentioned is there any more probability of their having arisen by slow variations and natural selection than by orthogenetic mutation?

In regard to the other hypotheses of the method of evolution, do they secure any support from the data under consideration? In the entire genus there is found present to a marked degree evolution and fluctuating variation in narrow limits in definite directions. Does it follow that orthogenesis (in Eimer's sense) has been the method of evolution pursued by this genus of beetles? Excepting for the existence of definite directions of evolution there is no evidence in support of this view. The determinate character of the variations and species differentiation can be just as well explained on the basis of slow variation and natural selection by the elimination of ail variations and species but those within narrow limits as upon Eimer's theory of orthogenesis. It would be equally easy for the neo-Lamarckians to devise a plausible argument as to the origin of the genus by the method of evolution demanded by their hypothesis, and likewise for the advocates of species formation by mutations and segregation in fittest environment to make out of the data a complete and satisfactory case in favor of their theory. We do know, however, that certain extreme variations or mutants occur, as, for example, melanothorax and rubicunda, and while these may argue in favor of species origin by mutation, in the remainder of the species no more such examples are known; and, as far as any evidence yet discovered is concerned, these have not produced permanent species. Moreover, the origin of the species in the genus can be explained by any one of the hypotheses we may choose, or rubicunda and melanothorax may be passed by as exceptional cases and of little significance.

Viewing the data and evidence fron a strictly impartial standpoint, as one having no more interest in one hypothesis than in any other, as far as I can discern there is no certain basis for asserting what method or methods of evolution have been followed in this genus of beetles. Some species, multitcniata and decemlineata, afford evidence strongly opposed to evolution by slow variation, while others, melanothorax and rubicunda, support the theory of evolution by mutations; but, although this evidence is suggestive, it is well to keep in mind the fact that there are other possible methods of evolution. Although frequently far-reaching conclusions are based upon evidence derived from these sources, such a proceeding is not justified. The neoLamarckian is prone to draw from variations distributed in time and space 
conclusions warranted from his point of view, but not from that of others. So, too, the advocate of orthogenesis, following Eimer, selects stages in variation here and there, and isolated facts of distribution, and draws sweeping conclusions therefrom. The supporters of selection can see no possibility of other methods of evolution, and the advocates of mutation are wildly enthusiastic over their newly discovered treasure.

The only conclusion regarding the method of evolution that, from an impartial standpoint, I am able to draw from this investigation of variation and distribution is that we can get no undoubted evidence to warrant a decision in favor of any one hypothesis more than another. W'e can interpret the conditions found by any of the current hypotheses; but explaining a condition by an hypothesis is not the same as that the conditions found are evidence in support of an hypothesis, although it is often so used. Although it is conclisive that no direct evidence of value or reliability concerning the method of evolution is to be derived from distribution and variation, three suggestive facts come out in the clearest possible manner: First, that species differentiation and variability have followed in the same lines or directions of evolution as is shown in distribution and variation; second, that three forms, melanothorax, angustovittata, and rubicunda, arise as extreme variations and are stable forms; third, that there is strong evidence, in the case of multitcniata and decemlineata, against the idea of the slow modification of a species by the incorporation into its constitution of fuctuating place or geographical variations. These facts have been investigated experimentally and otherwise and the results will be presented later.

The study of distribution and variation, although not affording conclusive evidence concerning the method of evolution, does give rather complete and reliable data upon the probable phylogenetic development of the genus, and also information concerning the limits, directions, and laws of variation, distribution, and migrations. This information is important, nay, indispensable, in the study of evolution, in that it shows us what the natural history of the material under investigation has been. This knowledge of the natural history of the genus I regard as of fundamental importance; and it can not, I believe, be neglected without seriously impairing the value of researches in experimental evolution.

The conclusions to be drawn from this study of distribution and variation in the genus Leptinotarsa are that species differentiation, as far as it is possible to determine, has been definite and not promiscuous, and that all variations are definite and not promiscuous, and also that both species differentiation and all variations are in the same directions and are in a most remarkable manner correlated with natural features of the general habitat. The data of distribution and variation can give no real basis for determining the method of evolution, nor does it enable us to arrive at the causes thereof. We can arrange the species of the genus in series, and opposite them place climatic and other 
environmental factors, in plausible juxtaposition, and base far-reaching conclusions thereon; but in any such process there are far too many assumptions that this possible factor and that observed result are cause and effect. The fact is lost sight of that the causes are numerous, and their action only remotely comprehended. Too often we neglect to consider tendencies inherent in the species, or to learn its physiology, its peculiarities of development, its habits and instincts, and much other information which is apparently of slight consequence, but which is of great importance in the economy of the species. It is necessary to know our material intimately and to experiment widely before we attempt to correlate observed variations with environmental factors or to determine the causes and methods of evolution. 


\section{CHAPTER III.}

\section{COLORATION IN LEPTINOTARSA.}

In this chapter, which deals with the colors and color patterns in the genus Leptinotarsa, I have attempted to foilow the development of the color phenomena, both ontogenetically and phylogenetically, and to determine the laws by which they are controlled and the environmental factors by which they are modified.

\section{COLOR PHENOMENA IN INSECTS.}

\section{COLOR CLASSES.}

The colors of insects are divided into three chief categories, dependent upon the causes by which they are produced. These classes of color we designate as chemical or pigmental, physical or structural, and chemico-physical or combination.

\section{CHEMICAL, OR PIGMENTAL COLORS.}

These colors owe their existence to the presence of a substance of a definite chemical composition, which has the property of absorbing some wave-lengths of light and of reflecting others. These compounds may be the product of the metabolism of the animal, or derived from the food (Poulton, I893), or they may be accidental inclusions. They may also be colored substances or coloring substances. The colors due to this cause are black, brown, orange, yellow, drab, many reds, rarely blue, green, and white. The pigments which produce them are soluble in various reagents.

It has been shown that the color-producing substances may be divided into three main classes, which differ in their location in the body and in chemical composition. It was demonstrated by Hagen that these color-producing substances are divisible into two classes, the dermal and the hypodermal, the dermal being located in the cuticula and the hypodermal in the cells of the hypodermis. Poulton and others have shown the existence of color-producing substances in the fat body and hæmolymph. These I have called subhypodermal colors. The dermal colors and the substances which produce them are located in the outer portion of the cuticula, and are diffuse pigments, and not present in the form of granules, as maintained by Hagen and Enteman. The hypodermal colors have been shown to be usually in the form of granules located in the hypodermal cells, or, more rarely, derived pigments.

The solubility of these pigments has been studied by Coste, Urech, Mayer, Tower, and Enteman. From these researches it appears that the colorproducing compounds are all soluble, but not with the same degree of ease. 
Some of these pigments are very unstable and break down on exposure to light or at death, while others are of great permanence and are soluble only after the most vigorous treatment with strong mineral acids. The colors, their location in the body, their solubility, and degree of permanence are summarized in the following table:

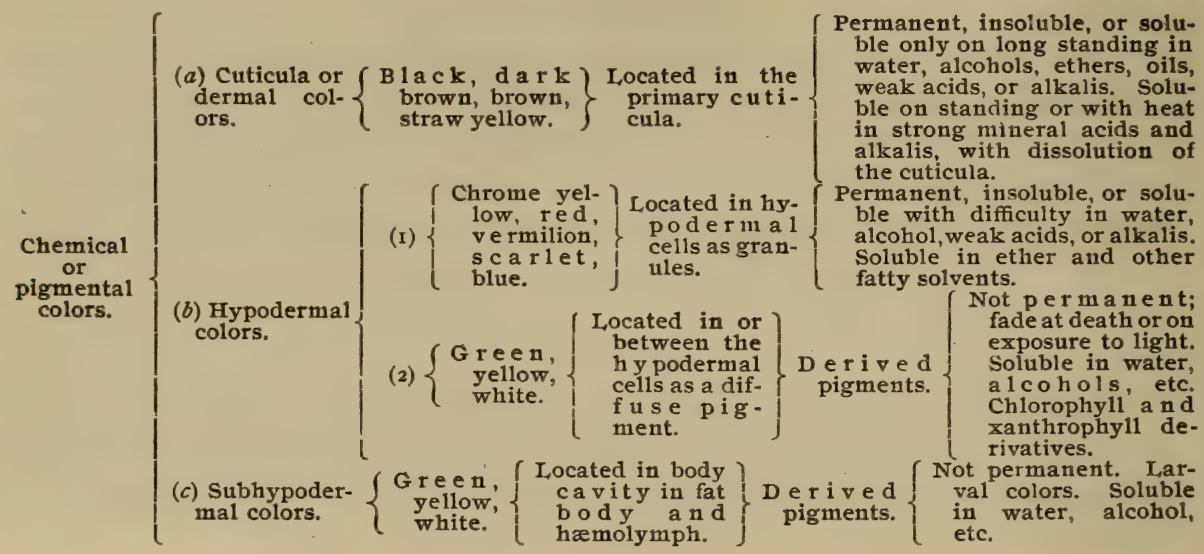

The chemical composition of the compounds which produce color has been studied by Krukenberg by spectrum analysis, and by this and other methods by Hopkins, Griffiths, Urech, Poulton, Mayer, Tower, Dewitz, Enteman, and others. The cuticula pigments are diffuse pigments elaborated from the primary cuticula through the action of an enzyme which I have isolated and called chitase. The product of this enzyme action is an azo compound, oxy-, di-, or amido-azo, and shows all the characteristic reactions of this group of organic compounds. It is maintained by Enteman that the pigment is elaborated in the hypodermal cells, and passes out through the pore canals of the cuticula to the primary cuticula, where it finally remains; while others, working on a wider range of material, find that it arises as a diffuse pigment through the action of an enzyme which has been elaborated as the result of chromatolysis of the nuclei of hypodermal cells upon the primary cuticula when in a soft condition-the action of the enzyme being akin to coagulation or gelatinization and the products being hard, stiff cuticula and the azo compounds.

The pigments which produce the hypodernal colors have been studied by Krukenberg by spectrum, by Zopf and Tower in the hypodermal cells proper, and by Hopkins, Griffiths, Urech, Mayer, Von Linden, and others in the scales of Lepidoptera. In the hypodermal cells proper Zopf and Tower find that the colors in Coleoptera, Hemiptera, Lepidoptera, and Hymenoptera are due to granules of pigment of a fatty nature. Some of these were shown to be lipochromes by Zopf in Coccinellidæ, and by Tower in other families of Cole- 
optera and in Hemiptera, Lepidoptera, and Hymenoptera. These pigments are elaborated in the cells in which they are found, and have no connection with the red pigments of the Malpighian tubules at pupation. In the scales of Lepidoptera, Hopkins has demonstrated in the Pieridæ the existence of compounds of uric acid which produce white and yellow pigments. Griffiths further isolates and studies a green pigment which is allied to uric acid, or is a uric-acid derivative called lepidopteric acid $\left(\mathrm{C}_{11} \mathrm{H}_{10} \mathrm{Az}_{2} \mathrm{~N}_{8} \mathrm{O}_{10}\right.$ ?). Urech, Mayer, and others have made various experiments and tests with the pigments in the scales of Lepidoptera, but without any definite results as far as their chemical nature is concerned. Mayer has shown that the pigments in the scales of some butterflies and moths are elaborated from the hæmolymph, possibly through the action of ferments. He has performed some interesting and instructive experiments with the hæmolymph of various moths, but comes to no satisfactory conclusion concerning the nature of the pigments.

The subhypodermal pigments have been most completely investigated by Poulton and his pupils in Lepidoptera, and by myself in Coleoptera. It appears from these researches that these pigments are largely characteristic of phytophagous larvæ, or of carnivorous larvæ which feed upon certain phytophagous species. Poulton has shown clearly that these pigments are derived from the food or, largely, from pigments contained in the food.

PHYSICAL, OR STRUCTURAL, COLORS.

These colors are produced by some of the various physical principles whereby light impinging upon a body is modified by reflection, refraction, defraction, or dispersion. These results are brought about by polished surfaces, lamellæ, pits, striæ, scales, or other surface modifications. As far as is known there is only one physical color in insects, namely, white, which is produced either by air in scales, by the flat faces of crystals, or by fine granules in the fat body, all of which give total reflection.

Although colors are produced by physical causes in insects with great frequency, they are, as shown by Mayer in Lepidoptera and by myself in other orders, usually combined with chemical or pigmental colors, and it is to these that insects owe their varied and brilliant hues.

CHEMICO-PHYSICAL, OR COMBINATION COLORS.

These colors were first clearly recognized and defined by Mayer (1897) in Lepidoptera. To this class belong all metallic, iridescent, and pearly colors, as well as blue, green, violet, and many reds. The combination of a structural and pigmental color in the same scale was early noticed by Urech, who showed that in some Vanessas the scales had pigments which produced color and interference colors due to striæ, and he gave a similar case in certain Lycænidæ. These colors I have studied extensively, and I find them to be the 
most widely distributed of all insect colors. The results of their examination have been summarized in the form of a table, which is here reproduced:

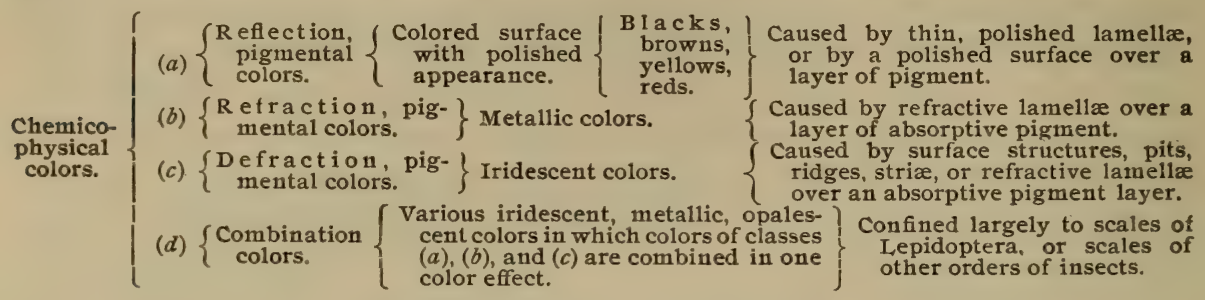

DEVELOPMENT OF COLORATION.

The ontogenetic development of color and color patterns in insects has been studied most in Lepidoptera and especially in the wings. The earliest studies of note were those of Schäffer, von Bemmelen, and Urech. These were followed by the more elaborate researches of Hasse, Mayer, and von Linden. In the other orders of insects studies have been made by Kunckel de Herculais in Orthoptera, Tower in various orders, but especially in Coleoptera, and Enteman in the hymenopterous genus Polistes.

The studies upon the origin of color in the wings of Lepidoptera have shown that there is a regular order of development, not only of colors, but also of the areas in which spots and stripes appear. The wings, which are colorless at first, become opaque, yellowish, or light drab, beginning first near the base of the wing and spreading distalward. Soon spots, stripes, and adult markings appear, at first proximad, then more and more distad, then between the nervules, and, last of all, upon the nervules. First the purely pigmental or chemical colors develop, and these are followed by the chemico-physical. Upon the body in various orders of insects I have found, as has also Enteman, that the color develops in segmentally arranged spots located upon important sclerites, usually over muscle insertions, and that from these centers it spreads out, giving a surface either uniformly colored or spotted, if the primary centers remain unfused. Development proceeds in general from before backward, and from proximal to distal. The order of succession in the colors has been found by these authors to be much the same as that in the wings of Lepidoptera ; the lighter and simpler colors appear first, followed by those which are darker and more complex, and these by the appearance and development of the chemico-physical colors. The ontogeny of larval and pupal coloration has not been studied.

\section{PURITY OF INSECT COLORS.}

The purity of insect colors has been investigated by Mayer (I897), who has found that there are few or perhaps no pure colors in butterflies. All the examinations made by this author have shown that a given color is in reality 
composed of several colors, and in all he found a surprisingly large percentage of black. The colors of other orders of insects have not been studied as regards their purity.

\section{EVOLUTION OF THE COLOR PATTERNS OF INSECTS.}

Studies in the evolution of the color patterns of insects have been made almost entirely upon Lepidoptera; in fact, outside of this order only two papers, excepting short notes scatiered here and there, have been published.

\section{LAWS OF COLORATION.}

The first author to deal with the laws of coloration in insects was Higgins, who maintained that the simplest and most fundamental color pattern is a uniform tint, and that later the pigment developing along the nervules forms darker markings which follow the lines of the nervules. Spots and ocelli he believed to arise by the migration of crescent-shaped areas from the nervules into the interspaces. The ontogenetic studies of von Bemmelen, Hasse, Mayer, and von Linden produce no data in support of this view. On the contrary, Mayer and von Linden show that the scales over the nervules and along their courses remain uncolored until after other parts are pigmented. It was shown by Darwin that ocelli can be traced through a continuous series backward into dark spots with lighter centers. Scudder and Bateson, in Lepidoptera, showed that ocelli are always located in interspaces and rarely upon the nervules. Mayer advanced the following laws as those which govern coloration in Lepidoptera :

(a) Any spot found upon the wing of a butterfly or moth tends to be bilaterally symmetrical, both as regards form and color; and the axis of symmetry is a line passing through the center of the interspace in which the spot is found, parallel to the longitudinal nervules. (b) Spots tend to appear, not in one interspace only, but in homologous places in a row of adjacent interspaces. (c) Bands of color are often made by the fusion of a row of adjacent spots, and, conversely, chains of spots are often formed by the breaking up of bands. (d) When in process of disappearance, bands of color usually shrink away at one end. (e) The ends of a series of spots are more variable than the middle. This is only a special case of Bateson's law. $(f)$ The position of spots situated near the outer edges of the wing is largely controlled by the wing folds or creases.

The same author (Mayer) later distinguishes three kinds of markings on the wings of Lepidoptera-spots, bands, and combination markings-the latter being a combination of spots and bands and more numerous than the first two classes. He also gives the following laws concerning their behavior:

Bands, rows of spots, and combination markings are usually unbroken, of uniform color, and isolated one from another; and only rarely do we find them broken, particolored, or fused one with another. All departures are much more apt to affect the ends than the middle of a marking. Rows of spots and combination markings are 
more apt to show these variations than are bands. Each genus or family follows these general laws of variations, but each displays modifications peculiar to itself; these modifications being sometimes of so marked a character as to constitute an exception to the general rule. Such wide departures from the rule are exhibited by broken rows of spots on the fore wing of Hesperidx. Also by double spots in rows of otherwise single spots on the hind wing of Hesperidæ. In both of these cases the variation is commoner in the middle than at the ends of the row. Like kinds of markings are more apt to fuse than are unlike. For example: Rows of spots often fuse with other rows of spots, or bands with other bands; but fusions between rows of spots and bands are rare. Fusions are commonly mere contacts, which are terminal for at least one of the fused rows. Each pair of fused markings is more apt to come in contact at their ends than at their middle. A definite relation obtains between the number of markings on the fore and hind wings. Also the markings on either wing tend to appear in definite order of frequency which is peculiar for each genus or family, but which, when plotted, gives a fairly regular frequency polygon, with one or two maximum points. The above statement applies to the number of spots in a row, and the length of bands, as well as to the number of rows of markings on the wings. These relations are too definite and orderly to be due to accident, and appear to be the expression of a natural law.

Among the other orders of insects I have shown that the color patterns on the body of Coleoptera, Orthoptera, Hemiptera, and Hymenoptera are composed of segmentally arranged spots, originating upon important sclerites or over muscle attachments. I consider the color pattern to be a segmental one, showing in successive segments a repetition of the same spots and color areas. Enteman has come to a similar conclusion concerning coloration in Polistes.

\section{PHYLOGENY OF COLORATION.}

The first thorough and consistent attempt to study and trace the phylogeny of insect coloration was made by Darwin, who developed around this subject to a considerable extent his theories of sexual selection, protective coloration, warning color, etc. Natural selection and segregation were for this author sufficient to account for the phenomena of insect coloration. The researches of Darwin, Wallace, Bates, Weismann, Poulton, Hasse, and others upon the coloration of insects, especially that in Lepidoptera, have developed a school which stoutly maintains that the brilliant colors of many insects, especially those in males, have been developed by a process of sexual selection. They likewise hold that mimicry, protective resemblance, etc., are due to selective influences alone, and Weismann has invented some ingenious theories to account for the rise of these phenomena by means of selection, natural, sexual, or otherwise.

Strongly opposed to the views of Darwin, Wallace, Weismann, and their followers is the theory promulgated by Eimer, who, in I889, conducted an extensive research upon coloration in the Papilionidx, and in 1898 published a still more extensive work along the same line. Eimer and his followers hold that the color patterns of insects are only slightly influenced by natural selec- 
tion, but are due to the influence of environmental conditions, food, moisture and temperature, which have caused variation along a few lines and in no others; and it is in these lines that species are developed by the segregation of units at points upon these lines of modification. This school holds the primitive color pattern to be that of longitudinal stripes which break up into spots and then fuse to form, first, transverse bands, and later a uniform color. New markings appear upon the body from behind forward and from above downward, or conversely, and old ones disappear in the same order and succession. Most of the data used in support of these views is drawn from the study of adult coloration in Lepidoptera, wherein most of the bands and rows of spots are transverse. But Eimer and his pupils boldly maintain that these are longitudinal because parallel with the long axis of the body, and they base their arguments for the validity of their doctrine thereon. With the exception of von Linden, all of Eimer's followers base their conclusions upon the study of adult color patterns, arranging these in series convenient for their purposes. Von Linden has studied the ontogeny of coloration in a number of Lepidoptera, and claims that her results are in strong accord with Eimer's views. However, an impartial examination of her observations and figures fails to reveal any real confirmation of the theories so vigorously defended. Likewise, the researches of Schäffer, von Bemmelen, Urech, Hasse, and Mayer fail utterly to give support to the views of Eimer and his pupils.

The researches of Piepers upon Pieridæ and the larvæ of Sphingidæ and my own studies upon several orders of insects show that there are definite lines of color-pattern development (phylogenetically), which are independent of environmental conditions and inherent in the animals themselves. Thus, in the Pieridæ, Piepers shows that red, orange, yellow, and white often follow in phylogenetic sequence, and black increases in amount as this progressive change goes on. Mayer holds that the force of Piepers's arguments is weakened by the fact that the colors of Pieridæ are produced by uric-acid derivatives, while those of other Lepidoptera are not.

In my paper of 1903 I have shown that in several orders of insects there are stages in development and many color-pattern features which are common to a wide range of insects, and that these are dependent upon physiological activities in a very definite way and are in no wise related to environment. Thus, in the pronotum of various Coleoptera, it is shown that even in distantly related families or in species living in diverse habitats there is a long series of developmental stages in common; and that it is only at the very end of the series that specific and generic differences come in. In this instance inherent structural and physiological characteristics are the controlling factors. Additional studies will undoubtedly verify and extend our knowledge of the range of these phenomena. 


\section{EFFECT OF ENVIRONMENT UPON COLORATION.}

Many well-known facts point to the immediate action of temperature, moisture, food, light, etc., upon the coloration of insects. That changes in temperature can and do effect modifications in coloration and dimorphism is abundantly proven by the work of Dorfmeister, Edwards, Weismann, Merrifield, Urech, Fischer, and Standfuss, while the last two authors have been able to produce an inheritance of the modification in the second generation. Seasonal variations as the result of the varying conditions of wet and dry seasons are of common occurrence in the tropics. As a rule, however, the modifications produced in experiments along this line have not been inherited in subsequent generations; and this has given Weismann, Poulton, and others a basis for strong arguments against the possibility of the validity of the Lamarckian doctrine of evolution in insect coloration through the inheritance of acquired characters.

PROTECTIVE RESEMBLANCE, WARNING COLORATION, MIMICRY.

Wallace's theory of warning coloration and Darwin's theory of protective resemblance, with its special phase of mimicry elaborated by Bates and Müller, have secured strong support from the observations in nature of Bates, Müller, Weismann, Tremen, and others, and from the experimental researches of Poulton and Finn. These phenomena can at present be best explained by the hypothesis of selection. Attempts at explanation by other theories always show lamentable weakness or peculiarities of logic not easily explained. In fact, natural selection as a cause of evolution in insect coloration receives its strongest support from the data and observations centered about these phenomena. Arguments against the theory of protective resemblance, warning coloration, and mimicry are few and of doubtful validity; and the facts used are cases of convergent evolution of questionable application. Altogether, no other phenomena, I believe, argue as strongly and successfully for the truth of the principle of natural selection as these marvelous phenomena of insect coloration.

THE PROBLEMS OF INSECT COLORATION TO-DAY.

It was truly and well said by Darwin that "the coloring of insects is a complex and obscure subject." Before we can proceed much farther in the subject we must understand better the nature, source, and development of color and color-producing substances and their relation to the physiology of the animals in question. When we have this knowledge at hand then shall we be prepared to investigate the action of environment upon coloration, and to understand more fully whether evolution has been along definite linesaccording to an orthogenetic principle, or fortuitous, guided by natural selection. 
At present the explanation of color phenomena is most difficult. Warning coloration, protective resemblance, and mimicry are, I believe, adequately and only explainable on the basis of natural selection. With other phenomena it is not so. The myriad hues and color combinations and patterns of insects and the brilliant colors of the males of many forms can not, I believe, be explained by natural selection, inheritance of acquired characters, orthogenesis, or mutation; at least no known explanation seems to be satisfactory to any considerable body of investigators. Nowhere else in the animal kingdom has evolution, as it were, so run riot as among insect colors; and yet its study has made comparatively little progress in recent years. The evolution of insect coloration in general seems at present to be practically inexplicable. A portion here and there is elucidated by one or another of the theories advanced; a few facts, a few laws, are known ; but, on the whole, our knowledge of these intricate and interesting phenomena is truly meager.

\section{THE COLORS OF THE GENUS LEPTINOTARSA.}

In the beetles which form the basis of this research, all of the three categories of color are found, either in the imagines or in the larvæ. These will be considered under their natural divisions.

\section{CHEMICAL，OR PIGMENTAL COLORS.}

It is to the colors of this category that the genus owes its characteristic coloration ; in fact, physical or chemico-physical colors enter but little into its color phenomena. In general the colors of the adults are cuticula and hypodermal, and those of the larvæ cuticula, hypodermal, and sub-hypodermal.

The cuticula colors, black, brown, and yellow, are at once recognizable by the fact that they are insoluble in water, alcohol, oils, ether, weak acids, or alkalis. In L. undecimlineata and decemlineata the black spots and stripes are not pure black, but a deep brown that owes its black appearance to the density of the deposit of pigment. If an elytron or a pronotum of one of these beetles be boiled in alcohol, water, or one of the essential oils at one atmosphere of pressure, even for several hours, no perceptible change in color is noted. Long standing in water or alcohol, or boiling in these reagents under two or three atmospheres pressure, will in a few hours result in complete extraction of the pigment. The same treatment with dilute $\mathrm{HNO}_{3}, \mathrm{HCL}$, $\mathrm{H}_{2} \mathrm{SO}_{4}, \mathrm{NH}_{4} \mathrm{OH}$, or $\mathrm{KOH}$ will produce solution after a sufficient period of boiling-two or three hours. These cuticula colors are absolutely permanent in these beetles, five years of constant exposure to light not effecting any perceptible change in them.

The black cuticula colors are uniform throughout the genus, $i . e$., they are due to dense deposits of a deep-brown pigment having the solubility and permanency given above. From the black we can pass through a graded series to the browns, such as those of the brown areas in $I_{r}$. zetterstedti, or the darkbrown spots and stripes of dilecta, belti, and others. The colors of these spe- 
cies are produced by cuticula pigments, are permanent, and are with difficulty soluble in the same reagents as the darker colors.

Between the browns and yellows transitions in the adult or in the larvæ are few, but in the ontogeny of the animal they are common, as in the development of the black or brown areas of the species mentioned. The yellow, as in L. decemlineata and its allies, is only slightly developed and is of no great permanence, fading on exposure to light, with age, or on treatment with reagents. It is in these beetles the least permanent of the cuticula colors, and is in fact of relatively little importance in the production of color patterns. ${ }^{1}$

The dark markings-that is, the black or brown spots-of the larvæ and pupæ of this genus are also cuticula pigments like those discussed above. These are the pigments described by Poulton in lepidopterous larvæ as "proper to the species."

When studied in sections of $3 \frac{1}{3} \mu$ to $6 \frac{2}{3} \mu$ thickness, these pigments are always seen to be diffuse and not in the form of granules, as claimed by Hagen, and recently by Enteman in Polistes. They are limited entirely to the primary cuticula, and the transitions from pigmented to unpigmented areas is rapid but continuous.

Always closely associated with the cuticula pigments in the production of color patterns in these beetles are the hypodermal pigments, which, as far as I know, are always yellows and reds in this genus. These two colors exist in the form of small granules in the hypodermal cells, and, although more or less permanent, they all fade at death or on exposure to light, and are easily soluble in water, alcohol, and other organic solvents. The chrome yellow so often seen in decemlineata when freshly emerged is due to these pigments; but undecimlineata never possesses them and is, therefore, of a white color with black markings. In decemlineata, however, the yellow color fades rapidly on exposure to light or with age, so that old specimens have the light areas between the black stripes nearly white. The white is opaque, however, and not translucent, as in undecimlineata. When freshly emerged from the pupa decemlineata has a distinct reddish color, which gives away to chrome yellow before the animal leaves the pupal cell, and later in life becomes white. In rubicunda, however, the red color is retained and grows more intense. It is not lost on exposure to light or with age, but fades to a dull yellowish white at death. In rubiginosa in life the color is deep red, but at death changes to a dull brick-red or yellow.

These same yellows and reds are also found in the larvæ of the species described, and, as far as surface observations can determine, are continued over from larva to pupa and imago. They are difficult to investigate in sections because the ordinary reagents of microscopic technic dissolve them completely long before the tissue is ready for study. By freezing, good

\footnotetext{
${ }^{1}$ These cuticula yellows must not be confused with the yellow colors often produced in the cuticula at death. These latter colors are due to post-mortem changes and to drying of the integument.
} 
sections have been obtained which show the location and character of these pigments.

The relation between the cuticula and hypodermal colors in the production of color patterns in these beetles is this: The hypodermal color plays the part of a ground upon which the darker browns and black stand out as spots and stripes; or, if the cuticula colors are extensively developed, the hypodermal colors show through holes and rifts in the cuticula color as lighter spots. Only rarely does one class prevail to the exclusion of the other. In rubiginosa the prevailing color is hypodermal, red, the dermal being confined to the appendages, whereas in modesta no hypodermal color is visible, and in puncticollis only a few small, yellowish spots are found.

The subhypodermal pigments play no part in the adult coloration of these beetles; for, although they are present in the larva, pupa, and imago, it is only in the larvæ of a few species that they are visible. When found the color is always a yellow or a reddish yellow, due to a modified, derived pigment, and it helps to intensify the yellow or red of the hypodermis. Sometimes, as in decemlineata, a change of food will change the nature of this derived pigment, and thereby the ground color of the larva. In this form larval color ranges from deep red to a pale yellowish red, due solely to variation in the subhypodermal pigment contained in the larval hæmolymph. In a few species, undecimlineata and diversa, the hæmolymph and fat body are unicolored, so that the larvæ have a white or a translucent appearance, depending upon their stage of development. These larvæ are translucent in early stages, but later on the development of the fat body gives them first a chalky white and then a pale creamy white ground color.

\section{PHYSICAL, OR STRUCTURAL, COLORS.}

Pure physical colors are absent in this genus, excepting white, which is produced by the fat body in larvæ (undecimlineata) or by reflection from crystals or other surfaces in the integument. This is of no importance in the coloration of the genus.

\section{CHEMICO-PHYSICAL, OR COMBINATION COLORS.}

In the larvæ and pupæ of Leptinotarsa these colors are wanting, but in the imago they, in connection with the cuticula colors, are productive of interesting changes. These changes consist in the forming of metallic colors, green, blue, violet, and combinations of these with black, green, greenish black, blue-black, etc., colors very common in this genus. These colors are all due to thin lamellæ over dark absorptive pigment. Scales and striæ are wanting, and pits are not developed sufficiently to produce physical color changes. The effect of these chemico-physical colors in this genus is to transform to a metallic color areas that would otherwise be a dull black, and thus in a simple but effective manner to produce differences, often of specific value. 


\section{THE DEVELOPMENT OF COLORS IN LEPTINOTARSA.}

\section{CHEMICAL OR PIGMENTAL COLORS.}

The most important of the chemical colors are those located in the cuticula and in the hypodermis. In the ontogeny of the animal, however, the cuticula colors are lost at each ecdysis, and are replaced by new developments thereof, whereas the hypodermal colors persist from larva to adult. In this account we shall first consider the development of the cuticula colors and the structures that carry them.

\section{CUTICULA COLORS.}

A section through the body wall of these beetles in any stage shows the following structures: On the outside is the primary cuticula, a layer of hard, homogeneous, unstratified material, everywhere of uniform thickness, not penetrated by pore canals, and carrying deep brown or yellowish diffuse cuticula pigments. Beneath this is a layer of varying thickness, composed of alternating layers of material having different refractive indices, and penetrated everywhere by minute pore canals, which reach outward to the edge of the primary cuticula. This layer is devoid of pigment, except in rare cases, and is always unpigmented in Leptinotarsa. The inner surface of this cuticula, the secondary cuticula, is uneven. Into the uneven places the hypodermal cells fit exactly, and from them send out long, delicate, protoplasmic processes, which fill the pore canals in life. The cells of the hypodermis vary in size and shape according to their position in the body and the ontogenetic stage of development in the individual. They are, however, always columnar, and are backed up on the inner surface by a delicate layer of mesodermal cells, endothelium, which lines the body cavity. In these hypodermal cells are found the granules of the hypodermal pigment and beneath them the diffuse subhypodermal color.

During the ontogeny of these beetles the integument undergoes a series of cycles of development whereby the cuticula colors are lost and redeveloped several times. These cycles of development are associated with ecdysis, and are important for the understanding of color ontogeny, especially that in the larvæ.

In the embryo, at about the end of the embryonic period, the cells of the hypodermis (ectodermal cells) secrete rapidly an even, homogeneous layer of cuticula over the entire surface. This layer is without visible structure, stains intensely in many stains, and is soft and pliable. No colors are seen at first; but in the few hours immediately preceding hatching color develops, at first as faint yellowish or opaque areas. These later change to a light yellowbrown, and remain so until after hatching, when they rapidly become darker, and finally black. These darker areas constitute the colors "proper to the 
species," and are developed in a short time-one or two hours after hatching. Almost as soon as the embryo emerges from the egg the primary cuticula begins to harden rapidly; and about the same time, and especially after the larva begins to feed, the secondary cuticula begins to be deposited, and its deposition continues until near the end of the first larval instar. The deposition of this second layer, however, does not completely separate the primary cuticula from the hypodermal cells, a connection being retained by means of the numerous protoplasmic processes occupying the pore canals of the secondary cuticula. Near the end of the larval instar the protoplasmic processes are withdrawn from the pore canals, the hypodermal cells lose their attachment to the lower side of the secondary cuticula, and the hypodermis and cuticula separate. The ordinary process of ecdysis now removes the old cuticula; but before this is accomplished a new, fresh, colorless layer of primary cuticula has developed beneath the old.

With each succeeding ecdysis all the cuticula colors of the entire body are lost and are redeveloped in the few hours immediately following. Although they usually reappear in the same areas where they existed in the previous stage, this process allows of variation in the coloration from instar to instar. The development of the cuticula color is always the same, no matter whether in a freshly hatched larva or in the transforming imago. Likewise the stages are the same-a cloudy appearance in the primary cuticula, and then a faint yellow followed by darker yellow, brown, and black. Cessation of development through any cause at any point in this series gives for the permanent coloration that color of the stage when development ceased. At each renewal of the colors the full development is attained in a short period of time immediately following the casting of the old cuticula covering.

Without exception in this genus, and, as I have shown, in insects in general, the successive development of cuticula color in the ontogeny of insects follows the same lines laid down in the general account of the process and its repetition. We shall now consider in detail the development of cuticula colors in this genus.

\section{THE CUTICULA, I'TS S'TRUC'TORE AND COMPOSITION.}

It has been shown by Vossler and Tower that the cuticula portion of the body wall of insects is composed of two distinct kinds of substances-an outer, homogeneous, primary cuticula, and an inner, stratified, secondary cuticula. The inner layer differs from the outer in that it gives a cellulose reaction and is akin to carbohydrates. The outer layer of the cuticula is, I believe, a derivative of some gelatinate and the secondary cuticula a carbohydrate.

Pupæ of decemlineata, two to five days old, taken before pigmentation or deposition of the secondary cuticula had begun, were crushed in a mortar, washed in distilled water, to remove all loose material, and then macerated with I per cent $\mathrm{KOH}$ for twenty-four hours at $18^{\circ}$ to $22^{\circ} \mathrm{C}$., with frequent 
agitation. By this method all tissues were removed and pure, or nearly pure, quantities of the primary cuticula were obtained and subjected to various tests.

Ledderhose showed that "chitin," in cold, concentrated solutions of HCL, or $\mathrm{H}_{2} \mathrm{SO}_{4}$, when dropped into water at $100^{\circ} \mathrm{C}$., gave glucosamine or glucose, which reduced copper suboxide in alkaline solution. This indicates, according to Ledderhose, that chitin is an amido-derivative of a carbohydrate. I have tried the following experiment with the primary cuticula prepared as above: Five grams of the dry primary cuticula were dissolved in cold concentrated HCL and the same amount in cold $\mathrm{H}_{2} \mathrm{SO}_{4}$. One cubic centimeter of each of these was then dropped into distilled water at $100^{\circ} \mathrm{C}$. and kept boiling for ten minutes, the solution being made alkaline with $\mathrm{Na}_{2} \mathrm{CO}_{3}$ and tested with copper suboxide. No reaction was observed, and it is certain that in this case there was no production of glucosides. Dilution of the solution of primary cuticula in concentrated $\mathrm{HCL}$ or $\mathrm{H}_{2} \mathrm{SO}_{4}$ with water, when tested with copper suboxide in alkaline solution, gave no reaction, thus showing the absence of glucosides or related carbohydrate compounds, although Strecher showed that chitin, dissolved in concentrated $\mathrm{HCL}$ or $\mathrm{H}_{2} \mathrm{SO}_{4}$, diluted with water, gave grape sugar and nitrogenous decomposition products $\left(\mathrm{NH}_{3}\right)$.

Chitin prepared from adult beetles by grinding, maceration, washing, and boiling in weak acids $\left(\mathrm{HCL}, \mathrm{HNO}_{3}, \mathrm{H}_{2} \mathrm{SO}_{4}\right.$, or $\mathrm{KOH}$, or $\mathrm{NaOH}$ ) until white, as done by Ledderhose and others, gives a product which is composed almost entirely of secondary cuticula, as I have before shown. If now 0.5 gram of this be dissolved in the cold in concentrated $\mathrm{HCL}$ or $\mathrm{H}_{2} \mathrm{SO}_{4}$, diluted with water, and the whole made alkaline and tested with copper suboxide, beautiful reductions of copper take place, showing the presence of abundant glucosides. It appears from these two experiments that from the primary cuticula no glucosides were produced in decomposition, whereas from the secondary cuticula there were abundant indications of them.

When dried primary cuticula was boiled in water under pressure for a long time, the result was a nearly complete solution, from which alcohol precipitated a colorless, gelatinous mass, which was, on further examination, found to give reaction tests for both gelatinates and albumen. No trace of glucosides was obtainable in this series of reactions. On the other hand, when secondary cuticula was boiled under pressure with water for a long time, the solution of a part was effected, and of the remainder when boiled in a slightly alkaline solution. This solution gave strong reaction for glucosides and carbohydrates, with traces of albumen and gelatinates.

We conclude from these experiments that the chitinous portion of the integument of these beetles is composed of two kinds of material recognized in sections by Vossler and Tower to be, the one an albumino-gelatinate, the other a carbohydrate or an amido-derivative of these, giving as decomposition products glucosides with traces of albumen and gelatinates. At present 
it is impossible to give formulæ for the composition of these two layers of the cuticula. This is a task for the organic and physiological chemist. Enough, however, has been determined for the purposes of this paper.

CHEMICAL EXAMINATION OF THE CUTICULA COLORS.

In making the examination of the colors of these beetles I have used fresh, dried, and alcoholic specimens of $L$. decemlineata, undecimlineata, multitceniata, rubicunda, dilecta, violescens, and signaticollis, and dried material of zetterstedti, lineolata, oblongata, signaticollis, and modesta. The isolation of the colors of these beetles is possible either by maceration, prolonged boiling in water under pressure, or by oxidation in strong mineral acids. Inasmuch as I have attained the same results by all three methods, I have made most frequent use of strong mineral acids as solvents of these pigments.

The method employed in preparing the pigmented material for extraction is as follows: Crush fresh, alcoholic, or dried specimens in a mortar, add distilled water plus I per cent of $\mathrm{KOH}$, and allow it to stand. Agitate at intervals of an hour or two, and at the end of twenty-four hours pour off the water and pound vigorously with a heavy pestle; then wash in running water for several hours, then in distilled water, and then dry. By this process all tissues are removed, as are also the smaller appendages, and the result is a nearly pure mass of chitin. L. decemlineata has proven the most satisfactory form to work with on account of the ease with which one can obtain unlimited material.

It has been shown by Coste and Urech, and more recently by Enteman, that the dark cuticula colors, when oxidized or acted upon by chemical reagents, undergo a series of progressive and regressive changes. Thus Enteman shows that the dark-brown or black areas of Polistes variatus, when acted upon by acids like $\mathrm{HNO}_{3}$, pass through a series of color changes, "deep red-brown, red-brown, orange-red, orange, orange-yellow, and pale yellow," and finally become colorless. If, however, the process of oxidation be interrupted at any point before the transparent stage, and the material be washed with water and treated with alkalis $\left(\mathrm{NH}_{4} \mathrm{OH}\right)$, color changes of reverse series set in, with the end result of restoring the original color. An exactly similar series of observations has been made upon decemlineata, signaticollis, rubicunda, violescens, modesta, and other species. Treatment with strong acids $\left(\mathrm{HNO}_{3}, \mathrm{H}_{2} \mathrm{SO}_{4}, \mathrm{HCL}\right)$ or with aqua regia result in the change of the dark pigment to dark brown, then to deep reddish-brown, orange-red, orange-yellow, and then to a colorless condition. Treatment with alkalis before the colorless stage produces a reverse series of color changes; but I have not been able to get a complete restoration of the original color, a small amount having gone into solution with the dissolving of the outer portion of the cuticula. If in either the progressive or regressive color changes the process be stopped by washing and neutralization, any intermediate color can 
be obtained in permanent condition. For example, if the black spots on the pronotum of decemlineata be treated with $\mathrm{HNO}_{3}$ until the color is reduced to a reddish brown, and is then washed and the acid neutralized, it will remain reddish brown for as long a time as the state productive of the color persists. In the case of brown species, like zetterstedti, I have not been able to produce black or a darker color by chemical processes, although lighter colors can be easily obtained. In these beetles the blacks are not real black, but are dense deposits of a dark-brown pigment which appears black by reflected light, and in zetterstedti the deposit of this brown pigment is not dense enough to allow of the development of a darker color. This deep-brown pigment seems to represent the end of a series of compounds beyond which no known chemical or natural process seems to be able to produce any that are darker. It represents the extreme of specialization of these pigments, but not necessarily the extreme of their chemical complexity.

Bottler, working on the hair of animals and on silk, has shown these pigments to be azo compounds, and in insects they belong to this same series. I have Iately made a second examination of them in I.eptinotarsa, and I find that my present results confirm entirely the views expressed in my I9O3 paper. I have previously shown that these colors are soluble in alcohol. If now an alcoholic solution of the cuticula pigments of $L$. decemlineata be made acid with $\mathrm{HCl}$, and put into a test tube with some mild reducing agent, as metallic tin, the solution passes through a series of color changes like those described above, finally becoming colorless. Any mild oxidizing agent will, on the other hand, produce the reverse series of color changes and restore the original color. This same series of color changes is found in the case of the azo compounds, of the hydrazo, azo, diazo, oxyazo, and amidoazo compounds series. That these colors are azo compounds can be further proven by the test with $\mathrm{H}_{2} \mathrm{SO}_{4}$, or with the glacial acetic-acid test. Thus, if a solution of the cuticula color of decemlineata in aicohol be added to a small amount of $\mathrm{H}_{2} \mathrm{SO}_{4}$, and then if $\mathrm{NH}_{4} \mathrm{OH}$ be added slowly and the whole shaken, the solution will acquire a rose color, the depth of color depending upon the degree of dilution. These tests are reliable and indicate clearly the presence of azo pigments.

We are safe, then, in concluding that these cuticula pigments are azo compounds, but whether they are azo, diazo, oxyazo, or amidoazo is not known. Their color and color reactions suggest a similarity to the oxyazo compounds, but this similarity is possibly only superficial.

DEVELOPMENT OF CUTICULA COLORS.

The first study of the development of these colors was made by myself in I900, when I advanced the view that they are secretions elaborated by the hypodermis and poured out upon the surface of the cuticula. Later I 
abandoned this view and concluded that the colors arise as the result of the action of a katalytic agent or enzyme upon the primary cuticula, which produces a hardening of the cuticula and the development of cuticula colors. This view is supported by microscopic and experimental evidence and by the isolation of enzymes that are able to produce colors. Later, Dewitz has obtained similar results in the study of the brown cuticula colors of lepidopterous pupæ. Recently, however, Enteman, discussing the color of Polistes, holds that the pigment is elaborated from the protoplasm of the hypodermal cells and passes through the pore canals to the outer surface, where it gathers in large drops which spread over the surface and fuse. This view, I believe, is not supported by any adequate evidence. ${ }^{1}$

In a former paper I have shown that neither light, oxidation, drying, nor kindred external agencies are factors which bring about the development of these colors, but that their cause is located within the animal itself. Here also it was shown that enzymes are active in the production of color changes. Since the publication of that paper I have experimented further upon species of this genus with the following results:

EXPERIMENTS POINTING TO THE EXISTENCE OF ENZYME ACTION.

In I895 I found that pupæ of decemlineata kept at temperatures of $43^{\circ}$ to $45^{\circ}$ C. showed a most peculiar phenomenon. In pupæ that were dead and had begun to undergo postmortem changes, the cuticula colors of the head, pronotum, and legs were observed to continue changing, often until the dark areas were normally developed. Since then I have often observed this in high-temperature experiments. Sometimes the color pattern developed is abnormal, but the colors are always normal in every way. I have found that other species-undecimlineata, multitcniata, rubicunda, dilecta, violescens, and signaticollis-also behave in the same manner; so that it appears that the phenomenon is a general one in the genus.

In low temperatures, $0^{\circ}$ to $-5^{\circ} \mathrm{C}$, which produce a great mortality, no color has been observed to develop. In these experiments both of the extreme temperature conditions produce an equal degree of mortality, but in one, color develops after death, and in the other it does not. Similar results have been observed in experiments with extreme conditions of moisture.

That this color development is due to causes within the animal and proper to it and not to outside factors, such as bacteria, temperature, or moisture, has been shown by the experiments which follow.

It is known that chloroform vapor stops the growth of bacteria and the ordinary activities of animals, but that katalytic agents are not affected by its presence. In a former paper I have given some experiments along this line, and I shall now add a new series upon the beetles of this genus. Pupæ

${ }^{1}$ A recent study of color development in tropical species of Polistes shows that there is no foundation for the belief expressed by Enteman. 
of decemlineata, undecimlineata, signaticollis, multitcniata, and dilecta were taken just as the development of pigment began, and the specimens of each species were divided into three lots. Of these one lot was killed in a vapor of $\mathrm{HCN}$, and then placed in an atmosphere saturated with chloroform vapor; another was put alive into the same conditions, and the third was kept for control. Of those put into the atmosphere of chloroform vapor, all, both living and dead, showed color development, and more than half in a normal manner.

I have shown in a former paper that if the pupæ are put into chloroform vapor before the pigment is ready to develop, color formation is permanently inhibited; and this I find to be true with several species of Leptinotarsa. These experiments point to the conclusion I had before reached that the development of cuticula color is not due to external agencies, nor to secretions, but to the action of an enzyme or katalytic agent upon the cuticula itself.

During the last two years I have investigated the development of these enzymes, especially in Leptinotarsa, and I find my later results wholly confirm those given in my former paper, but I have not been able to learn more of the nature of the chemical processes involved nor of the compounds produced.

The existence of enzymes in the hypodermal cells can be shown in two ways-by microscopical examination, or by extraction and partial isolation. Their action has been demonstrated by microscopical study and experiment with the extracted enzymes.

The microscopical proof of the existence of enzymes and their action is demonstrated by the study of the developing cuticula color in sections after proper killing and staining. I have studied these substances in L. decemlineata, multitaniata, signaticollis, and dilecta with the same results in each species, so that their development is probably the same in the entire genus.

In the extraction of the chitases of Leptinotarsas I have made use of the same methods given in a former paper ( 1903$)$. Most of the extractions were made in 35 per cent alcohol and 2 per cent glacial acetic acid, or in 50 per cent alcohol and to per cent glycerin. Both proved satisfactory solvents.

With extracts of decemlineata, multitcniata, and signaticollis experiments were tried that confirm and extend the observations given in my 1903 paper. With the extract made from the pronotum of decemlineata experiments were performed as follows:

The experiments were always performed under as nearly aseptic conditions as possible, in sterilized dishes, with distilled sterile water, and always in the presence of chloroform vapor, thus insuring as nearly as may be freedom from error.

Experiment I.-One cubic centimeter of the alcoholic extract of the enzymes from the pronotum of decemlineata, and a similar amount from the pronotum of signaticollis, plus o.I per cent glacial acetic acid, were placed in 
sterile test tubes and diluted with I cc. of distilled water. After twelve hours, into each of these tubes was placed the pronotum of the corresponding species, which had been taken from the pupæ before the enzyme had developed in the hypodermis below, and had been freed from all hypodermal cells. After thirty-six hours the tubes were examined, and each pronotum had developed a normal dark-brown color over its entire surface, but without any tendency to form spots.

Experiment II.-A series of tubes were prepared as in Experiment I, and were placed at temperatures of $0^{\circ}, 5^{\circ}, 10^{\circ}, 15^{\circ}, 20^{\circ}, 30^{\circ}, 35^{\circ}, 40^{\circ}, 42^{\circ}$, and $45^{\circ}$ C., and at the expiration of forty-eight hours the cultures were examined. In the tubes at $0^{\circ}, 5^{\circ}$, and $10^{\circ} \mathrm{C}$. no action had taken place. In those from $15^{\circ}$ to $30^{\circ} \mathrm{C}$. results like those in Experiment I were found. In tubes kept at $35^{\circ}$ to $40^{\circ} \mathrm{C}$. the development of color was accelerated with the increase of temperature, but at $42^{\circ} \mathrm{C}$. development was practically wanting, and at $45^{\circ} \mathrm{C}$. no color whatever appeared. At the expiration of seventy-two hours, in the tubes at low temperatures, color was found to be developing in those at $10^{\circ}$ C., and at $5^{\circ}$ C. a trace was found, but none at $0^{\circ}$ C. At the end of ninetysix hours color development had ceased in all tubes above $15^{\circ} \mathrm{C}$., the deepest colors being produced in tubes kept at $35^{\circ}$ to $40^{\circ} \mathrm{C}$. At the end of ten days the color development had entirely ceased in all tubes, with the result that at $0^{\circ} \mathrm{C}$. no color developed, at $5^{\circ}$ to $10^{\circ} \mathrm{C}$. dark color appeared, from $15^{\circ}$ to $30^{\circ} \mathrm{C}$. color as in Experiment I, and at higher temperatures as stated above.

Experiment III.-To tubes of extract.prepared as in Experiment I above, the pronota of species not proper to the extract were added; $i e$., in extract from signaticollis pronota of decemlineata were placed, and vice versa. These were kept at laboratory temperature $\left(17^{\circ}\right.$ to $22^{\circ} \mathrm{C}$.). At the end of three days the tubes were examined and a trace of color was found; at the end of six days this had deepened somewhat, but rather irregularly, and all activity had ceased at the end of ten days.

From the preceding experiments and study of the development of these colors in Leptinotarsa, it follows that cuticula colors deevlop as the direct result of an enzyme action upon the primary cuticula, which produces azo colors and at the same time a hardening of the cuticula. It further appears that color development in experiment is stopped at $0^{\circ} \mathrm{C}$. and at $40^{\circ} \mathrm{C}$., that it is most developed at about $10^{\circ} \mathrm{C}$. and at $35^{\circ}$ to $40^{\circ} \mathrm{C}$, and that there are average conditions between these two. Color appears in spots under natural conditions, and over the entire surface in experiment, which indicates that the color-producing enzymes are produced only in certain areas and not over the entire surface. It seems probable that a group of closely related enzymes are at work, the most general one being chitase, which produces the hardening of the cuticula. 
HYPODERMAL, COLORS.

The hypodermal colors in this genus are red, orange-red, orange, yellow, pale yellow, and pale yellow-white. Of these the reds, yellows, and pale yellow-whites are most permanent, but all fade on exposure to light, with age, or at death. They are products of the metabolism of the hypodermal cells, in the ectodermal portions of which they exist as granules, and serve as a background for the pattern formed by the cuticula colors. They are practically the same over the entire animal, only rarely exhibiting local variations. They are permanent throughout life, persisting through larva and pupa into the imago, where they form the lighter portion of the color pattern.

CHEMICAL, EXAMINATION OF THE HYPODERMAL, COL,ORS.

The chief hypodermal colors are yellows and reds, or combinations thereof. They exist as granules in the hypodermal cells of the larva, pupa, and imago.

If an elytron of decemlineata be taken a day or two after emergence, when it is of a yellow color, and treated with dilute acid, the yellow become orangeyellow, orange, orange-red, and then red, and this color is made permanent if the wing be washed free of acid and dried. Alkalis, on the contrary, reduce this red to a yellow, and further reduce the yellow to a colorless or whitish condition, from which it is not possible for it to regain the original yellow. Portions of the integument of rubicunda, which has a bright red color in life, are changed to yellow by alkali and to pale yellow-white if the treatment is continued; but if they are washed and soaked in dilute $\mathrm{HCl}$ the red color is permanently restored. With rubiginosa like results may be obtained. If integument from undecimlineata be treated with acids, a progressive series of changes from the normal pale yellow-white to a wine-red color follows, and the reverse series accompanies treatment in alkalis. These changes can be repeated several times in the same specimen.

Color reactions like these have been described by Coste and Urech in the scales of Lepidoptera, and by Zopf and others in Coccinellidx. Zopf has shown that these colors in Coccinellidæ are lipochromes; and the red and yellow alternatives found in Leptinotarsas suggest that these are the same.

All of the hypodermal colors are easily soluble when treated in alcohol or ether, and often in water, giving solutions which on concentration by evaporation have the color of the insect treated. Acids and bases produce with these solutions progressive and regressive color changes as described above. I have also made with them repeated tests for azo pigments, but no trace has been detected, and I hold that they are in no way related to azo colors, as is claimed by Enteman.

Tests for the presence of lipochromes with Soudan III and like reagents show decided reactions indicating the presence of fatty pigments of the lipochrome series. 
MICROSCOPICAL, EXAMINATION OF HYPODERMAL, PIGMENTS.

The study of these colors by cytological methods is difficult, owing to their solubility in alcohol and essential oils, but by freezing good results may be obtained with ease. In frozen sections of the integument of decemlineata, signaticollis, rubicunda, and other species, these pigments exist as granules in the cytoplasm of the cells. In such sections color reactions and changes like those described above may be observed, and the color changes followed in the case of individual granules.

When frozen sections carrying the lipochrome pigments are treated with an alkali (KOH), I.5 per cent aqueous solution, the color is destroyed, but the bodies or granules remain as pale yellow-white granules which stain strongly in Soudan III. These are soluble in ether, benzol, or allied oils, leaving very characteristic round vacuoles, which are often found in ordinary microscopical preparations.

DEVELOPMENT OF HYPODERMAL, PIGMENTS.

We may conclude that these hypodermal pigments found in granular form are lipochromes, a conclusion based upon their color reactions, solubility, and specific tests. They are present as complex molecules attached to fatty bodies which are developed in the cells. These fatty bodies first appear in the embryo, and are left behind on the extraction or destruction of the colorproducing molecules. They may be extracted by ether, oils, etc., leaving characteristic vacuoles in the cytoplasm. It appears that the pigment-producing substances and the fat bodies are separate, the fat body acting merely as a nucleus about which the color-producing molecules gather. From these they may be dislodged by prolonged action of alkalis, when they show the characteristic alternations of color found in lipochromes. This phenomenon is due, I believe, to a change in the molecular arrangement of the color-producing substance-isomerism-and not to the presence of two or more associated colors, one of which appears in the acid state and the other in the alkaline. In some species, undecimlineata, diversa, and their larvæ, the only hypodermal color present seems to be the pale yellow-white produced by the lipochrome pigment nuclei; while others, as decemlineata, have developed through stages of undecimlineata to a yellow and yellow-red condition of these pigments, and still others, as rubicunda, have reached a full red. The same phenomenon is seen in other groups of the genus.

DIFFUSE HYPODERMAL, PIGMENTS

In larvæ and in some pupæ and imagines the cytoplasn of the hypodermal cells is seen to be uniformly yellow or yellow-red or rarely a dull red. These colors fade quickly on exposure to light and are soluble instantly in water and alcohol. They are not lipochromes, nor are they in any way related to them, as they do not appear until after the development of the lipochromes and after 
feeding has begun. They are not related to the azo-cuticula colors, but are simply the derived pigments of the hæmolymph that have been absorbed into the hypodermal cells. In every way they behave as do the subhypodermal colors. They can be studied only in frozen sections.

\section{SUBHYPODERMAL, COLORS}

These colors were first recognized by Poulton in lepidopterous larvæ. Later I distinguished them in phytophagous Coleoptera. In Leptinotarsa they are present in all larvæ, and are directly derived from the pigments of the food. They have been studied in the same manner as were the Lepidoptera by Poulton, and with the same results. As they are purely larval colors and are modified by temporary conditions and in no permanent manner, they may be passed by without further comment.

PHYSICAL, COLORS.

The only physical color in Leptinotarsa is white, and this is due to total reflection from the granules in the fat body in larvæ and the fatty lipochromebearing bodies of the hypodermal cells. These colors are relatively unimportant in the evolution of color patterns and need no further mention.

\section{CHEMICO-PHYSICAL, COLORS.}

No complicated colors of this class are found in this genus of beetles. Metallic colors-green, violet, copper, and blue-with faint metallic reflections over many dark areas, are all the chemico-physical colors that these beetles display. Iridescent colors or those due to scales are lacking, as are also those due to pits, striæ, etc.

The manner in which these colors are produced has been described in a former paper. In forms like violescens the violet color is due to the differentiation on the outer surface of a highly refractive portion of the primary cuticula which is only slightly pigmented, and the development just beneath this of dark azo colors. Light impinging upon the surface is acted upon by refraction in such a manner that the violet and blue rays are reflected and the rest are absorbed in the pigment beneath. The result is that the surface has a dark violet color, and when to this is added the white light reflected from the surface a metallic appearance is produced. As far as I know, this is the only method of chemico-physical color formation in this genus.

This outer, modified portion of the primary cuticula appears only after the beginning of the dark azo colors. As these develop, the chemico-physical colors grow stronger and stronger as the amount of pigment increases until it reaches its full intensity.

In the main the colors of these beetles are of chemical or pigmental origin. They are due to cuticula or azo pigments or to hypodermal or lipochrome pigments, and in larvæ slightly to subhypodermal or derived pigments. Phys- 
ical colors are rare and chemico-physical of no great importance. The color patterns, therefore, are largely pigmental, although to these may be added a few instances of the specialized categories of color in the more specialized species. As far as the colors themselves are concerned this genus exhibits a full development of pigmental coloration, with the earliest stage in the development of the more highly specialized physical and chemico-physical.

\section{THE ONTOGENY OF COLOR AND COLOR PATTERNS,}

\section{IN THE, LARVA\&.}

The ontogeny of larval or youthful ornamentation in animals has received little attention from zoölogists, although most interesting, suggestive, and conclusive data may be obtained from this source. Paleontologists, especially Hyatt and his pupils, have obtained some notable results from their studies along this line on fossil organisms.

I have shown in a former paper that the color patterns of insects are of segmental origin and that the various spots and stripes are in all probability

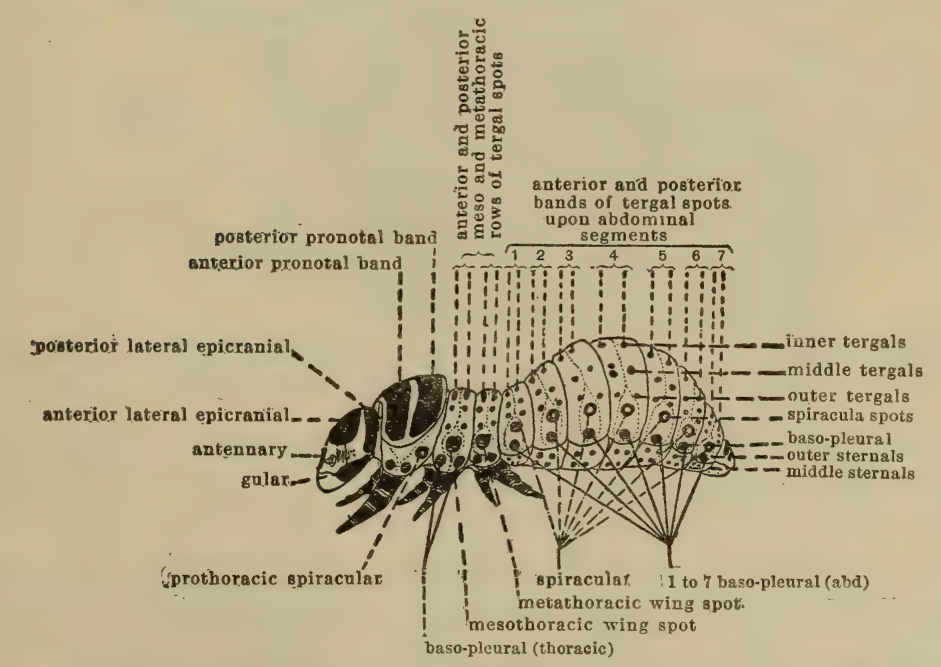

TEXT-FIGURE 7.-Diagrammatic representation of the centers of color development found in the young larvæ of Leptinotarsas. Drawn from a young larva of $L$. undecimlineata, as seen in side view.

directly derived from modified or combined, segmentally placed centers. In Leptinotarsa this idea has been put to a most exact test with the result, as will appear in the following pages, that it appears to be in all respects valid.

In the young larvæ of very many Chrysomelidæ, Coccinellidæ, Cassidæ, and other forms is found a system of color centers which is highly suggestive and, as we shall see later, ideal in its simplicity. In late embryos or newly hatched 
larvæ of many Leptinotarsas (undecimlineata, decemlineata, signaticollis, etc.) we find color areas or centers which are represented diagrammatically in textfigure 7 as seen from the side, and in text-figure 8 as seen from above. An abdominal segment (text-fig. 9), which represents the simplest condition, shows the skeletal ring composed of paired tergæ, pleuræ, and sternæ. Upon each of these are color centers which are placed in a constant morphological position and have definite relations to the structure of the animal. Upon the tergum are found on either side of the median line three pairs of color centers divided by a crease or furrow into two series. These are designated the outer, middle, and inner tergal centers, and they exist as an anterior and posterior series (text-figs. 7 and 8). Each of these centers may consist of one, two,

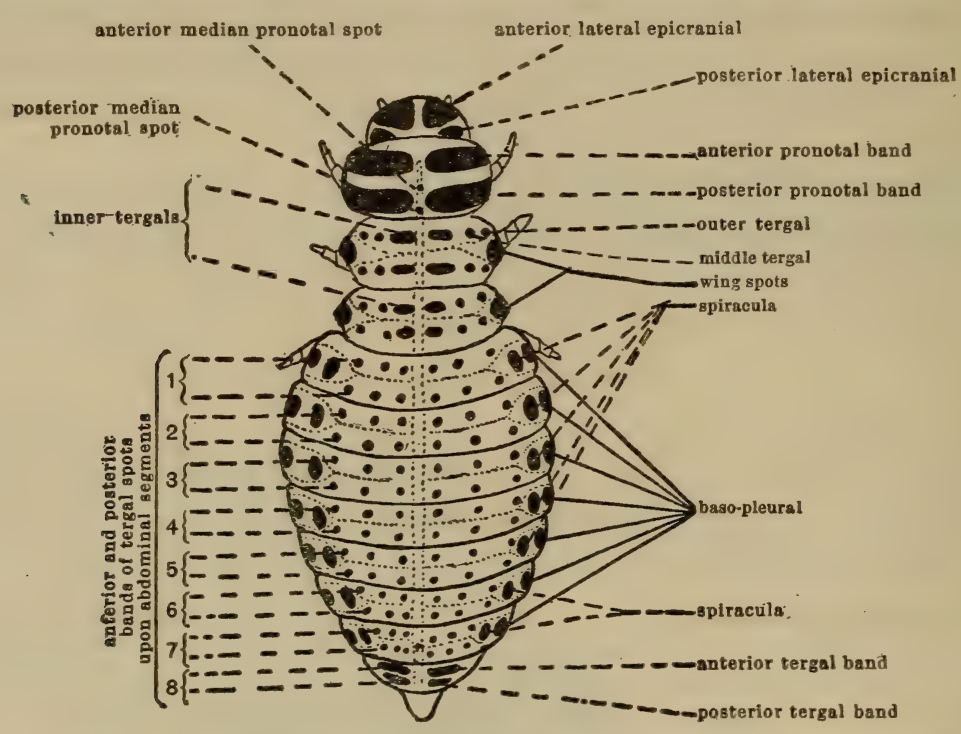

TEXT-FIGURE 8.-Diagrammatic representation of the color centers shown in text-figure 7 when seen from the dorsal side.

or three small, closely placed spots, and in many species they are the locations of spines. This type of coloration is found not only upon all the tergæ of the abdominal segments, but also upon the last two thoracic tergæ. Upon the anterior thoracic tergum or pronotum, however, there appear in the larvæ the anterior and posterior pronotal bands (text-figs. 7 and 9), which are homodynamous with the anterior and posterior tergal system of centers of the posterior segments. This same type, further obscured, is seen in the epicranium, where there exist the anterior and posterior lateral epicranial areas, each homodynamous with the abdominal tergal areas. The anterior and posterior median spots (text-fig. 8), which often appear upon the pronotum, are the only ones not found in this series of abdominal tergal centers. On the side 
pieces or pleuræ, on all abdominal segments and on the prothoracic segments, are found the spiracular spots which are represented on the wing-bearing segments by the wing spots. Beneath these, on the abdominal segments, at the base of the pleuræ, are one or, rarely, two basal tergal spots (text-figs. 7 and 8 ).

On the sternæ also a series of color centers is found corresponding to those of the tergæ in that there are outer, middle, and inner areas, but these are rarely present as anterior and posterior systems, although frequently in variations there are found strong indications of this anterior and posterior division. These areas continue forward in a homodynamic series over the thoracic segments.

This system of color centers is not confined to the Coleoptera nor to a few families thereof, but is, I find, of most general occurrence among the Tracheates, and,as I shall show in another paper, is the fundamental pattern upon which all insect coloration is founded. With this system of color centers it

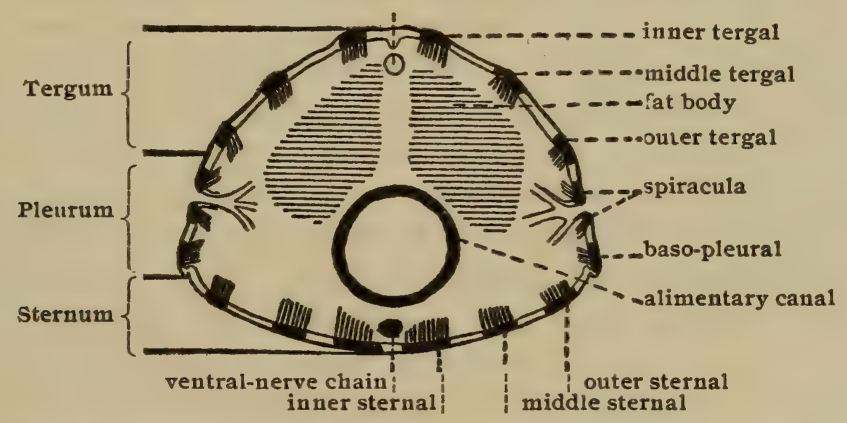

TEXT-FIGURE 9.-Diagrammatic representation of a segment, showing the position of the different spots upon the sclerites which compose it.

is a simple process to develop longitudinal stripes or transverse bars, or both, or combinations thereof. It would also be easy for the followers of Eimer to see in this a system of longitudinal stripes, and for others to see a system of transverse bars, as the fundamental color pattern. In truth, however, this system of color centers is neither of the latter; it is a metameric repetition of homodynamous areas, or modifications thereof, on every individual segment; and any other interpretation is warped in favor of some particular theory. It is true that the various elements may be so modified as to give on superficial examination the general idea of stripes or bands, and as such these combinations do function in color patterns; but in ontogeny and phylogeny, in experiment and in heredity, each metameric portion of any such color marking behaves as a metameric structure, and in no other way.

In the larvæ of $L$. undecimlineata at this time the color scheme is to a large extent the same as that shown in text-figures 7 and 8, excepting that the anterior and posterior pronotal stripes and all the areas of the epicranium are combined into one uniform black color. Upon the abdominal and last two thoracic 
segments, however, the elementary color pattern is retained in full, as may be seen by comparing fig. I on plate I 7 with text-figures 7 and 8 . Each color center bears one or more single or slightly branched spines on the tergal and sternal sclerites of each segment. In the pleural region these spines are small, and are limited to the baso-pleural centers. As the small larvæ push about through the abundant trichomes on the leaves of their food plants, a large accumulation of these become lodged among and cemented to the spines by the secretion of the dermal glands, until the larva presents the color and appearance of a ball of dislodged trichomes. At the first ecdysis the color pattern of the larva changes strikingly, as is shown in fig. 2 on plate I7. In the second stage the epicranium and pronotum remain black, while all the color centers are lost, excepting the abdominal and prothoracic spiracular spots, the wing spots, and the baso-pleural thoracic spots. The integument in this second stage is smooth and entirely devoid of spines on the tergal and sternal elements of the segments. Owing to the sticky secretion of the dermal glands a deposit of trichomes gathers on the larva in this stage, though, owing to the absence of spines, this deposit is thinner than in the previous stage. The true body color now is a pale, transparent greenish-white, as is shown in the figure. Between this stage and the final one shown in fig. 3 on plate $\mathrm{I} 7$, there are no modifications in the color markings, although the general body color is changed to an opaque, pale yellowish-white, which is due solely to the development of the fat body. In the final stage the increase in the body surface, which is not accompanied by any great increase in the number of dermal glands, results in there being on the body only a very slight deposit of trichomes, if any at all, so that the larvæ are freely exposed on the leaves of their food plant. The final body color varies from a pure white to pale lemon yellow, the average condition being represented by fig. 3 on plate 17.

The nearest relative of $L$. undecimlineata is $L$. diversa, and it is of interest to compare the ontogeny of the larvæ of the two species. In the first instar diversa has the appearance and all the characteristics of a larva of undecimlineata at the same stage of development. In fact, the larvæ of the two species are then alike, as may be seen by comparing figs. I and 4 on plate I 7 . During the first instar L. diversa has likewise the habit of covering itself with the trichomes of its food plant, so that the two can not be distinguished from each other either in coloration or in habits. The second instar is, as in undecimlineata, very unlike the first, there being a striking loss of color centers and of spines, while in color and habits the two species are at this stage almost duplicates of each other, as may be observed in figs. 2 and 5 . In the final stage, however, as is shown in figs. 3 and 6, there appear striking differences between the two species in color and color pattern. L. diversa now develops a series of black tergal markings that are characteristic and constant, and which clearly differentiate the two species of larvæ. The black tergal mark- 



\section{Explanation OF Plate I7.}

This plate illustrates the changes in the coloration exhibited by the larvæ of several species of Leptinotarsa during their ontogeny.

Figs. I, 2 and $3, L$. undecimlineata Stál. From Tierra Blanca, Vera Cruz.

Figs. 4, 5, and 6, L. diversa (n. sp.). From Guadalajara, Jalisco, Mexico.

Figs. 7, 8, and 9, L. signaticollis Stål. From Cuernavaca, Morelos, Mexico.

Figs. Io, II, and 12, L. multitaniata Stâl. From Guadalupe, Federal District, Mexico.

Figs. 13, I4, and 15, L. oblongata (n. sp.). From Cuernavaca, Morelos, Mexico.

Figs. 16, 17, and 18, L. rubicunda (n. sp.). From Toluca, Mexico, Mex.

Figs. 19, 20, and 21, $L$. decemlineata Say. From Chicago, Illinois.

Figs. 22, 23, and 24, L. juncta Guer. From Experiment, Georgia.

Figs. 25, 26, and 27, L. haldemani Stål. From Cuernavaca, Morelos, Mexico.

Figs. 28, 29, and 30. L. dilecta Stål. From Cuernavaca, Morelos, Mexico.

Figs. 31, 32, and 33, L. violescens Suffr. From Orizaba, Vera Cruz.

Figs. 34, 35, and 36, L. rubiginosa Rogers. From Santa FÉ, Federal District, Mexico. 

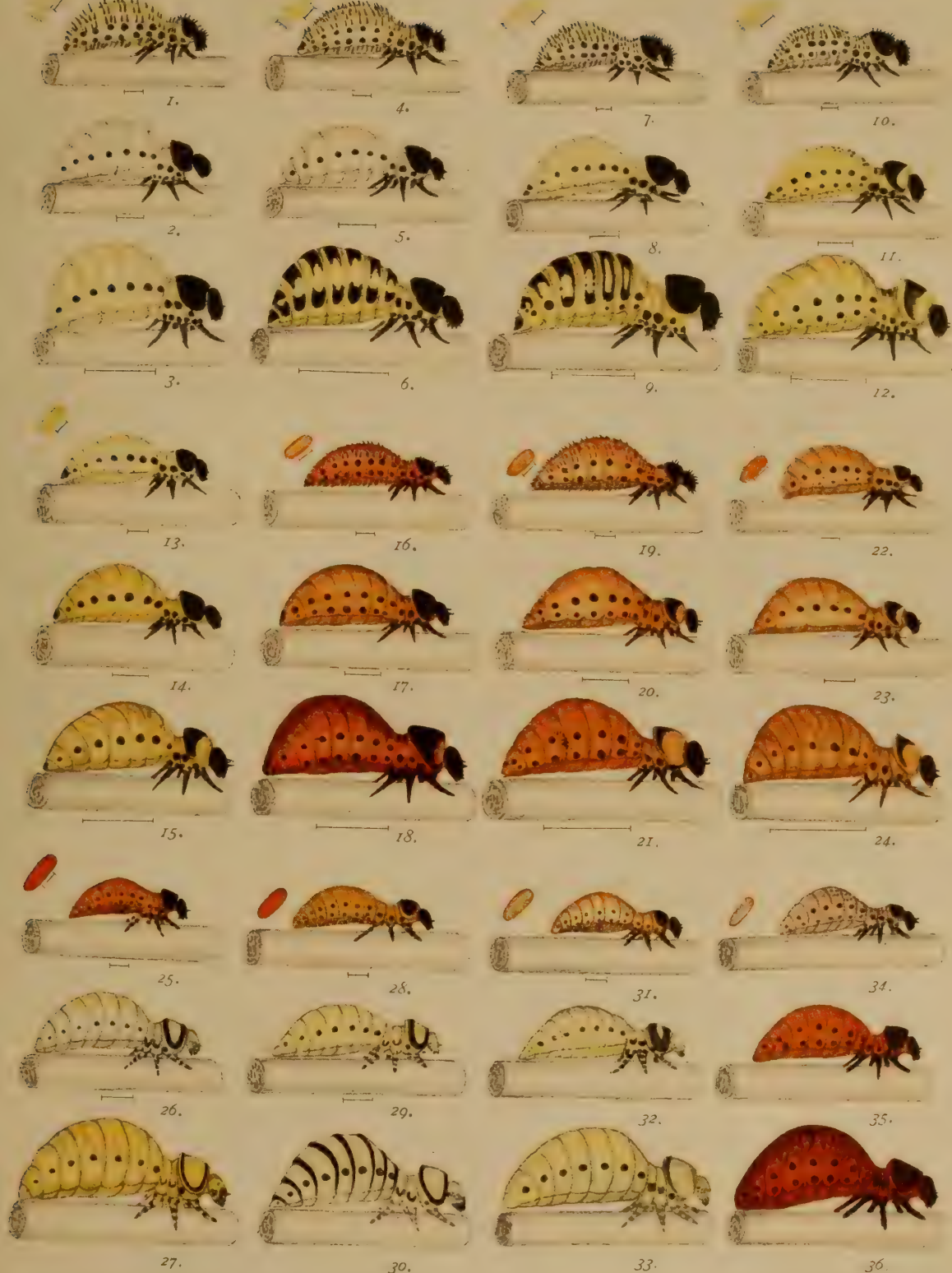

W.L.T. del. 

ings develop around the centers of color described as anterior and posterior bands, which later fuse, first in the middle portion of the body and still later toward the ends, but which are always distinguishable laterally. These markings are confined to the abdominal segments. The general body color also changes in this stage from the pale, transparent lemon yellow of undecimineata to a chalky or ocher yellow. The color of the head, and sometimes that of the pronotum, shows a change to brown, as do also the legs.

Closely allied to the two preceding species is signaticollis, whose larval coloration has ontogenetic stages very much like those of diversa. The first stage in signaticollis (pl. I7, fig. I) is the same as the corresponding ones in diversa and undecimlineata; the spines and viscous secretions enable the trichomes of its food plant to become entangled and cemented to the body in signaticollis in the same manner as in the two species just described, so that in life on their native food plants the three species are indistinguishable. So, too, the second stage of signaticollis is like the second stage of the other two species, in that all excepting the spiracular, wing, and basal-pleural thoracic spots are lost; and there is the same habit of decorating the body surface with the trichomes of its food plant. In the third and last stage, however, occurs a striking change in coloration and habits. The color centers now redevelop color on all the abdominal segments excepting the first three or four basopleural spots and the anterior and posterior tergal areas (pl. I7, fig. 9). The tergal bands arise on the three pairs of tergal centers and fuse first distalward, and then, beginning mediad, fuse caudad to some extent; but a large part of both tergal bands remain free, as in the figure given. Sometimes the two do not fuse or coalesce at all, but are clearly distinct. The general body color likewise changes from a pale, transparent yellow to an opaque ocher or chrome yellow. This change is due first to the appearance of lipochrome pigments in the hypodermis, and, second, to the development of the opaque yellow fat body. There is a striking parallel in the ontogeny of the coloration of diversa and signaticollis.

In L. multitceniata and its allies the color development is also suggestive. The first larval stage (pl. I7, fig. Io) has a color pattern exactly like those of undecimlineata, diversa, and signaticollis, the four species being in their coloration so nearly alike in the first larval stage as to be indistinguishable. L. multiteniata, however, does not have the habit of covering its body with trichomes, and it soon develops a deposit of bright yellow lipochrome hypodermal pigments, which give it a bright yellow color of about the same shade as the large, hard yellow spines of its food plant, Solanum rostratum. In the second stage of development a change of coloration occurs, but one not as pronounced as those in the three species just described. In multiteniata all the spiracular, wing, and basal-pleural spots are retained in this stage, as are also the inner and middle pairs of tergal centers on the last two thoracic and the first three or four abdominal segments (pl. I7, fig. II). The body color 
is also bright opaque yellow, quite different from the translucent pale yellow of the previously described species. Upon the pronotum a change is also found in the reduction of the anterior pronotal band. In the last stage, which is shown in fig. 12 on plate 17 , almost no further change of coloration is found.

Closely allied to multitcriata are oblongata, decemlineata, rubicunda, and juncta. L. oblongata, which in the adult condition is almost undistinguishable from multitceniata, is in the larval stages quite different, as may be seen from the representation of the first larval stage in fig. I3 on plate 17 . In this form the only color centers that are represented are the spiracular, wing, and baso-pleural thoracic spots. All other spots, as well as all spines, are wanting in the earlier stages of this species. Like multitceniata, it is at first almost white, but soon changes to corn yellow. In the second and third stages no modifications of color occur, excepting the loss of the anterior pronotal stripe in the last stage, although the general body color gradually becomes more opaque and yellow (pl. I7, figs. I4 and I5). This species, oblongata, is quite remarkable for its early complete loss of all but a few color centers; but that the animal is not without the fundamentals of these is shown by their brief appearance in the late embryo, and by their reappearance as color centers in the pupa and imago.

L. intermedia, rubicunda, and decemlineata present stages of development almost exactly like those of multitcniata. All have in the first larval stage a complete system of color centers and a full armament of spines, as are shown in rubicunda in fig. 16 , and in decemlineata in fig. I9 on plate 17 . The general body color of these forms differs from that of multitcniata in that rubicunda is bright red, intermedia a dull yellow, and decemlineata a dull red. In the second stage each of these four retains the spiracula, wing, and all basopleural spots, and the inner and middle tergal pairs of color centers on the last two thoracic and the first three or four abdominal segments. The outer part of the anterior band on the pronotum is lost in rubicunda in the last instar, and in intermedia and decemlineata in the second instar.

The species juncta and defecta also exhibit interesting stages of color ontogeny. In juncta, in the first larval stage, only the spiracular and baso-pleural spots are present, and there are no spines (pl. I7, fig. 22). In the second and last stages (figs. 23 and 24) the baso-pleural spots have been obliterated, so that only the posterior pronotal band remains, while the baso-pleural spots of the thoracic segments are small or wanting. Often all the color areas are light brown in color.

These species of Leptinotarsa all belong to the lineata group, which contains the most generalized members of the genus. In the coloration of the larvæ of these beetles I find that in undecimlineata, signaticollis, angustovittata, diversa, multitceniata, intermedia, decemlineata, rubicunda, and melano- 
thorax, the first larval stage has a color pattern of a generalized character, with all the color centers described in the beginning of this section clearly represented. The second stage, however, shows in all a marked change in color pattern in the reduction of many centers. The centers first to go are the posterior tergal and sternal, and the last are the thoracic baso-pleural, while the spiracula and wing centers are never lost, although the posterior members may be reduced. On the pronotum it is the anterior band that is reduced. In the species oblongata, juncta, and defecta the first larval stage possesses a color pattern like the second stage of the other species of this group; and if the color centers not found in the larvæ appear at all it is only in the embryo as very transient characters, or in the imago. Thus it appears that these centers are not lost when the stages are missing, but are only quiescent.

In other groups of this genus the larvæ likewise show stages or series of stages which are of interest. These, however, do not present the generalized conditions found in the lineata group, although the coloration of the larvæ of the entire genus starts with a condition comparable to the earlier stages in that group. In haldemani and violescens the first larval stage shows the spiracular, wing, baso-pleural, and sternal centers of coloration on the anterior four or five abdominal segments. The general body color is red, due to red lipochromes in the hypodermal cells (pl. I7, figs. 25 and $3 \mathrm{I}$ ). In the second stage of both species all of the color centers are lost, excepting the spiracular and wing and traces of the baso-pleural thoracic spots. The wing spots are reduced to crescentic markings and the pronotal bands are much reduced, as is shown in figs. 26 and 32 , plate 17 . On the head the reduction of color is carried to the extent that all dark markings are lost, excepting the retinal pigment and that at the tips of the mandibles. There is also a marked change in the body color from opaque reddish to a nearly transparent pale yellow-white. In the last stage the reduction of the dark color is somewhat more marked, but the chief change is in the body color, which becomes pale opaque yellow in violescens and corn yellow in haldemani (pl. I7, figs. 27 and 33 ).

In L. dilecta is found a series of color-pattern stages which are in the main comparable to those just described for haldemani and violescens. The larva is at first red, with spiracular, wing, baso-pleural, and sternal centers of coloration represented, and with spines on the ventral surface (p1. I7, fig. 28). In the second stage all excepting the spiracula and wing centers are lost, the pronotal stripes are reduced, and color disappears from the head. The body is a general transparent pale yellow-white. In the last stage the color becomes grayish yellow, the anterior tergals unite to form bands, the wing spots are mere crescentic lines, and the larva shows the condition rather unusual for this genus, which is shown in fig. 30. In forms like rubiginosa larval development starts with the centers much reduced, and finally reaches the condition shown on plate 17 , fig. 36 . 
In all of the species in which the ontogeny of larval coloration has been described, and in all in which it has been studied, there appear sharply marked stages, some generalized, others highly specialized. We find, also, that certain color centers are exceedingly persistent, and others transient; that, in general, the tergal and sternal centers are the less persistent, and that the posterior members are more variable in their degree of permanency than the anterior. The sharp demarkation of stages is, of course, due to the phenomenon of ecdysis, which periodically removes one entire set of coloration characters and affords an opportunity for them to be replaced by a similar set or a different one, as the case may be. In the phenomenon of ecdysis there are at work processes of high importance. Thus, in the first instar in $L$. diversa, there are groups of metamerically arranged cells which develop the necessary enzyme for the production of the color centers, and, accompanying them, are cells which develop spines; but at the first ecdysis these spines are all removed, which means that the setigerous cells hold in abeyance their power of forming spines. Likewise, the cells which develop the enzyme necessary for the formation of the many centers of coloration in the first stage do not exercise this function in the reconstruction of the color pattern during the first ecdysis, and only the spiracula, wing, and basal-pleural thoracic centers retain this function through the first ecdysis. At the second ecdysis, when the second color pattern is removed and the third is developed, color-enzyme forming cells, inactive in the formation of the second pattern, become active and produce the dark tergal markings of the last larval stage. These tergal markings develop first about the primary centers, but they are soon joined by deposits of pigment, and thus form the anterior and posterior bands.

The pigment and its formation is the same in both sets of colors; but why does color appear in some centers in the first stage and disappear entirely in the second, and then reappear in the third stage in increased area? Here are fundamental processes which will be considered at some length later on.

As has been stated, all traces of the cuticula colors are removed at ecdysis, and only the general body color is left to the larva. On its emergence from the old larval skin the larva is yellow, red, or some other color, depending upon the color of the body, and is without a trace of dark markings, excepting the pigment of the ocelli on the head. The first dark colors to develop are the spiracula and wing spots, which are a homodynamous series of color centers, and the color in these areas may even begin to form before the larval skin is cast off. The color changes have been described elsewhere and need not be restated. Color next appears in the appendlages of the head-first in the mandibles, next in the palpæ and other mouth parts, then in the legs, and finally in the baso-pleural centers. In figs. I to 4 , on plate 18 , is figured the development of the second color pattern of signaticollis, and in figs. 5 to 8 , on the same plate, that of the third color pattern for the same species. 
At ecdysis in this genus the color pattern or the dark elements thereof develop around the centers of color and from there spread out to form larger colored areas. In sequence the development is as follows: (I) Spiracula and wing, (2) baso-tergal, (3) inner tergal, (4) middle tergal and inner sternal, and (5) outer tergal and middle and outer sternal. The anterior members appear earlier and are at all times more completely developed than are the posterior members of the same homodynamous series. Exceptions to the above are found only in some few species, in the larvæ of which the sternal centers develop before the tergal. These exceptions are of such small moment in larval coloration that they may be passed over as of no significance. It is of interest to note that the order of the appearance of color centers at ecdysis and of their development in the embryo are identical. In fact, ecdysis, at regularly recurring periods reduces the color pattern of a larva to an embryonic condition from which may arise the same color pattern or a new one; but the new pattern is always developed around the same old centers.

In the ontogeny of the coloration of the larvæ each species studied passes through a series of stages, beginning with one more or less simple or generalized and ending with another of a more special character. Some species, as, for example, undecimlineata and signaticollis, start with a very generalized color pattern and pass rapidly through stages which end in a fairly specialized condition. Other species, oblongata and dilecta, do not begin their larval coloration with as generalized a pattern as does undecimlineata and others, but with a pattern which corresponds very exactly to the second stage in the development of the color in undecimlineata. In these instances have we an example of Hyatt's principle of acceleration? And have we here also the existence of localized stages in development corresponding to phyletic stages? These are questions whose discussion can best be postponed until after we have examined the data of the ontogeny of imaginal coloration.

The ecdysis at pupation removes all traces of larval cuticula colors, so that such colors as exist during the pupal stage are developed therein. The pupal stage, which is passed in the ground, is in most species characterized by an absence of color, excepting the spots upon the abdominal tergæe and sternæ, which in some species, as, for example, in signaticollis and oblongata, are modified into black bands. These areas of markings, which can be of no possible use to the animal, as it is completely hidden in the earth, represent simply the revival of the color-producing power of the cells in the tergal and sternal centers. All this pupal coloration, however, has no relation to that of the imago, as it is cast away at emergence. The imaginal color develops either under the pupal skin before emergence or in the hours immediately following the final transformation. 
IN THE IMAGINES.

In all the species of Leptinotarsa which I have studied, the development of the imaginal color pattern begins in the latter part of the pupal stage and is completed after emergence while the young imago is still in the pupal cell. The full intensity of the adult coloration is not attained until after the beetle has emerged from the ground and has been feeding for several days, that is, just before it begins to breed. Soon after reproduction has commenced, however, the colors begin to fade.

\section{The Ontogeny of Color on the Epicranium and Pronotum.}

The color patterns on the epicranium and pronotum begin to develop on the average about three days before the final transformation; but in some species, and in individual instances, the time may be longer or shorter. Thus, in decemlineata, color may appear on the epicranium four or five days before the insect emerges, while in oblongata, dilecta, and other species there may be no trace of color upon these parts until ten or twelve hours before the final transformation.

The color development upon the epicranium of undecimlineata is typical of those species which have a pattern composed of spots of dark cuticula color upon a lighter background. On plate I8, figs. 9 to I4, are represented six stages in this development. In the first stage (fig. 9) two lightly traced areas upon the epicranium are observed as two faint yellow-brown spots. These mark the beginning of the two centers $\left(g\right.$ and $\left.g^{\prime}\right)$ which in later stages fuse to form a median heart-shaped spot. On the pronotum no color is yet visible. A stage closely following this is represented in fig. Io, with the color on the epicranium deeper and with two new faint yellow-brown areas on the pronotum in the position later occupied by the spots $a$ and $a^{\prime}$. Simultaneously two color areas have appeared in the outer posterior portion of the epicranium, which are the beginnings of the spots $h$ and $h^{\prime}$. In each of the spots $a$ and $a^{\prime}$ on the pronotum there are traces of anterior and posterior centers which are usually visible for a brief period. In the third stage (fig. II) the spots $g$ and $g^{\prime}$ have grown considerably larger and have fused across the median line posteriorly, while $h$ and $h^{\prime}$ have also grown and extended medianward. On the pronotum $a$ and $a^{\prime}$ have increased in depth of color and have spread peripherally, while anteriorly new areas, the beginnings of $b$ and $b^{\prime}$ and $c$ and $c^{\prime}$, have appeared, and posteriorly $e$ and $e^{\prime}$ are recognizable. In the following stage (fig. I2), $g$ and $g^{\prime}$ have grown larger and have also extencled posteriorly until they almost unite with $h$ and $h^{\prime}$ in the median posterior portion of the epicranium. This union is completed in the next stage (fig. I3). Upon the pronotum $d$ and $d^{\prime}$ and $f$ and $f^{\prime}$ now appear, and the $a, b, c$, and $e$ spots have grown in size and depth of color. In the remaining stages represented (figs. I3 and I4) the color pattern is finished; $g$ and $g^{\prime}$ completely fuse with 
each other and also with $h$ and $h^{\prime}$ (fig. I4), so that the epicranium has a very considerable portion of its surface black. On the pronotum $a$ and $a^{\prime}$ fuse posteriorly with each other to form the usual V-shaped marking, and anteriorly with $b$ and $b^{\prime}$, while on either side $e$ and $f$ fuse with each other (fig. I4). The changes in the color of the cuticula pigments from a faint yellowishbrown through brown, deep brown, and opaque brown which appears black, are shown on the plate and are the ontological series of changes usual with colors of this class.

During the development of the cuticula color of the epicranium and pronotum the hypodermal color changes little, and the insect emerges as an imago with the pale yellow-white tint shown in figs. 9 to I2. Neither does the hypodermal color change to any extent during the life of the adult, excepting in the latter part, when it becomes white.

For the purpose of comparison, the development of the color pattern of the pronotum and epicranium of multiteniata is shown on plate 18 in figs. I5 to 20. In this series the figures show, as far as the cuticula colors are concerned, the same order of appearance of spots and increase in size and the same directions of fusion between the elementary centers as those found in undecimlineata. We note a change in the hypodermal color, however, in that there has been a slight development of a yellowish tinge; and after the insect leaves the ground and begins to feed this color appears rapidly, soon attaining the intensity characteristic of the sexually mature beetle (fig. 20). In this feature multiteniata shows a higher or more advanced degree of development than that found in undecimlineata. In other respects the type of ontogenetic development found in both species is, as far as the cuticula colors are concerned, the same as that found in all of the lineata group. In the development of the color on the epicranium and pronotum of melanothora.x (pl. I8, figs. 21 to 26), there are some features of interest. Comparison of figs. 2 I and 22 of melanothorax with figs. 9, Io, and II of undecimlineata shows little difference between the two species, excepting that melanothorax has crowded as much into two stages as undecimlineata has in three; or rather, melanothorax has pushed back to an earlier period in ontogeny the appearance of certain spots. In figs. 23 and 24 of melanothorax a difference begins to appear in that on the anterior border of the pronotum the anterior end of $a$, together with $b$ and $c$, become involved in a general band-like fusion, and the same takes place on the posterior end with $a$ and $d$ and $e$; thus are formed the anterior and posterior bands, which spread rapidly (fig. 24) and fuse until they finally cover the entire pronotum (fig. 25) excepting a narrow margin, which is also soon obliterated (fig. 26).

The cuticula colors in these three species, especially those upon the pronotum, have the same color centers as those which appear in the ontogeny of the larval colors, and they follow the same course of development. There are dis- 
tinguishable three anterior and three posterior centers, corresponding to the inner, middle, and outer pairs of tergal centers found in the larvæ. The inner and outer pairs of centers develop before the middle pair; and lateralward fusions form anterior and posterior bands such as are found in the larvæ and in the ontogeny of melanothorax. These fusions are of exactly the same type as those shown in the abdominal segments of larvæ of signaticollis.

Suggestive also along this same line are stages in the ontogeny of species like violescens and dilecta, which have a unicolorous pronotum. Stages in the color ontogeny of violescens are represented on plate 18 , figs. 27 to 32 , and of dilecta in figs. 33 to 38 . Figs. 27 to 29 show features of colo: levelopment in violescens comparable with stages found in melanothorax and to be interpreted in the same mianner.

Those species of Leptinotarsa which have unicolorous epicrania and pronota and some development of chemico-physical colors also present interesting stages of growth. Illustrations of the development of the color pattern of two such species, dilecta and violescens, have already been given and the earlier stages have been discussed. In the later stage the relation of the cuticula color to the appearance of the metallic luster of the adult is seen. In the stages shown on plate 18 it is evident that the cuticula color must precede the physical portion of the chemico-physical coloration and must reach a considerable degree of intensity before the latter can become visible; for as the cuticula color gains in intensity and absorptive power the chemico-physical color becomes more and more apparent.

\section{ThE ONTOGENy OF COLOR ON THE Wings.}

ON THE ELYTRA.

In Leptinotarsa no color develops on the elytra until after the animal has left the pupal stage and the elytra are fully expanded and possess a relatively firm texture. After their emergence from the pupa and the development of their adult form, these beetles, like most of the Coleoptera, spend many hours and often several days in the absolutely dark pupal cell; and it is in this period of adolescence that the wing colors are developed.

The ontogeny of coloration in the elytra of $L$. undecimlineata is shown on plate I9, figs. I to 6. In fig. I the elytron is represented as it appears several hours after emergence, when it is of a uniform pale yellow-white with delicate traces of dark color, and when the tracheæ are well filled with air and stand out conspicuously against the darker opaque body-color beneath. The first well-developed traces of markings are shown in fig. 2, where faint yellowbrown areas of color appear anteriorly in the costal and subcostal spaces and extend distalwards over perhaps one-third the length of the elytron. This color extends posteriorly, deepens rapidly, and also appears in the other interspaces of the wing (fig. 2); and this process is continued until each of the 

Explanation of Plate i8.

This plate illustrates the development of coloration in the larvæ at ecdysis, and upon the head and epicranium of the imago in the pupal stage.

Figs. I, 2, 3, and 4, L. signaticollis Stål, illustrate the change of the larvæ at the second ecdysis. From Tierra Blanca, Vera Cruz, Mexico.

Figs. 5, 6, 7, and 8, L. signaticollis Stå1, illustrate development of coloration at the second ecdysis. From Cuernavaca, Morelos, Mexico.

Development of coloration upon the epicranium and pronotum of the imagines:

Figs. 9 to $14, L$. undecimlineata.

Figs. 15 to $20, L$. multitaniata.

Figs. 21 to $26, L$. melanothorax.

Figs. 27 to $32, L$. violescens.

Figs. 33 to $38, L$. dilecta (green form). 

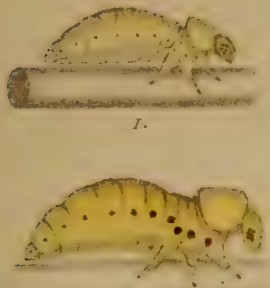

5.
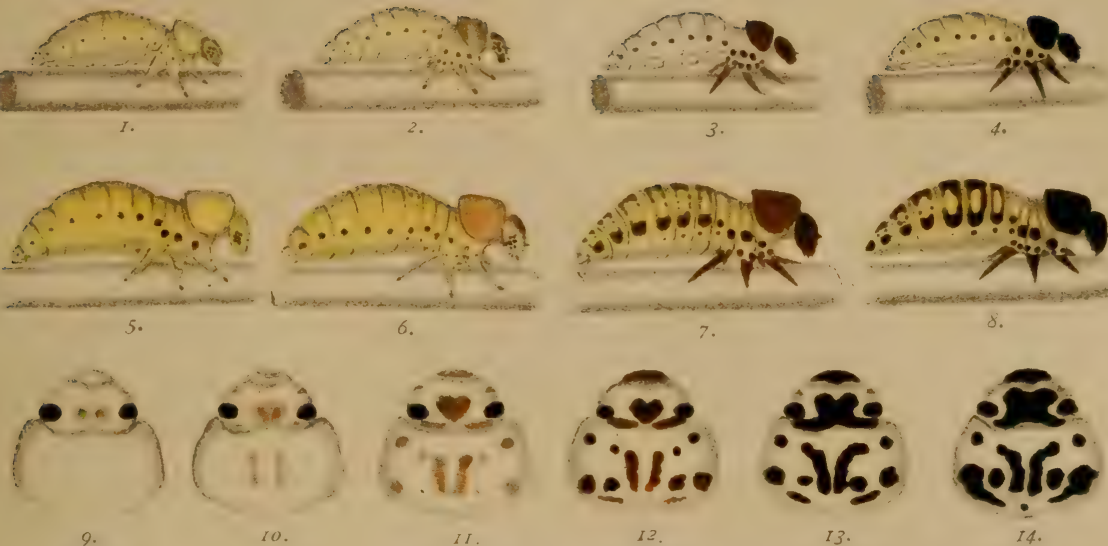

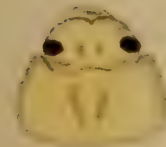

15.

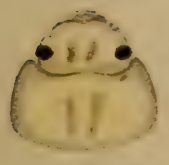

$2 I$.

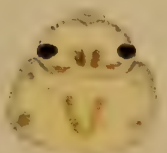

I6.

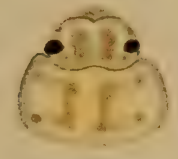

22.

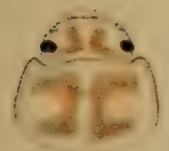

27.

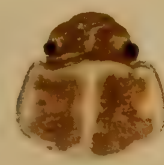

28.

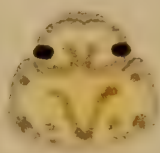

I7.

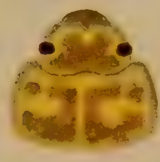

23.

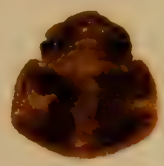

29.

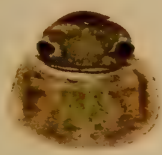

35.
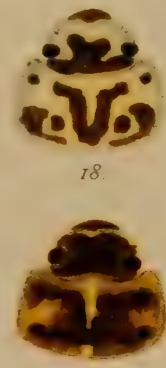

24.

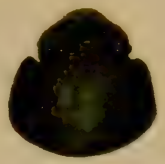

30

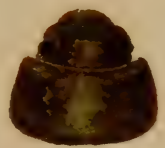

36.

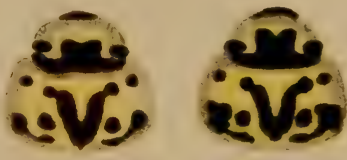

Io.

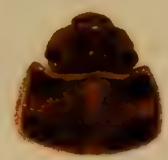

25 .

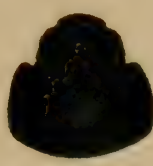

31.

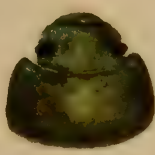

37
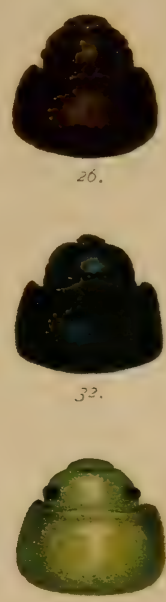

38.

W. L.T. del.

DEVELOPMENT OF COLORATION IN LARVAE OF LEPTINOTARSA AT ECDYSIS AND UPON THE HEAD AND PRONOTUM OF THE IMAGO IN LATE PUPAL STAGES 

adult color areas is delineated upon the elytron by a yellowish-brown deposit of pigment (fig. 3). The stages in development shown in figs. I to 3 are passed through rapidly, not more than forty-five minutes being required ordinarily for their completion, and frequently much less time than this; but after the color pattern is fully blocked out development proceeds much more slowly, many hours and often days being consumed in its completion. After the color pattern has been outlined the remainder of the developmental process consists in the gradual increase in the depth of color, which is simply the deposition of more and more dense azo pigments. In figs. 4, 5, and 6 are shown stages in this process as they appear from the surface.

When the elytral stripes have attained a fairly dark color (fig. 6), there appears a faint metallic green, which becomes more intense after the beetle has emerged from the ground and begun to feed. As the beetle leaves the pupal cell with its elytral coloration in about the condition shown in figs. 5 or 6 , it is necessary that a part of the development should go on after it has emerged and begun to feed. Thus the ontogeny of its coloration is distributed over a considerable period of time.

In allied species, as, for example, in multiteniata, there are found stages in color development of a similar nature, which differ only slightly in detail from those shown in undecimlineata. These are the periods of the demarkation of the color pattern and of the intensification of the cuticula color. In multitcniata, however, the ground color changes as development proceeds, beginning with the pale yellow-white and ending with the full yellow of the adult at sexual maturity. These color changes go on independently of the cuticula colors, as they are due to the development of the lipochromes in the hypodermal cells.

Likewise, in rubicunda, stages in the development of the cuticula colors are found which are like those in undecimlineata (pl. 19, figs. I9 to 24). The changes in the hypodermal color are greater and more rapid, however, than in either of the preceding species, beginning with the same pale yellow-white (fig. 2I), orange-yellow, orange-red (fig. 22), red (fig. 23), and finally becoming the bright red of the mature beetle shown in fig. 24 .

These three species, undecimlineata, multiteniata, and rubicunda, are all closely related members of the lineata group and might naturally be expected to show similar stages in ontogeny. Other members of the genus also present stages in development which are of interest; of these some are figured on plate 19.

In L. dilecta the development of the elytral coloration is shown in figs. 7 to I2, plate 19. The initial stage (fig. 7) differs in no respect from the corresponding one in the species of the lineata group, the beginnings of coloration observed here being in the proximal portion of the costal and subcostal spaces. In succeeding stages color spreads from these regions distally and 
caudalward, as shown in figs. 8 and 9, and in the line of the stripes found in the lineata group, excepting that almost no color is ever formed in certain parts of the stripes. In figs. 8 and 9 are shown the beginnings of the bands of spots placed between the elytral stripes. In fig. 9 the entire color pattern of the adult is outlined; and in figs. Io to 12 the color changes are simply those of intensification. The hypodermal or ground color (figs. 7 to 12) presents a series of changes much like those found in the lineata group. That which is of the greatest interest in the ontogeny of the elytral color pattern of dilecta is the fact that the bands of spots develop after the markings belonging to the intertracheal stripes have appeared and are fairly well marked out. These centers, which develop over the tracheæ and in rows transverse to them, represent possibly a younger system of color markings than that of rows between the trachex and parallel thereto. We can better interpret this relationship after we have examined the condition of color ontogeny in other species of this genus.

The elytra of $L$. zetterstedti, shown on plate I9, figs. I3 to I8, prescnt several interesting points in their ontogeny. The initial stage (fig. I3) resembles in general ground color the corresponding stage of other species; and the order of the development of the cuticula colors follows much the same course. These appear first in the intertracheal spaces at the proximal end of the wing and soon move distally (figs. I3 and 14 ). Then there are developed the transverse bands of spots which connect the intertracheal bands at certain points (fig. I5), and finally complete the outline of the adult color pattern (fig. I6). After the color pattern has been fully outlined the further development consists in the deepening of the cuticula colors and the slight changes observed in the hypodermal.

All the species thus far considered have a pattern consisting of dark markings upon a lighter background of hypodermal color. There are some species of Leptinotarsa, however, that have unicolorous elytra and an additional development of chemico-physical colors. A study of the ontogeny of the elytral colors of $L$. violescens will serve to show the features of color development in beetles of this class. The initial stage in violescens is shown on plate I9, fig. 25, where the uniformly yellow-white elytron is faintly tinged with light yellow-brown in the proximal portion of the wing, and especially in the intertracheal spaces. This stage, which is extremely transient, lasting only ten or fifteen minutes, is succeeded by the condition represented in fig. 26 , when the light yellow-brown has spread over almost the entire wing, but in the distal portion is still darkest in the intertracheal spaces. In a short time the entire wing becomes a uniform yellow-brown without any trace of bands, spots, or stripes, but it is still darker at the base than at the tip (fig. 27). The changes represented in figs. 25 to 28 take place with great rapidity, occupying frequently not more than fifteen or twenty minutes, and rarely over thirty; but 



\section{Explanation of Plate ig.}

This plate illustrates the development of the color pattern upon the elytra of several species of Leptinotarsa.

Figs. I to $6, L$. undecimlineata.

Figs. 7 to $12, L$. dilecta.

Figs. $\mathrm{I}_{3}$ to $18, \mathrm{~L}$. zetterstedti.

Figs. 19 to 24, L. rubiginosa.

Figs. 25 to $30, L$. violescens. 

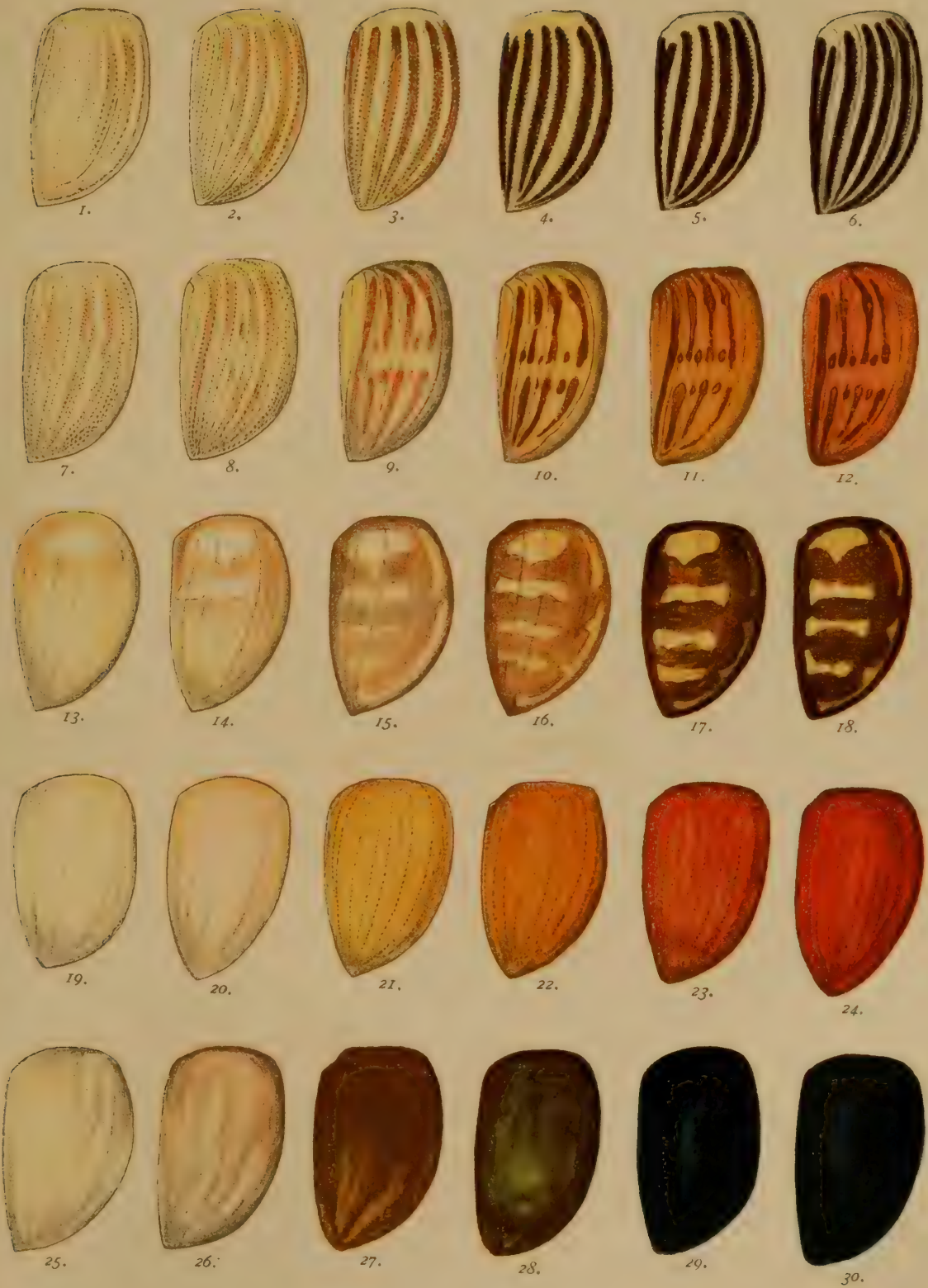

W.L.T. del 

after the wing has become uniform in color, development is slower, many hours being consumed in its completion. After the attainment of the condition represented in fig. 27 the wing turns darker (fig. 28), and then becomes nearly black (fig. 29). In fig. 28 a faint greenish color, which is due to physical causes, can be distinguished overlying the developing cuticula color. This physical color increases as the cuticula color deepens and becomes a more effectual absorptive layer, until from the faint greenish-blue tinge first observed a blue-black, and finally a violet-black, has developed, as is shown in figs. 29 and 30.

\section{ON THE HIND WINGS.}

Upon the secondaries or hind wings of Coleoptera the color pattern is always simple. In Leptinotarsa it consists of patterns in which the uniformly colored surface is broken by areas of bright color, usually red. On plate 20, figs. 21 to 32 , are given figures showing the ontogeny of the color in the hind wings of signaticollis, oblongata, and dilecta. In signaticollis, soon after the beetle leaves the pupa, the wing has the same opaque yellow-white color as the elytron (fig. 2I), and this is retained for some time. The adult color consists of faint yellow-drab at the base of the wing (fig. 22) and between the tracheæ, which spreads rapidly distalward (fig. 23). In later stages this becomes darker, and finally covers the trachex and the entire wings. The completed adult coloration is represented in fig. 24. In oblongata (figs. 25 to 28) and dilecta (figs. 29 to 32 ) are found similar stages, excepting that in these, as in oblongata, a red color develops after the yellow-drab and moves distalward from the basal portion of the wing to about its middle.

Fundamental likenesses are clearly distinguishable in the ontogeny of the color pattern of the wings of these beetles, even although they are specialized. Thus both possess initial stages which are identical as far as color is concerned, and both have a brief period during which the color pattern is marked out and a longer one during which it is developed. Further, in the development of both elytra and hind wings, color appears first proximally in the costal, subcostal, and ramous interspaces, and spreads distalward and caudalward.

The, ONTOge, OF Color on The ABdominal, and Thoracic Segments.

The development of the color pattern on the abdominal segments follows in Leptinotarsa the same laws which have been found to hold for Coleoptera in general. That is, the color pattern begins in a series of metamerically placed centers, and from these spreads out. This color development is represented on plate 20 as found on the ventral surface of the segments of undecimlineata (figs. 6 to Io) and of oblongata (figs. I to 5). In the figures given both have a similar initial stage in which the general pattern on the segments is a 
pale yellow-white hypodermal color, with the initial appearance of cuticula color on the anterior segments in the inner and outer sternal centers, although the middle sternal center lags somewhat behind the others (figs. 2 and 7). A difference between the two species may now be easily seen. In L. undecimlineata color spreads from the centers peripherally (fig. 8) until very soon dark bands are found completely across the anterior half of the segment, and these later extend caudalward and over the entire segment. In oblongata, however, color does not extend beyond the centers to any great extent, the modifications being limited to the fusions of centers shown in figs. 2 to 5 . As far as changes in the cuticula color are concerned both species pass through essentially the same stages.

The pleural and tergal portions of the segments show exactly the same phenomena of color development as those found on the sternæ. These are represented in side view in these two species in figs. I I to 20 . Upon all parts of the abdominal segments the centers of coloration found in the corresponding segments of the larvæ are preserved; and although in the adult these centers may fuse to form a unicolorous surface, the fact that in ontogeny it is in these centers that color first appears indicates that they are of great persistence as color units.

On the last two thoracic segments also the color development is almost exactly a duplicate of that found upon the abdominal segments. The homodynamous centers of coloration are clearly distinguishable and present in all respects the same conditions as those found upon the abdomen.

\section{GENERAL ASPECTS OF COLOR AND COLOR-PATTERN ONTOGENY.}

Studies upon the ontogeny of the color pattern on the body of insects are few, those of Kunckel de Herculais, of Enteman, and of myself being all that are extant, excepting a few fragmentary observations. All the observations that have been made along this line are, however, in accordance with the laws which I have found to apply in general to insects.

The general color development over the entire body in Leptinotarsa does not differ in any respect from that which I have described for many other genera of Coleoptera and other groups of insects, nor from that described by Enteman for Polistes. Color is seen first on the head in the pigment cells of the eye; and this appearance of pigment in the eye is the best indication that the color pattern is about to develop. Of the color pattern proper traces are found first upon the mouth parts and upon the epicranium in the paired centers already described; soon thereafter it appears upon the pronotum and upon the sternal elements of the thoracic and abdominal segments. Upon the dorsal side in most species the color lags behind, and on the wings in all species its appearance is postponed until after emergence, while the full adult color is not attained on any part until some time after emergence from the 
Explanation of Plate 20.

This plate illustrates the ontogeny of the coloration upon the abdominal segmeuts and the hind wings of several species of Leptinotarsa.

Figs. I to $5, L$. oblongata.

Figs. 6 to ro, L. undecimlineata.

Figs. II to I5, L. undecimlineata.

Figs. 16 to 20, L. multitaniata.

Figs. 21 to $24, L$. signaticollis.

Figs. 25 to 28, L. oblongata.

Figs. 29 to $32, L$. dilecta. 

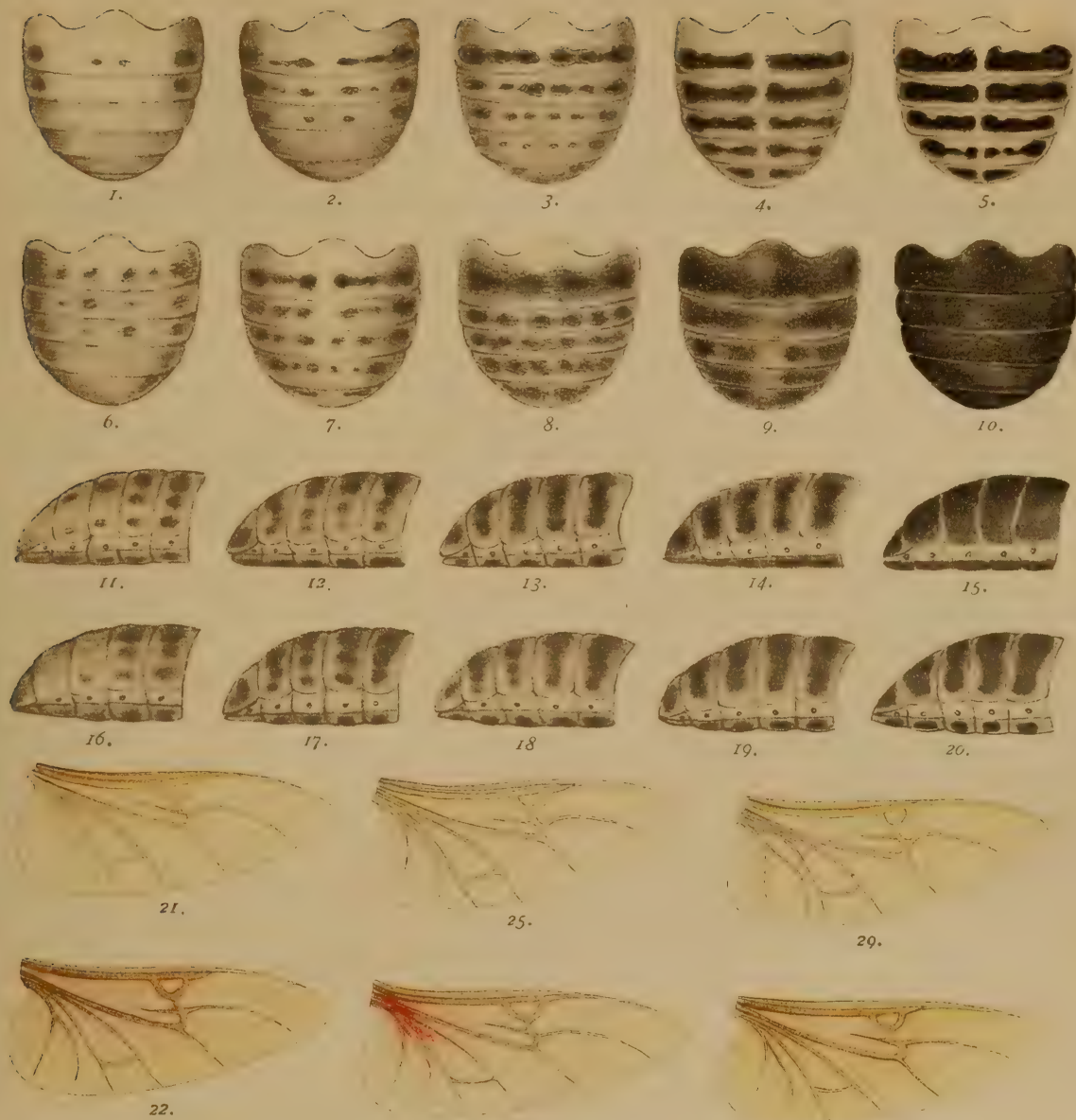

29.

22.

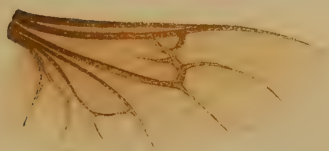

23.

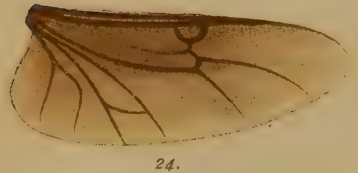

W.L.T. del

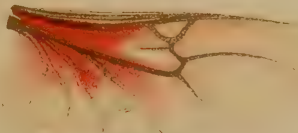

27.

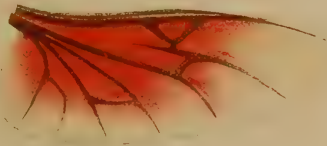

28.

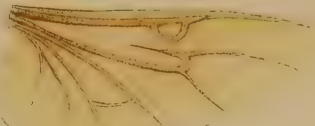

30.

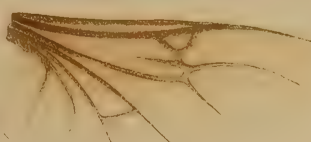

31.

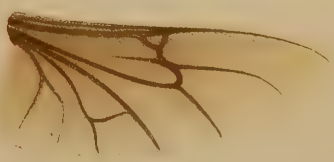

32.

ONTOGENY OF COLOR PATTERN UPON THE ABDOMINAL SEGMENTS AND

HIND WINGS IN LEPTINOTARSA 

pupa. These rules for the order of the development of insect coloration seem to be of almost universal application. This universal similarity in development, however, is exactly what we should expect to find in animals so definitely metameric as are the insects.

Of great interest and worthy of a most careful embryological investigation are the centers of coloration which are found in the larvæ, upon the various elements which comprise the segment ring. These centers as they appear in the late embryo are first recognizable as groups of cells which are associated with setigerous cells. These are observed to appear first upon the most anterior portions of the body and then to develop progressively caudalward, first upon the sternæ, then upon the pleuræ, and last upon the tergæ. Each center consists of setigerous and specialized hypodermal cells, which before each ecdysis may develop color-forming enzymes. These cells may be differentiated from the ordinary hypodermal cells by proper cytological methods. In the earlier stages in the embryo they are very few in number, but they multiply, and at hatching are often scattered thickly over the surface, as in the epicranium and pronotum of most young larvæ. In the larval stages and in the ontogeny of coloration at each ecdysis we have seen that the color pattern develops either around these areas or not at all. Of peculiar significance is the discontinuity in the larval patterns; but this is more apparent than real, because after a color pattern has been developed-as, for example, that of the first instar-there is no possibility of altering it excepting by ecdysis. The cells which are responsible for color formation show, however, no such discontinuity. Thus, in undecimlineata, the color-enzyme forming cells are active in the late embryo, the full phyletic number of color centers being then developed; but in the early part of the first instar these cells become inactive in all color centers excepting a few-that is, they form no zymogen granules-and, consequently, color is not developed anywhere excepting in the spiracula, wing, and baso-thoracic pleural centers, and upon the pronotum and epicranium. All of the tergal, sternal, and baso-pleural abdominal centers remain quiescent throughout the larval life, and become active again only toward the close of pupation. During this interval, however, they increase greatly in number, and late in pupal life are quite generally distributed over the body segments; so that the imaginal color of these parts is deep metallic black. In other species, as signaticollis, these cells lie dormant during the second instar, but become active in the third, and remain so throughout the pupal stage and in the imago.

The division of the centers upon the dorsal surface into anterior and posterior series is, I believe, due to the development of a fold in the integument of most larvæ, which results in the mechanical separation of each center into anterior and posterior portions. In the late embryo the cells are closely bunched, and it is only in the development which follows that the two sub- 
centers become differentiated. This separation of the centers into subcenters upon the tergal elements is, however, a constant feature of insect coloration, so that it must be a fundamental one which, as far as I am able to see, can have no other significance than that it is due to a mechanical division of each segment by a median fold. It appears to me to be entirely explainable on the basis of physiology and ontogenetic adaptation, and to be without any phylogenetic value.

All the evidence derived from study of the embryonic development of these centers points to the conclusion that they are true metameric structures which are produced by the successive division of mother centers as successive segments are marked out, and that the mother centers are probably derived from one or a group of blastomeres, yet to be distinguished, which arise early in the embryonic history. These homodynamous groups of cells I have been able to recognize very early in embryonic life, often at the time of the formation of the limb buds, and always soon thereafter. The existence of these homodynamous centers, their relation in later life to sclerite formation, attachment of muscles, and to the later color patterns, show them to be structures a knowledge of whose development and behavior is all important to the proper interpretation of insect coloration.

These centers or groups of color-enzyme forming cells may in the ontogeny of the insect become quiet, developing no zymogen, they may be entirely lost, or they may become extremely active and increase in numbers until they come to occupy larger or smaller areas in successive stages of the ontogenetic history. It is with these stages and the laws which they follow that we have to do largely in the study of color-pattern ontogeny. Upon the wings which form so conspicuous a portion of insect coloration there are other systems of fundamental coloration which we shall discuss presently.

During the ontogenetic development of these insects the behavior of the color centers follows closely along definite paths and in rather regular sequences. Thus, in the larvæ, it has already been shown that the spiracula and wing areas are the most permanent and least variable; that the middle, tergal, and sternal are the least permanent and most variable; and that the posterior members of each series are more variable than the anterior. In the ontogeny of the imaginal color patterns we have seen that the color develops around these centers, and in no other way. Thus, on the pronotum, color appears first at points homologous to the inner and outer tergal centers, and later in the middle tergal. Moreover, the inner tergal centers are frequently united to form the spots $a$ and $a^{\prime}$, while the middle and outer tergal centers are united anterio-posteriorly, but less frequently, there being a more frequent union between the middle and outer series, or between $d$ and $e$ or $a$ and $b$. A comparison of the figures given shows the equivalence between the color ontogeny of the pronotum and that on the abdominal segments. It 
is highly significant that these ontogenetic color changes, that is, the order, direction, and frequency of union of color centers, is the same as that of spots in individual variation. Thus we have in ontogeny the basis for understanding and interpreting the facts of variation.

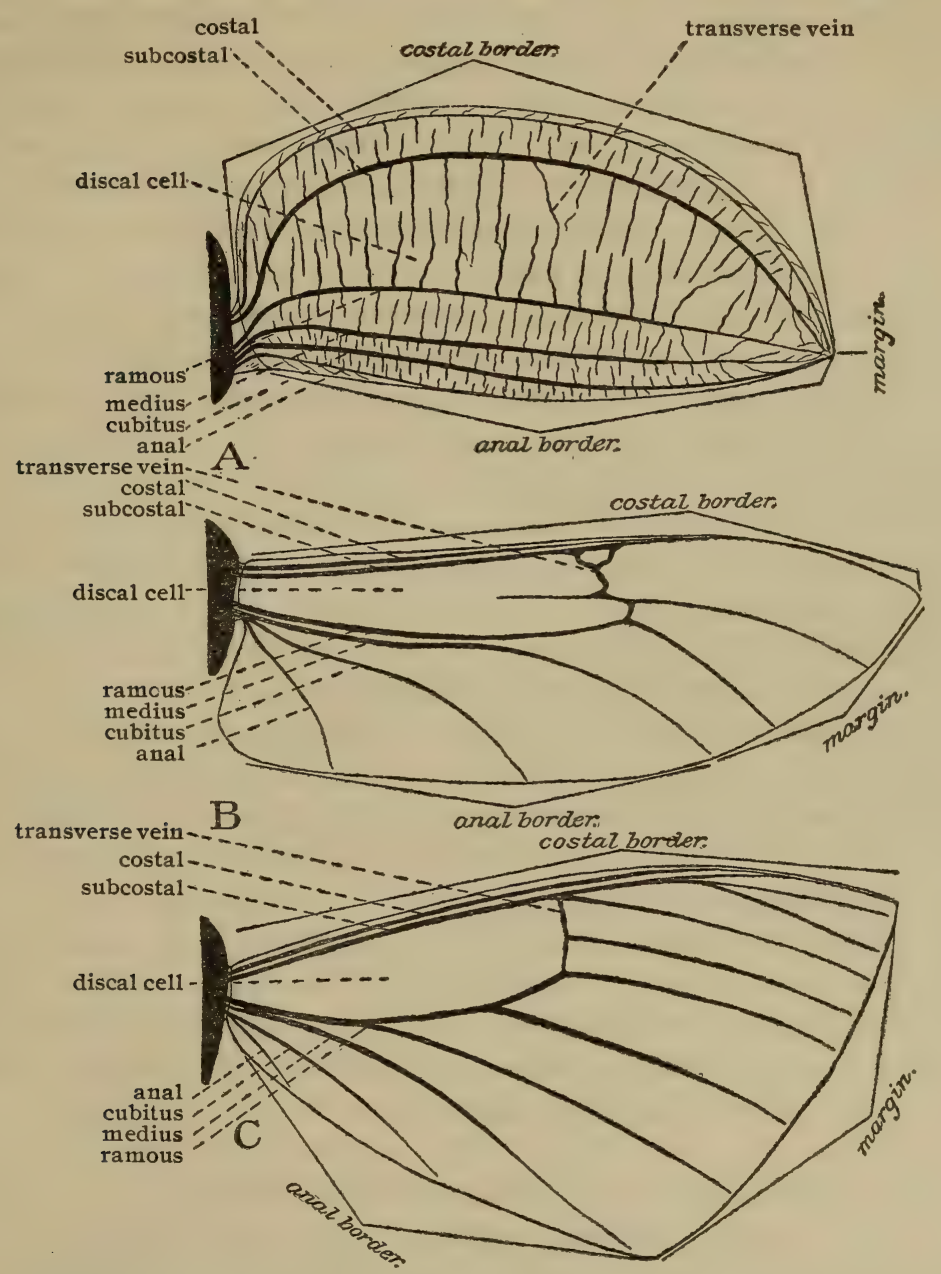

TEXT-FIGURE 10.-Diagrammatic figures of an elytron (A), a coleopterous hind wing (B), and a butterfly fore wing (C), to show homology of parts and the obliteration of the margin in elytra.

The wings, which are flattened, bag-like evaginations of the body wall, variously modified and ornamented, carry the most complicated, and, for certain lines of inquiry, the most significant parts of the color pattern of the entire insect. The coloration of the wings has justly received the lion's share of attention from those studying insect coloration. This is especially true of the Lepidoptera. 
The normal position of the wing is that in which the axis forms a high angle with the longitudinal axis of the body and is not parallel with it, as some writers have claimed. Each wing is composed of three clearly marked areas: First, the anterior, which is supported by the costal and subcostal veins and which we shall call the anterior system; second, the middle area, devoid of veins, or the discal cell lying between the subcostal and ramous veins; and third, the area supported by the ramous, cubitus, medius, and anal veins, which we shall call the posterior system. Each of these areas is clearly seen in the wings of all insects, and even in the specialized elytra of Coleoptera (see textfig. 10). In text-figure Io $\mathrm{C}$ are represented these areas in the wing of a but. terfly, and in text-figure Iо в in the hind wing of a Leptinotarsa. Although there are great differences between these, the homologous areas are clearly seen. In text-figure Io A the elytron, although specialized, shows the anterior system condensed and crowded into the costal border, the tip of which is further bent caudalward until it meets the anterior vein of the posterior system, the ramous. At the junction of these the apex of the elytron is formed, and between them is inclosed the discal or central space. Posteriorly the anal and cubital veins are crowded together. In the elytron the costal border is not diminished, but the margin (text-fig. Io A) is obliterated, and the costal border and the outer extremity of the posterior system meet, while the anal area is condensed. The least modified area of all is the central or discal area. This is often divided, almost always in many orders, by a transverse vein from the subcostal to the ramous (text-figs. IO A and IO B), and in the elytra of beetles this position is marked in many genera and families by a cross vein of varying size and distinction. Although highly specialized, the elytron is clearly homologous to the wings of other insects.

In the ontogeny of elytral coloration I have shown that color appears earliest at the proximal portion of the wing in the interspaces between the veins, and first of all in the central space, and that from these beginnings it spreads distalward in species with color stripes between the veins, and across the veins in unicolorous species. Of importance is the fact that in Coleoptera, as in Lepidoptera, as has been shown by numerous writers, color should first appear in the interspaces between the veins at the base of the wing, in the central cell, and the area immediately anterior and posterior thereto. There is therefore between the wings of these orders a complete homology, not only of the larger parts, but also of the initial stages of color development. In the further development of the color pattern of the wings of these beetles it appears from the observations given that color, whether it be spot or stripe, develops first between the veins and later over them. In this they are in perfect accord with the Lepidoptera. In the development of the transverse bands of spots, which represent a system not found in Lepidoptera, color is found over the veins. These transverse bands of spots consist of the basal band at the proximal end of the wing, the distal band at the apex of the wing, which 
is the condensed marginal band of other insects, and the outer, middle, and inner transverse bands, of which the middle lies over the transverse vein across the distal cell.

The wing in development starts from a minute invagination of cells in the region of the wing spot, which is an area, as shown by Verson, myself, and others, homologous to the spiracular center of other segments. This invagination grows inward, and the dorsal portion thickens and grows downward into a tongue-like process either in a pocket of the hypodermis or between the hypodermis and cutticula. These thickenings are found very early, as are also the cell arrangements of the anterior and posterior systems and of the central space. Likewise, before pupation, the interspaces between the veins are fully formed. Later on, in these interspaces in the pupal wings, the enzyme-forming cells are found, but of their earlier history we are as yet quite ignorant. The manner of the growth of the wing and the arrangement of the glands, etc., in parallel bands strongly suggest that there exist in the wing fundament of all insects, mother cells, which, by division, give rise to the rows of pigmentenzyme forming cells in the interspaces, and that from these rows they spread in all directions in species of a unicolorous condition, or in special regions only in banded species. It would be difficult to account for these conditions of color development upon any other basis; and when to this is added all the data of variation, of phylogeny, and of experiment, no other hypothesis seems tenable. It is known that the whole process of wing development is similar in all insects, even, as I have shown, in forms which are as diverse as those with incomplete and complete metamorphosis; and inasmuch as the initial stages in color development are identical in all, it is highly probable that the above hypothesis is correct. With this hypothesis and the data of ontogeny which so strongly support it, and with our knowledge of the existence of color centers upon the body from which the color patterns develop, we have a basis for the working out and logical interpretation of the phenomena of localized stages in growth and of the laws of the evolution of insect coloration and the various phenomena connected therewith.

\section{LOCALIZED STAGES IN ONTOGENY OF COLORATION.}

The existence in the young of ontogenetic stages or conditions simulating adult characters of related species or genera, ancient and modern, has been abundantly described and studied in plants, and especially in fossils of both plants and animals. The idea that embryonic, larval, and juvenile conditions are the atavistic reappearances of ancestral adult stages, an old idea revived and modified by L. Agassiz and later crystallized by Haeckel into the dictum that "Ontogeny repeats phylogeny," has been greatly misused, especially by paleontologists, although it is in many cases a valuable aid in phylogenetic study. Jackson, Cushman, and others have described in plants and animals 
having periods of interrupted growth, stages and characters found at the resumption of growth which they believe to be the atavistic reappearances of ancestral adult characters. More recently, Shull, investigating these stages in Sium cicutcfolium, comes to the conclusion that these stages represent, not ancestral adult characters, but simpler conditions of structure which are explainable upon physiological instead of phylogenetic grounds. In insects these stages have not, as far as I am aware, been investigated.

In the ontogeny of both the larval and imaginal coloration in Leptinotarsa there are clearly distinguishable the following stages: $(a)$ The preparatory stage, the time when the color is the uniform yellow of the pupa, and the period of active zymogen formation; $(b)$ the initial stage, during which the color appears over the centers of coloration and the color pattern is marked out; and $(c)$ color intensification stage, when the colors develop to their full intensity. These stages are clearly defined and recognized in all insects whose color development has been studied. Do these three stages, which are common to all insects in their development, represent three great steps in the evolution of the coloration of the class? Are we to believe that the preparatory stage is the atavistic repetition of the adult coloration of the hypothetical ancestor of the tracheate phylum? that the initial or second stage represents the first developments of coloration, and the third the condensed recapitulation of more modern specialization and differentiation in insect colors? Such a view is perfectly in accord with those of Cope, Hyatt, and others. The interpretation of these stages, widespread though they are in insects, does not rest with studies in phylogeny; it is a question solely of the investigation of adaptation to ontogenetic ends; that is, they are physiological and developmental, and not phylogenetic phenomena.

Almost all tracheates are subject to periodic changes of the chitinous portion of their body wall, and at these ecdyses the color pattern, as far as the markings arising from the dark cuticula pigment are concerned, is removed and must be replaced by a new development thereof. The removal of the chitinous layer reduces the animal to a condition which, as far as the integument is concerned, is practically embryonic. This is a fact which any one who wishes may verify. From this condition the animal must retrieve itself as soon as possible by the development of a new cuticula carrying new color markings. At each recurring ecdysis this process is repeated, and the three main stages are passed through. We admit that ecdysis is necessary to growth in these forms, and that growth is in a sense periodically interrupted by ecdysis. It is probably true that in the evolution of insect color there were three stages corresponding roughly with the stages in development already described; but that these should be repeated so exactly at each ecdysis is a phenomenon the reasons for which it is hard to imagine. On the other hand, its interpretation on the basis of an ontogenetic adaptation alone would involve 
no difficulties in reasoning. Ecdysis removes all dark color from the body, and this is redeveloped, and in development passes through stages which may in a broad way simulate stages which we suppose may have existed in the general evolution of color. The fact that in diverse orders of insects the same conditions are found is not necessarily evidence for its phylogenetic interpretation, but rather for the opposite, because the process of ecdysis is the same in all insects, and like destructive and constructive stages and processes are common to all. It is also true that the supposed phylogenetic stages are products of our imagination, creatures brought into being for the purpose of making observed conditions in ontogeny agree with cherished hypotheses. Direct evidence upon this question is of course difficult to obtain, and it must, at least for the present, remain one of opinion as far as its larger phases are concerned. The smaller and more special phases, however, may perhaps be more easily interpreted, and to these we shall next direct attention.

On plate I7 are shown the succession of color patterns found in the larvæ of twelve species of Leptinotarsa. These figures represent well the different types of species and color patterns found. In them we have clearly marked "localized stages in development," and the question to be considered is whether they are to be interpreted on the basis of atavism or on that of physiology and development.

On superficial examination it is strikingly apparent that in the lineata group, for example, the larvæ all have a similar generalized color pattern in the first larval stage, that this is succeeded by one quite different in the second stage, and in some species by still another in the third instar. When we trace back the phylogeny of the genus we find that it goes directly to Zygogramma, where many of the adult larvæ have color patterns like those shown in the second stage of so many Leptinotarsas. Back one step more in the ancestry is Calligrapha, in which many of the adult larvæ have spines and color patterns like the young of Leptinotarsa. What further proof of biogenesis could we desire? In the first instar of Leptinotarsa we have a Calligrapha condition, in the second a Zygogramma condition, and finally the pattern characteristic of Leptinotarsa is attained. If we accept in all sincerity Haeckel's dictum and apply it in the rigid manner of Cope, Hyatt, Jackson, and others, the superficial evidence appears complete.

In the face of evidence apparently so indubitable, I admit that the chances that any other explanation will meet with favor are poor indeed; yet I am thoroughly convinced that these stages figured in the species of Leptinotarsa on plate I7 are not to be explained upon the basis of atavism, but upon that of the morphological and physiological constitution alone, and that the connection with ancestral or racial conditions is only a general one. Evidence in support of this side of the question is not entirely wanting. 
It has been shown that color in these beetles is limited in its appearance to definite centers, and that all patterns must, as far as is known, originate from continuations of these centers, so that color patterns are in a degree limited. This character is one of such wide distribution in insects that I consider it to be a character of the phyletic race-one that is so firmly fixed in the constitution of the tracheate protoplasm that it can not be eradicated. It is one of those phyletic characters whose origins are unexplained excepting by theory. In the Coleoptera, and especially in the Chrysomelidæ, the existence of these centers in development is beyond doubt. Their presence gives to each species a like back ground out of zhich each species creates its own distinctive color pattern. That is, all start in ontogeny endowed with an identical arrangement of color-producing centers, which become variously modified, suppressed, or accentuated in different stages and in different species.

Strong evidence against the idea of specific ancestral influence is found in the three species undecimlincata, multitaniata, and oblongata. L. undecimlineata is undoubtedly the ancestor of multitceniata, and oblongata arose from the latter. On plate I7, figs. I to 3, are given the three stages of undecimlineata, beginning with a condition which is generalized and ending with that shown in fig. 3. L. multitaniata (figs. Io to I2) never goes as far in the modification of its color pattern as its ancestor undecimlineata, while oblongata starts in life with a condition far beyond its parent in its specialization. Here is a condition difficult to explain upon the basis of a literal interpretation of the biogenetic law, of a species starting its ontogeny far in advance of the adult parental condition. This surely is Hyatt's idea of acceleration in development carried on with great speed. Now, I find that the cells which form the centers of coloration are developed in the embryo of oblongata, but that they remain quiescent until the pupal period, when they become active and produce color areas in the proper place, as is shown on plate 20. I am not able to understand how this condition found in oblongata can be the result of ancestral influence. Surely there are no indications of the process in the parent, and in the grandparent species the same modifications of color have taken place in the larva in the second instar (fig. 2). The extreme advocate of the law of biogenesis will in this instance claim that through acceleration in development the earlier stages have been dropped off in the embryo, so that the larva of oblongata starts in life with the mature color pattern of its grandparent species. This would all be very well were it not for the presence of the color-forming cells in the late embryo, and the fact, above mentioned, that they remain inactive throughout the larval life and become active and produce color areas in the pupa. This can not be successfully explained by the theory of temporary retardation of development, because we have the phenomenon slightly varied in many species. Nor do I see how how the idea of the recapitulation of the immediate ancestral stages in growth can 
throw any light upon the subject. These localized stages in the development of the color pattern of Leptinotarsa are of value phylogenetically only as indicating a similarity of constitution and organization between species. That each stage represents the repeated color pattern of some ancestor is a view not in accordance with the conditions shown to exist in this genus of beetles.

I have interpreted these localized stages on the basis of similarity of original constitution and modification in development. The successive stages in Leptinotarsa are not, however, simpler conditions, but more specialized. They are not comparable to the condition found by Shull in Sium, where the localized stages are simpler states; although in both cases the explanation is physiological and developmental and not phylogenetic.

In Leptinotarsa each species, as far as we can discover, starts in larval development endowed with a definite system of color-enzyme producing cells; that is, all start alike from a racial condition. Given this racial endorement, each species from the start modifies, holds in check, or increases the activities of the centers in its own manner, without any dependence upon the actions of its immediate parental or grandparental species. In the evolution of the color pattern, in the rise of new species, each species inherits this general racial system of coloration entire in its germ plasm, and the fundaments thereof appear in development. In the production of the nerv race the capacity to modify this general color scheme is inherent in the germ plasm, and in heredity is transmitted to the offspring of the same kind as in the parent; but in the new race it is changed, the modified capacity producing new developments of the color centers which we recognize as the differentials of the new races or species.

I am convinced that in these beetles at least the apparent localized stages in ontogeny are nothing more than the physiological expression of similarities in constitution and in developmental tendencies.

Likewise the stages in development found in the imaginal color pattern are best and most logically explained in this manner. Ancestry exerts its influence only by providing a general racial or generic background out of which each species takes characters and variously modifies them as its specific constitution demands, to create its color pattern in the different stages of its ontogeny. Each species, however, is absolutely dependent upon this ancestral background for its characters, and can not, under any conceivable conditions, develop traits or characters which are not based upon some trait or character existing in the ancestral background. 


\section{THE EXPERIMENTAL MODIFICATION OF COLOR AND COLOR PATTERNS.}

Animal colors are to a considerable extent directly modified by the action of external agents, such as temperature, moisture, food, altitude, and light. In the genus Leptinotarsa variations in color corresponding to different localities or seasonal changes are common, and these have been considered under the topics of place and geographical variation. The methods of biometry are not, however, adequate for the analysis or interpretation of these color changes; as from this source we gain knowledge only of the existence of the phenomena, of their extent, and of the laws governing the observed changes. We shall now inquire into the causes of color changes-their nature and extent.

\section{MODIFICATION OF COLOR IN L. DECEMLINEATA.}

My experiments in the modification of both larval and adult color in decemlineata cover a period of ten years, and comprise work with temperature, moisture, food, light, soil, composition of the atmosphere, and atmospheric pressure.

TEMPERATURE EXPERIMENTS.

Temperature experiments were begun in 1894 , and have been continued each year since then. The results are given in condensed form, the data of many experiments of the same kind being combined into one comprehensive statement.

EXPERIMENT I.-To determine the effect of a slightly increased temperature upon the color and color pattern of $L$. decemineata.

Conditions.-Temperature on the average $5.78^{\circ} \mathrm{C}$. above that in nature. Other conditions normal.

Apparatus.-Glass cages and glass breeding tanks, warmed by the sun and protected from radiation at night.

In these experiments, which were conducted during the years I894 to I90I, 5,500 larvæ of this beetle taken at randon from potato fields were used. They were placed in the conditions of the experiment in late larval life, and remained there until the full imaginal colors had been developed. The temperature records for the series are given in the following table:

TABLE 44.-Temperature conditions.

\begin{tabular}{|c|c|c|c|c|c|c|c|}
\hline Conditions- & $7 \mathrm{a} . \mathrm{m}$. & I p. $\mathrm{m}$. & 8 p. m. & $\begin{array}{l}\text { Maxi- } \\
\text { mum. }\end{array}$ & $\begin{array}{l}\text { Mini- } \\
\text { mum. }\end{array}$ & $\begin{array}{l}\text { Aver- } \\
\text { age. }\end{array}$ & $\begin{array}{l}\text { Deviation } \\
\text { from } \\
\text { normal. }\end{array}$ \\
\hline In nature ...... & $\begin{array}{l}\circ \mathrm{C} . \\
19.2\end{array}$ & $\begin{array}{l}{ }^{\circ} \mathrm{C} . \\
30.62\end{array}$ & $\begin{array}{l}\circ \mathrm{C} . \\
17 \cdot 389\end{array}$ & $\begin{array}{l}{ }^{\circ} \mathrm{C} . \\
33 \cdot 5\end{array}$ & $\begin{array}{l}{ }^{\circ} \mathrm{C} \text {. } \\
\text { I3.0 }\end{array}$ & $\begin{array}{l}\circ \mathrm{C} . \\
22.4 \mathrm{O} 3 \\
28.88\end{array}$ & $\begin{array}{l}{ }^{\circ} \mathrm{C} . \\
\circ \\
+\end{array}$ \\
\hline 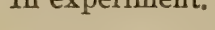 & 23.9 & 33.5 & 27.17 & & & 28.188 & +5.78 \\
\hline
\end{tabular}


In these experiments 10.8 per cent died in the larval stage, 46.I per cent in the pupal, and 43.I per cent completed their transformation. Of the latter there was about an equal division as regards sex, there being $5^{\mathrm{I}} .5$ per cent males and 48.5 per cent females. The size and form were normal.

In the shape, position, and fusions of the spots the color pattern was unmodified; but the size of the spots or the amount of dark color was increased so that as regards general color there was a slight shifting of the modal condition. This is shown in the following table, which gives the conditions of the parent generations and those of the material used in experimentation and in the control:

TABLE; 45.-General color of beetles used.

\begin{tabular}{|c|c|c|c|c|c|c|c|c|c|c|c|c|c|}
\hline Class...... & 5 & 6 & 7 & 8 & 9 & Io & II & 12 & $I_{3}$ & I4 & I5 & I6 & I7 \\
\hline & P.ct. & P.ct. & P.ct. & P.ct. & P.ct. & P.ct. & P.ct. & P.ct. & P.ct. & P.ct. & P.ct. & P.ct. & P.ct. \\
\hline Parents.... & I & 2 & 5 & 20 & 42 & I8 & 9 & 2 & I & $\ldots$ & $\cdots$ & $\cdots$ & . \\
\hline Control..... & . & 2 & 7 & Io & 23 & 30 & 16 & 6 & 5 & I & $\cdots$ & $\cdots$ & . \\
\hline Experiment & -. & .. & I & I & 5 & II & I8 & 46 & IO & 5 & I & I & I \\
\hline
\end{tabular}

Empirical mode of parents .... 9 . Modal deviation of parents ..... 0 Empirical mode of control ....... r. ro Modal deviation of control....... I

Empirical mode in experiment.. I2 Modal deviation in experiment.. + 3

In all of these experiments there was a slight histonic skewness of from one to four classes in each separate lot of individuals experimented upon, the average being three classes. The skewness is histonic in this case toward a more melanic condition, such as characterizes the ancestor of this beetle, L. multitcniata.

EXPERIMENT 2.-To determine the effect of a considerable increase in temperature upon the color and color pattern of $L$. decemlineata.

Conditions.-Temperature on an average $9.767^{\circ} \mathrm{C}$. above that in nature. Other conditions normal.

Apparatus.-Glass cages and special breeding tanks warmed by the sun or by artificial heat, and protected from radiation at night.

In this experiment, in which are combined the data and results of many experiments extending from I893 to I904, 7,800 larvæ taken at random from potato fields were used. These were all placed in the conditions of the experiment in the last larval instar before the beginning of the prepupal period. Food, moisture, light, soil, and other conditions were kept normal, the temperature only being varied. The temperature records are as follows:

TABLE 46-Temperature conditions.

\begin{tabular}{|c|c|c|c|c|c|c|c|}
\hline Conditions- & 7 a. m. & I p. m. & 8 p. m. & $\begin{array}{l}\text { Maxi- } \\
\text { mum. }\end{array}$ & $\begin{array}{l}\text { Mini- } \\
\text { mum. }\end{array}$ & $\begin{array}{l}\text { Aver- } \\
\text { age. }\end{array}$ & $\begin{array}{l}\text { Deviation } \\
\text { from } \\
\text { normal. }\end{array}$ \\
\hline $\begin{array}{l}\text { In nature ..... } \\
\text { In experiment }\end{array}$ & $\begin{array}{l}{ }^{\circ} \mathrm{C} . \\
\mathrm{I} 9.2\end{array}$ & $\begin{array}{l}{ }^{\circ} \mathrm{C} . \\
3^{0} \cdot{ }^{2}\end{array}$ & $\begin{array}{l}{ }^{\circ} \mathrm{C} \\
\mathrm{I} 7 \cdot 3^{8} 9\end{array}$ & $\begin{array}{l}{ }^{\circ} \mathrm{C} . \\
33.5\end{array}$ & $\begin{array}{l}{ }^{\circ} \mathrm{C} . \\
\mathrm{I}_{3}\end{array}$ & $\begin{array}{c}\circ \mathrm{C} . \\
22.403\end{array}$ & ${ }^{\circ} \mathrm{C}$. \\
\hline periment. & 25 & $38 \cdot 5$ & 33 & $4 \mathrm{r} .4$ & 22 & 32.17 & +9.767 \\
\hline
\end{tabular}


In these experiments 55 per cent died in the larval stage, 45 per cent in the pupal, and 5 per cent completed their transformation. These were normal in shape, but 23 per cent below the average in size. The color and color patterns were changed as follows: The hypodermal color became pale yellowishwhite, and the areas of cuticula pigments were considerably altered. All of the elytral stripes were shortened and narrowed, and showed no fusions; the spots on the pronotum and epicranium were also without fusions and small, $f$ and $f^{\prime}$ being continually absent, and $d$ and $b$ being represented only by traces of color. On the ventral surface nearly all the color was lost, traces only of the outer sternals remaining, and rarely of the inner sternals. The general appearance of the imagines and their seriations as regards general color are shown in the following table:

TABLE 47.-General color of beetles used.

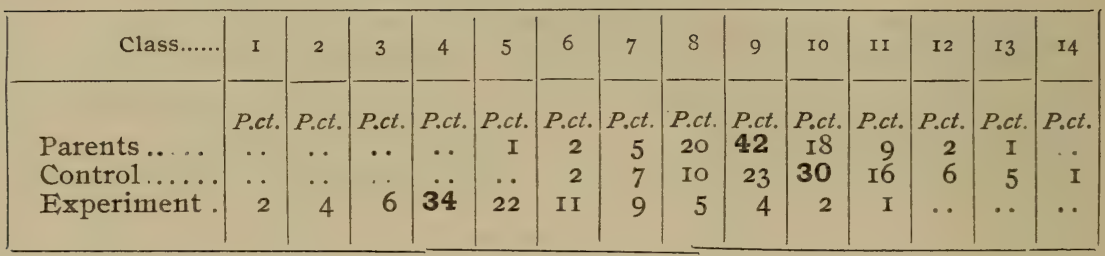

Empirical mode of parents ..... 9

Empirical mode of control....... Io

Empirical mode in experiment .. 4

Modal deviation of parents..... Modal deviation of control ...... +

Modal deviation in experiment. . -5

In each of the separate experiments comprising this second set the resulting individuals showed a strong prophetic skewness toward an albinic condition. This was due to the general reduction in size of all areas of cuticula pigment, to the loss of many, and to the change in the hypodermal color already noted.

EXPERIMENT 3.-To determine the effect of a high average deviation of temperature upon the color and color pattern of $L$. decemlineata.

Conditions.-Temperature on the average $12.097^{\circ} \mathrm{C}$. above that in nature. Other conditions normal.

Apparatus.-The same as in experiment I, artificial heat, however, being used to some extent.

Ten thousand one hundred larvæ of $L$. decemlineata, taken at random from potato fields, were subjected to the conditions of this experiment, which extended over the years 1894 to I904. All the larvæ were placed at the beginning of the last instar, a temperature condition similar to that found in nature, and the temperature was raised in four or five days to the desired degree. Food, moisture, light, soil, etc., were kept normal. The temperature records are given in the following table: 
TABLE 48.-Temperature conditions.

\begin{tabular}{|c|c|c|c|c|c|c|c|}
\hline Conditions- & 7 a. m. & 4 p. m. & 8 p. m. & $\begin{array}{l}\text { Maxi- } \\
\text { mum. }\end{array}$ & $\begin{array}{l}\text { Mini- } \\
\text { mum. }\end{array}$ & $\begin{array}{l}\text { Aver- } \\
\text { age. }\end{array}$ & $\begin{array}{l}\text { Deviation } \\
\text { from } \\
\text { normal. }\end{array}$ \\
\hline $\begin{array}{l}\text { In nature....... } \\
\text { In experiment. }\end{array}$ & $\begin{array}{l}{ }^{\circ} \mathrm{C} . \\
19.2 \\
28\end{array}$ & $\begin{array}{l}{ }^{\circ} C . \\
30.62 \\
45 \cdot 5\end{array}$ & $\begin{array}{l}{ }^{\circ} \mathrm{C} . \\
17.389 \\
30\end{array}$ & $\begin{array}{l}{ }^{\circ} \mathrm{C} . \\
33 \cdot 5 \\
47\end{array}$ & $\begin{array}{l}{ }^{\circ} \mathrm{C} . \\
13 \\
25\end{array}$ & $\begin{array}{l}{ }^{\circ} \mathrm{C} . \\
22.403 \\
34.5\end{array}$ & $\begin{aligned} &{ }^{\circ} \mathrm{C} . \\
& 0 \\
&+ \\
& 2.097\end{aligned}$ \\
\hline
\end{tabular}

In these experiments 95 per cent died in the last larval stage, especially in the prepupal period, 4 per cent in the pupal period, and I per cent appeared as imagines. These latter were equally divided as regards sex, and were 39 per cent below the average in size. The hypodermal color was pale yellowish-white, without a trace of lipochrome pigments, and the cuticula color was much reduced. On the epicranium all spots were completely absent; while on the pronotum $b, d, f$, and $e$ were absent, $c$ was very small, and $a$ was divided into two spots, the anterior and posterior. On the elytra the costal, anal, and cubital stripes were either wanting or very rudimentary, while the others were reduced in size and were light brown in color. Upon the ventral surface the legs had no dark color and all spots were reduced, excepting the outer sternals, which were represented by the merest traces upon the thoracic and first two abdominal segments. The general color of these beetles is shown in the following table:

TABLE 49.-General color of beetles used.

\begin{tabular}{|c|c|c|c|c|c|c|c|c|c|c|c|c|c|c|}
\hline Class... & I & 2 & 3 & 4 & 5 & 6 & 7 & 8 & 9 & Io & II & I2 & I3 & 14 \\
\hline Parents. & P.ct. & P.ct. & P.ct. & P.ct. & P.ct. & P.ct. & P.ct. & $\begin{array}{c}\text { P.ct. } \\
20\end{array}$ & $\begin{array}{c}\text { P.ct. } \\
42\end{array}$ & $\begin{array}{c}\text { P.ct. } \\
\text { I8 }\end{array}$ & P.ct. & $\begin{array}{c}\text { P.ct. } \\
2\end{array}$ & P.ct. & P.ct. \\
\hline Control...... & . & .. & & - & ․ & 2 & 7 & Io & 23 & 30 & 16 & 6 & 5 & I \\
\hline Experiment. . & 3 & I4 & 38 & 23 & I5 & 4 & 3 & $\cdots$ & - & . & . & . & $\cdots$ & -. \\
\hline
\end{tabular}

Empirical mode of parents..... 9

Empirical mode of control..... r. ro

Empirical mode in experiment.. -3
Modal deviation of parents ..... o Modal deviation of control $\ldots \ldots+$ I Modal deviation in experiment . -6

In experiment 3 the limit is almost reached of the average deviation of temperature to which it is possible to subject these insects without their being previously adapted to a higher temperature, an average increase of $\mathrm{I}^{\circ} \mathrm{C}$. above the condition of experiment 3 resulting in a mortality of Ioo per cent.

EXPERIMENT 4.-To determine the effect of a slightly lowered average temperature upon the color and color pattern of $L_{\text {. }}$ undecimlineata.

Conditions.-Temperature on an average $6.5^{\circ}$ C. below that in nature. Other conditions normal.

Apparatus.-Special breeding tanks with inner and outer glass walls, between which there were $21 / 2$ to 3 inches of constantly changing cooled water. Ice boxes were also used. 
In this experiment, which extended over the years I895 to I903, 6,000 larvæ were used, taken at random in the last instar. In the earlier experiments, those covering the years 1895 to 1898 , an ice box was used; and in the later ones the special tanks. Food, moisture, light, and other conditions were kept normal. The temperature records are as follows:

TABLE 50.-Temperature conditions.

\begin{tabular}{|c|c|c|c|c|c|c|c|}
\hline Conditions- & 7 a. m. & I p. m. & 8 p. m. & $\begin{array}{l}\text { Maxi- } \\
\text { mum. }\end{array}$ & $\begin{array}{l}\text { Mini- } \\
\text { mum. }\end{array}$ & $\begin{array}{l}\text { Aver- } \\
\text { age. }\end{array}$ & $\begin{array}{c}\text { Deviation } \\
\text { from } \\
\text { normal. }\end{array}$ \\
\hline In nature ..... & $\begin{array}{l}{ }^{\circ} \mathrm{C} . \\
\mathrm{I} 9.2\end{array}$ & ${ }_{30}^{\circ} \mathrm{C} .62$ & $\begin{array}{c}{ }^{\circ} \mathrm{C} \\
17 \cdot 3^{8} 9\end{array}$ & $\begin{array}{l}{ }^{\circ} \mathrm{C} . \\
33.5\end{array}$ & $\begin{array}{l}{ }^{\circ} \mathrm{C} . \\
{ }_{1} 3\end{array}$ & $\begin{array}{c}{ }^{\circ} \mathrm{C} \\
22.403\end{array}$ & ${ }^{\circ} \mathrm{C}$. \\
\hline In experiment. & I 4.306 & I8.409 & I5 & 23.5 & I2 & I5.903 & -6.5 \\
\hline
\end{tabular}

In these experiments 4 per cent died in the larval stage, 6 per cent in the pupal, and 90 per cent appeared as imagines. In size these were normal, or slightly larger than normal. The average duration of pupal life was increased one and a half days. The color and color pattern were modified as follows: The hypodermal color became a more intense yellow, often with a reddish tinge; the cuticula color became a dense black, and all the areas thereof were slightly increased in size, which gave the specimens a more melanic appearance, as is shown in the following table of their seriations:

TABLE 5I.-General color of beetles used.

\begin{tabular}{|c|c|c|c|c|c|c|c|c|c|c|c|c|}
\hline Class..... & 5 & 6 & 7 & 8 & 9 & 10 & II & I2 & I3 & I4 & I5 & I6 \\
\hline & P.ct. & P.ct. & P.ct. & P.ct. & P.ct. & F.ct. & P.ct. & P.ct. & P.ct. & P.ct. & P.ct. & P.ct. \\
\hline Parents & I & 2 & 5 & 20 & 42 & I8 & 9 & 2 & I & . & . & . \\
\hline Control ..... & - & 2 & 7 & Io & 23 & 30 & I6 & 6 & 5 & I & . & . \\
\hline Experiment. & $\cdots$ & $\ldots$ & I & 2 & 3 & 7 & I2 & 22 & 39 & IO & 3 & I \\
\hline
\end{tabular}

Empirical mode of parents..... 9

Empirical mode of control ...... ro

Empirical mode in experiment.. I3
Modal deviation of parents....... o Modal deviation of control. ....... I

Modal deviation in experiment... + 3

A striking parallel exists between the seriations of this experiment and those of experiment $\mathrm{I}$ in that the conditions of both act as a stimulus toward an increase in the amount of pigmentation, and hence toward a more general melanic appearance.

\section{EXPERIMENT 5.-To determine the effect of a considerably decreased average temper- ature upon the color and color pattern of $L$. decemlineata.}

Conditions.-Temperature on the average $9.5^{\circ} \mathrm{C}$. below that in nature, with other conditions normal.

Apparatus.-The same as in experiment 4. 
In this experiment, which extended over the years 1895 to $1903,6,300$ larvæ of $L$. decemlineata were used. All were taken at random in the last instar. Food, moisture, light, soil, and other conditions were kept normal. The temperature records are as follows:

TABLE 52.-Temperature conditions.

\begin{tabular}{|c|c|c|c|c|c|c|c|}
\hline Conditions - & 7 a. m. & I p. m. & 8 p. m. & $\begin{array}{l}\text { Maxi- } \\
\text { mum. }\end{array}$ & $\begin{array}{l}\text { Mini- } \\
\text { mum. }\end{array}$ & $\begin{array}{l}\text { Aver- } \\
\text { age. }\end{array}$ & $\begin{array}{c}\text { Deviation } \\
\text { from } \\
\text { normal. }\end{array}$ \\
\hline In nature....... & $\begin{array}{l}{ }^{\circ} \mathrm{C} . \\
19.2\end{array}$ & ${ }^{\circ} \mathrm{C}$. & $\begin{array}{c}{ }^{\circ} \mathrm{C} . \\
17.3^{89}\end{array}$ & ${ }^{\circ} \mathrm{C}$. & ${ }^{\circ} \mathrm{C}$. & $\begin{array}{l}{ }^{\circ} \mathrm{C} . \\
22.403\end{array}$ & $\begin{array}{l}{ }^{\circ} \mathrm{C} . \\
0 \\
-0\end{array}$ \\
\hline 10 experment. & 9 & 17.109 & & & $5 \cdot 4$ & 12.903 & $-9 \cdot 5$ \\
\hline
\end{tabular}

In these experiments 64.7 per cent died in the larval stage, 25.3 per cent in the pupal, and Io per cent completed their transformation. Of these 50 per cent were males and 50 per cent females. The pupal period was on an average 32 days, or more than three times the duration of this stage in nature; while the imagines were on an average 6.2 per cent below the normal in size. The hypodermal color had become lighter, being yellow. The cuticula pigments of the dorsal side, however, were only slightly reduced, and no spots were entirely absent; but fusions between the spots were not common. On the ventral surface all spots were reduced in size, but none were absent. The general appearance was slightly albinic, as may be seen in the following seriations :

TABLE 53.-General color of beetles used.

\begin{tabular}{|c|c|c|c|c|c|c|c|c|c|c|c|}
\hline Class...... & 4 & 5 & 6 & 7 & 8 & 9 & 10 & II & 12 & $\mathrm{I} 3$ & 14 \\
\hline & P.ct. & $\mathrm{Pcl}$. & P.ct. & P.ct. & $\mathrm{PCl}$. & $\begin{array}{l}P . c l \\
42\end{array}$ & P.ct. & P.ct. & P.ct. & P.ct. & P.ct. \\
\hline Contro & 0 & & 2 & 7 & ro & 23 & 30 & r6 & 6 & 5 & I \\
\hline Fxperiment. & i & 2 & 7 & 9 & 36 & 20 & 15 & 8 & I & I & \\
\hline
\end{tabular}

Empirical mode of parents.......
Empirical mode of control...... 9 ro

Modal deviation of parents.....

Empirical mode of control....... ro 8 in

Modal deviation of control..... + I

Modal deviation in experiment . - I

EXPERIMENT 6.-To determine the effects of a large decrease in the average temperature upon the color and color pattern of $L$. decemlineatu.

Conditions.-Temperature on the average $13.4^{\circ} \mathrm{C}$. below that in nature, with other conditions normal.

Apparatus.-The same as in experiments 4 and 5 .

In this experiment, which extended over the years 1897 to 1903 , 3,000 larva taken at random in the last instar were used. The temperature records are as follows: 
TABLE 54--Temperature conditions.

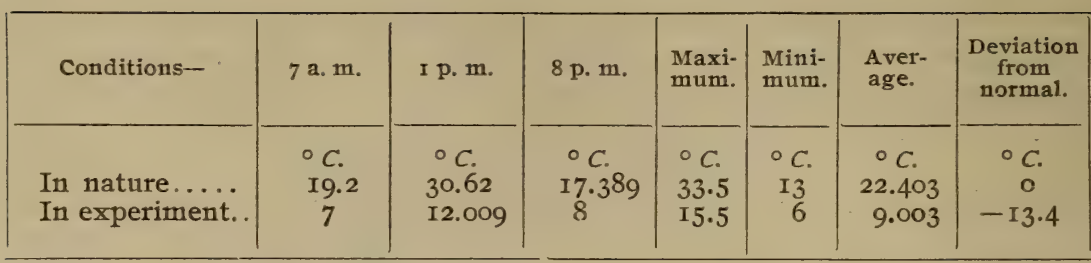

In these experiments 88 per cent died in the larval and prepupal stages, 7 per cent in the pupal, and 5 per cent appeared as imagines, of which there were 70 females and 80 males. The pupal period averaged 43 days, or over four times that in nature. The hypodermal color was a light yellowish-white, and many of the spots of the cuticula were absent or small. On the epicranium $g$ and $g^{\prime}$ were separate, small, and light brown in color, while $h$ and $h^{\prime}$ were often absent. On the pronotum there were no fusions, and $b, d$, and $f$ were always very small and frequently absent. The elytral stripes were shortened and were light in color, while upon the ventral surface the middle. sternals were largely wanting, and the legs were almost devoid of dark color. The general appearance was decidedly albinic, as is shown by the following seriations :

TABLE 55.-General color of beetles used.

\begin{tabular}{|r|r|r|r|r|r|r|r|r|r|r|r|}
\hline class.... & 4 & 5 & 6 & 7 & 8 & 9 & I0 & II & I2 & I3 & I4 \\
\hline & P.ct. & P.ct. & P.ct. & Pct. & P.ct. & P.ct. & P.ct. & P.ct. & P.ct. & P.ct. & P.ct. \\
Parents...... & $\ldots$ & I & 2 & 5 & 20 & 42 & I8 & 9 & 2 & I & $\ldots$ \\
Contro1...... & $\ldots$ & $\ldots$ & 2 & 7 & I0 & 23 & 30 & I6 & 6 & 5 & I \\
Experiment. & 2 & I0 & 24 & 22 & 20 & I2 & 8 & 2 & $\ldots$ & $\ldots$ & $\ldots$ \\
\hline
\end{tabular}

Empirical mode of parents..... . 9

Empirical mode of control....... ro

Empirical mode in experiment... 6
Modal deviation of parents..... o Modal deviation of control...... + I Modal deviation in experiment. . - 3

EXPERIMENT 7.-To determine the effect of an extremely low temperature deviation upon the color and color pattern of $L$. decemlineata.

Conditions.-Temperature on the average $23.5^{\circ} \mathrm{C}$. below that in nature. Relative humidity increased in some experiments 7 to Io per cent; light decreased to one-half its normal intensity.

Apparatus.-Glass tanks with jacket of ice and salt between. Use was also made of an ice box.

In this experiment, which was conducted during the years I900 to I904, 2,000 larvæ were used. These were taken at random from potato patches in the last instar and were placed in glass vessels. Food, moisture, and soil were the same as in nature, but the light was greatly diminished or entirely want- 
ing. Light, however, is a factor of no importance, as the colors are always developed in the dark. The temperature records are as follows :

TABLE 56.-Temperature conditions.

\begin{tabular}{|c|c|c|c|c|c|c|c|}
\hline Conditions- & 7 a. m. & I p. m. & $8 \mathrm{p.m}$. & $\begin{array}{l}\text { Maxi- } \\
\text { mum. }\end{array}$ & $\begin{array}{l}\text { Mini- } \\
\text { mum. }\end{array}$ & $\begin{array}{l}\text { Aver- } \\
\text { age. }\end{array}$ & $\begin{array}{l}\text { Deviation } \\
\text { from } \\
\text { normal. }\end{array}$ \\
\hline $\begin{array}{l}\text { In nature.... } \\
\text { In experiment. }\end{array}$ & $\begin{array}{l}{ }^{\circ} \mathrm{C} . \\
\mathrm{I} 9.2\end{array}$ & $\begin{array}{l}{ }^{\circ} \mathrm{C} \text {. } \\
30.62\end{array}$ & $\begin{array}{l}{ }^{\circ} \mathrm{C} . \\
\text { I } 7.3^{89}\end{array}$ & $\begin{array}{l}{ }^{\circ} \mathrm{C} . \\
+3\end{array}$ & $\begin{array}{c}{ }^{\circ} \mathrm{C} \\
-\mathrm{I} 3\end{array}$ & $\begin{array}{l}{ }^{\circ} \mathrm{C} . \\
22.403\end{array}$ & ${ }^{\circ} \mathrm{C}$. \\
\hline in experiment. & -3.30 & 0.5 & -.5 & 2 & -4.5 & $-\mathrm{I} \cdot \mathrm{I}$ & -23.5 \\
\hline
\end{tabular}

In this experiment 92 per cent died in the larval and prepupal stages, 6 per cent in the pupal, and 2 per cent, 20 males and I 2 females, completed their metamorphosis. The pupal period averaged 64 days, or more than six times its duration in nature. The imagines were all strongly modified toward an albinic appearance, having a pale yellow-white hypodermal color. The dark color of the epicranium was wanting, as were also the spots $b, d, e$, and $f$ on the pronotum; $c$ and $a$ were much reduced, and $a$ was divided. On the elytra the costal and anal stripes were wanting, and the others were reduced in size and were lighter in color. Upon the ventral surface the legs were devoid of color and only the outer sternal spots were found, and these only upon the thoracic and the three or four anterior abdominal segments. The extreme albinism of the beetles is apparent from the following seriations:

TABLE 57.-General color of beetles used.

\begin{tabular}{|r|r|r|r|r|r|r|r|r|r|r|r|r|}
\hline class..... & 2 & 3 & 4 & 5 & 6 & 7 & 8 & 9 & I0 & II & I2 & I3 \\
\hline & P.ct. & P.ct. & P.ct & P.ct. & Pct. & P.ct. & P.ct. & P.ct. & P.ct. & P.ct. & P.ct. & P.ct. \\
Parents...... & $\ldots$ & $\ldots$ & $\ldots$ & $\mathrm{I}$ & 2 & 5 & 20 & $\mathbf{4 2}$ & $\mathrm{I} 8$ & 9 & 2 & $\mathrm{I}$ \\
Control...... & $\ldots$ & $\ldots$ & . & $\mathrm{I}$ & 2 & 6 & 22 & $\mathbf{2 8}$ & 25 & 9 & 5 & 2 \\
Experiment. & $\mathrm{I}$ & $\mathrm{I} 3$ & $\mathbf{4 3}$ & 29 & $\mathrm{I} 3$ & $\mathrm{I}$ & $\ldots$ & $\ldots$ & $\ldots$ & $\ldots$ & $\ldots$ & $\ldots$ \\
\hline
\end{tabular}

Empirical mode of parents....... 9

Empirical mode of control....... 9

Empirical mode in experiment.... 4
Modal deviation of parents...... 0

Modal deviation of control...... o

Modal deviation in experiment .. -5

Between this experiment and experiment 3 there was a close similarity in the mortality and modifications produced, and also in the fact that in both any further decrease of average temperature was fatal to Ioo per cent of the beetles, so that as far as the development of color was concerned, experiments 3 and 7 attained to the highest limits at which color and color patterns could be produced in these beetles without their being previously acclimatized to higher or lower temperatures.

In experiments I to 7, 40,700 larvæ of decemlineata from Massachusetts, Long Island, Ohio, and Illinois were used, and from these there emerged 
8,86I imagines. These beetles were subjected to conditions of temperature such as might be produced in nature by the coming on of a cold or hot spell when the larva were about to pupate, and the continuance thereof during the pupal period. Such cold or hot spells do occur frequently in nature, and are productive of modifications in the coloration of animals and plants. These experiments show what would happen in the way of modified color or color patterns if by accident or intentionally a lot of nearly grown larvæ were to be transported from, let us say, the average conditions of the northeastern United

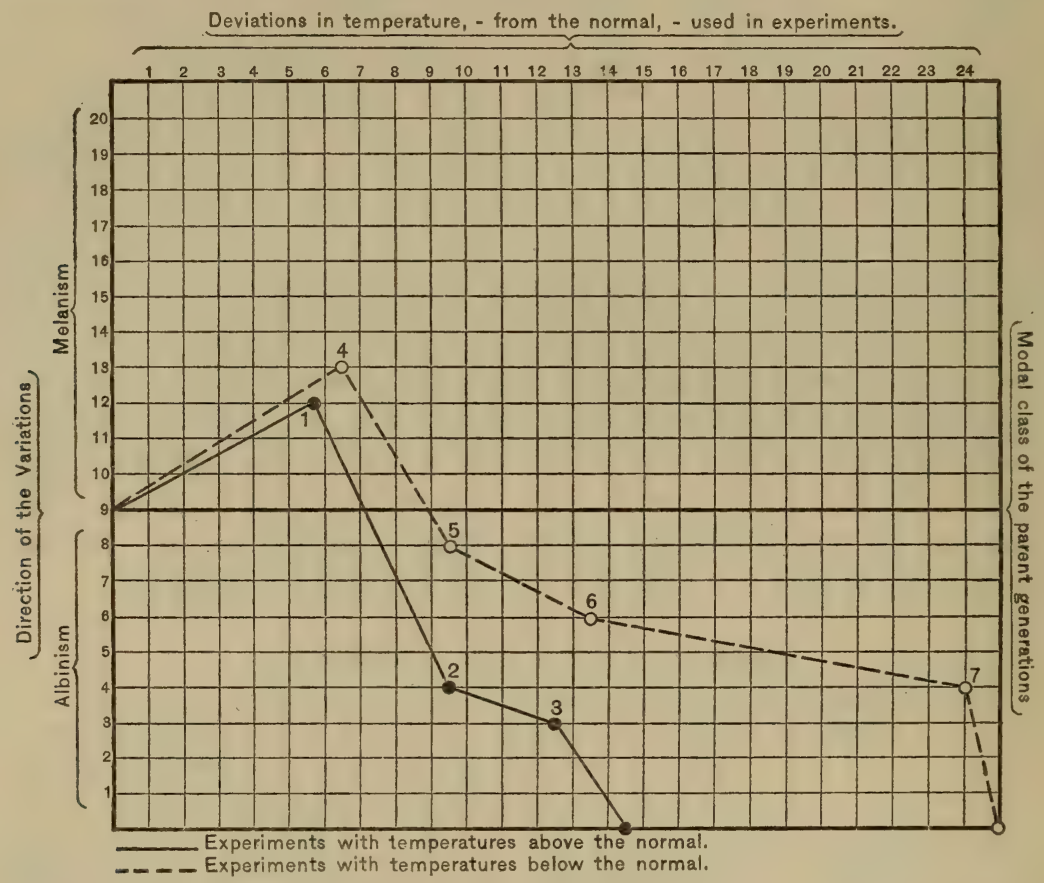

TEXT-FIQURE II.-Diagrammatic representation of the results obtained in experiments I to 7 , showing in both high and low temperature experiments the production of melanic conditions by the first devia tion followed by the production of albinic tendencies as the temperature is further increased or decreased. The heavy line across the middle of the figure on class 9 is the modal class of the parents above and below which the tendency is melanic and albinic, respectively. The deviations in temperature are given in degrees centigrade.

States to Arizona or New Mexico (experiments I and 2), or to the Yuma Desert (experiment 3), to Nova Scotia or Newfoundland (experiment 4), or to Labrador (experiments 5,6 , and 7 ).

The general results derived from these experiments have been put into the form of a table in text-figure II. In this figure the high-temperature experiments are represented by the solid lines and the low by the broken lines. In both sets of experiments the result produced by either a higher or a lower temperature is the development of a greater amount of pigmentation and a 
consequent melanic tendency in variations. This stimulus in both directions to increased pigmentation reaches a maximum between $5^{\circ}$ and $7^{\circ} \mathrm{C}$. deviation from the normal. Beyond these, as the temperature further deviates, there is a rapid fall in melanism, first to the normal, and then to a condition below normal, until a marked albinic tendency is found; and this decrease in pigmentation continues until the zero point is reached, beyond which no pigment whatever is produced. The zero point is reached much sooner, however, in high-temperature experiments than in the low.

The increased pigmentation caused by a slight raising of the temperature can be accounted for by the fact, which has been proven by experiment, that pigmentation is due solely to the action of enzymes, and that the action of these enzymes is accelerated by an increase in temperature up to a certain point, and thereafter retarded. With low-temperature experiments, however, the phenomenon of increased pigmentation is due to the prolongation of the period during which the enzymes act. The lowered temperature inhibits the developmental process, and consequently emergence from the pupa; but it does not interfere to the same degree with the action of the color-forming enzymes. Hence, even though the amount of enzymes produced in a low temperature may be less than that produced in a temperature correspondingly high, the resulting pigmentation may be approximately equal in both cases, owing to the retardation of development in the lower temperature and the longer continued action of the pigment-producing enzymes.

From these seven experiments, conditions of coloration were produced in the imagines which simulate those found in nature in several geographical areas. This becomes evident from a comparison of the distribution of the variation in these experiments with that in the tables of place variation. Thus the results produced by experiments $I$ and 4 are like the melanic conditions found in occasional generations in the northeastern United States; or a like parallel may be found by comparing the effects of experiments 2 and 5 with the place variations of the south and west, or of experiments 3 and 6 with those in Arizona and New Mexico. This production in experiment of conditions found in nature in different geographical areas is conclusive proof of the statement made in regard to place and geographical variations that they are due solely to the natural conditions of existence.

Another point of interest in this connection is the fact that the variation of the color pattern in experiment follows the laws found in individual variation, and is in strict accordance with the observations and laws derived from the study of color-pattern ontogeny.

These experiments are similar to those conducted by Dorfmeister, Weismann, Edwards, Merrifield, Standfuss, Fischer, and others in that larvæ were suddenly transported just before pupation from normal conditions in nature to the conditions of the experiment. The difference between my experiments 
and those of others is that a special effort has been made to change one factor only in the environment. In this I have been successful. In most of the experiments that have been recorded no attention was paid to relative humidity. When pupa are inclosed in a dish or box in an atmosphere in summer where the relative humidity is 60 to 70 per cent, and are then placed in an ice box, the temperature is lowered, but the relative humidity is increased, and thus two important factors are changed. Or if pupæ are placed free in an ice box the temperature is lowered, and the humidity is also increased almost to saturation. On the other hand, in high-temperature experiments in which an incubator is used the temperature is increased and the relative humidity decreased to a point below that of the driest deserts. In such experiments two or perhaps more factors are changed, so that the results are due to changed complexes, and not to deviations in any single factor. In these experiments a special effort has been made to change the one factor of temperature alone, the relative humidity being kept between 65 and 70 per cent.

The general conclusions derived from these experiments accord well with those of Fischer working upon Vanessidæ, as also with those of a like nature that have been made by others upon Lepidoptera. In the set of experiments which follows the procedure has been quite different from that just described, the animals having been reared throughout the entire generation under the conditions of the experiment. In these experiments it was necessary that much smaller numbers of insects be used, but the results are nevertheless equally as conclusive as those of the preceding set.

EXPERIMENT 8.-To determine the effect of increased temperature upon the color and color pattern of L. decemlineata when applied throughout life.

Conditions.-Temperature on the average $5.33^{\circ} \mathrm{C}$. above that in nature, with other conditions normal.

Apparatus.-Glass breeding tanks, as in experiments I and 2.

In these experiments, which were conducted in the years 1898 to 1904, 2,000 larvæ were used. The eggs were taken from a state of nature within eight or ten hours after being laid, and placed in the conditions of the experiment. From the 3,200 eggs used 2,000 larvæ were hatched. These were kept under the best of conditions as regards food and cleanliness. The temperature records in the experiments are as follows:

TABLE 58.-Temperature conditions.

\begin{tabular}{|c|c|c|c|c|c|c|c|}
\hline Conditions-- & 8 a. m. & I p. m. & 8 p. m. & $\begin{array}{l}\text { Maxi- } \\
\text { mum. }\end{array}$ & $\begin{array}{l}\text { Mini- } \\
\text { mum. }\end{array}$ & $\begin{array}{l}\text { Aver- } \\
\text { age. }\end{array}$ & $\begin{array}{l}\text { Deviation } \\
\text { from } \\
\text { normal. }\end{array}$ \\
\hline In nature... & $\begin{array}{l}{ }^{\circ} \mathrm{C} . \\
\text { I9 }\end{array}$ & $\begin{array}{r}{ }^{\circ} \mathrm{C} . \\
3 \mathrm{I}\end{array}$ & ${ }^{\circ} \mathrm{C}$. & $\begin{array}{l}{ }^{\circ} \mathrm{C} . \\
3^{8}\end{array}$ & $\begin{array}{l}{ }^{\circ} \mathrm{C} . \\
{ }_{13}\end{array}$ & $\begin{array}{l}{ }^{\circ} \mathrm{C} .6 \\
23.66\end{array}$ & $\begin{array}{c}{ }^{\circ} C . \\
0\end{array}$ \\
\hline In experiment & 23 & $3^{8}$ & 26 & 39.5 & 20 & & $+5 \cdot 33$ \\
\hline
\end{tabular}


During these experiments 12 per cent died in the larval stage, 23 per cent in the pupal, and 65 per cent, equally divided between the sexes, emerged. These were 15 per cent below the normal in size, and their development was accelerated about 3.5 per cent. The hypodermal color was normal or slightly darker than normal, but the dark markings were increased in size so much that the imagines presented a distinct melanic appearance. On the ventral surface especially the increased pigmentation was marked, the middle and inner sternal spots being found in 80 per cent of the variates. The seriation of these beetles into classes is as follows:

TABLE 59.-General color of beetles used.

\begin{tabular}{|c|c|c|c|c|c|c|c|c|c|c|c|}
\hline Class...... & 4 & 5 & 6 & 7 & 8 & 9 & ro & II & 12 & I3 & $I_{4}$ \\
\hline $\begin{array}{l}\text { Parents...... } \\
\text { Control... } \\
\text { Experiment. }\end{array}$ & $\begin{array}{c}\text { P.ct. } \\
\cdots \\
\mathrm{I} \\
\cdots\end{array}$ & $\begin{array}{c}\text { P.ct. } \\
\mathrm{I} \\
\mathrm{I} \\
\mathrm{P}\end{array}$ & $\begin{array}{c}\text { P.ct. } \\
2 \\
7 \\
\cdots\end{array}$ & $\begin{array}{c}P . c t . \\
5 \\
8 \\
\mathrm{I}\end{array}$ & $\begin{array}{r}P c t \\
20 \\
17 \\
4\end{array}$ & $\begin{array}{l}\text { P.ct. } \\
42 \\
39 \\
6\end{array}$ & $\begin{array}{l}\text { P.ct. } \\
\text { I } \\
\text { I9 } \\
\text { I } 2\end{array}$ & $\begin{array}{r}\text { P.ct. } \\
9 \\
6 \\
20\end{array}$ & $\begin{array}{c}\text { P.ct. } \\
2 \\
1 \\
48\end{array}$ & $\begin{array}{c}\text { P.ct. } \\
\mathrm{I} \\
\mathrm{I} \\
7\end{array}$ & $\begin{array}{l}\text { P.ct. } \\
\cdots \\
\cdots \\
2\end{array}$ \\
\hline
\end{tabular}

Empirical mode of parents ...... 9

Empirical mole of control ....... 9

Empirical mode in experiment... I2
Modal deviation of parents ...... o Modal deviation of control...... o

Modal deviation in experiment .. .

The conditions of this experiment are nearly the same as those of experiment I, the resulting modifications of the elements of the color pattern, of the colors themselves, and of the whole color effect being almost identical, as may be seen by a comparison of tables 45 and 59. In this experiment, however, the mortality was decreased, there being a total difference of 22 per cent in favor of the latter.

EXPERIMENT 9.-To determine effects of an increased average deviation of temperature

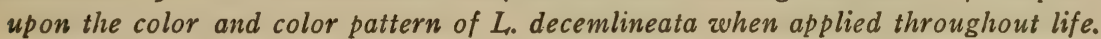

Conditions.-Temperature on the average $9.5^{\circ} \mathrm{C}$. above that in nature, with other conditions normal.

Apparatus.-The same as in experiment 8.

In these experiments, which were conducted in the years 1898 to 1904, I,600 larvæ were used, which hatched from 2, I00 eggs placed in the experiment rooms. The temperature conditions during the experiment were as follows:

TABLE 60.-Temperature conditions.

\begin{tabular}{|c|c|c|c|c|c|c|c|}
\hline Conditions- & $8 \mathrm{a} . \mathrm{m}$. & I p. m. & 8 p. m. & $\begin{array}{l}\text { Maxi- } \\
\text { mum. }\end{array}$ & $\begin{array}{l}\text { Mini- } \\
\text { mum. }\end{array}$ & $\begin{array}{l}\text { Aver- } \\
\text { age. }\end{array}$ & $\begin{array}{c}\text { Deviation } \\
\text { from } \\
\text { normal. }\end{array}$ \\
\hline $\begin{array}{l}\text { In nature } \ldots . . \\
\text { In experiment. }\end{array}$ & $\begin{array}{l}{ }^{\circ} \mathrm{C} . \\
\mathrm{Ig}\end{array}$ & $\begin{array}{l}{ }^{\circ} \mathrm{C} . \\
3^{\mathrm{I}}\end{array}$ & $\begin{array}{l}{ }^{\circ} \mathrm{C} \text { : } \\
{ }^{2} \mathrm{I}\end{array}$ & $\begin{array}{l}{ }^{\circ} \mathrm{C} . \\
33\end{array}$ & $\begin{array}{l}{ }^{\circ} \mathrm{C} . \\
{ }^{\mathrm{r}} 3\end{array}$ & $\begin{array}{l}{ }^{\circ} \mathrm{C} . \\
23.66\end{array}$ & $\begin{array}{l}{ }^{\circ} \mathrm{C} . \\
0 \\
+ \\
+\end{array}$ \\
\hline In experiment. & 28 & $4 \mathrm{I} \cdot 5$ & 30 & 43 & & 33.16 & +9.5 \\
\hline
\end{tabular}


During this experiment there was a mortality of 55 per cent in the larvæ and of 30 per cent in the pupx, 15 per cent emerging as imagines. These were 35 per cent below the normal size and equally divided between the sexes. The hypodermal color was pale yellow and the dark markings were much altered. Upon the epicranium and pronotum the spots were small, and there were no fusions. The epicranial spots $h$ and $h^{\prime}$ were wanting, as were also the pronotal spots $f$ and $f^{\prime}$ and often $d$ and $d^{\prime}$, while $b$ and $b^{\prime}$ were much reduced and $a$ and $a^{\prime}$ were nearly divided into two spots each. In the larvæ the basal-pleural spots were lost in part of the larvæ in the second instar, and the tergal spots all disappeared. The cuticula pigments were also lighter, being a dark brown. The general color tendency was albinic, as is shown in the following seriations:

TABLE 6I.-General color of beetles used.

\begin{tabular}{|c|c|c|c|c|c|c|c|c|c|c|}
\hline Class...... & 4 & 5 & 6 & 7 & 8 & 9 & 10 & II & 12 & 13 \\
\hline & P.ct. & P.ct. & P.ct. & P.ct. & P.ct. & P.ct. & P.ct. & P.ct. & P.ct. & P.ct. \\
\hline Parents...... & $\cdots$ & I & 2 & 5 & 20 & 42 & 18 & 9 & 2. & $\mathbf{I}$ \\
\hline Control....... & I & I & 7 & 8 & 17 & 39 & 19 & 6 & $\mathbf{I}$ & $\mathbf{I}$ \\
\hline Experiment. . & 2 & 12 & 42 & 27 & II & 3 & $\mathbf{I}$ & 5 & $\cdots$ & $\cdots$ \\
\hline
\end{tabular}

Empirical mode of parents ...... 9 Empirical mode of control ....... 9 9 Empirical mode in experiment ... 6

Modal deviation of parents ..... Q Modal deviation of control ...... o Modal deviation in experiment . -3

EXPERIMENT 10.-To determine the effect of a large average increase in temperature applied throughout life upon the color and color pattern of L. decemlineata.

Conditions.-Temperature on the average $14.5^{\circ} \mathrm{C}$. above that in nature, with other factors normal.

Apparatus.-The same as in experiments 7 and 8.

In this experiment 2,000 larvæ hatched from 3,850 eggs were used. These eggs were taken at random from potato plants soon after they were laid, and were placed at once in the conditions of the experiment. The temperature records are as follows:

TABLE, 62.-Temperature conditions.

\begin{tabular}{|c|c|c|c|c|c|c|c|}
\hline Conditions- & 8 a. $\mathrm{m}$. & I p. m. & 8 p. m. & $\begin{array}{l}\text { Maxi- } \\
\text { mum. }\end{array}$ & $\begin{array}{l}\text { Mini- } \\
\text { mum. }\end{array}$ & $\begin{array}{l}\text { Aver- } \\
\text { age. }\end{array}$ & $\begin{array}{c}\text { Deviation } \\
\text { from } \\
\text { normal. }\end{array}$ \\
\hline In nature & $\begin{array}{l}{ }^{\circ} \mathrm{C} . \\
19\end{array}$ & ${ }^{\circ} \mathrm{C}$. & $\begin{array}{l}{ }^{\circ} \mathrm{C} . \\
2 \mathrm{I}\end{array}$ & $\begin{array}{c}{ }^{\circ} \mathrm{C} . \\
33 \\
48\end{array}$ & $\begin{array}{l}{ }^{\circ} \mathrm{C} . \\
{ }_{13}\end{array}$ & $\begin{array}{l}\circ \mathrm{C} \text {. } \\
23.66\end{array}$ & ${ }^{\circ} \mathrm{C}$. \\
\hline & & & & & & & +14.5 \\
\hline
\end{tabular}


In these experiments 62 per cent died in the larval stage, 34 per cent in the pupal, and 6 per cent completed their transformations. In the larvæ at hatching the dorsal color marks were small, and many were absent; and in the second instar all spots had disappeared, excepting the spiracular and wing, and the pronotum and epicranium were light brown in color. The imagines were 39 per cent below the normal in size and were equally divided between the sexes. The hypodermal color was white, and there were no dark spots upon the epicranium, nor any upon the pronotum excepting $a$ and $c$. The elytral stripes were shortened, and the anal, cubital, and costal were wanting. On the ventral surface all spots were obliterated, excepting the anterior sternals upon the thoracic and abdominal segments, and those upon the tarsi of the legs. The general appearance was strongly albinic, as is shown by the following seriation :

TABLE 63.-General color of beetles used.

\begin{tabular}{|c|c|c|c|c|c|c|c|c|c|c|c|c|c|}
\hline Class.... & I & 2 & 3 & 4 & 5 & 6 & 7 & 8 & 9 & 10 & II & 12 & I3 \\
\hline Parents & P.ct. & $\begin{array}{c}\text { P.ct. } \\
\cdots\end{array}$ & $\begin{array}{c}\text { P.ct. } \\
\cdots\end{array}$ & $\begin{array}{c}\text { P.ct. } \\
\cdots\end{array}$ & $\begin{array}{c}\text { P.ct. } \\
\text { I }\end{array}$ & $\begin{array}{c}\text { P.ct. } \\
2\end{array}$ & $\begin{array}{r}\text { P.ct. } \\
5\end{array}$ & $\begin{array}{c}\text { P.ct. } \\
20\end{array}$ & $\begin{array}{l}\text { P.ct. } \\
42\end{array}$ & $\begin{array}{l}\text { P.ct. } \\
\text { I8 }\end{array}$ & $\begin{array}{c}\text { P.ct. } \\
9\end{array}$ & P.ct. & $\begin{array}{r}\text { P.ct. } \\
\mathbf{1}\end{array}$ \\
\hline $\begin{array}{l}\text { Control ..... } \\
\text { Experiment* }\end{array}$ & I & $\ddot{7}$ & 46 & $\begin{array}{r}1 \\
33\end{array}$ & $\begin{array}{r}I \\
22\end{array}$ & $\begin{array}{l}7 \\
8\end{array}$ & $\begin{array}{l}8 \\
2\end{array}$ & $\begin{array}{r}17 \\
\text { I }\end{array}$ & $\begin{array}{l}39 \\
. .\end{array}$ & 19 & $\begin{array}{c}\mathrm{I} \\
. .\end{array}$ & $\begin{array}{c}\mathbf{I} \\
. .\end{array}$ & $\begin{array}{l}0 \\
. .\end{array}$ \\
\hline
\end{tabular}

* Number of individuals.

Empirical mode of parents....... 9 Empirical mode of control ....... 9 Empirical mode in experiment ... 3
Modal deviation of parents...... o

Modal deviation of control....... o

Modal deviation in experiment.. -6

EXPERMENT II.-To determine the effect of a small average decrease in temperature upon the color and color pattern of L. decemlineata when applied throughout life.

Conditions.-Temperature on the average $6.5^{\circ} \mathrm{C}$. below that in nature, with other conditions normal.

Apparatus.-The same as in experiment 8.

In this experiment 3,300 freshly laid eggs taken at random were placed in the conditions of the experiment as soon as they were obtained, and from these 2,700 larvæ were hatched. The experiments were conducted during the years 1898 to I904. The temperature records are as follows:

TABLE 64.-Temperature conditions.

\begin{tabular}{|c|c|c|c|c|c|c|c|}
\hline Conditions- & 8 a. m. & I p. m. & 8 p. m. & $\begin{array}{l}\text { Maxi- } \\
\text { mum. }\end{array}$ & $\begin{array}{l}\text { Mini- } \\
\text { mum. }\end{array}$ & $\begin{array}{l}\text { A ver- } \\
\text { age. }\end{array}$ & $\begin{array}{c}\text { Deviation } \\
\text { from } \\
\text { normal. }\end{array}$ \\
\hline $\begin{array}{l}\text { In nature ....... } \\
\text { In experiment }\end{array}$ & $\begin{array}{r}{ }^{\circ} \mathrm{C} . \\
19 \\
16\end{array}$ & $\begin{array}{l}{ }^{\circ} \mathrm{C} . \\
3 \mathrm{I} \\
\text { I9. } 48\end{array}$ & $\begin{array}{r}{ }^{\circ} C . \\
2 \mathrm{I} \\
\mathrm{I} 6\end{array}$ & $\begin{array}{l}{ }^{\circ} \mathrm{C} . \\
33 \\
20.5\end{array}$ & $\begin{array}{l}{ }^{\circ} \mathrm{C} . \\
13 \\
12\end{array}$ & $\begin{array}{l}{ }^{\circ} \mathrm{C} . \\
23.66 \\
17.16\end{array}$ & $\begin{array}{l}{ }^{\circ} C . \\
0 \\
-6.5\end{array}$ \\
\hline
\end{tabular}


In these experiments no color modifications were noticed in the larvæ, but the length of the larval life was prolonged Io to I2 per cent. During the experiment 2I per cent died in the larval stage, I 5 per cent in the pupal, and 54 per cent emerged, of which 47 per cent were females and 53 per cent males. The color modifications were almost exactly the same as those described for experiment 5. The following seriations have been made to illustrate the general color tendencies:

TABLE 65.-General color of beetles used.

\begin{tabular}{|c|c|c|c|c|c|c|c|c|c|c|c|c|c|}
\hline Class...... & 4 & 5 & 6 & 7 & 8 & 9 & I0 & II & I2 & 13 & I4 & 15 & I6 \\
\hline & P.ct. & P.ct. & P.ct. & P.ct. & P.ct. & P.ct. & Pct. & P.ct. & P.ct. & P.ct. & P.ct. & P.ct. & P.ct. \\
\hline Parents. & $\ldots$ & I & 2 & 5 & 20 & 42 & I 8 & 9. & 2 & I & . & . & $\cdots$ \\
\hline Control .. & I & I & 7 & 8 & I7 & 39 & I9 & 6 & I & I & & . & . \\
\hline Experiment. & $\cdots$ & $\cdots$ & $\therefore$ & . & .. & I & 4 & 8 & Io & 23 & 42 & 9 & 3 \\
\hline
\end{tabular}

Empirical mode of parents ..... 9 Empirical mode of control ...... 9 Empirical mode in experiment... I4
Modal deviation of parents ..... o Modal deviation of control ...... o Modal deviation in experiment. . +5

EXPERIMENT 12.-To determine the effect of a considerable average reduction in temperature upon the color and color pattern of L. decemlineata when applied throughout life.

Conditions.-Temperature on the average $12^{\circ} \mathrm{C}$. below that in nature, with other conditions normal.

Apparatus.-The same as in experiment 8.

In these experiments, which were conducted during the years I900 to I904, 2,900 eggs were placed in the condition of the experiment, and from these I,500 larvæ were hatched. The temperature records are as follows:

TABLE 66.-Temperature conditions.

\begin{tabular}{|c|c|c|c|c|c|c|c|}
\hline Conditions- & 8 a. m. & I p. m. & 8 p. m. & $\begin{array}{l}\text { Maxi- } \\
\text { mum. }\end{array}$ & $\begin{array}{l}\text { Mini- } \\
\text { mum. }\end{array}$ & $\begin{array}{l}\text { Aver- } \\
\text { age. }\end{array}$ & $\begin{array}{l}\text { Deviation } \\
\text { from } \\
\text { normal. }\end{array}$ \\
\hline $\begin{array}{l}\text { In nature ..... } \\
\text { In experiment. }\end{array}$ & $\begin{array}{l}{ }^{\circ} C . \\
19 \\
10\end{array}$ & $\begin{array}{l}{ }^{\circ} \mathrm{C} . \\
3 \mathrm{I} \\
\text { I4. } 98\end{array}$ & $\begin{array}{l}{ }^{\circ} \mathrm{C} . \\
2 \mathrm{I} \\
\text { IO }\end{array}$ & $\begin{array}{l}{ }^{\circ} \mathrm{C} . \\
33 \\
\text { I5.5 }\end{array}$ & $\begin{array}{l}{ }^{\circ} \mathrm{C} . \\
\mathrm{I}_{3} \\
8\end{array}$ & $\begin{array}{l}{ }^{\circ} C_{.} \\
23.66 \\
11.66\end{array}$ & $\begin{array}{r}{ }^{\circ} \mathrm{C} . \\
0 \\
-12\end{array}$ \\
\hline
\end{tabular}

In these experiments the hypodermal color of the larvæ was duller than normal, all the tergal and posterior basal pleural spots were dropped out, and the legs, head, and pronotum were dark brown in color. During the experiment 60 per cent died in the larval stage, 22 per cent in the pupal, and 12 per cent appeared as imagines. These showed the same color modifications as those described for experiment 5. Their seriations into color classes are as shown in table 67 . 
TABLE 67.-General color of beetles used.

\begin{tabular}{|r|r|r|r|r|r|r|r|r|r|r|r|r|}
\hline class..... & 4 & 5 & 6 & 7 & 8 & 9 & I0 & II & 12 & I3 \\
\hline & P.ct. & P.ct. & P.ct. & P.ct. & P.ct. & P.ct & P.ct. & P.ct. & P.ct. & P.ct. \\
Parents...... & $\ldots$ & $\mathrm{I}$ & 2 & 5 & 20 & 42 & $\mathrm{I} 8$ & 9 & 2 & $\mathrm{I}$ \\
Control....... & $\mathrm{I}$ & $\mathrm{I}$ & 7 & 8 & $\mathrm{I} 7$ & 39 & $\mathrm{I} 9$ & 6 & $\mathrm{I}$ & $\mathrm{I}$ \\
Experiment*. & $\ldots$ & $\ldots$ & 5 & 50 & 20 & 20 & 5 & $\ldots$ & $\ldots$ & $\ldots$ \\
\hline
\end{tabular}

* Number of individuals.

Empirical mode of parents....... 9

Empirical mode of control........ 9

Empirical mode in experiment ... 7
Modal deviation of parents......

Modal deviation of control........

Modal deviation in experiment ... -2

EXPERIMENT 13.-To determine the effect upon the color and color pattern of $L$. decemlineata of a large decrease in average temperature when applied throughout life.

Conditions.-Temperature on the average $20^{\circ} \mathrm{C}$. below that in nature, with other conditions abnormal, as described in experiment 7 .

Apparatus.-The same as in experiment 7 .

In these experiments 4,250 freshly laid eggs collected at random were used; of these I,I50 hatched, but only I,000 lived to begin feeding. The larvæ were modified in their coloration, as in experiment 12, and the larval period was three times its normal length. The following temperatures were used:

TABLE 68.-Temperature conditions.

\begin{tabular}{|c|c|c|c|c|c|c|c|}
\hline Conditions- & 8 a. m. & I p. m. & 8 p. m. & $\begin{array}{l}\text { Maxi- } \\
\text { mum. }\end{array}$ & $\begin{array}{l}\text { Mini- } \\
\text { mum. }\end{array}$ & $\begin{array}{l}\text { Aver- } \\
\text { age. }\end{array}$ & $\begin{array}{c}\text { Deviation } \\
\text { from } \\
\text { normal. }\end{array}$ \\
\hline $\begin{array}{l}\text { In nature ...... } \\
\text { In experiment. }\end{array}$ & $\begin{array}{c}\circ C . \\
19 \\
2\end{array}$ & $\begin{array}{l}{ }^{\circ} \mathrm{C} . \\
\text { 3I } \\
5.98\end{array}$ & $\begin{array}{c}{ }^{\circ} C . \\
2 \mathrm{I} \\
3\end{array}$ & $\begin{array}{l}{ }^{\circ} C . \\
33 \\
6.5\end{array}$ & $\begin{array}{r}{ }^{\circ} \mathrm{C} . \\
\mathrm{I}_{3} \\
\mathrm{O}\end{array}$ & $\begin{array}{r}{ }^{\circ} \mathrm{C} . \\
23.66 \\
366\end{array}$ & $\begin{array}{r}{ }^{\circ} C_{0} \\
0 \\
-20\end{array}$ \\
\hline
\end{tabular}

In these experiments 79 per cent died in the larval stage, I I per cent in the pupal, and ro per cent completed their transformations. The pupal stage was prolonged to five times its normal length. The variations found were exactly the same as those described for experiment 7 . The seriations of the imagines are as follows:

TABLE 69.-General color of beetles used.

\begin{tabular}{|c|c|c|c|c|c|c|c|c|c|c|c|c|c|}
\hline Class..... & 2 & 3 & 4 & 5 & 6 & 7 & 8 & 9 & Io & II & 12 & 13 & 14 \\
\hline & P.ct. & P.ct. & P.ct. & P.ct. & P.ct. & P.ct. & P.ct. & P.ct. & P.ct. & P.ct. & P.ct. & P.ct. & P.ct. \\
\hline $\begin{array}{l}\text { Parents.. } \\
\text { Control. }\end{array}$ & $\because$ & . & i & $\begin{array}{l}I \\
I\end{array}$ & 2 & $\begin{array}{l}5 \\
8\end{array}$ & 20 & $\begin{array}{l}42 \\
39\end{array}$ & I8 & $\begin{array}{l}9 \\
6\end{array}$ & $\begin{array}{l}2 \\
I\end{array}$ & $\begin{array}{l}\mathrm{I} \\
\mathrm{I}\end{array}$ & $\because$ \\
\hline Experiment. . & I & Io & 43 & $2 \mathrm{I}$ & I5 & 8 & 2 & . & $\cdots$ & .. & .. & .. & .. \\
\hline
\end{tabular}

Empirical morle of parents....... 9

Empirical mode of control....... 9

Modal deviation of parents...... o

Empirical mode in experiment.... 4

Modal deviation of control ...... o

Modal deviation in experiment .. - 5 
In this set of experiments ( 8 to 13 ), in which the beetles were subjected to the conditions of the experiment throughout life, beginning a few hours after fertilization, results were obtained in imaginal color modification that are identical with those in experiments I to 7 , where the beetles were used during the late larval and pupal stages only. These results I have represented in text-figure 12. Hence the conclusion to be drawn from these experiments is that as far as adult coloration is concerned it makes no difference whether the stimulus of increased or decreased temperature be applied for the entire life or for the pupal stage only. That is, there does not appear to be any accumulated effect of a temperature stimulus.

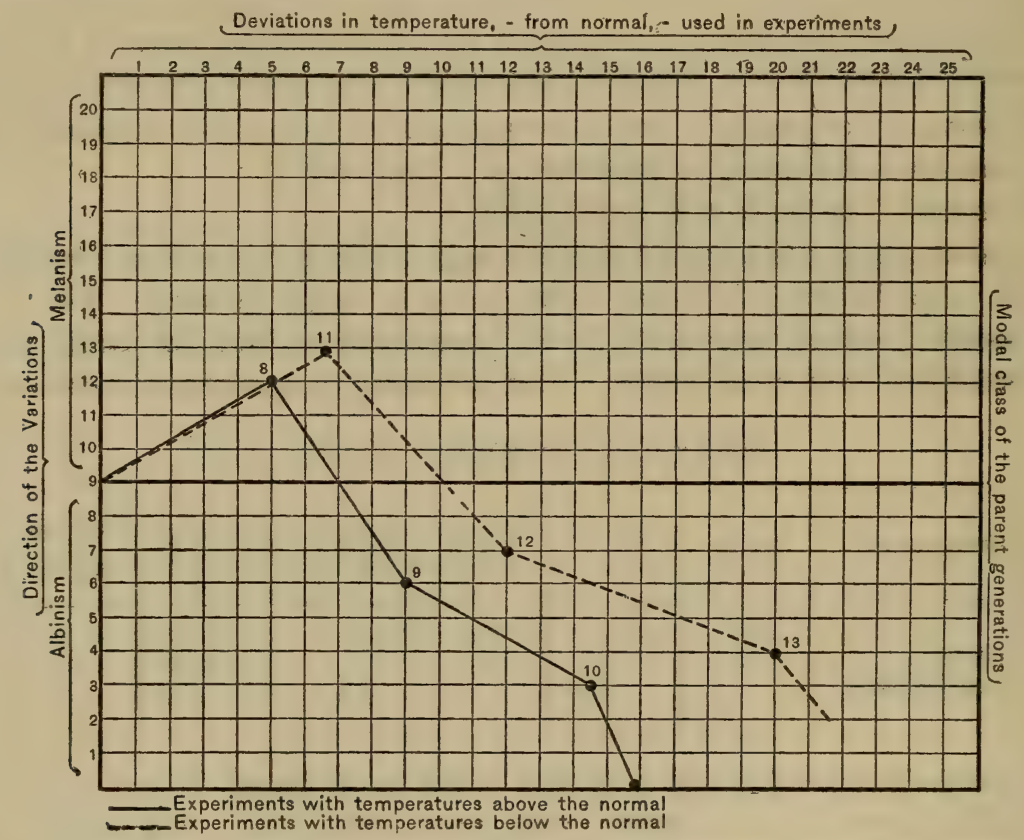

TEXT-FIGURE 12.-To illustrate graphically the results obtained in experiments 8 to 13 .

It has been shown that the influence of high and low temperature upon the larval color pattern is much the same as that upon the adult. Therefore it would seem that the effect upon the color-enzyme forming cells at each period of activity is immediate and persists only as long as the stimulus is applied, and that there is no accumulated influence stored up through the larval period. This has been conclusively shown by a set of experiments made to test this point. In these experiments larvæ reared up to the prepupal period under the conditions of experiments $I$ to 7 were at pupation placed in normal surroundings. Now, if the effects of stimuli applied to the larvæ were cumulative, the fact ought to be apparent in the adults. Two experiments taken from this set will serve to illustrate the results obtained from this entire series of seven experiments. 
EXPERIMENT I4.-To determine the effect upon adult coloration of $L$. decemlineata of a considerable increase in average temperature applied throughout the larval stage only.

Conditions.-Temperature on the average $14.5^{\circ} \mathrm{C}$. above that in nature, with other conditions normal.

Apparatus.-The same as in experiment 10.

In this experiment 2,000 larvæ were used, hatched from 3,300 eggs which were taken at random soon after being laid, and placed in the conditions of the experiment. The larvæ were kept there until time for pupation-that is, until the beginning of the prepupal period-when they were returned to normal surroundings. The temperature records are as follows:

TABLE 70.-Temperature conditions.

\begin{tabular}{|c|c|c|c|c|c|c|c|}
\hline Conditions- & 8 a. m. & I p. m. & 8 p. m. & $\begin{array}{l}\text { Maxi- } \\
\text { mum. }\end{array}$ & $\begin{array}{l}\text { Mini- } \\
\text { mum. }\end{array}$ & $\begin{array}{l}\text { Aver- } \\
\text { age. }\end{array}$ & $\begin{array}{c}\text { Deviation } \\
\text { from } \\
\text { normal. }\end{array}$ \\
\hline $\begin{array}{l}\text { In nature ...... } \\
\text { In experiment. }\end{array}$ & $\begin{array}{l}{ }^{\circ} C . \\
19 \\
33\end{array}$ & $\begin{array}{l}{ }^{\circ} C . \\
3 \mathrm{I} \\
46.48\end{array}$ & $\begin{array}{l}{ }^{\circ} C . \\
2 \mathrm{I} \\
35\end{array}$ & $\begin{array}{l}\circ C . \\
33 \\
48\end{array}$ & $\begin{array}{l}{ }^{\circ} C . \\
13 \\
28\end{array}$ & $\begin{array}{l}{ }^{\circ} C . \\
23.66 \\
38.16\end{array}$ & $\begin{array}{c}\circ C . \\
0 \\
+\mathrm{I} 4.5\end{array}$ \\
\hline
\end{tabular}

In this experiment, which is an exact duplicate of experiment Io as far as the larvæ are concerned, the mortality was approximately the same in the larval stage, but lower in the pupal-that is, 60 per cent died in the larval stage, Io per cent in the pupal, and 30 per cent appeared as imagines. The imagines were normal, as is apparent in the following table:

TABLE 7I.-General color of beetles used.

\begin{tabular}{|c|c|c|c|c|c|c|c|c|c|c|}
\hline Class...... & 4 & 5 & 6 & 7 & 8 & 9 & Io & II & 12 & I3 \\
\hline & P.ct. & P.ct. & P.ct. & P.ct. & P.ct. & P.ct. & P.ct. & P.ct. & P.ct. & P.ct. \\
\hline Control. & $\ddot{I}$ & $\begin{array}{l}I \\
I\end{array}$ & 2 & $\begin{array}{l}5 \\
8\end{array}$ & $\begin{array}{l}20 \\
17\end{array}$ & 39 & $\begin{array}{l}10 \\
19\end{array}$ & $\begin{array}{l}9 \\
6\end{array}$ & 2 & I \\
\hline Experiment.... & I & 2 & 3 & 7 & I5 & 45 & I8 & 6 & 2 & I \\
\hline
\end{tabular}

Empirical mode of parents ......, 9

Empirical mode of control......... 9

Empirical mode in experiment .... 9
Modal deviation of parents.......

Modal deviation of control.......

Modal deviation in experiment... o

EXPERIMENT 15-To determine the effect upon adult coloration of L. decemlineata of a considerable average decrease in temperature when applied throughout the larval stage only.

Conditions.-Temperature on the average $12^{\circ} \mathrm{C}$. below that in nature, with conditions as in experiment 10.

Apparatus.-The same as in experiment 10.

In this experiment, from 3,I00 eggs were obtained I, 500 larvæ, which were kept in the conditions of the experiment until the beginning of the prepupal period, and were then returned to a normal environment. 
The temperature records are as follows:

TABLE 72.-Tempcrature conditions.

\begin{tabular}{|c|c|c|c|c|c|c|c|}
\hline Conditions- & 8 a.m. & I p. $\mathrm{m}$. & 8 p. m. & $\begin{array}{l}\text { Maxi- } \\
\text { mum. }\end{array}$ & $\begin{array}{l}\text { Mini- } \\
\text { mum. }\end{array}$ & $\begin{array}{l}\text { Aver- } \\
\text { age. }\end{array}$ & $\begin{array}{l}\text { Deviation } \\
\text { from } \\
\text { normal. }\end{array}$ \\
\hline In nature...... & $\begin{array}{r}{ }^{\circ} \mathrm{C} . \\
\text { I9 }\end{array}$ & $\begin{array}{l}{ }^{\circ} \mathrm{C} . \\
3 \mathrm{I}\end{array}$ & $\begin{array}{c}{ }^{\circ} \mathrm{C} . \\
2 \mathrm{I}\end{array}$ & $\begin{array}{l}{ }^{\circ} \mathrm{C} . \\
33\end{array}$ & $\begin{array}{l}{ }^{\circ} \mathrm{C} . \\
{ }^{3} 3\end{array}$ & $\begin{array}{c}{ }^{\circ} C_{\text {. }} \\
23.66\end{array}$ & $\begin{array}{r}{ }^{\circ} \mathrm{C} . \\
\mathrm{o}\end{array}$ \\
\hline In experiment. & Io & I 4.98 & IO & I5. 5 & 8 & II 1.66 & -12 \\
\hline
\end{tabular}

In this experiment the larvæ showed the same color changes as those in No. IO. The mortality was 60 per cent in the larval stage, I2 per cent in the pupal, and 38 per cent emerged as imagines. The seriations of these are shown in the following table:

TABLE 73.-General color of beetles used.

\begin{tabular}{|c|c|c|c|c|c|c|c|c|c|}
\hline Class........ & 5 & 6 & 7 & 8 & 9 & ro & II & 12 & $I_{3}$ \\
\hline Parents. & $\begin{array}{c}\text { Perct. } \\
\text { I }\end{array}$ & $\begin{array}{c}\operatorname{Per} c t . \\
2\end{array}$ & $\begin{array}{c}\text { Perct. } \\
5\end{array}$ & $\begin{array}{c}\text { Perct. } \\
20\end{array}$ & $\begin{array}{c}\text { Perct. } \\
\mathbf{4 2}\end{array}$ & $\begin{array}{c}\text { Perct. } \\
\text { I8 }\end{array}$ & $\begin{array}{c}\text { Perct. } \\
9\end{array}$ & $\begin{array}{c}\text { Per ct. } \\
2\end{array}$ & $\begin{array}{c}\text { Perct. } \\
\text { I }\end{array}$ \\
\hline Control.. & 2 & 7 & 8 & I7 & 39 & I9 & 6 & I & I \\
\hline Experimeut. & I & 5 & 7 & 18 & 40 & 20 & 7 & 2 & .. \\
\hline
\end{tabular}

Empirical mode of parents....... 9 Empirical mode of control........ 9 Empirical mode in experiment.... 9
Modal deviation of parents....... o Modal deviation of control....... o

Modal deviation in experiment... o

In these experiments the adult coloration was not affected by temperature stimuli applied throughout the larval stage alone. This fact is made clearer in text-figure I3, where the curve of the entire series of these experiments is represented. Not the slightest indication is here apparent of any influence upon imaginal coloration of the conditions of temperature to which the larvæ have been subjected.

The modifications of coloration produced by external stimuli during the ontogeny of $L$. decemlineata are purely somatic variations, there being no accumulations of the effects of stimuli applied at one stage upon the coloration of a later one. The influence of temperature upon coloration is felt during the development of coloration of a particular instar only, and consists in the acceleration or retardation of the action of the color-producing enzymes. Neither is there any accumulation of the resuits of repeated temperature stimuli nor any increase of response even when repeated for several generations. This is apparent in text-figure I4, where are given the results derived from a series of experiments made in the years 1901 to 1904 , in which these beetles were subjected to the conditions of increased or decreased temperature during 


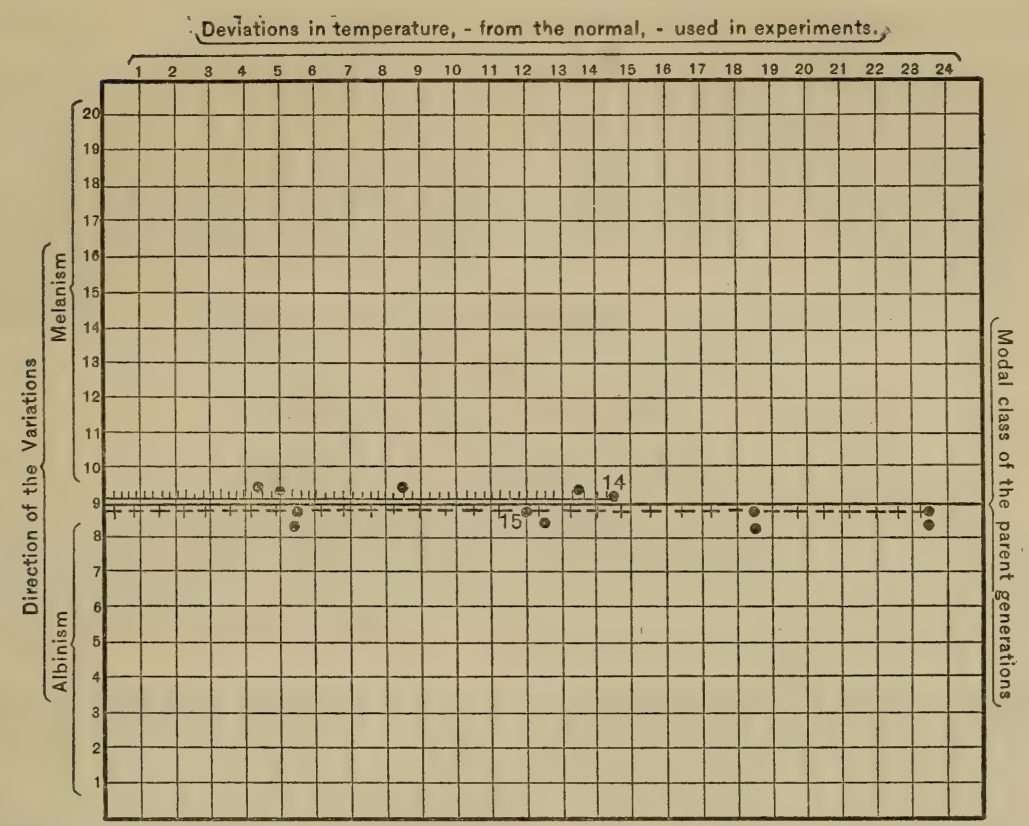

TIXT-FIGURE I3.-To illustrate the results obtained in a series of experiments of which two (I4 and I5 are described in the text, the results obtained in the others being shown by the figure.

\begin{tabular}{|c|c|c|c|c|c|c|c|}
\hline \multicolumn{2}{|c|}{1901} & \multicolumn{2}{|c|}{1902} & \multicolumn{2}{|c|}{1903} & \multicolumn{2}{|c|}{1904} \\
\hline Gen. I. & Gen. II. & Gen. III. & Gen. IV. & Gen. $\underline{\bar{v}}$ & Gen. ㅍ․ & Gen. VII. & Gen. VIII. \\
\hline
\end{tabular}

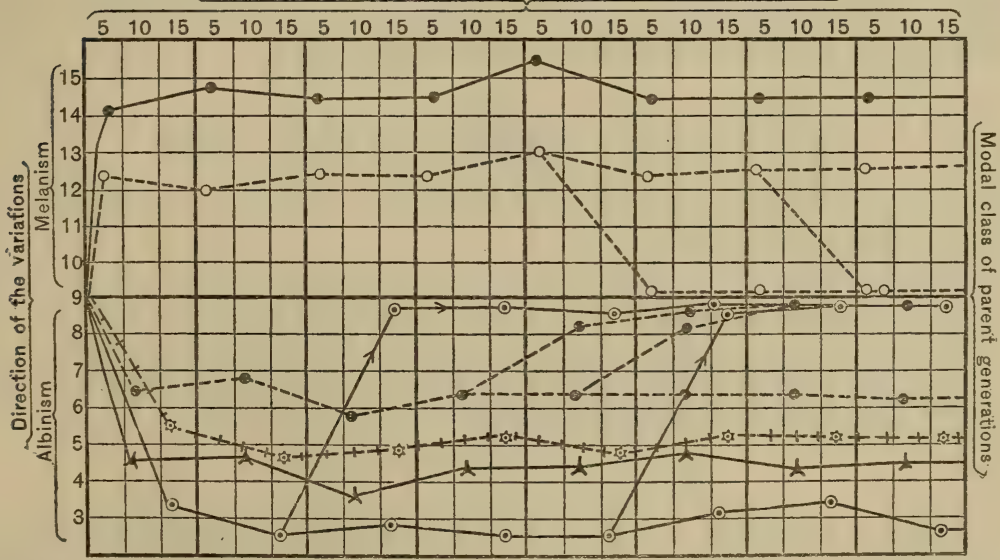

TEIT-FIGURE I4.-To illustrate the resuits that were obtained in a series of experiments as described in the text when continued for a number of generations. Each of the different lines represents a series of experiments and the arrow heads the direction taken by different parts of each set when the stimulus was removed or applied. In all the sets of experiments represented lines going toward the modal line of the parents indicate the rapid return of the beetles to the modal condition when the stimulus was removed. 
their color ontogeny in successive lineal generations. Moreover, if the stimulus be removed the coloration at once shows its ephemeral character by going back to the normal condition, and does not in succeeding generations exhibit any tendency to repeat the modification. Some of my material, which was experimented upon along this line for from twelve to fifteen lineal generations, still showed no trace whatever of permanent modification even with intense selection.

I conclude, therefore, that deviations in temperature, when applied to $L$. decemlineata, act simply as stimuli toward the acceleration or retardation of pigmentation, and that the responses attain their maxima at once, are never increased (unless the stimulus be changed), and disappear as soon as the stimuli are removed. The results in color modification are purely transient, somatic variations, which, however, may produce a strong prophetic or historic skewness in the variation polygon, and may correspond very closely, as I have found in many of my experiments, to those variations found to exist in nature as place and geographical variations.

Nowhere in these experiments does evidence appear which would indicate that temperature has any specific effect upon the coloration of these beetles. It in all cases acts simply as a stimulus toward the production of results which are exactly the same as those which I have brought about by other agencies.

\section{MOISTURE EXPERIMENTS.}

The effects of moisture upon the production of color modification has been determined by subjecting $L$. decemlineata to varying percentages of relative humidity. Numerous experiments have been tried which I shall combine into a few large experiments, as in those with temperature.

\section{EXPERIMENT I6.-To determine the effect of a moderate increase in relative humidity upon the color and color pattern of $L$. decemlineata.}

Conditions.-Relative humidity Io per cent above the average in nature, with other conditions normal.

Apparatus.-Glass tanks arranged for the absolute control of moisture.

In these experiments, which were conducted during the years 1898 to 1904 , 4,500 eggs collected at random were used, from which 4,000 larvæ hatched. These were kept in the following conditions throughout life:

TABLE 74.-Humidity conditions.

\begin{tabular}{|c|c|c|c|c|c|c|c|c|c|}
\hline Humidity- & 7 a. m. & Io a. $\mathrm{m}$. & I p. m. & 3 p. m. & $8 \mathrm{p.m}$. & $\begin{array}{l}\text { Maxi- } \\
\text { mum. }\end{array}$ & $\begin{array}{l}\text { Mini- } \\
\text { mum. }\end{array}$ & $\begin{array}{l}\text { Aver- } \\
\text { age. }\end{array}$ & $\begin{array}{c}\text { Deviation } \\
\text { from } \\
\text { normal. }\end{array}$ \\
\hline $\begin{array}{l}\text { In nature...... } \\
\text { In experiment. }\end{array}$ & $\begin{array}{c}\text { Perct. } \\
{ }^{*} \mathrm{IOO} \\
{ }^{*} \mathrm{IOO}\end{array}$ & $\begin{array}{c}\text { Perct. } \\
65 \\
85\end{array}$ & $\begin{array}{c}\text { Perct. } \\
50 \\
60\end{array}$ & $\begin{array}{c}\text { Perct. } \\
55 \\
75\end{array}$ & $\begin{array}{l}\text { Perct. } \\
\text { * Ioo } \\
\text { * Ioo }\end{array}$ & $\begin{array}{r}\text { Perct. } \\
\text { IOO } \\
\text { IOO }\end{array}$ & $\begin{array}{c}\text { Perct. } \\
43 \\
55\end{array}$ & $\begin{array}{c}\text { Per ct. } \\
74 \\
84\end{array}$ & $\begin{array}{c}\text { Perct. } \\
0 \\
+10\end{array}$ \\
\hline
\end{tabular}

* Dew. 
In these experiments 6.3 per cent died in the larval stage, 8.7 per cent in the pupal, and 85 per cent emerged. The coloration of the larvæ was a deep wine red, and all dark spots were large and of a polished black. On the tergæ the inner tergal spots were quite uniformly present. The imagines were either normal in size or slightly large. The hypodermal color was a strong ocher yellow, tinged frequently with red. The dark markings, which were large and frequently fused, were of a dense black color. Their general appearance was melanic, as is shown by their seriations in the following table:

TABLE 75.-General color of beetles used.

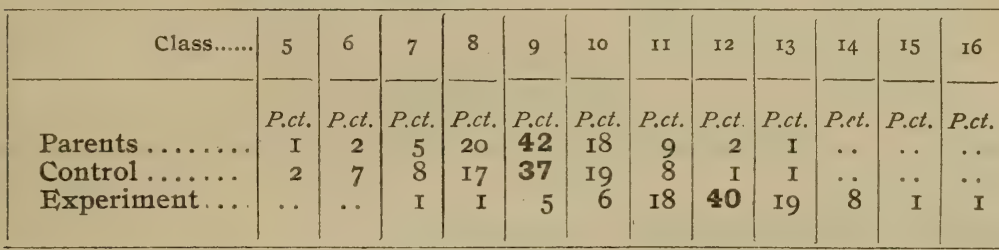

Empirical mode of parents...... 9 Empirical mode of control........ 9

Fimpirical mode in experiment.... I 2
Modal deviation of parents...... o

Modal deviation of control ...... o

Modal deviation in experiment .. + 3

EXPERIMENT 17.-To determine the effect of a large increase in relative humidity upon the coloration of $L$. decemlineata.

Conditions.-Relative humidity on the average $2 \mathrm{I}$ per cent above that in nature, with other conditions normal.

Apparatus.-The same as in experiment I6.

In these experiments, which were conducted during the years 1898 to I904, 3,500 eggs were used, from which were hatchea 3 , I00 larvæ. The conditions of experimentation were as follows:

TABLE 76.-Humidity conditions.

\begin{tabular}{|c|c|c|c|c|c|c|c|c|c|}
\hline Humidity - & $7 \mathrm{a.m}$. & ro a. m. & I p.m. & $3 \mathrm{p.m}$. & 8p. m. & $\begin{array}{l}\text { Maxi- } \\
\text { mum. }\end{array}$ & $\begin{array}{l}\text { Mini- } \\
\text { mum. }\end{array}$ & $\begin{array}{c}\text { Aver- } \\
\text { age. }\end{array}$ & $\begin{array}{l}\text { Deviation } \\
\text { from } \\
\text { normal. }\end{array}$ \\
\hline $\begin{array}{l}\text { In nature } \ldots . . . \\
\text { In experiment. }\end{array}$ & $\begin{array}{l}\text { Per ct. } \\
{ }^{*} \text { IOO } \\
{ }^{*} \text { IOO }\end{array}$ & $\begin{array}{c}\text { Per ct. } \\
65 \\
85\end{array}$ & $\begin{array}{c}\text { Per ct. } \\
50 \\
85\end{array}$ & $\begin{array}{r}\text { Per ct. } \\
\text { I0O } \\
90\end{array}$ & $\begin{array}{l}\text { Per ct. } \\
{ }^{*} \mathrm{IOO} \\
{ }^{*} \mathrm{IOO}\end{array}$ & $\begin{array}{c}\text { Perct. } \\
\text { IOO } \\
\text { IOO }\end{array}$ & $\begin{array}{c}\text { Per ct. } \\
43 \\
82\end{array}$ & $\begin{array}{c}\text { Per ct. } \\
74 \\
95\end{array}$ & $\begin{array}{c}\text { Perct. } \\
0 \\
+2 I\end{array}$ \\
\hline
\end{tabular}

* Dew.

In these experiments I2.4 per cent died in the larval stage, I7.6 per cent in the pupal, and 70 per cent emerged. The larval color pattern was changed in that the hypodermal color became paler, and had a translucent appearance and the dark spots were not as large nor were the dorsal areas as well developed. The imaginal color was also modified, the hypodermal color being pale yellow, with the dark areas smaller than is normal and with few fusions. In size the beetles were normal. The general color tendency was albinic, as is shown in table 77 . 
TABLE 77.-General color of beetles used.

\begin{tabular}{|r|r|r|r|r|r|r|r|r|r|r|r|r|}
\hline class...... & 3 & 4 & 5 & 6 & 7 & 8 & 9 & Io & II & 12 & 13 \\
\hline & P.ct. & P.ct. & P.ct. & P.ct. & P.ct. & P.ct. & P.ct. & P.ct & P.ct. & P.ct. & P.ct. \\
Parents...... & $\ldots$ & $\ldots$ & $\mathrm{I}$ & 2 & 5 & 20 & $\mathbf{4 2}$ & $\mathrm{I} 8$ & 9 & 2 & $\mathrm{I}$ \\
Control...... & $\ldots$ & $\ldots$ & 2 & 7 & 8 & $\mathrm{I} 7$ & $\mathbf{3 7}$ & $\mathrm{I} 9$ & 8 & $\mathrm{I}$ & $\mathrm{I}$ \\
Experiment & 2 & 3 & 7 & $\mathrm{I} 7$ & $\mathbf{3 8}$ & $\mathbf{2 1}$ & 9 & 2 & $\mathrm{I}$ & $\ldots$ & $\ldots$ \\
\hline
\end{tabular}

Empirical mode of parents....... 9

Empirical mode of control......... 9

Empirical mode in experiment..... 7
Modal deviation of parents ..... 0 Modal deviation of control....... o Modal deviation in experiment . -2

EXPERIMENT I8.-To determine the effect of a saturated atmosphere upon the coloration of $L$. decemlineata.

Conditions.-Relative humidity 26 per cent above that in nature, with other conditions normal.

Apparatus.-The same as in experiment 16 .

In this experiment, which was conducted during the years 1899 to 1904 , 2,000 larvæ, hatched from 4,450 eggs, were subjected to the following conditions :

TABLE 78.-Humidity conditions.

\begin{tabular}{|c|c|c|c|c|c|c|c|c|c|}
\hline Humidity - & 7 a. $\mathrm{m}$ & Io a. m. & I p. m. & 3 p. m. & 8 p. m. & $\begin{array}{l}\text { Maxi- } \\
\text { mum. }\end{array}$ & $\begin{array}{l}\text { Mini- } \\
\text { mum. }\end{array}$ & $\begin{array}{l}\text { Aver- } \\
\text { age. }\end{array}$ & $\begin{array}{l}\text { Deviation } \\
\text { from } \\
\text { normal. }\end{array}$ \\
\hline $\begin{array}{l}\text { In nature...... } \\
\text { In experiment. }\end{array}$ & $\begin{array}{l}\text { Per ct. } \\
{ }^{*} \text { roo } \\
{ }^{*} 100\end{array}$ & $\begin{array}{r}\text { Per ct. } \\
65 \\
{ }^{*} 100\end{array}$ & $\begin{array}{c}\text { Per ct. } \\
50 \\
100\end{array}$ & $\begin{array}{r}\text { Per ct. } \\
55 \\
{ }^{*} \text { IOO }\end{array}$ & $\begin{array}{c}\text { Per ct. } \\
{ }^{*} \text { roo } \\
{ }^{*} \text { IOO }\end{array}$ & $\begin{array}{l}\text { Perct. } \\
\text { IOo } \\
\text { IOO }\end{array}$ & $\begin{array}{c}\text { Per ct. } \\
43 \\
\text { I0O }\end{array}$ & $\begin{array}{c}\text { Perct. } \\
74 \\
100\end{array}$ & $\begin{array}{c}\text { Perct. } \\
0 \\
+26\end{array}$ \\
\hline
\end{tabular}

* Dew.

In the experiments of this series 52 per cent died in the larval stage, 38 per cent in the pupal, and Io per cent emerged. In the larvæ the hypodermal color was a light, translucent, yellowish red, and the dark areas were small and brown in color. All dorsal markings were wanting, as were also the posterior four or five basal pleural centers. In the imagines the hypodermal color was pale yellowish-white and the dark spots were much reduced in size. On the epicranium $h$ and $h^{\prime}$ were wanting and $g$ and $g^{\prime}$ were represented by mere traces of color. On the pronotum $f$ and $f^{\prime}$ were absent entirely; $d$ and $d^{\prime}, b$ and $b^{\prime}$ were absent in 40 per cent of the variates, and $e$ and $e^{\prime}$ in I2 per cent. The spots $a$ and $a^{\prime}$ were in 8 per cent of the variates divided into anterior and posterior parts. On the elytra all stripes were reduced and the anal was absent. On the ventral surface all spots were represented by mere traces, and the entire series of middle sternals was absent. The legs, with the exception of the tarsæ, were devoid of color and the general appearance was decidedly albinic, as is shown in the following seriations: 
TABLE 79.-General color of beetles used.

\begin{tabular}{|c|c|c|c|c|c|c|c|c|c|c|c|c|}
\hline Class... & 2 & 3 & 4 & 5 & 6 & 7 & 8 & 9 & I0 & II & 12 & 13 \\
\hline Parents & P.ct. & P.ct. & P.ct. & P.ct. & $\begin{array}{c}\text { P.ct. } \\
2\end{array}$ & P.ct. & $\begin{array}{l}\text { P.ct. } \\
20\end{array}$ & $\begin{array}{c}\text { P.ct. } \\
\mathbf{4 2}\end{array}$ & $\begin{array}{l}\text { P.ct. } \\
\text { I8 }\end{array}$ & P.ct. & $\begin{array}{c}\text { P.ct. } \\
2\end{array}$ & $\begin{array}{c}\text { P.ct. } \\
\text { I }\end{array}$ \\
\hline Control.. & $\cdots$ & 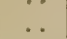 & & 2 & 7 & 8 & I7 & 37 & I9 & 8 & I & I \\
\hline Experiment. & 2 & 9 & 39 & 28 & 12 & 7 & 2 & I & .. & .. & . . & . \\
\hline
\end{tabular}

Empirical mode of parents........99

Empirical mode of control. ....... 9

Empirical mode in experiment.... 5
Modal deviation of parents ..... o

Modal deviation of control...... o

Modal deviation in experiment. . - 5

EXPERIMENT 19.-To determine the effect of a moderately diminished average relative humidity upon the color and color pattern of $L$. decemlineata.

Conditions.-Relative humidity on the average 8 per cent below that in nature, with other conditions normal.

Apparatus.-The same as in experiment 16.

In this experiment, which was conducted during the years 1898 to I904, 2,500 larvæ, hatched from 3,I60 eggs, were used. The conditions of experimentation were as follows:

TABLE 80.-Humidity conditions.

\begin{tabular}{|c|c|c|c|c|c|c|c|c|c|}
\hline Humidity- & $7 \mathrm{a} . \mathrm{m}$ & to a.m. & I p. m. & 3 p. m. & 8 p. m. & $\begin{array}{l}\text { Maxi- } \\
\text { mum. }\end{array}$ & $\begin{array}{l}\text { Mini- } \\
\text { mum. }\end{array}$ & $\begin{array}{l}\text { Aver- } \\
\text { age. }\end{array}$ & $\begin{array}{l}\text { Deviation } \\
\text { from } \\
\text { normal. }\end{array}$ \\
\hline $\begin{array}{l}\text { In nature...... } \\
\text { In experiment }\end{array}$ & $\begin{array}{c}\text { Per ct. } \\
\text { IoO } \\
\text { Ioo }\end{array}$ & $\begin{array}{c}\text { Perct. } \\
65 \\
60\end{array}$ & $\begin{array}{c}\text { Per ct. } \\
50 \\
40\end{array}$ & $\begin{array}{c}\text { Per ct. } \\
55 \\
40\end{array}$ & $\begin{array}{r}\text { Per ct. } \\
\text { roo } \\
90\end{array}$ & $\begin{array}{c}\text { Per ct. } \\
\text { IOO } \\
\text { IoO }\end{array}$ & $\begin{array}{c}\text { Per ct. } \\
43 \\
33\end{array}$ & $\begin{array}{c}\text { Per ct. } \\
74 \\
66\end{array}$ & $\begin{array}{c}\text { Perct. } \\
0 \\
-8\end{array}$ \\
\hline
\end{tabular}

In the experiments of this series I7 per cent died in the larval stage, I8 per cent in the pupal, and 65 per cent emerged. The larvæ were modified slightly, the hypodermal color becoming dull red and the dorsal abdominal spots being largely reduced. The imagines were 6.5 per cent below the size of the parents and of those under control. The hypodermal color was chrome yellow, with frequent fusions among the darker spots on both surfaces. The range of variation was large, but the general appearance was melanic, as may be seen in the following table:

TABLE 81.-General color of beetles used.

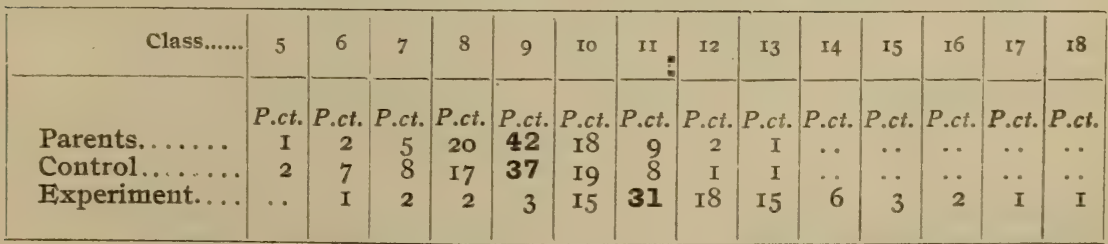

Empirical mode of parents....... 9

Empirical mode of control......... 9

Empirical mode in experiment..... I I I4-T
Modal deviation of parents..... o Modal deviation of control ..... o Modal deviation in experiment. . +2 
EXPERIMENT 20.-To determine the effect of a considerable decrease in relative humidity upon the color and color pattern of $L$. decemlineata.

Conditions.-Relative humidity on the average I4 per cent below that in nature, with other conditions normal.

Apparatus.-The same as in experiment I6.

In this series of experiments, conducted during the years 1899 to 1904, 3,860 eggs were used which were taken at random and subjected soon after being laid to the conditions of the experiment. From these 2,000 larvæ were hatched.

The conditions of the experiment were as follows:

TABLE 82.-Humidity conditions.

\begin{tabular}{|c|c|c|c|c|c|c|c|c|c|}
\hline Humidity- & 7 a.m. & Io a.m. & x p. m. & 3 p. m. & 8 p. m. & $\begin{array}{l}\text { Maxi- } \\
\text { mum. }\end{array}$ & $\begin{array}{l}\text { Mini- } \\
\text { mum. }\end{array}$ & $\begin{array}{c}\text { Aver- } \\
\text { age. }\end{array}$ & $\begin{array}{l}\text { Deviation } \\
\text { from } \\
\text { normal. }\end{array}$ \\
\hline In nature..... & $\begin{array}{c}\text { Per ct. } \\
\text { IOO }\end{array}$ & $\begin{array}{c}\text { Per ct. } \\
65\end{array}$ & $\begin{array}{c}\text { Per ct. } \\
50\end{array}$ & $\begin{array}{c}\text { Perct. } \\
55\end{array}$ & $\begin{array}{r}\text { Per ct. } \\
100\end{array}$ & $\begin{array}{c}\text { Per ct. } \\
100\end{array}$ & $\begin{array}{c}\text { Per ct. } \\
43\end{array}$ & $\begin{array}{c}\text { Per ct. } \\
74\end{array}$ & $\begin{array}{c}\text { Perct. } \\
0\end{array}$ \\
\hline In experiment. & 95 & 55 & 40 & 40 & 70 & 100 & 30 & 60 & -14 \\
\hline
\end{tabular}

In this series of experiments 38 per cent died in the larval stage, 42 per cent in the pupal, and 20 per cent emerged. The larvæ were all small in size and light in color, and the basal pleural spots were wanting. The imagines were 25 per cent below the average size of the parent, and were strongly albinic. The hypodermal color was light yellow. On the epicraniun the spots were entirely absent in 70 per cent of the variates, and in the remainder rudiments of $g$ and $g^{\prime}$ only were found. On the pronotum the spots $f$ and $f^{\prime}$ and $d$ and $d^{\prime}$ were absent and $b$ and $b^{\prime}$ and $e$ and $e^{\prime}$ were reduced to mere traces. On the elytra all the stripes were reduced posteriorly and the anal and costal were absent. The ventral surface was almost unicolorous, traces of the outer sternal spots only being found in the thoracic and anterior abdominal region. The entire lot was strongly albinic, as may be seen in the following seriations:

TABLE 83.-General color of beetles used.

\begin{tabular}{|c|c|c|c|c|c|c|c|c|c|c|c|}
\hline Class...... & 3 & 4 & 5 & 6 & 7 & 8 & 9 & Io & II & I 2 & I3 \\
\hline & P.ct. & P.ct. & P.ct. & P.ct. & P.ct. & P.ct. & P.ct. & P.ct. & P.ct. & P.ct. & P.ct. \\
\hline Parents. & .. & .. & I & 2 & 5 & 20 & 42 & 18 & 9 & 2 & $\mathbf{I}$ \\
\hline Control..... & . & . & 2 & 7 & 8 & 17 & 37 & I9 & 8 & I & $\mathbf{I}$ \\
\hline Experiment. & 2 & 12 & 40 & 23 & Io & 7 & 3 & 2 & I & . & . \\
\hline
\end{tabular}

Empirical mode of parents...... 9 Empirical mode of control....... 9 Empirical mode in experiment... 5
Modal deviation of parents ...... o Modal deviation of control....... o Modal deviation in experiment... -4 
EXPERIMENT 21.-To determine the effect of a large average decrease in the relative humidity upon the coloration of $L$. decemlineata.

Conditions.-Relative humidity on the average 24 per cent below that in nature, with other conditions normal.

Apparatus.-The same as in experiment 16.

In this series of experiments, conducted during the years 1899 to 1904, there were used 3,000 larvæ, hatched from 5,300 eggs collected at random and subjected to the conditions of experiment soon after being laid. The conditions were as follows:

TABLE 84.-Humidity conditions.

\begin{tabular}{|c|c|c|c|c|c|c|c|c|c|}
\hline Humidity- & 7 a. m. & Io a. $\mathrm{m}$. & I p.m. & 3 p. m. & $8 \mathrm{p.m}$. & $\begin{array}{l}\text { Maxi- } \\
\text { mum. }\end{array}$ & $\begin{array}{l}\text { Mini- } \\
\text { mum. }\end{array}$ & $\begin{array}{l}\text { Aver- } \\
\text { age. }\end{array}$ & $\begin{array}{l}\text { Deviation } \\
\text { from } \\
\text { normal. }\end{array}$ \\
\hline $\begin{array}{l}\text { In nature. . . } \\
\text { In experiment. }\end{array}$ & $\begin{array}{c}\text { Per ct. } \\
\text { I0O } \\
75\end{array}$ & $\begin{array}{c}\text { Per ct. } \\
65 \\
40\end{array}$ & $\begin{array}{c}\text { Per ct. } \\
50 \\
30\end{array}$ & $\begin{array}{c}\text { Per ct. } \\
55 \\
40\end{array}$ & $\begin{array}{c}\text { Per ct. } \\
100 \\
65\end{array}$ & \begin{tabular}{|c} 
Per ct. \\
IOO \\
83
\end{tabular} & $\begin{array}{c}\text { Per ct. } \\
43 \\
25\end{array}$ & $\begin{array}{c}\text { Per ct. } \\
74 \\
50\end{array}$ & $\begin{array}{c}\text { Per ct. } \\
0 \\
-24\end{array}$ \\
\hline
\end{tabular}

In this series of experiments 52 per cent died in the larval stage, 40 per cent in the pupal, and 8 per cent emerged. All larvæ and imagines were developed in the same directions as those in experiment 20 , although to a greater extent. The size of the imagines was 38 per cent below that of the parents and the general color appearance was strongly albinic, as is shown in the following table:

TABLE 85-General color of beetles used.

\begin{tabular}{|c|c|c|c|c|c|c|c|c|c|c|c|c|c|}
\hline Class...... & I & 2 & 3 & 4 & 5 & 6 & 7 & 8 & 9 & Io & II & 12 & 13 \\
\hline & P.ct. & P.ct. & P.ct. & P.ct. & P.ct. & P.ct. & P.ct. & P.ct. & P.ct. & P.ct. & P.ct. & P.ct. & P.ct. \\
\hline Parents. & $\cdots$ & $\cdots$ & $\ldots$ & $\cdots$ & I & 2 & 5 & 20 & 42 & 18 & 9 & 2 & $I$ \\
\hline Control...... & $\cdots$ & 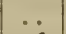 & & .. & 2 & 7 & 8 & I7 & 37 & 19 & 8 & I & I \\
\hline Experiment. . & 3 & 6 & 43 & 30 & I 2 & 5 & I & . & .. & . & $\because$ & .. & . \\
\hline
\end{tabular}

Empirical mode of parents ..... . 99 Empirical mode of control........ 9

Empirical mode in experiment.... . 3
Modal deviation of parents..... 0 Modal deviation of control..... Modal deviation in experiment . -6

EXPERIMENT 22.-To determine the effect of an extremely low relative humidity upon the color and color pattern of $L$. decemlineata.

Conditions.-Relative humidity on the average 40 per cent below that in nature, with other conditions normal.

Apparatus.-The same as in experiment 16.

In these experiments, conducted during the years 1899 to $1903,6,500$ larvæ, hatched from 14,300 eggs taken at random, were used. The conditions of experimentation were as follows: 
TABLE 86-Humidity conditions.

\begin{tabular}{|c|c|c|c|c|c|c|c|c|c|}
\hline Humidity- & 7 a.m. & ro a. $\mathbf{m}$. & I p. m. & 3 p. m. & 8 p. m. & $\begin{array}{l}\text { Maxi- } \\
\text { mum. }\end{array}$ & $\begin{array}{l}\text { Mini- } \\
\text { mum. }\end{array}$ & $\begin{array}{l}\text { Aver- } \\
\text { age. }\end{array}$ & $\begin{array}{l}\text { Deviation } \\
\text { from } \\
\text { normal. }\end{array}$ \\
\hline $\begin{array}{l}\text { In nature...... } \\
\text { In experiment. }\end{array}$ & $\begin{array}{c}\text { Per ct. } \\
\text { IoO } \\
45\end{array}$ & $\begin{array}{c}\text { Per ct. } \\
65 \\
35\end{array}$ & $\begin{array}{c}\text { Per ct. } \\
50 \\
20\end{array}$ & $\begin{array}{c}\text { Per ct. } \\
55 \\
30\end{array}$ & $\begin{array}{c}\text { Per ct. } \\
\text { IOO } \\
40\end{array}$ & $\begin{array}{c}\text { Per ct. } \\
\text { I0O } \\
55\end{array}$ & $\begin{array}{c}\text { Perct. } \\
43 \\
\text { I0 }\end{array}$ & $\begin{array}{c}\text { Per ct. } \\
74 \\
34\end{array}$ & $\begin{array}{c}\text { Per ct. } \\
0 \\
-40\end{array}$ \\
\hline
\end{tabular}

In these experiments 93 per cent died in the larval stage, 6.6 per cent in the pupal, and 0.4 per cent emerged. All stages were highly albinic, and the imagines extremely so, as is shown in the following table:

TABLE 87.-General color of beetles used.

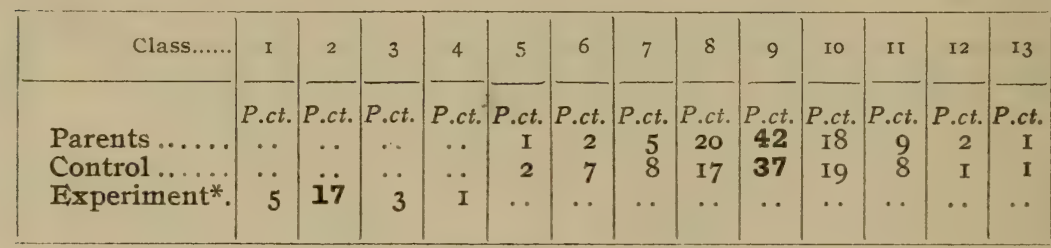

* Individuals $=26$.

Empirical mode of parents....... 9

Empirical mode of control.......99

Empirical mode in experiment.... 2
Modal deviation of parents.... o

Modal deviation of control..... o

Modal deviation in experiment. . - 7

In this series of experiments the hypodermal color was a pure, translucent white without any development of lipochrome pigments; all the dark markings were lighter in color and many were entirely wanting.

The general results derived from these humidity experiments have been put into text-figure I5. It is apparent from a study of these records that the results of experiments with deviations of humidity are almost exactly the same as those which were obtained from experiments with deviations of temperature. Such deviations from the normal, either toward an increase or a decrease, produce up to a maximum increased pigmentation and a consequent melanic tendency, but beyond this the effect is reversed, pigmentation is retarded, and the tendency toward albinism becomes more and more pronounced as the deviation from the normal becomes greater. These results are well shown in text-figures II to I5. Neither temperature nor humidity seems to have any specific influence upon the coloration of this beetle; but each acts as a stimulus toward the production of an increase in activity under slight deviations, and toward a decrease under larger deviations; and the curve of the response is similar to that obtained from very many physiological experiments. 
EXPERIMENTS With TEMPERATURE AND MOISTURE Both VARIABLE.

In nature the deviation of one environmental factor alone is of rare occurrence, for when one factor is changed, as, for example, temperature, a correlated modification also occurs in others. Thus, in nature, if the temperature in a given environment is lowered, the percentage of relative humidity is increased, evaporation is decreased, the sensible temperature is altered, winds

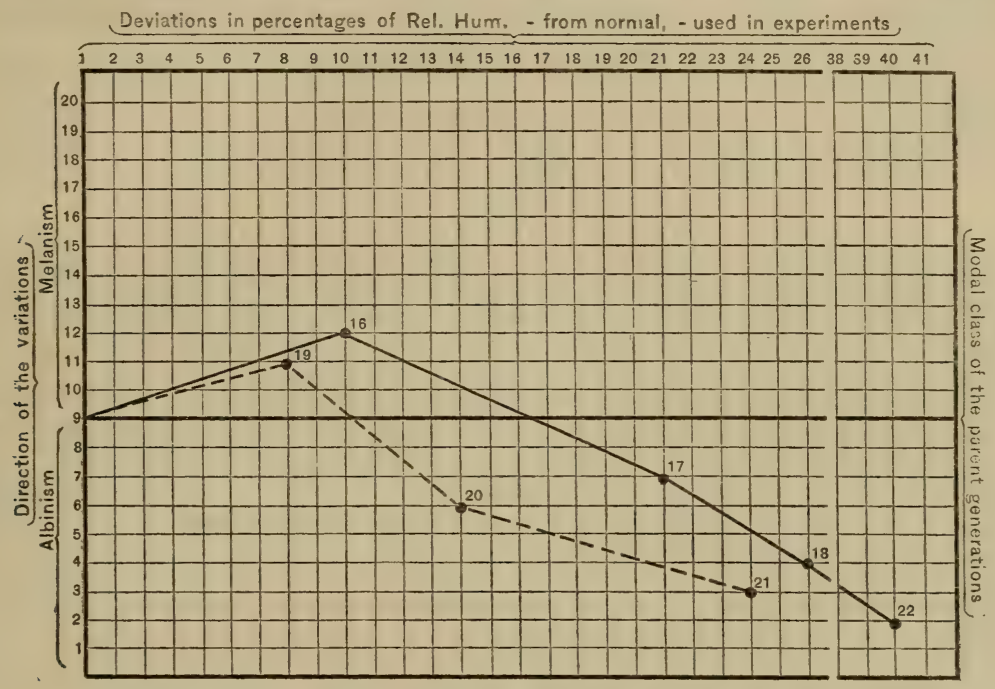

TEXT-FIGURE 15.-To illustrate the results obtained through the use of moisture as a stimulus, showing almost identical results to those obtained by the use of temperature as a stimulus. Compare with text-figures II and 12.

due to convection may start, and thus many changes follow from a slight alteration in one environmental factor. Hence, in an investigation of environmental influences, the results of changes in entire complexes must be studied and interpreted. In the following section are given the results obtained from experiments in which various groups of factors were changed.

EXPERIMENTS IN WHICH TEMPERATURE AND RELATIVE HUMIDITY VARY TOGETHER in THE SAME DIRECTION ABOVE, OR BELOW THE NORMaL.

EXPERIMENT 23-To determine the effects of a moderately increased average deviation in both temperature and moisture upon the color and color pattern of L. decemlineata.

Conditions.-Temperature $6^{\circ} \mathrm{C}$. and relative humidity io per cent on the average above that in nature, with other conditions normal.

Apparatus.-Glass breeding tanks specially constructed.

In these experiments, which were conducted during the years I899 to I 904 , 3,700 eggs were placed in the cages within a few hours after being laid. From these 3,000 larvæ were obtained, which were subjected to the following conditions : 
TABLE 88.-Temperature and humidity conditions.

\begin{tabular}{|c|c|c|c|c|c|c|c|c|c|}
\hline & 7 a. m. & Io a. m & I p. m. & 3 p. m. & $8 \mathrm{p.m}$. & $\begin{array}{l}\text { Maxi- } \\
\text { mum. }\end{array}$ & $\begin{array}{l}\text { Mini- } \\
\text { mum. }\end{array}$ & $\begin{array}{l}\text { Aver- } \\
\text { age. }\end{array}$ & $\begin{array}{l}\text { Deviation } \\
\text { from } \\
\text { normal. }\end{array}$ \\
\hline Temperature, dry bulb: & ${ }^{\circ} \mathrm{C}$. & ${ }^{\circ} \mathrm{C}$. & ${ }^{\circ} \mathrm{C}$ & ${ }^{\circ} \mathrm{C}$. & ${ }^{\circ} \mathrm{C}$. & ${ }^{\circ} \mathrm{C}$. & ${ }^{\circ} \mathrm{C}$. & ${ }^{\circ} \mathrm{C}$. & ${ }^{\circ} \mathrm{C}$. \\
\hline In $\mathrm{n}$ & 19 & 22 & 3 & 24 & 22 & 3. & I3 & 22.2 & 0 \\
\hline In experiment & 22 & 28 & 38 & $3 \mathrm{I}$ & 23 & 40 & I9 & 28.4 & +6 \\
\hline Relative & Per ct. & Perct. & Perct. & Perct. & Perct. & Perct. & Perct. & Perct. & Perct. \\
\hline In nature..... & * IOO & 65 & 50 & 65 & ${ }^{*}$ IOO & 100 & 43 & 74 & o \\
\hline In experiment & ${ }^{*}$ IOO & 85 & 60 & 75 & ${ }^{*}$ IOO & 100 & 55 & 84 & + ro \\
\hline
\end{tabular}

* Dew.

In these experiments 19 per cent died in the larval stage, I I per cent in the pupal, and 70 per cent, equally divided as to sex, emerged as imagines. The larval stage was shortened on the average 4 days and the pupal I I 2 days.

The larvæ were large and well nourished, being 5 per cent above the normal in size and 7 per cent above in weight. Their hypodermal color was a deep wine-red, with all dark markings a brilliant black. The imagines were also strong and active, being 6 per cent above the normal in size. Their colors were also dark, the hypodermal color being chrome yellow, often with a distinct reddish tinge. All areas of cuticula pigment were well developed and fusions were frequent. The general appearance of the beetles was melanic, the mode of the entire series being strongly toward the melanic end of the color range, as may be seen in the following table:

TABLE 89.-General color of beetles used.

\begin{tabular}{|c|c|c|c|c|c|c|c|c|c|c|c|c|c|}
\hline Class...... & 5 & 6 & 7 & 8 & 9 & I0 & II & 12 & 13 & 14 & 15 & 16 & 17 \\
\hline Parents & P.ct. & P.ct. & P.ct. & P.ct. & $\begin{array}{l}P \text {. ct. } \\
\text {. }\end{array}$ & P.ct. & P.ct. & P.ct. & P.ct. & P.ct. & P.ct. & P.ct. & P.ct. \\
\hline Control. & 2 & 7 & 8 & 17 & 39 & 19 & 6 & I & I & $\cdots$ & $\cdots$ & $\cdots$ & $\because$ \\
\hline Experiment... & . & .. & . & & 2 & 3 & 7 & I2 & I5 & 20 & 34 & 6 & I \\
\hline
\end{tabular}

Empirical mode of parents...... 9

Empirical mode of control ...... 9

Empirical mode in experiment... I4
Modal deviation of parents..... o

Modal deviation of control...... o

Modal deviation in experiment... +6

EXPERIMENT 24.-To determine the effects of a considerably increased average deviation of both temperature and moisture upon the color and color pattern of L. decemlineata.

Conditions.-Temperature on the average $10.6^{\circ} \mathrm{C}$. and relative humidity 2I per cent above that in nature, with other conditions normal.

Apparatus.-The same as in experiment 23.

In the experiments of this series, which also covered the years 1899 to 1904, 2,000 larvæ hatched from 3,600 eggs were reared under the following conditions of experiment: 
TABLE 90.-Temperature and humidity conditions.

\begin{tabular}{|c|c|c|c|c|c|c|c|c|c|}
\hline & $7 \mathrm{a} \cdot \mathrm{m}$ & 10 a. $\mathbf{m}$. & I p. m. & 3 p. m. & 8 p.m. & $\begin{array}{l}\text { Maxi- } \\
\text { mum. }\end{array}$ & $\begin{array}{l}\text { Mini- } \\
\text { mum. }\end{array}$ & $\begin{array}{c}\text { Aver- } \\
\text { age. }\end{array}$ & $\begin{array}{l}\text { Deviation } \\
\text { from } \\
\text { normal. }\end{array}$ \\
\hline Temperature, dry bulb: & ${ }^{\circ} \mathrm{C}$. & $\circ C$. & $\circ C$. & ${ }^{\circ} \mathrm{C}$. & ${ }^{\circ} \mathrm{C}$. & ${ }^{\circ} \mathrm{C}$. & ${ }^{\circ} \mathrm{C}$. & ${ }^{\circ} C$. & $\circ \mathrm{C}$. \\
\hline In nature..... & Io & 22 & 30 & 24 & 22 & 33 & I3 & 22.2 & 0 \\
\hline In experiment.... & 26 & 32 & 40 & 34 & 32 & 42 & 22 & 33.8 & +10.6 \\
\hline Relative humidity : & Per ct. & Perct. & Per ct. & Per ct. & Per ct. & Perct. & Per ct. & Per ct. & Perct. \\
\hline In nature........ & * IOO & 65 & 50 & 55 & ${ }^{*}$ IOO & 100 & 43 & 74 & o \\
\hline In experiment.... & ${ }^{*} \mathrm{I} C \mathrm{O}$ & IOO & 85 & 90 & ${ }^{*}$ IOO & IOO & 82 & 95 & $+2 I$ \\
\hline
\end{tabular}

* Dew.

In these experiments 35 per cent died in the larval stage, 15 per cent in the pupal, and 50 per cent emerged. The growth and development in the larvæ and pupæ were not on the average hastened. There was a tendency in some specimens toward a hastening of growth and in others toward a retardation, but these extreme cases about balanced each other.

The larvæ were normal in size, but their coloration was modified as follows: The hypodermal color became a dull opalescent pink, and the basal tergal spots were highly variable and often wanting, and always brown in color; the spiracular spots were small and variable, but never black; the pronotum, head, and legs were light brown in color, and the latter very light.

The imaginal colors were strongly modified. The hypodermal color was light yellow, and all spots were distinct and fusions between them were not numerous. On the epicranium $g$ and $g^{\prime}$ were separate in 70 per cent of the variates and $h$ and $h^{\prime}$ were wanting in 32 per cent. On the pronotum $f$ and $f^{\prime}$ were absent in 89 per cent of the variates, and $b, d$, and $e$ were absent in varying percentages. The elytral stripes were reduced posteriorly and the anal stripe was wanting in 94 per cent. Although the spots on the ventral surface were small, they were all present. The general color appearance was albinic, as is shown in the following table:

TABLE 9I.-Color of beetles used.

\begin{tabular}{|c|c|c|c|c|c|c|c|c|c|c|c|}
\hline Class...... & 3 & 4 & 5 & 6 & 7 & 8 & 9 & I0. & II & I2 & 13 \\
\hline & P.ct. & P.ct. & P.ct. & P.ct. & P.ct. & P.ct. & P.ct. & P.ct. & P.ct. & P.ct. & P.ct. \\
\hline Parents,.. & $\ldots$ & .. & $\mathrm{I}$ & 2 & 5 & 20 & 42 & I8 & 9 & 2 & I \\
\hline Control...... & . & . & 2 & 7 & 8 & I7 & 39 & i9 & 6 & I & I \\
\hline Experiment. . & I & 2 & 3 & I2 & 38 & 20 & II & 7 & 4 & 2 & . \\
\hline
\end{tabular}

Empirical mode of parents ...... 9 Empirical mode of control....... 9 Empirical mode in experiment...
Modal deviation of parents...... o Modal deviation of control....... o Modal deviation in experiment.. -2 
EXPERIMENT 25.-T'o determine the effects of a large average increase in temperature and moisture upon the coloration of L. decemlineata.

Conditions.-Temperature $13^{\circ} \mathrm{C}$. and relative humidity 26 per cent above that in nature, with other conditions normal.

Apparatus.-The same as in experiment 23.

In this series of experiments, which was conducted during the years I90I to I904, 2,500 larvæ were used, which were hatched from 4,500 eggs placed under the conditions of experiment soon after being laid. The conditions of experimentation were as follows:

TABLE 92.-Temperature and humidity conditions.

\begin{tabular}{|c|c|c|c|c|c|c|c|c|c|}
\hline & $7 \mathrm{a} . \mathrm{m}$. & roa, $\mathrm{m}$. & I p. m. & 3 p. m. & 8 p.m. & $\begin{array}{l}\text { Maxi- } \\
\text { mum. }\end{array}$ & $\begin{array}{l}\text { Mini- } \\
\text { mum. }\end{array}$ & $\begin{array}{l}\text { Aver- } \\
\text { age. }\end{array}$ & $\begin{array}{c}\text { Deviation } \\
\text { from } \\
\text { normal. }\end{array}$ \\
\hline Temperature, dry bulb & ${ }^{\circ} \mathrm{C}$. & ${ }^{\circ} \mathrm{C}$. & ${ }^{\circ} \mathrm{C}$. & ${ }^{\circ} \mathrm{C}$. & ${ }^{\circ} \mathrm{C}$. & ${ }^{\circ} \mathrm{C}$. & ${ }^{\circ} \mathrm{C}$. & ${ }^{\circ} \mathrm{C}$. & ${ }^{\circ} \mathrm{C}$. \\
\hline In nature...$\ldots \ldots$ & 19 & 22 & 30 & 24 & 22 & 33 & I3 & 22.2 & 0 \\
\hline In experiment....... & 28 & 35 & 45 & $3^{8}$ & 30 & 47 & 25 & 35.2 & $+I_{3}$ \\
\hline Relative humidity: & Per ct. & Perct. & Perct. & Perct. & Perct. & Perct. & Perct. & Perct. & Perct. \\
\hline In nature....$\ldots \ldots$ & $*^{*}$ IOO & 65 & 50 & 55 & *Ioo & 100 & 43 & 74 & 80 \\
\hline In experiment....... & ${ }^{*} 100$ & "IOO & 100 & *IOO & *IOO & 100 & 100 & 100 & +26 \\
\hline
\end{tabular}

* Dew.

In this series of experiments 56 per cent died in the larval stage, 39 per cent in the pupal, and 5 per cent, or 125 individuals, emerged, of which 70 were males and 55 females.

The larval colors were modified as in experiment 24, only to a much greater extent. The imaginal coloration was strongly albinic, being almost the duplicate of that found in experiments 3,7 , and 18 . The beetles were all small, 40 per cent below standard size, and light colored. The dark markings were all brown, no black being visible in any part. The strong albinic tendency is shown in the following seriations:

TABLE 93-General color of beetles used.

\begin{tabular}{|c|c|c|c|c|c|c|c|c|c|c|c|c|c|}
\hline Class...... & I & 2 & 3 & 4 & 5 & 6 & 7 & 8 & 9 & 10 & II & I2 & 13 \\
\hline & P.ct. & P.ct. & P.ct. & P.ct. & P.ct. & P.ct. & P.ct. & P.ct. & P.ct. & P.ct. & P.ct. & P.ct. & P. ct. \\
\hline Parents..... & $\ldots$ & .. & $\cdots$ & $\cdots$ & I & 2 & 5 & 20 & 42 & 18 & 9 & 2 & . \\
\hline Control..... & . & . & & . & 2 & 7 & 8 & I7 & 37 & I9 & 8 & I & I \\
\hline Experiment*. & I & 20 & 64 & I9 & II & 8 & 2 & . & - & $\cdots$ & $\cdots$ & $\cdots$ & $\cdots$ \\
\hline
\end{tabular}

* Individuals $=$ I25.

Empirical mode of parents....... 9 Empirical mode of control....... 9 Empirical mode in experiment... . 3
Modal deviation of parents........ o Modal deviation of control......... o Modal deviation in experiment.... -6 
In experiments 23 to 25 , where deviations in temperature and relative humidity were both high, the results obtained were very much like those already described for experiments in which temperature and moisture were used alone. Not only are the mortality percentages closely parallel, but the order and degree of color changes are the same. I conclude, therefore, that temperature and moisture, when varying together in the same direction, act as a stimulus upon the coloration of decemlineata, producing, with slight deviations, an increase in pigmentation, or melanism, and with larger deviations a decrease, or albinism, the curve of the response being the same as that found in experiments where the varying factors are used alone.

I have also conducted series of experiments corresponding to 23 to 25 , in which temperature and moisure varied together in decreasing average amounts. The results, however, were in every way the same as those obtained from like experiments in which these factors were used alone-that is, the production of melanism by slight deviations, and of albinism by large deviations.

\section{EXPERIMENT 26.}

In this experiment I have brought together the results of twenty separate sets of experiments which were conducted during the years I895 to 1904 . The object of these was to determine the effects in combination of deviations of temperature and relative humidity in opposite directions by which cool dry, cool moist, hot dry, and hot moist conditions in different degrees were produced. The conditions of the experiments, stated briefly, are as follows:

\section{EXPERIMENTS IN WHICH THE TEMPERATURE AND RELATIVE HUMIDITY VARIED TOGETHER IN OPPOSITE DIRECTIONS ABOVE OR BELOW THE NORMAL.}

\begin{tabular}{|c|c|c|c|c|c|c|c|c|c|}
\hline \multirow{2}{*}{ No. } & \multicolumn{2}{|c|}{ Temperature. } & \multicolumn{2}{|c|}{$\begin{array}{l}\text { Relative hu- } \\
\text { midity. }\end{array}$} & \multirow{2}{*}{ No. } & \multicolumn{2}{|c|}{ Temperature. } & \multicolumn{2}{|c|}{$\begin{array}{l}\text { Relative hu- } \\
\text { midity. }\end{array}$} \\
\hline & A bove. & Below. & $\begin{array}{c}\text { A bove } \\
\text { aver- } \\
\text { age. }\end{array}$ & $\begin{array}{l}\text { Below } \\
\text { aver- } \\
\text { age. }\end{array}$ & & Above. & Below. & $\begin{array}{c}\text { Above } \\
\text { aver- } \\
\text { age. }\end{array}$ & $\begin{array}{l}\text { Below } \\
\text { aver- } \\
\text { age. }\end{array}$ \\
\hline & ${ }^{\circ} \mathrm{C}$. & ${ }^{\circ} \mathrm{C}$. & Perct. & Per ct. & & ${ }^{\circ} \mathrm{C}$. & ${ }^{\circ} \mathrm{C}$. & Per ct. & Perct. \\
\hline $26 a \ldots \ldots$ & 6 & . & . & Io & $26 l . . \ldots \ldots$ & . & 6.5 & 35 & . \\
\hline $26 b \ldots \ldots$ & Io & . & . & IO & $26 m \ldots \ldots$ & . & Io & 10 & . \\
\hline $26 c \ldots \ldots$ & I3 & . & . & IO & $26 n \ldots . .$. & . & Io & $2 I$ & . \\
\hline $26 d . \ldots$. & 6 & - & . & $2 I$ & $260 \ldots \ldots$ & . & Io & 39 & $\therefore$ \\
\hline $26 e \ldots . .$. & IO & - & . & $2 I$ & $26 p \ldots . .$. & . & $\mathrm{I}_{5}$ & Io & . \\
\hline $26 f . \ldots$. & $I_{3}$ & . & . & $2 I$ & $26 q \ldots \ldots$ & . & I5 & $2 I$ & . \\
\hline $26 g \ldots . .$. & 6 & - & . & 35 & $26 r . \ldots \ldots$ & . & I5 & 39 & $\cdots$ \\
\hline $26 h \ldots . .$. & ro & . & . & 35 & $26 s . \ldots \ldots$ & . & 24 & Io & . \\
\hline $26 i \ldots .$. & $\mathrm{I}_{3}$ & & . & 35 & $26 t \ldots \ldots$ & . & 24 & $2 I$ & - \\
\hline $26 j \ldots . .$. & . & 6.5 & Io & . & $26 u \ldots .$. & .. & 24 & 39 & . \\
\hline $26 k \ldots .$. & - & 6.5 & $2 \mathrm{I}$ & . & & & & & \\
\hline
\end{tabular}

In these experiments, in which 10,600 larvæ, hatched from about 17,000 eggs, were used, 39 per cent died in the larval stage, $3^{I}$ per cent in the pupal, 
and 30 per cent $(3,180)$ emerged. In both larvæ and adults the color modifications and the order and direction of fusion or obliteration of markings were the same as those that have already been described. The general results derived from these experiments are represented in the curves given in textfigure 16.

In experiments $a, b$, and $c$, the result as expressed in text-figure 16 was a shifting of the mode toward the albinic side, which was slight (to class 8.5 ) in $a$, more pronounced (to class 7 ) in $b$, and extreme (to class 5 ) in $c$. In $a$ the

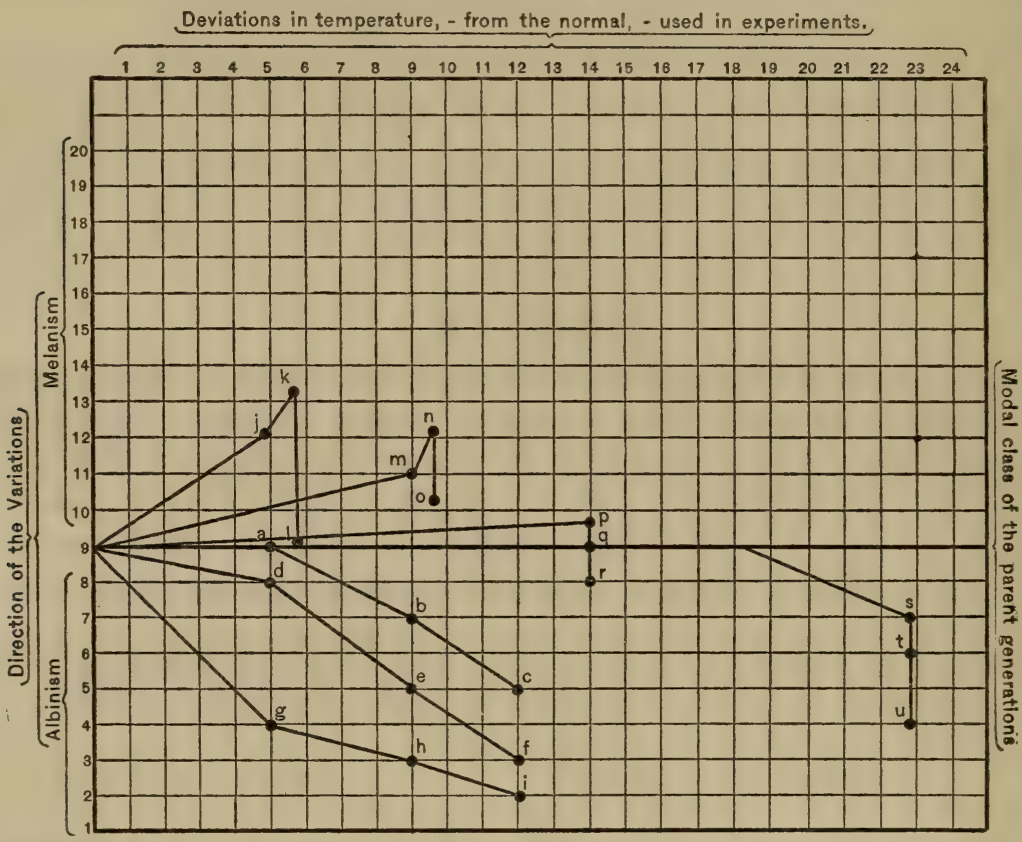

TExT-FIGURE I6.-To illustrate the general results obtained in a series of twenty-one experiments wherein both temperature and moisture were used in combination as stimuli.

temperature $\left(6^{\circ} \mathrm{C}\right.$. above the average), which alone would produce a modal deviation of two or three classes toward a melanic condition, was overpowered by the other factor of Io per cent relative humidity below the average, or it was at any rate neutralized thereby, so that the resulting imagines were practically normal. In $b$ and $c$ the temperature had become inhibitory, so that the result was a rapid fall in general coloration toward albinism. In experiments $d, e$, and $f$ much the same results were obtained. In $d$ the temperature $\left(6^{\circ} \mathrm{C}\right.$.), which alone would produce melanism, was overpowered by the more highly deviating relative humidity, and albinic tendencies were produced, which were further increased in $e$ and $f$, where the temperatures were higher. Likewise in $g, h$, and $i$ the modification was albinic even at the start, and increased rapidly as the temperature became inhibitory. In experiments $j$ to $u$, 
when the temperature did not vary below the normal much beyond $5^{\circ}$ to $7^{\circ}$ C., the resulting color modifications were controlled by the relative humidity. Thus, in $j$ melanic conditions were produced, but in $k$ and $l$ the high humidity inhibited coloration slightly, so that the curve dropped back toward the normal. This same condition, less pronounced, was also found in $m$, $n$, and $o$. In experiments $p$ to $u$, on account of the greatly reduced temperature used, the modifications were all toward albinism.

From these experiments the following conclusions may be drawn:

(I) When the temperature deviates above and the humidity below the normal the general trend of color modification is albinic.

(2) When the temperature varies below and the humidity above the normal the general trend of color modification is melanic, unless the temperature deviation is extreme, $15^{\circ}$ to $25^{\circ} \mathrm{C}$. below the normal, when the color trend is albinic.

(3) From (I) and (2) we may draw the more general conclusion that when temperature and moisture are the variables in a given environmental complex, the trend of general color modification is controlled by moisture (relative humidity), excepting in conditions where the temperature deviation is so excessive that the ordinary physiological and developmental processes are greatly inhibited (experiments $p$ to $u$ ). In experiments approximating natural environmental complexes, however, moisture is the dominant factor in influencing coloration.

EXPerimentS IN WHICH L. DECEMLINEATA WAS REARED DURING SUCCESSIVE GeinERATIONS WITH BOTH TEMPERATURE AND MOISTURE, VARYING TOGETHER, OR IN OPPOSITE DIRECTIONS ABOVE OR BELOW THE NORMAL.

The object in these experiments was to rear the beetles in successive generations under conditions applied during ontogeny, and especially during the development of the coloration. The plan was to allow each generation to breed and begin its development under conditions simulating those in nature, and then to let the ontogeny be completed under an environmental complex deviating from the normal. By this process, repeated generation after generation, data was obtained as to the inheritance of somatic modifications. Of the many experiments of this kind which were tried, one alone is sufficient to illustrate the results obtained.

EXPERIMENT 27.-T'o determine whether coloration changes produced as the result of changed environmental conditions are inherited, increased, or dropped in successive generations.

Conditions.-Temperature on the average $6^{\circ} \mathrm{C}$. and relative humidity io per cent above that in nature, with other conditions normal. These conditions were planned to produce melanic tendencies in variation.

Apparatus.-The same as in experiment 23. 
The experiments in this series were conducted in the years 1900 to 1904 , and were carried through ten lineal generations. The conditions of temperature and moisture were as follows:

TABLE 94.-Temperature and humidity conditions.

\begin{tabular}{|c|c|c|c|c|c|c|c|c|c|}
\hline & 7 a.m. & Io a.m & I p.m. & 3 p.m. & 8 p.m. & $\begin{array}{l}\text { Maxi- } \\
\text { mum. }\end{array}$ & $\begin{array}{l}\text { Mini- } \\
\text { mum. }\end{array}$ & $\begin{array}{l}\text { Ayer- } \\
\text { age. }\end{array}$ & $\begin{array}{l}\text { Devia- } \\
\text { tion from } \\
\text { normal. }\end{array}$ \\
\hline Temperature, dry bulb: & ${ }^{\circ} \mathrm{C}$. & ${ }^{\circ} \mathrm{C}$ & ${ }^{\circ} \mathrm{C}$. & ${ }^{\circ} \mathrm{C}$. & ${ }^{\circ} \mathrm{C}$. & ${ }^{\circ} \mathrm{C}$. & ${ }^{\circ} \mathrm{C}$. & ${ }^{\circ} \mathrm{C}$. & ${ }^{\circ} \mathrm{C}$. \\
\hline In nature......... & 19 & 22 & $3 I$ & 23 & 22 & 33 & 13 & 22.2 & 0 \\
\hline In experiment... & 22 & 28 & $3 I$ & $3 I$ & 23 & 40 & 19 & 28.4 & +6 \\
\hline Relative humidity: & Perct. & Perct. & Perct. & Perct. & Per ct. & Perct. & Perct. & Perct. & Perct. \\
\hline $\begin{array}{l}\text { In nature. ... } \ldots \\
\text { In experiment } . . .\end{array}$ & $\begin{array}{l}{ }^{*} \text { IOO } \\
\text { *IOO }^{\prime} \text { IOO }\end{array}$ & $\begin{array}{l}65 \\
85\end{array}$ & 50 & 55 & ${ }^{*}$ IOO & Ioo & 43 & 74 & $\begin{array}{r}0 \\
+\mathrm{I}\end{array}$ \\
\hline
\end{tabular}

* Dew.

In this series of experiments $2 \mathrm{I}$ per cent died in the larval stage and 9 per cent in the pupal, while 70 per cent appeared as imagines with the color modifications described in experiment 23. Throughout the whole series the greatest care was taken to prevent the conditions of experiment from having any possible influence upon the germ cells in their growth periods and during maturation and fertilization. This was accomplished by removing the adults

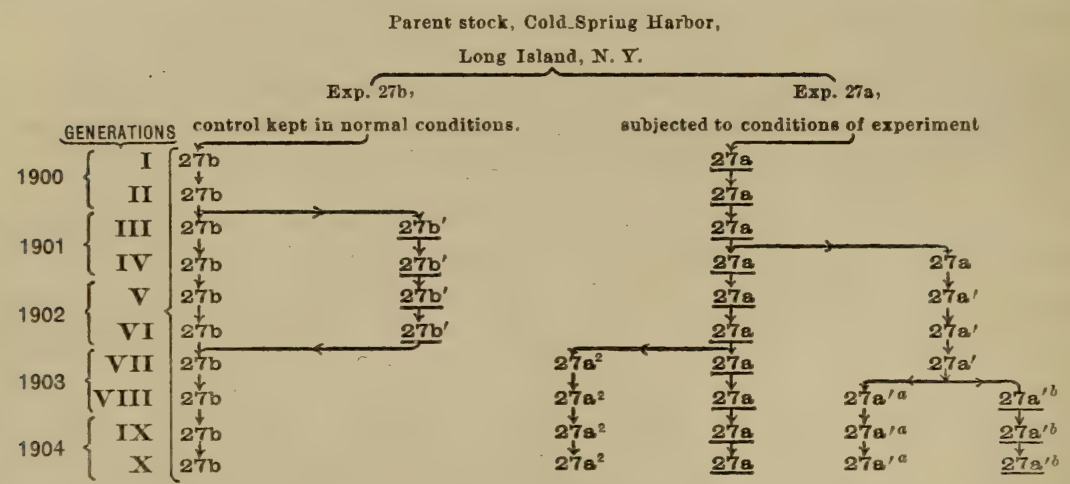

TEXT-FIGURE I7. - The relation of the various parts of experiment 27. (The generations underscored were subjected to the conditions of the experiment; those not underscored were kept in natural surroundings.)

to normal condition during the period of germ-cell growth and fertilization, the fertilized eggs being returned as soon as laid to the conditions of experiment. By this means the color changes induced by these experiments were known to be purely somatic modifications. Moreover, a control series, derived from the same parents, was kept under nornal conditions as a check. During the series also several lots were taken from the experiments and placed for several generations in normal conditions, and were then returned 


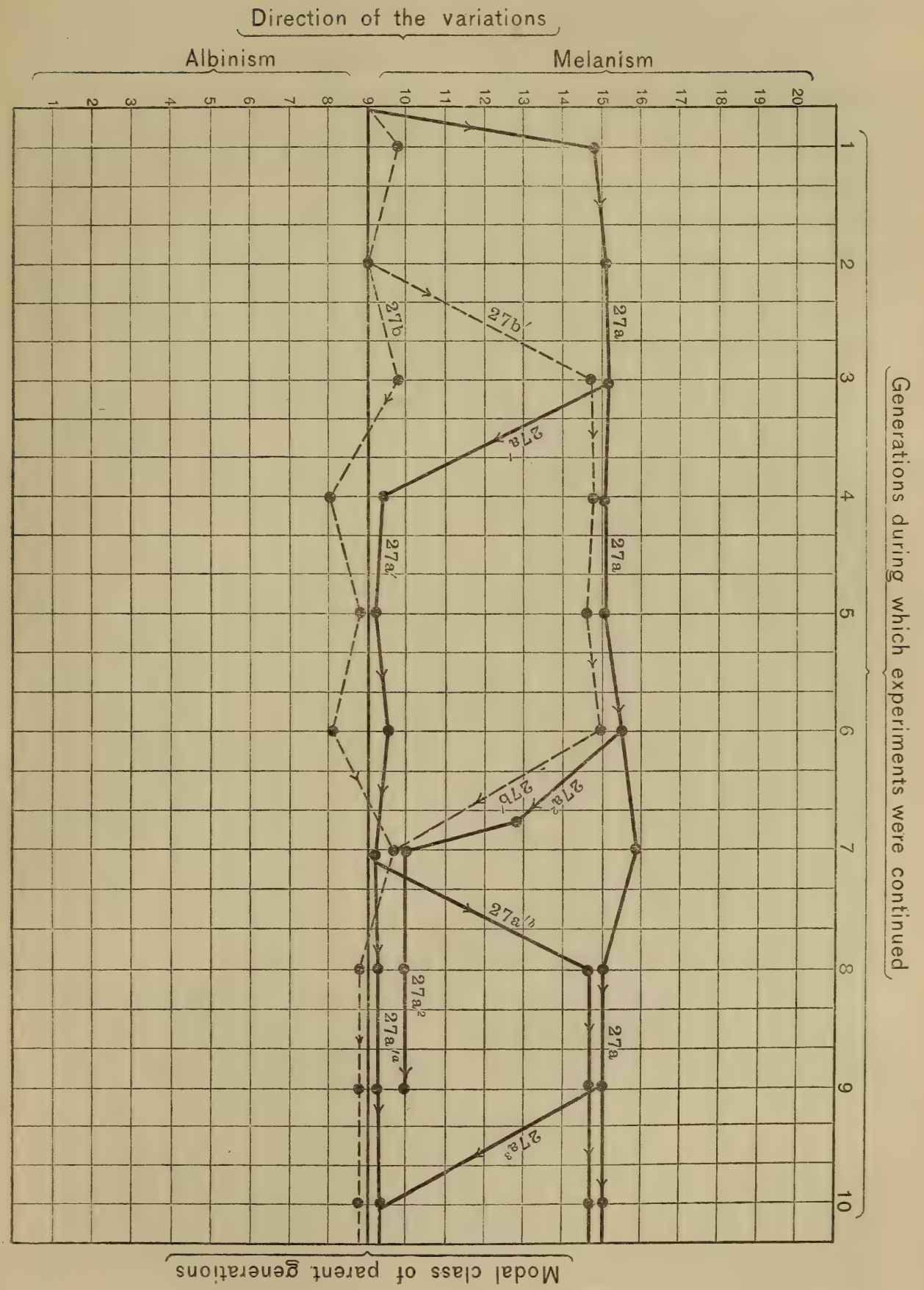

TEXT-FIGURE I8.-To illustrate the results obtained in the different parts of experiment as described in the text. 
to experiment; and likewise lots were taken from the control and placed in experiment, and subsequently returned to control. In this way a complete check was kept on the experiments. In text-figure 17 are represented the generations experimented upon and the proceedings followed with each.

Experiment 27 was divided into two parts-the experiment proper (27a) and the control $(27 b)$. In $27 a$ the beetles were subjected to the conditions of experiment during ten lineal generations, with results shown in text-figure 18. A maximum deviation in coloration was produced at once toward a melanic state (class 15), from which there was no deviation either above or below in the succeeding generation. In the third generation of $27 a$ the progeny were divided into two lots of equal size, one of which was kept in the conditions of experimentation, and the other returned to normal conditions. This second lot, known as $27 a^{1}$, after being bred during four generations in normal surroundings, was further separated into two portions, one of which was still kept in normal conditions as $27 a^{\mathrm{Ia}}$, while the other was returned to the conditions of experimentation as $27 a^{1 \mathrm{~b}}$. When the beetles in $27 a^{1}$ were returned to normal surroundings they at once resumed their natural characters (seetext-fig. I8), and did not deviate therefrom during the four generations of $27 a$ and the three of $27 a^{\mathrm{Ia}}$, or seven in all. However, the effect upon $27 a^{\mathrm{rb}}$ of being returned to the conditions of experiment was an immediate return to the maximum melanic tendency before observed. From the sixth generation in $27 a$ another lot of beetles, $27 a^{2}$, were taken and reared in normal conditions, with the result that they also inmediately reverted to the parental condition, and the same was true of $27 a^{3}$ in the ninth generation. In experiment $27 b$ there appears a slight oscillating variability (text-fig. I8), which, however, is of no consequence. In the second generation $27 b$ was likewise separated into two lots of equal size, one of which, $27 b$, was retained as a control, while the other, $27 b^{1}$, was placed in the conditions of experimentation for four generations, and later in the seventh generation returned to control with $27 b$. The effect upon $27 b^{1}$ was an immediate production of the maximum melanic condition (class 15), which was retained throughout the four generations of experimentation, and lost only when $27 b^{1}$ was returned to control.

In experiment 27 there was no artificial selection, all imagines being allowed freedom to mate and breed as in nature; hence the only selective influences present were those exercised in the mating of the beetles and by the conditions of the experiment, which eliminated a small percentage.

From the data of this experiment the following conclusions are drawn:

(I) A deviation in an environmental complex at once causes the polygon of somatic variation and the modal class to shift as far from the normal as it can go under the given condition, and keeps them there until there is a return to the normal environmental complex, when the somatic variations also at once return to their normal state. 
(2) The color variations employed in experiment, which are purely somatic, are the direct result of a response to changed environmental conditions, in terms of increased or decreased activity in pigmentation. 'They may change as rapidly, as frequently, and in as many different directions as the conditions producing them change, and they have no influence whatsoever upon the coloration of succeeding generations.

In this whole line of experiments, conducted with the purpose of determining the effects of temperature and moisture upon the coloration of decemlineata, many thousands of individuals have been subjected to experiment for single generations, either throughout ontogeny or during the pupal period, and others for successive lineal generations. I find in all, even where the most extreme stimuli have been used and great modifications of coloration have been produced, that the determinate character of the variations, their order of appearance, and their degree of stability follow strictly the laws of variation already stated.

Temperature and moisture, the cardinal factors of environment, do not, however, as is often stated, have any specific effect upon the coloration of decemlineata, but each acts simply as a stimulus to accelerate or retard the physiological processes involved in the production of coloration, and whether alone or in combination produce identical results. Of the two factors when in combination moisture is by far the more important and the determining agent in the modification of color, excepting when the other is more highly abnormal, a condition not often found in nature.

The modifications produced in experiment are purely somatic and follow exactly the laws of fluctuating variation. In many experiments, however, the modifications effected by experiment were exactly like those found in different geographical areas, as, for example, when in beetles from Chicago there were produced conditions characteristic of those from Arizona. This fact is at once important and suggestive on account of its bearing upon the interpretation of the phenomena described in the section on "Place and Geographical Variation." Finally, in experiment 27 , it is clearly demonstrated that the somatic variations in color are not inherited, but that they are fluctuating, transient, and due solely to environmental stimuli which accelerate or retard color development. It is from experiments like No. 27 and those preceding it that the proper explanation is found of the place and geographical variations of this plastic species.

\section{EXPERIMENTS WITH DIFFERENT FOODS.}

The influence of specific foods upon animal coloration has been investigated to some extent in birds and insects. Poulton has shown in Lepidoptera and I in Coleoptera the part that derived plant pigments play in the coloration of larvæ, where they are usually found as subhypodermal colors, which are not, 
as far as is known, inherited by succeeding generations, but may serve, however, as valuable protection during the life of the individual.

With decemlineata, experiments have been tried with the following food plants: Solanum tuberostum, rostratum, eleagnifolium, carolinense, dulcamara, nigrum, and melongena, Lycospersium esculentum, and Physales, three species. Larvæ fed upon these different plants showed some modifications of the subhypodermal color, but none of importance. Thus, Solanum nigrum produced a redder color in the larvæ and S. carolinense a light dirty winered, but I was not able to obtain the results attributed by Riley to the influence of this food, and I conclude that they were almost certainly due to temperature and moisture, and not to food. From S. rostratum a yellowish color was obtained in the larvæ, but the woody Solanums produced no changes.

With etiolated food white and transparent larvæ were obtained exactly as in Lepidoptera, but such modifications are manifestly of no importance in species evolution. Also, when the food supply is scanty or the nutrition of the larvæ is interfered with, changes in coloration result, but these are due to malnutrition and starvation, and not to the direct influence of any specific food.

\section{EXPERIMENTS WITH SOILS.}

The direct influence of soils upon animals is exerted in three general ways: First, by supplying the inorganic salts needed in the formation of protecting or supporting tissues; second, by a continued production of proper conditions of moisture for hibernation or development in the ground; and third, by the control and modification of temperature.

The first of these influences may be discarded, as in Leptinotarsa no salts are used in the production of protective or supporting tissues. The second and third, however, are of great importance, not because of the chemical composition of the soil, but because of its control of humidity and temperature, and, through them, of coloration; for all species of this genus pupate in the ground, and are, therefore, subjected to the alterations in temperature and humidity which soils induce.

The modifying effects of soil are especially important in ecological studies, and these will be considered in a subsequent paper. These influences are exerted largely through the contained water-that is, a dry soil becomes intensely hot by day and cools to a low degree at night by radiation, while a soil containing much water warms slowly by day and cools slowly at night, owing to the great amount of heat which water is capable of absorbing, and the reluctance with which it is given up. The water content of soil is controlled, not by abundant rainfall, nor by telluric water, but almost wholly by adhesion and capillarity in the soil-that is, physical conditions alone, such as permeability, capillarity, and the power to absorb and to retain water are the factors which influence the moisture content of soil, and hence the coloration of these 
beetles. In all soils the pores which do not contain water are filled with air in which the percentage of relative humidity is controlled by the amount of water in neighboring pores. Likewise the cells in which these beetles pupate are filled with air, the relative humidity of which is controlled by the water in the pores of the surrounding earth.

With Leptinotarsa I have used the following soils in experiment: (I) Glacial clay, (2) glacial till, (3) fine-grained soil, rich in humus, (4) fine sandy soil, poor in humus, and (5) coarse sandy soil. The absolute water capacity of these (water remaining after the excess had been drained off) and the relative humidity of the cavities therein were as follows:

TABLE 95.-Soils used.

\begin{tabular}{|c|c|c|c|c|}
\hline Soil. & $\begin{array}{c}\text { Absolute } \\
\text { water } \\
\text { capacity. }\end{array}$ & $\begin{array}{l}\text { Relative } \\
\text { humidity } \\
\text { in small } \\
\text { cavities. }\end{array}$ & $\begin{array}{l}\text { Air } \\
\text { capacity. }\end{array}$ & Source of soil. \\
\hline Glacial clay.... & $\begin{array}{c}\text { Per cent. } \\
40.3\end{array}$ & $\begin{array}{c}\text { Per cent. } \\
92\end{array}$ & $\begin{array}{c}\text { Percent. } \\
50.7\end{array}$ & Brick clays, Bridgewater, Mas- \\
\hline Glacial till.. & 40.8 & 85 & 59.2 & $\begin{array}{l}\text { Moraines of eastern Massa- } \\
\text { chusetts. }\end{array}$ \\
\hline Fine soil rich in humus & 32.6 & 74 & 64.4 & Market-garden soil in Chicago. \\
\hline Fine soil poor in humus & 15.0 & 43 & 85.0 & $\begin{array}{l}\text { Edge of sand dunes near Chi- } \\
\text { cago. }\end{array}$ \\
\hline Coarse sandy soil.. & 10.3 & 33 & 89.7 & Sand dunes near Chicago. \\
\hline
\end{tabular}

Larvæ of $L$. decemlineata were allowed to pupate in these soils, which were frequently flooded and drained, so that the absolute water content and relative humidity were kept constant. The resulting modifications expressed in the seriation of their variations in the imagines are as follows:

TABLE 96.-Coloration of beetles, with various soils used.

\begin{tabular}{|c|c|c|c|c|c|c|c|c|c|c|c|c|c|c|c|}
\hline Class...... & 3 & 4 & 5 & 6 & 7 & 8 & 9 & Io & II & 12 & I3 & I4 & 15 & 16 & 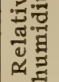 \\
\hline & P.ct. & P.ct. & P.ct. & P.ct. & F.ct. & P.ct. & P.ct. & P.ct. & P.ct. & P.ct. & P.ct. & P.ct. & P.ct. & P.ct. & P.ct. \\
\hline $\begin{array}{l}\text { Parents ...... } \\
\text { Glacial clay. }\end{array}$ & . & $\cdots$ & I & 2 & 5 & 20 & 42 & 18 & 9 & 2 & I & $\ddot{8}$ & $\because$ & $\because$ & 72 \\
\hline Glacial till. & $\cdots$ & $\cdots$ & - & . & . & I & 3 & $\begin{array}{l}7 \\
8 \\
\end{array}$ & $\begin{array}{lll}\text { II } \\
\text { I }\end{array}$ & $\begin{array}{r}21 \\
39\end{array}$ & 47 & 8 & I & $\mathbf{I}$ & 92 \\
\hline Fine soil rich in humus & .. & $\therefore$ & . & 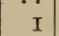 & 5 & Io & 25 & 39 & 17 & 2 & I & .. & .. & $\because$ & 74 \\
\hline Fine soil poor in humus & & .. & 1 & 4 & 45 & 23 & 22 & 3 & 2 & .. & .. & .. & .. & .. & 43 \\
\hline Coarse sandy soil... & 2 & 9 & 44 & 20 & I4 & 9 & I & $\mathrm{T}$ & $\therefore$ & .. & & .. & .. & .. & 33 \\
\hline
\end{tabular}

In this table the strong influence of the soil in modifying moisture conditions and producing color changes is apparent. The polygons of variation shift either toward albinism or melanism as the moisture content of the dif- 
ferent soils is high or low, and the deviations are the same as those found in the experiments with moisture.

I conclude, therefore, that clay soils (glacial clays, glacial tills, etc.) are productive of melanic tendencies in color variation; that from fine-grained soils rich in humus we have average or slightly melanic conditions; while sandy soils poor in humus and coarse sands produce albinic tendencies.

These results correspond well with conditions found in nature. Over the northeastern part of the United States and Lower Canada, in the region of glacial soils which contain a high percentage of clay, the general tendency of coloration in decemlineata is melanic. In the prairie country and in the region of residual soils, in the middle latitudes of the United States, average or slightly melanic conditions are found, while in the west and southwest, in the sandy soils poor in humus, the tendency is albinic. Soil acting upon coloration through the contained moisture may, therefore, be an important factor in geographical and place variation, as also in distribution and ecology.

\section{EXPERIMENTS WITH LIGHT.}

It is frequently stated that light has an important influence upon coloration, and there is frequently assumed to exist a sort of bio-photography of the environment upon the animal; but with the exception of the results of the experiments of Poulton and his pupils upon Lepidoptera there is not to my knowledge any evidence of value on this subject.

For several years ( 1897 to 1904) I have experimented with decemlineata to determine the action of light upon coloration. All separate colors of light or different intensities thereof-parallel rays, cross-rays, and absolute darkness-have been used, but with none have I been able to obtain any variations in color in decemlineata. I therefore conclude that in this beetle at least light-that is, its action in different wave-lengths and intensities-certainly has no effect upon color-pattern variations. The beetle responds to light, but in other ways, and not by changes in coloration.

\section{EXPERIMENTS WITH ATMOSPHERIC PRESSURE.}

Experiments with altered atmospheric pressure, wherein alpine conditions were simulated, have been tried, but not with any success. While it is easy to produce rarefication of air and the conditions of temperature and moisture found in alpine regions, it is not possible to produce the same kind of atmosphere, nor the intense sunlight. These experiments were continued for three years, but although as far as atmospheric pressure was concerned it was possible to obtain conditions equal to an altitude of 22,000 to 23,000 feet, the beetles showed no resulting modifications of coloration. When, however, opportunity came to transport them to an altitude of 9,000 feet, a marked change was noticeable, which indicates that something was lacking in the environmental elements in the experiment made in the laboratory. 
Experiments with increased atmospheric pressure have also been made, but thus far without any decisive results. I conclude, therefore, that as far as variation in atmospheric pressure is concerned, it is a matter of no moment in the color variations of decemlineata. However, altitude in nature is a factor of importance, but whether the modifications produced are the effects of atmospheric pressure or of other factors that are active in alpine regions has not yet been determined.

From these experiments upon this beetle, extending over a period of ten years, I have reached the following general conclusions:

(I) Somatic color variations are due to the action of environmental stimuli which accelerate or retard the physiological processes involved in colorpattern formation, and thus cause the color pattern and its elements to vary in definite directions toward an increase or decrease of pigmentation.

(2) The environmental factors do not have any specific effect, but each acts as a stimulus, which, when applied to the animals, produces modifications in coloration by accelerating or retarding the physiological processes which are productive of coloration; hence many different stimuli may produce identical results.

(3) Temperature and moisture are the two prime factors in the production of color changes, and of these moisture is the more important.

(4) Soil acts as an important factor indirectly through moisture.

\section{MODIFICATION OF COLOR IN L. SIGNATICOLLIS.}

It has already been shown that signaticollis is a stable species, of low variability and of very conservative constitution; and I have therefore selected it for experimental work as the type of one extreme in certain species of the genus, while decemlineata represents the other extreme. My experiments with signaticollis do not extend over as long a period as those with decemlineata, but the results are quite as conclusive.

\section{TEMPERATURE EXPERIMENTS.}

EXPERIMENT 28.-To determine the effects of a slight average increase in temperature upon the coloration of $L$. signaticollis.

Conditions.-Temperature on the average $6^{\circ} \mathrm{C}$. above that in control, with other conditions normal.

Apparatus.-Glass tank, as in experiment 23.

In this experiment 800 larvæ from three generations were used. The material was brought from Cuernavaca, Morelos, Mexico, and subjected to experimentation in the greenhouse at the University of Chicago. The temperature conditions were as shown in table 97. 
TABLE 97.-Temperature conditions.

\begin{tabular}{|c|c|c|c|c|c|c|c|c|c|}
\hline Conditions- & $7 \mathrm{a} . \mathrm{m}$ & ro a. $\mathrm{m}$. & I p. m. & 3 p. m. & 8 p.m. & $\begin{array}{l}\text { Maxi- } \\
\text { mum. }\end{array}$ & $\begin{array}{l}\text { Mini- } \\
\text { mum. }\end{array}$ & $\begin{array}{l}\text { Aver- } \\
\text { age. }\end{array}$ & $\begin{array}{c}\text { Deviation } \\
\text { from } \\
\text { normal. }\end{array}$ \\
\hline In control & $\begin{array}{l}{ }^{\circ} \mathrm{C} . \\
20\end{array}$ & ${ }^{\circ} \mathrm{C}$. & $\begin{array}{l}{ }^{\circ} \mathrm{C} . \\
3^{2}\end{array}$ & ${ }^{\circ} \mathrm{C}$. & $\begin{array}{l}{ }^{\circ} \mathrm{C} . \\
2 \mathrm{I}\end{array}$ & $\begin{array}{l}{ }^{\circ} \mathrm{C} . \\
35\end{array}$ & $\begin{array}{l}{ }^{\circ} \mathrm{C} . \\
\text { I8 }\end{array}$ & $\begin{array}{l}{ }^{\circ} C . \\
24 \cdot 4\end{array}$ & $\begin{array}{l}\circ C . \\
+3\end{array}$ \\
\hline In experiment. & 23 & 28 & 40 & 32 & 29 & 43 & 20 & 30.4 & +6 \\
\hline
\end{tabular}

In the experiment 9 per cent died in the larval stage, 2I per cent in the pupal, and 70 per cent emerged. In both larvæ and imagines the coloration was unmodified, as is shown for the adults in the following table:

TABLE 98.-Coloration of adults.

\begin{tabular}{|r|r|r|r|r|r|r|r|}
\hline Class..... & Io & II & I2 & I3 & I4 & I5 & I6 \\
\hline & P.ct. & P.ct. & P.ct. & P.ct. & P.ct. & P.ct. & P.ct. \\
Parents...... & $\ldots$ & 3 & 4 & 7 & I6 & 50 & 20 \\
Contro1...... & $\cdots$ & $\mathrm{I}$ & 5 & 8 & $\mathrm{I} 8$ & $\mathbf{4 6}$ & 22 \\
Experiment. & $\mathrm{I}$ & 2 & 5 & 7 & I6 & 45 & 24 \\
\hline
\end{tabular}

Empirical mode of parents....... I5

Empirical mode of control...... I5

Empirical mode in experiment... I5
Modal deviation of parents....... o

Modal deviation of control........ o

Modal deviation in experiment... o

EXPERIMENT 29.-To determine the effects of a considerable average increase in temperature upon the coloration of $L_{\text {. }}$ signaticollis.

Conditions.- Temperature on the average $12^{\circ} \mathrm{C}$. above that in the control, with other conditions normal.

Apparatus.-The same as in experiment 23.

In this experiment the material was the same as that used in experiment 28. Nine hundred larvæ from three generations were subjected to experimentation under the following conditions :

TABLE 99.-Temperature conditions.

\begin{tabular}{|c|c|c|c|c|c|c|c|c|c|}
\hline Conditions- & 7 a. m. & Io a. m. & I p. m. & 3 p. m. & 8 p. m. & $\begin{array}{l}\text { Maxi- } \\
\text { mum. }\end{array}$ & $\begin{array}{l}\text { Mini- } \\
\text { mum. }\end{array}$ & $\begin{array}{c}\text { Aver- } \\
\text { age. }\end{array}$ & $\begin{array}{l}\text { Deviation } \\
\text { from } \\
\text { normal. }\end{array}$ \\
\hline In control. & ${ }_{20}^{\circ} \mathrm{C}$. & ${ }^{\circ} \mathrm{C}$. & ${ }^{\circ} \mathrm{C}$. & $\begin{array}{c}{ }^{\circ} C . \\
25\end{array}$ & ${ }^{\circ} C$. & ${ }^{\circ} \mathrm{C}$. & $\begin{array}{l}{ }^{\circ} C . \\
18\end{array}$ & $\begin{array}{l}\circ C . \\
24.4\end{array}$ & $\begin{array}{l}\circ C . \\
+\quad 3\end{array}$ \\
\hline In experiment. & 30 & 32 & 44 & 39 & 37 & 46 & 25 & 36.4 & +12 \\
\hline
\end{tabular}

In this experiment 34 per cent died in the larval stage, 56 per cent in the pupal, and Io per cent emerged. In both larvæ and imagines a small increased variability was found, but there was no modal change, as may be seen in the table Ioo. 
TABLE roo.-General color of beetles used.

\begin{tabular}{|c|c|c|c|c|c|c|c|c|c|}
\hline Class...... & 6 & & II & 12 & 13 & I4 & I5 & 16 & I7 \\
\hline $\begin{array}{l}\text { Parents ...... } \\
\text { Control ....... } \\
\text { Experiment. }\end{array}$ & $\begin{array}{c}P . c t . \\
\cdots \\
\cdots \\
\mathrm{I}\end{array}$ & $\begin{array}{c}P . c t . \\
\cdots \\
\mathrm{I}\end{array}$ & $\begin{array}{c}P . c t . \\
3 \\
1 \\
2\end{array}$ & $\begin{array}{r}\text { P.ct. } \\
4 \\
5 \\
4\end{array}$ & $\begin{array}{c}\text { P.ct. } \\
7 \\
8 \\
9\end{array}$ & $\begin{array}{c}\text { P.ct. } \\
\text { I6 } \\
\text { I } 8 \\
\text { I4 }\end{array}$ & $\begin{array}{l}\text { P.ct. } \\
50 \\
46 \\
47\end{array}$ & $\begin{array}{c}\text { P.ct. } \\
20 \\
22 \\
20\end{array}$ & $\begin{array}{c}P . c t . \\
\cdots \\
\cdots \\
2\end{array}$ \\
\hline
\end{tabular}

In experiments where an average increase in temperature of more than I $2^{\circ} \mathrm{C}$. was used the mortality was too high for the observations to be of any value. Experiments conducted with lowered temperatures gave results like those in increased temperatures. In fact, in all the experiments with signaticollis the same result was obtained-that there was no modal shifting of the species as the result of increased or decreased temperature. This is in close accord with my observations of this species in nature, where it is apparently extremely stable and conservative, and varies as little as in experiment.

\section{MOISTURE EIXPERIMENTS.}

L. signaticollis was also experimented upon with deviations in relative humidity similar to those used with decemlineata, but without any resulting color modification.

In signaticollis is found a species which differs greatly from decemlineata in that it does not respond to stimuli by altered coloration. Pure somatic variation in signaticollis is therefore very limited and of a low degree, a fact that has already been arrived at in the study of variations. We are not to conclude from this that signaticollis does not vary, because it gives rise to most interesting modifications. These, however, are germinal, and not somatic. But, as far as purely somatic modifications of color are concerned, signaticollis is highly conservative, and a striking contrast to decemlineata.

MODIFICATIONS OF COLOR IN OTHER SPECIES OF LEPTINOTARSA.

Experiments with the environmental factors used with $L$. decemlineata and signaticollis have to some extent been tried upon undecimlineata, dilecta, violescens, oblongata, juncta, rubicunda, and multitaniata. From these experiments, the data of which it seems unnecessary to give, I find that species like multitaniata and undecimlineata, which are variable in nature, are likewise variable in experiment; while those which are stable in nature are also stable in experiment. However, this rule applies only to the variations produced in the organism during ontogeny-that is, after fertilization-by the action of such external stimuli as those which are used in the production of the variations which we usually call fluctuating, and which are largely the cause of the high place and geographical variability in adults. 
With these several species the responses in color changes were always definite and in the same directions as those already described for decemlineata. Likewise, they were not the effects of specific agents, but of stimuli which accelerated or retarded the processes of pigmentation. All responses reached the maximum at once, showed no accumulated effects of repeated stimulation, disappeared as soon as the stimuli were removed, and did not reappear until they were applied again.

GENERAL RESULTS DERIVED FROM EXPERIMENTAL MODIFICATION OF COLOR.

In all investigations dealing with variation we must, whenever possible, distinguish clearly between variations which arise in the germ plasm and those which arise in the soma after fertilization, or during ontogeny. It is therefore important in experimental work that the conditions of experiment be applied at such a time that either the germ cells or the soma alone may be affected, this being the only method by which we shall be able to arrive at a solution of the vexed question of the part taken by somatic variations in evolution.

In my experiments with Leptinotarsa I have been fortunate in that this much-desired result has been easily accomplished on account of the fact that the germ cells do not begin growth until after the time in ontogeny when the color patterns can be influenced by external stimuli. Although the germ cells are present during all the time of experiment, they are in the division periods, in which condition, as far as I can discover, they do not seem to be influenced by stimuli. It is during the growth and maturation periods that they are most sensitive, and these in Leptinotarsa do not begin until after coloration is completed. It was possible, therefore, during ontogeny, and especially during the development of the adult coloration, to apply strong stimuli to which the germ cells were not at that time sensitive, and obtain a transient somatic variation, and later on to apply the same stimuli during the period of the growth of the germ cells and obtain modifications which were similar, but which were permanent in heredity and in subsequent generations. Although later on I shall devote an entire chapter to a consideration of this subject, a statement of the above results seems necessary at this point.

The correctness of my methods of experimentation and the observations upon which it is based is proven by the fact that, among the thousands of somatic variations which I have produced in my experiments on color modifcations, not one has ever given the least indication of permanency in succeeding generations, or in crossing; nor can they be preserved by the most intense selection after the removal of the stimulus which produced them. This possibility in Leptinotarsa of so surely isolating somatic and germinal variations and their production has enabled me to conduct experiments and obtain results which would not be possible with the material used by other workers along this line. 
Among the long list of workers who have experimented upon Lepidoptera with deviations of temperature and moisture, Weismann, Standfuss, and Fischer stand preëminent as the most successful. Although each of these workers obtained modifications which were produced in experiment and inherited in succeeding generations, the fact that in the Lepidoptera used the germ cells were in the more sensitive stages during the period of color formation when the experiments were performed, leads one to conclude that the apparent inheritance of somatic modifications was due to the direct result of stimuli applied to the germ cells, and not to the inheritance of somatic modifications. Superficially somatic and germinai variations are often indistinguishable, but their different nature is shown in heredity. It is a fact, the importance of which can not be overestimated, that out of the thousands of experimentally produced color variations (somatic variations) recorded in the literature of the last fifty years, as also in the experiments described above, not one case of the unquestionable inheritance of such modifications has been described. This fact is a most difficult one for the neo-Lamarckian to explain away, because in it lies the direct experimental refutation of their cardinal principle.

In a large portion of the published work along the line of the experimental modification of color the experiments described have been of too short duration to be productive of any generally reliable results. Many workers have been contented to produce "aberrations," which have been interpreted as atavistic repetitions of ancestral stages (Dixey, Merrifield), without any attention being given to the question of the natural variability and its direction in the species experimented upon. There has been also a marked tendency to ascribe specific effects to both temperature and moisture; whereas, as both Fischer and I have shown, like results are produced by diverse stimuli. In this connection it must be kept in mind that the experiments of Weismann, Edwards, and others with dimorphic species of butterflies are not to be compared with the experiments herein described; because in their experiments it is the production of changes in the alternation of dimorphic generations that is brought about by experiment, and this is a phenomenon in no way associated with the experimental modification of coloration in non-dimorphic species.

From the above-described experiments with Leptinotarsa I have drawn the following conclusions, which are, I believe, generally true for all insects. At least, all published data, on careful analysis, falls directly in line with these conclusions, although often it is not so interpreted by its authors.

(I) The different factors of the environmental complex do not have any specific influence upon coloration, but all act alike as stimuli, either alone or 
in combinations, to accelerate or retard color development, and thus to modify coloration in the following ways:

(a) Toward melanic or albinic conditions, which are the most general and important in coloration.

(b) Toward suppression or accentuation of particular color areas or groups thereof.

(c) Toward changes in the colors themselves.

(2) The factors most potent in the modification of coloration are temperature and moisture ; soil and altitude act indirectly through moisture and temperature, while the influence of food, light, and other factors is very slight.

(3) Any factor acting as a stimulus produces at once the maximum response which the deviation in the factor is capable of producing, and this maximum response remains constant as long as the stimulus is in force, but varies as the stimulus varies, and is lost when the stimulus is removed.

(4) Any factor which deviates either above or below the normal has the effect up to a certain point of producing increased pigmentation, and beyond that point of retarding it.

(5) Variations produced by the action of environmental factors during ontogeny always follow the laws of fluctuating variation. New combinations of color characters never appear as the result of stimuli applied during ontogeny, and the modifications found are all in the line of accentuation or reduction of the color characters natural to the species.

(6) The variations produced in experiment resemble in their polygons of distribution and in their modal classes conditions found in nature in places or in seasons in which the conditions of existence are similar to those of the experiment; and a variation found in nature is to be interpreted as the result of a deviation of some factor of the environment acting as a stimulus to produce a modification of coloration.

(7) The variations produced by somatic stimuli are never inherited, no matter how long the stimuli be applied. They are therefore of no importance in evolution. They are of importance, however, in a consideration of the phenomena of place and geographical variation.

(8) Species of high variability in nature are also highly variable in experiment, and conversely, those which are constant in nature are the same in experiment; hence the observed variability of a species is a good index of the presence or absence of somatic plasticity, but is not necessarily an indication of its ability to produce germinal variations and become a factor in evolution.

To these conclusions the objection might be raised that in nature the factors of environment act as stimuli not only after the eggs are laid-that is, during ontogeny-but also before; that they would have the same influence upon the germ plasm as upon the soma, and should, therefore, produce in the germ plasm variations of permanency. In all animals, however, the soma acts as a protecting or insulating layer which, during the growth and fertiliza- 
tion of the germ cells, shields them from external stimuli by its capacity to absorb or compensate therefor. (O) more importance, however, is the fact that animals, or Leptinotarsa, at any rate, reproduce or mature the germ cells only under favorable conditions, and then within narrow limits. Of still greater moment is the fact that the germ cells are not equally sensitive to stimuli in all their stages of development. Thus, in Leptinotarsa, in both tropical and temperate latitudes, the germ cells do not develop nor reproduction take place until the conditions of temperature and moisture are favorable. For example, I have found specimens of signaticollis which were active as early as April I5, whose germ cells did not begin to grow or that did not begin to reproduce until about June I, when the arrival of the rainy season insured the necessary amount of moisture. In the dry plateau of northern Mexico and the southwestern part of the United States Leptinotarsa may emerge from æstivation weeks before the rains come, but they do not breed until the rains begin. Likewise, in the northern United States and Canada, decemlineata may emerge from the ground in April, but the germ cells do not begin to grow until the coming of the warm, moist days in May, or possibly June. In experiment it has been my most difficult problem to induce these beetles to breed under changed conditions. Germ-cell growth and reproduction for a given species takes place, therefore, only under conditions within the narrow limits to which it is adapted, but after the eggs are fertilized and laid, hot, cold, wet, or dry spells act as stimuli upon the soma and produce results like those which we have already described under "Place and geographical variation."

Permanent, heritable color modifications of Leptinotarsa have been found in nature, and are indistinguishable from somatic variations excepting in their capacity for being transmitted to subsequent generations. They, however, have no relation to the variations herein described.

\section{ADAPTATION IN COLORATION.}

WARNING COLORATION.

Almost all the species of Leptinotarsa are conspicuously colored white and black, yellow and black, red and black, metallic green, or blue; and all, both larvæ and adults, live freely exposed upon their food plants. The combinations of yellow, white, or red with blacks are regarded as warning colors, especially by the supporters of the theory of natural selection, and serve to give notice of the supposed inedibility of the possessor of the colors. This theory of warning colors has been developed mostly by the English naturalists, Darwin, Wallace, and Bates, and by Müller, Hasse, and others from observations, and by Poulton from experimentation, all of whom consider warning coloration to be due to natural selection. I have had an opportunity to examine this phenomenon quite extensively in Leptinotarsa, and to obtain data from nature and in experiment that goes to support the idea of utility in the above color combinations. 
The adults of almost all Leptinotarsa have strongly contrasting colors, and are visible from a distance of many feet, often yards. For example, $L_{\text {. }}$ undecimlineata, with its white hypodermal color and deep, glassy greenish-black markings, is an object which may be easily seen from a distance of from 30 to 40 feet, and often, when viewed from an elevation, for greater distances. It stands out clearly and sharply against the green of its food plant, where it lives boldly exposed upon the upper surface of the topmost leaves in a situation where it is at once recognizable and is most easily seen and attacked. The photograph (plate 2I, fig. I) shows the sharp contrast which this species makes with its food plant, as also the total absence of even the most superficial resemblance to any object in its environment which might afford it protection from its enemies.

I have frequently taken a position in which I could observe a colony of undecimlineata in nature, and I have never seen one of them attacked at any time of day by any of the insectivorous vertebrates. I have repeatedly seen birds-tanagers, warblers, fly-catchers, etc--visit the same branch upon which the beetles were resting, and take other insects (Diabrotica, etc.), but pass undecimlineata by. The same observations were made with reference to several genera of Lacertilia. Additional evidence that they are not eaten has been obtained by an examination of the stomach contents of insectivorous birds, both diurnal and nocturnal, but no trace of these beetles was found therein. Yet I have found, although rarely, mutilated specimens with the elytra broken and the body crushed and torn, as if it had been picked up by a bird or lizard and partly chewed, and then thrown away. These mutilations, however, might have been due to injury from other causes, such as being stepped upon by cattle or other large mammals, and can not be considered as good circumstantial evidence of their being taken as prey by insectivorous vertebrates and then rejected on account of some objectionable quality.

Various insectivorous lizards and toads which have been confined in cages with these beetles have rejected them as food. If, however, no other food is provided and the starvation point is reached undecimlineata is eaten, and without any apparent harm. This fact that under extreme shortage of food lizards and toads eat these beetles is of absolutely no significance, because all animals-even man-will eat anything under the conditions of starvation; hence feeding experiments in which the supposed objectionable food only is supplied have no weight whatsoever against the idea of warning or protective coloration. When a variety of food was supplied the toads and lizards passed undecimlineata by unmolested, although other forms only a few centimeters away were seized and eaten. I have frequently in nature seen lizards examine the beetles carefully, and then pass them by to take other food; and I do not think that there can be the least doubt that the conspicuous black and white coloration of undecimlineata secures to it a high degree of immunity from its enemies. 
Other species of the genus also possess the same combination of characters. Thus, lacerata, the largest species in the genus, is a conspicuous object on account of its black and white color. Like undecimlineata, it lives exposed upon the upper side of the leaves of the topmost branches of its food plant, where it is most liable to attack. On the green leaf in the bright tropical sunshine its black and white pattern is conspicuous, even at a distance of 50 to 75 feet, and could not fail to be observed by the keen-eyed insectivorous birds and lizards; yet, in spite of its coloration and position, I have never seen it attacked, nor have I ever found mutilated specimens.

The adults of $L$. rubiginosa are of a uniform bright red color, and as they are large the red color it makes upon the green leaves of its food plant may be seen with ease from a considerable distance. Other species of the genus are also conspicuously colored-violescens and libatrix, with their brilliant metallic blue-green colors, and dilecta and its allies, and many others-and they all rest in exposed positions.

The species multitcniata, oblongata, melanothorax, rubicunda, and decemlineata have a conspicuous color pattern of yellow and black or red and black, and are quite as well protected from their enemies as are those with white and black. During the years of the dissemination of decemlineata numerous experiments were made to discover whether domestic fowls-ducks, geese, and turkeys - would eat the intruders. The universal observation was that decemlineata was eaten sparingly, if at all, and then mostly by young birds. One ingenuous experimenter in Massachusetts inclosed fowls in a yard without other food than these beetles, and announced with great satisfaction the fact that after some days the beetles "were eaten with great relish." It would be interesting to know whether the same might not have been recorded of the experimenter himself under similar conditions. Various birds, orioles, grosbeaks, cuckoos, etc., have been observed by others to attack this beetle, and the "bobwhite" eats potato bugs freely (vide Yearbook U. S. Dept. Agr., I903); also, they have been found in the stomachs of a considerable number of species, but there is little, if any, evidence to indicate whether these birds were young or whether they were experienced. I have also frequently seen decemilineata in nature picked up by orioles, blackbirds, catbirds, robins, grosbeaks, and other birds, and then dropped without being crushed or eaten.

L. decemlineata has on the elytra and around the edge of the thorax closely set rows of compound glands which secrete an oily, bad-tasting and badsmelling fluid. If one of these beetles be picked up between the thumb and forefinger gently, and the elytra examined under a hand lens, no secretion will be found, but if ever so gentle a pressure be exerted upon the beetle, and the elytron watched under a hand lens, minute drops of the yellow, oily liquid will be seen to be suddenly extruded from each of the numerous glands. When a bird picks up one of these beetles and exerts pressure upon it with either beak or tongue, the result is an immediate extrusion of the repugnatorial fluid, in 
small amounts if the pressure is slight, and in greater amounts as the pressure is increased. This liquid is volatile, and to the human senses has an unpleasant odor and a rather unpleasant taste, and I see no reason why it might not be equally disagreeable to insectivorous animals. At any rate, the glands as a protective device have a high degree of efficiency, and although some of the insects are eaten, the great majority are well protected thereby. I have observed that young fowls, when turned loose in a potato field where the beetles are common, attack them at first eagerly, but learn in three or four days that, although they are easily found and tempting, they are not choice morsels as food. Hence, after a few days, they are recognized by their striking yellow and black surface and are avoided thenceforth, and to all intents and purposes they are immune from that particular generation of fowls.

I have also tried the experiment of mixing decemiineata with edible insects in about equal quantities and feeding them to fowls, with the result that the experienced fowls unerringly selected the edible and rejected the distasteful insects, whereas the inexperienced fowls did not so certainly select the agreeable from the nauseous. The different elements in the mixture were at first taken in about the proportion of edible 65 per cent and inedible 35 per cent, which would indicate that even although the new food had not been previously encountered and its distastefulness experienced, the mere fact that its coloration was novel and different from the usual run of food caused it to be investigated with some care before being consumed in quantities. At any rate, the fowls soon learned to recognize and avoid this insect on account of its conspicuous coloration. This fact was proven by an experiment in which beetles whose yellow areas had been painted with blackened shellac were fed to experienced fowls. The insects were eagerly seized at first, but as soon as their distasteful qualities were discerned they were rejected.

It can not be doubted that decemlineata, on account of its striking coloration and its accompanying inedible qualities, enjoys a high degree of immunity from its vertebrate enemies, and not because there is any instinctive avoidance of the beetle by fowls and birds, but because each succeeding generation very soon becomes acquainted with its distasteful qualities and learns to associate it with the sharply contrasted colors of its color pattern. In this process of educating its public enemies decemlineata yearly sacrifices a small percentage of its numbers, probably less than half of I per cent, but this sacrifice gives to the remaining 99 per cent far greater immunity from enemies than could otherwise be obtained.

L. multitcniata and oblongata, which possess this same coloration and the glands, are also, as far as I can discover, practically immune from the attacks of insectivorous enemies. In fact, every species in the genus Leptinotarsa possesses these glands to a greater or less degree, and almost all are marked with bright colors in most striking contrast to one another and to their surroundings, which render them as conspicuous as possible. Moreover, as far 

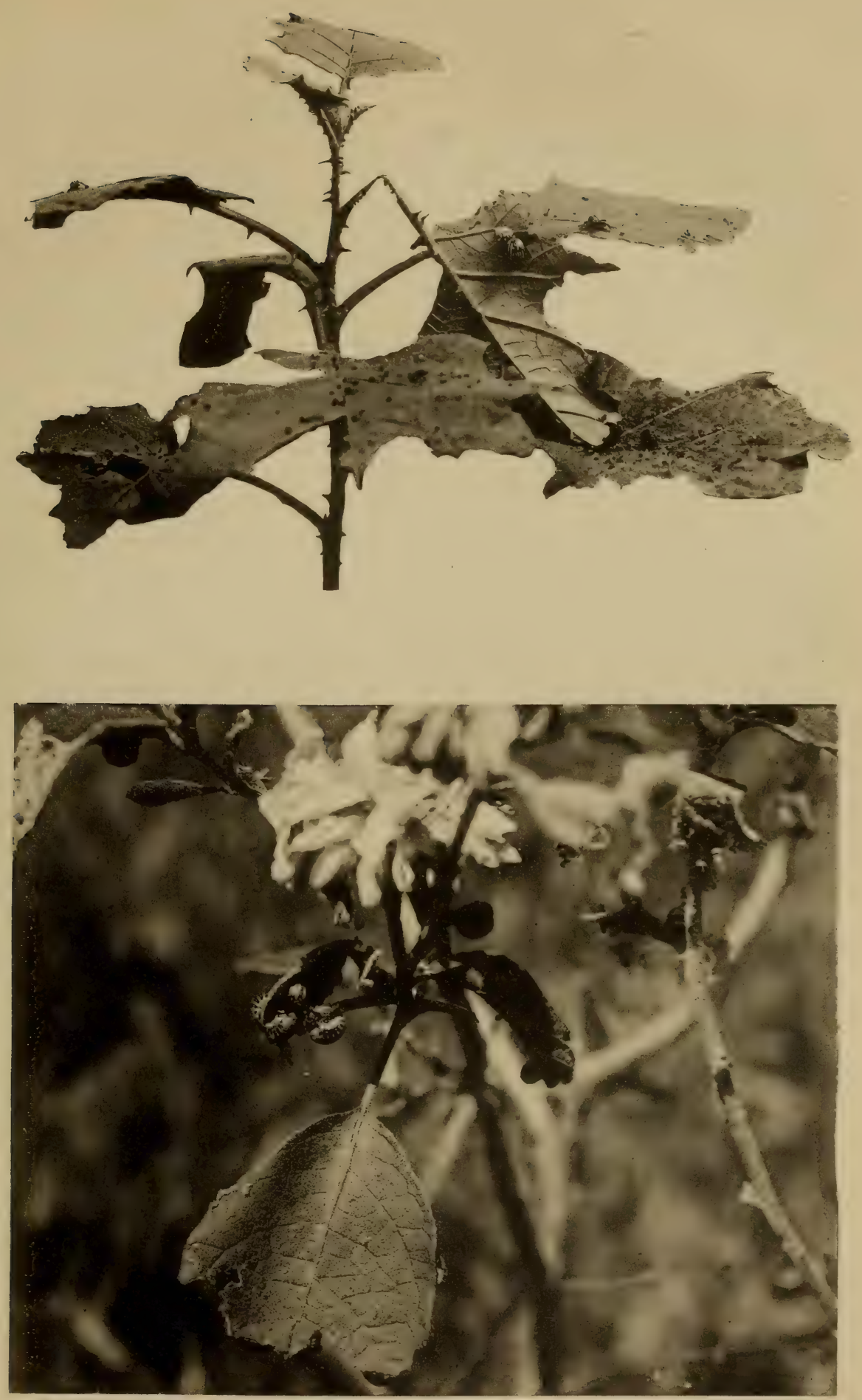

Photographs showing conspicuous nature of coloration of larvæ and imagines of Leptinotarsa.

Fig. 1, L. undecimlineata; the striking black and white coloration of this beetle makes it a conspicuous object upon the leaves of its food plant.

Fig. 2. L. signaticollis; larvæ in the last larval stage, living exposed on leaves of the food plant and rendered conspicuous by their bright yellow and black colors. 

as I have been able to discover, the genus as a whole is almost entirely free from the attacks of insectivorous animals upon the adults. I can, therefore, come to no other conclusion than that the conspicuousness of the coloration of the adult beetles serves to advertise for the mutual benefit of themselves and their enemies their inedible character.

The larvæ of Leptinotarsa also possess striking colors and display them in a most conspicuous fashion upon their food plants. In rubiginosa, rubicunda, and decemlineata the larvæ are bright red; in diversa and signaticollis, when mature, they are yellow and black; in lineolata they are banded black and white, and in multitaniata and oblongata, when mature, they are a brilliant yellow. All larvæ also possess glands which secrete pungent and ill-tasting fluids, and extrude them on the least provocation. To vertebrate enemies these larvæ are quite immune, as I have repeatedly proven with decemlineata by feeding it to fowls, and with multitcniata and oblongata by feeding them to toads and lizards.

These colors do not, however, afford protection from insect enemies, as I have abundant evidence that the brilliantly colored larvæ of multitaniata, signaticollis, diversa, undecimlineata, decemlineata, and lacerata are attacked by predacious Hemiptera for the purpose of sucking out the body fluids. However, the attacks of these enemies are of little moment, and do not seem to appreciably reduce the numbers of any species of Leptinotarsa. The Hemipteron attacks the beetle by making a small puncture and sucking out the hæmolymph, and as it does not come in contact with the glandular secretion it is not repelled thereby. Although a considerable number of larvæ may be destroyed by these insects, it is the vertebrate enemies that are most effective, and against which protection is really needed.

In almost all Leptinotarsas it is the mature larvæ only that are brilliantly colored. The earlier stages, which are often devoid of bright colors, are protected by their resemblance to their food plant or to other objects in their environment. Thus, in signaticollis and undecimlineata, the larvæ of the first two instars, covered with trichomes gathered from their food plant, crowd closely together so that they resemble withered leaves or dust; while in the last stage they live freely exposed, but are protected by their brilliant coloration. These conditions will be considered later on under the head of "Protective resemblances in coloration."

Although I find in Leptinotarsa, in both adults and larvæ, the phenomenon of warning coloration present and producing the immunity from vertebrate enemies which the originator of the theory attributed to it, I must acknowledge that to find and recognize the phenomenon and its utility in the economy of the species is one thing, but to discover how the various combinations of strongly contrasted colors came about, or how the final adaptation of warning colors to environment was accomplished, is another and entirely different question. Likewise, to explain the observed phenomena and their undoubted 
utility by one hypothesis is one thing, and very easy, but to determine the cause of the phenomena is quite another, and not easy.

The most approved current hypothesis employed in the explanation of the phenomenon of warning coloration is that of natural selection. All are familiar with the use made of this hypothesis by Darwin, Wallace, and later writers in their treatment of the subject of protective coloration, and the plausible explanations that have been made upon the basis of this hypothesis of natural selection. While I think that no one can doubt the utility of the end result-that is, the fully developed warning coloration-it is indisputable that we are as yet ignorant of the earlier stages in the development of warning coloration, excepting as we create them in our imagination. No one, to my knowledge, has as yet recorded from actual observation the beginning of the development of warning coloration either in nature or in experiment, and the supposed utility of the initial stages still remain an unproven assumption. Altogether the explanation of warning coloration by natural selection, while it may be a true one, is at present based upon assumptions the correctness of which is open to doubt. Those writers who, in highly involved language and through circuitous logic, dogmatically assert that these phenomena "can only" have come about by natural selection, are themselves indulging in the same dogmatism as that which once so generally characterized a kindred branch of human knowledge, and which the same scientists have vigorously denounced and held up to ridicule. In Leptinotarsa we shall for the present recognize the existence and utility of the phenomenon of warning coloration without attempting at present to account for its production.

\section{PROTECTIVE RESEMBLANCE.}

The widespread distribution of this phenomenon among all animals, and especially among insects, and the interest which these wonderful adaptations have aroused, have made them the basis of some of the wildest and most absurd speculations to be found in modern biological literature.

In Leptinotarsa color adaptations which arise as protective resemblances are not numerous. The eggs, many of the larvæ, and most adults are conspicuously colored. Some few larvæ, however, do show protective coloration in the early stages. Thus, in multitceniata, oblongata, rubicunda, and melanothorax the young larvæ are all light yellow, exactly the color of the long yellow spines on their food plants, among which they rest. In these larvæ the only protection comes from the general correspondence in color, and is, I believe, purely a matter of accident, and not an adaptation. At any rate, the larvæ quite as frequently lie on the green part of the plant as upon the yellow spines, and it would take more imagination than I possess to make out of this a case of protective resemblance.

Some larvæ, undecimlineata, diversa, signaticollis, dilecta, violescens, libatrix, and other species, are colorless, or nearly so, in certain stages. This 
semi-transparent condition is usually found in the second instar, when the larva is full of clear hæmolymph and the fat body has not yet developed. They are then translucent, and resemble closely the color of their food plant. This combination of conditions, which gives a considerable degree of concealment to the larvæ, is to be interpreted as accidental, and not as a real adaptation for the purpose of concealment and protection.

The adults of Leptinotarsa, as far as I know, present no protective resemblances in color adaptation, but all show the warning coloration already described. Mimicry also is entirely wanting, and while it would be easy to match up Leptinotarsa with species in Doryphora, Labidomera, Calligrapha, Stilodes, etc., and create cases of mimicry, there would be no foundation in fact for them. If I had never seen these genera in nature, and did not know that they and the species having similar color patterns are not found together-that is, if I knew them from museum specimens alone-I might be pardoned for creating with them more new cases of mimicry; but in these beetles in nature there is not the slightest trace of mimetic phenomena, and the creation of any cases of mimicry is, I believe, absolutely unpardonable unless the cases have been thoroughly studied in nature. The literature is already overloaded with purely imaginary examples of this phase of protective coloration.

The adaptations in coloration in Leptinotarsa are largely warning coloration with a few examples of protective resemblance, and no really good evidence has been found which would tend to show how these came into existence. It is true that oblongata, rubicunda, and melanothorax all have warning colors, and that they arise by sudden transformation from multitcniata; but multitcniata is itself provided with warning colors, and as these species arise from a species in which zvarning colors were already developed, we shall have to go farther back in their genealogy for the origin of the phenomenon. These species afford evidence only of the transmissibility of warning colors from species to species, and not of its first production. The fact that warning coloration is handed on in evolution from species to species is, I believe, of considerable importance. In these three species, at least, this character is handed down from the parent species to the descendant species in its full intensity.

Inasmuch as this phenomenon is general throughout the genus, and is, as I have just shown, handed on in evolution from one species to another, I conclude that the wide distribution of striking colors which serve as warning colors has not been developed within the genus Leptinotarsa at all, but that it is inherited by this genus from its ancestors. Hence it is not to be expected that evidence of the origin of the phenomenon would be found in Leptinotarsa; and in my experiments with these beetles none has appeared. 


\section{THE EVOLUTION OF COLORATION.}

One of the most conspicuous traits of the genus Leptinotarsa is the development of its specific characters along definite lines, and not in all directions.

Upon the elytra of Leptinotarsa the color pattern is composed of stripes, spots, or bands, or combinations thereof. The stripes are color marks parallel to and between the veins, the bands cross the veins at right angles, while the spots usually lie between the veins, or sometimes over them. These elytral color patterns are represented in table IOI, where the number of species characterized by the different patterns is also shown.

TABLE IOI.-Different types of color pattern in the elytra of Leptinotarsa, and the number of species which exhibit them.

\begin{tabular}{|c|c|c|c|}
\hline Types of color pattern. & $\begin{array}{l}\text { Number } \\
\text { of } \\
\text { species. }\end{array}$ & Types of color pattern. & $\begin{array}{c}\text { Number } \\
\text { of } \\
\text { species. }\end{array}$ \\
\hline 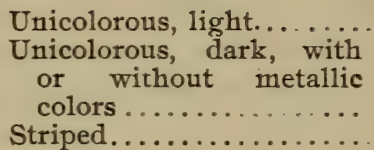 & $\begin{array}{r}7 \\
\text { I6 }\end{array}$ & 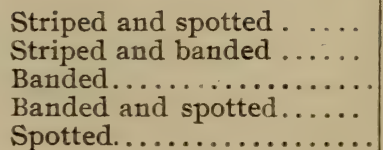 & $\begin{array}{l}4 \\
5 \\
1 \\
0 \\
8\end{array}$ \\
\hline
\end{tabular}

It is apparent in this table that among the 43 species in the genus, 16 have an elytral color pattern which consists solely of stripes, and 4 have a pattern of both stripes and spots, in which the stripes are dominant. Therefore, the prevailing element in the coloration is the stripe, 20 species in the genus having striped elytral patterns and the remainder unicolorous, spotted or banded. From the table it is also evident that there are four directions of elytral color-pattern evolution in the genus-first, toward a unicolorous condition ( 9 species) ; second, toward a striped condition ( 20 species) ; spotted ( 8 species), and banded (6 species). If we compare the table with the groups of the genus outlined in the first paper we find that the flavopustulata group is made up of spotted or banded-striped species; the haldemani group of striped and dark unicolorous species; the lacerata group of spotted, banded, banded-striped, and dark unicolorous species; the rubiginosa group of light unicolorous species; the lineata group of striped or light unicolorous species, and the dilecta group of striped, striped-spotted, or spotted species. The most casual inspection of plates 22 and 23, where the color patterns of the genus are represented, will at once reveal the fact that the four types of color pattern are really due to the combinations possible between the two systens described in the section on color ontogeny, namely, stripes or bands, the spots resulting simply from the breaking up of the two other elenients.

In the second chapter it is shown that the variation of the color pattern follows along definite lines, and later, in the discussion of color ontogeny, that color first develops between the veins, and crosses them at five definite points; and when it fails to develop it is lost first at certain regions or 
interbands. (See L. dilecta, plate 19.) Likewise on the figures on plates 22 and 23 it is apparent that species differentiation has followed along the same lines. For example, the banded and spotted color pattern represented on plate 22 shows plainly the combination of the bands with the spots.

The immediate ancestor of these beetles is the genus Zygogramma, and the next removed is Calligrapha. The color pattern on the elytron of $C$. intermedia, which is represented on plate 22, fig. I, is one from which all of the elytral designs in Calligrapha are easily derived by slight changes of the elements thereof. Thus, a slight change consisting in the fusion of the elements in the central space, and the further development of the proximal, middle, and distal band, or of spots representing them in the ramous interspace, will give the conditions found in Zygogramma clathrata, a highly variable species, which is represented in two of its "variates" in figs. $2 a$ and $2 b$ on plate 22. Likewise, by a continued development of the color centers of the central space and of the transverse bands, the pattern found in another variable species, $Z$. ornata, is easily produced. This species also shows two divergent varieties-figs. $3^{a}$ and $3 b$, on plate 22 .

From the variety $Z$. ornata, represented in fig. $3^{b}$, the elytral patterns of L. hogei (fig. 4) and dahlbomi (fig. 5) might easily be derived. Also from the variety $3 b$, by a continued increase of pigmentation, the forms $L$. haldemani (fig. 6) and its allies might easily be produced. Or the series $L$. heydeni (fig. 7), modesta (fig. I6), and puncticollis (fig. I5), might have originated from the variety $3 a$ of $Z$. ornata. Also the species L. lacerata (fig. 8) and chalcospila (fig. I4) might be derived from the same condition by a reduction of the spots and a development of the bands (lacerata), and then by the further reduction of the bands the spotted pattern of chalcospila might be produced. Also from the pattern found in $Z$. clathrata, variation $b$, the pattern of the elytron of $L$. stali (fig. 9) could be produced by the reduction of the stripe of the central space in the region of the proximal interband; and likewise, from the variety $2 a$ of $Z$. clathrata, the color pattern of L. Alavopustulata (fig. IO), belti (fig. II), dohmi (fig. I2), and evanescens (fig. I3).

On plate 23 are represented color patterns of another type, which, however, can all be derived in much the same way. If we start with a pattern such as is represented in fig. I of $Z$. dulcis, which is almost the exact counterpart of $C$. intermedia, geographica, etc., we can pass from a Calligrapha type of pattern through the species of $Z$. malva, stali, aneovittata, and novemvirgata to the striped Leptinotarsa elytral pattern, simply by the fusion of spots in the interspaces to form stripes, a process well represented in figs. I to 5. Z. novem-virgata is an extremely variable form which shows numerous elementary species, and from this group of elementary species the conditions of color pattern represented on plate 23 could easily have been derived.

It is perfectly evident that as far as the elytral color patterns are concerned the species of the genus Leptinotarsa can be arranged in a perfectly consistent 
and complete orthogenetic series. These elytral color patterns are the most important of the specific differentials, are perfectly stable characters in each species, and are as reliable as indicators of relationship and evolution as any other characters we may examine. Let us ignore for the moment the question of the relationship of the species and the order and evidence of their evolution, and concentrate our attention upon the very plain case of orthogenesis presented in the effort to discover why this orthogenesis exists.

In the construction of plates 23 and 24 the species were not selected to illustrate orthogenesis, but every species of the genus is represented save two-L. rubiginosa, a unicolorous bright red form, and L. zetterstedti, a brown-banded species. Both these excluded species stand wide apart from the rest of the genus, and are more nearly related to species of Zygogramma. They are in reality the end results of lines of modification in that genus, and show the same phenomena of orthogenesis. The fact that all the species of the genus show this phenomenon is of itself adequate proof without further argument of the formation of species in definite directions. ( $\mathrm{I}$ use the word orthogenesis in the sense in which it was first used, and not in that employed by Eimer.) However, upon whatever basis we are content to explain this condition, the fact remains that the species as we now recognize them have elytral color patterns of such a character that their arrangement in an orthogenetic system is accomplished with ease. This fact might be explained upon the basis of Eimer's orthogenesis, by an internal perfecting tendency irresistibly forcing the species in certain directions, by natural selection through an elimination of all variations excepting those along the lines which were of utility to the species, by the neo-Lamarckian factors, or by mutation. And yet, with each or all of these hypotheses, we are far from any real elucidation of the question as to why the establishment of species along certain lines has taken place. A possible explanation of the problem is to be found in the phenomena of development, and it is quite possible that the final interpretation will rest upon the laws of ontogenetic development and physiology alone.

In the ontogeny of elytral coloration and in the coloration of adults it has been shown that color develops in stripes, bands, or spots, and that the evolution of patterns has been orthogenetic, by means of various combinations of these bands, stripes, or spots. If now we can arrive at some explanation of these fundamental color elements, we shall be better able to understand the whole problem. In order to do this we shall first have to consider some of the phenomena in the development of the wings.

The wings of these beetles and of all insects arise from thickenings upon the sides of the last two thoracic segments, followed by invagination, and later by evagination, to form the wing fundament. In Leptinotarsa they always arise beneath the wing spots, which, as I have shown, are homodynamous with the spiracular spots. The wing fundament consists at first of a minute area in which the cells are more closely crowded together than in the 



\section{Explanation of Plate 22.}

This plate illustrates the orthogenesis in the color patterns of the elytra in the genus Leptinotarsa.

Fig. I, Calligrapha intermedia.

Fig. 2, Zygogramma clathrata (two varieties).

Fig. 3, Zygogramma ornata (two varieties).

Fig. 4, Leptinotarsa hogei.

Fig. 5, Leptinotarsa dahlbomi.

Fig. 6, Leptinotarsa haldemani.

Fig. 7, Leptinotarsa heydeni.

Fig. 8, Leptinotarsa lacerata.

Fig. 9, Leptinotarsa stali.

Fig. Io, Leptinotarsa flavopustulata.
Fig. II, Leptinotarsa belti.

Fig. I2, Leptinotarsa dohrni.

Fig. I3, Leptinotarsa evanescens.

Fig. I4, Leptinotarsa chalcospila.

Fig. I5, Leptinotarsa puncticollis.

Fig. I6, Leptinotarsa modesta.

Fig. I7, Leptinotarsa litigiosa.

Fig. I8, Leptinotarsa tlascalana.

Fig. I9, Leptinotarsa libatrix.

Fig. 20, Leptinotarsa cyanescens.

Fig. 2I, Leptinotarsa violescens. 

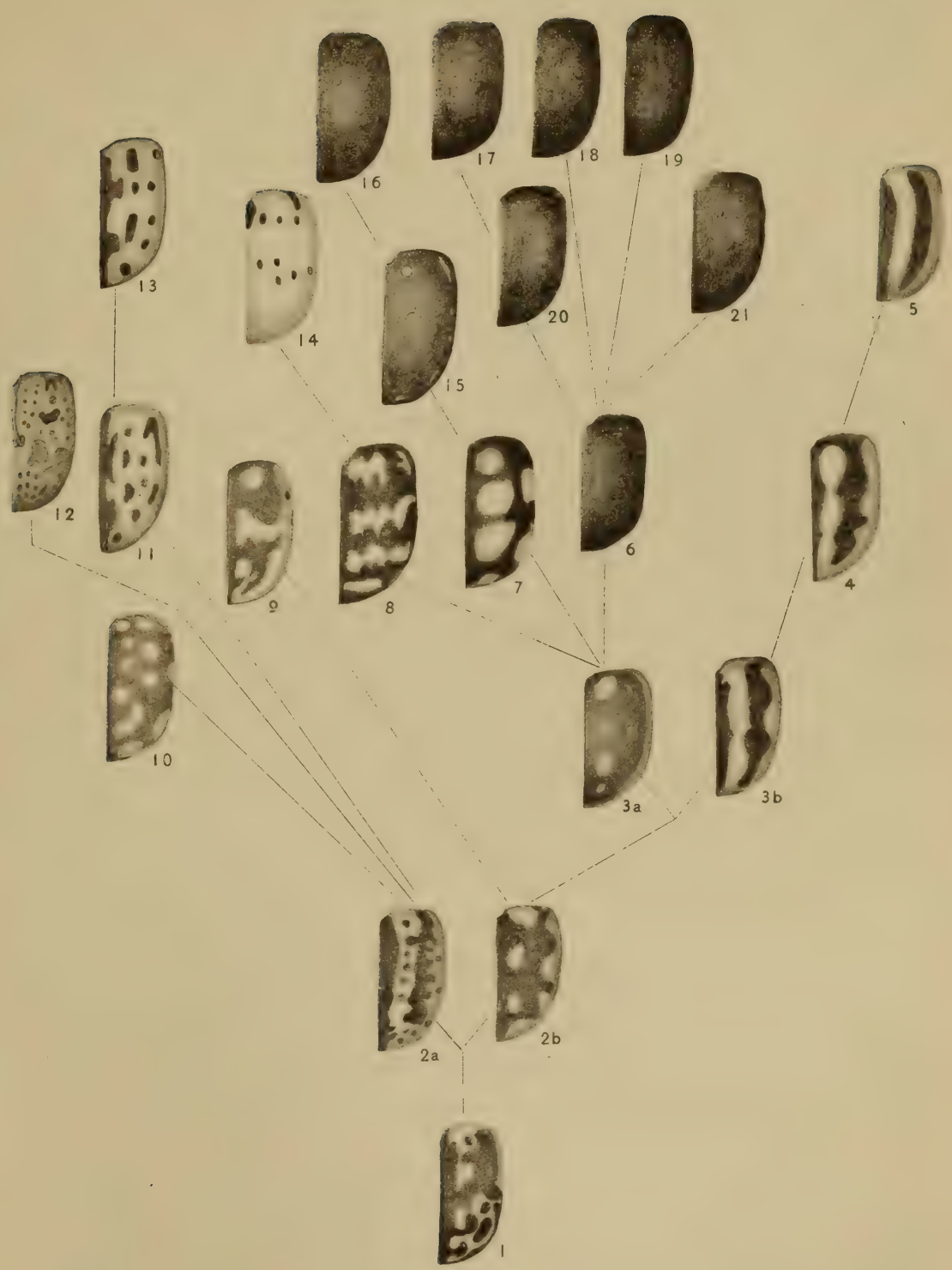

W. L. T. DEL. 

neighboring hypodermis, and which has a single distinct trachea distributed to it from the main tracheal trunk. In the early embryo the homodynamous thickenings occur upon all of the segments, in the position of the spiracular spots, and from these develop the tracheal invaginations and the pigmentenzyme cells of the spiracula spots. The entire set of homodynamous spiracula and wing spots receive from the same source in the embryo some cells which are later specialized for the purpose of producing pigment enzymes, others for the development of the trachex, and still others for the general hypodermis. The existence of these specialized cells has been demonstrated cytologically in the embryo, and experimentally in the larva.

In the development of the wing the fundament takes out of the tissue beneath the wing spot ordinary hypodermal and color-producing cells. As the wing fundament forms a connection is retained at the point where the trachea touched the fundament, and it becomes the apex or margin of the wing. The wing grows largely from the apex, the base remaining relatively fixed. As the apex grows outward the various areas of the wing are laid down, and into the spaces formed the permanent tracheæ enter later. As the wing grows outward from its base the outer end (apex or margin) forms behind it the structure of the adult wing, and from the color mother cells there are left in rows, bands, or spots the cells which are to produce the color pattern. In this growth of the wing the base is always ahead in development, and is completed first, the tip last. The essential fact in wing development, as far as coloration is concerned, is that the wing is derived from one of the systems of the homodynamous color areas on the body wall of the insect, and that from this area it receives both hypodermal and pigment-forming cells, the latter of which give rise to the cells which form the adult coloration. This arrangement, which is characteristic of all Coleoptera at least, and I believe of insects in general, is the basis upon which we must explain color patterns and color evolution. It can be traced back to the homodynamous centers, and from there to the highly probable but not yet demonstrated mother cells of the body centers of coloration; then still farther back to the original blastomere, then to the formative substance of the ovum, and finally, in our imagination, to the more remote and less tangible elements of organic structure and activity. From this we may gain some little appreciation of how fundamental and how early provided for in development is the coloration of an animal. Here in the general phyletic constitution of insects we see a fundamental system provided out of which is to be shaped a great variety of color patterns by many forces acting in diverse directions.

In the phyletic development of color patterns of genera and species this fundamental plan of coloration is variously modified, and this furnishes a basis for the determination of color pattern homologies in insects. We are not able to explain why in Leptinotarsa the mother color cells leave behind rows of cells to form stripes in some species and bands or spots in others. We 
say it is due to the morphological and physiological constitution of the species, to ids and determinants, or to internal perfecting forces, all of which explanations are attempts to appear wise when we are ignorant.

When the facts as to the source of the color-producing cells of the wings and their general behavior in ontogeny are joined to those of the variation and ontogeny of coloration - the production of stripes, bands, or spots, or unicolorous conditions - they enable us to gain a clearer comprehension of coloration than is otherwise possible and to understand how orthogenesis is produced in variation and evolution, yet we are still ignorant as to the causes.

Let us examine our material in the light of the above conclusions, and we shall be better able to explain the conditions found in elytral coloration. In calceata, dilecta, lineolata, and typographica (plate 23, figs. I3 to I6) we see species formation along a definite line and a distribution from southern Mexico to Texas. In this series the evolution, variation, and distribution all show indisputably the existence of orthogenesis; for it is highly improbable that the conditions could be due to chance. Finally, when we take into consideration the fact that the entire genus shows these conditions of distribution, variation, and coloration there exists not the slightest doubt of orthogenesis in the genus Leptinotarsa.

The existence of a fundamental color pattern which each species or genus variously modifies in its own fashion has been proven, but why each species should do thus or so with this general plan of coloration is exactly the same problem as why species do thus and so with the fundamental plan found in other organs. This is the problem of the origin of species, and the explanation of the existence of the general plan of each system of organs belongs to the still more remote problem of the origin of phyla.

Although we can not at present explain the observed conditions otherwise than through speculation, we have gained evidence which is of value in the interpretation of the phenomena of distribution, variation, and coloration. We might examine other characters in the genus, such as the epicranium, pronotum, legs, etc., but we should consume space and time unnecessarily and arrive at the same conclusion.

It must be admitted that there exists in Leptinotarsa a race tendency, no matter how it may be accounted for, which from the general system of color centers existing in the genus as a phyletic character produces coloration of a certain type, spots, bands, stripes, or combinations thereof, which type is variously modified by each species. The study of coloration deals largely with these racial tendencies, and leads to the following general conclusions:

(I) Centers of color origin.-In ontogeny and in evolution (species formation) color appears first in centers which upon the body are metamerically repeated spots and upon the wings are either spots, stripes, or bands. In development the anterior or proximal centers develop first because they are first 



\section{Explanation of Plate 23.}

This plate illustrates orthogenesis in the color patterns of the elytra of the genus Leptinotarsa.

Fig. I, Zygogramma dulcis.

Fig. 2, Zygogramma malva.

Fig. 3, Zygogramma stali.

Fig. 4, Zygogramma anovittata.

Fig. 5, Zygogramma novem-virgata.

Fig. 6, Leptinotarsa flavitarsis.

Fig. 7, Leptinotarsa nitidicollis.

Fig. 8, Leptinotarsa cacica.

Fig. 9, Leptinotarsa novemlineata.

Fig. Io, Leptinotarsa obliterata.

Fig. II, Leptinotarsa pudica.

Fig. I2, Leptinotarsa distinguenda.

Fig. 13, Leptinotarsa calceata.

Fig. I4, Leptinotarsa dilecta.

Fig. I5, Leptinotarsa lineolata.

Fig. 16, Leptinotarsa typographica.
Fig. I7, Zygogramma novem-virgata.

Fig. 18, Zygogramma novem-virgata.

Fig. 19, Leptinotarsa juncta.

Fig. 20, Leptinotarsa defecta.

Fig. 21, Leptinotarsa defecta.

Fig. 22, Leptinotarsa undecimlineata.

Fig. 23, Leptinotarsa angustovittata.

Fig. 24, Leptinotarsa signaticollis.

Fig. 25, Leptinotarsa diversa.

Fig. 26, Leptinotarsa decemlineata.

Fig. 27, Leptinotarsa intermedia.

Fig. 28, Leptinotarsa melanothorax.

Fig. 29, Leptinotarsa rubicunda.

Fig. 30, Leptinotarsa multitcniata.

Fig. 3I, Leptinotarsa oblongata. 
PLATE 23.

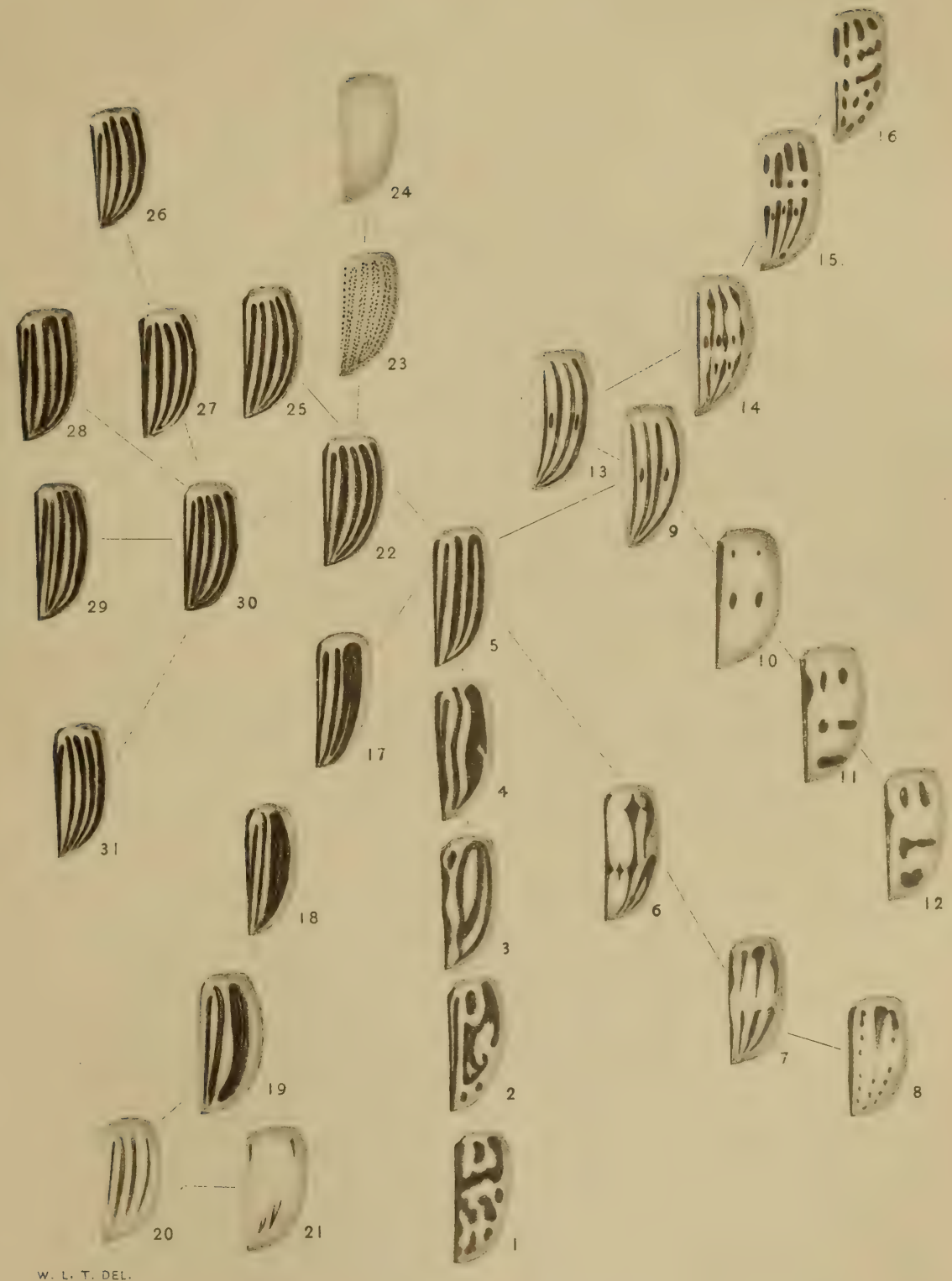



laid down in ontogeny, and hence mature first. This phenomenon of priority in development is not at all of a phylogenetic nature; it allows, I believe, of no other interpretation than that it is simply a phase of the general law that the anterior and proximal portions of an animal develop ahead of and faster than the posterior and distal. In variation the posterior distal and dorsal are most variable, as they are the last developed, and are hence the longest subjected to the causes of somatic variation when in an undifferentiated state.

(2) Color patterns.-The color patterns of the body are built up of color areas derived from the phyletic system, of segmental centers of coloration, which appear in the embryo. Of these centers the species uses those which its peculiar constitution demands and suppresses all others. Upon the wings color appears in centers, but each species in the ontogeny of the wing develops pigment cells in the centers where the constitution of the species demands them. In general these are developed in stripes, bands, or spots, located at very definite and invariable positions upon the wing. Stripes are always found between the veins and bands at right angles to them (plate 24, fig. 2), and at the following places: Base, apex (margin), middle, above the transverse vein, one half-way between the basal and middle bands, and another half-way between the middle and marginal. Spots occur most frequently at the point of intersection of bands and stripes.

(3) Color characters.-In development and evolution the units of coloration upon the body are the segmentally placed centers, while upon the wings they vary in different races, but are in general whole bands or stripes, or portions thereof.

(4) Color-pattern evolution and color variations, both somatic and germinal, coincide, and are orthogenetic upon the body because of the existence of the system of phyletic color centers, which follow in variation and evolution the laws governing metamerically repeated structures, and on the wings because of the phyletic system of stripes and bands which follow their own laws.

(5) Color-pattern evolution tendencies exist which produce patterns of definite type due to some force characteristic of the germ plasm. This force takes certain color centers from the phyletic system in the embryo, and by various modifications thereof produces diversity in coloration. In Leptinotarsa there exists a general generic tendency which controls the entire genus, a group tendency which governs groups of species, and a race tendency which is limited to a few species. These tendencies are not to be confounded with the "internal perfecting principle" of Nageli and others, but they are entirely a matter of germ-plasm constitution and of heredity, and any change of the latter will modify the tendency. The difference betwen these two ideas is this: the "internal perfecting principle" involves the conception of an ideal for the race toward which it is driven by the directive force of some more remote agency; while a "tendency," as I use the term, is an expression for a 
more or less stable condition which exists in the germ plasm for longer or shorter periods of time, through whose influence certain characters are taken from the general phyletic backgound and specialized in various ways to build up the color pattern of the race or species.

(6) The color phenomena of insects show, first, a general phyletic color pattern which consists of the metamerically repeated homodynamous centers of coloration and the wing stripes and bands; and, second, ordinal, generic, and racial types of color pattern, which consist of modifications and specializations within groups, superimposed upon the phyletic type. The phyletic type of coloration belongs with other characters of the phylum, and its explanation can be undertaken only when we know better the origin of phyla. The ordinal, generic, and racial types are those with which we are concerned in present day studies of evolution, and they are open to investigation by experimental and other methods of research.

In this discussion of coloration data and observations from several lines of research have been brought tngether and used in building up the final conclusions and conceptions given in the last section of this paper. Coloration is here shown to be a fundamental character of animais, and not an accident. Moreover, it is found to be governed by laws as strict as those which control all morphological and physiological characters of animals in general. It is therefore a trustworthy character for use in experimental evolution, being as capable, as is any other character of giving accurate data as to the laws of evolution. Finally, the conclusions reached herein may be used for the purpose of more fully verifying and comprehending the facts and tentative conclusions set forth in the discussions of variation and distribution.

Although in this study of coloration important and fundamental conclusions are reached as to the laws governing its evolution, we in nowise derive any valid basis for speculation as to the causes of evolution beyond that already brought forward in previous chapters. The experiments in somatic color modification do remove, to a large extent, if not absolutely, from the range of possibility as causes of color evolution, the neo-Lamarckian factorsthe inheritance of somatic variations acquired through the action of external stimuli upon the soma during ontogeny. Hence it is to the germ plasm in the period before cleavage and differentiation begins that we must turn our attention in the study of evolution.

If somatic variation is eliminated as a cause of color evolution, the only other possible explanation of the phenomenon that presents itself is that variations of permanence and utility in evolution arise in the germ plasm; but whether these variations are due to selection, mutation, or to the direct infuence of environment, is a matter for observation and experiment, and not for idle speculation. 



\section{Eixplanation of Plate 24.}

This plate illustrates the laws of coloration in the genus Leptinotarsa.

The figures are semi-diagrammatic representations of the condition found in different species of the genus. The lettering used on this plate is the same as employed in textfigures $\mathrm{I}, 2,3,7,8,9$, and $\mathrm{Io}$.

Figs. I to 8, elytra of several species to illustrate the laws of coloration of the elytra. Figs. 9 to $I 6$, pronota of several species to illustrate the laws of coloration.

Figs. I7 to 22, to illustrate the laws of coloration upon the body segments. 
PLATE 24.

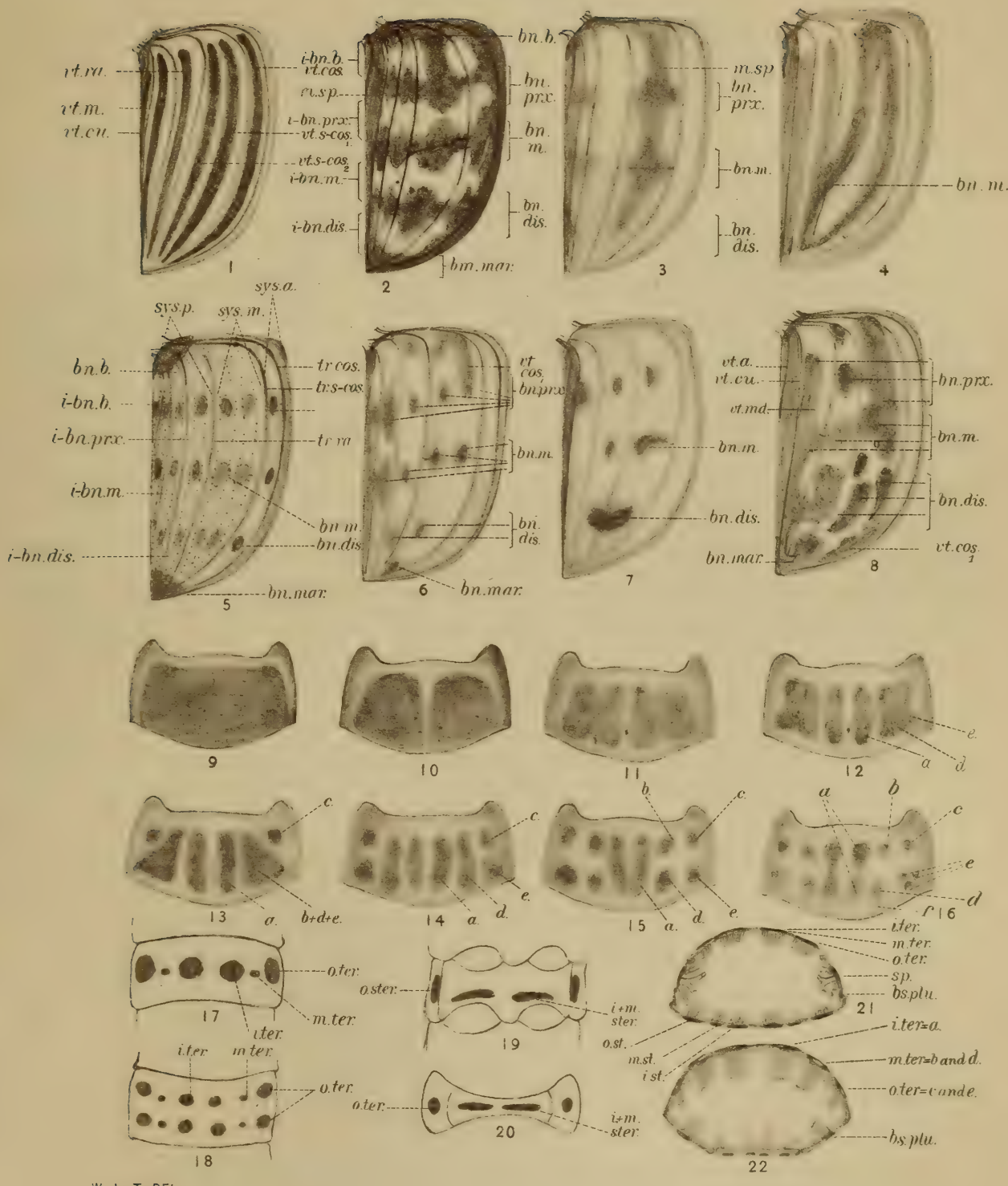

To illustrate the laws of coloration in the genus Leptinotarsa. 



\section{CHAPTER IV.}

\section{HABITS AND INSTINCTS IN LEPTINOTARSA.}

In the preceding chapters on geographical distribution, variation, and coloration in the genus Leptinotarsa morphological characters alone were considered, and the ways in which they show evidences of evolution. In this chapter we shall have to deal with characters and processes that are physiological, instinctive, and selective. These we shall discuss under three general heads: (I) Habits and instincts connected with reproduction; (2) habits and instincts connected with hibernation and rstivation; (3) habits and instincts connected with self-preservation.

\section{HABITS AND INSTINCTS CONNECTED WITH REPRODUCTION.}

A considerable portion of the habits and instincts found in the genus Leptinotarsa are centered about the reproduction of these beetles, and contribute directly or indirectly to the success or failure of this process. Some of these, such as the mating habits, are concerned directly in the reproduction of the species, while others, such as preferential or selective mating, while they are not so vital to the perpetuation of the species, are of paramount importance in the molding of the character of the subsequent generation. Of significance also is the adaptation exhibited by these beetles in the habits and instincts which center around the process of reproduction; and inasmuch as these habits and instincts have at various times shown their sensitiveness to the processes of evolution by being modified permanently in experiment in the same way as have morphological characters, an attempt will now be made to gain as clear an understanding as is possible of these habits and instincts as they occur naturally in the genus, and of their importance to the species displaying them; for by this means may be gained a basis in fact for the discussion of the modified conditions that have been produced in experiment. Finally, as much as possible must be learned concerning the adaptation of these characters to the needs and surroundings of the individual species.

MATING HABITS.

As far as I have been able to discover, the mating habits of these beetles are much the same in all the species in the genus, so that a description of them in two or three species will suffice for all. 
In all the species of this genus the beetles on emergence from hibernation or æstivation, or when freshly hatched from the pupa, are sexually immature and do not seem to possess any attraction for the opposite sex. In both temperate and tropical regions, when the different species of Leptinotarsa emerge in the springtime from the dormant condition in which they have passed the winter or the dry season, as the case may be, they are emaciated, weighing less than half as much as they did when they disappeared in the autumn before. Moreover, the germ cells are not developed, and the scent glands connected with the reproductive organs are inactive and devoid of secretions. At this time the sexes mingle as so many individuals, without the least trace of interest in each other. They fly or move about their food plants or in the observation cages in search of food and water, and when they find them they set upon them with a most ravenous appetite, so that large quantities are devoured in a short time. But after feeding for several days, or perhaps longer, the beetles have become well nourished, the germ-cells have matured, the reproductive organs are ready for use, and the characteristic habits of the mating period begin to appear. The changes which take place in this interval between emergence from hibernation or æstivation and the beginning of reproduction will be considered in the second division of this paper.

As soon as the beetles have attained sexual maturity they become exceedingly restless and active. They move about in search of the opposite sex, and if it is not to be found this restlessness results often, especially in the males, in movements so violent and prolonged that the animals become completely exhausted, and death not infrequently follows. If during the neutral period the sexes be separated and allowed to attain maturity in separate observation cages, they will, after the period of neutrality, show a great and increasing activity. This is manifested in both sexes by a cessation of feeding and an incessant, aimless wandering about at a rate of movement so excessive that complete exhaustion and death may follow in a day or two. When thus separated the females are less violent in their activities than are the males, and both sexes show large individual differences in their manifestations of uneasiness at the absence of the opposite sex.

The experiment was tried, with rather interesting results, of keeping the sexes separated entirely throughout the breeding period. When decemlineata was thus experimented upon some of both sexes died in a few days, but others, especially among the females, lived for two or even three months when kept in proper conditions of temperature and moisture and given food of good quality. All experiments of this kind are sumnarized in the following table, in which is shown the duration of life of the two sexes when separated and not allowed to breed. 
TABLE 102.-Duration of life when the two sexes are separated and not allowed to breed.

\begin{tabular}{|c|c|c|c|c|c|}
\hline $\begin{array}{l}\text { Duration } \\
\text { of life. }\end{array}$ & Males. & Females. & $\begin{array}{l}\text { Duration } \\
\text { of life. }\end{array}$ & Males. & Females. \\
\hline $\begin{array}{c}\text { Days. } \\
5\end{array}$ & $\begin{array}{l}\text { Perct. } \\
18\end{array}$ & $\begin{array}{c}\text { Perct. } \\
6\end{array}$ & $\begin{array}{c}\text { Days. } \\
55\end{array}$ & $\begin{array}{c}\text { Per ct. } \\
\text { I }\end{array}$ & $\begin{array}{c}\text { Per ct. } \\
\mathrm{I}\end{array}$ \\
\hline Io & 33 & 20 & 60 & I & $\ldots$ \\
\hline I5 & 36 & 24 & 65 & $\ldots$ & I \\
\hline 20 & 4 & I5 & 70 & $\ldots$ & $\ldots$ \\
\hline 25 & 2 & IO & 75 & $\ldots$ & I \\
\hline 30 & I & 5 & 80 & $\ldots$ & I \\
\hline 35 & I & 3 & 85 & $\ldots$ & 3 \\
\hline 40 & I & 5 & 90 & $\ldots$ & 2 \\
\hline 45 & I & I & 95 & $\ldots$ & I \\
\hline 50 & I & $\ldots$ & 100 & $\ldots$ & I \\
\hline
\end{tabular}

From this table it is evident that the lack of an opportunity for reproduction caused the untimely death of at least half of the beetles experimented upon, but that there was in the population a certain small proportion, especially of the females, that were able to survive for a long period of time. When the beetles are allowed to reproduce normally the death rate is as follows :

TABLE 103.-Duration of life when beetles are allowed to reproduce normally.

\begin{tabular}{|c|c|c|c|c|c|}
\hline $\begin{array}{l}\text { Duration } \\
\text { of life. }\end{array}$ & Males. & Females. & $\begin{array}{l}\text { Duration } \\
\text { of life. }\end{array}$ & Males. & Females. \\
\hline Days. & Perct. & Perct. & Days. & Per ct. & Per ct. \\
\hline $\begin{array}{r}5 \\
10\end{array}$ & $\begin{array}{l}2 \\
8\end{array}$ & $\begin{array}{l}1 \\
3\end{array}$ & $\begin{array}{l}45 \\
50\end{array}$ & I & 2 \\
\hline$x_{5}$ & 22 & 6 & 55 & $\ldots$ & I \\
\hline 20 & 35 & 28 & 60 & $\ldots$ & I \\
\hline 25 & $2 \mathrm{I}$ & 20 & 65 & $\ldots$ & I \\
\hline 30 & 6 & I 7 & 70 & .... & 3 \\
\hline 35 & 3 & I0 & 75 & $\ldots$. & I \\
\hline 40 & I & 4 & & & \\
\hline
\end{tabular}

A comparison of the two tables shows at once that the prevention of normal reproduction produces a decided increase in early mortality, but that in both of the series there are individuals, both male and female, that live to a much greater age than their fellows. This ability of some of the beetles to live for a considerable time has been put to good use in experiment in the preservation of variations which for one reason or another were not able to breed with their own generation, but could be kept alive until reproduction was effected with the generation following. It is quite possible that the same process might occur in nature, where in a restricted locality all the progeny of a given generation were, for some reason, of one sex, and were therefore unable to breed until beetles from another colony should reach the first one in the following generation. The normal length of time between generations in 
this genus is thirty-five days, and yet I have often bred these long-lived adults with the offspring of their own generation, and on several occasions with those of the following generation.

With other species of the genus, as, for example, multitaniata, oblongata, undecimlineata, dilecta, and signaticollis, the same results have been obtained, excepting that there is a variation in the length of time that each species will live.

It is apparent that there is a high degree of difference between the species of the genus in their ability to resist the abnormal condition of not being able to reproduce at the proper time, and that this resistance is greatest in those species which are from habitats where there is a great chance of unfavorable conditions, as, for example, from the plateau of Mexico, where local conditions may make necessary the prolongation of the reproduction period. In the species decemlineata, multiteniata, and oblongata this ability is developed to a marked degree, and these species live in habitats where the conditions of existence are much more variable than are those of the species dilecta, undecimlineata, or violescens, which do not show as much resistance along this line. This ability to hold in abeyance the reproductive capacity for longer or shorter periods of time is characteristic of the entire genus; it is quite possible that it is an adaptation which has been preserved by selection, but I do not believe it could have been caused thereby. Of course, if one is credulous enough to accept Weismann's doctrine of germinal selection he might consider that the whole phenomenon has been originated and controlled by selective processes. If it is an adaptation, it is one that is not yet fully formed, in that some of the individuals of the species do not show the slightest ability to resist the prevention of their reproductive activities. However, such a character does offer an opportunity to test the possibility of creating experimentally by selection an adaptation to changed conditions of existence; because if in experiment one could create a race in which all the individuals possessed this capacity, it could not be considered in any other light than as an adaptation developed in the species to enable it to meet unfavorable conditions in its environment at the time of its normal reproduction.

The importance of a habit like this to the species living upon the Mexican Plateau, for example, is very great. In the North Mesa it often happens that when a slight rain occurs in the spring these beetles emerge from æstivation, and then there is no more rain for weeks. Inasmuch as very circumscribed conditions are necessary for successful reproduction, it results that unless the species is able to meet these suddenly introduced unfavorable conditions it is exterminated. It is here that the habit which we have been discussing would be of value for the purpose of preventing a wholesale destruction of the species. Furthermore, only those individuals which possessed this trait would be able to survive and reproduce, and thus the character would be preserved 
by selection. However, before natural selection could act, this character must already have been in existence and developed to the extent that it had a selectional value to the species. How such a character could first arise and attain a development sufficient to give it selectional value is quite another problem. Here we simply admit the existence of the character and its usefulness in the economy of the species when it is developed to such an extent as to be of selectional value; its origin and its development up to this point will be considered later.

Under normal conditions of existence these beetles, after they have passed the period of feeding and maturing the reproductive products, begin a most ardent courtship, which in a relatively short time results in mating and fertilization. In general the males mature first, and begin actively at once to search for females that are in condition for reproductive purposes, or that are willing to receive them in coitus; for often the female receives the male before her eggs are ready for fertilization.

The courting habits of these beetles are of the simplest kind. The male normally approaches the female quickly, with his antennæ vibrating rapidly in a rotary manner in front of his head, and after a few passes of the antennæ over the body of the female he climbs quickly upon her back, and there attempts to secure a firm hold with his legs. If the female is not averse to mating she stands quietly, but if, because of immaturity or for some other reason, she does not care for the attention of this male or of any male at this time, she will run away or take flight at his approach. Even when the male succeeds in gaining a firm foothold upon the back of the female, he can not copulate unless she opens the plates which surround the genital passage. Often when a female is busy feeding a male will approach her quickly and gain a perch upon her back before she is able to escape, and then with extruded penis will attempt to force an entrance between the plates which guard the entrance to the vagina, but I have never seen one accomplish this. Usually after a few vigorous attempts to copulate the male retracts the penis and rides around on the back of the female, often for an hour or more, before he becomes weary of this occupation and seeks for a more responsive female.

When the female is in a receptive condition and the male has secured a firm footing upon her back, he settles backwards upon her body, the two plates which guard the entrance to the vagina are opened, and the penis of the male is allowed to enter. The beginning of copulation is accompanied in both animals by a few convulsive movements which consist of spasmodic expansions and contractions of the abdominal segments in both, and of the raising and lowering of the body of the male. These convulsive movements, however, last for only a short time, when both animals become quiet, and the female frequently resumes her feeding. At intervals of five, ten, or fifteen minutes thereafter, however, the male raises and lowers his body rapidly 
three or four times, and then becomes quiet again. Copulation lasts from two or three minutes up to ten or twelve hours, the first coitus, however, being usually far longer than those which occur subsequently. When the act is completed the two sexes separate, and within a short time each may be found in copulation with some other individual.

As far as I have been able to discover, there are no complicated habits associated with the mating of these beetles, it being effected with the least trouble or ceremony when they are ready for copulation. Rarely, in some species, as in decemlineata, oblongata, dilecta, and others, the two animals contemplating mating will first feel each other over with their antennæ, while others will walk around as if inspecting each other. In oblongata the male will sometimes open his elytra to expose the bright red color of his hind wings, but as he is quite as apt to do this when the female is not present it is probable that this action has no particular significance. After these more complicated courting movements copulation is no more apt to follow than it is if the male approaches the female and attempts to begin copulation without any previous ceremony. When compared with the accounts that have been published of the courting habits of various other insects those of Leptinotarsa seem simple indeed. I have often watched for these highly complicated and romantic courtships among insects, but I have not yet been able to see them; and I should be very much interested to know just how much of the ceremonies described was furnished by the insects and how much by the imagination.

The directness of the mating of the sexes in Leptinotarsa and its lack of ceremony leaves very little room for the play of sexual selection in these forms, for, although there is no dearth of bright colors, they do not seem to play any part in the bringing together of the sexes. Indeed, the only action that can be interpreted at all as in the nature of ceremony is the opening of the elytra of the male to display the bright color of the hind wings; but as this is done as frequently in the absence of the other sex as in its presence, and also by both sexes, no one but the extreme advocate of sexual selection could see in this act one of utility as an attraction to the opposite sex.

The attracting of the two sexes is largely accomplished by the odors secreted by the glands of the body, and especially by the glands of the genital organs. I have often tried the experiment with decemlineata, oblongata, dilecta, and undecimlineata of removing the antennæ and palpæ of the males and then turning them loose in an observation cage with a number of females in condition for copulation. As far as observed, the males were unable to distinguish the sex of their companions, and if they attempted copulation at all they were as apt to choose males as females. However, if by accident a male minus his olfactory organs came upon a female and succeeded in mounting her back, he was just as able to copulate as any other male, but he had to depend upon chance to bring him to the female. Under normal conditions a 
male frequently mounts the back of another male, but I have never seen one attempt to copulate. When mutilated, however, they try most vigorously and persistently for a long time to effect copulation with other males, thus showing their inability to recognize the difference between the sexes without the help of their olfactory organs.

Similar results were obtained by the experiment of painting the antennæ and palpæ with paraffin, balsam, shellac, and other substances which prevent the use of the olfactory organs, but do not give the shock occasioned by the removal of the antennæ and palpæ. Beetles thus painted were quite as unable to distinguish the sex of their companions as were those without these organs; but when this coating of paraffin was removed they could distinguish the other sex as readily as those beetles that had not been experimented with.

I also tried the experiment of painting the bodies of the animals black, red, white, green, and other colors, using largely individuals of the species decemlineata, multitcniata, dilecta, undecimlineata, violescens, and lacerata. As far as I have been able to observe, the giving to either male or female a color not natural to it had no influence whatsoever upon the mating in any species, neither when the color was applied to one sex alone nor when it was applied to both.

Experiments were tried in which the abdomen of the female was covered with shellac, paraffin, or other substances which would prevent the odor of the sexual glands from escaping; the result was that the males passed by the females so treated without recognizing them as females at all. Experiments with various mutilations were tried, but in all the same result was obtained, that if the olfactory organs and the scent glands remained intact the sexes unerringly recognized each other; but any interference with either of these organs at once prevented the recognition of the opposite sex. In these beetles, as in Lepidoptera (Mayer, I900), sex recognition is accomplished solely through the olfactory organs and scent glands, the colors playing no part whatsoever in the process. Whether these glands vary or not it has not been possible for me to demonstrate, although there is no reason why they should not show variation in the same manner as do other characters of the body. If there is a variation in the scent glands either in number, in the strength of their secretions, or in the ability of the male to perceive the odor, it is not great enough to produce any observable selection in the mating of those beetles which have come under my observation.

In all the species of the genus Leptinotarsa copulation occurs many times in the reproductive period, and with different individuals, so that often by the time the first eggs are laid the receptaculum seminis contains spermatozoa of several different males, and hence the offspring of one female may have several different males for the other parent. This results in a great commingling of the species in reproduction, and a consequent tendency to keep 
the species in a mediocre condition by decreasing greatly the probability of extreme individuals arising in any great numbers through their exclusive breeding.

Although copulation is accomplished with ease and without ceremony in these beetles, it is not effected unless the conditions of existence are proper for the act, or nearly so. The reason for its failure is largely, if not entirely, the non-development of the germ-cell, any change in the normal rhythm of reproduction being usually associated with changes in the environment, such as excessive heat, cold, or moisture.

The laying of the eggs does not present any features of special interest, excepting that if the conditions of existence are too extreme the eggs, although they may be fully formed and fertilized, are not laid, but are retained in the passages of the female reproductive organs until they are resorbed, or, as more frequently happens, until the female dies. This failure to deposit the eggs seems to be caused solely either by the drying of the secretions or by the inability of the female to produce them in the accessory glands.

In the normal laying of the eggs in decemlineata the female selects a proper spot, and, raising her body high upon the legs, protrudes the posterior segments, opens slightly the genital plates, and, touching the tip of the abdomen to the leaf, allows a drop of a yellow oily fluid to escape; then as the abdomen is slightly raised the egg protrudes and is fixed by its posterior pole in the drop of fluid already deposited. The fluid now hardens rapidly and cements the egg in place. One egg having been deposited, the female moves along a slight distance, and there places another by the side of the first, and so on until there is a row of from five to ten eggs in a nearly straight line on the leaf. A second, third, fourth, and often as many as ten rows are thus laid, each of which is more or less closely placed to the previously laid rows, and forms therewith a compact bunch. I have observed the egg-laying in some 20 species of this genus, and in all the procedure is the same. All the eggs that are ripe at a given time may be deposited in one spot, or the beetle may lay a few and then move on to another place to deposit a few more, and thus the 30 to 75 eggs which mature at one time in these beetles may be laid on a half dozen different plants.

In all of these beetles the eggs are developed in batches, each of which is laid before another is developed. The average number of eggs laid by the females in this genus is 375 , although there is considerable variation both in the number of eggs laid by the different species and in the number of batches.

The data on hand along this line are brought together in table I04, on the following page. 
TABLE I04.-Number of eggs and number of batches of eggs laid by different species of the genus Leptinotarsa.

\begin{tabular}{|c|c|c|c|c|c|c|c|}
\hline \multirow[b]{2}{*}{ Species. } & \multirow{2}{*}{$\begin{array}{l}\text { Average } \\
\text { number of } \\
\text { eggs. }\end{array}$} & \multirow{2}{*}{$\begin{array}{c}\text { Average } \\
\text { number of } \\
\text { batches. }\end{array}$} & \multirow{2}{*}{$\begin{array}{c}\text { Average } \\
\text { length of } \\
\text { egg-laying } \\
\text { period } \\
\text { in days. }\end{array}$} & \multicolumn{4}{|c|}{ Variation in egg-laying. } \\
\hline & & & & $\begin{array}{c}\text { Maximum } \\
\text { number of } \\
\text { eggs. }\end{array}$ & $\begin{array}{c}\text { Minimum } \\
\text { number of } \\
\text { eggs. }\end{array}$ & $\left|\begin{array}{c}\text { Maximum } \\
\text { number of } \\
\text { batches. }\end{array}\right|$ & $\begin{array}{l}\text { Minimum } \\
\text { number of } \\
\text { batches. }\end{array}$ \\
\hline L.decemlineata. . & 450 & 12 & 30 & 600 & I90 & I8 & 4 \\
\hline multitæniata.. & 425 & Io & 30 & 783 & $2 \mathrm{II}$ & 22 & 3 \\
\hline oblongata... & 300 & 10 & 25 & 448 & II 4 & I4 & 7 \\
\hline rubicunda. & 300 & IO & 30 & 372 & 185 & 14 & 6 \\
\hline undecimlineata & 400 & 12 & 25 & $62 \mathrm{I}$ & I54 & 20 & 4 \\
\hline signaticollis . & 425 & 6 & 35 & 643 & 396 & I 2 & 5 \\
\hline dilecta. : & 200 & 12 & I5 & 310 & 107 & I5 & IO \\
\hline dahlbomi. . & I75 & I4 & 20 & 242 & $3 \mathrm{I}$ & 20 & Io \\
\hline violescens & I75 & 8 & I4 & 210 & Io & Io & 6 \\
\hline lacerata. & 250 & 7 & 20 & 290 & 200 & I2 & 6 \\
\hline modesta & 270 & 7 & 20 & $38 \mathrm{I}$ & 200 & I4 & 5 \\
\hline zetterstedti & 200 & 9 & 20 & 242 & I76 & 13 & 6 \\
\hline rubiginosa. & 200 & II & 20 & 260 & I40 & 17 & 7 \\
\hline haldemani. . & I75 & 6 & 23 & 234 & 152 & 4 & 8 \\
\hline lineolata... & 200 & 7 & 22 & 300 & 109 & 5 & 8 \\
\hline
\end{tabular}

Concerning the breeding habits of these beetles three facts have been learned which are of importance in succeeding studies. First, the habits of these beetles in normal reproduction are promiscuous; hencethe offspring from any one female may have several different male parents, and from material taken in nature in copulation or otherwise we can not be sure of results in breeding experiments until we have reared such material in experiment for at least one or two generations, and are certain of the purity of the race under experimentation; second, the eggs are laid and developed in batches, which in the genital passages of the female do not mingle with successive batchesthat is, each is distinct from that which precedes and from that which follows-a fact that has been made great use of in the experiments in the production of modifications; third, the conditions of existence may prevent the deposition of the eggs either through the inhibition of copulation or of the development of the ova, or through the mechanical prevention of egg-laying by the inability of the female to secrete in the accessory glands the fluid which enables the eggs to pass easily through the lower part of the genital passages, and which serves also to cement the eggs to the leaves. These three facts are of paramount importance in the carrying on of continued and successful experiments in pedigree breeding and in the experimental production of new races and modifications.

It has been clearly shown that there is not the slightest trace in the breeding of these beetles of any selective influence due to color or form, that elaborate mating habits are wanting, and that the sole means of sexual recognition is through the olfactory sense and the odoriferous secretions of the accessory 
glands of the reproductive organs, which are active on the maturing of the genital products. It appears, further, that as far as can be determined there is no selective influence exerted upon mating by the variations which probably exist in the strength of the glandular secretions and in the ability of the different males to detect the scent. If such selective influence be present, it is so slight that it is not to be detected by any method known to me.

\section{ASSORTIVE MATING.}

Assortive mating, which implies the tendency of certain conditions to be brought together in reproduction with greater frequency than other conditions, is believed by some of the modern selectionists to be a constant and a rather important factor in the mating of animals. This idea is a further and perhaps more logical extension of the sexual-selection principle which has been used to account for many ornaments found in animals. In the genus Leptinotarsa assortive mating is found in the habit that extreme individuals have of showing a strong tendency in mating to select partners of a more mediocre condition than themselves, whereas the more ordinary individuals usually select partners that are their exact counterparts; and this is true of each pairing, whether it be a first or a subsequent one. There seems to be inherent in the species of this genus the habit of rejecting in reproduction those individuals which possess extreme or unusual characters. I have investigated this phenomenon in decemlineata, oblongata, undecimineata, and dilecta, all of which species have furnished evidence of the existence of this selective influence.

The most satisfactory material in the genus for the investigation of this problem is the species oblongata, in which the assortive mating as regards size, general albinic or melanic tendencies, and the dimorphic red and yellow conditions in both sexes affords an excellent opportunity to test the action and existence of this phenomenon.

In respect to size there is a most distinct assortive mating in this beetle, a fact that has been determined both statistically and by a close study of the beetles in nature. In these observations it was apparent that the extreme individuals were not, as a rule, able to obtain partners in the reproductive act. Thus the largest and smallest of the individuals of both sexes were far more apt to be found unmated in nature than were the more mediocre individuals. This is much more clearly shown in the tables of the seriations of these beetles in respect to size. In these seriations the classification has been made upon the basis of ten classes, in which I represents the smallest condition known and Io the largest. The unit used in the measurement of these beetles was the perpendicular distance between parallel lines passing through the apex of the elytron and the median posterior side of the pronotum when the beetle was at rest. The entire length can not be used because of the great variation 
in the position of the head and pronotum, which would increase or decrease the body length in individual cases without having any significance, and would, therefore, introduce a large error into the result. The unit chosen is not subject to any such error, and is a reliable index of size.

TABLE 105.-Assortive mating found in L. oblongata, size being taken as the selective character.

\begin{tabular}{|c|c|c|c|c|c|c|c|c|c|c|}
\hline \multirow{2}{*}{ Sex. } & \multicolumn{10}{|c|}{ Normal range of variation-Class. } \\
\hline & I & 2 & 3 & 4 & 5 & 6 & 7 & 8 & 9 & ro \\
\hline $\begin{array}{l}\text { Males ............ } \\
\text { Females........ }\end{array}$ & $\begin{array}{c}\text { Per ct. } \\
0.5 \\
2\end{array}$ & $\begin{array}{c}\text { Per ct. } \\
\text { I } \\
3\end{array}$ & $\begin{array}{c}\text { Per ct. } \\
3 \\
4\end{array}$ & $\begin{array}{c}\text { Per ct. } \\
6 \\
4\end{array}$ & $\begin{array}{c}\text { Per ct. } \\
15 \\
5\end{array}$ & $\begin{array}{c}\text { Per ct. } \\
40 \\
\text { I } 2\end{array}$ & $\begin{array}{c}\text { Per ct. } \\
\text { I7 } \\
38\end{array}$ & $\begin{array}{c}\text { Per ct. } \\
\text { I0 } \\
\text { I9 }\end{array}$ & $\begin{array}{c}\text { Per ct. } \\
6 \\
\text { 10 }\end{array}$ & $\begin{array}{c}\text { Per ct } \\
\text { I. } 5 \\
3\end{array}$ \\
\hline
\end{tabular}

Per cent of males of each class which mated with individuals in the various classes into which the females were grouped as regards size.

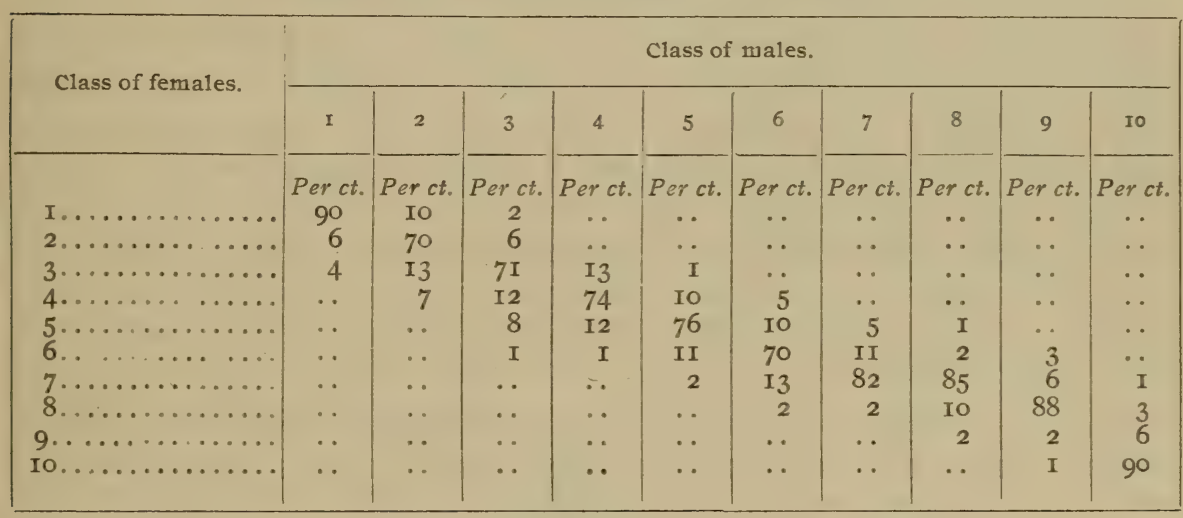

In the above table there is shown to be a striking correlation between the size of the sexes in each pair, matings between males and females of very unlike size not occurring at all in the series. Moreover, the number of unmated individuals in any population is far greater among the extremes than among the more mediocre individuals of the population.

It is highly significant that extremely large or small beetles are unable to find partners among the more moderate individuals, and are thus effectually prevented from becoming parents to the following generation, and thereby perpetuating their more or less extreme conditions, should they happen to possess heritable qualities. This inability of extreme individuals to find partners does not seem to be due to any aversion to them exhibited by the more mediocre part of the population; it may rather be attributed entirely to the fact that the exremely large or small beetles are not able to effect copulation with the others. In mating not the slighest appearance is found of a desire 
to avoid the extremes, a large male being on the average just as apt to attempt to mate with a small female as with one more nearly his own size, allowing, of course, for the greater opportunity for finding a female more nearly suited to his size among the females of the general mediocre population. At any rate, the attempt of a large male to mate with a small female invariably results in failure, owing to his inability to force an entrance into the small genital passage of the female. On the other hand, large females and small males do not seem to be able to mate with any degree of success on account of the lack of adaptation in the size of the reproductive organs.

I have attempted to obtain statistical data upon this point, but the difficulty of dissecting out the organs and the distortion that inevitably results are so great that the error introduced is probably greater than the range of variation. At any rate, it is evident from the table that the extremes only very rarely mate, and that when they do it is most frequently with mediocre individuals, as might be expected. Therefore, there is to a large extent in the mating of these beetles an elimination of all but the mediocre individuals from the parenthood of the following generation. Hence it follows that no matter whether the characters of the extreme individuals be heritable or not, there is little or no chance for transmission of them to the following generation, and thus an effective although unconscious selective mating as regards size is brought about in this species. The selective factor is, as has been shown by Crampton in Lepidoptera, a lack of adaptation in the size of the reproductive organs of the sexes; the end result is the preservation in the population of an extremely mediocre condition as regards size, with a very few only in the more extreme classes.

Assortive mating between beetles of the same general color value-that is, between beetles which belong in the same class of color value as regards albinism or melanism-has also been studied in oblongata, but with quite different results. As regards color alone there does not seem to be the slightest trace of any selective influence in the mating of these beetles. Among 500 copulating pairs examined, it was found that a highly albinic male was on the average just as apt to mate with a melanic female as with one nearer its own color. Of course, if the albinism or melanism was associated with abnormalities in size, there was a rejection of the individual, but upon the basis of size and not upon that of color. From the general habits of this beetle in mating and its entire lack of appreciation of color, we should not expect to find any assortive mating upon this basis. Nor has there been discovered the least trace of any selective mating or segregation on this basis in the dimorphic males and females of this species; that is, males and females of like color have not been found in copulation with any greater frequency than have those of different colors. The data from 500 copulating pairs, taken from three different generations, have not shown the slightest trace of preferential mating in regard to these characters. 
I have examined this phenomenon in decemlineata, undecimlineata, and dilecta, and have obtained results exactly like those just described for $o b$ longata. Among 300 copulating pairs of decemlineata from Cold Spring Harbor, Long Island, New York, Ioo pairs each from Woods Holl, Massachusetts, and Newport, Rhode Island, 200 from Yellow Springs, Ohio, and 300 from Chicago, Illinois, or I,000 pairs in all, I found that extreme individuals were to a large extent absent, and I conclude that it was because of their being unable to copulate properly with the opposite sex. However, when color was taken as a basis of selection, there was not the slightest trace of preferential mating.

It appears, therefore, that selective mating exists in these beetles, but that it is not found in any character excepting size, and that even here it is due solely to the inability of abmodal individuals to properly perform the sexual act. We do not ordinarily realize how narrow are the limits within which successful copulation can take place in insects, or how slight a variation is sufficient to prevent the performance of the sexual act with such completeness as to insure the leaving of progeny. The work of Crampton has shown this most clearly in Lepidoptera, where, fortunately, the genital organs can be measured without the introduction of an enormous error. Although in Leptinotarsa successful measurement is impracticable, it is certain that a like slight variation in the size of the genitalia or in their position is enough to eliminate the possessor thereof from participation in the perpetuation of the species. Hence there results a most effective selective mating in which only the modal individuals, or those in near-by classes, are able to leave any large number of progeny, and whether the variations are heritable or not, the extreme variations have little or no chance to be transmitted to succeeding generations. It is noticeable in all of the seriations which have been made of different characters in this genus that there is a constant high percentage of the individuals in or near the modal class, nearly 75 per cent in the polygon of variation being usually found in the modal class or in the classes immediately above and below it; and this is due largely, if not entirely, to the selective mating which eliminates in reproduction the perpetuation of the more extreme conditions.

In the preferential or assortive mating in these beetles we must therefore recognize a selective process which acts to keep the species as close as possible to the mode or standard by the elimination of extremes. Hence it is a conservative factor, and not one that would tend toward the production of modifications. If, however, from any cause whatsoever there should occur a rapid or slow shifting of the mode of the species, preferential mating would still keep it closely aggregated about the new mode, and thus bring about a modification in the entire polygon of distribution. In this way selective mating has undoubtedly been and is now a valuable aid in the formation of races and spe- 
cies. It is just the kind of a process which would be best adapted for the splitting up of a polymorphic species through the limitation of reproduction to the more mediocre of the individuals in each group, and the tendency to eliminate intermediates, and also perhaps to prevent the crossing of closely related forms. Assortive mating is no doubt equivalent to some one of Gulick's (I905) divisions of segregation, but I can not see the need of the extremely finely divided divisions of segregation, and prefer to use for the present the simplest terminology. Although assortive mating (or segregation or isolation in reproduction) is undoubtedly a valuable aid in the formation of species, it must nevertheless find characters already developed to the extent of having a selective value before it can begin to exert any influence. It can not bring into existence anything; it can only preserve that which is already in existence. Moreover, in the genus Leptinotarsa at least, a great. many characters, as, for example, color and ornamentation, are not influenced at all by this form of selection, so that if, perchance, these non-selective characters should exist in combination with characters which have a selective value, they would be carried along with the selective characters in the segregations which assortive mating brings about. In this way non-utilitarian characters might be preserved by selection through being associated with others which are perhaps less conspicuous, but which have selective value. However, in order to explain all nature and evolution through selection, one must not assert that all apparently non-selective characters are correlated with selective characters which have not as yet been discovered, and perhaps never can be. Assortive mating has been invaluable in the production of new characters in experiment and in the perpetuation of the new races which have arisen in my experiments, and I can see no valid reason why it should not be an equally important factor in nature, although this is not as capable of demonstration or of experimental proof. It is possible, however, as I shall show later, that there is the best of circumstantial evidence that this selective process has been a powerful factor in the evolution of this genus of beetles; and if it is a potent factor here, why should it not also be one in other cases? Although in these beetles, as far as we can determine, color and ornamentation seem to play no part in selective mating, there is no reason apparent why these factors may not be of selective value in other animals. It is well to remember that we are viewing these beetles as outsiders, and are not, therefore, able to appreciate the minute individual differences which they exhibit and which may play important rôles in the mating of the species. It is quite possible that there are in animals characters of a selective value which we are unable to recognize, but which the animals themselves appreciate. Even in our own species, the individuals when in a crowd appear so much alike that we are unable to recognize persons whom we know from strangers. In foreign races of our own species we recognize individual differences and 
attractive qualities with difficulty, or not at all; and the same difficulty must be experienced in our observation and appreciation of individual differences and attractive qualities in animals, but to an immensely greater extent. This limitation of our appreciation of the qualities of animals should not be used as a screen behind which to take refuge with some cherished hypothesis, there to maintain its universal validity; for although these processes and conditions may exist, their existence is not open to proof or disproof.

\section{NUMBER OF GENERATIONS.}

The number of generations in Leptinotarsa each year, in both temperate and tropical latitudes, is a remarkably constant character, and might well be used as a generic differential. As far as I know, the number in all of the species is limited to two. Thus, there are two generations throughout the range of decemlineata, although Lugger has recorded three in Minnesota, and others have supposed that there may be three in the southern United States. I have not, however, been able to get decemlineata to breed more than twice in a season without a period of hibernation or æstivation. In the spring decemlineata emerges from the ground, and after a period of feeding, during which the germ-cells are also maturing, it breeds and lays the eggs for the first generation. These are usually all deposited at about the same time, but there are always for a month or more some individuals that are laying eggs, and of course the larvæ and imagines resulting from these eggs which are last laid are much later in maturing than are the majority of the population. The first brood, on emergence, feeds for a few days, and then deposits the eggs for the second generation. The majority of these eggs hatch late in the summer, and after the animals feed and fly around for a month or more they burrow into the ground, and there hibernate until the following spring. The second generation does not develop the germ-cells nor show any reproductive activity until after it has passed through a period of hibernation or æstivation. Beetles are found breeding even late in the autumn, but these are the belated individuals of either the first or second generation. As far as I can discover, the life cycle in this species is that given above. In the tropics, where one might think that the constant high temperature would keep the beetles breeding all the year through, there are likewise only two generations a year in all the species that I have studied, it being necessary in all of them that the second generation have a period of rest before resuming its reproductive activity. Normally this rest is passed in the ground in æstivation, but by stimulation the beetles may be kept active, although they will not breed until a period of at least two or three months has elapsed. The species in the genus are therefore double-brooded, the second brood undergoing hibernation or æstivation before reproductive activity is resumed. Owing to the long time in each generation during which the beetles may breed, there are found in nature at the 
same time throughout the whole season eggs, larvæ, and adults, so that it seems on first sight that there are a large number of generations in every year in the tropics. In all the species of the genus the only difference between the two generations is that the second does not develop the germ-cells until after a period of rest, while the other develops them at once, or soon after emergence.

The length of the season during which any given species is active varies greatly in the different species, and also in the different parts of the continent of North America, the season being longest in the moist regions of Vera Cruz, Chiapas, and southward, and shortest in the arid semidesert and desert regions of northern Mexico and the southwestern United States. The lengthening of the period of reproduction is the cause of the long time during which these beetles are found active in the more humid districts, and, vice versa, the reduction of the length of the reproductive period is responsible for the lessened period of activity in the more dry regions. Nowhere, however, is the duration of the embryonic period, of the larval life, or of the pupal stage subject to any great amount of variation. The time of the appearance of the different generations, their duration, and various other data have been condensed into the following table:

TABLE 106.-Compilation of data concerning generations in the genus Leptinotarsa.

\begin{tabular}{|c|c|c|c|c|c|c|c|c|}
\hline Species. & $\begin{array}{l}\text { No. of } \\
\text { gener- } \\
\text { ations. }\end{array}$ & $\begin{array}{l}\text { Date of } \\
\text { emer- } \\
\text { gence. }\end{array}$ & $\begin{array}{r}\text { Date of } \\
\text { breedin }\end{array}$ & & $\begin{array}{l}\text { First gen- } \\
\text { eration. }\end{array}$ & $\begin{array}{l}\text { Second } \\
\text { gener- } \\
\text { ation. }\end{array}$ & $\begin{array}{l}\text { Average } \\
\text { length of } \\
\text { repro-- } \\
\text { ductive } \\
\text { period. }\end{array}$ & $\begin{array}{l}\text { Length of } \\
\text { season. }\end{array}$ \\
\hline 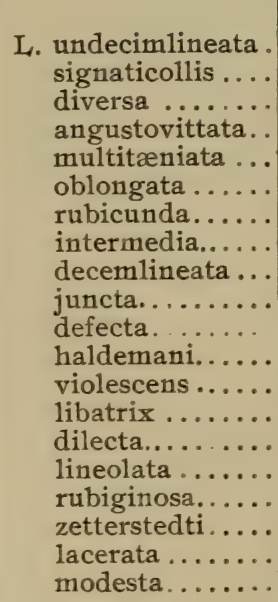 & $\begin{array}{l}2 \\
2 \\
2 \\
2 \\
2 \\
2 \\
2 \\
2 \\
2 \\
2(?) \\
2 \\
2 \\
2 \\
2 \\
2 \\
2 \\
2 \\
2 \\
2 \\
2\end{array}$ & $\begin{array}{l}\text { May I5 } \\
\text { May I } \\
\text { May 20 } \\
\text { May I5 } \\
\text { June } 7 \\
\text { June I } \\
\text { June I } \\
\text { June Io } \\
\text { May I5 } \\
\text { May I5 } \\
\text { May I5 } \\
\text { June I } \\
\text { June I } \\
\text { May Io } \\
\text { May 30 } \\
\text { May 30 } \\
\text { June I } \\
\text { June I } \\
\text { May 25 } \\
\text { May 30 }\end{array}$ & $\begin{array}{l}\text { June } \\
\text { June I- } \\
\text { June } \\
\text { June I- } \\
\text { June } \\
\text { June } \\
\text { June } \\
\text { June } \\
\text { June } \\
\text { June } \\
\text { May } \\
\text { June } \\
\text { June } \\
\text { June } \\
\text { June } \\
\text { June } \\
\text { June } \\
\text { June } \\
\text { June } \\
\text { June }\end{array}$ & 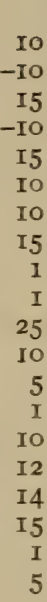 & 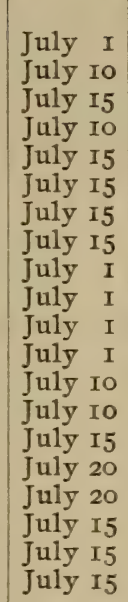 & $\begin{array}{l}\text { Sept. I5 } \\
\text { Sept. I I } \\
\text { Sept. I I } \\
\text { Sept.r I } \\
\text { Sept. } 5 \\
\text { Aug. 25 } \\
\text { Aug. 25 } \\
\text { Sept. Io } \\
\text { Sept. I } \\
\text { Aug. 20 } \\
\text { Aug. 20 } \\
\text { Aug. I5 } \\
\text { Aug. 25 } \\
\text { Sept. I } \\
\text { Sept. I5 } \\
\text { Sept. I } \\
\text { Sept. I } \\
\text { Sept. Io } \\
\text { Sept. I5 } \\
\text { Sept. I }\end{array}$ & $\begin{array}{c}\text { Days. } \\
20 \\
30 \\
18 \\
21 \\
35 \\
20 \\
14 \\
30 \\
35 \\
20 \\
20 \\
20 \\
23 \\
25 \\
15 \\
22 \\
25 \\
20 \\
14 \\
19\end{array}$ & $\begin{array}{r}\text { Days. } \\
240 \\
150 \\
150 \\
200 \\
150 \\
150 \\
120 \\
100 \\
125 \\
150 \\
130 \\
120 \\
120 \\
120 \\
100 \\
100 \\
120 \\
150 \\
150 \\
150\end{array}$ \\
\hline
\end{tabular}




\section{HABITS AND INSTINCTS CONNECTED WITH HIBERNATION AND AESTIVATION.}

As has been shown in the preceding section, all Leptinotarsas either hibernate or æstivate in each alternating generation. This phenomenon is one of importance in the life cycle of each species, as it occurs in that portion of the year when conditions of existence are least favorable. As far as is known, all of the species in the genus are in this dormant state for at least three months of the year, and the larger portion of them for five or more months. Hibernation and rstivation are fundamentally one and the same process, the term hibernation being applied to the dormant period produced by lowered temperatures, and æstivation to that which follows the coming on of the dry season in the warmer parts of the earth. There is, I believe, no reason for the existence of two terms to describe this phenomenon, as both apply to the same physiological process, the only difference being that found in the factors which initiate them. In this paper I shall use them as the synonymous terms, which they really are, and we shall see later that in these beetles the two processes are the same.

Throughout the whole of the United States, after the second brood of decemlineata has emerged in late September or early October, it devours a large amount of food in the first few days of its adult life, and stores up in the fat body a reserve supply to be used in the ensuing period of hibernation and in starting the germ cell onward in development in the spring. This storing up of food accomplished, the beetles stop feeding, and the preparations for hibernation are begun. This is initiated by the emptying of the alimentary canal of all food and the elimination by the malpighian tubules of the excessive quantity of waste products. These are often red, as they are at pupation. This clearing out of the alimentary canal and the elimination from the body of as much of the waste of metabolism as is possible requires from three to as many as ten days for its accomplishment, it being effected rapidly in warm, clear weather, and retarded in cold or cloudy weather. The beetles now no longer pass the nights upon the plants, but late in the afternoon, as the sun's rays become more and more slanting, they are found burrowing into the ground, often to a depth of 3 or 4 inches, where they remain until the next morning, crawling out again when the sun's rays have warmed the earth; and if the day be cool the beetles do not come out in any numbers, and may even remain in the ground for several days if the temperature is constantly rather low.

After the contents of the alimentary canal have been emptied out and the excretion of the excessive amount of waste products from the malpighian tubules has commenced, the body weight begins to fall rapidly and continues to do so until on the average there has been a loss of about 30 per cent of the gross weight of the beetle by the beginning of preparation for hibernation. This reduction in weight is occasioned by the emptying of the contents of the 
alimentary canal, which, on the average, makes 3 per cent, and by the removal of the watery material from the excretory organs and the evaporation from the body surface, which make the remaining 27 per cent. The average dry weight of the beetles does not decrease at all, however, but is rather increased by the excessive feeding that has gone before; hence in its net dry weight the beetle is heavier when it goes into hibernation than it was when it emerged from the pupa, although its gross weight is somewhat less.

It is evident that preparation for hibernation consists largely in a reduction of the watery contents of the body and in an elimination of all food and other substances from the alimentary canal. In other words, preparation for hibernation consists in a physiological change in the constitution of the body for the time being and a consequent lowering of the freezing-point of its tissues in exactly the same way that the spores of many plants and the overwintering eggs of Rotifers prepare for the coming on of unfavorable conditions in their environment. Through the loss of water the protoplasm becomes denser, and takes on characters that are at once recognized in cytological preparations. The cells of the body also become shrunken and flattened, the nuclei take on a most extreme vegetative appearance, and in some cases it has not been possible to demonstrate the existence of chromatin in cells where six or eight months later abundant and active chromatic conditions will be found. In all of the cells the protoplasm takes on a peculiar colloidal or else a fine granular appearance and retains it throughout the whole period of hibernation. In the hypodermal cell the lipochrome colors fade and the beetles become light straw yellow, or often white.

All parts of the body participate in the preparation for hibernation, in which the essential process is the elimination of water until the maximum and minimum at which the protoplasm of the animal can still survive is increased in both directions to such an extent that lowered or increased temperature will not be likely to produce fatal results. After the beetles have made preparations for hibernation they do not long delay the final burrowing into the ground and the beginning of the long period of dormancy. L. decemlineata hibernates at an average depth of from 18 inches to 2 feet, and I believe that if the winter is very cold it may in some cases work down even farther.

In decemlineata I have not by any process been able to prevent this preparation for hibernation in beetles which should normally hibernate. By high temperatures and moisture it is possible to greatly inhibit the process, often to the extent that it is not completed, and as a result many of the beetles die. Even if they do not burrow into the ground, the hibernation preparation is completed at the proper time in the life cycle of the species, and, although the beetles are active and out of the ground, they do not feed for weeks at a time, but rest upon the sides of the observation cages or on the food plants. In this way they may pass three or four months, when they again begin to feed, and in a few days are ready for reproduction. 
Upon emergence from hibernation changes are found which are the reverse of those which take place in the preparation for hibernation. Immediately upon emergence a beetle voids the waste products that have accumulated in the malpighian tubules, and, if food is at hand, begins to devour it most ravenously, so that it increases in weight with marvelous rapidity, until in three or four days from the time of emergence it weighs more than it did at the beginning of the preparation for hibernation. The beetles on emergence from hibernation weigh less in both net dry and gross weight than they did at the beginning of hibernation, which shows that there has been a low grade of metabolism going on throughout the period of hibernation.

We see that there is a rapid gain in the water content of the body as well as a net gain in the solid. In this period important cytological and histological changes are also going on in the soma cells of the body. The protoplasm becomes more watery and vacuoles appear, while cells become larger and more turgid and the chromatic elements in the nuclei increase greatly in size and stain deeply, thus presenting all the signs of intense activity. In general the body on emergence passes through the same changes as those which are connected with the preparation for hibernation, but in the reverse order.

This process is a deep-seated one in decemlineata, and one that can not by any known method be postponed or prevented. The process can be modified in various ways, but it can not be eliminated from the life cycle of the species, and, although through excessive and highly abnormal stimuli I have succeeded in causing a semi-active hibernation, I have not been able by selection and continued stimulation to modify this habit in the slightest.

Hibernation has, in decemlineata at least, a decided selective influence which acts to produce much the same result as does assortive mating. That is, a very small number, if any, of the more extreme individuals of a population are able to survive the hibernation period, and the most extreme of the variations found in any generation in the autumn are almost certain not to emerge in the following spring. In nature the second generation frequently contains a considerable percentage of rather extreme individuals, so that the polygon of variation is strongly skewed in one or the other direction; but in the spring the beetles which emerge from hibernation are not as strongly skewed, if at all, which shows the leveling action of hibernation through the elimination of extremes in variation. Just why these extreme variations should not be able to survive the hibernation period is at present unexplained. The selective influence of hibernation is well shown in the table on page 248 .

The selection produced through the elimination of the extremes during hibernation is entirely in the direction of conservatism, tending to preserve those individuals only which conform most exactly to the modal standard of the species at a particular time and place. Hence, in the preservation of this species and in the evolution of species in general, this selective influence would act in precisely the same manner as does assortive mating. Likewise a large 
number of the attributes of an animal, as, for example, all the color characters, would fail to come directly under the influence of this kind of selection because of their non-selective value, and their elimination or preservation would therefore depend upon whether or not they were associated with some character which did have a selective value to the species.

TABLE 107.-Selective action exerted upon L. decemlineata by the hibernation period.

[Hibernation in the winter of 1903 to I904 at Chicago, Illinois. The table is based upon the species as a whole, and has been obtained by seriating the individuals into classes according to their likeness to each other.]

\begin{tabular}{|c|c|c|c|c|c|c|c|c|c|c|c|c|}
\hline \multirow{2}{*}{ Period. } & \multicolumn{12}{|c|}{ Class. } \\
\hline & 2 & 3 & 4 & 5 & 6 & 7 & 8 & 9 & I0 & II & 12 & 13 \\
\hline $\begin{array}{l}\text { Before hibernation. } \\
\text { After hibernation }\end{array}$ & 0.5 & I & I. 5 & 2 & 3 & 4 & I9 & $\begin{array}{l}42 \\
54\end{array}$ & $2 I$ & 3 & 2 & I \\
\hline Aler moernation... & $\cdots$ & $\cdots$ & $\cdots$ & .. & $\cdots$ & 1 & 25 & & 19 & 1 & $\cdots$ & $\cdots$ \\
\hline
\end{tabular}

The species of this genus that live in the tropical or semi-tropical regions also pass a portion of each year in a dormant state, which has been termed rstivation. The cause of this hibernation in tropical species is the coming on of the dry season, which produces the same physiological results as does cold in the northern latitudes. I have studied the conditions of æstivation in a number of species in this genus, two of which will serve to illustrate the phenomenon as it is found in the tropical members of the genus. The conditions found in undecimlineata are representative of species which live in the more moist regions, and those of multitcmiata of species which live on the high and dry plateau, where the moisture conditions tend strongly toward aridity. The proper apparatus has not been available for the accurate weighing of these two species in nature, but this in no way vitiates the general results that have been derived from the study of æstivation in these beetles.

Leptinotarsa undecimlineata, like decemlineata and all the other species in the genus, hibernates in the second generation of each year, no matter whether the proper time is reached in the rainy season, at its close, or thereafter. When the beetles are ready to hibernate they will do so, in spite of the conditions immediately surrounding them. The second brood in this species is found in general in the months of September and October, hibernation beginning in October or November with the cessation of the rains. After emerging from the pupa the second generation of this beetle feeds often for as long a time as three weeks or a month, but not as ravenously as does decemlineata in the north. During this time the weight, both gross and dry, increases steadily until the animal gradually ceases feeding. The intestine is then emptied of all food and the malpighian tubules secrete an excessive amount of waste, which is often tinged reddish in color. Then there is the reduction in 
the gross weight due to the loss of water. There is, however, no loss in the dry weight during this preparation for æstivation. Yet even when fully prepared for the advent of the dry season, the beetle does not at once enter upon the dormant state, but may live in a rather inactive condition upon its food plant for days or even weeks before it burrows into the ground to pass the dry season. When, however, the dry winds come at the cessation of the rains, the beetles usually seek retirement in the ground, but they do not now burrow down more than 6 or 8 inches, and often may be found within only an inch or so of the surface. They remain in restivation until the rains come at the beginning of the following season, when they are awakened to renewed activity and another series of generations. On emergence from æstivation they go through the changes found in the preparation therefor, but in reverse order.

The preparation for æstivation in undecimlineata results in a reduction of the water content of the body, and hence in an increase in its capacity to meet the high temperatures which often occur, especially at the end of the dry season, when the lack of moisture and the intense sunshine in a cloudless sky heat the soil up to a high degree. Soil temperatures taken on the savannas of Vera Cruz in April, I904, in places where these beetles were æstivating, were frequently as high as $60^{\circ}$ and $65^{\circ} \mathrm{C}$. It is for the purpose of successfully passing through these high temperatures at the end of the dry season that the physiological changes involved in æstivation are due. Moreover, in the same regions the temperature frequently falls rather low at night during the dry season, although there are never frosts, $3^{\circ} \mathrm{C}$. being the lowest recorded temperature.

With multitceniata, which lives on the cold, dry plateau, the preparation for æstivation is the same as that described for the two preceding species. This form has to encounter in the dry season not only high temperatures by day, but also freezing conditions at night, and great desiccation at all times for seven or eight months of the year. Although the environment differs greatly in the three species, the manner of preparing for the season of the year when unfavorable conditions of existence are most apt to obtain is the same in all. The process is simply that of storing up a reserve food supply in the fat-body and removing all matters which might ferment, decay, or become poisonous to the animal, and the reduction of the water content to a lower percentage. It is this last which gives to the organism the ability to resist the extremes of temperature and moisture which it surely will encounter in the course of the ensuing winter or dry season. The concentration of the protoplasm very greatly widens its range of existence for the time being. This concentration of the protoplasm in hibernation and rstivation has been studied much in plant spores and in the lower animals, and the general conclusion has been reached that increased capacity to resist high or low temperatures or extreme desiccation is always due to the loss of water in the protoplasm; and like$18-T$ 
wise, in the higher forms, as in insects, increased capacity to resist extremes is due to the lowering of the water content in the protoplasm.

In the more arid portions of the American continent which are inhabited by these beetles, as, for example, on the Pacific coast of Mexico or the northern portion of the same country, the dry season is frequently prolonged for weeks or even, in extreme cases, for a year or more. In many such places these beetles live and are not exterminated by this excessive variation in their environment, or, more correctly, there is no evidence that they are, and it is of interest to know how they are able to withstand this extreme condition. I have not had an opportunity to study this phenomenon in nature, but I have reproduced in experiment such conditions with success and with suggestive and conclusive results.

In September, I902, I placed a lot of 300 decemlineata in a cage which was prepared for maintaining constantly a high temperature and a low percentage of humidity. These beetles, which were of the second generation of 1902, had been reared under normal conditions and would have hibernated in a few days, and yet hibernation was postponed for weeks, although by about December I all that were alive had entered the ground. The beetles in this experiment were kept constantly dry and warm, although the diurnal range in temperature was considerable, and a small amount of moisture was added from time to time to compensate for that which would be supplied in nature by dew and by the soil lower down. The beetles continued their hibernation through the remainder of the year 1902, all the year 1903, and the winter of 1903-1904, and only finally emerged when, in May, I904, I gradually increased the amount of moisture in the tank until the conditions found in nature at that time were reproduced. Near the end of the month 76 beetles emerged and began feeding, and during the summer of 1904 two normal generations were produced, the second of which hibernated in due course of time. As far as I was able to see this prolonged rstivation did the beetles no harm whatsoever; and it is quite possible that if I had been able to restrain my curiosity as to whether they were alive or not, they might still be contentedly hibernating in their tank, to emerge at some future time. This experiment shows how these beetles may be enabled to pass successfully over unfavorable conditions of long duration, and I have not the slightest doubt that this is the way in which the beetles of Chihuahua, San Luis Potosi, and other States in northern Mexico manage to survive where there occur from time to time seasons or a succession of seasons in which there is not enough rainfall to start vegetation and animal life into activity. At any rate, the beetles are found in these regions now, and if they have been exterminated in the past, they have been able to reoccupy the region by immigration from the surrounding territory with a swiftness which is astonishing and improbable, owing to the slowness of the dispersal of these beetles in arid regions. More probable, especially in the light of this experiment, is the hypothesis that they 
are able to extend hibernation much longer than is normal, and thus bridge over periods when impossible conditions of existence prevail.

Closely associated with the hibernation of the second generation in these beetles is the quiescent or resting period in the cycle of the germ plasm. That is, the germ cells do not develop at all in the autumn, but remain as oocytes or spermatocytes, which are relatively few in number, until the following spring after emergence from hibernation, when they develop rapidly. This period of inactivity in the reproductive elements has been regarded as due to some inherent necessity for rest in the germ plasm. However, it does not seem to me to be of this nature; it is rather in the nature of a very deep-seated adaptation, like æstivation, which has been developed and retained not only in this genus, but also in the whole insect phylum, for the purpose of enabling them to pass successfully over the season of the year when unfavorable conditions of existence are most apt to occur. In my experiments a race arose suddenly in which there were five generations, and then a period of rest, and then five more, and so on. In all insects, however, there is normally this period of cessation of reproductive activity, which comes at some time in the life cycle of each species, and corresponds in all exactly with the time of the year when unfavorable conditions of existence are most apt to occur. In some species it is passed over in the egg, in others in the larva, the pupa, or the adult, and there seems to be no general law by which to determine in which of the stages of existence the dormant period shall be passed. Inasmuch as closely related forms pass this period in different stages, and after different numbers of generations, there seems to be no alternative to the conclusion that we must regard this phenomenon as an important and fundamental adaptation which has been developed and preserved in the phylum for the reasons already stated. The points of chief interest in this research, however, are the adaptation which appears in alternative generations purely as a matter of hereditary influence and the fact that changes in the environment can not postpone the habit, although they may modify it to a considerable extent in its unimportant features. The deep-seated character of the physiological process involved in æstivation and its appearance in every second generation as an inherited habit or instinct makes it one of the most interesting of the physiological characters found in these beetles, or, indeed, in all insects. It has therefore been used in this research as a character well adapted for experimental investigation, and the attempts to obtain permanent modifications of it have been remarkably successful. Because of its clear-cut nature it has been of the greatest service in the investigation of the inheritance of habits and instincts in these beetles.

In nature, besides the utility of this perod of rest as a means of carrying the beetles over the dry season or the winter, it also acts as a strong selective factor. This has been shown statistically for decemlineata, and could be for other species were it worth while. The selection, however, is all in the direction of conservatism-that is, only those individuals that conform most 
exactly with the standard of the race are able to survive in any numbers. That is, here natural selection eliminates, and not perpetuates, the extremes of variation. It is a self-evident fact that the major portion of any species numerically strong must be well adapted to its conditions of existence, and these beetles are no exception to the rule. In these beetles, however, we find that the selective action of assortive mating and hibernation, both of which are strong and important selective agents, tend in the direction of segregation and an elimination of the individuals farthest removed from the standard of the race. This conservative or segregational selection has been an important factor in the evolution of the genus Leptinotarsa, and also in evolution in general.

\section{HABITS AND INSTINCTS CONNECTED WITH SELF-PRESERVATION.}

The devices exhibited by these beetles in one way or another, which enable them to obtain a measure of immunity from the attacks of their enemies, have already been examined in a preceding chapter. These have been found to be largely bright colors which, accompanied by the exposed situation in which the beetles live, make them conspicuous objects upon their food plants, and thus serve to advertise the inedibility of the possessors thereof. These warning colors do not entirely protect the beetles from their enemies, because we find that each generation of enemies has to be educated, and in this education a small percentage of the insects are killed. The influence of warning coloration, however, is purely passive; yet there are in this genus habits that are active agents of protection, and that are brought into play only on the approach of danger. It is these which will now be considered.

The most widely distributed protective habit shown by animals on the approach of danger is that of assuming a perfectly motionless position, with all the organs and appendages as closely drawn together as is possible. Observations upon habits of this kind have frequently been made upon birds and mammals, but less frequently upon lower forms. Many insects have this habit as fully developed and display it in the same manner as do the higher classes of animals. In the genus Leptinotarsa it appears to a greater or less extent, most frequently when the food plant is shaken or there is a sudden noise or a shadow passes quickly across the beetles. Oblongata and signaticollis respond to these stimuli, which are unusual in the habitat, by stopping quite still wherever they are and drawing the legs and antennæ as close to the body as is possible. In this perfectly motionless position they are far less easily seen than they are when moving. The length of time during which this pose continues depends upon the nature of the stimulus and its duration. If it is a passing shadow which is not repeated, the beetle within a few seconds goes on with its activities, whereas if the shadow passes back and forth over the beetle repeatedly it remains in this pose for some minutes, and if the stimulus 
is long continued seeks relief therefrom in flight, crawling rapidly to a darker portion of the food plant, usually on the under side of a leaf, where it again assumes a similar pose. Stimulation through noise, unusual odors, or the shaking of the food plant produce exactly the same response.

During the breeding period the beetles are far less responsive to the abovementioned stimuli. Frequently they will take no notice of the odors, shaking of the food plant, or noise which would at other times drive them to flight and secretion in the darkest and most secluded spots. At such times the overpowering influence of sexual instinct seems to render them oblivious to all other stimuli. Throughout the entire genus there is little or no variation in this habitat; and it seems to be one that is inherited, for the beetles display it as soon as they emerge from the ground. The protective value of the habit seems to be relatively slight, for it does not serve to conceal the animals from the enemies that are actively looking for them. Its real use seems rather to be that of momentarily decreasing their conspicuousness so that they may be passed unnoticed by any possible enemy. It also affords them an opportunity to determine better the nature of the disturbing stimulus and the direction from which it comes, and, possibly, also to decide what to do in order to escape from the injurious effects which the cause behind the stimulus might bring to them. At any rate, if the stimulus be long continued, the beetles soon seek more efficient protection by other means, and these are either concealment in some shaded and not easily visible portion of the food plant, usually the under sides of leaves, or by more energetic measures, such as falling to the ground, and there remaining motionless as if dead until the danger is past. The attempt to escape through hiding on the under sides of the leaves shows the simple instinct of fear and the response by seeking safety in flight. The imitation of death is, however, a more complicated instinct, which is developed in some and not in other species, and also to different degrees in the same species.

When an unsuccessful attempt is made to capture one of these beetles with the fingers or forceps, it almost always relaxes its hold upon the food plant, falls to the ground, and rolls away. It remains perfectly motionless where it stops, with legs, antennæ, and all parts of the body closely folded together, and whether it has landed on its back, head, or in a natural position, it does not move until all danger has passed. Even in the most exposed situations the habit is highly efficient as a protection, and in the usual conditions of the habitat of these beetles, where the food plant is surrounded by grass and other low, closely packed vegetation, it is a perfect protective device, as most diligent and prolonged search is necessary if one wishes to discover them when thus concealed.

The position assumed is to a considerable extent a specific characteristic. Oblongata, multitcniata, and decemlineata all likewise draw the appendages close to the body, which is not the death position, either for these species or for 
the others. Although the position assumed is constant within a given species, it varies in different species, as, for example, in rubicunda, which falls with the appendages held in a rigid position straight out from the body. In the two species, multitceniata and rubicunda, a point of great interest is presented. In the production of the new species there is rapid change in this protective habit as well as in the morphological characters. Hence it follows that modifications in the habit may arise suddenly as well as by selection, and this opens the question as to whether or not the habit itself may not have arisen in the same way.

While being handled the beetles often assume this attitude for a short time, but if the stimulation be continued they soon cease the attempt to escape through concealment, and begin to struggle vigorously; hence they do not carry the habit to the extent that has often been described in many insects that they allow themselves to be eaten or mutilated without manifesting a sign of life. I have examined several reputed cases of this kind in the tropics, but for some reason or other when under my observation they did not act as they should according to the published accounts. At any rate, in the genus Leptinotarsa the beetles do not carry the habit to the very evidently injurious extent to which it has been carried by other forms that have been destroyed.

That the habit is really of use to the species in the genus which possesses it there is not the slightest doubt. In nature I have seen undecimlineata, when approached and examined by a gecko, relax its hold upon the food plant, fall to the ground as if dead, and remain there until it considered that danger had passed, when it would crawl back upon the plant. Of the utility of such an act there can not be the slightest doubt. Of course it might often happen that in falling the beetle would get into a worse predicament than the one from which it sought to escape, but, as far as I can see, there is no possible means of determining this point other than by having a trained observer constantly watch the movements of a beetle throughout its adult life. As regards the selective value of the habit, it seems to me to be small, owing partly to the already existing high degree of protection afforded by warning colors, and quite as much to the fact that an insectivorous animal is keen of eye and does not often miss its mark. When, therefore, one of these beetles happens to be the target, the aim is so true and the attack comes so suddenly that the beetle has an extremely small chance of bringing this protective habit into play. Rarely, as with the gecko, the beetle may have a chance to use the habit to advantage, but such opportunities are few and far between, and hence can not play any appreciable part in the preservation of the species.

After years of observation of these beetles I find it impossible to regard the nature and purpose of this habit to be that usually attributed to the same reaction in other animals. I have described the habit in detail, and have shown that while it does have a certain protective value to the species, this value is 
so slight that it is hardly worthy of consideration. After a long acquaintance with these beetles, both in the tropics and in the temperate regions, it seems to me that the habit is no more than the response produced by excessive fear. There can not be the slightest doubt that fear is a psychic phenomenon which is found in all animals and may be aroused by quite varied stimuli. In the higher animals the continued application of a stimulus that excites fear produces a condition of muscle tension and inability to move, and frequently a state of complete unconsciousness, while in the human race these states are always accompanied by characteristic outward signs-pallor, trembling, protrusion of the eyeballs, clenched fists, tense muscles, and other characters.

If a slight noise be made with a tuning fork these beetles pause and assume the pose described; if the noise be continued they seek safety in flight; and then, if it be greatly increased, they assume the so-called death attitude, from which they emerge only after the stimulus has passed away and sufficient time has elapsed for the beetles to recover from their fright. The attitude assumed while in this state is caused simply by the nervous shock received by the body of the beetle, and especially by the muscular system, the reaction differing in no way from the well-known effects upon the muscular system of similar states in the human subject. Therefore, until more conclusive evidence is produced to show that the habit has the high utility so often attributed to it, death-feigning must be regarded as the specific response to continued or excessive fear-producing stimuli. In these beetles the habit is, I should judge, quite as frequently productive of ill results as of beneficial ones. I am of the same opinion as Morgan, that "the origin of these trophisms can not be accounted for on the ground of their benefit to the individual or the race." Certain it is that in Leptinotarsa there is not the slightest evidence that this habit has any selective value, or that it is of any constant or marked utility to the race. It may occasionally be of use in the preservation of an individual beetle, but such rare and sporadic utility of the habit would not bring it under the operation of natural selection, and I can not conceive of any rational way in which it would have been produced by this agency. On superficial examination or on first sight this habit would appear to be one of great value to the species, but a better understanding of the conditions of life in the species and of the relation of enemies thereto shows clearly that the habit is really of little utility in the life and death struggle of the species, and, therefore, has an extremely low selectional value, if any at all. For the purposes of this research, however, it is a useful character in that it is inherited in its full intensity and has a manner of outward manifestation that is more or less characteristic for each species. Moreover, when a new species arises, the habit may also be modified at the same time, which shows conclusively that not only are the most superficial structures, such as color and ornamentation, able to make rapid developments in their evolution, but that instincts and deep-seated nervous reactions can also change as quickly and easily as do the supposedly 
less fundamental characters which are usually associated with this rapid development of new forms.

The only other habit that can claim classification as a protective one has already been discussed. It is the habit which the larvæ of undecimlineata, diversa, and signaticollis have of covering themselves with the trichomes of their food plant. This, however, is an extremely passive habit, which is due solely to the facts that the beetles feed upon species of Solamum that have a rich development of trichomes on the under sides of the leaves, and that the young larvæ are supplied with spines in greater or less number and integumentary glands which secrete a sticky fluid, so that the trichomes become attached to the larva as it moves around upon the leaf. This habit is found in the first two instars only, when the larvæ are small and not active; as they become larger, however, the trichomes, even when they do adhere to the body, are not apt to remain there, because of the more active movements. The effect upon the young larvæ is to produce a rather efficient disguise.

This habit or protective device is, however, accidental, because whenever any of these beetles happen to feed upon a species of Solanum which does not have the dense deposit of trichomes, they thrive just as well, both in nature and experiment. Hence this apparently protective habit is simply the accidental accumulation of trichomes upon the body which is found in these three closely related species, because they all feed upon identical or closely related food plants. As far as I can discover, the habit has neither utility to the species nor has it injurious effects, and therefore it can not become a means of selective action until the time shall arrive when it is either of advantage or disadvantage to the species.

The three great groups of habits in these beetles have been examined not with the purpose of an animal psychologist, but in order to learn what part they play in the life of these beetles, which are being used as material for the study of animal evolution. The reader must not, therefore, be greatly disappointed if he fails to find herein the "final solution and explanation" of the habits of these insects. In this paper an insight has been gained into the part played by these various habits in the econony of the species, and to a certain extent into the manner in which these habits may act in the evolution of the genus. It has been clearly shown that some of the habits have a decidedly selective influence, but in all the habits discovered this influence is exerted in the direction of conservatism, and is of no use whatsoever in the preservation of a newly-appearing variation, no matter how useful it may be to the species. This conservative tendency, however, is a highly important factor in keeping the species true to the modal type, and may thereby be a far greater force in evolution than it would be if it concerned itself with every little variation possessing a slight degree of utility to the species. I am strongly of the opinion that when we are really better acquainted with the process of natural selec- 
tion we shall find that it has been the most important factor in evolution, but that its importance as a conservator of species is due not to the tendency usually attributed to it to preserve as many of the useful variations as possible, but to the fact that it holds the species, race, or variety to the modal standard. So, too, it might with equal effectiveness be productive of the development of varieties or of groups of species in highly variable forms through this same strong tendency to segregate the species about one or more conditions, and by the equally intense elimination of extreme or remote individuals. With any but the rabid selectionist it would go without comment that the material must exist in such a state that selection can get a hold, or, in other words, that the characters must have a selectional value either one way or another before they can enter at all into the process. How these characters reach this state of development is a subject for experimentation and research, and not for idle speculation. Finally, it has been seen that some habits appear on first sight to be of great utility to the species, but are not able to bear out this rôle when subjected to a broader and more careful analysis. 



\section{CHAPTER V.}

\section{PRODUCTION IN EXPERIMENT OF RACES, NEW CHARACTERS, AND SPECIES IN LEPTINOTARSA.}

The species of Leptinotarsa are clearly and distinctly separated from one another, and each has its particular groups of characters. This isolation, or lack of continuity, exists everywhere among all the species, when taken as a whole, and also in their particular attributes; and even though species possess the same character in common, or the characters overlap, each in its totality of characters is distinct from the sum total of characteristics discoverable in its most immediate relative.

According to the Darwinian hypothesis this distinctness of species is supposed to be the result of the extinction of intermediate forms; however, few traces of such a process have as yet been certainly demonstrated. In plants, De Vries has described elemental species separated from one another by lesser magnitudes than those separating species. The further extension of this idea and its investigation in Enothera has shown that in plants elementary species arise by sudden development, so that the new is always separated from the old by definite characteristics. This sudden permanent change of form is a phenomenon more or less well known to plant and animal breeders, and has been the means through which many of our domesticated animals and cultivated plants are supposed to have arisen; but it was until recently considered to be a process peculiar to domesticated races, and the Darwinian idea of slow isolation as the result of extinction was the generally accepted hypothetical process in nature. The work of De Vries, however, shows conclusively that in plants the rapid development of new forms takes place also in nature, and it is now an established fact that it is not confined to domesticated races, but is common to both wild and cultivated plants. Among animals, however, the state of our information is far less satisfactory, and it is decidedly an open question as to whether the origin of species in animals has been by slow modification and extinction, rapid transmutation, or by "mutation."

The attack upon this problem in animals is far more difficult than in plants, the obstacles to be overcome and the apparatus and expense demanded being so excessive that but poor headway will be made as compared with that of the plant evolutionist. Moreover, the problem is more complex in animals than in plants, and the ramifications, whose solutions are necessary before we can arrive at a really safe hypothesis, are numerous. The attack must be made from two sources: First, from careful observation in nature of the material under investigation, that the observer may become thoroughly 
acquainted with his material in all its natural phases; and second, by longcontinued experimental investigation. In the study of evolution in Leptinotarsa I have carried on the two lines of investigation stated. The first line of inquiry has been presented in the first chapters of this paper. In this chapter, in which will be taken up the second line of attack, it will not be out of place to review briefly and bring together the general results of the first inquiry, since it is these conclusions which form the starting-point for the experimental portion of this research.

The genus Leptinotarsa everywhere lives in situations where the earth is covered with perennial grasses, with a greater or less growth of herbaceous plants, some of which must be Solanacex, upon which the beetles feed. They are typical grassland forms. This fact explains their general distribution over the American continent-their presence in some parts and absence in others. To the conditions of existence of a grassland habitat they are singularly adapted. The general climatic conditions of grasslands are frequent although often small precipitation during the growing season, which keeps the superficial soil moist and the lower stratum of air humid through evaporation, followed by a dry season of greater or less duration. I have shown how the beetles are limited by these very factors of soil and atmospheric moisture in their general and local distribution, and how their life histories, reproduction, æstivation, and physiology are adapted to these conditions.

But the grasslands are not all alike; some are more, others less humid; some are warm, others cold; hence a particular trend in species evolution in the genus shows closely related species occupying adjoining but differing environmental complexes; and we inquire whether these species have come about by slow modification and extinction or by sudden transformation. We have examined the variations, fluctuating, place, and geographical, and get no satisfactory evidence as to the method of evolution, too much supposition being required to connect variations with evolution. This study of distribution and variation gives no information concerning the method of evolution, but it shows conclusively, first, that species formation has been definite, the successive and related species having developed in contiguous habitats as the genus evolved; and, second, that variations are in the same direction as species formation. Evolution has been definite and not promiscuous; it is orthogenetic.

Throughout there appears a growing body of evidence tending to show that selection does not create nor even preserve extremes of variation, but that it acts as a conservative factor to eliminate extremes and to confine the species close to the mode. Correspondingly, there is found in increasing volume evidence that new races and characters develop rapidly, but always in conformity with the general orthogenetic trend of evolution of the group or genus. 
Two questions which can be solved only by experiment are before us: (I) Do new characters, races, and species arise by rapid development only, or do they arise by both rapid development and by slow variation and isolation through extinction? (2) What is the cause of these transformations of characters and species? is it external or internal, or both? and can they be produced in experiment?

\section{PEDIGREE BREEDING OF L. DECEMLINEATA.}

\section{EXPERIMENTS IN RACE PRODUCTION AND MODIFICATION BY ARTIFICIAL SELECTION.}

From 1896 to 1904 I carried on continuous and rather extensive experiments in selection. In these experiments the beetles were kept under constant conditions, especially during ontogeny, and in each generation individuals which showed extreme variations were isolated and became the parents of following generations. This is a comparatively simple process, and one which can without doubt be kept up for a long series of generations. It is these experiments which will now be considered.

I began with the idea of showing experimentally that where there are closely related species similar in most of their characters, but isolated by gaps, evolution has been through slow progressive modal shifting and the extinction of intermediate forms by selective processes. Thus, for example, in the series multitaniata, intermedia, and decemlineata, multiteniata is most melanic in general coloration, and decemlineata least. It is possible, by environmental influence and selection, to change species one into the other?

\section{SELECTION EXPERIMENTS WITH COLOR CHARACTERS.}

My experiments with color characters dealt both with special areas of color and with general color tendencies, such as melanism, albinism, xanthism, and rufism.

I attempted by selection to create a race of decemlineata in which the spots $a$ and $a^{\prime}$ upon the pronotum would always be fused posteriorly, as they are in some species, and at the same time to increase their size. In this experiment the most rigorous selection was practiced, and every opportunity given for selection to produce the desired result, but to no purpose. In one part of this experiment the selection was carried out in a most rigorous way for eleven generations without any discoverable result (plate 25, $A$ ). In each generation the progeny of extreme melanic parents presented, as far as the character in question was concerned, about the normal range of variation. The entire negative result in this experiment may be interpreted as an example of the total inefficiency of selection, or, what is more probable, as indicating that the selected variations of the character were not capable of transmission, being purely fluctuating somatic variations. In the chapter on coloration I have 
shown that color variations produced by environmental conditions during the larval and pupal periods are not inherited at all.

In another part of this experiment a single pair of beetles gave offspring of two sorts-one with the extreme conditions of the parents, the other with the conditions of the first set. The parents of this series were from the same stock as that which gave entire negative results, and were indistinguishable from several other like pairs that were not able to transmit their peculiarity to the next generation. There is, therefore, a difference in the variations experimented with, one being inheritable, the other not. The relationship and behavior of these two series I have represented on plate 25. In this plate, in which the curves of the selected parents and offspring are brought together, it is clearly demonstrated in the series $A$ that there is no accumulation of the character through selection. The series $B$, however, which arises from a single pair indistinguishable from the rest of the parents of generation 5, shows two distinct groups of offspring. These were isolated and reared in several succeeding generations. One of these groups $\left(B^{\prime}\right)$ was always strongly like the parents, and showed little or no tendency to revert to the racial standard as did the individuals of $B^{\prime \prime}$. In the pair that were the parents of series $B$, one or both had the selected variation of transmissible quality, and passed it on to the following generation, but to part only. It would appear, therefore, either that one parent had the character selected transmissible and the other not, and that part of the offspring received the transmitted character in inheritable form and part did not, or it is possible that both parents had the character latent in some germ cells and not in others, and that in reproduction there was a union of like germs. I believe that the first proposition is the correct one; but which parent possessed the character in transmissible form I do not know in this case, and for this series of experiments this is of little importance.

A glance at plate 25 shows that the series of cultures $B^{\prime}$ are very different from $A$ or $B^{\prime \prime}$ in that in $B^{\prime}$ selection was able to keep offspring up to the parental mode, and to raise the mode of the race. In the others, however, i. e., $B^{\prime \prime}$ and $A$, this was not possible, nor was I able to maintain the same, nor approximately the same, modal standard for parents and offspring. In $B^{\prime}$, however, I was not able to carry the selective development of the race beyond the usual range of variations of the species; that is, within the number of generations experimented upon in $B^{\prime}$, and the same result was obtained in six other identical series. The limits of variability of the species seem to be limits beyond which artificial selective processes are unable to carry the modification of the race. On the other hand, by selection we can rapidly create races up to the natural limit of variation of the parent form, and maintain them there with ease by the same process, and I can see no reason why artificial selection should not be able to carry the species beyond its natural 
PLATE 25

"Normal " range of variation.

Mode.

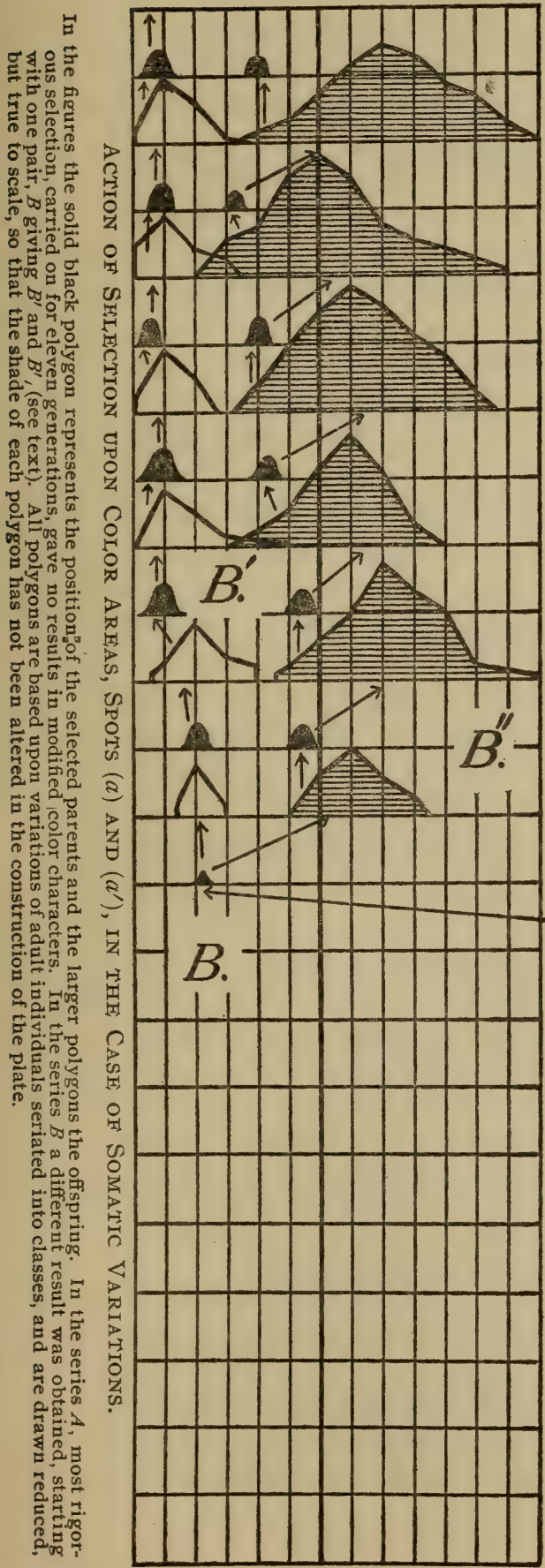

"Normal" range of variation.

Mode.

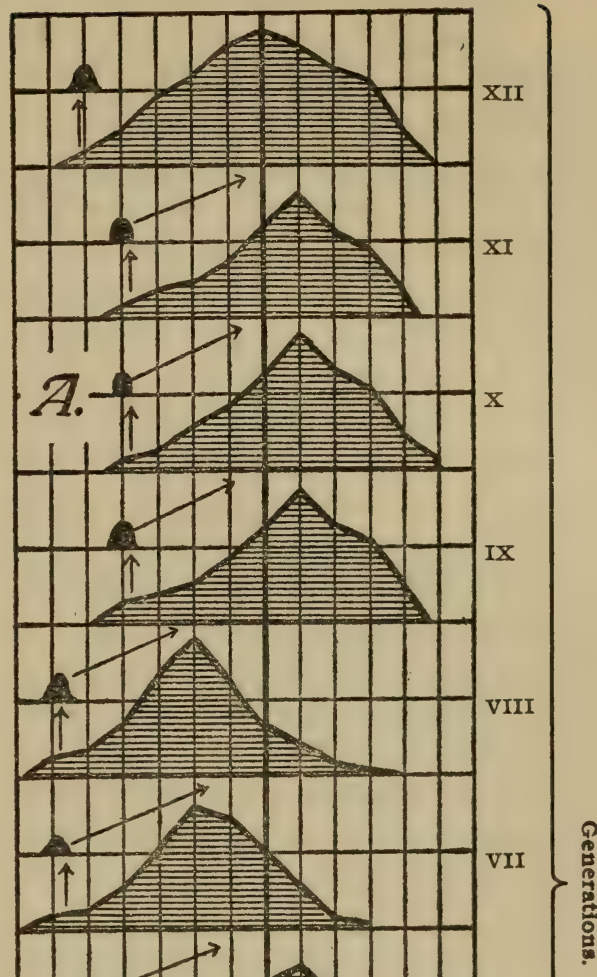

욜 

limits of variation, if selection is the powerful evolutionary factor its advocates hold it to be. It is possible that my experiments were not conducted over a sufficient number of generations to bring about greater changes.

From this series of experiments it is evident that in the character chosen some variations are transmitted, others not; and, as far as my experience goes, there is no middle ground. To all appearance these variations are alike, and are distinguishable only by their behavior in pedigree breeding.

The results of the above experiment are paralleled by similar conditions found in nature. Thus, from selected pairs of parents found in nature, only about 4 per cent pass on their extreme characters to their progeny, showing how small a percentage of the variations are transmissible. In nature, where crossing is going on, such heritable variations are swamped as soon as they arise-a fact that I have proven experimentally by allowing such variations to breed freely with the general population. It is only when we practice artificial selection or isolation that they are preserved. With such characters as the spots used in the above series of experiments, which are absolutely neutral and could not by any conceivable process come within the domain of selection, and are yet good, specific characters, it is certain that the character as it exists in the different species could never have come about as the result of selection and extinction. It is possible that it may be correlated with some other characters of direct selective value, but I have not been able to establish any such connection. As far as the experiments go, the variations are either transmissible or not, and there appears to be no intermediate state of partial or weak inheritance. Experiments were also tried with other spots on the pronotum, $c, d$, and $e$, and with spots upon the epicranium and upon the legs and ventral surface of the abdominal segments, with exactly the same results.

When we combine variations and treat them statistically, we get results that are false. Thus, on the basis of statistical method the variations of $B, A, A^{\prime}, B^{\prime}$ are continuous and of the same kind, while in reality they are different; and by no method of biometry could we discover the two kinds. These can be discovered only by the observation of individual cases and by breeding. When we examine the pairs possessing heritable variations, it is found that in the population of any generation they stand apart, separated from the mode of the species, and that intermediate states are absent. It is true that when many of these individuals are brought together, "lumped," they form a regular polygon of distribution. The reason for this is that while each individual represents a distinct deviation from the mode of the species, these deviations are not all of the same size-some are large, others small, and the latter are far more numerous than the former. Moreover, we do not find many of the larger variations in any given generation. Considered statistically, we should recognize these as continuous variations; examI9-T 
ined singly, they are unmistakably seen to be deviations of greater or less size from the mode of the species.

I have shown that these spots behave as units in the ontogeny and evolution of coloration. In these selection experiments, also, they behave as units. If we combine large numbers of cases they follow Quetelet's law in the polygon of distribution; but this in no wise presents the real fact, namely, that each heritable variation is a divergence from the species mode in some individual line of descent. ${ }^{1}$ The distribution, in the long run, according to the law of error, of these diverging heritable variations is not without interest or importance, indicating, as it does, that the causes productive of the transmissible variations also diverge from their standard, now more, now less, and in different directions; but whether there is continuity or not can not be determined until we know the causes. In any event, the distribution of the causes of heritable variations according to the law of error results in the long run in producing heritable variations in decemlineata that are also distributed according to the law of error, so that the species is thereby kept upon an even basis.

The behavior of general color characters, such as melanism, albinism, xanthism, and rufism has been studied, especially with the object of creating races by the selection of variations through successive generations. Out of the many sets of experiments tried, two will serve to illustrate the general results obtained. I shall describe experiments for the production of albinism and rufism.

I attempted by selection to create an albinic race of decemlineata in two ways-first, by selecting for breeding the most extreme albinic variations found in nature, and, second, by creating extreme albinic conditions in experiment and breeding from them. For the first set of experiments the selection was made from numbers of copulating pairs found in nature. The selected pairs were kept in separate cages, as were their progeny, the only lumping of material being in the statistical treatment of it. The great majority of such pairs and their offspring were not of any interest. Out of 3 II pairs selected and mated in the years I896-1904, only 26 , or $8 \frac{1}{3}$ per cent of the total number of pairs tried, were found capable of transmitting their particular variations. In many of these pairs it was certain that only one of the beetles had the character in transmissible form, so that in $3^{\text {II }}$ pairs, or 622

\footnotetext{
${ }^{1}$ That is, between any given variation and the species mode the intermediate stages are a greater or less distance back in the line of individual descent. Moreover, in the lines of individual descent intermediate stages are always discernible, no matter how suddenly the variation may seem to appear. In all of the cases that I have studied there are no jumps or discontinuity of any kind in the heritable variations, but there always exist transition stages, passed frequently in ontogeny, but nevertheless real and directly observable, between the characters of parent and offspring. There is then no saltation or "mutation," either large or small, in Leptinotarsa, nor are there "immutable" unit characters.
} 

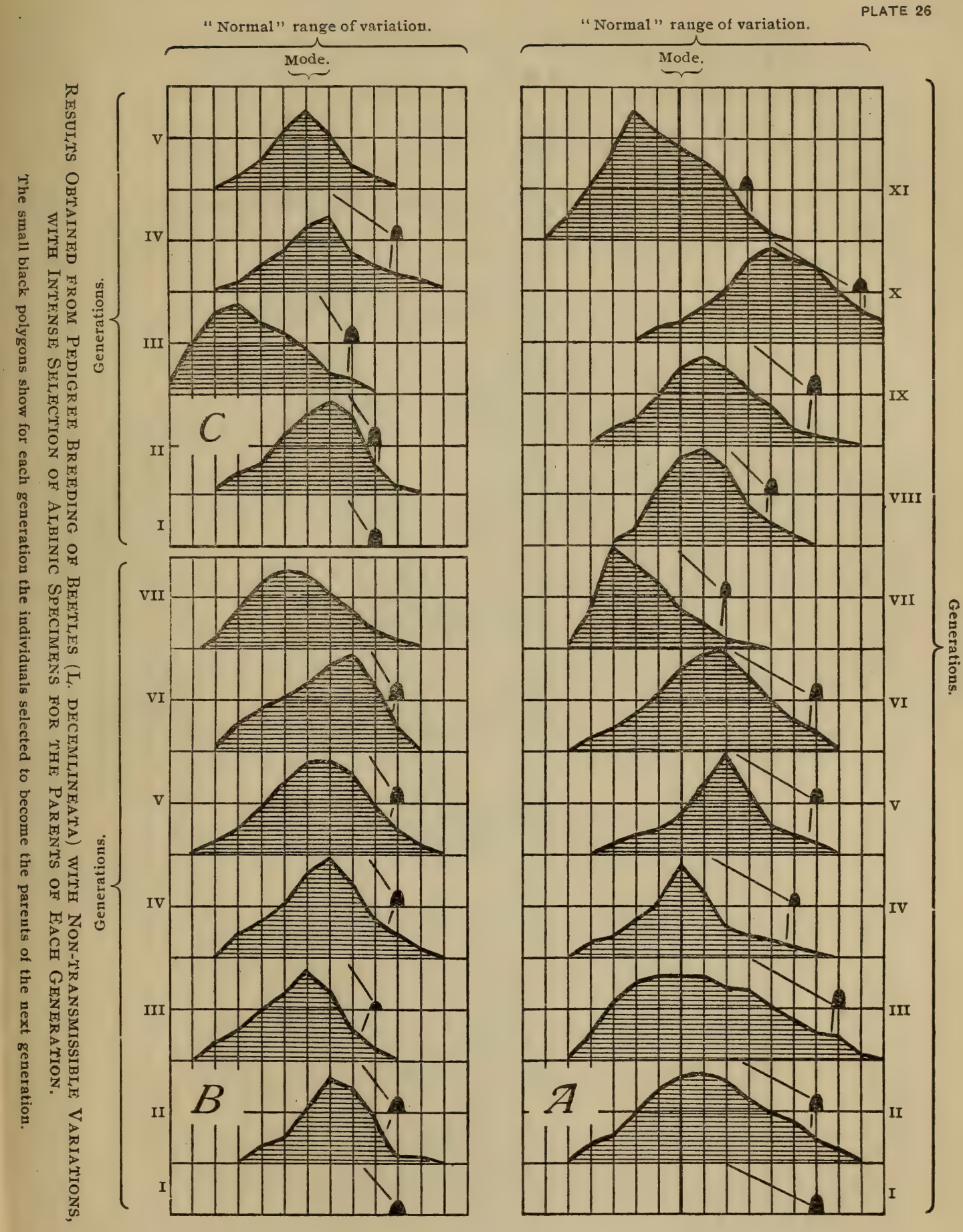



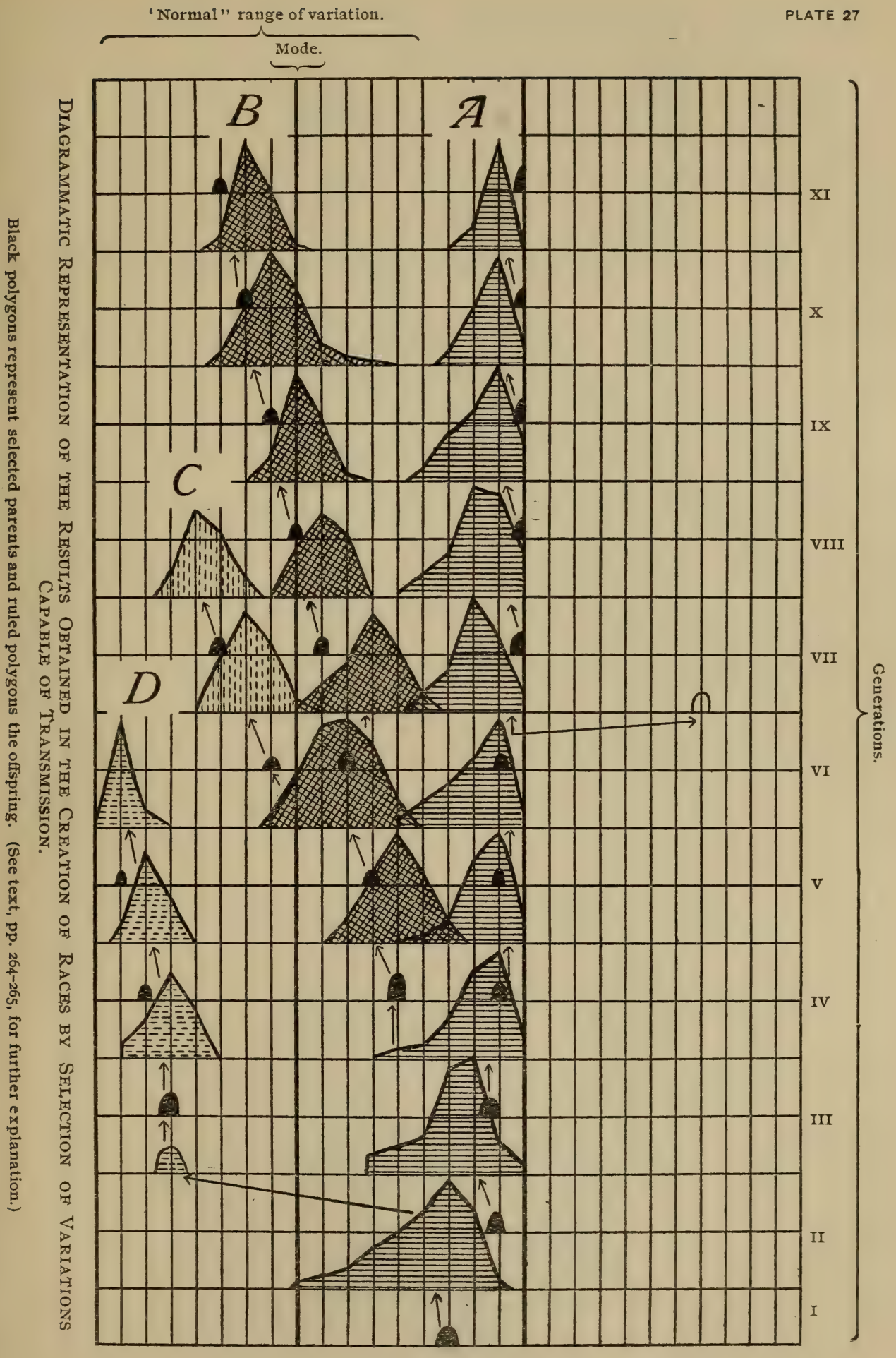





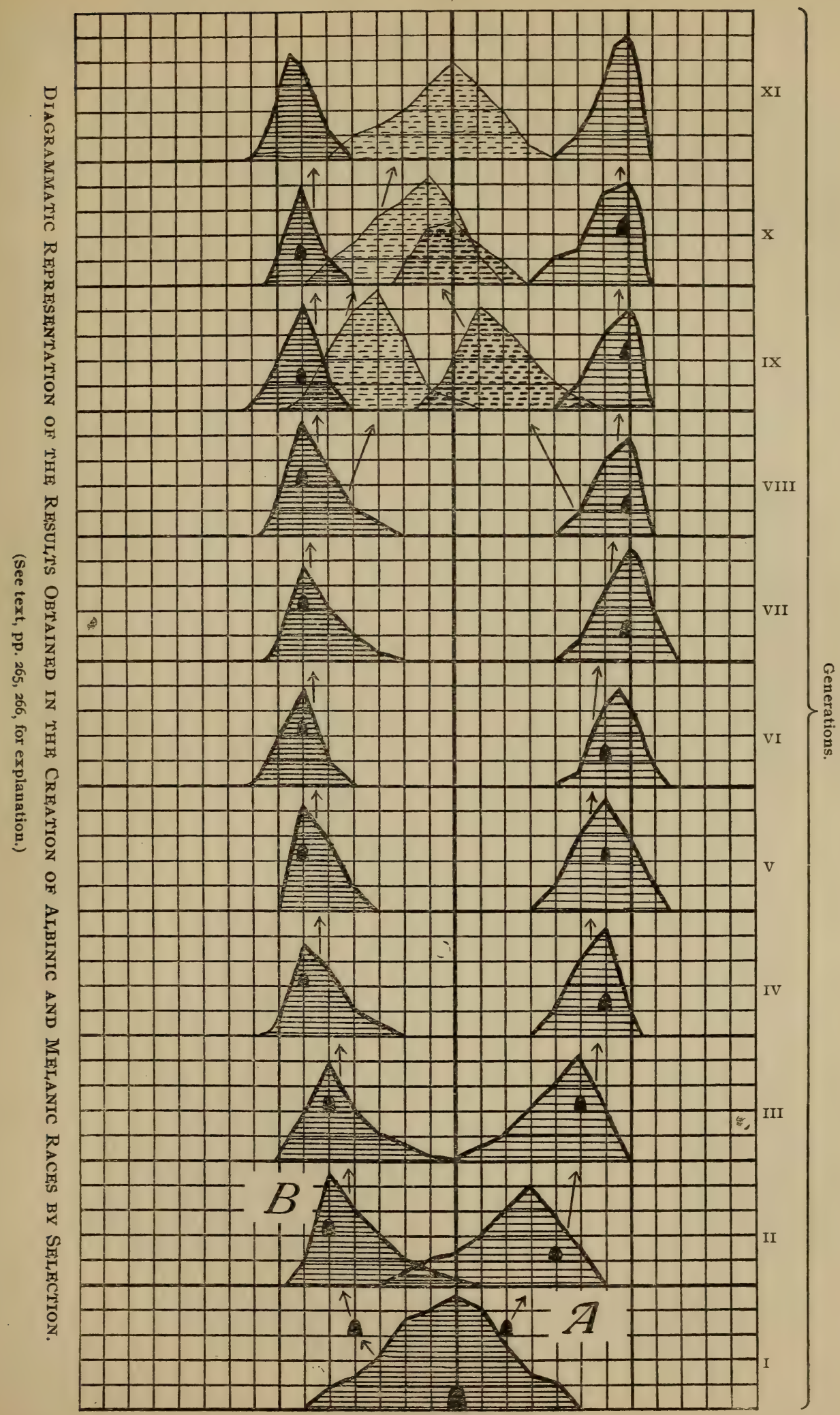





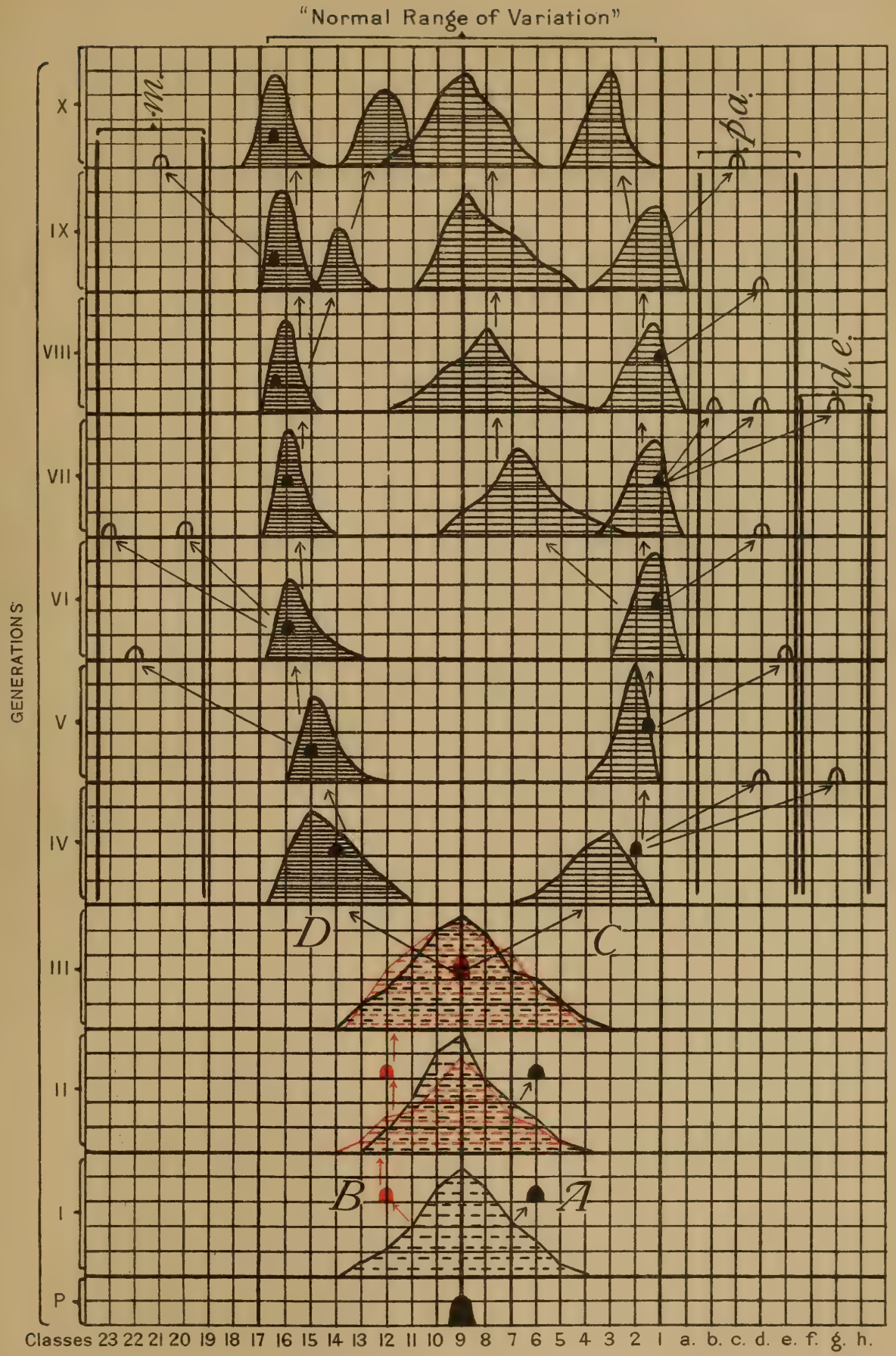

DIAGRAMMATIC REPRESENTATION OF THE RESULTS OBTAINED IN THE ATTEMPT TO CREATE ALBINIC AND MELANIC RACES BY THE COMBINED INFLUENCE OF SELECTIVE AND ENVIRONMENTAL STIMULI 

individuals, the actual percentage of specimens showing heritable variations was probably not far from 4 or 5 per cent.

In plate $26 \mathrm{I}$ have shown the results obtained from three experiments, $A, B$, and $C$, each starting from a single pair of beetles where extreme and nontransmissible variations were the parents of each generation and were selected most rigorously, all others being exterminated. In these experiments with general color characters there was no influence exerted upon the progeny by selection of the parents. In general color characters exactly the same results were obtained as in the selection of unit color characters. In plate 27 , however, are seen quite different results from those portrayed in plates 25 and 26 .

Starting from a single pair of albinic beetles in which the selected character was transmissible, and following the line of descent from generation to generation, the fact is graphically shown that the particular variation of the parent was not only preserved, but carried close to the limit of normal variability of the species, and that by selection the race was changed from one which was variable to one which was relatively invariable-that is, selection resulted in the production of a race of albinic beetles of low variability, which, no doubt, it would have been easy to maintain for a long period of time. From the third generation a selection was made for the parents of the fourth of the most and least albinic individuals, $A$ still being the albinic race, and $B$ the divergent race tending toward the opposite extreme. These two lots of parents gave in the fourth generation two distinct polygons which overlapped only in the slightest extent. By continued selection the poiygons in the fifth generation did not overlap, and in this generation further division was made of $B$ into $B$ and $C$. These two lines were continued for several generations, diverging from the $A$ line, but not far nor rapidly. In the second generation there arose two distinct groups separated by a wide gap, $A$ and $D$, the latter being the exact opposite of the $A$ race. This $D$ race was propagated, and by selection produced the result shown in the polygons along the line of descent $D$, giving in the last generation of the race a group of beetles of almost uniform condition. In all the lines of descent, $A, B, C$, and $D$, artificial selection did just what it was found to do in the elements of coloration, namely, it created a race of low variability about the standard chosen, which it maintained as long as selection was practiced; but it did not carry the race beyond the normal range of variation of the species. That is, artificial selection can, as De Vries points out, produce races and maintain them, but its power to develop these races beyond the natural range of variability is yet to be demonstrated.

From the series of cultures represented in plate 27 it is shown that it is easy by selection to create races from a species, which would, as long as the artificial selection lasted, breed true to the ideal chosen. Such an experiment was made and two races breeding true were produced. Their history is rep- 
resented in plate 28. From the parent generation two selected groups, one melanic $(B)$, the other albinic $(A)$, were taken, and from these, two clearly defined races without trace of intermediate condition were produced. During each of eight consecutive generations slightly variable, light and dark races were maintained. At the end of this time the material was divided and selection was stopped in one group and continued in the other, but the lots were not allowed to interbreed. The removal of the selective factor at once resulted in a regressive shifting of the mode of each unselected race and in increased variability, and this change continued through the eleventh generation, when both unselected lots had moved back to the mode of the species.

These experiments with color characters show very clearly that artificial selection is with transmissible variations a powerful factor and can greatly accentuate any character and maintain it in an extreme condition, but that there are limits beyond which I was not able to modify the characters by this agency. The experiments also show that artificial selection works rapidly, and not, as has been so often assumed, with extreme slowness. True, in experiment I practiced a most rigorous selection, but not more rigorous than that which the natural selectionists believe exists in nature. The general feature of these experiments I shall postpone discussing until after the data from other selection experiments have been considered.

The experimental production of general color variations and their preservation by selective breeding give many points of interest. In this I have confined my attention almost entirely to extreme light and dark forms. To produce light forms I have used hot and dry conditions, and for dark forms, warm and moist. The conditions productive of these variations have already been discussed and recorded(Chapter III). The experiments herein recorded differ from those already given in that the entire life of the beetles was passed in the conditions of experiment, and not the larval and pupal stages alone, as in the experiments upon coloration.

In plate 29 are brought together in diagrammatic form the data and general history of cultures where both light and dark forms were produced and further subjected to experiment. The black polygons represent the selected groups of parents, the ruled polygons the offspring. The appearance of "mutants" beyond the normal range of variability is indicated by the small white polygons. $p a=L$. Pallida, with its range of variation; de = defectopunctata; $m=L$. melanicum. The series is a complex one, involving processes other than artificial selection and introducing factors of interest which are the key to further experimental study. At present we shall consider only that portion directly concerned with selection or selective processes.

In the first, or parent, generation I selected 6 copulating pairs of beetles from the hibernating population, and kept them and their progeny in natural conditions. From the 6 pairs were obtained in the second generation I,320 
mature beetles, and from these, two groups of copulating pairs of Io each $(A$ and $B$ ) were selected and reared in the third generation, but showed no modifications as the result of selection. These hibernated, and selections from each lot were reared in the fourth generation, but showed no modification. I now felt sure that the material was pure, that is, normal, and carried no tendencies to appear in divergent extreme variations. Accordingly, from the two series selection was made of as nearly modal individuals as possible, and the two selected lots were mixed and divided into two lots of Io pairs each, $C$ and $D$. These were placed, as soon as possible after emerging, in surroundings productive of dark and light conditions of coloration, and allowed to breed, producing in the fifth generation two distinct lots of descendants, one light, the other dark. These hibernated, and after emerging in the following spring were allowed to breed, when it was found that out of 50 mated pairs 3I, or 62 per cent, were able to transmit their particular variation in full strength, a huge increase over that found in selections from nature. From each group 5 pairs were selected as the parents of the sixth generation. These gave, as was expected, distinct lots of individuals more melanic and more albinic than their parents, and each also produced individuals differing in many respects from the parent stock, and beyond the usual range of variability. In the five following generations the same thing was repeated, as may be seen from plate 29; that is, from each group of selected parents there came a general population less and less variable, and a greater or less number of highly divergent forms beyond the normal range of variability of the species. These latter we shall consider in another place.

In this series of cultures a normal parent stock has been subjected to artificial selection aided by powerful environmental stimuli, both having the production of the same end in view. The results, however, were a keen disappointment; the inability to produce in this experiment by selection and powerful environmental influences a race much beyond the normal limits of variability of the species might easily be taken to indicate the impotency of selection. The ease with which the beetles moved back toward the species mode when selection was no longer practiced and the conditions of existence became modal, when joined to the data of place and geographical variations, allows only of the conclusion that while differently colored races and modifications of this beetle occur in nature and are produced in experiment by artificial selective processes and local environmental influences, such modifications are limited by the natural limits of variation of the species and persists only as long as the maintaining processes are present, and are utterly incapable of existence under adverse or even natural conditions, reverting to the species type. That is, artificial selections or local influences are able to modify, and to a certain extent create races founded upon those variations which are ordinarily killed off by natural selection (Chapter IV); but in the creation 
of such races we really have two forces-a species selective tendency and a local (or artificial in experiment) - acting against one another, with the result that selective divergence to a certain limit is attained, but beyond that the racial divergence is slow or entirely stopped. When the local or artificial selection is removed the species selective tendency causes a regression to the type of the species. It may be objected that my experiments do not cover a sufficiently long series of generations to have accomplished the result intended, and this may be true; but selection is a powerful formative factor and works rapidly up to a certain limit, and this has been abundantly proven by plant and animal breeding for fifty years. Why should it not also be able to establish a race on permanent footing with the same rapidity? We know from the rearing of domestic animals and plants that constant selection is necessary to maintain the race. In as far as these color characters are concerned, by artificial selection we can easily produce and maintain a race, but we can not establish it as an independent one; we can create isolated races from extreme variations, and by selection keep them isolated, but we can not permanently establish them. On the whole, selection would appear as a relatively impotent factor in the evolution of these color characters were it not for the fact that we usually try in our experiments to work against the far more powerful natural selective tendencies of the parent species. Two points we may note in passing, namely, the number of highly divergent variations beyond the normal range of fluctuating variation produced in this series of experiments, and the increased percentage of individuals which show variations capable of being transmitted to the progeny.

\section{ShLECTION EXPERIMENTS With STRUCTURAL Characters.}

It is often asserted that color characters are not reliable for the study of variation and evolution. The assertion is, I think, due entirely to ignorance of the real nature of color characters. I have made a series of selection experiments with structural characters-general, such as size and shape; and special, such as glands, punctation, spines, etc.

There exists in this species a very considerable variation in size between the sexes, and also in the same sex, and this provides a good general structural character for the experimental study of artificial selection and selective processes. Four main sets of experiments were tried, each aiming to create by selection a race having certain characters. Four conditions were aimed at: (a) To have both sexes large; (b) both sexes small; (c) females large and males small; $(d)$ and males large and fenales small. Only the first two sets gave results of any value, the last two failing because of the difficulty of breeding opposite extremes. Therefore I give here the data and conclusion from the first two series. The general results of these experiments are given in plate 30 , the procedure and results being in general not unlike the experiments with the color characters. 


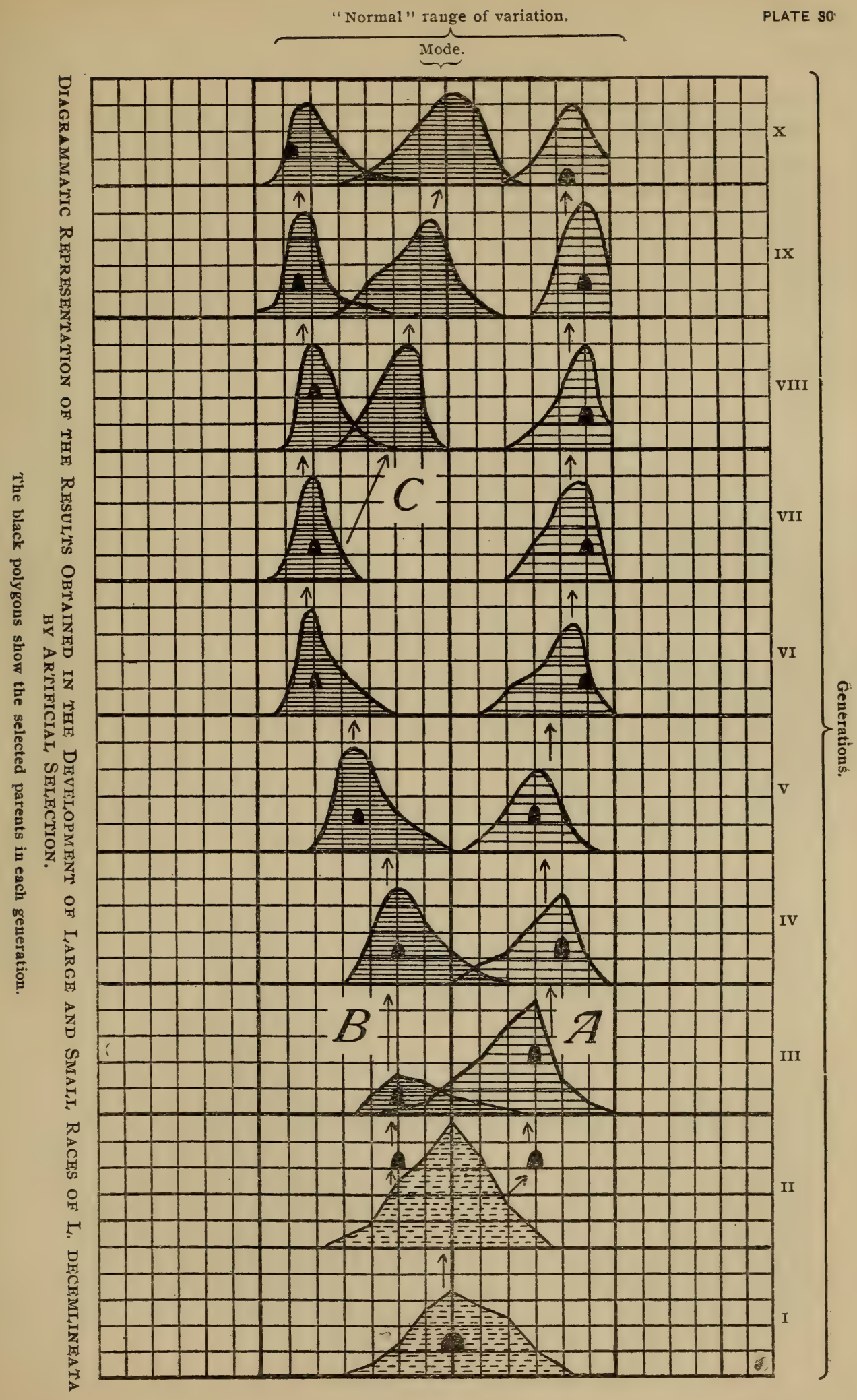



I started in these experiments with Io pairs of modal beetles that had hibernated, and bred them, getting a second generation, normal in every respect, and from these selected to modal pairs and obtained a third normal generation of I, 288 beetles. From this third generation, out of I IO pairs 2 were found that had variations capable of transmission, giving two divergent groups of beetles in the fourth generation. One of these consisted of beetles larger on the average than the parents and the other beetles smaller than the parents. From the fifth to the tenth generations I practiced constant rigorous selection, and in the eighth there was a relaxation in the selection of part of the large beetles, with the general result shown in plate 30 . It is possible to increase and decrease the size, but the mode of any one generation could not be brought to the limits of the variability of the species. This result, with the general structural character, size, differs in no way from that obtained with color characters, nor from the common experience of breeders of domestic animals and plants. The breeder of large horses has not yet by selection been able to create dray horses as large as elephants, nor is it possible to double the size of these beetles by the same process. The change produced in size was, if selection was removed, as shown in plate 30 , immediately obliterated through regression to the standard of the race.

An interesting set of experiments with the scent glands was made. I have shown how these glands act as protective structures, and how distasteful their secretions are to insectivorous birds, reptiles, and amphibia. They are therefore highly useful to the beetles, serving as active protection, hence of real utility, and they ought by selection to be capable of increase in number and in quantity of secretion, a result that could not be otherwise than a decided advantage to the race, since it is shown that the species most numerous, widely distributed, and immune from attack are those with the largest number of these glands.

All that the experiments with the glands show is that, given a variation capable of being inherited, with it as a basis we can by selection create a race that possesses as its modal condition very nearly the extreme variations in the characters chosen for experiment; but the race persists only as long as the stimulus of selection is continued, and I do not see how this process could lead to the establishment of independent races or species.

While the selection experiments with structural characters show that the same results are obtained as with color characters, they are strong evidence against the assumed ease with which useful characters can be augmented and preserved by selection. They, however, show clearly that in these beetles even a most useful protective device is not easily modified in a permanent manner by artificial selective processes. In this series of cultures we are not dealing with uncertain and unknown quantities. We know the direct and important use to which these glands are put by the beetles; we know that in the genus some beetles possess more, others less; and that those species with 
the greatest numerical strength and extensive distribution are provided with numerous protective glands. Moreover, we know from the experiments that the parents were normal, and that the selected parents possessed the variations in transmissible form. In the culture I acted as the insectivorous enemy, eliminating all but those with the most glands, which were allowed to breed. In this experiment were combined the conditions ideal for selective modification, but the results in no wise differed from those obtained from experiments with characters of no utility to the species. The similarity between the results obtained in characters of utility and characters of no utility is most interesting, and admits of only one conclusion-that as far as. the experiments with these beetles go local or artificial selection is a weak factor, able to produce little or no real change in the species, and unable to create a permanent race by the preservation of extreme variations.

\section{Selection Experiments with Physiological Characters.}

During the years 1899-1904 various experimental pedigree cultures were made in which physiological characters, such as habits and instinctive responses, were chosen for experimentation. These characters were found to be only in the slightest degree influenced by selection, and the changes found were too small to be of any real value or afford a basis for conclusions. The failure to get positive results was not due to the non-heritable qualities of the characters, but to the failure to get hold of sufficiently extreme variations to. form a basis for selective experiments. All of the variations used were so near the mode that they afforded no real basis for work, and I was not able by selection to increase such variations as were found.

It has been shown in respect to these physiological characters that they were exceedingly conservative. Thus, in the various habits associated with reproduction or hibernation, only the modal individuals are able to go through the habit with success, and a variation of any moment is sufficient to exclude the possessor thereof from participation in the propagation of the race. As a matter of fact, variations of these characters are rare, and the species are separated by wide divergences, far larger than those existing in the case of morphological characters.

When we bring together the results of the selection experiments upon L. decemlineata several points of general interest are brought to light. First and of fundamental importance is the fact that all of the heritable variations are discontinuous in any given generation, and that continuity exists only in individual lines of descent where discontimuity is impossible. The second point of interest is the failure to carry, by selective processes, races beyond the normal range of variation of the species. The third is the sudden development of extreme variations differing in many points from the parents, and lying beyond the range of fluctuating variations. These were found with especial frequency in the series of experiments with general color tendencies. 
In as far as we can judge from these experiments, while the selection of the inheritable variations when continued for ten or twelve generations is able to give well-defined races which persist as long as selection is practiced, it is not able to establish these races so that they can exist alone. The results from the experiments fall in line with the general experience of breeders of domesticated plants and animals. In these beetles, as De Vries also points out in plants, selection is able to produce races by isolation only (selection) of extreme heritable individual variations.

I am aware that against this view the selectionists will at once say that far more generations are needed, which I grant is possibly true; but how many? I have shown that geographical races of this beetle living in places where there have been the same environmental and local selective tendencies for at least 400 or 500 generations have not yet become permanently modified in form in such locations. It is true that a large part of geographical variation is purely somatic, but not all; hence, if local selective influences are so powerful, it would seem that a series of several hundred generations were ample time for selection to begin to show its action. In experimental breeding selection works rapidly, and in nature why should it not act with equal rapidity-that is, where it is operative at all? In any event, until there is evidence to the contrary it will not be unfair to hold that pedigree cultures of ten to fifteen generations do show fairly well how potent local or artificial selection really is as a means of modification in these beetles. We must not confuse local or artificial selection (isolation) with the specific selection characteristic of the entire species. The former is productive of divergence, the latter of conservation, and my experiments are in reality a contest between the two with the conservative one victor in the end.

EXPERIMENTAL PEDIGREE BREEDING OF NEW CHARACTERS AND SPECIES.

There have arisen in my experiments, and I have found in nature, variations of $L$. decemlineata which differed from the parent stocks in one or many characters and stood beyond the limits of fluctuating variations. These sports-saltatory variations, discontinuous variations, or "mutations," whatever we may call them-often bred true, and were able in many instances, but not in all, to hand on their variations in full intensity. Whenever found these interesting variations have been seized upon and made the basis of instructive experimental cultures.

It has been shown that in nature three well-defined species of Leptinotarsamelanothorax, rubicunda, and angustovittata-arise through rapid transformation, and that rubicunda is possibly becoming established as a permanent species. In treating of variations I have figured under the head of extreme variations some of those observed to have arisen from decemlineata. 
The occurrence in nature of these variations from decemlineata is, as a rule, rare. Owing to the abundance and concentration of decemlineata upon potato fields, it is possible to examine huge series of these beetles. Some idea of the infrequency of sports under normal conditions of existence can be conveyed by the following observations made at various localities and for different broods and years:

West Bridgervater, Massachusetts, 1895.-First brood: Examined from one field I3,210 beetles, no sports; from a second field, II,84I, I sport, form melanicum. Second brood: From same field as first brood, 2I,400 beetles, I sport of form melanicum.

Cold Spring Harbor, Long Island, I899.-First brood: Examined from one field 14,600 beetles, 2 sports-forms pallida, melanicum. Second brood: From same field, I3,500 beetles, no sports.

Cabin John Bridge, Maryland, r9oo.-Second brood: From one field II,792 beetles, 82 sports-forms melanicum, minuta, pallida, tortuosa.

McKeesport, Pennsylvania, 1900.-Second brood: 9,460 beetles, no sports.

Yellow Springs, Ohio, I9oI.-First brood: I6,002 beetles, no sports. Second brood: I4,200 beetles, I7 sports-pallida, minuta, immaculothorax.

Chicago, Illinois, I902.-Hibernating beetles from collections on lake beach, I0,109 beetles, no sports. First generation: 12,019 beetles, 2 sports-form pallida. Second generation: 17,008 beetles, no sports. 1903, from same localities, 16,200 beetles of the hibernating generation, I sport-form minuta. First generation: I3:I00 beetles, no sports. Second generation: 12,400 beetles, no sports.

San Antonio, Texas, 1904.-Second brood: 1,100 beetles, 12 sports-tortuosa, albida, minuta.

From these records in nature we see the great rarity of these forms, and taking all the counts, out of $207,89 \mathrm{I}$ beetles examined there were II 8 sports, or in the ratio of $1,76 \mathrm{I}$ to $\mathrm{I}$. This high ratio, however, is due to the lot from Cabin John Bridge, where there were an enormous number of sports, due to most unusual conditions of environment. If we remove these the remaining I96,099 show 36 sports, or in the ratio of 5,447 to I. Taking all the available data gathered from I894 to I904, I find that on the average about I beetle in 6,000 is of the class which is designated as sports, discontinuous variations, or mutants.

These figures demonstrate two interesting points: First, the average rarity of these variations, and the necessity of handling large numbers of specimens to discover them; second, the great production of these under extreme and sudden changes of environment as at Cabin John Bridge. I have already described the same phenomenon in the section on variation, wherein I showed that place variation, when extreme, was accompanied by a great increase in the number of these variations produced, as compared with the normal ratio of production.

The finding of these extreme and permanent variations in nature at the right time for experimentation, and the successful breeding of them is necessarily a matter of chance and open to great liability to failure. In my experience these sports are in nature mostly found singly, and in culture must 
be crossed with the parent stock, because similar variations of the other sex are usually wanting. Cultures of these become, then, largely experiments in crossing these variations with the parent species, as they must and will be in nature.

The variations of this kind observed to arise from decemlineata and the number of specimens are: of melanicum, $3 \mathrm{I}$; tortuosa, 3 ; minuta, 2 ; immaculothorax, 2; pallida, 63; rubrivittata, I ; defectopunctata, I ; albida, I, and obscurata, 4. Some of these I have been able to propagate with success; others, like defectopunctata and obscurata, I have been unable to cross successfully with the parents. It is, however, certain that these variations are a normal product found in nature produced in different ratios-a ratio seemingly dependent upon fluctuations in the environment. The point is that these variations are natural and not the result of domestication or confinement, and it can not be charged that in this material their appearance is due to cultivation, because the foregoing data are drawn directly from nature, and the material for the following pedigree cultures came from the same source. My material is pure, never having been subjected to the supposed vicious influences of cultivation or domestication.

It should also be noted here that the same kind of variations were found to arise in the selection experiments. These were especially numerous in the experiments where I attempted to produce extreme racial conditions through changed surroundings, accompanied by selection, and they are also numerous in the other selection experiments as the races diverge from the mean and mode of the parent species; but they are not numerous in any case, excepting where changed environmental complexes have been employed in conjunction with selection. In many respects these results resemble De Vries's experiments with Enothera, excepting that here we have evidence converging from many sources and pointing strongly to the conclusion that the production of these rare variations is in some way connected with variations in the environmental complexes. This point we shall investigate in a subsequent section of this chapter.

One of the earliest observed variations of this class from decemlineata is the form pallida, which was used in some of my earlier cultures. (See plate I6, fig. 7.) It is not a variety of decemlineata formed by the taking away of characters, but it is a step forward in the line of evolution represented by L. multitceniata, intermedia, and decemlineata-that is, pallida is the next logical step in the orthogenetic evolution of the series of species. This species has been found in the last ten years many times and in divers parts of the United States, and is not limited to any one region.

At various times I have been able to secure 2 or 3 and once 6 specimens of pallida at the same time, and I have made experimental cultures of these with interesting results. In August, IgOI, I found 6 specimens of pallida at Clifton, Ohio. Four of these were males and 2 females; all were well nourished, 
robust, healthy specimens, and were allowed to hibernate through the winter in nature. In the following spring two males and one female emerged from hibernation, the others not being able to pass through this ordeal. With this material as parents, two sets of experimental cultures were started, one a normal cross between male and female pallida, the other between a male pallida and a modal female decemlineata.

The pure cultures of pallida gave in the first generation 30 adult male and 2I female pallida without any trace of reversion to the ancestral species. The polygon of distribution as worked out for this generation is nornal, without trace of skewness, and is separated widely from that of the parent species. From this generation I allowed Io male and I4 female pallida to breed together in one cage, and obtained from the culture 201 male and 282 female pallida, again without trace of tendency to revert to the condition of the parent species. This third generation hibernated, and were unfortunately almost entirely killed off by freezing, so that only 3 male and 4 female pallida emerged from hibernation. I allowed these adults to breed freely together as in nature, and obtained a fourth generation of 76 male and $8 \mathrm{I}$ female pallida, all true to type. From these 20 males and 20 females, representing the entire range of the variations found in pallida, were allowed to breed freely, giving a fifth generation of 292 male and 306 female pallida. The entire lot hibernated, and again a freeze so reduced the number that only 9 males and 7 females emerged in the spring. These were bred together freely, giving a sixth generation of IIO males and I 46 females true to type. From these I selected 40 males and 45 females, covering the entire range of variations found, as parents of the seventh generation, which gave every promise of abundant and typical pallida, when the experiment was abruptly terminated in July, I904, by the accident which brought all of my experiments to an end.

In this series of cultures with pallida there is a striking constancy of form. No selection of parents for each generation was made-only a reduction because my quarters could not accommodate all. Moreover, free interbreeding was allowed in each generation as in nature. Under these conditions paliida showed no tendency to revert to the parental species nor any trace of skewness of the polygons of distribution.

In the first generation 10 male and 12 female pallida were placed in a tank with I $_{5}$ male and I5 female decemlineata, and all allowed to breed freely. Crossings of male pallida $\times$ female decemlineata and male decemlineata $\times$ female pallida, as well as normal crossings, were observed, and the proportion of normal crosses to abnormal was 7 to I. From this mixture, allowed to breed freely as would be the case in nature, I got in the second generation, L. decemlineata, I3I male and II4 female; L. pallida, I33 male and 162 female. These hibernated, and there emerged in the following May, L. decemlineata, Io male and I8 female; L. pallida, 9 male 
and to female. I allowed these to breed freely as before, and obtained in the fourth generation, L. decemlineata, 80 male and 106 female; $L_{\text {. }}$ pallida, I90 male and 2 Io female.

I then transferred the entire lot to nature in a situation where I could keep control of them.

In the fifth generation I gathered all the adults and found: L. decemlineata, 2 I I male and 209 female; L. pallida, 509 male and 540 female.

It was evident that pallida was more than holding its own in this experiment. All were subsequently returned to the plot where the experiment was being conducted to hibernate. The following winter was a hard one, and the plot where the beetles were was frequently subjected to freezing and thawing-conditions most unfavorable to hibernation. In the spring there emerged, L. decemlineata, 6 male and Io female; L. pallida, I4 male and I 5 female. These I allowed to breed together upon a plot of potatoes supplied for the purpose, and counted in the sixth generation, L. decemlineata, 3I4 male and $30 \mathrm{I}$ female; $L$. pallida, 8I9 male and $76 \mathrm{I}$ female. It is clear that pallida was becoming well adapted to the condition of its environment. I felt that further experiment with this form unconfined in nature was neither safe nor desirable, and exterminated the entire lot in the sixth generation. It would have been of great interest to have allowed this experiment to go on and to have given the insects freedom to spread over the country, to see how fast and how far they would have gone, but the nature of the species, its huge capacity for food, and the plants attacked unfortunately made such an experiment entirely out of the question.

At the beginning of these experiments with pallida a single male pallida was crossed with 4 females of decemlineata, giving the first hybrid generation with the decemlineata character dominant. From these beetles I selected lots of to males and to females, and got offspring as follows: (A) L. pallida, 2I males and Io females $=R$; (B) L. decemlineata, $5^{8}$ male and 5 I female $=$ $D+2 D r$.

These lots were now reared in succeeding generations.

Lot A.-These hibernated, and there emerged of pallida 3 males and 2 females, which were bred, and gave a fourth generation which consisted of L. pallida, 2I male and Io female, without traces of intermediate or decemlineata characters. These were bred for the fifth generation, giving of $L$. pallida $4 \mathrm{I}$ male and 40 female. This generation hibernated, and thereafter emerged and were bred in cultures, giving in the sixth generation of $L$. pallida 82 male and 61 female, with no trace of decemlineata. This series was in the seventh generation exterminated by an accident in late larval and pupal stages. It is evident, however, that the material of lot $\mathrm{A}$ was either pure pallida or that pallida was dominant to the extent of submerging and keeping submerged any decemlineata characters. 
Lot B.-This lot, consisting of a mixture of hybrids and decemlineata from the first hybrid generation (the $D+2 D r$ ), gave in the fourth lineal generation after hibernating, of $L$. decemlineata, 92 male and 9I female; L. pallida, I9 male and $3 \mathrm{I}$ female. These were separated and known as lot B 2 (de-

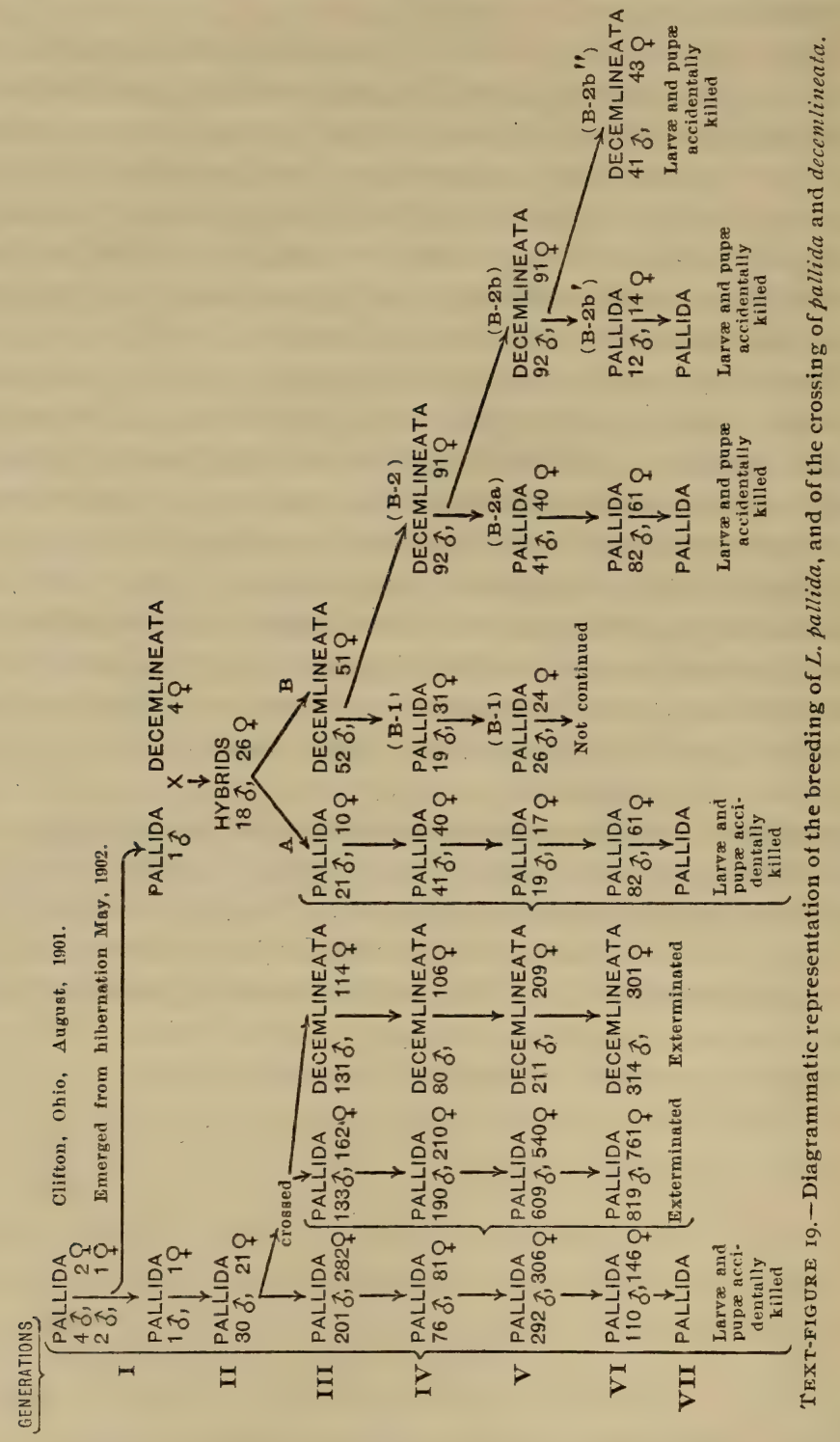

cemlineata hybrids) and lot B I (pallida) and reared in the fifth generation, giving from lot B I of $L$. pallida 20 male and 24 female; and from lot B 2

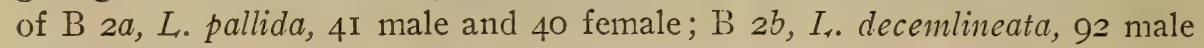
and 9 I female. 
From lot $2 b$, continued in the sixth generation, I got of $\mathrm{B} 2 b^{\prime}, L$. pallida, I 2 male and I4 female; $\mathrm{B} 2 b^{\prime \prime}$ and $L$. decemlineata, $4 \mathrm{I}$ male and 43 female; and from $\mathrm{B} 2 a$, after hibernating, I reared a sixth generation of $L$. pallida, 82 male and 6r female, which were all killed by a fungus disease during the pupal period of the following generation.

These experiments with $L$. pallida cover a wide range of phenomena and bring forth many points of interest. Some, especially the data bearing upon heredity, we shall touch upon only slightly in this series of papers, and only as far as it bears directly upon the main point of investigation-the origin in evolution of new characters and species. If, therefore, I seem to pass lightly over evident facts and interesting experiments instructive from the standpoint of heredity, it is not because I am unmindful of them. I shall present the evidence gathered concerning heredity in following papers.

I can give a clearer and more diagrammatic idea of the nature of L. pallida and the results obtained in these experiments by the aid of text-figure I9.

On the basis of these cultures of L. pallida it is shown that it behaves in crossing exactly as we should expect independent and isolated species or elementary species to do. Without selection it remains true to type, differing thus in fundamental attributes from races and many of the so-called discontinuous variations. Moreover, pallida behaves like an independent species when reared with decemlineata in a general culture where free hybridization is possible, and we see that it not only is not obliterated, but eventually becomes even more numerous than decemlincata. I see no other possible conclusion than that pallida is a true elementary species, developing suddenly from decemlineata, and behaving from the start as an independent specific unit.

The question may be raised that if pallida is so well able to stand alone, so well able to increase even when there is opportunity to cross freely with the parent species, why do we not find it becoming established in nature? The answer to this question would be difficult to frame did we not know well the natural history of the material. I have shown that, taking all the nine variations of this class, we find only one of them in 6,000 cases, excepting under rare circumstances, so that we may fairly expect to find a particular variation only once in 54,000 cases. Pallida, however, is the most common one, occurring once in every 5,000 cases. Suppose one to arise in nature. I have shown that there is close selective mating in decemlineata, and that in confinement the chances are 7 to I against pallida mating with decemlincata. When we add to these conditions the great mortality during hibernation which is especially fatal to extremes of variability, the probability of a single variation of this class being able to propagate itself is so remote as to become a real impossibility. It is only under rarely realized conditions, when, as at Cabin John Bridge, variations are for some reason especially numerous, that they would perhaps be able to get the necessary foothold to 
become established. My original material in this series of cultures came from potato fields widely separated at Clifton, Ohio, so that had I not gathered and cared for the material nothing would have come of it. I doubt if it is possible in the light of what we know of the natural history of decemlineata for the species pallida to become established as an independent species. L. decemlineata, although the parent of many of these variations, gives them in nature so rarely that the collection of immense numbers is necessary to discover even single specimens. $L$. decemlineata differs widely in this respect from many plants, as also from its tropical relatives.

In the selection experiments with melanism and albinism a single male of the mutant pallida appeared in the sixth generation. As far as could be determined this specimen was just like those from nature. It was crossed with two female decemlineata of modal color. The offspring of this cross, when reared under normal conditions of existence, gave a hybrid progeny in which decemlineata was dominant. These were bred inter se, and gave: (A) L. decemlineata, 29 male and 33 female (62), and (B) L. pallida, II male and 8 female (19), without any intermediates. From these cultures were again made, and from (A) I obtained of $\left(\mathrm{A}^{\prime}\right), L$. decemlineata, 62 male and $7 \mathrm{I}$ female (I33), (B'), L. pallida, 54 male and 67 female (I2I); and from (B) I obtained L. pallida, 46 male and 44 female (90), and no trace of other conditions. (B) was now reared through six lineal generations, and gave pure pallida only. The (A) series was also reared through six generations, giving in each generation the two forms, pallida and decemlineata, the pallida breeding true to type where isolated. I did not try in this series the experiment of rearing pallida along with decemlineata in a state of nature, owing to lack of room, but I can see no reason why it should have behaved differently.

The general behavior of this series I have put in the form of a diagram (text-fig. 20), which shows the history of each generation in the experiment.

In this series, as in the previous set, decemlineata is the dominant member of the cross in the hybrid generation, but in the succeeding generation we get a Mendelian separation, the two forms appearing in each subsequent generation. The chief point of interest to us is the further demonstration of the fixity of type in pallida, no matter whether we obtain it from nature or from material in captivity. This point, which is an important one, is for pallida sufficiently demonstrated by the two sets of cultures described. Thus far we have considered only one extreme variation, but before attempting to arrive at any final decision we must examine the cultures made from other variations from decemlineata.

One not quite as common as pallida, and differing from it almost diametrically, is melanicum. Although one of the commonest of the variations of this class arising from decemlineata, it is one of the most difficult to propagate. Out of the $3 \mathrm{Tr}$ specimens found in nature, 20 were males, and these were 
all, excepting one, unable to breed successfully with decemlineata, and I have never had both sexes of melanicum from nature at the same time.

In June, I902, I found a male melanicum and a female decemlineata in copulation, which were at once transferred to the vivarium, where they gave a hybrid generation of $I_{4}$ adult beetles, with the decemlineata characters dominant. These I4 beetles, 6 male and 8 female, were bred inter se, and, while relatively infertile, gave in the second generation 36 beetles, Io of pure melanicum and 26 of decemlineata type. The entire lot now went into hibernation, but were all killed during the winter of 1902-'O3 by a freeze. The series, short and incomplete as it is, shows that melanicum behaves in crossing exactly as does pallida. At other times I have made crossings of melanicum and decemlineata, but without result; although copulation was

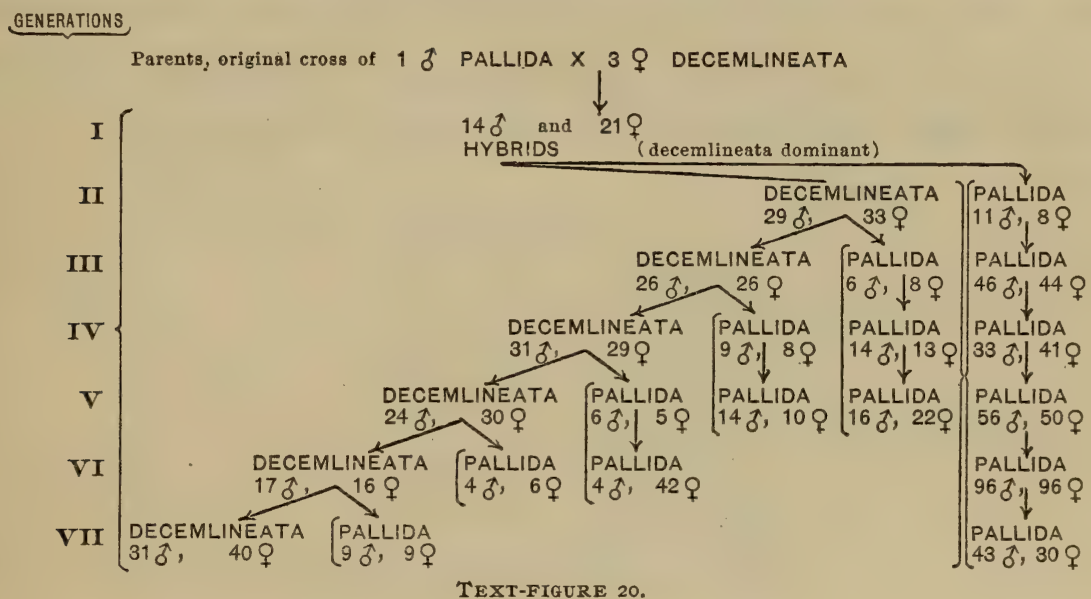

usually observed, fertile eggs were not produced. This variation is evidently much more isolated from its parent species than pallida, and has also much more remote chances of gaining a foothold in nature under ordinary conditions. Extraordinary conditions wherein there arise a large number of melanicum might give it a start, but such conditions do not seem to have been realized in nature. It is, moreover, ill adapted to the habitat of decemlineata, into which it must be born, as it is apparently able to live or reproduce only in a high percentage of humidity. My experience with them is that only the above condition can be used for their propagation in experiment, and there is every reason to believe they would require a like condition in nature.

A variation resembling melanicum, but differing from it in having the whole surface closely set with minute black dots and the color marking in general irregular, occurs rarely, only two specimens of it ever having come into my possession. Both of these specimens were females and were found 
in the second or hibernating generation, and both died during hibernation, so that I have had no opportunity to make cultures.

One of the rarest of the extreme variations from decemlineata is the form tortuosa, which, however, must not be confounded with some of the somatic variations of decemineata, that often exactly resemble it. It seems to be confined to the south, and only once have I obtained it north of the Ohio River. Two specimens, male and female, were found in a lot of decemlineata from Georgia in 1902, and were reared, giving a pure tortuosa progeny of 18 males and 16 females, and from these I again reared a second generation of 24 males and 33 females, pure tortuosa. These hibernated, and there emerged in May, I903, 6 males and 7 females, which gave a brood consisting of 31 males and 30 females. This breeding was continued until August, I904, when they were all destroyed. Crosses were also made between tortuosa and decemlineata, but not with ease, and such crosses gave a true Mendelianlike splitting. The procedure and results of this experiment with tortuosa I can best show in the form of the diagram given in text-figure $2 \mathrm{I}$.

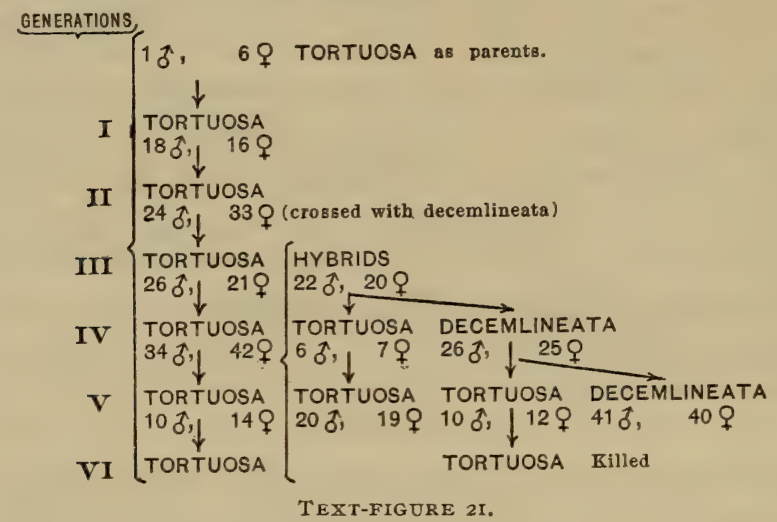

As far as discovered, tortuosa behaves like a species, handing on its characters unchanged to its progeny for six generations without selection other than isolation from other species. In the culture full opportunity was given for promiscuous crossing such as occurs in nature.

A variation which arose from deceminineata obtained at McPherson, Kansas, appeared in my culture in June, I904. This was rubrivittata, of striking form and coloration, of which there was a single male. The parents, which were collected in July, I903, near McPherson, Kansas, were sent to Chicago and reared in a second generation which was normal; they hibernated until May, I904, and then emerged, reproduced, and among the progeny was this single male rubrivittata. This male was crossed with a female decemlineata from Chicago, and gave a hybric brood intermediate in character between the parents. Three males and one female of this lot escaped the general exter- 
mination of my experiments in July, and were carried over into I905, giving after transfer to Mexico in March, I905, a Mendelian splitting into typical rubrivittata and hybrid forms (text-fig. 22). These .were separated and reared. The pure cultures of rubrivittata showed as the result a new character, namely, that its life history as well as less important characters were changed, there being three generations in its yearly cycle instead of two, as in the parent species, and in all the species in its immediate ancestry.

This change in the life cycle from hibernating in every second generation, as do most of the species in the genus, to hibernating in every third, is striking and significant, the three generations being gone through in about

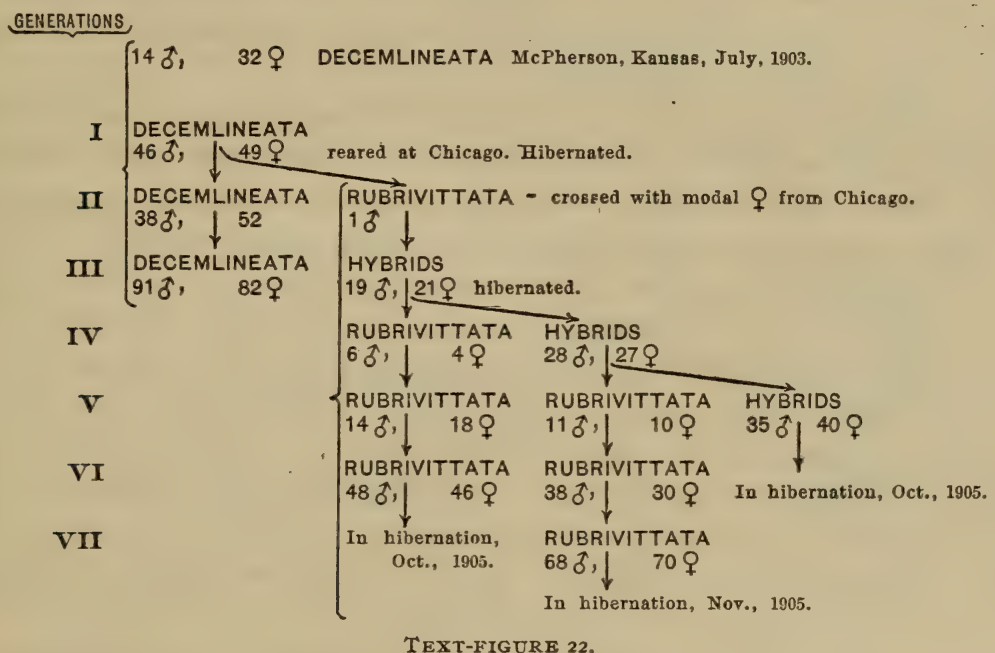

the same time as the two of the parent species. The cultures with rubrivittata demonstrate clearly that changes in physiological characters can take place rapidly, as do changes in structure, and that these changes may alter not only unimportant characters, but a most fundamental one as well. We shall have occasion to consider a similar case even more striking and interesting in a later part of this chapter.

With the variations albida, minuta, defectopunctata, and immaculothorax found in nature, I have succeeded in obtaining cultures for one or two generations only, and these I shall not dwell upon, since they add only slightly to this account. We shall, however, meet with these in the experimental production of extreme variations, where it has been possible to get cultures, owing to the greatly increased number available for experimentation.

With these variations from nature and the cultures made from them, it is conclusively demonstrated that there do appear in nature rapidly developing extreme variations which stand apart from the normal fluctuating variations 
and breed true to their type. These differ in many characters from the parents, and this new combination of characteristics is, as my cultures show, handed down from generation to generation with undiminished intensity and unchanged arrangement. These behave in heredity, especially in crossing, exactly as do independent species.

As far as I can judge, my variations from decemlineata are as pure and strong as De Vries's mutants from Enothera, holding their own even in crossing with the parent species. The experiments with pallida are strong evidence in favor of the origin of species by rapid change, better, perhaps, than that afforded by De Vries's plants, because pallida, given the necessary start, needs neither selection nor attention to take care of itself, and my cultures would, I have no doubt, have spread widely in nature, as they began to do, had I allowed them to continue.

It is probable that, in view of the evidence which is herein produced, there will be raised the objection to the origin of species by rapid evolution that, as I have shown, these rapidly developing extreme variations occur rarelyvery rarely-and are usually single individuals, which are able to increase in numbers only when cared for in cultures, and hence can not be of any marked utility in the evolution of species, owing to the immense improbability, as shown, of their being able to get a start from a single individual. This objection is valid only in as far as it concerns single individuals. I have given evidence in the case of the Cabin John Bridge specimens, and in the section on place variations it is shown that under fluctuations in the environment there are produced sometimes a considerable number of these extreme and permanent variations. Given a fair numerical start, pallida was able to take care of itself, so that the point is not that it is impossible, but that it must get a fair start numerically in order to succeed, and, although decemlineata shows several of these extreme variations, they occur at so infrequent intervals that I doubt if under present conditions any of these forms could become established in nature. Whatever we maybelieve concerning the future of these variations in the evolution of the genus Leptinotarsa, my cultures of decemlineata show in a clear and unmistakable manner the inadequacy of selection to create new elemental species and the fact that such do arise by sudden transformation. By selection we can create races, but we must maintain them by the same process, else they revert to the mediocre of the parent species. Races, too, differ in one or two characters from the parent elementary species in a complex of characters which often maintain their fixity without the aid of selection. Races and elementary species, therefore, differ in several attributes, but I think the difference is not in kind, but only in degree. They stand apart, and apparently there is no intermediate ground, yet our observations are all too meager and our attention too much distracted by the striking variations. It is my firm conviction that we shall later discern plenty of 
intermediate stages between these two types of permanent variability, which are, I believe, the extremes of one and the same phenomenon. At least, as far as I have observed in decemlineala, I interpret the conditions as stated rather than that there is the fundamental difference between races and species postulated by De Vries.

\section{PEDIGREE BREEDING IN L. MULTITAENIATA.}

It has been shown that $L$. multitceniata is the immediate tropical ancestor of $L$. decemlineata, and lives only upon the southern end of the Mexican highlands. My experience and cultures with this species, covering part of I903 and the years I904 and I905, extend and confirm, as far as is possible in three years, the results obtained from the longer continued studies of $L$. decemlineata. This species, we have already seen, is variable, wide ranging, and gives rise to extreme variations under the influence of changing sur-

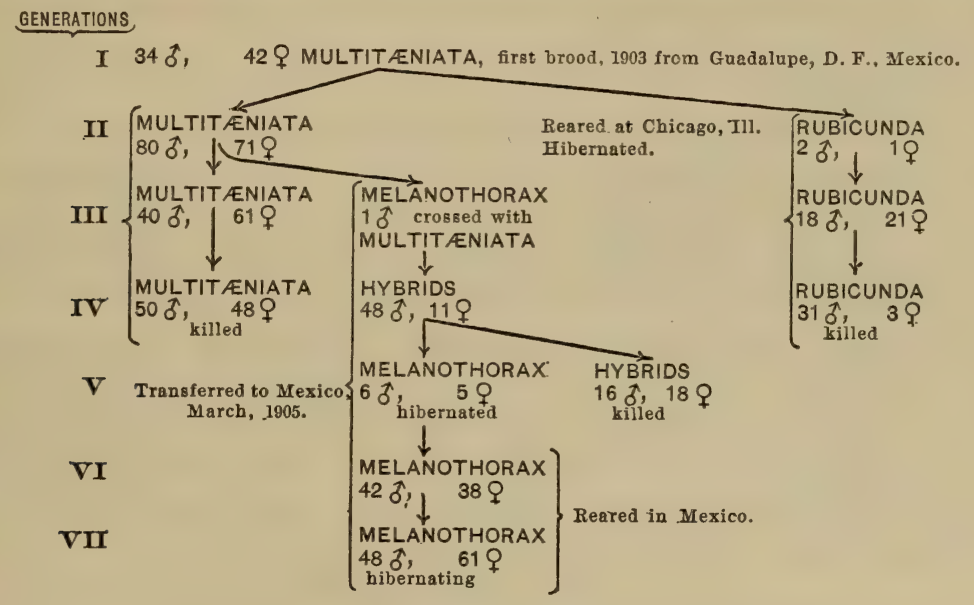

TEXT-FIGURE 23.

roundings or fluctuations in its environment. My experiments with this species are still going on in the tropics, and I shall give here only such results as bear directly upon the problem of the origin of species.

In August, I903, I obtained a large number of L. multitaniata from Guadalupe, near Mexico City, which were taken to Chicago and there reared under conditions as nearly normal as was possible. At Chicago these beetles were bred in September and October, giving a progeny of 80 males and 7 I females, with 2 males and I female of the species rubicunda, which I had found at Toluca, but never at Guadalupe. These all hibernated, and there emerged in February of the typical multiteniata 20 males and 26 females and I male and I female of rubicunda. These were isolated and 
reared, the rubicunda giving in the two following generations typical rubicunda without a trace of reversion, and the multitceniata no more rubicunda. In the second generation of multitceniata reared at Chicago there was found a single male melanothorax, which was crossed with a normal female multitcniata, giving a hybrid progeny of I4 males and II females intermediate between the two parents. These hybrids were again bred inter se, and gave a Mendelian splitting of melanothorax 6 males and 5 females, and multitaniata (hybrids) I6 males and 18 females. In July, I904, the series was all killed excepting the melanothorax portion; these hibernated, and were transferred to Mexico in March, 1905, where they have gone through two more generations and are now hibernating. Thus far they have shown no trace of reversion to the parental type. The history of this experiment is given in text-figure 23 .

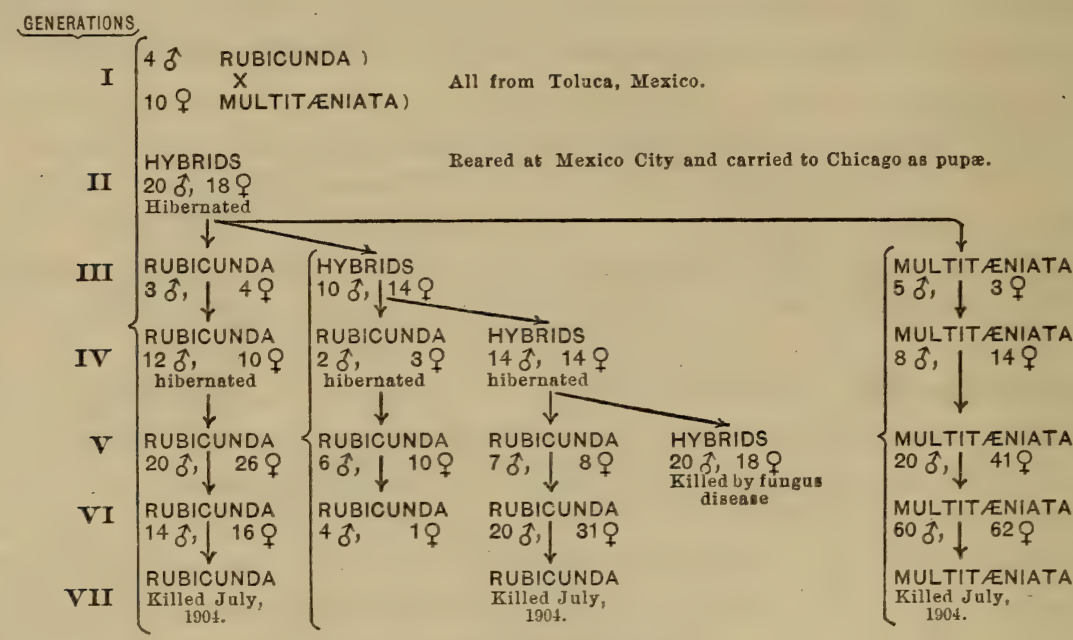

TEXT-FIGURE 24

During 1904 and 1905 several other sets of cultures with this species were started, but they have not yet gone far enough to give results of certainty. Unfinished as is the above experiment, it shows quite conclusively that there develop suddenly from multitcniata, as there did from decemlineata, extreme variations which breed true to type and behave in hybridization like species of permanency.

In August, I903, I obtained at Toluca four males of the form rubicunda, which were bred to ten females of multiteniata from the same place, and from these were obtained a hybrid progeny intermediate between the two parent forms. These hybrids were transferred to Chicago, where they were again bred, and gave a Mendelian splitting into rubicunda, multitcniata, and hybrids. These cultures were placed in a greenhouse, giving short hibernations and life cycles, with the results shown in text-figure 24 . 
These experiments with multiteniata and its transmutations, rubicunda and melanothorax, simply confirm and extend the results obtained from cultures of decemlineata and its descendant species, but are much clearer in many respects than the culture with decemlineata. This is especially true in the last culture described, where there was a clear and unmistakable Mendelian splitting of the hybrids into $D+2 D R+R$, which was continued for several generations. This behavior in crossing and the complete heritable quality of the modifications found in rubicunda and melanothorax show conclusively that in these forms we have to deal with variations of permanency, which are able to take part in the evolution of species.

This pedigree breeding in Leptinotarsa, which has been extended to other species of the genus as well as to the two described above, brings us to several interesting and suggestive conclusions.

(I) It is demonstrated that among the fluctuating variations there are individuals which are able to transmit their particular variations and give rise by selection to a race, while the majority are not able to hand on their particular conditions to their progeny. Races developed by selection from such variations have not by the methods used been carried beyond the normal limit of variability of the species, which circumstance may be attributed either to the inefficiency of selection to overstep the normal limits of variation, or, with more probability, to imperfect methods, and to the brevity of the experimentation. At present I see no means of deciding which is the correct solution of the limitation found in race formation through selection.

(2) It is demonstrated that there are found at irregular intervals in nature and in cultures extreme variations which differ from the parent species in many and constant characters, and are shown to breed true to type. Moreover, in crossing, these forms behave as do species, so that no matter what we call them or how we attempt to explain them and their rapidity of development, the facts as stated above are clearly shown.

(3) It was found in some of the cultures where selection was aided by changed environment that heritable fluctuating variations and extreme variations were greatly increased in number. It was further recorded that at Cabin John Bridge unusual conditions in the environmental complex produced an unusual number of these variations. Further, in the discussion of place variations I have shown that when the polygon of variation of these beetles swings toward extreme conditions, it is accompanied by an increased production of these peculiar and extreme variations, and that when the environmental complex assumes a normal or modal condition the production of these variations also becomes modal-that is, very few are produced. This convergence of evidence from diverse sources most strongly suggests that the production of numbers of heritable, fluctuating variations, or the 
development of extreme variations, is associated with, if not due to changes in the environmental complex in different directions from the mean or average conditions. In the light of this converging evidence, it will not be unfair to draw the conclusion that these variations, which are shown in my cultures to be true factors in the formation of races and species, are due to the relations existing between the parent species and the changed environmental complex. The phenomenon is a natural one and not due to agencies or causes not capable of investigation. I have planned and carried out, in the years 1899 up to date, a series of experiments and cultures to test and further elaborate this tentative hypothesis, reached as the result of pedigree culture, observation, and study of these beetles in nature. I shall give in the next section some of the experiments, their results, and the conclusions arrived at; after their presentation we shall be in a better position to discuss the general results derived from this series of cultures and experiments.

\section{EXPERIMENT IN PRODUCTION OF NEW CHARACTERS AND SPECIES.}

I have shown that, as far as can be discovered, all variations of permanency in these beetles arise in the germ cells and are in nowise the result of inherited somatic modifications. This point is so repeatedly demonstrated in my experiments with these beetles that I have come to regard the somatic origin of permanent variations as untenable until we have experimental proof of its existence. The origin of germinal variations in these beetles appears to be correlated with environmental changes, and I have repeatedly noted the appearance of permanent variations in nature and in experiment where there was a wide deviation in the factors of the environmental complex. I therefore, some years ago, came to the conclusion that the environment did not act in any specific manner, but solely as a stimulus, which, when brought to bear upon the germ plasm, produced a response or change which took the form of permanent variations in some one or more characters. To test this hypothesis several sets of experiments were begun in the year 1899 , continued to the termination of my series in 1904, and started again in 1905 .

In these experiments I followed the plan of subjecting the parents to environmental stimuli during the growth and maturation of the germ cells, and then, after fertilization, of allowing the subsequent development to take place under normal conditions. The beetles emerge from the pupa or from the winter hibernation with the germ cells in an undeveloped condition, and these undergo their development, especially the ova, during the few days following emergence. None of the beetles develop all their eggs at once, as do the Lepidoptera and many other insects, but in batches, each batch being laid before the next begins development, so that between the laying of each two batches there is an interval of some four to ten days. All of the beetles in 
the genus show this rhythmical development, especially of the ova, but some more than others, and decemlineata least of all.

The development of successive lots of eggs results in a definite cycle of external changes in the form of the female, so that one can tell very exactly, after a little experience, the state of the ova, but, unfortunately, this is not possible in the case of the male. This condition makes possible a great variety of interesting and crucial experiments, especially in the female, because whatever stimulus is brought to bear upon the animals can not further modify the parents, since they have attained their final state, and can, therefore, not develop further, even if they could transmit any acquired modifications. Moreover, since the ontogeny is passed in normal surroundings there is no gainsaying the fact that whatever modifications are produced originate in the germ. Many and various experiments have been made with this material, some bearing directly upon the question of the origin of permanent variations and new characters, others of singular import in the study of heredity and theoretical considerations of germ-plasm constitution. I shall present here experiments in the production of new characters and species only, and those bearing directly upon heredity and other questions I shall publish in a later report.

\section{EXPERIMENTS WITH L. DECEMLINEATA.}

This species, although the least satisfactory and most difficult of all in the genus to work with, has given interesting results.

In May, I90I, I subjected 4 males and 4 females from the hibernating population of decemlineata to extremely hot (average $35^{\circ} \mathrm{C}$.), dry (relative humidity, average 45 per cent) conditions, accompanied by low atmospheric pressure (I9 to $2 \mathrm{I}$ inches), during the growth and fertilization of the first three lots of eggs, which were placed as soon as laid in natural conditions and reared. The last two lots were laid and reared in normal conditions. The first I designated Lot A, the second Lot B. All were reared during their ontogeny from the earliest embryonic stage to adults in normal environment. From 506 larvæ which hatched from Lot A I obtained 96 adult beetles, of which 82 were of the form pallida, 2 of the form immaculothorax, and 14 unmodified. From Lot B, of 319 eggs I got 6I normal beetles. A bacterial disease killed off my immaculothorax and all but two of my pallida, which were crossed with normal females, and gave in the following generation hybrids with the decemlineata characters dominant. The B lot bred true to type in the second generation. All now hibernated, and there emerged a few (8) of the hybrids in the following spring, which, when bred inter se, gave a characteristic Mendelian separation into pure pallida, decemlineata, and hybrids, the two latter being indistinguishable. Both series were carried into the winter of 1902, when all were killed by freezing. Text-figure 25 shows exactly the history of this experiment. 
At the time this experiment was started, in May, I90I, beetles of the same generation were taken and reared in cultures until May, 1902, and showed no tendency to give, under normal conditions, extreme variations. In May, I902, these were subjected to two sets of conditions, one hot and dry, the other hot, dry, and low pressure. These two lots will be considered separately.

From the apparently pure stock, 7 -males and 7 females were in May, I902, subjected during the first half of their reproductive period to hot, dry conditions, during which time they laid 409 eggs. For the latter half of the reproductive cycle they were kept in normal condition, laying 840 eggs. From the 409 eggs developed and laid in changed surroundings I obtained 64 adults, as follows :

(A I) Normal (apparently) decemlineata, I2 males, 8 females; (A 2) $L$. pallida, Io males, 13 females; (A 3) L. immaculothorax, 2 males, 3 females;

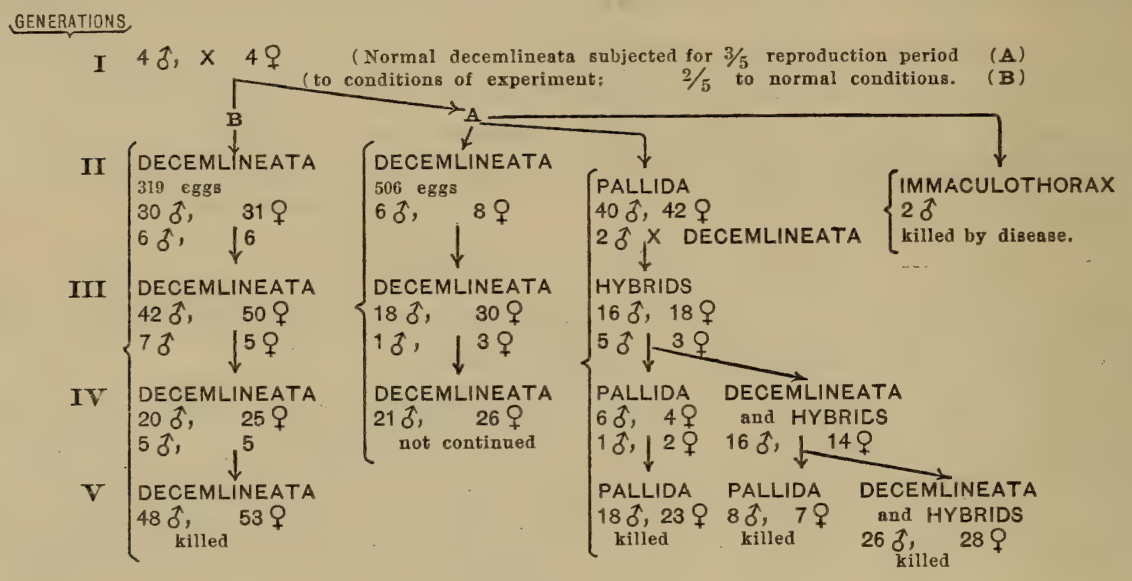

TEXT-FIGURE 25.

and (A 4) L. albida, 9 males, 7 females. These four lots were separated and reared, with the exception of pallida. The 840 eggs laid in normal conditions gave I23 normal decemlineata, and these I designated B.

The Lots A I and B were reared side by side in the following generations and both gave normal beetles as far as could be determined, but as the period for hibernation approached, those of A I, instead of going deep into the ground, as did B and as is normal, æstivated on top or close to the top. The Lot B went into hibernation in September, A I in late October and early November. In January (January 2) Lot A I emerged from æstivation and began breeding, giving a brood, part of which hibernated and part continued breeding for five generations, then hibernated, and then emerged and bred through five more generations. These hibernated again, and in the fourth generation of the third cycle of five generations were killed in July, I904. These successive generations were all reared under exactly similar conditions, 
nor was there any conscious selection practiced. Free interbreeding in each lot was allowed. The general result is expressed in text-figure 26 .

This race with a cycle of five generations is of great interest, showing the profound modification resulting in the reproductive cycle. None of the

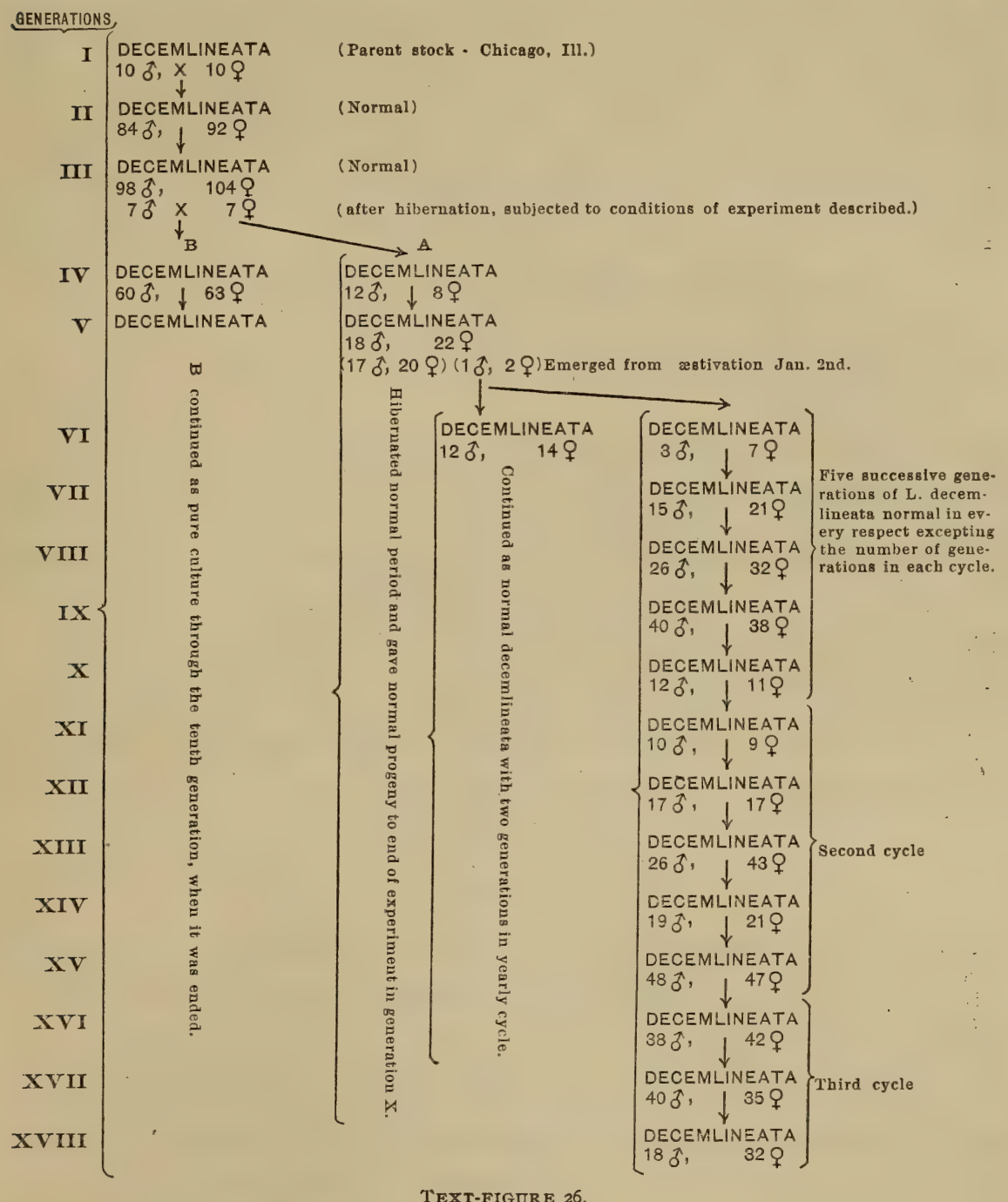

beetles of the lineata group, to which this beetle belongs, have more than two, or rarely three, generations per year, and there are none known in the genus that have over three. Clearly, then, this race with five generations in each cycle is quite a new character in the genus, and was, as far as discovered, 
constant from the start, showing in the fourteen generations no tendency to revert to the parental standard. As far as I can discover, this case can be explained only as the direct response of the germ plasm to the extreme stimuli used in the experiment. It seems impossible to account for the condition produced upon the basis of a latent character of this kind somewhere in the ancestry of this genus. Moreover, all the beetles in this experiment had an equal chance to be accelerated by the conditions of existence, so that this factor could not by any stretch of the imagination be held to account for the development of this change. As far as is known, the only changed factor in this experiment was that used in the third generation upon the 7 males and 7 females for three-fifths of the reproduction period. ${ }^{1}$ From the germ cells

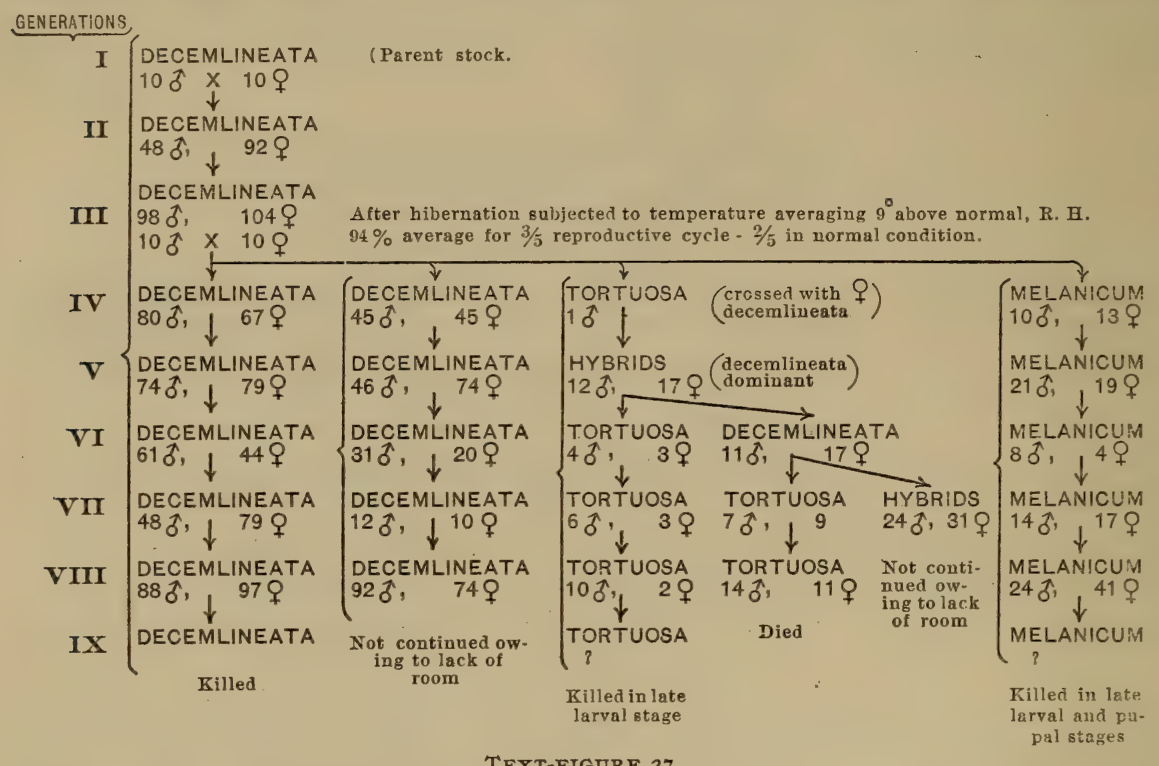

TEXT-FIGURE 27 .

subjected to stimuli this race arose, but not at once, two generations being necessary in which to disentangle the changed characters from the nonmodified decemlineata.

The forms immaculothorax and albida produced in this experiment were reared through three and two generations respectively, but were weak, illadapted variations, and were kept alive only by closest attention. Although these variations have arisen many times in my experiments, they are never strong, nor do they produce many eggs, but die quickly. When they do

\footnotetext{
${ }^{1}$ The fact, clearly shown in this experiment, that the response (modification) does not always follow the stimulus at once, but may not appear for some generations, is a point of great moment. It shows that the appearance of a "mutant" must not be attributed to "internal forces" unless we are able to say that there has not been a previous stimulus due to changed environment, habits, etc.
} 
breed, however, as far as my experience goes, they breed true to type, but from the nature of this work and the brevity of my experience with these forms, I do not care to be very positive concerning them.

Experiments with other conditions, as, for example, hot moist, cold moist, and cold dry, have also been tried with varying success. Thus ro males and Io females, apparently pure-pedigreed material, were subjected to a hot moist condition for the first three-fifths of the reproduction cycle and kept in normal conditions for the remainder. The two lots of eggs obtained numbered (A) 6or, (B) 590. From (A) I got I24 imagines, as follows : of tortuosa I male, of melanicum Io males and $\mathrm{I} 3$ females, and of normal decemlineata 45 males and 45 females. The tortuosa male (A I) was crossed with a female decemlineata, giving hybrid offspring, with decemlineata dominant, and in the following generations a Mendelian separation into tortuosa, hybrids, and pure decemlineata. This continued, the tortuosa breeding pure. The melanicum were reared and bred true to type, as did the unmodified decemlineata. Text-figure 27 shows the procedure and the results from this experiment.

This series of cultures, grouped as one experiment, shows again in a clear manner that the variations arose only in those germ cells subjected to extreme stimuli, while the germ cells developed and fertilized under normal conditions did not show in any of these experiments the slightest trace of the production of these highly divergent permanent variations.

L. decemlineata, although most easily accessible and hardy, and not difficult to breed within limits, is, however, the poorest of the entire genus for this kind of work, owing to its adaptation to a wide range of environmental conditions, to which it adjusts itself without any apparent change. It is necessary, therefore, to use extreme conditions to get the requisite stimuli, and unless one be fully acquainted with the peculiarities of the habits and needs of these beetles the experiment can end only in failure, as did my earlier efforts, and not a few of the later ones. Among the tropical members of the genus are many excellent species for this kind of experimental work, owing to their adaptation to rather uniform conditions and to their ability to exist and reproduce under changed conditions quite different from their normal environment. The limits of life are about the same for all the species of the genus, but decemlineata is adapted and adjusts itself to nearly threefourths of the entire range, while the tropical species are adapted to only onethird or one-half the range; hence experimentation with the tropical species is far easier and much more satisfactory.

As far as I have gone in this investigation my experiments with decemlineata show that when the animals with developing germ cells are subjected to strong stimuli many of the individuals derived from these same germ cells often show intense heritable modifications, whereas those not acted upon, 
although of the same parents, do not show these changes. It also appears that both structural and physiological characteristics are modified by this process.

During the last three years I have been able to experiment with the tropical members of the genus, and although the work is as yet in its earliest stages and very incomplete, the results obtained thus far support and extend those found in decemlineata. Of these I shall give only a few of the clearest and best worked out series, reserving until a future date a more elaborate presentation of this line of experimentation.

\section{EXPERIMENTS WITH L. MULTITANIATA.}

My experiments with this species cover the short period of three years, and are now being continued. From specimens obtained at Guadalupe, Federal District, Mexico, in August, I903, a generation was reared at Chicago in September and October of 1903, which hibernated until February, 1904. This generation was to all appearances normal. From this material 6 males and

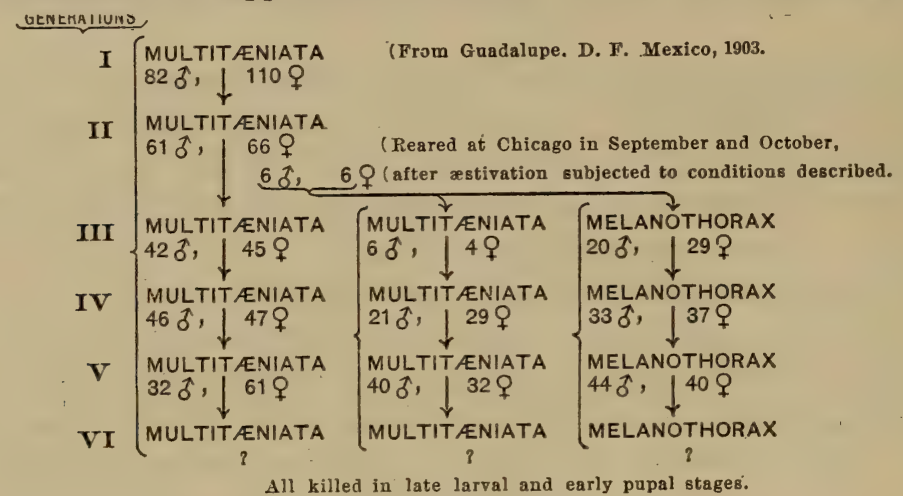

All killed in late larval and early pupal stages.

TEXT-FIGURE $2 \delta$.

6 females were taken and subjected to conditions in which the relative humidity was 100 per cent and the average temperature $30^{\circ} \mathrm{C}$.-both considerably above the normal condition for the species. The beetles were kept in this for one-half the reproductive cycle, and then transferred to normal conditions. During the period of changed condition 492 eggs were laid and 509 eggs in the second period. These were reared in normal conditions, and there came from the first lot 59 beetles, of which there were Io normal beetles, 6 males and 4 females, and 49 of the form melanothorax, 20 males and 29 females. From the second lot of eggs came 82 normal beetles. These lots were now continued and reared, giving in successive generations pure forms without traces of reversion. All the lots went through the regular cycle of two generations, and then hibernated for six weeks, and after emerging from æstivation, began reproduction, but were killed in July, 1904. The data of the experiment in diagrammatic form is given in text-figure 28 . 
At the time the foregoing experiment was started another one was begun in which the sexes matured their germ cells under the conditions of experiment, but copulation and fertilization took place under normal conditions. In the experiment 6 females were kept during the development of the first lot of ova in normal condition and bred to normal males. During the development of the second, third, and fourth batches they were kept under the conditions of experiment, and bred to males whose germ cells had been developed under the conditions of experiment, while the fifth and sixth lots were developed under normal conditions and fertilized by normal males. The three lots of eggs obtained we shall call A, B, and C. The results from the lots were rather interesting, and are given in diagrammatic form in text-figure 29.

These two experiments with L. multiteniata show that when the imagines are subjected to strong stimuli during the development of the germ cells the result is the production of a large number of rapidly developing extreme and

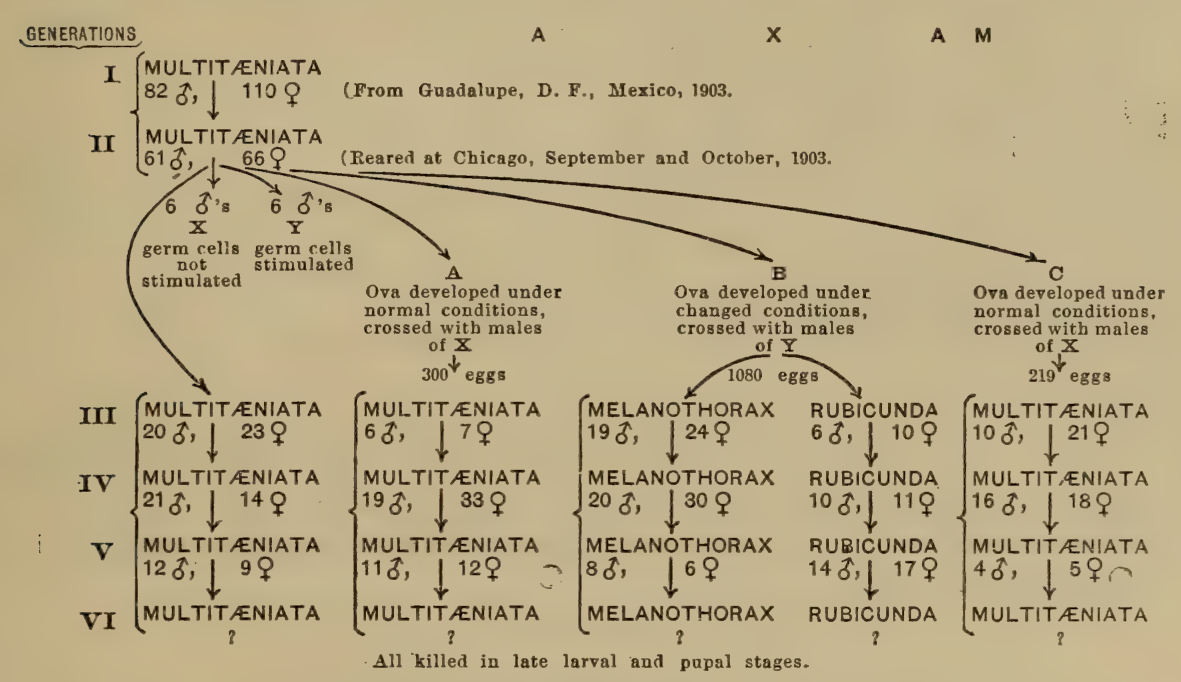

TEXT-FIGURE 29.

permanent modifications. There is a rapid transformation of the characters of the stimulated germs into new arrangements, giving us new characteristics and incipient species. The first series of cultures are in all respects like those given for decemlineata - that is, parent beetles reared under the condition of the experiment gave a higher percentage of offspring with modification of permanency. The second experiment, however, shows clearly that it is only those germ cells that are acted upon during growth and maturation that are changed, and that, although others are present as primitive germ cells in the body of the parent, they do not seem to be modified unless they, too, are subjected to stimuli in the growth periods; that is, it is in the growth period, 
when the differentiation of the germ plasm begins and preparations are made for the following generation, that these changes are easiest to bring to pass.

EXXPERIMENTS WITH L. UNDECIMLINEATA.

Living material of $L$. undecimlineata from Orizaba, Vera Cruz, Mexico, brought to Chicago in August, 1904, and reared in September and October, was, after hibernation, subjected, during the growth of the germ cells, to an extreme stimulus of high temperature, $10^{\circ} \mathrm{C}$. above the average, and a relative humidity of 40 per cent, with the result that out of the 190 eggs laid there emerged II beetles, all of the form angustovittata. They were reared, and gave pure progeny.

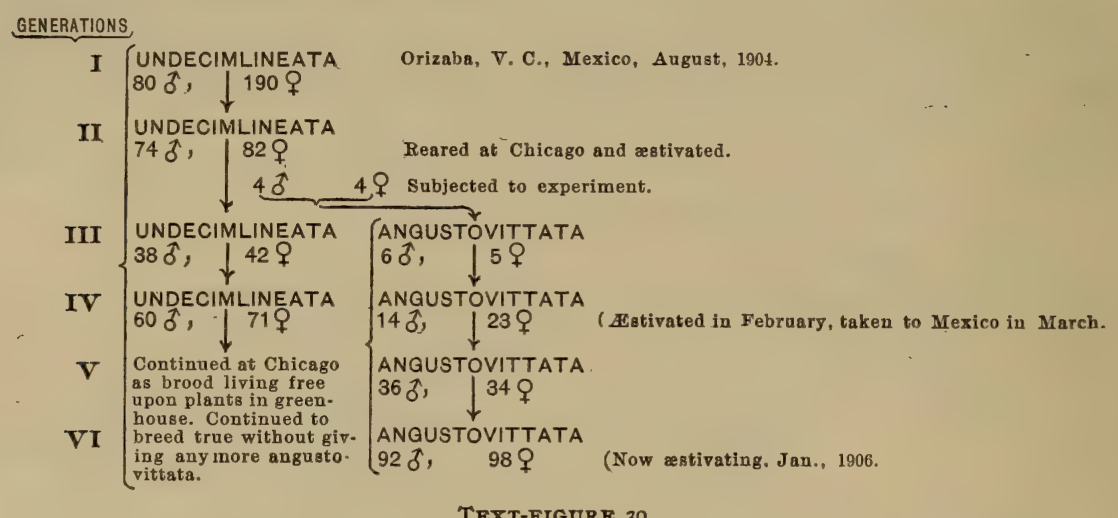

TEXT-FIGURE 30 .

As far as was discovered in these cultures of $L$. undecimlineata the results of the experiment in the stimulation of the growing germ cells were the same as those obtained in the ohers experimented with, namely, permanent variations, which bred true to type.

\section{CONCLUSION.}

I have presented in these few pages some results obtained in a line of investigation which is as yet in its infancy and which is being actively continued. Besides the experiments given, I have tried and am continuing other experiments upon the same species, as well as upon other species of the genus Leptinotarsa and species in closely related genera. Of this experimental work I introduce here only my longest continued and clearest examples as part of the argument for the method of evolution which I believe is followed in insects. I shall present in some future report a full statement of these experiments, and at that time shall be able to go more completely into the details and theoretical aspects of the problem. Herein, however, I shall be content to make a simple statement of the results, reserving theoretical consideration 
until such time as I have accumulated a sufficient body of observations to warrant it.

A careful consideration of the various lines of experimentation recorded and of the pedigree cultures and the data from observation in nature irresistibly forces one to the conclusion that in these beetles the only variations of permanence are germinal, and that the only possibility of evolution is through germinal variations. Those germinal variations which arise in nature are permanent, and the same variations, of the same degree of permanence, are produced in experiment. The diverse kinds of evidence produced in this and in preceding chapters all go to show that under varying conditions of their surroundings these beetles vary, and that as they become more and more extreme an increasing percentage of striking, permanent variations is found; and as I have just shown, it is possible in experiment to produce in this same way a variety of permanent modifications. From all this evidence, however, there nowhere appears the least trace of a suggestion of any specific action of the conditions of existence, but everywhere there appears only the action of environment as a stimulus, while the response is entirely determined by the organism. All of these variations of purely temporary and of permanent kinds resolve themselves into responses of the organism to the stimuli of its environment, but the nature of the response is entirely determined within the organism. It is true that different intensities of the same stimuli call forth different responses, but, as is shown in the chapter on coloration, the response is entirely determined within the organism, which is adjusted to different intensities of stimuli and reacts according to its own method and on the basis of its own constitution, there being no specific reaction called forth by a given stimulus.

I conclude, in the light of these experiments, that the production of heritable variations, slight or extreme, represents in these beetles the response of the germ plasm to stimuli. In my experiments these stimuli were external, but there is no a priori reason why they might not also be internal. The response, however, is absolutely determined within the organism.

Since the above statements were written, MacDougal (1906) has given a preliminary account of his experiments with Raimannia, wherein salt solutions were injected into the ovule just previous to fertilization, with the result that variations, "potentially new species, were secured as a result of chemical and osmotic action exerted on unfertilized ovules." These results, he believes, "demonstrate conclusively that factors external to the protoplast may exert a profound influence upon its heredity characters, and call out qualities not hitherto exhibited by the line of descent affected." These results of McDougal's exactly confirm in plants the results that I have obtained in these beetles, so that the point is now doubly certain that heritable variations are produced as the direct response to external stimuli. In my 
own experiments I have used for three years past salt solutions as well as electric stimuli, with the same results as are described in this paper for temperature and moisture, and in all their action is simply as a stimulus, and nothing more. The same is also probably true in MacDougal's plants. In plants we shall undoubtedly find that the influence of salt solutions is far greater than in animals, owing to the intimate relations of plants to the soil.

MacDougal admits that he has not been able to analyze the manner in which this result is brought about in the germ plasm, and it seems to me a waste of time and energy to speculate upon this point until we have some direct investigation of this problem.

Of considerable importance is the strong evidence which points to the general conclusion that these permanent variations arise during the growth periods of the germ cells, and do not appear to arise before or after this period. Just what this signifies is at present difficult to determine, further experiments and cytological studies being necessary before we shall be able to arrive at a more complete understanding of it. 


\section{CHAPTER VI.}

\section{THE PROBLEM OF THE ORIGIN OF SPECIES-DISCUSSION, SUMMARY, AND CONCLUSION.}

In the preceding chapters facts from observation and experiment have been brought together and correlated within narrow fields, and these in turn within broader fields, in the attempt to arrive at the more general axioms concerning animal evolution as it is revealed through the study of Leptinotarsa. This investigation began with the most general facts concerning these beetles, their systematic position, distribution, and ecology, and from these passed to more important and critical phases of their history. In this chapter we shall attempt to bring together and correlate the accumulation of facts and minor conclusions in the preceding chapters, that we may derive, if possible, more general axioms concerning the phenomena of evolution as discovered in these beetles.

The slow evolution of the idea of evolution, from its crude beginnings to its wonderful development within the past century, has not solved the riddle, but only crystallized out the separate fundamental problems, which, although interdependent, can for the present be best investigated as separate problems, and the results combined into more general laws. The fundamental problems of animal evolution are those of-

(I) Heredity, the most important and most difficult of solution.

(2) Variation, next to heredity the most widespread of organic phenomena.

(3) Method of evolution-that is, in what manner or by what methods have species, genera, and larger systematic groups been brought into existence?

(4) Adaptation, or the adjustment of the animal to some one set of conditions of existence.

In this paper we are largely concerned with the method of evolution-that is, whether species come through variation and heredity by one or the other, or all of the methods proposed during the last hundred years. In this chapter, therefore, I shall consider the accumulated facts as they bear upon the problem of the method of the origin of species. The great factor, heredity, we must accept as acting, as we know it does, without attempting to examine into it at all. If we accept heredity as a process acting in nature, we shall in no way invalidate any arguments or conclusions that we may enter into concerning the origin of species. In thus broadly accepting heredity as at work in evolution, I also include within this same acceptance that of the 
doctrine of the continuity of the germ plasm in its broad sense-i. e., the genetic continuity of germinal material-as a true generalization, undemonstrated, to be sure, but upheld by all of the best observational, experimental, and theoretical work. The acceptance of the doctrine of the continuity of the germ plasm, irrespective of how we conceive it to exist, is an absolutely necessary accompaniment to the fact of the existence of heredity. With the exception of Eimer and his followers, practically all biologists accept this doctrine unreservedly in one form or another. Indeed, without it the most ordinary facts of development and heredity become inexplicable, excepting as miracles, and orderly evolution and development become inconceivable processes.

\section{THE METHOD OF EVOLUTION.}

On the basis of our present knowledge the problem of the method of evolution presents two separate minor problems for consideration: (I) the origin, or the cause and control of variations: (2) the preservation, or the action of natural selection upon the new variations as they appear. These two divisions of the main problem we shall here consider separately.

Variation and natural selection in their various aspects furnish the entire solution to the problem of the method of evolution and of adaptation, and could we arrive at a solution of the course and sequence of stages in variation and natural selection, we should have the basis for a complete solution of the problem of the origin of species. Such a solution we can not hope to arrive at, at least not for a long time to come, and probably ultimately the best we can do is to push back to some impassable limit the description of the sequence of stages, the primal stages remaining unknown.

The Nature, Cause, and Contror, of Variation.

The phenomenon of variation primarily owes its existence to the fact that community of descent and heredity tend to produce the exact counterpart of the parent organism; the process of development, however, is not carried out under absolutely constant or uniform conditions, but in a world wherein there exist changing environmental states in endless perplexity. This results in the turning aside of the line of development from the parental standard, perhaps ever so little or only in one character; but in this we have deviation or variation.

While we can not hope to explain, excepting through philosophical speculation, the origin of the phenomenon of variation, we do know the law or sequence of events which variations follow. It has been abundantly demonstrated in the physical and mathematical sciences that variations follow precisely the law of error, and in organisms it is becoming more and more certain that all variations follow most rigorously the same law. In organ- 
isms, however, the conditions are immensely more complicated than in the mathematical or physical sciences, and it will necessarily be a long time before we can even begin in one single instance to follow the order of events in any given variation in organisms.

In the explanation of the origin of variation in organisms the only assumption we need make is that the original unit of organic matter was possessed of the attributes which characterize organic matter to-day-motion, sensation, growth, and reproduction. This assumption can not meet with any serious objection unless we change our ideas and definition of organic units. Granted the existence of one single organic unit endowed as above, there is no reason for introducing further complications by the explanation of phenomena through undemonstrable hypotheses, because the fact of variation in organic units can be explained solely through their existence in a natural world surrounded by varying conditions of existence. The original organic unit could not do otherwise than encounter changing conditions, or do otherwise than react to the stimuli it encountered, even though it were so lowly organized that all stimuli were perceived as one and reacted to by the sole response of contraction. In this we have all the conditions requisite for variation in full conformity with the law of trial and error.

The simplest existing organisms, greatly specialized, and the heredity product of countless generations of similar simple organisms, react to stimuli according to the method of trial and error. Thus Jennings says, regarding the responses of the lowest organisms to stimuli:

In these creatures [Amobæ] the behavior is not, as a rule, on the tropism plan-a set, forced method of reacting to each particular agent-but takes place in a much more flexible, less directly machine-like way, by the method of trial and error. This method involves many of the fundamental qualities which we find in the behavior of higher animals, yet with the simplest possible basis in ways of action; a great portion of the behavior consisting often of but one or two definite movements--movements that are stereotyped when considered by themselves, but not stereotyped in their relation to the environment.

It may be objected that Jennings is dealing entirely with sensory characters, reactions; yet wherein lies the real objection? Are not activities, responses, behavior, indissolubly associated with structures? Should we look for one law of structure and another of activities? Undoubtedly structures respond to stimuli. We know it to be a fact, and they follow in structural variations the same law of trial and error. Were this not so, the observed variations would not fall so truly into the probability of error distribution.

There does not exist, as far as I can discover, any real reason why organic and inorganic variations are not the manifestation of the universal law of error (trial and error); nor is there any necessity of introducing latencies or predeterminations into the explanation of organic variations. Theoretically, at 
least, variation in organisms is to be explained from its start by the principle of trial and error-trial due to stimuli, response according to the nature of the organism. The response, however, is entirely conditioned within the organism, and is manifestly a success or error. If now we are able to discover whether or not variations in complicated organisms are the responses to stimuli, we shall be better able to judge whether organic variations are explicable in conformity with the general law of variability of mathematical and physical science, or as peculiar phenomena sufficient unto themselves and needing undemonstrable hypotheses to explain their origin and workings.

In the second chapter there is brought together data concerning variations in the genus Leptinotarsa, and the fact is demonstrated that variations in these forms are distributed according to the law of the distribution of error, as are the variations of all organisms thus far studied. In the third chapter, where color characters are used as subjects, it is demonstrated that variation is directly produced by stimuli-that from relatively invariable parents, stimuli produce variable offspring; and again in the fifth chapter it is shown that variations arise in direct response to stimuli. Similar facts exist in abundance in the literature of the action of temperature and moisture on insects, of pressure or friction, causing callouses and exostoces in Vertebrata, and of changes of plant form through the stimuli of soil, light, and moisture. So an endless recital of facts might be given to show that there is variation in response to stimuli, and I have shown this to be true for these beetles. That all variations are responses to stimuli will be admitted by some [neoLamarckians], denied by others. That some variations may be responses to stimuli, others not, will be the contention of the Weismannians.

In Leptinotarsa it is shown that there are variations which are inheritable, and others that are not; and in Chapters III and V it is further shown that the heritable variations as far as discovered arose in the germ plasm, the non-inheritable during development in the soma. Further, the experiments of Chapter $\mathrm{V}$ show that heritable variations arise as the response to stimuli applied to the germ plasm. These responses, moreover, follow exactly the law of error in their distribution about the normal mean. I maintain, therefore, that all organic variations are responses to stimuli, and are not due to inherent tendencies or latencies, or the product of mystical elements.

The correctness of this conclusion regarding the nature of variations will be immediately granted by many, but the supporters of Weismannism will, I think, be prone to say that while the variations did result from the stimuli used in the experiments, the variations were due to the existence of ids, or determinants, carrying the variations in question, and were by the stimuli employed brought forward, and so on. These elements, and the Weismannian view that an "organ is undoubtedly predetermined in the germ plasm," together with all its activities and variations, "can only" result in one 
of two situations. Either the whole hypothesis of ids, determinants, and biophores is a product of the imagination, or, if they do exist, further attempts to solve the riddle of evolution will be futile.

In the experiments with Leptinotarsa new permanent variations arose as a direct response to stimuli applied to the germ plasm (germ cells). In one experiment, in the rise of a five-brooded race, there was a pure, perfectly constant inheritable character arising as the response to stimuli applied to the germ plasm. Eleven years of study of this and related genera have shown that in none of the family, or relatives of the family, are there traces of fivebrooded races or species. How, then, can we explain this on the basis of the id-determinant-biophore hypothesis? By supposing ids, determinants, or biophores to have existed latent in the germ plasm from some extremely remote ancestor who had a five-brooded condition, and then by germinal selection lost it, a few stray ids of the five-brooded condition remaining latent for countless generations, finally to appear in my experiments? If we accept such an explanation science has no further excuse for its existence.

I believe that the rise of this five-brooded race is a direct experimental demonstration of the falsity of the whole id-determinant-biophore hypothesis. Possibly we could explain the origin of this race upon the supposition of mutation, sudden jumps of ids or determinants from a two-brooded to a fivebrooded condition, but here we encounter the cherished hypothesis of germinal selection, and obviously there was no time in this experiment for selection to produce the results obtained. Moreover, the mutation hypothesis, with its basic assumption of pangenes, each carrying "unit characters" absolutely isolated from one another, affords only a superficial explanation. The most logical interpretation is that this variation is a response of the germ plasm, in changed chemical or physical constitution, due to stimuli which produce an inheritable variation differing in no respect in its transmissibility and permanency from the other variations produced.

Weismann admits that unicellular organisms may vary even in response to external stimuli, which we know follow the general laws of variability, and I can see no reason for a difference in kind of organic variability. Moreover, my experiments with Leptinotarsa point clearly to the unity of variability in its conformity to the general law of variability expressed in the method of trial, with errors distributed according to the probability of error. Now, while I believe that the law of variation is a general one, it does not and never can explain anything. All that we can ever get out of this law of variation, or any other, for that matter, is a more and more concise formula whereby we may express our accumulated, systematized experiences concerning variations. The best we can do is to describe and determine the relations and sequences of stages, and in the sense that an antecedent stage is the cause of a following stage, we can determine "causes," but we shall never 
reach a point beyond which there will not be innumerable causative stages which our perceptions can not discover. In this sense, then, the above law of variation seeks only to express concisely and briefly the stages in their general sequence as I perceive them.

Variation, then, in organisms resolves itself into trial and error. The trial we can not conceive of as arising de novo in the organism, but there must have been an antecedent stage, which we call a stimulus, and it is shown that when a stimulus is applied in experiment to organisms there is a trial in that there follows a response (movement, modification) dependent upon pre-existing stages in the constitution of the organism, and more remotely, perhaps, upon the nature of the stimulus. Thus we see that even though we can express the sequence of stages briefly by this law, and find it of use in systematizing our perceptions of variation, in any single case, it simply states what we may expect to happen when an organism meets the condition of its existence.

This discussion brings us to the point where we see that variation is the response or sequence of stages following the meeting of two preëxisting series of stages, one in the material world environment, the other within the organism. Obviously, if we hope to state more clearly the sequence of stages in variation phenomena, such as orthogenetic variations, fluctuating variations, skew variations (or "mutations"), we must understand more fully the developmental principles underlying the antecedent stages within the organism before they meet the causes of the variations. It has been demonstrated in my experiments that there is no specific response (variation) following any given stimulus; hence I conclude (Chapter III) that the environment acts simply as a stimulus, and, therefore, its sequence of stages is of no importance. It is shown (Chapters III and V) that the response (variation) following stimulus is entirely determined within the organism. In the organism, therefore, there are series of steps (stages) whose sequence and relation we must understand before we can begin to get at the questions of orthogenetic variation, "mutation," etc. This all-important series of states can be investigated only through the study of development. Any other plan of attack seems utterly hopeless.

The first and one of the most fundamental questions which we have to consider is whether development is an epigenetic or a predetermined process; upon how we answer this question will depend the progress we shall be able to make in the analysis of the phenomena of variation and evolution.

That development in Leptinotarsa is an epigenetic process has been demonstrated in the study of their embryonic development and coloration. In Chapter III it was shown that there is no predetermination of the coloration, but a development, unfolding, or specialization based upon a general phyletic system 
of color centers of metameric origin and arrangement. This ancestral endowment, which represents simply the repetition for an immense number of generations of the same series of stages, is used, as I have shown by all the species in the genus, as the background of antecedent stages, upon which are further worked out, as each group and species by its specific nature dictates, its type of coloration. The same fact is true of the other systems of organs. The question at issue is not so much the sequence of stages, because that all will admit, but how we are to interpret this? We know that development is a complicated, orderly, constant phenomenon, and the real question is whether this orderly development is conditioned and controlled by material units preëxisting in the germ plasm, each endowed with all the attributes and potentialities of the parent organisms, or whether it is due to the conditioning of any given stage by the preceding stages. In other words, are we to conceive of the germ plasm as a composite aggregation of an immense number of individually endowed vital units, each in reality a unit organism, and this complex society creating the individual (soma) for its use and habitation, or shall we conceive of the germ plasm as an entity, as protoplasm differing from other organic matter only in its conservative and generalized nature? Unfortunately we can not decide this question in positive terms in the present state of our knowledge.

Biologists seem to be nearly all of the opinion that the germ plasm is probably contained within the nucleus, and is largely, if not entirely, represented by the chromatin of the nucleus. From this chromatin come, according to recent researches, a considerable part of the cytoplasmic contents of the germ cells; also from the nuclei by chromatolysis are derived the internal secretions, enzymes, cytolyzines, cellular toxins, etc., whose action directly controls and conditions growth and nutrition. Even such characters as color are directly initiated and controlled by the production of materials elaborated from the chromatin of the nucleus, which react upon one another to produce, as in these beetles, chitin and oxy-azo pigments. From the investigations in physiological chemistry it is rapidly becoming more and more certain that all organic products of the body are directly or indirectly the product of the chemical activity of the nuclear material. At the present time there are known a great variety of purely chemical processes and products originating from the chromatin, and upon the basis of the predetermination hypothesis they must be predetermined also, and there must therefore exist within the germ plasm an immense number of units, say "biophores" or "pangenes," to be later localized in particular cells and to control the multifarious chemical processes due to chromatic activity. These ultimate units, according to Weismann, "all possess the fundamental characters of life, dissimilation, assimilation, growth, and multiplication by division. We must also ascribe to these in some degree the power of movement and sensibility" (p. 369). Now, this is all very 
pleasing, but what conditions or determines growth, nutrition, sensibility, movement, and reproduction in these ultimate units? In higher units we must ascribe the existence of these same attributes to the "necessary condition" that we "can only" explain evolution by supposing the existence of such units. There simply results this state of things: Either we must assume that the fundamental attributes of organism are one thing in an organism and another in the ultimate vital units, or we must, to be logical, go on creating cycles of ultimate units one within the other ad infinitum. In any event, we always arrive at exactly the same point. How shall we connect in any logical way these vital units with the chemico-physical phenomena, which must ultimately form the basis of the interpretation of organic phenomena?

Weismann says of these units :

As to their size, we can only say that they are far below the limits of visibility, and that even the minutest granules, which we can barely perceive by means of our most powerful microscopes, can not be small individual biophores, but must be aggregates of these. On the other hand, the biophores must be larger than any chemical molecule, because they themselves consist of a group of molecules among which are some of complex composition, and therefore of relatively considerable size.

And De Vries says:

The pangenes are invisibly small . . . all the various kinds of pangenes occur in the nucleus.

We must accept Weismann's dictum that the biophore is larger than any "organic molecule," but he evidently forgets that some of the organic molecules approach dangerously near the limits of visibility. The determinants, very numerous in all animals, and reaching in Arthropods "hundreds of thousands," are not in multicellular animals "single biophores," but the determinant "is a group of biophores which are bound together by internal forces to form a higher vital unit." "On this basis the germ plasm represented by the chromatin of the egg nucleus of an insect egg must contain 'hundreds of thousands' of these determinants, each made up of biophores, each in turn larger than any organic molecule." Now we know with considerable accuracy the size of many organic molecules, and if there be biophores endowed as Weismann supposes, each vital unit must be constituted of enough organic molecules to carry on the "fundamental characters." When this is further followed out the whole idea becomes an all too obvious absurdity, because the amount of the chromatin in the germ cells of Leptinotarsa is far too small to contain the amount of organic molecules that it must according to Weismann's hypothesis. By measuring during the oögonial and spermatogonial divisions the diameter and length of the chromosomes, I have come to the conclusion that the maximum amount of chromatin in the oögonia or spermatogonia is not over $0.0000225 \mathrm{c} . \mathrm{mm}$. If we suppose each biophore to be made up of only five molecules (an unthinkable supposition), and each determinant of only two biophores and 
only 100,000 determinants-a number far below Weismann's supposition for insects-we shall have on this basis $5 \times 2 \times 100,000$, or $1,000,000$ organic molecules compressed into the space of $0.0000225 \mathrm{c}$. $\mathrm{mm}$. Now, it is obvious that the initial five molecules can not be the simple $\mathrm{CH}$ groups, but are extremely complex and large molecules, and each molecule can have but the $0.000,000,000,022,5 \mathrm{c}$. mm. of space, and this only upon the basis that the chromatin is absolutely solid, with no space for molecular movement. We know, however, that the chromatin as we can see it is not solid, but is more or less an aggregation of particles; and if we follow out the idea, each of the necessary $\mathrm{I}, 000,000$ molecules in the assumption has certainly far less than the $0.000,000,000,022,5 \mathrm{c}$. mm. in cubic contents. It is obvious from this data that, giving the id-determinant-biophore hypothesis every chance and the benefit of every doubt, there still remains the insurmountable difficulty that it "can only" in a superficial way explain up to a certain point, but when pushed beyond that point it fails utterly. As a general conception of development and evolution the Weismannian id-determinant-biophore hypothesis does not stand the test of examination and trial in the light of our present knowledge of organic activity.

How shall we conceive of the germ plasm? Most obviously, in order to investigate variation and the method of evolution, we must form some conception of the nature of the germ plasm. Whether the chromatin is the germ plasm or not, we know it to be an extremely complicated series of complex organic substances constantly in process of chemical change, and giving off elaborated cell products for diverse purposes. As far as we have any real knowledge, the chromatin is wholly concerned in metabolic processes, and although it is the most complicated and most discussed material in the cell, especially in cell reproduction, the fact is undeniable that the part taken by the chromatin in the process of reproduction is much more passive than that taken by the plasma. Cell division or cell reproduction is an activity in which many of the important elements are non-chromatic, and are as constant structures as the chromatin, even though not so strikingly present in cytological preparations. Sensation, motion, and the mechanism of reproduction lie in the materials outside of the chromatin; the trophic activities lie, as far as our knowledge goes, within the chromatin.

It is undeniably true that the plasma is nourished or even perhaps derived from the nucleus-that is, there is growth of the plasma-but we never find chromatin without plasma, nor plasma without chromatin. They are interdependent. The plasma is the seat of response, motion, and the mechanism of reproduction; the chromatin is the seat of metabolic activity, and they can not be separated. We can no more say that since the plasma grows at the expense of the activity of the chromatin, the chromatin is primary and the plasma secondary, than we can argue that the metabolic mechanism of man is 
primary and all the rest is purely secondary. True enough, man is for his bodily structure entirely dependent upon the metabolic mechanism within him, but I think the mechanism would fare badly for materials for its activity if left to its own devices to supply them. Is it different in the cell?

It is wrong, I believe, to hold that either chromatin or plasma is either primary or secondary, because each is absolutely necessary to the other-the chromatin functioning largely in the phenomena of metabolism and growth, the plasma in sensation and motion, and both active in reproduction. The germ plasm we must consider, I believe, to consist of both plasma and chromatin. Many, on the basis of the phenomena of cell reproduction, will combat this idea with the argument-Why is it that the most conspicuous element in reproduction, the chromatin, occupies in this conception a place of minor importance? But have we any basis, other than the tendency of the last twenty years, which has developed methods to render the chromatin conspicuous, for believing that other elements are not equally important and constant? Has any one shown that in cell reproduction there is an unequal or haphazard division of centrosomes, archoplasm, nucleo-plasm, plasma of the asters, and spindle fibers? These structures are divided with the same impartiality between the daughter cells as are the chromosomes. There exists beyond any question a regularly ordered, nearly exact halving of many of the plasmatic structures of the cell in reproduction, and although the daughter cells may differ in size this is always the result of stored foodstuffs; the plasma, especially that concerned in cell reproduction, is shared alike. Our attention has been too much fixed upon the chromatin, which, because of easy demonstration and nicety of results, has blinded us to the significance and equal importance of the process of cell reproduction in the plasma. All our available information as to the chromatin activity, the formation of cell products, enzymes, glandular secretions, nutritives contents of ova, and so on, shows chromatin only as a seat of chemical activity, a trophic material, extremely important, to be sure, but not the whole life of the cell. I believe that from the present state of our knowledge we should regard the chromatin material solely as the seat of nutritive processes and growth activity, the plasma, as the seat of motion and sensation, and reproduction, as involving both. At present there exists not one whit of evidence to show that chromatin is endowed with other metabolic and growth processes. Reproduction seems to and must of sheer necessity concern both, resulting in an equal distribution to the daughter cells of the plasmic and chromatic constituents of the germ plasm. Reproduction is in reality the only process common to the entire cell mass, and in reproduction the activities of the plasma are equal in importance to those in the chromatin.

The logical outcome of this conception is that the germ plasm, instead of representing a mosaic or colony of vital elements living within a protoplasmic 
body in symbiotic relation, must be thought of as a unit or separate entity. That is, a germ cell is not germ plasm plus protoplasm and stored food, but the germ cell, with its initial endowment of plasma, which it derived by division from its ancestors, and which it alway's retains and hands on from generation to generation in each species, is all germ plasm. Each germ cell later, by the accumulation of stored food or the elaboration of other materials, becomes differentiated, but the original chromatic and plasmic endowment is singularly constant. In Leptinotarsa each germ cell comes to the beginning of its period of differentiation (growth period) with an almost exactly similar endowment of dense homogeneous plasmic material.

While we can not, I think, at the present time form any adequate picture or frame any conception of the architecture of the germ plasm, we can not, however, escape the conviction that the germ cell is an entity, and is the product of a series of developmental stages which always recur in the same order and are relatively invariable. It is able to repeat these stages in development, to overcome serious difficulties, and in the end attain the same general result, which differs only from its specific type in relatively minor points. Beyond all doubt, this sequence of stages is conditioned in the germ plasm, but not predetermined in the germinal material as material particles, each the bearer of particular attributes of one or more cells or cell groups. Rather we must think of the germ plasm as containing a few general characters from which, in some wholly unknown way, there come the sequence of stages in development of the diverse organs and the apparent isolation and unity of characters which we find. We have good reason, therefore, for the belief that development is an epigenetic process, that one state is conditioned by preëxisting stages, and that a variation is the result of responses in the plastic developing organism; that is, variation is to be interpreted upon the basis of responses to stimuli directed by the stage of development reached and the nature of the preexisting stages. Variation is also epigenetic and not a predetermined character in organisms.

\section{MUTATION.}

De Vries and his followers maintain that variations standing far apart from the general population, and differing often in many characters, differ fundamentally from the normal inheritable fluctuating variations. De Vries's "mutants" bred true, but with intense selection and in-and-in breeding; and in my experiments with Leptinotarsa there have been found and reared, without intense selection, examples of these same extreme variations. De Vries maintains that the "mutants" of Enothera are in all directions, which may be true; but, after examining his work and seeing the various "mutants" growing, I should say that they were not in all directions, but in two chief directions, and that the "mutation" consists in plus and minus changes of the 
parental characteristics. In Leptinotarsa these variations, which came from the various species of the genus, are orthogenetic.

The question whether or not we shall consider these extreme variations as fundamentally different from those nearer to the parental mean is crucial. While I have no basis for judging the nature of these extreme variations ("mutants") in plants, those which have appeared in my cultures are all the results of responses to stimuli acting upon the germ plasm, as shown in Chapter V, and, as far as I am able to discover, they differ from smaller variations only in the amount of the deviation from the mean of the parents. All of my "mutants" are found to deviate from the parents most in one character and to a far less degree in others. I am convinced, therefore, that the one is the real permanently changed character, and that the less strongly marked changes are due to correlation in variability. This point I can not at present be positive of, because it needs sufficient material for adequate quantitative treatment, and an attempt to make positive assertions on any other basis is not warranted. It offers, however, a most plausible explanation of the fact that mutants differ from the parent in several characters.

There is no reason for regarding the "mutants" of Leptinotarsa as other than responses to stimuli, which, acting upon the germ plasm, produce the variations found. I have demonstrated in Chapter $\mathrm{V}$ that all inheritable variations behave alike, and in no case is there any evidence that there is a fundamental difference between "mutants" and any other heritable variation. The mutations in Leptinotarsa are solely responses to stimuli, orthogenetic (Chapter II), and are distributed in their distances from the parental mean in full conformity with the law of the distribution of error.

In text-figure $3^{\mathrm{I}} \mathrm{I}$ have represented the distribution of the heritable variations about the mean of Leptinotarsa decemlineata. This figure is based upon the inheritable variations of general color (albinism and melanism), which carry in correlative variability other characters, and with this distribution is given the occurrence of the "mutants" in their order and degree of removal from the parental mean. To the left of the polygon are the variations in increased coloration, melanism, with which are also correlated increased size, etc., and to the right, albinism, with the correlated variation in decreased size and punctation. The polygon is based upon one character, and, although through correlation other characters also vary, it represents the general distribution of permanent variations about the mean of the species. It is shown that in nature we find about one of these "mutants" in every $6,000(5,447)$ beetles examined. So when by chance in any lot of variates one of these extreme variations is found, we ought not to jump to the conclusion that it is not a part of the normal variability, because it is. To determine the distribution of the variations in a few hundred variates is perhaps useful, but it represents only the distribution of the variations on the average, and not the distribution of variation in the long run. 
I maintain, therefore, that "mutation" is not a special kind of variability, different from that of "ordinary fluctuating variation," but it is a part of the normal variability, and the direct response of the germ plasm to stimuli. This is fully borne out by the data and experiments with Leptinotarsa. This, how-

Range of " normal fuctuating variability."

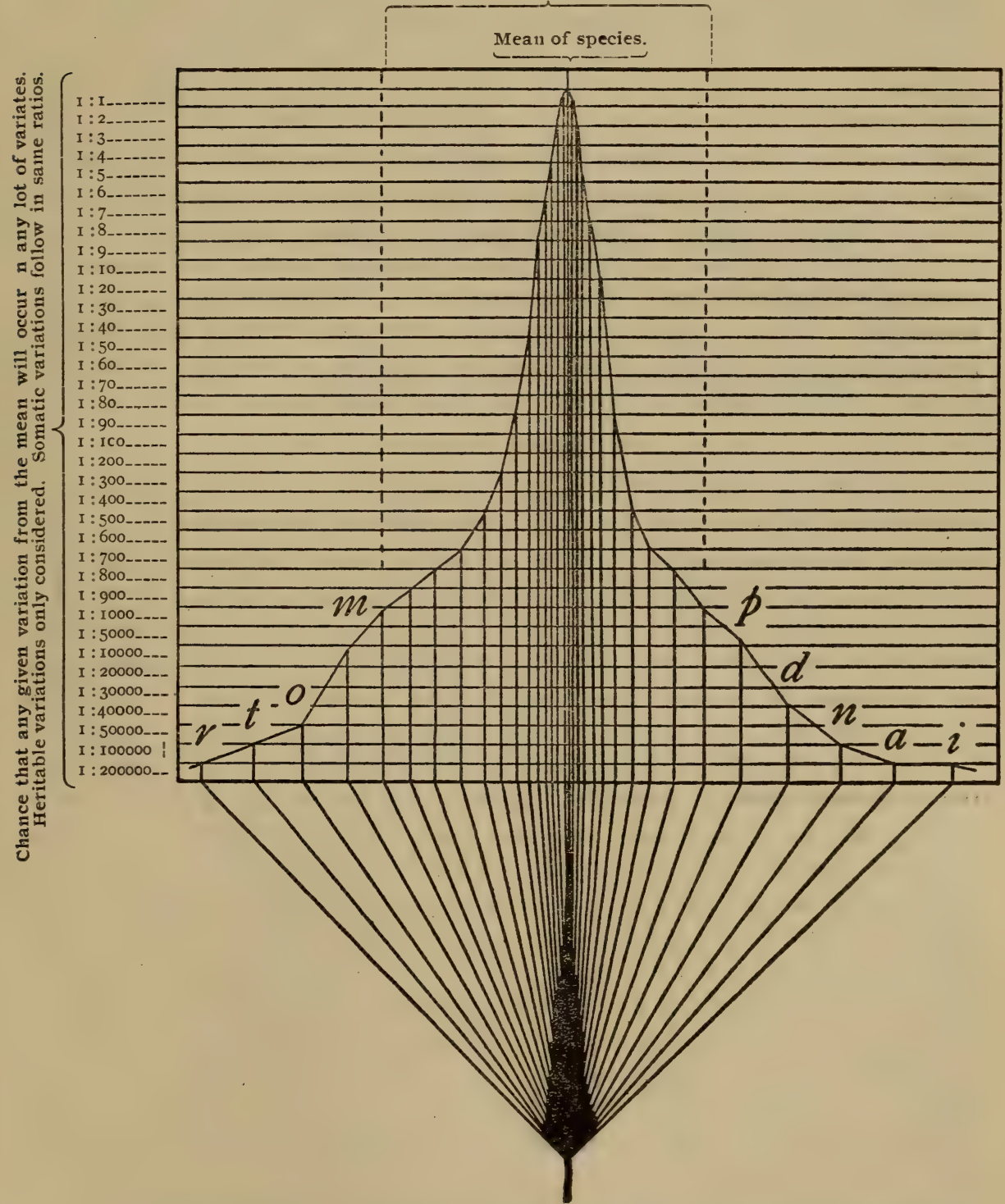

TEXT-FIGURE 31.-To show the distribution of inheritable variations about the mean of $L$. dccemlineata. $p=L$. pallida; $d=L$. defectopunctata; $n=L$. minuta; $i=L$. immaculothorax; $m=L$. melanicum; $0=L$. obsoleta $t=L$. tortuosa; $r=L$. rubrivittata. 
ever, need not necessarily alter our conception of the part these variations may play in evolution. It simply brings them into line with the general phenomena of variation. ${ }^{1}$

We must conclude, in the light of the evidence herein gathered and correlated, that all variation represents solely the response of plastic organic material to stimuli according to the method of trial and error. Permanent variations are also of the same origin, and, as shown in Chapter V, are produced or primarily arise in the germ plasm, and later or secondarily appear in the soma, through the production of the soma from the germ. It is shown, too, that these permanent variations or divergences may be small or large, but they obey the law of the distribution of error in their proportionate appearances and distance from the mean. There is, then, no necessary incongruity between gradual small variation and rapid large variation in the origin of species, but the two are the extremes of the same process. That variations are not predetermined, but are epigenetic, arising as the result of the interaction of preëxisting series of stages in the organism and its environment, seems to be the only possible method of interpreting these experiments.

\section{THE ORIGIN OF SPECIES.}

On the basis of our present knowledge the problem of the origin of species divides itself into two chief questions-the origin and the preservation. Biologists at present are divided as to the origin, one school, the neo-Lamarckians, maintaining that variations may first arise in the soma through mechanical or chemical causes, and later be transferred to the germ; the other, that they arise in the germ plasm, and later appear in the soma. All acknowledge that the variation, to become transmissible, must ultimately come to be incorporated into the germ plasm. There exists at present not one single fact to show the inheritance of acquired somatic variations or their incorporation into germ plasm. Moreover, the neo-Lamarckians are at fault in overlooking the very fundamental fact that the variations found to arise in the soma are possible only because the germ-plasm constitution has developed a soma in which variation in certain directions is possible and impossible in others. That is to say, we find a particular variation because the germ plasm has so constituted the soma that it can vary in certain directions and not in others, and in the same direction as the germ plasm itself is varying. It is a curious fact, moreover, that the idea of the inheritance of acquired characters is supported almost entirely by the data of anatomy and paleontology, two lines of investigation which, least of all, are capable of giving data upon the question. Both deal with end results, and can show only what has happened.

\footnotetext{
${ }^{1}$ In this paper I have avoided any consideration of the hypothesis of unit characters and their isolation as postulated by De Vries. The data and conclusions upon this and allied problems will be presented in another paper.
} 
As I have pointed out, there is not at present evidence to show the origin of any heritable variations in the soma. Moreover, I have shown that in these beetles we can get new permanent variations by stimulating the germ cells, and in no other way. The question is one for direct experimentation, and not for the plausible arrangement of paleontological evidence. That the Lamarckian factor could explain the phenomenon of evolution all admit, could the fundamental assumption be established even in one single case. Cope, of all the neo-Lamarckians, undoubtedly saw most clearly the real issue and its results. Thus he writes:

It is evident that evolutionists are reaching greater harmony of opinion on the question of inheritance. In fact, the discussion is sometimes a logomachy dependent on the significance which one attaches to the term "acquired characters." Thus Von Rath remarks: "There is nothing in the way of the opinion that by the continued working of such external influences and stimuli the molecular structure of the germ-plasm also experiences a change which can lead to a transmission of transformations. Above all, it ought not to be forgotten in this case that somatic cells are in no way the first to be modified by the stimulus, and that then, by some sort of unexplained process (pangenesis or intracellular pangenesis), this stimulus is transmitted gradually by these cells to the plasma of the germ-cells. The influence on the germ plasm is rather a direct one, and if by continued influence a transformation of the structure of this plasm takes place and transmission occurs, we have then simply a transmission of blastogenic, and by no means of somatogenic characters, and therein is not the slightest admission of the transmission of acquired characters.

This paragraph contains an admission of the doctrine of diplogenesis, and does not regard the phenomena as including a transmission of acquired characters. Nevertheless the stimuli traverse the soma in order to reach the germ-plasma. Such an energy is evidently, then, not of blastogenic origin, although it is such in its effects. Moreover, Von Rath omits to mention the fact that in traversing the soma the stimulus frequently, if not always, produces effects on the latter similar to those which it produces on the germ plasma. I should call this process the inheritance of an acquired character, even in the case where no corresponding modification appears in the soma, since the causative energy is acquired by the soma, and is not derived from the existing germ plasma.

The acceptance of Von Rath's view, and the assertion that because "causative energy traverses the soma" it is therefore acquired from the soma, is largely a matter of definition of the terms used. The soma in this case is a medium through which the stimulus passes, as through water, air, or earth; and while it is true that the "causative energy" is not derived from the existing germ plasm, neither is it derived from the soma, nor acquired by the soma, but both soma and germ respond to the only stimuli which they can ever experience-those, which are primarily external. After all, it would seem that the question really comes down to a play upon words. The only question is-Can the effects of a stimulus which produces only a somatic variation, as in the pupa in Poulton's experiments, or the beetles in the experiments of the third chapter, be later transferred to the germ plasm? Only experimental investigation can answer this question, and at present all the data give a 
most decided negative answer. Because the stimuli pass through the soma on their way to the germ in no wise enters into the question. That all heritable variations-hence factors in evolution-arise primarily in the germ plasm, and secondarily in the soma, is on the basis of all of our present evidence the only acceptable hypothesis.

The recent compilation of data by Redfield concerning "dynamic inheritance" of speed in race horses, and of other characters in dogs and men, wherein he attempts to show the inherited effects of use, fail in that there exists in every case the unproven assumption that the ancestor of the race was an ordinary animal, whereas the very fact that the original progenitor of the American race horse was able to train so long and to such good effect showes that it reas in its initial make-up different from other horscs, and the further development of the race horse seems to be purely a selective process. Were this not so there is no reason why there should not have been a dozen or five hundred horses of the same class. The very fact that this original race-horse progenitor was able to develop speed beyond the ordinary, and keep it up longer, is about all the evidence one needs that the original progenitor varied from the common race of horses in just those characters which now form the basis of the traits of American race horses. The physical capacity in this case was primary, the dynamic development later, and there is no reason to suppose that the original capacity for dynamic development arose other than first in the germ plasm. As far as any evidence goes that we can get at, Redfield's "dynamic development" is a selective process based upon an initial germinal variation.

Students of evolution are coming more and more to believe in the origin in the germ plasm of all variations that are effective in evolution. Evidence is constantly being accumulated, as Fischer, Standfuss, and MacDougal have shown in a few cases, and as shown here in larger series, that permanent variations are direct responses in the changed constitution of the germ plasm to stimuli. How these are effected is not at present known, and is a subject for investigation and not for anticipation. Further, that these variations follow the law of trial and error is for these beetles fully shown, and it is further shown that just this method would result in orthogenesis, and even mutation, without the introduction of "forces," "ultimate vital units," or "latencies." How these modifications are preserved is the second part of the problem of the method of evolution.

Although evolutionists differ in their opinions in regard to the extent and importance of natural selection, all, with the possible exception of the Eimerites, give it an important place in organic evolution. Of late there has grown up, since the publication of De Vries's work, a tendency to ascribe to "mutation" a far greater importance and to a considerable extent to substitute that process for all others in evolution, even though De Vries distinctly 
points out that "mutation" is complementary and not antagonistic to natural selection, and that the two are necessary in evolution-that is, "mutation" explains the origin of variations in evolution, and natural selection their preservation.

As I understand natural selection, Darwin never claimed that it originated anything, but only worked upon that which was already in existence; but we must admit that since any variation depends upon the antecedent series of stages in the organism, that any stages in the organism which survive through natural selection or are not eliminated thereby, as in characters of nonselective value, exert a powerful influence in evolution in that they limit variation to certain possibilities. Morgan calls this "very plausible," but careful study of any set of organisms and their variations shows that it is actually true. This fact we saw clearly in the second and third chapters of this paper. In this way selection, by determining the survival, acts also to eliminate certain possibilities from future evolution.

Of recent years there has been a deal of writing in which natural selection is denounced as incompetent and trivial. However, few, if any, of these "incontrovertible proofs" rest upon anything more than poor logic. Natural selection is a subject for investigation, not for argumentative denunciation.

In relatively few cases do we know just how selection works-just what selection does-and not until we know accurately the action of selection can we begin to estimate its effect in evolution. In various ways selection has been shown to be actively at work in Leptinotarsa, but as far as discovered always in conservative ways, eliminating extremes and limiting the reproductive population to the individuals nearest to the racial mean. Thus in hibernation the extreme variations are all eliminated as far as the evidence goes, and a "mutant" like pallida or melanicum has only the remotest chances of becoming established in nature. It is not possible to say at present how poor their chances are, but their occurrence once in 6,000 cases is not favorable to their becoming established. If enough mutants arose at one time we could easily imagine how they might become established, but this does not seem to happen. In the tropics L. melanothorax has been known for nearly fifty years, yet it has not been able to gain a foothold, although it is far more numerous than pallida. L. rubicunda seems more fortunate, but its distribution is as yet very limited, and seems to be decreasing, being one-third less in 1905 than in 1904. Its future history will depend on whether it will or will not be able to meet the conditions of its existence.

The real question in the method of evolution at present is whether species arise by the preservation of large variations or "mutants" or by small accumulated variations. It appears that in both plants and animals large variations occur in nature, but these, as far as all evidence goes to show, are most rigorously exterminated by natural selection, and only the mean and 
modal individuals survive and reproduce the species. I have failed utterly to discover in these beetles evidence that mutants have taken any great part in evolution, all evidence shozving them to be most rigorously exterminated by natural selection (Chapter IV). On the other hand, the study of geographical distribution and variation gives the strongest of circumstantial evidences for direct rapid transformation in response to environmental stimuli as the result of dispersion. I am therefore of the opinion that the evolution of the genus Leptinotarsa, and of animals in general, has been continuous and direct, developing new species in migrating races by direct response to the conditions of existence. In this evolution natural selection has acted to determine antecedent states and the persistence of new variations, but in each race or species it acts as the conservator of the race, keeping down extreme variations through their elimination in hibernation, larval life, and selective mating. It is in Leptinotarsa the conservator of the racial mean and mode, the destroyer of all variation diverging much from the orthogenetic trend of evolution, which is itself a product of natural selection.

The evolution of the genus Leptinotarsa, according to data gathered, has been through response to the stimuli of the conditions of existence in changed germ-plasm constitution, according to the method of trial and error, with natural selection acting as the conservator of the race by limiting the variations to a narrow range of possibilities. The breeding "mutants" in our gardens and laboratories can not tell us how they would succeed in nature; my experience with these beetles is that they fare badly, and, as far as I can discover, that they play a minor rôle in the evolution of species. This view differs, therefore, from that of De Vries, who sees in "mutants" the origin of species; the real test is, as De Vries clearly sees, the fate of these "mutants" in nature. This I have been able in some measure to test, and at present there seem to be insuperable difficulties in the path of all observed "mutants" in Leptinotarsa. I therefore regard mutations as prophetic variations indicating what may perhaps be the next species in the evolution of the race. How this evolution is brought about in nature is a subject for observation and experiment, and not for anticipation. The method of the origin of variation herein developed does account for the origin of variation upon a natural basis, and "mutation" is shown to be but part of the general phenomena of variability. That is, in variability there is unity and not discontinuity, and inheritable variations differ not in kind, but only in degree. 


\section{BIBLIOGRAPHY.}

In the following bibliography I have given only the more important references. Some of the smaller references are printed in the text, but a far larger number, amounting to several hundred, do not appear at all.

ADAMS, C. C.

I902. Southeastern United States as a center of Geographical Distribution of Fauna and Flora. Biol. Bull., vol. III, No. 3, pp. II5-I3I.

AGASSIZ, L.

I848-I849. Twelve Lectures on Comparative Embryology. Boston, Lowell Institute.

ALLEN, J. A.

1877. The Influence of Physical Conditions in the Genesis of Species. The Radical Review, pp. I07-I40; May.

BATES, H. W.

1862. Contributions to an Insect Fauna of the Amazon Valley. Lepidoptera : Heliconidæ. Trans. Linn. Soc. London, vol. XXIII, pp. 495-566, pls. 55-58.

BATESON, W.

I894. Materials for the Study of Variation, Treated with Special Regard to Discontinuity in the Origin of Species. London, $598 \mathrm{pp}$.

BEMMELEN, J. F. VAN.

1889. Ueber die Entwicklung der Färben und Adern auf den Schmetterlingsflügeln. Tijdsch. der Nederland. Dierkundige Vereeniging, Ser. 2, Deel 2, pp. 235-247.

BOTTLER, MAX.

I894. Die animalischen Faserstoffe. Ein Hilfs- und Handbuch für die Praxis, umfassend Vorkommen, Gewinnung, Eigenschaften und technische Verwendung sowie Bleichen und Färben tierischer Faserstoffe, nach dem gegenwärtigen Standpunkte der Wissenschaft bearbeitet. viii +215 pp., I6 figs. Wien : A. Hartleben.

Bumpus, H. C.

The Variations and Mutations of the Introduced Sparrow, Passer domesticus,

BURKILL, I. H. Biol. Lect., Woods Holl, in I896. pp. I-I 5. Boston.

I895. On Some Variations in the Number of Stamens and Carpels. Jour. Linn. Soc。 Bot., vol. 3r, pp. 216-245.

BURT, H.

1865. Potato Beetle. Coleman's Rura1 World, Sept. I5, 1865.

Colinins, C. C.

I870. Colorado Potato Beetle. Am. Ent. and Bot., vol, 2, p. 34I.

COPE, E. D.

I904. The Primary Factors of Organic Evolution, pp. vii +547 . Chicago.

COSTE, F. H. P.

I890-I89I. Contributions to the Chemistry of Insect Colors. The Entomologist, vol. XXIII, pp. I28-I32, I55-i68, etc. Continued and concluded in vol. XXIY.

Crampton, H. E.

1904. Experimental and Statistical Studies upon Lepidoptera. I, Variation and Elimination in Philosamina cynthia. Biometrika, vol. III, pp. II3-Izo. 
Cushman, J. A.

I903. Studies of Localized Stages in Some Plants of the Botanic Gardens of Harvard University. Amer. Nat., vol. XxxvII, pp. 243-259.

1904. Localized Stages in Common Roadside Plants. Amer. Nat., vol. xxxvIIr, pp. $819-832$.

1902. Studies of Localized Stages of Growth of Some New England Plants. Amer. Nat., vol. $x \times x v i$, pp. $865-885$.

DARWIN, C. R.

I859. The Origin of Species.

I87I. The Descent of Man.

DAVENPORT, C. B.

I904. The Animal Ecology of the Cold Spring Sand Spit. The Decennial Publications, The University of Chicago, First Series, vol. $x$, pp. I57-I76. (Dated 1903.)

1904. Statistical Methods, with 'Special Reference to Biological Variation. New

DEWITZ, J. York. pp. viii-223.

1903. Ueber die Herkunft des Farbstoffes und des Materials der Lepidopterenkokons.

DODGE, J. R. Zool. Anz., xxvir, pp. 16I-I68.

1866. Monthly Rep. U. S. Dept. of Agri., pp. 245-356.

I866. Monthly Rep. U. S. Dept. of Agri., pp. 287, 344, 388.

I867. Monthly Rep. U. S. Dept. of Agri., pp. 244, 365 .

I870. Monthly Rep. U. S. Dept. of Agri., pp. I9I-332.

I87x. Monthly Rep. U. S. Dept. of Agri., pp. I9I-332.

1872. Monthly Rep. U. S. Dept. of Agri., p. 217.

I876. Monthly Rep. U. S. Dept. of Agri., p. 345.

DORFMEISTER, G.

I864. Ueber die Einwirkung verschiedener, während der Entwickelungsperioden angewendter Wärmegräde auf die Färbung und Zeichnung der Schmetter-

EDgERTON, J. linge. Mittheil. des Naturwiss. Vereins für Steiermark, Heft II, p. 99.

I86r. Potato Insects. Prairie Farmer, Aug. 29, p. II6.

EDWARDS, H. W.

1875. An abstract of Dr. Aug. Weismann's paper on "The Seasonal Dimorphism of Butterflies." Can. Ent., vol. vir, p. 228.

1884. Further experiments upon the effect of cold applied to the chrysalids of but. terflies. Can. Ent., vol. Xvi, p. 232.

EIMER, G. H. T.

I889. Die Artbildung und Verwandtschaft bei den Schmetterlingen. Jena. 243 pp., 4 taf.

1897. Entstehung der Arten. Theil Ir : Orthogenesis der Schmetterlinge. Jena. 5 I3 pp., 2 taf.

ENTEMAN, W. H.

1904. Coloration in Polistes. The Carnegie Institution of Washington. Publication

FISCHER, E. No. I9, pp. I-88; 6 plates.

Firch, A.

(See numerous papers in Allgemeine Zeitschrift für Entomologie, vols. II-vIIr.)

I865. Injurious Insects. Trans. N. Y. State Agr. Soc., p. 798.

GAGE, J.

I867. Rep. Sta. Bd. Agr. Mich., I867, pp. 7I-77.

GILIMAN, H.

1870. The Progress of the [Colorado] Potato Bug. Am. Ent. and Bot., vol. 2, pp. $84-85$.

1873. The Colorado Potato Beetle Varying its Food. Am. Nat., vol. 7, pp. 430-43I.

Grover, T.

I873. Monthly Rep. U. S. Dept. of Agri., pp. 237, 345, 426, 496.

1874. Monthly Rep. U. S. Dept. of Agri., p. 374.

1875. Monthly Rep. U. S. Dept. of Agri., pp. 228-307. 
GRIFFITHS, A. B.

I892. Recherches sur les Couleurs de Quelques Insectes. Comptes Rendus Acad. Sci. Paris, tome cxv, pp. 958-959.

GÜLICK, J. T.

I905. Evolution, Racial and Habitudinal. The Carnegie Institution of Washington. Publication 25, pp. XII +269 .

HAASE, E.

I89I-92. Untersuchungen über die Mimicry auf Grundlage eines natürlichen Systems der Papilioniden. Bibliotheca Zoologica, Heft vIII, pp. I20, I4 taf. Cassel.

HAECKEL, E.

I866. Generelle Morphologie der Organismen. I-II. Berlin.

HAGEN, H. A.

I882. On the Color and the Pattern of Insects. Proc. Am. Acad. Arts and Sci., XVII (n. s., vol. IX), pp. 234-267.

HAZEN, R. W.

I865. Colorado Beetle. N. Y. Semi-Weekly Tribune, July I8.

Holman, D. S.

I870. Colorado Beetle around Springfield. Am. Ent. and Bot., vol, II, pp. 370-37r.

Hopkins, F. G.

1895. The Pigments of the Pieridæ. Philos. Trans., Lond., I86 в, pp. 66I-682.

HORN, G. H.

1872. Coleoptera in the Preliminary Report of the United States Geological Survey of Montana and Adjacent Territories, pp. 382-392.

JACKSON, R. T.

1899. Localized Stages in Development in Plants and Animals. Mem. Bost. Soc. Nat. Hist., v, No. 4, pp. 89-152, pls. 16-25.

JАСову, M.

I880-I892. Coleoptera Phytophaga. Biologica Centrali-Americana. Coleoptera, vol. vi, part I.

JENNINGS, H. S.

1904. Contributions to the Study of the Behavior of Lower Organisms. Carnegie Institution of Washington. Publication No. I6, pp. 256.

KUKENBERG, C. F. W.

1884. Grundzüg einer vergleichenden Physiologie der Farbenstoffe und der Farben. Vergl. Phys., Vorträge, III, Io2 pp.

LEDDERHOSE, G.

I878. Ueber Chitin und seine Spaltungsprodukte. Zeitschr. f. physiologische Chemie, Bd. II, pp. 2I3-227.

LINDEN, M. VON.

I898. Untersuchungen über die Entwicklung der Zeichung des Schmetterlingsflügels in der Puppe. Zeitschr. für Wiss. Zool., Bd. IXV, pp. I-49, pls. I-III.

1902. Le dessin des ailes des Lepidoptères, recherches sur les évolutions sans antogenèse et la phylogenèse des espèces, son origine et sa valeur systématique. Am. Sci. Nat., XIV, pp. I-I96, pls. I-XX.

LUDWIG, F.

I90I. Variationsstatistische Problem und Materialien. Biometrica, vol, I, pp. II-29.

LUGGER, O.

1895. Univ. Minn. Agr. Exp. Sta., U. S. Dept. Agr., Div. Ent., Bull. 43.

MAcDougaL, D. T.

I906. The Induction of New Species. Science, N. S., vol. XxIIr, No. 585, p. 422.

MACLEOD, J.

I899. Over de correlatie tusschen het aantal meeldraden en het antal stampers bij het Speenkruid (Ficaria ranunculoides). Bot. Jaarboek. Dodonæa, XI, P. 9I, 
MAYER, A. G.

I897. On the Colors and Color Patterns of Moths and Butterflies. Proc. Bost. Soc. Nat. Hist., vol. xxvII, No. I4, pp. 243-330, Io pls.

I9oo. On the Mating Instinct in Moths. Ann. and Mag. of Nat. Hist., ser. 7, vol. v, pp. I53-I9o; also Psyche, vol. IX, pp. I5-20.

1902. Effects of Natural Selection and Race Tendency upon the Color Patterns of Lepidoptera. Museum of Brooklyn Institute of Arts and Sciences. Science Bulletin, vol. I, No. 2, pp. 3I-88.

MERRIFIELD, F.

(Temperature Experiments upon Pupæ.) Trans. Ent. Soc. Lond., I89o, p. I3r ; I891, p. I55; I892, p. 33 ; I893, p. 55 ; I894, p. 425.

MoRgan, T. H.

1903. Evolution and Adaptation, pp. xiii +470 . New York.

MÜLLER, F.

I879. Ituna und Thyridia. Kosmos, Bd. 5, p. Ioo-108, figs. I-4. Translation, by R. Meldola, in Transact. Ent. Soc. Lond., 1879, pp. 20-29.

MURPHY, T.

I862. A New Horticultural Foe. A letter to N. J. Colman, editor Valley Farmer, July, pp. 209-210.

NовLE, G.

I89I. Abundance of Colorado Beetle in Georgia. U. S. Dept. Agri., Insect Life, vol. IV, p. I35.

OSBORN, H.

I892. Notes on Injurious Insects of I892. U. S. Dept. Agri., Insect Life, vol. v, pp. II I-II4.

PACKARD, A. S.

I875. Report on the Rocky Mountain Locust and Other Insects now Injuring (or likely to) Field or Garden Crops in the Western States. U. S. Geol, and Geog. Surv. of Colorado and Adjacent Territory. Colorado Potato Beetle, pp. $721-729$.

1876. The Colorado Potato Beetle in Massachusetts. Sci. Farmer, vol. I, pp. I04-I05. I876. The Colorado Potato Beetle. Sci. Farmer, vol. I, p. I68.

PEARSON, $\mathrm{K}$.

1900. The Grammar of Science, pp. xviii-548. London.

PhaRES, D. L.

I889. The Potato Beetle in the South. U. S. Dept. Agri, Insect Life, vol, II, p. 22.

Poulton, E. B.

1887. The Experimental Proof of the Protective Value of Color and Color Markings in Insects in Reference to their Vertebrate Enemies. Proc. Zool. Soc. Lond., pp. I9I-274.

1893. The Experimental Proof that the Colours of Certain Lepidopterous Larvæ are Largely Due to Modified Plant Pigments Derived from Food. Proc. Roy. Soc. Lond., vol. LIV, pp. 4I 7-430, pIs. III-IV.

I898. Natural Selection the Cause of Memetic Resemblance and Common Warning Colors. Jour. Linn. Soc. Lond., Zool., vol. XXVI, pp. 558-612, pls. 40-44.

PRIEST, O. E.

I.865. New York Semi-Weekly Tribune, Aug. 29, I865.

REED, E. B.

1872. Insects Injurious to the Potato. Ann. Rept. of the Ent. Soc. of Ont. for I872, pp. 48-50.

REINÖHL, F.

1903. Die Variation im Androeceum der Stellaria media Cyr. Bot. Zeit., vol. 61,

RILEY, C. V. pp. $159-200$.

1868. First Annual Report on the Noxious, Beneficial, and Other Insects of the State of Missouri. Jefferson City, Mo., pp. IOI-II7.

1870. Third Report on the Noxious, Beneficial, and Other Insects of the State of Missouri. Jefferson City, Mo., pp. 92-Ior. 
RILEY, C. V.-Continued.

I871. Fourth Report on the Noxious, Beneficial, and Other Insects of the State of Missouri. Jefferson City, Mo., pp. I-22.

I872. Fifth Report on the Noxious, Beneficial, and Other Insects of the State of Missouri. Jefferson City, Mo., pp. II-I6.

1876. Potato Pests: Being an Illustrated Account of the Potato Beetle and Other Insect Foes of the Potato in North America, with Suggestions for their Repression and Methods for their Destruction. New York, Orange Judd Co., 108 pp., 49 figs,

1882. Change of Habit: Two New Enemies of the Egg Plant. Am. Nat., vol. xvI, pp. 678-679.

I892. The Colorado Potato Beetle in the South. U. S. Dept. Agr., Insect Life, vol. V, p. 50.

ROGERS, R. V.

1872. Doryphora Io-lineata. Can. Eint., vol. IV, p. 200.

SAFFER, L. G.

I870. Colorado Potato Beetle in Indiana. Am. Ent. and Bot., vol. II, p. 304.

SAUNDERS, W.

I878. Annual Address of the President of the Entomological Club of the Am. Assoc. Adv. Sci. Can. Ent., vol, x, pp. I7I-rgo.

I88o. Annual Address of the President of the Entomological Society of Ontario. Rep. Eint. Soc. Ont. for 188o, p. 8.

SAY, T.

I824. (Description of Doryphora Io-lineata n. sp.) Jour. Acad. Nat. Sci., Phila., vol. 3 , part II, p. 453 .

SCUDDER, S. H.

I887. The Introduction and Spread of Pieris rape in North America. Mem. Bost. Soc. Nat. Hist., vol. IV, No. 3, pp. 52-69.

SHIMER, H.

I866. Notes on Doryphora Io-lineata. Pract. Ent., vol. I, p. 84.

1870. Insects Injurious to the Potato. Am. Nat., vol. III, pp. 9I-99.

SHULI, G. H.

I902. A Quantitative Study of Variation in the Rays, Bracts, and Diskflorets of Aster shortii Hook., $A$. Nova-Anglice L., $A$. puniceus L., and $A$. prenanthoides Muhl., from Yellow Springs, Ohio. Am. Nat., vol. 36, pp. III-I52.

1904. Place-constants for Aster prenanthoides. Bot. Gaz., vol. 38, pp. 333-375.

I905. Stages in the Development of Sium cicutifolium. The Carnegie Institution of Washington. Publication No. 30, pp. I-28.

STRECKER, A.

I882. A Short Text Book of Organic Chemistry. New York, xvIII $+789 \mathrm{pp}$.

TOWER, W. L.

1902. Variation in the Ray-flowers of Chrysanthemum leucanthemum L., at Yellow Spring, Green County, Ohio, with Remarks upon the Determination of Modes. Biometrika, vol, I, pp. 309-3I5.

1903. Colors and Color Patterns of Coleoptera. The Decennial Publications. The University of Chicago, vol, $\mathrm{X}$, pp. 33-69, pls. I-III.

TOWNSEND, C. H. T.

1892. Notes of Interest. U. S. Dept. Agri., Insect Life, vol. IV, p. 26-27.

ULKE, H.

1873. List of Species of Coleoptera Collected by Lieut. W. L. Carpenter, U. S. A., for the U. S. Geological Survey of Colorado. U. S. Geol. and Geog. Surv. of Colorado, pp. 567-57I.

URECH, F.

I89I. Beobachtungen über die verschiedenen Schuppenfärben und die zeitliche Succession ihres Auftretens (Färbenfelderung) auf den Puppenflügelchen von Vanessa urticce und V. Io. Zool. Anz., Jahrg. Xiv, 466-475.

1893. Beiträge zur Kenntnis der Färben von Insektenschuppen. Zeitschr. Wiss. Zool., Bd. LVII, Heft 2, pp. 306-384.

23-T 
VRIES, HUGO DE.

I90I. Die Mutationstheorie. Versuche und Beobachtungen über die Entstehung von Arten im Pflanzenreich. 2 Bde., pp. xii +648 , xiv $+75^{2}$. Leipzig.

I905. Species and Varieties, Their Origin by Mutation. pp. xviii +847 . Chicago.

WEBSTER, F. M.

I889. Southern Spread of the Colorado Potato Beetle. U. S. Dept. Agri., Insect Life, vol. II, p. I22.

190I. The Trend of Insect Diffusion in North America. 32d Rept. Ent. Soc. Ont., Igor, pp. 63-67.

1903. The Diffusion of Insects in North America. Psyche, April, I903, pp. 47-58.

WALLACE, A. R.

1867. [Theory of Warning Coloration.] Trans. Ent. Soc. Lond., series 3, vol. 5, (Journal of Proc.), pp. 1xxx-1xxxi.

WAISH, B. D.

1865. The New Potato-bug and Its Natural History. Pract. Ent., vol. I, No. I.

I866a. The New Potato Bug. Pract. Ent., vol. I, p. 88.

I866b. The New Potato Bug. Pract. Ent., vol. II, p. I3.

I867a. The New or Colorado Potato Bug. Pract. Ent., vol. II, p. IOI.

I867 $b$. The Colorado Potato Bug. Pract. Ent., vol, II, p. II6.

I868. The Colorado Potato Bug; Its Past History and Future Progress. Am. Ent. and Bot., vol. I, pp. 4I-49.

WeISMANN, A.

I882. Studies in the Theory of Descent. 2 vols., $729 \mathrm{pp}$.

1902. The Evolution Theory. Translated by J. A. and M. R. Thompson. Two vols.,

YULE, G. U. pp. $x v i+4 I 6,405$. London, I904.

1902. Variation in the Number of Sepals in Anemone necorosa. Biometrika, vol. I, pp. 307-309.

ZOPF, W.

I892-93. Beiträge zur Physiologie u. Morphologie niederer Organismen. Leipzig, Heften I, II, III. 


\section{ERRATA.}

Page 2, foot-note, second line: For " there" read "these."

Page 4, L. libatrix, first line: For "undistinguishable" read "indistinguishable."

Page I7, line I I : For "western" read " eastern."

Page 67, table Io, Under 7, for " $a+b+c+e+f$ " read " $a+b-d+e+$ $f$ ". Under 8, for " $a^{\prime}+b^{\prime}+c^{\prime}+c^{\prime}+\left\{\begin{array}{l}c^{\prime}, " \\ f^{\prime}\end{array}\right.$ read " $a^{\prime}+b^{\prime}+d^{\prime}+e^{\prime}-\left\{\begin{array}{l}c^{\prime} \\ f^{\prime}, "\end{array}\right.$

Page 8o, table 25, top of second column: For "Per cent of value in modal class" read "Per cent in Modal class."

Page 9I, table 32 : Line 8, first column, "I4" set in wrong font.

Page I08, table 4I : Line I7, "98" set in wrong font.

Page 309, legend of text-figure 3I : Add $a=L$. albida .

Plate 25 , in legend, last line: For "shade" read "shape." 






1194

MiCnOFICM $A C A C$

CNIVEMSITY Micno Ficons Ann Anson, Micht

$S T R_{1}-1$ 
